Comparative Effectiveness Review

Number 226

\title{
Labor Dystocia
}




\section{Comparative Effectiveness Review}

Number 226

\section{Labor Dystocia}

Prepared for:

Agency for Healthcare Research and Quality

U.S. Department of Health and Human Services

5600 Fishers Lane

Rockville, MD 20857

www.ahrq.gov

Contract No. 290-2015-00004-I

Prepared by:

Duke Evidence-based Practice Center

Durham, NC

Investigators:

Evan R. Myers, M.D., M.P.H.

Gillian D. Sanders, Ph.D.

Remy R. Coeytaux, M.D., Ph.D.

Kara A. McElligott, M.D., M.P.H.

Patricia G. Moorman, Ph.D., M.S.P.H.

Karen Hicklin, Ph.D.

Chad Grotegut, M.D., M.H.Sc.

Margaret Villers, M.D.

Adam Goode, D.P.T, Ph.D.

Hilary Campbell, Pharm.D., J.D.

Deanna Befus, Ph.D.

Amanda J. McBroom, Ph.D.

J. Kelly Davis, B.A.

Kathryn Lallinger, M.S.L.S.

Robyn Fortman, B.A.

Andrzej Kosinski, Ph.D.

AHRQ Publication No. 20-EHC007

May 2020 


\section{Key Messages}

\section{Purpose of Review}

To review the evidence on the definition of "normal" labor progression and the comparative effectiveness of different strategies for treating labor dystocia in women with otherwise uncomplicated pregnancies. Strategies assessed include amniotomy, supportive care measures, epidural analgesia, frequency of cervical examination, intrauterine pressure catheters, highversus low-dose oxytocin protocols, electronic fetal monitoring or intermittent auscultation during augmentation with oxytocin, and delayed or Valsalva pushing.

\section{Key Messages}

- Use of partograms did not impact important maternal or neonatal outcomes.

- Amniotomy plus oxytocin decreases duration of labor without increasing cesarean delivery rates.

- Emotional support interventions may reduce cesarean deliveries and instrumental deliveries.

- Much of the evidence on different interventions came from studies performed outside the United States. Differences in patient, provider, health system, and other characteristics may affect the applicability of these results to a U.S. setting. 
This report is based on research conducted by the Duke Evidence-based Practice Center under contract to the Agency for Healthcare Research and Quality (AHRQ), Rockville, MD (Contract No. 290-2015-00004-I). The findings and conclusions in this document are those of the authors, who are responsible for its contents; the findings and conclusions do not necessarily represent the views of AHRQ. Therefore, no statement in this report should be construed as an official position of AHRQ or of the U.S. Department of Health and Human Services.

\section{None of the investigators have any affiliations or financial involvement that conflicts with the material presented in this report.}

The information in this report is intended to help healthcare decision makers—patients and clinicians, health system leaders, and policymakers, among others—make well-informed decisions and thereby improve the quality of healthcare services. This report is not intended to be a substitute for the application of clinical judgment. Anyone who makes decisions concerning the provision of clinical care should consider this report in the same way as any medical reference and in conjunction with all other pertinent information, i.e., in the context of available resources and circumstances presented by individual patients.

This report is made available to the public under the terms of a licensing agreement between the author and the Agency for Healthcare Research and Quality. This report may be used and reprinted without permission except those copyrighted materials that are clearly noted in the report. Further reproduction of those copyrighted materials is prohibited without the express permission of copyright holders.

AHRQ or U.S. Department of Health and Human Services endorsement of any derivative products that may be developed from this report, such as clinical practice guidelines, other quality enhancement tools, or reimbursement or coverage policies, may not be stated or implied.

This report may periodically be assessed for the currency of conclusions. If an assessment is done, the resulting surveillance report describing the methodology and findings will be found on the Effective Health Care Program website at www.effectivehealthcare.ahrq.gov. Search on the title of the report.

Suggested citation: Myers ER, Sanders GD, Coeytaux RR, McElligott KA, Moorman PG, Hicklin K, Grotegut C, Villers M, Goode A, Campbell H, Befus D, McBroom AJ, Davis JK, Lallinger K, Fortman R, Kosinski A. Labor Dystocia. Comparative Effectiveness Review No. 226. (Prepared by the Duke Evidence-based Practice Center under Contract No. 290-2015-00004I.) AHRQ Publication No. 29-EHC007. Rockville, MD: Agency for Healthcare Research and Quality; May 2020. DOI: https://doi.org/10.23970/AHRQEPCCER226. Posted final reports are located on the Effective Health Care Program search page. 


\section{Preface}

The Agency for Healthcare Research and Quality (AHRQ), through its Evidence-based Practice Centers (EPCs), sponsors the development of systematic reviews to assist public- and private-sector organizations in their efforts to improve the quality of healthcare in the United States. These reviews provide comprehensive, science-based information on common, costly medical conditions, and new healthcare technologies and strategies.

Systematic reviews are the building blocks underlying evidence-based practice; they focus attention on the strength and limits of evidence from research studies about the effectiveness and safety of a clinical intervention. In the context of developing recommendations for practice, systematic reviews can help clarify whether assertions about the value of the intervention are based on strong evidence from clinical studies. For more information about AHRQ EPC systematic reviews, see www.effectivehealthcare.ahrq.gov/reference/purpose.cfm.

AHRQ expects that these systematic reviews will be helpful to health plans, providers, purchasers, government programs, and the healthcare system as a whole. Transparency and stakeholder input are essential to the Effective Health Care Program. Please visit the website (www.effectivehealthcare.ahrq.gov) to see draft research questions and reports or to join an email list to learn about new program products and opportunities for input.

If you have comments on this systematic review, they may be sent by mail to the Task Order Officer named below at: Agency for Healthcare Research and Quality, 5600 Fishers Lane, Rockville, MD 20857, or by email to epc@ahrq.hhs.gov.

Gopal Khanna, M.B.A.

Director

Agency for Healthcare Research and Quality

Stephanie Chang, M.D., M.P.H.

Director

Evidence-based Practice Center Program

Center for Evidence and Practice Improvement Agency for Healthcare Research and Quality
Arlene S. Bierman, M.D., M.S.

Director

Center for Evidence and Practice Improvement Agency for Healthcare Research and Quality

Suchitra Iyer, Ph.D.

Task Order Officer

Center for Evidence and Practice Improvement Agency for Healthcare Research and Quality 


\section{Acknowledgments}

The authors thank Megan Van Noord, M.S.L.S., for help with the literature search and retrieval; Samantha Bowen, Ph.D., for project leadership; Megan Chobot, M.S.L.S., for assistance with project coordination; and Liz Wing, M.A., and Rebecca Gray, Ph.D., for editorial assistance.

\section{Key Informants}

In designing the study questions, the EPC consulted several Key Informants who represent the end-users of research. The EPC sought the Key Informant input on the priority areas for research and synthesis. Key Informants are not involved in the analysis of the evidence or the writing of the report. Therefore, in the end, study questions, design, methodological approaches, and/or conclusions do not necessarily represent the views of individual Key Informants.

Key Informants must disclose any financial conflicts of interest greater than \$5,000 and any other relevant business or professional conflicts of interest. Because of their role as end-users, individuals with potential conflicts may be retained. The TOO and the EPC work to balance, manage, or mitigate any conflicts of interest.

The list of Key Informants who provided input to this report follows:

Alison G. Cahill, M.D., M.S.C.I.

The University of Texas at Austin

Austin, TX

William Callaghan, M.D.

Centers for Disease Control and Prevention

Atlanta, GA

Mary Ann Cooney, M.P.H., M.S., R.N.

NH Department of Health and Human

Services

Concord, $\mathrm{NH}$

Anjali Kaimal, M.D., M.A.S.

Massachusetts General Hospital

Boston, MA

Anne Lyerly, M.D., M.A.

University of North Carolina, Chapel Hill

Chapel Hill, NC

Uma Reddy, M.D., M.P.H.

National Institute of Child Health and

Human Development

National Institutes of Health

Bethesda, MD
Angel Rios, M.D., FAAP

Albany Medical Center

Albany, NY

Amy Romano, M.B.A., M.S.N., C.N.M.

Our Bodies, Ourselves

Milford, CT

Susan Stapleton, B.S., M.S., D.N.P.

American Association of Birth Centers

Perkiomenville, PA

Ellen L. Tilden, Ph.D., C.N.M., FACNM

American College of Nurse-Midwives

Silver Spring, MD

John Vallee, M.D.

Kaiser Permanente

Oakland, CA 


\section{Technical Expert Panel}

In designing the study questions and methodology at the outset of this report, the EPC consulted several technical and content experts. Broad expertise and perspectives were sought. Divergent and conflicting opinions are common and perceived as healthy scientific discourse that results in a thoughtful, relevant systematic review. Therefore, in the end, study questions, design, methodologic approaches, and/or conclusions do not necessarily represent the views of individual technical and content experts.

Technical Experts must disclose any financial conflicts of interest greater than \$5,000 and any other relevant business or professional conflicts of interest. Because of their unique clinical or content expertise, individuals with potential conflicts may be retained. The TOO and the EPC work to balance, manage, or mitigate any potential conflicts of interest identified.

The list of Technical Experts who provided input to this report follows:

Alison G. Cahill, M.D., M.S.C.I.*

The University of Texas at Austin

Austin, TX

William Callaghan, M.D.

Centers for Disease Control and Prevention

Atlanta, GA

Melissa McPheeters, Ph.D., M.P.H.

Vanderbilt University

Nashville, TN

Errol R. Norwitz, M.D., Ph.D., M.B.A. *

Tufts Medical Center

Boston, MA

Uma Reddy, M.D., M.P.H.

National Institute of Child Health and

Human Development

National Institutes of Health

Bethesda, MD

*Provided input on Draft Report.
Angel Rios, M.D., FAAP

Albany Medical Center

Albany, NY

Amy Romano, M.B.A., M.S.N., C.N.M.

Our Bodies, Ourselves

Milford, CT

Susan Stapleton, B.S., M.S., D.N.P.

American Association of Birth Centers

Perkiomenville, PA

Ellen L. Tilden, Ph.D., C.N.M., FACNM*

American College of Nurse-Midwives

Silver Spring, MD 


\section{Peer Reviewers}

Prior to publication of the final evidence report, EPCs sought input from independent Peer Reviewers without financial conflicts of interest. However, the conclusions and synthesis of the scientific literature presented in this report do not necessarily represent the views of individual reviewers.

Peer Reviewers must disclose any financial conflicts of interest greater than $\$ 5,000$ and any other relevant business or professional conflicts of interest. Because of their unique clinical or content expertise, individuals with potential nonfinancial conflicts may be retained. The TOO and the EPC work to balance, manage, or mitigate any potential nonfinancial conflicts of interest identified.

The list of Peer Reviewers follows:

Radek K. Bukowski, M.D., Ph.D.

The University of Texas at Austin

Austin, TX

Gary Dildy, M.D.

Baylor College of Medicine

Houston, TX

Lisa D. Levine, M.D., M.S.C.E.

University of Pennsylvania

Philadelphia, PA

Nancy K. Lowe, Ph.D., C.N.M., FACNM, FAAN

University of Colorado

Denver, CO 


\section{Labor Dystocia}

\section{Structured Abstract}

Objectives. This review evaluates the comparative effectiveness of different strategies for treating labor dystocia in women with otherwise uncomplicated pregnancies.

Data sources. We searched PubMed ${ }^{\circledR}$, Embase ${ }^{\circledR}$, CINAHL $^{\circledR}$, and the Cochrane Database of Systematic Reviews (CDSR), limiting the searches to studies in the English language and comparative studies published from January 1, 2005, to February 15, 2019.

Review methods. Two investigators screened each abstract and full-text article for inclusion, abstracted data, rated quality and applicability, and graded evidence. When possible, randomeffects models were used to compute summary estimates of effects.

Results. Our review included 167 articles (158 unique studies). Studies included 25 relevant to defining abnormal labor, 12 relevant to amniotomy, 75 relevant to supportive care measures, 25 relevant to epidural analgesia, 1 relevant to cervical examination, 1 relevant to intrauterine pressure catheters, 17 relevant to high-dose versus low-dose oxytocin protocols, 1 relevant to fetal monitoring strategies, and 7 relevant to timing of pushing in the second stage.

Evidence suggests that the duration and pattern of "normal” labor progress based on modern management are quite different from historical data, and that labor progress differs between nulliparous and parous women. Use of partograms did not change important maternal or neonatal outcomes, although the applicability of this evidence to modern U.S. settings is limited. Routine amniotomy decreased the total duration of labor in nulliparous women without affecting other outcomes (moderate strength of evidence [SOE]); routine amniotomy with oxytocin augmentation decreased labor duration without increasing cesarean delivery (high SOE). Although supportive care is considered to improve parental satisfaction with the birthing process, satisfaction outcomes were rarely assessed in the included clinical trials. An existing systematic review of 11 studies found that women receiving continuous emotional support were less likely to rate their birth experience negatively. Of the different types of supportive therapies, only emotional support interventions showed reductions in cesarean (low SOE for doula support, moderate SOE for continuous emotional support) and instrumental deliveries (moderate SOE). For women choosing analgesia (epidural vs. combined spinal epidural, or epidural vs. patientcontrolled intravenous analgesia), neither type nor timing affected cesarean delivery rates (moderate SOE).

Conclusions. The normal progress of labor given current practice is quite different from that originally described, although there is still uncertainty about the duration of "normal” labor in the absence of augmentation. Further work is needed to identify (1) the cesarean delivery rate that optimally balances maternal and neonatal outcomes and patient preferences, and (2) the best strategies to achieve this rate. 


\section{Contents}

Evidence Summary ........................................................................................................................... ES-1

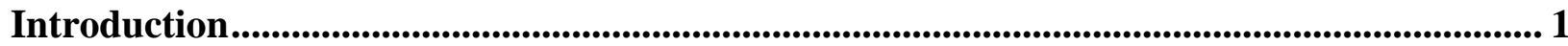

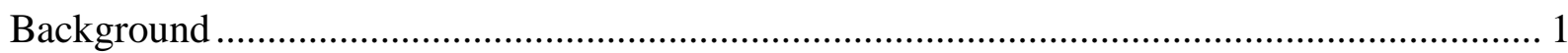

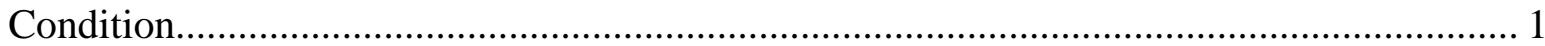

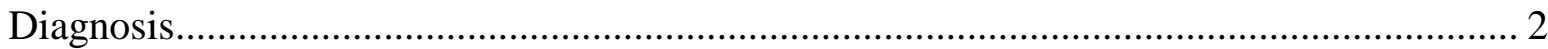

Prevention and Treatment Strategies ……………………………………………….... 2

Scope and Key Questions .............................................................................................. 3

Scope of the Review ……………………………………....................................... 3

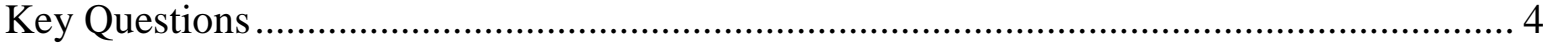

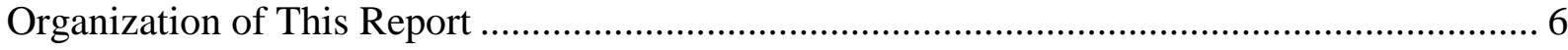

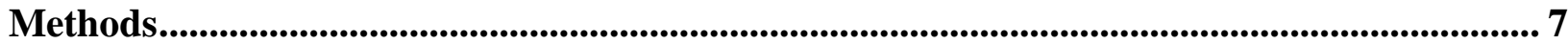

Topic Refinement and Review Protocol ............................................................................ 7

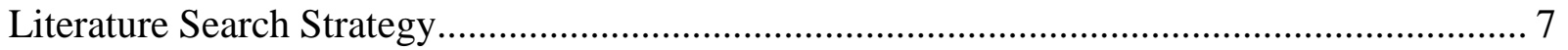

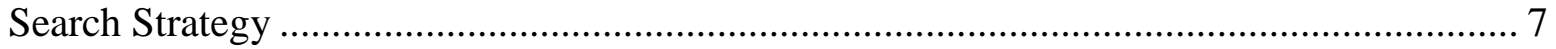

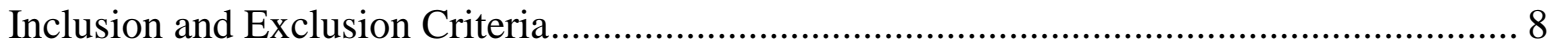

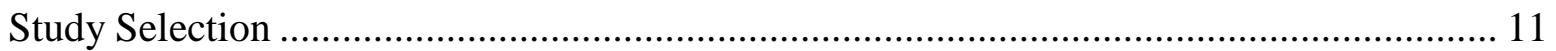

Data Extraction ............................................................................................................... 12

Quality (Risk of Bias) Assessment of Individual Studies.......................................................... 12

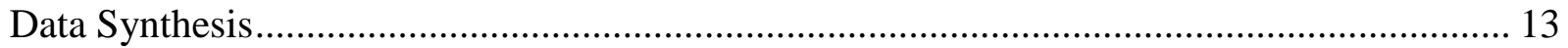

Strength of the Body of Evidence ..................................................................................... 14

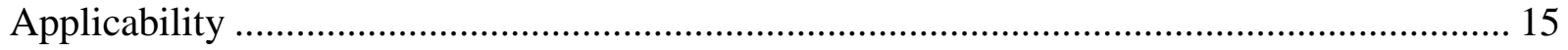

Peer Review and Public Commentary ..................................................................... 16

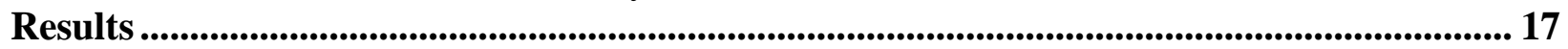

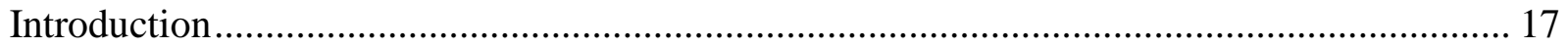

Results of Literature Searches ....................................................................................... 17

Description of Included Studies........................................................................................... 19

Key Question 1. Criteria Used To Define Abnormal Labor.............................................................. 19

Description of Included Studies ....................................................................................... 19

Key Points for Criteria Used To Define Abnormal Labor...................................................... 20

Detailed Synthesis for Criteria Used To Define Abnormal Labor ........................................ 20

Pregnancy Outcomes Based on Criteria Used To Define Abnormal Labor ...................... 20

What Constitutes Normal Duration of Labor?.................................................................... 30

Strength of Evidence for Criteria Used To Define Abnormal Labor........................................ 36

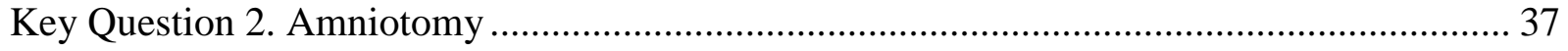

Description of Included Studies...................................................................................... 38

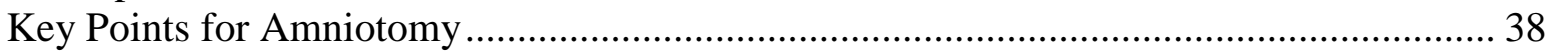

Detailed Synthesis for Amniotomy................................................................................ 39

Amniotomy Versus Control Treatment .......................................................................... 39

Amniotomy Plus Oxytocin Versus Control Treatment...................................................... 47

Key Question 3. Supportive Care............................................................................................. 52

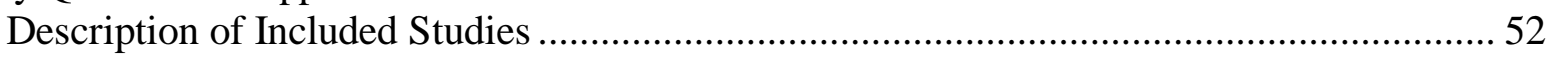

Key Points for Supportive Care ...................................................................................... 53

Detailed Synthesis for Supportive Care............................................................................... 54

Continuous Emotional Support Versus Control Treatment ................................................ 54

Perineal Compresses or Massage Versus Control Treatment ............................................. 57 
Massage During Labor Versus Control Treatment ............................................................ 60

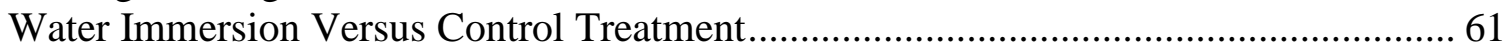

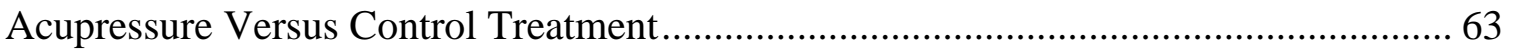

Acupuncture Versus Control Treatment ......................................................................... 64

Aromatherapy Versus Control Treatment......................................................................... 71

Anetheum Graveolens (Dill) Seeds Versus Control Treatment ......................................... 73

Ambulation and Positioning Strategies Versus Control Treatment................................... 74

Specific Nutritional Intervention and Oral or Parenteral Hydration Intervention

Recommendations or Limitations Versus Control Treatment ........................................ 84

TENS Versus Control Treatment............................................................................. 94

Oral Bicarbonate Versus Control Treatment ……………............................................... 95

Hyoscine or Hot Shower Versus Control Treatment ...................................................... 95

Assessment and Support During Early Labor Versus Control Treatment.......................... 96

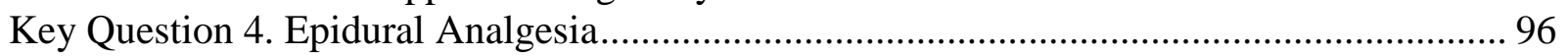

Description of Included Studies ....................................................................................... 96

Key Points for Epidural Analgesia ……………............................................................... 97

Detailed Synthesis for Epidural Analgesia ………….......................................................... 97

Epidural Analgesia Versus Combined Spinal Epidural Analgesia .................................... 98

Epidural Analgesia Versus Patient-Controlled Intravenous Analgesia ............................ 106

Epidural Analgesia Versus Intravascular Tramadol ........................................................ 112

Early Versus Late Epidural Analgesia .......................................................................... 112

Routine Epidural Analgesia Versus Analgesia on Request ............................................. 114

Combined Spinal Epidural Analgesia Versus Nonpharmacologic Pain Relief ............... 115

Epidural Analgesia Versus Intravenous Meperidine .................................................... 117

Epidural Analgesia Versus Low-Dose Infusion Epidural Analgesia................................ 119

Epidural Analgesia Versus Acupuncture ...................................................................... 119

Epidural Analgesia Versus No Epidural Analgesia .................................................... 122

Key Question 5. Frequency of Cervical Examination .............................................................. 125

Description of Included Studies ......................................................................................... 125

Key Point for Frequency of Cervical Examination............................................................... 125

Detailed Synthesis for Frequency of Cervical Examination............................................... 125

Strength of Evidence for Frequency of Cervical Examination........................................... 126

Key Question 6. Intrauterine Pressure Catheters........................................................................ 126

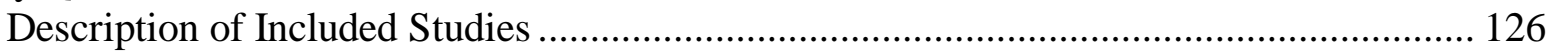

Key Point for Intrauterine Pressure Catheters ................................................................ 126

Detailed Synthesis for Intrauterine Pressure Catheters........................................................ 126

Strength of Evidence for Intrauterine Pressure Catheters.................................................. 127

Key Question 7. High-Dose Versus Low-Dose Oxytocin Protocols................................................. 128

Description of Included Studies ..................................................................................... 128

Key Points for High-Dose Versus Low-Dose Oxytocin Protocols...................................... 128

Detailed Synthesis for High-Dose Versus Low-Dose Oxytocin Protocol ............................ 129

Timing of Oxytocin Administration ............................................................................... 137

Strength of Evidence for Oxytocin Versus Expectant Management ................................... 146

Key Question 8. Electronic Fetal Monitoring Versus Intermittent Auscultation................................ 146

Description of Included Studies ...................................................................................... 146

Key Point for Electronic Fetal Monitoring Versus Intermittent Auscultation..................... 146 
Detailed Synthesis for Electronic Fetal Monitoring Versus Intermittent Auscultation...... 147

Key Question 9. Timing of Pushing in the Second Stage ................................................ 147

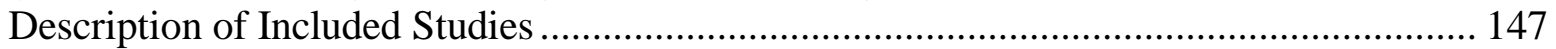

Key Points for Timing of Pushing ......................................................................... 148

Detailed Synthesis for Timing of Pushing ............................................................... 148

Coached Pushing Versus Uncoached Pushing.......................................................... 148

Immediate Versus Delayed Pushing Among Nulliparous Women................................ 151

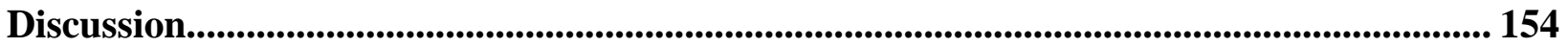

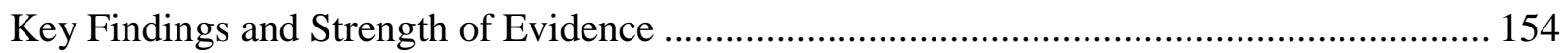

Findings in Relationship to What Is Already Known.................................................... 154

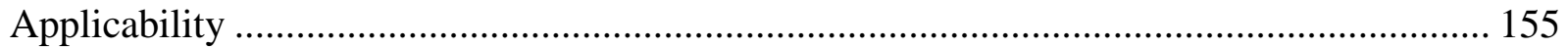

Implications for Clinical and Policy Decision Making................................................. 157

Limitations of the Systematic Review Process ............................................................. 158

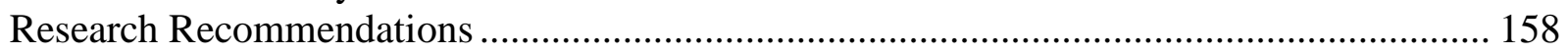

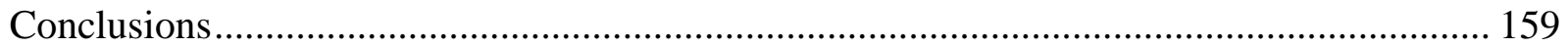

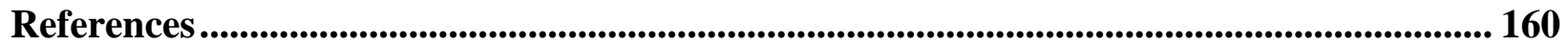

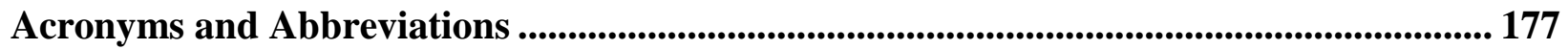

\section{Tables}

Table A. Partogram use: Evidence summary for major outcomes and adverse events ............ ES-9

Table B. Early amniotomy versus control: Evidence summary in nulliparous women.......... ES-10

Table C. Early amniotomy versus control: Evidence summary in women with unspecified

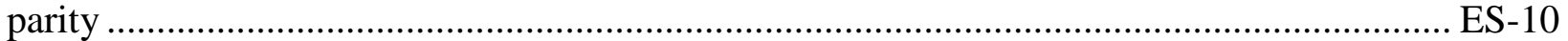

Table D. Amniotomy plus oxytocin versus control: Evidence summary in nulliparous

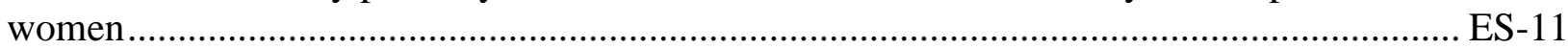

Table E. Amniotomy plus oxytocin versus control: Evidence summary in women with

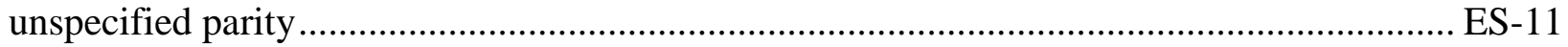

Table F. Amniotomy plus oxytocin versus control: Evidence summary in parous women ... ES-12 Table H. Perineal compresses or massage versus control: Evidence summary in nulliparous

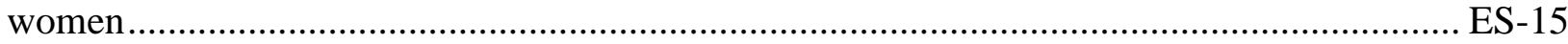
Table I. Perineal compresses or massage versus control: Evidence summary in women of mixed

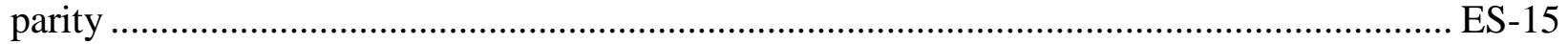

Table J. Massage during labor versus control: Evidence summary in nulliparous women.... ES-15 Table K. Water birth versus control: Evidence summary in women of mixed parity ............ ES-16 Table L. Acupuncture/acupoint nerve stimulator versus control: Evidence summary in

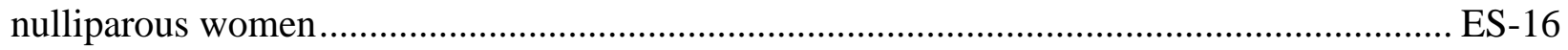
Table M. Acupuncture/acupoint nerve stimulator versus control: Evidence summary in women of

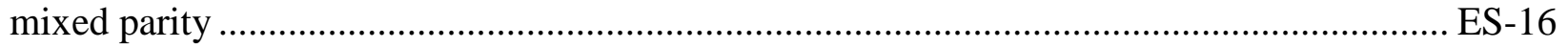

Table N. Ambulation versus control: Evidence summary in nulliparous women ................. ES-17

Table O. Positioning versus control: Evidence summary in nulliparous women ................... ES-17

Table P. Positioning versus control: Evidence summary in women of mixed parity ............. ES-18 Table Q. Specific nutritional intervention and oral or parenteral hydration intervention recommendations or limitations: Evidence summary in nulliparous women ....................... ES-18 Table R. Epidural analgesia versus combined spinal epidural: Evidence summary in nulliparous women.......................................................................................... ES-19

Table S. Epidural analgesia versus combined spinal epidural: Evidence summary in women of mixed parity 
Table T. Epidural analgesia versus patient-controlled intravenous analgesia: Evidence summary

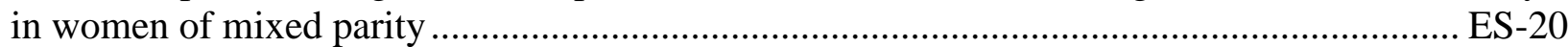

Table U. Early versus late epidural analgesia: Evidence summary in nulliparous women .... ES-21 Table V. Epidural analgesia versus no epidural analgesia: Evidence summary in women of mixed parity ES-22

Table W. Intrauterine pressure catheters versus external monitoring: Evidence summary in women of unspecified parity....

Table X. High-dose versus low-dose oxytocin protocols: Evidence summary in nulliparous women.

Table Y. Early versus delayed oxytocin protocols: Evidence summary in nulliparous women.

Table Z. Pulsatile versus continuous oxytocin protocols: Evidence summary in women of mixed parity

Table AA. Oxytocin versus expectant management: Evidence summary in women of mixed

parity

Table BB. Spontaneous pushing versus Valsalva pushing: Evidence summary in nulliparous women

Table CC. Immediate versus delayed pushing: Evidence summary in nulliparous women ... ES-27

Table 1. Inclusion and exclusion criteria

Table 2. Definitions of overall quality ratings ................................................................. 12

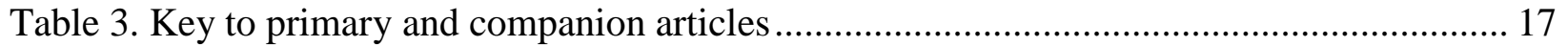

Table 4. Summary of labor outcomes using partograms ....................................................... 23

Table 5. Median time intervals (hours) by cervical dilation in nulliparous women, Japanese

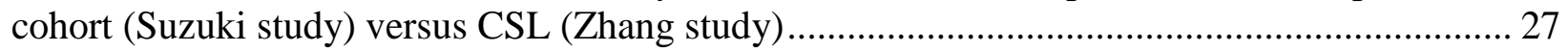

Table 6. Labor outcomes by active management of labor ......................................................... 29

Table 7. Median time intervals (hours) by cervical dilation and parity from one cervical dilation

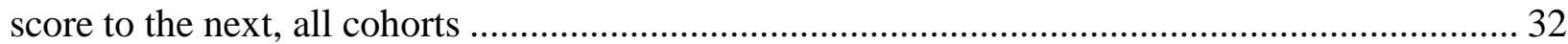

Table 8. Duration of labor in hours for cervical dilation to the next centimeter with oxytocin

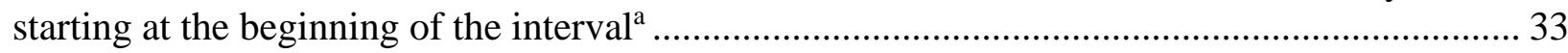

Table 9. Duration of labor in hours for cervical dilation to the next centimeter with oxytocin reaching the highest dose before the start of the interval.................................................... 34

Table 10. Duration of labor and oxytocin augmentation in the Frigo, Friedman, and CSL

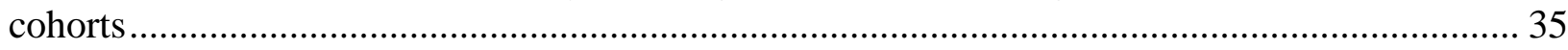

Table 11. Maternal outcomes by duration of the first stage of labor ..................................... 35

Table 12. Duration of labor (minutes) by maternal age .......................................................... 36

Table 13. Partogram use: Strength of evidence for major outcomes and adverse events............ 37 Table 14. Amniotomy versus control in nulliparous women-total duration of labor and cesarean

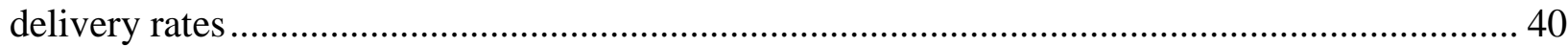

Table 15. Amniotomy versus control in nulliparous women-trauma to the pelvic floor .......... 41

Table 16. Early amniotomy versus control: Evidence profile in nulliparous women ................. 45 Table 17. Early amniotomy versus control: Evidence profile in women with unspecified parity 46 Table 18. Early amniotomy versus control: Evidence profile in parous women ........................ 47 Table 19. Amniotomy plus oxytocin versus control: Evidence profile in nulliparous women .... 50 Table 20. Amniotomy plus oxytocin versus control: Evidence profile in women with unspecified

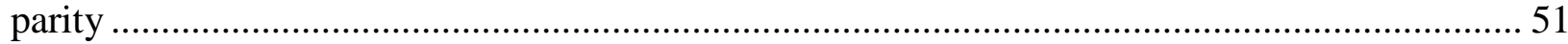

Table 21. Amniotomy plus oxytocin versus control: Evidence profile in parous women............ 52 
Table 22. Continuous emotional support versus control: Evidence profile in nulliparous women

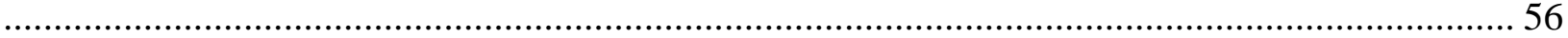

Table 23. Continuous emotional support versus control: Evidence profile in women of mixed parity .

Table 24. Perineal compresses or massage versus control: Evidence profile in nulliparous women

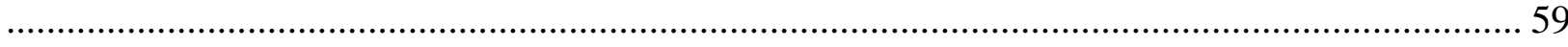

Table 25. Perineal compresses or massage versus control: Evidence profile in women of mixed

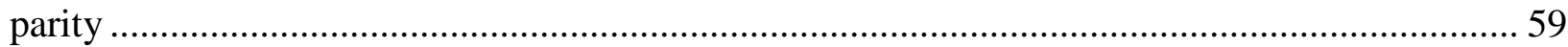

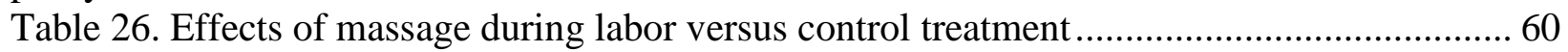

Table 27. Massage during labor versus control: Evidence profile in nulliparous women............ 61

Table 28. Massage during labor versus control: Evidence profile in women of mixed parity ..... 61

Table 29. Water birth versus control: Evidence profile in nulliparous women ........................... 62

Table 30. Water birth versus control: Evidence profile in women of mixed parity .................... 63

Table 31. Acupressure versus control: Evidence profile in nulliparous women ........................ 64

Table 32. Acupressure versus control: Evidence profile in women of mixed parity................... 64

Table 33. Effects of acupuncture versus control treatment.................................................. 67

Table 34. Acupuncture/acupoint nerve stimulator versus control: Evidence profile in nulliparous

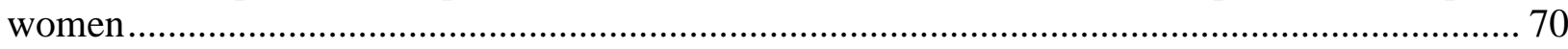

Table 35. Acupuncture/acupoint nerve stimulator versus control: Evidence profile in women of

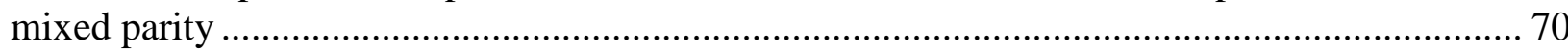

Table 36. Effects of aromatherapy versus control treatment ................................................. 72

Table 37. Aromatherapy versus control: Evidence profile in nulliparous women ..................... 73

Table 38. Anetheum graveolens seeds versus control: Evidence profile in nulliparous women .. 74 Table 39. Anetheum graveolens seeds versus control: Evidence profile in women of mixed parity

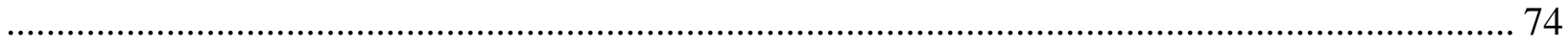

Table 40. Effects of ambulation versus control treatment .................................................. 77

Table 41. Ambulation versus control: Evidence profile in nulliparous women ......................... 82

Table 42. Positioning versus control: Evidence profile in nulliparous women .......................... 83

Table 43. Ambulation/positioning versus control: Evidence profile in women of mixed parity . 83

Table 45. Specific nutritional intervention and oral or parenteral hydration intervention recommendations or limitations: Evidence profile in nulliparous women ............................... 93

Table 46. Specific nutritional intervention and oral or parenteral hydration intervention recommendations or limitations: Evidence profile in women of mixed parity ......................... 94

Table 47. Effects of TENS versus control treatment ............................................................ 95

Table 48. Effects of epidural analgesia versus combined spinal epidural in nulliparous women 99 Table 49. Effects of epidural analgesia versus combined spinal epidural in women of mixed or unspecified parity ......................................................................................................... 103 Table 50. Epidural analgesia versus combined spinal epidural: Evidence profile in nulliparous women. 105

Table 51. Epidural analgesia versus combined spinal epidural: Evidence profile in women of mixed parity ....................................................................................................... 106 Table 52. Effects of epidural analgesia versus patient-controlled intravenous analgesia in women

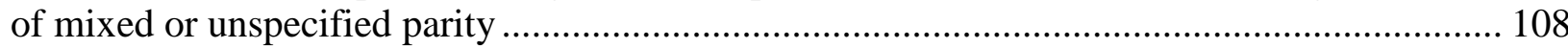
Table 53. Epidural analgesia versus patient-controlled intravenous analgesia: Evidence profile in nulliparous women. 
Table 54. Epidural analgesia versus patient-controlled intravenous analgesia: Evidence profile in women of mixed parity

Table 55. Epidural analgesia versus intravascular tramadol: Evidence profile in women of mixed parity

Table 56. Early versus late epidural analgesia: Evidence profile in nulliparous women ${ }^{\mathrm{a}}$.......... 113 Table 57. Routine epidural analgesia versus analgesia on request: Evidence profile in women of mixed parity ....

Table 58. Strength of evidence for combined spinal epidural analgesia versus nonpharmacologic

pain relief in women of mixed parity.....

Table 59. Epidural analgesia versus intravenous meperidine: Evidence profile in nulliparous women

Table 60. Epidural analgesia versus low-dose infusion epidural analgesia: Evidence profile in nulliparous women.

Table 61. Epidural analgesia versus acupuncture point nerve stimulation: Evidence profile in nulliparous women.

Table 62. Epidural analgesia versus acupuncture point nerve stimulation: Evidence profile in women of mixed parity

Table 63. Epidural analgesia versus no epidural analgesia: Evidence profile in nulliparous women.

Table 64. Epidural analgesia versus no epidural analgesia: Evidence profile in women of mixed parity

Table 65. Cervical examination versus other strategies: Evidence profile in women of unspecified parity. Table 66. Intrauterine pressure catheters versus external monitoring: Evidence profile in women of unspecified parity

Table 67. Low-dose and high-dose oxytocin infusion protocols ......................................... 129

Table 68. Labor outcomes by high- and low-dose oxytocin protocols in nulliparous women... 131

Strength of Evidence for High-Dose Versus Low-Dose Oxytocin in Nulliparous Women ....... 133 Table 69. High-dose versus low-dose oxytocin protocols: Evidence profile in nulliparous women

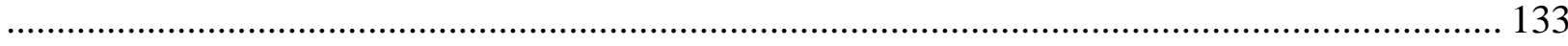

Table 70. Labor outcomes by high- and low-dose oxytocin protocols in parous women .......... 135

Table 71. High-dose versus low-dose oxytocin protocols: Evidence profile in parous women. 136

Table 72. Labor outcomes by timing of oxytocin administration in nulliparous women........... 138

Table 73. Early versus delayed oxytocin protocols: Evidence profile in nulliparous women.... 140

Table 74. Labor outcomes with pulsatile oxytocin or with adjuvants in women of mixed parity

Table 75. Pulsatile versus continuous oxytocin protocols: Evidence profile in women of mixed parity

Table 76. Labor outcomes with oxytocin compared to expectant management in women of mixed parity .

Table 77. Oxytocin versus expectant management: Evidence profile in women of mixed parity

Table 78. Duration of labor and cesarean delivery rates for spontaneous pushing versus Valsalva pushing 149

Table 79. Maternal adverse outcomes for spontaneous pushing versus Valsalva pushing ........ 150 
Table 80. Spontaneous pushing versus Valsalva pushing: Evidence profile in nulliparous women

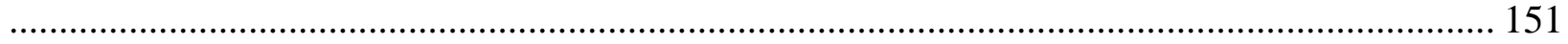

Table 81. Immediate versus delayed pushing: Evidence profile in nulliparous women ............. 152

Table 82. Potential issues with applicability of included studies .................................................. 156

\section{Figures}

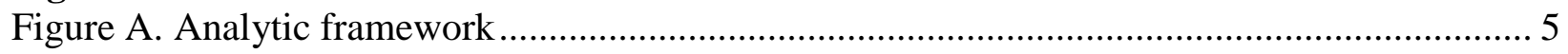

Figure 1. Analytic framework ..................................................................................... 5

Figure 2. Literature flow diagram ............................................................................... 18

Figure 3. Forest plot of cesarean delivery rate for oral hydration versus high-level intravenous hydration (number of events) ................................................................................................... 86 Figure 4. Epidural analgesia versus combined spinal epidural in nulliparous women —duration of

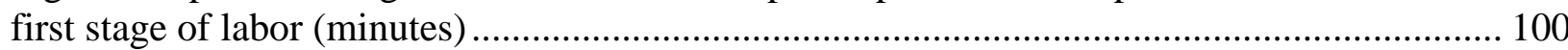
Figure 5. Epidural analgesia versus combined spinal epidural in nulliparous women—duration of

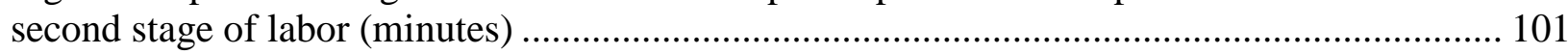
Figure 6. Epidural analgesia versus combined spinal epidural in nulliparous women-total

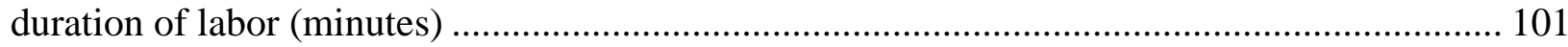
Figure 7. Epidural analgesia versus combined spinal epidural in nulliparous women—cesarean delivery rates (number of events) ......................................................................................... 102 Figure 8. Epidural analgesia versus combined spinal epidural in women of mixed or unspecified parity — cesarean delivery rates (number of events) 104 Figure 9. Epidural analgesia versus patient-controlled intravenous analgesia in women of mixed or unspecified parity — total duration of labor (minutes) ........................................................... 109 Figure 10. Epidural analgesia versus patient-controlled intravenous analgesia in women of mixed or unspecified parity—cesarean delivery rates (number of events). 110

\section{Appendixes}

Appendix A. Exact Search Strings

Appendix B. Data Abstraction Elements

Appendix C. List of Included Studies

Appendix D. List of Excluded Studies

Appendix E. Characteristics of Included Studies

Appendix F. AMSTAR Quality Assessment for Systematic Reviews

Appendix G. Risk of Bias Assessment for Included Studies 


\section{Evidence Summary}

\section{Background}

\section{Condition and Treatment Strategies}

Approximately 80 percent of American women will eventually have at least one child, ${ }^{1}$ and the majority of these women will undergo labor. "Labor dystocia"- difficult or obstructed labor ${ }^{2}$ - encompasses a variety of concepts, ranging from "abnormally" slow dilation of the cervix or descent of the fetus during active labor ${ }^{3}$ to entrapment of the fetal shoulders after delivery of the head ("shoulder dystocia," an obstetric emergency). For the purposes of this systematic review, we assume that "labor dystocia” refers to "abnormal” labor progression during the latent (up to 4-6 cm dilation) or active phases (from 4-6 cm until full dilation) of the first stage of labor, or during the second stage (from complete cervical dilation until delivery of the baby, although, as discussed below, there have been substantial changes in practice since these "traditional" definitions were developed which raise questions about their generalizability to modern populations. We also limit our review to women in spontaneous labor, with definitions varying somewhat between studies but generally including the onset of spontaneous uterine contractions, and explicitly exclude studies of women undergoing induction, or women with premature rupture of membranes at term in the absence of contractions.

Prolonged labor may increase the risk for maternal and neonatal infection, fetal distress, neonatal hypoxia, uterine rupture, and postpartum hemorrhage; it may also be a marker for increased risk of maternal pelvic floor and genital trauma during delivery (with a subsequent increased risk for future incontinence and pelvic organ prolapse). ${ }^{4}$ Reducing the likelihood of these adverse maternal and neonatal outcomes is the underlying rationale for performing a cesarean delivery for the primary indication of labor dystocia. ${ }^{3}$

However, there is a tradeoff, since cesarean delivery itself increases the risk of maternal hemorrhage, venous thromboembolism, and injury to the bladder and other internal organs, and can affect post-delivery mother-baby interactions. ${ }^{3,5}$ Further, having one cesarean delivery increases the likelihood of having subsequent cesarean deliveries. ${ }^{3}$ A woman's risk for abnormal placentation (placenta previa or accreta, each of which is associated with significant maternal and neonatal morbidity and mortality) is directly related to the number of prior cesarean deliveries she has had. ${ }^{6}$

Although there is no consensus on the "optimal" cesarean delivery rate (conceptually, the rate that strikes a balance between benefits and harms for both mother and baby that is considered acceptable to most patients), there is general consensus that current rates in the United States are too high, ${ }^{3,7}$ although whether the factors driving this rate are amenable to evidence-based solutions has been questioned. ${ }^{8}$ There is also growing concern about increases in rates internationally, as reflected by a World Health Organization consensus statement. ${ }^{9}$ Strategies to prevent a woman's first, or primary, caesarean delivery may therefore lead to significant improvements in maternal and neonatal outcomes by reducing both the number of primary and repeat cesareans. ${ }^{3}$ For this reason, the American College of Obstetricians and Gynecologists (ACOG) and the Society for Maternal-Fetal Medicine (SMFM) have issued a joint consensus statement aimed at "preventing the first cesarean delivery."3 with similar efforts instituted by the American College of Nurse Midwives. ${ }^{10}$ Since abnormalities of labor progression are the single most common cause of primary cesarean delivery in the United 
States, ${ }^{3,11}$ strategies aimed at reducing cesarean delivery for dystocia may have the largest potential impact on overall cesarean rates.

The effective management of labor dystocia is first dependent on the tool used to diagnose the disorder. In the 1950s, Friedman published his observations on the rate of cervical change among a cohort of women in spontaneous labor ${ }^{12}$ and from this constructed labor curves representing the expected rate of cervical change in a population. Deviations from these curves, particularly rates of cervical change slower than expected from the Friedman curve are referred to as protracted or arrest disorders and represent labor dystocia. The Friedman curve has been the primary tool used to diagnose abnormal labor since then, though more recent data from the Consortium on Safe Labor have demonstrated that rates and characteristics of cervical change seen in modern obstetrics are quite different from that represented by the Friedman curve. ${ }^{13}$ Identifying what constitutes normal labor is an important initial step in the management of labor dystocia as it first dictates when various treatment options are initiated. Variation between providers about definitions or perceptions of "abnormal" labor length may contribute to variations in rates of diagnosis.

There are a number of strategies that may either facilitate earlier diagnosis of labor, directly or indirectly (e.g., choice of pain management strategies) prevent a diagnosis of labor dystocia, or accelerate labor progress after a diagnosis of dystocia. Strategies addressed in this report include:

- Use of graphs of cervical dilation over time ("partograms”) to identify patients with slow labor progress, often with an indicator of when intervention is appropriate.

- Timing of the artificial rupture of the amniotic membranes (amniotomy) during labor.

- Various options for maternal positioning, ambulation, and feeding during labor.

- Use of epidural analgesia, or, alternatively, variations in technique (timing, choice of analgesic agents).

- Variations in monitoring labor progress (such as frequency of cervical examination or use of intrauterine pressure catheters) and fetal well-being (fetal heart rate monitoring).

- Variations in strategies for how oxytocin is used during labor augmentation including timing of augmentation relative to labor progress and variation in dosing regimens.

- Variations in strategies for reducing the length of the second stage of labor (after cervical dilation is complete but before the baby has delivered), including different approaches to maternal pushing.

The overall goal of treating labor dystocia is to optimize delivery outcomes for mother and child, while reducing excess cesarean delivery. 


\section{Scope and Key Questions}

This systematic review evaluates the comparative effectiveness of different strategies for treating labor dystocia in women with otherwise uncomplicated pregnancies. We also limit our review to women in spontaneous labor and exclude those who are undergoing induced labor. In addition, one potential source of uncertainty in the available evidence may be variability in the definitions for different phases of labor, and what constitutes "normal” labor across studies and likely in practice as well. In order to better understand the impact of this variability on the evidence on specific interventions, we also review the evidence on the definition of "normal" labor progression.

We explicitly excluded studies which included women with other potential indications for cesarean section (e.g., multiple pregnancies, prior cesarean) or other conditions which might affect either the likelihood of diagnosis of dystocia (e.g., use of magnesium sulfate in preeclampsia) or lead to contraindications to some interventions (e.g., HIV and amniotomy). We also did not include interventions such as estimation of fetal size or clinical pelvimetry which might affect physician perception of the risk of labor dystocia.

The specific Key Questions (KQs) addressed in this review are listed below, and Figure A displays the analytic framework that guided our work.

KQ 1: Do delivery outcomes for management of abnormal labor differ based on the criteria used to define protracted or arrested labor at different stages of the labor process?

KQ 2: What are the benefits and harms of amniotomy in women in spontaneous labor?

KQ 3: What are the benefits and harms of supportive care measures, including emotional support, ambulation, nutrition, and hydration, during spontaneous labor?

KQ 4: What are the benefits and harms of epidural analgesia in labor, particularly in terms of the risk of a diagnosis of prolonged labor?

KQ 5: How does the frequency of cervical examination affect the probability of specific benefits and harms?

KQ 6: What are the benefits and harms of intrauterine pressure catheters in the diagnosis and management of labor dystocia?

KQ 7: For women with abnormal labor, what are the relative benefits and harms of high- versus low-dose oxytocin protocols (including nipple stimulation)? 
KQ 8: For women in spontaneous labor undergoing augmentation with oxytocin, what are the relative benefits and harms (in terms of both maternal and neonatal outcomes) of electronic fetal monitoring versus intermittent auscultation?

KQ 9: For women in the second stage of labor, is there a benefit from delayed or Valsalva pushing for time to delivery or mode of delivery? 
Figure A. Analytic framework

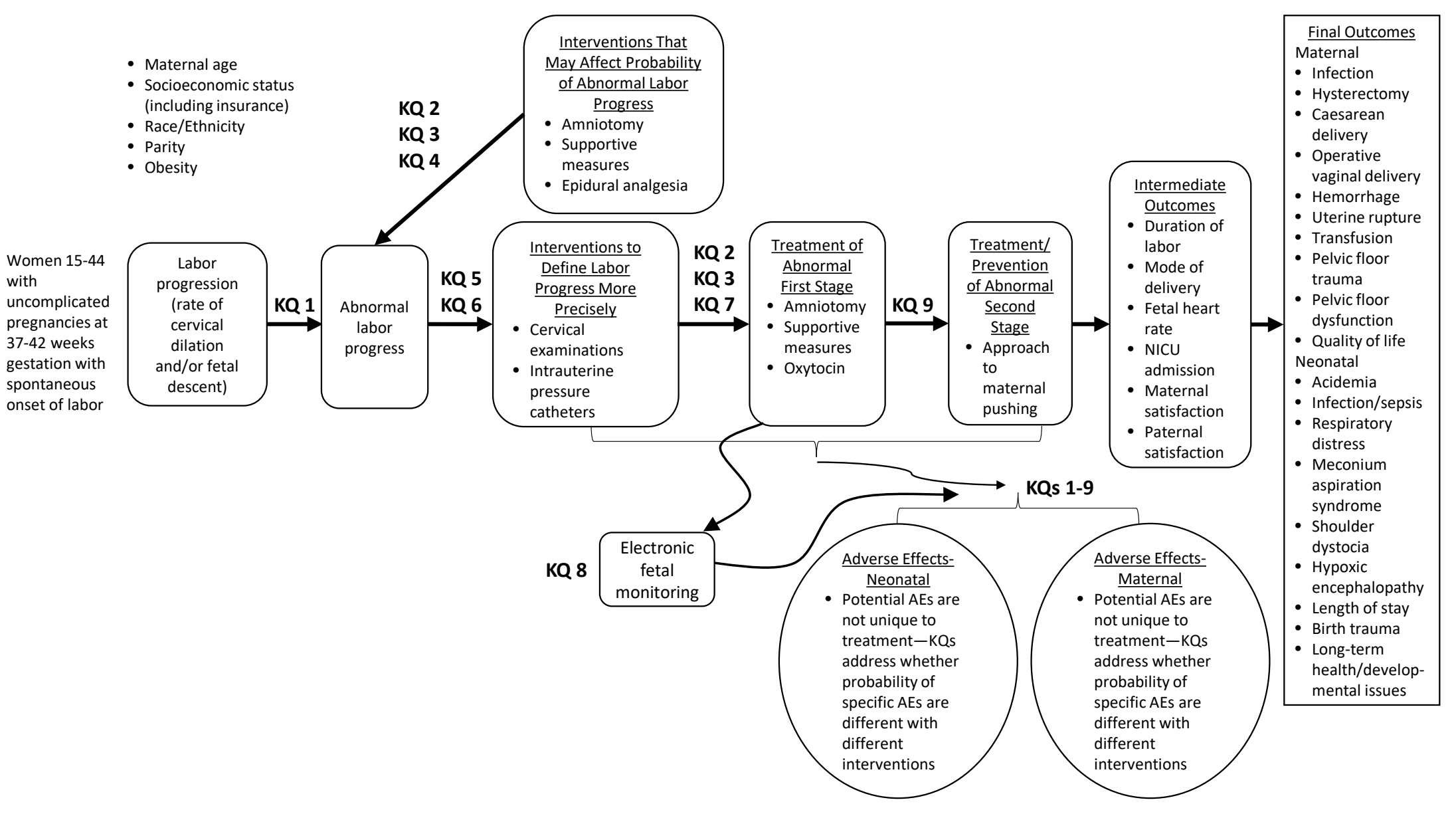

Abbreviations: AEs=adverse effects; KQ=Key Question; NICU=neonatal intensive care unit 


\section{Methods}

Detailed methods are available in the full report and the posted protocol (https://effectivehealthcare.ahrq.gov/products/labor-dystocia/research-protocol). Our literature search was limited to studies published in English from January 1, 2005, to February 15, 2019, depending on the database. We also completed manual searches of citations from a set of key primary and review articles. Additionally, we attempted to identify relevant grey literature. We graded the strength of evidence for each outcome assessed using the approach described in the Agency for Healthcare Research and Quality (AHRQ) Methods Guide for Effectiveness and Comparative Effectiveness Reviews. ${ }^{14-16}$ A more detailed description of our search and our risk of bias and strength of evidence calculations can be found in the full report.

\section{Literature Search Strategy}

To identify relevant published literature, we searched PubMed ${ }^{\circledR}$, Embase $^{\circledR}$, CINAHL $^{\circledR}$, and the Cochrane Database of Systematic Reviews (CDSR), limiting the searches to studies published in English from January 1, 2005, to February 15, 2019. These databases were selected based on internal expert opinion that they would identify most of the relevant literature on this topic and that they reflect the databases used in related systematic reviews (SRs), particularly reviews conducted by the Cochrane Pregnancy and Childbirth Group. An experienced search librarian guided all searches. The exact search strings used are given in Appendix A.

We supplemented the electronic searches with a manual search of citations from a set of key primary and review articles. The reference lists for identified key articles were manually searched and cross-referenced against our database, and additional relevant articles not already under consideration were retrieved for screening. All citations were imported into an electronic bibliographical database (EndNote ${ }^{\circledR}$ Version X7; Thomson Reuters, Philadelphia, PA).

To identify relevant gray literature, the EPC Scientific Resource Center notified stakeholders that the EPC was interested in receiving information relevant to the KQs. We also searched ClinicalTrials.gov for two purposes: (1) to identify relevant articles from completed studies that may not have appeared through other search strategies and (2) as one mechanism to ascertain publication bias in recent studies. For the latter goal, we sought to identify completed but unpublished studies that could impact the findings of the review. We also explored the possibility of publication bias specifically in our quantitative synthesis of the included literature through meta-analysis (MA) techniques such as funnel plots when appropriate. Further gray literature assessment included searching the World Health Organization International Clinical Trials Registry Platform search portal and the National Guidelines Clearinghouse to identify potentially relevant study records; we subsequently searched for relevant articles from among the completed studies.

We specified our inclusion and exclusion criteria based on the PICOTS (populations, interventions, comparators, outcomes, timing, and settings) identified for each question. For citations retrieved from PubMed, Embase, and the Cochrane Database of Systematic Reviews, two reviewers independently screened each title and abstract for potential relevance to the research questions using prespecified inclusion/exclusion criteria. Articles included by either reviewer underwent full-text screening. Articles meeting eligibility criteria at the full-text stage were included for data abstraction. Based on their clinical and methodological expertise, a pair of researchers were assigned to abstract data from each of the eligible articles. One researcher abstracted the data, and the second over-read the article and the accompanying abstraction to 
check for accuracy and completeness. Disagreements were resolved by consensus or by obtaining a third reviewer's opinion if consensus could not be reached.

\section{Risk of Bias Assessment of Individual Studies}

We assessed methodological quality, or risk of bias, for randomized and nonrandomized individual study designs using a components approach, assessing each study for specific aspects of design or conduct (such as allocation concealment for randomized controlled trials (RCTs), or use of methods to address potential confounding), as detailed in AHRQ's Methods Guide for Effectiveness and Comparative Effectiveness Reviews. ${ }^{14}$ Briefly, we rated each study as being of good, fair, or poor quality based on its adherence to well-accepted standard methodologies. For each study, one investigator assigned a summary quality rating, which was then reviewed by a second investigator; disagreements were resolved by consensus or by a third investigator if agreement could not be reached.

\section{Data Synthesis}

We began by summarizing key features of the included studies for each KQ. To the degree that data were available, we abstracted information on study design; patient characteristics; clinical settings; interventions; and intermediate, final, and adverse event outcomes.

We then determined the feasibility of completing a quantitative synthesis (i.e., meta-analysis, decision analysis, or simulation model). For a meta-analysis, feasibility depends on the volume of relevant literature (requiring at least three relevant studies), conceptual homogeneity of the studies (similar intervention comparisons and outcome definitions), completeness of the reporting of results, and the adequacy and completeness of any existing meta-analyses (MAs).

\section{Strength of the Body of Evidence}

We graded the strength of evidence for each outcome assessed using the approach described in AHRQ's Methods Guide. ${ }^{14-16}$ We also discussed the consistency of our findings with recent SRs, along with possible causes for disagreement and impact on strength of evidence ratings, in the results. Newly identified studies are presented separately from the results of existing reviews. Overall strength of evidence findings are based on the primary evidence. Existing SRs were incorporated into the summary strength of evidence (SOE) when available. Only good- and fairquality SRs were considered, with heavier weighting to findings from good-quality SRs. A summary rating of high, moderate, or low strength of evidence was assigned for each outcome after discussion by two reviewers. When no evidence was available, or when evidence on the outcome was too weak, sparse, or inconsistent to permit any conclusion to be drawn, a grade of "insufficient” was assigned. 


\section{Results}

We briefly summarize the results of our literature searches, description of included studies, key points, and strength of evidence for each KQ.

\section{Summary of Studies}

The literature search yielded 11,746 unique citations. In total, 1,082 full-text articles were retrieved and screened. Of these, 915 were excluded at the full-text screening stage, leaving 167 articles for data abstraction. These 167 articles described 158 unique studies. The relationship of studies to the review questions is as follows: 25 studies relevant to KQ 1, 12 studies relevant to KQ 2, 75 studies relevant to KQ 3, 25 studies relevant to KQ 4, 1 study relevant to KQ 5, 1 study relevant to KQ 6, 17 studies relevant to KQ 7, 1 study relevant to KQ 8, and 7 studies relevant to KQ 9 (some studies were relevant to more than one KQ).

In all tables, criteria for downgrading SOE are described as "Rationale;" when these criteria are insufficient for understanding the final SOE, additional explanation is provided. Abbreviations common to all tables include RCT for randomized controlled trial, SOE for strength of evidence, and SR for systematic review.

\section{Key Question 1. Criteria Used To Define Abnormal Labor}

We identified 19 individual studies that examined whether labor outcomes among women in spontaneous labor differed based on the criteria used to define abnormal labor. ${ }^{17-33}$ Key findings include:

- $\quad$ No differences were seen in postpartum hemorrhage rates (moderate SOE), neonatal acidemia rates (low SOE), or vaginal delivery rates (moderate SOE) between women managed with varying partogram strategies.

- Maternal satisfaction was also no different between partogram strategies (low SOE).

- Modern labor curves constructed from the Consortium on Safe Labor (CSL) demonstrate significantly different rates of cervical change, duration of labor, and appearance of the curve (absence or presence of an inflection point) between nulliparous and parous women.

- Modern labor curves constructed from the CSL cohort vary significantly from curves constructed from historical cohorts (Friedman or National Collaborative Perinatal Project [NCPP]), with modern curves suggesting a longer duration of the first stage of labor.

- Maternal age influences the duration of the first and second stage of labor among nulliparous women (older women having longer labors).

Table A summarizes the SOE for the use of partograms. In general, the SOE was reduced for outcomes because the evidence was based on findings from non-U.S. settings (and several studies focused on low-resource settings). 
Table A. Partogram use: Evidence summary for major outcomes and adverse events

\begin{tabular}{|c|c|c|c|c|}
\hline Category & Outcome & $\begin{array}{l}\text { Study Design } \\
\text { (Sample Size) }\end{array}$ & Conclusion & $\begin{array}{c}\text { SOE } \\
\text { (Rationale) }^{\mathrm{a}}\end{array}$ \\
\hline \multirow[t]{2}{*}{$\begin{array}{l}\text { Intermediate } \\
\text { or Final } \\
\text { Outcomes }\end{array}$} & $\begin{array}{l}\text { Process Related } \\
\text { Outcomes - } \\
\text { Operative Vaginal } \\
\text { Delivery }\end{array}$ & $\begin{array}{l}1 \mathrm{RCT}^{24} \\
(1,929) \\
1 \mathrm{SR}^{34} \\
(1,813 \\
\text { patients, } 3 \\
\text { studies) } \\
\end{array}$ & $\begin{array}{l}\text { No difference: No difference in } \\
\text { operative vaginal delivery rates } \\
\text { between women managed with } \\
\text { varying partogram strategies. }\end{array}$ & $\begin{array}{l}\text { Moderate } \\
\text { (non-U.S. setting) } \\
\text { Findings consistent with } \\
\text { SR }\end{array}$ \\
\hline & $\begin{array}{l}\text { Process Related } \\
\text { Outcomes - } \\
\text { Parental } \\
\text { Preferences }\end{array}$ & $\begin{array}{l}1 \mathrm{RCT}^{24} \\
(1,929)\end{array}$ & $\begin{array}{l}\text { No difference: An RCT in the } \\
\text { UK demonstrated no difference } \\
\text { in maternal satisfaction scores } \\
\text { between women managed with } \\
\text { a two-hour action line } \\
\text { partogram compared to women } \\
\text { managed with a four-hour } \\
\text { action line partogram. }\end{array}$ & $\begin{array}{l}\text { Low } \\
\text { (non-U.S. setting, } 1 \\
\text { study) }\end{array}$ \\
\hline \multirow[t]{2}{*}{$\begin{array}{l}\text { Adverse } \\
\text { Events }\end{array}$} & $\begin{array}{l}\text { Maternal } \\
\text { Outcomes - } \\
\text { Hemorrhage }\end{array}$ & $\begin{array}{l}3 \mathrm{RCTs}^{24,25,29} \\
(3,700)\end{array}$ & $\begin{array}{l}\text { No difference: No difference } \\
\text { postpartum hemorrhage rates } \\
\text { among women managed with } \\
\text { varying partogram strategies. }\end{array}$ & $\begin{array}{l}\text { Moderate (non-U.S. } \\
\text { setting) }\end{array}$ \\
\hline & $\begin{array}{l}\text { Neonatal } \\
\text { Outcomes - } \\
\text { Acidemia }\end{array}$ & $\begin{array}{l}1 \mathrm{RCT}^{24} \\
(1,929)\end{array}$ & $\begin{array}{l}\text { No difference: No difference in } \\
\text { neonatal acidemia rates } \\
\text { between women managed with } \\
\text { varying partogram strategies. }\end{array}$ & $\begin{array}{l}\text { Low } \\
\text { (non-U.S. setting, } 1 \\
\text { study) }\end{array}$ \\
\hline
\end{tabular}

${ }^{a}$ Criteria for downgrading SOE are described as Rationale; when these criteria are insufficient for understanding the final SOE, additional explanation is provided.

Abbreviations: RCT=randomized controlled trial; SOE=strength of evidence; SR=systematic review

\section{Key Question 2. Amniotomy}

We identified nine RCTs that examined the benefits and harms of amniotomy ( \pm oxytocin) in women in spontaneous labor. ${ }^{35-43}$ Key findings include:

- Amniotomy decreases the total duration of labor in nulliparous women (moderate SOE) and those with unspecified parity (low SOE).

- There was no difference in the rate of cesarean delivery for early amniotomy versus control in women with unspecified parity (moderate SOE)

- There were no differences in rates of maternal infection, hemorrhage, or trauma to the pelvic floor (moderate SOE) for early amniotomy versus control.

- Routine amniotomy plus oxytocin decreases the duration of labor and has a similar effect in both nulliparous and parous women (high SOE).

- Routine amniotomy plus oxytocin does not differ compared with control treatment in cesarean delivery rates in both nulliparous and parous women (high SOE).

Tables B-F summarize the SOE for amniotomy ( \pm oxytocin) versus control treatment. 
Table B. Early amniotomy versus control: Evidence summary in nulliparous women

\begin{tabular}{|c|c|c|c|c|}
\hline Category & Outcome & $\begin{array}{l}\text { Study Design } \\
\text { (Sample Size) }\end{array}$ & Conclusion & $\begin{array}{c}\text { SOE } \\
\text { (Rationale) }^{\mathrm{a}}\end{array}$ \\
\hline $\begin{array}{l}\text { Intermediate } \\
\text { or Final } \\
\text { Outcomes }\end{array}$ & $\begin{array}{l}\text { Process Related } \\
\text { Outcomes - } \\
\text { Duration of Total } \\
\text { Labor }\end{array}$ & $\begin{array}{l}5 \text { RCTS }^{35-37,40,42} \\
(1,593) \\
1 \text { SR (379 } \\
\text { patients, } 4 \\
\text { studies) }^{44}\end{array}$ & $\begin{array}{l}\text { Improvement with early } \\
\text { amniotomy: All trials } \\
\text { demonstrated a decrease in the } \\
\text { duration of labor in women } \\
\text { randomized to early amniotomy. }\end{array}$ & $\begin{array}{l}\text { Moderate } \\
\text { (Medium risk of bias, } \\
\text { Inconsistent, Indirect) } \\
\text { SOE was reduced } \\
\text { given inconsistency } \\
\text { with existing SR which } \\
\text { found no difference in } \\
\text { less contemporary } \\
\text { RCTs }\end{array}$ \\
\hline \multirow[t]{2}{*}{$\begin{array}{l}\text { Adverse } \\
\text { Events }\end{array}$} & $\begin{array}{l}\text { Maternal } \\
\text { Outcomes - } \\
\text { Infection }\end{array}$ & $\begin{array}{l}3 \mathrm{RCTS}^{36,37,42} \\
(1,593)\end{array}$ & $\begin{array}{l}\text { No difference: Two good } \\
\text { quality RCTs and one fair- } \\
\text { quality RCT support no } \\
\text { increased risk of infection }\end{array}$ & Moderate (imprecise) \\
\hline & $\begin{array}{l}\text { Maternal } \\
\text { Outcomes - } \\
\text { Trauma to pelvic } \\
\text { floor }\end{array}$ & $\begin{array}{l}3 \mathrm{RCTs}^{36,37,40} \\
(437)\end{array}$ & $\begin{array}{l}\text { No difference: Three good } \\
\text { quality RCTs support no } \\
\text { evidence of increased risk of } \\
\text { pelvic floor trauma }\end{array}$ & Moderate (imprecise) \\
\hline
\end{tabular}

${ }^{a}$ Criteria for downgrading SOE are described as Rationale; when these criteria are insufficient for understanding the final SOE, additional explanation is provided.

Abbreviations: RCT=randomized controlled trial; SOE=strength of evidence; SR=systematic review

Table C. Early amniotomy versus control: Evidence summary in women with unspecified parity

\begin{tabular}{|c|c|c|c|c|}
\hline Category & Outcome & $\begin{array}{l}\text { Study Design } \\
\text { (Sample Size) }\end{array}$ & Conclusion & $\begin{array}{c}\text { SOE } \\
\text { (Rationale) }^{\mathrm{a}}\end{array}$ \\
\hline \multirow[t]{2}{*}{$\begin{array}{l}\text { Intermediate } \\
\text { or Final } \\
\text { Outcomes }\end{array}$} & $\begin{array}{l}\text { Process Related } \\
\text { Outcomes - } \\
\text { Duration of Total } \\
\text { Labor }\end{array}$ & $\begin{array}{l}4 \mathrm{RCTS}^{36,38,41,43} \\
(912)\end{array}$ & $\begin{array}{l}\text { Improvement with early } \\
\text { amniotomy: Three studies } \\
\text { suggest shorter duration of total } \\
\text { labor with early amniotomy. } \\
\text { One study from the middle east } \\
\text { did not find a difference. }\end{array}$ & $\begin{array}{l}\text { Low (Indirect, } \\
\text { inconsistent) }\end{array}$ \\
\hline & $\begin{array}{l}\text { Process Related } \\
\text { Outcomes - Mode } \\
\text { of Delivery } \\
\text { (Cesarean } \\
\text { Delivery) }\end{array}$ & $\begin{array}{l}4 \mathrm{RCTS}^{36,38,41,43} \\
(912) \\
1 \text { SR (874 } \\
\text { patients, } 3 \\
\text { studies) }^{44}\end{array}$ & $\begin{array}{l}\text { No difference: There was no } \\
\text { difference in the rate of } \\
\text { cesarean delivery between } \\
\text { women randomized to early } \\
\text { amniotomy versus control. }\end{array}$ & $\begin{array}{l}\text { Moderate } \\
\text { (Indirect, consistent) } \\
\text { Existing SR was } \\
\text { consistent with RCT } \\
\text { findings }\end{array}$ \\
\hline \multirow[t]{4}{*}{$\begin{array}{l}\text { Adverse } \\
\text { Events }\end{array}$} & $\begin{array}{l}\text { Maternal } \\
\text { Outcomes - } \\
\text { Infection }\end{array}$ & $\begin{array}{l}2 \mathrm{RCTS}^{36,37} \\
(973)\end{array}$ & $\begin{array}{l}\text { No difference: There was no } \\
\text { evidence of increased risk of } \\
\text { infection associated with early } \\
\text { amniotomy versus control. }\end{array}$ & Moderate (Imprecise) \\
\hline & $\begin{array}{l}\text { Maternal } \\
\text { Outcomes - } \\
\text { Hemorrhage }\end{array}$ & $\begin{array}{l}2 \mathrm{RCTS}^{36,37} \\
(973)\end{array}$ & $\begin{array}{l}\text { No difference: There was no } \\
\text { evidence of increased risk of } \\
\text { maternal hemorrhage } \\
\text { associated with early } \\
\text { amniotomy. }\end{array}$ & Moderate (Imprecise) \\
\hline & $\begin{array}{l}\text { Maternal } \\
\text { Outcomes - } \\
\text { Trauma to Pelvic } \\
\text { Floor }\end{array}$ & $\begin{array}{l}3 \mathrm{RCTs}^{36,37,40} \\
(683)\end{array}$ & $\begin{array}{l}\text { No difference: There was no } \\
\text { evidence of increased risk of } \\
\text { trauma to the pelvic floor } \\
\text { associated with early } \\
\text { amniotomy. }\end{array}$ & $\begin{array}{l}\text { Moderate } \\
\text { (Medium risk of bias) }\end{array}$ \\
\hline & $\begin{array}{l}\text { Neonatal } \\
\text { Outcomes - } \\
\text { Infection }\end{array}$ & $\begin{array}{l}1 \mathrm{RCT}^{37} \\
(690)\end{array}$ & $\begin{array}{l}\text { No difference: There was no } \\
\text { evidence of increased risk of } \\
\text { neonatal infection associated } \\
\text { with early amniotomy. }\end{array}$ & $\begin{array}{l}\text { Low } \\
\text { (1 study) }\end{array}$ \\
\hline
\end{tabular}




\begin{tabular}{|c|l|l|l|l|}
\hline Category & \multicolumn{1}{|c|}{ Outcome } & $\begin{array}{l}\text { Study Design } \\
\text { (Sample Size) }\end{array}$ & \multicolumn{1}{c|}{ Conclusion } & \multicolumn{1}{c|}{$\begin{array}{c}\text { SOE } \\
\text { (Rationale) }^{\mathbf{a}}\end{array}$} \\
\hline & $\begin{array}{l}\text { Process Related } \\
\text { Outcomes - Mode } \\
\text { of Delivery } \\
\text { (Operative } \\
\text { Vaginal Delivery) }\end{array}$ & $\begin{array}{l}\text { (611) } \\
\text { Vafi,38, }\end{array}$ & $\begin{array}{l}\text { No difference: There was no } \\
\text { evidence of increased risk of } \\
\text { operative vaginal delivery } \\
\text { associated with early } \\
\text { amniotomy. }\end{array}$ & $\begin{array}{l}\text { Low } \\
\text { (Indirect, imprecise) }\end{array}$ \\
\hline
\end{tabular}

${ }^{\mathrm{a}}$ Criteria for downgrading SOE are described as Rationale; when these criteria are insufficient for understanding the final SOE, additional explanation is provided.

Abbreviations: RCT=randomized controlled trial; SOE=strength of evidence; SR=systematic review

Table D. Amniotomy plus oxytocin versus control: Evidence summary in nulliparous women

\begin{tabular}{|c|c|c|c|c|}
\hline Category & Outcome & $\begin{array}{l}\text { Study Design } \\
\text { (Sample Size) }\end{array}$ & Conclusion & $\begin{array}{c}\text { SOE } \\
\text { (Rationale) }^{\mathrm{a}}\end{array}$ \\
\hline \multirow[t]{4}{*}{$\begin{array}{l}\text { Intermediate } \\
\text { or Final } \\
\text { Outcomes }\end{array}$} & $\begin{array}{l}\text { Process Related } \\
\text { Outcomes - } \\
\text { Duration of } 1^{\text {st }} \\
\text { Stage Labor }\end{array}$ & $\begin{array}{l}2 \mathrm{SRs}^{45,46} \\
(2,431 \\
\text { patients, } 4 \\
\text { studies) }\end{array}$ & $\begin{array}{l}\text { Improvement with amniotomy } \\
\text { plus oxytocin: Amniotomy plus } \\
\text { oxytocin decreased the duration } \\
\text { of the first stage of labor. }\end{array}$ & High \\
\hline & $\begin{array}{l}\text { Process Related } \\
\text { Outcomes - } \\
\text { Duration of } 2^{\text {nd }} \\
\text { Stage Labor }\end{array}$ & $\begin{array}{l}1 \mathrm{SR}^{45} \\
(2,737 \\
\text { patients, } 5 \\
\text { studies) }\end{array}$ & $\begin{array}{l}\text { No difference: There was no } \\
\text { difference in the duration of } \\
\text { second stage of labor between } \\
\text { groups. }\end{array}$ & Moderate (Imprecise) \\
\hline & $\begin{array}{l}\text { Process Related } \\
\text { Outcomes - } \\
\text { Duration of Total } \\
\text { Labor }\end{array}$ & $\begin{array}{l}2 \mathrm{SRs}^{45,46} \\
(4,675 \\
\text { patients, } 7 \\
\text { studies) }\end{array}$ & $\begin{array}{l}\text { Improvement with amniotomy } \\
\text { plus oxytocin: The duration of } \\
\text { labor was shortened in women } \\
\text { randomized to amniotomy plus } \\
\text { oxytocin as compared to routine } \\
\text { care. }\end{array}$ & High \\
\hline & $\begin{array}{l}\text { Process Related } \\
\text { Outcomes - Mode } \\
\text { of Delivery } \\
\text { (Cesarean } \\
\text { Delivery) }\end{array}$ & $\begin{array}{l}2 \mathrm{SRs}^{45,46} \\
(7,653 \\
\text { patients, } 11 \\
\text { studies) }\end{array}$ & $\begin{array}{l}\text { No difference: There was no } \\
\text { difference in cesarean delivery } \\
\text { rates between amniotomy plus } \\
\text { oxytocin compared with control. }\end{array}$ & High \\
\hline
\end{tabular}

${ }^{a}$ Criteria for downgrading SOE are described as Rationale; when these criteria are insufficient for understanding the final SOE, additional explanation is provided.

Abbreviations: RCT=randomized controlled trial; SOE=strength of evidence; SR=systematic review

Table E. Amniotomy plus oxytocin versus control: Evidence summary in women with unspecified parity

\begin{tabular}{|c|c|c|c|c|}
\hline Category & Outcome & $\begin{array}{l}\text { Study Design } \\
\text { (Sample Size) }\end{array}$ & Conclusion & $\begin{array}{c}\text { SOE } \\
\text { (Rationale) }^{a}\end{array}$ \\
\hline \multirow[t]{4}{*}{$\begin{array}{l}\text { Intermediate } \\
\text { or Final } \\
\text { Outcomes }\end{array}$} & $\begin{array}{l}\text { Process Related } \\
\text { Outcomes }- \\
\text { Duration of } 1^{\text {st }} \\
\text { Stage Labor }\end{array}$ & $\begin{array}{l}2 \mathrm{SRs}^{45,46} \\
(2,431 \\
\text { patients, } 4 \\
\text { studies) }\end{array}$ & $\begin{array}{l}\text { Improvement with amniotomy } \\
\text { plus oxytocin: Amniotomy plus } \\
\text { oxytocin decreased the duration } \\
\text { of the first stage of labor. }\end{array}$ & High \\
\hline & $\begin{array}{l}\text { Process Related } \\
\text { Outcomes - } \\
\text { Duration of } 2^{\text {nd }} \\
\text { Stage Labor }\end{array}$ & $\begin{array}{l}1 \mathrm{SR}^{45} \\
(2,737 \\
\text { patients, } 5 \\
\text { studies) }\end{array}$ & $\begin{array}{l}\text { No difference: There was no } \\
\text { difference in the duration of the } \\
\text { second stage of labor in the } \\
\text { amniotomy plus oxytocin group } \\
\text { as compared with control. }\end{array}$ & Moderate (Imprecise) \\
\hline & $\begin{array}{l}\text { Process Related } \\
\text { Outcomes - } \\
\text { Duration of Total } \\
\text { Labor }\end{array}$ & $\begin{array}{l}2 \mathrm{SRs}^{45,46} \\
(4,675 \\
\text { patients, } 7 \\
\text { studies) }\end{array}$ & $\begin{array}{l}\text { Improvement with amniotomy } \\
\text { plus oxytocin: Amniotomy plus } \\
\text { oxytocin decreased the total } \\
\text { duration of labor. }\end{array}$ & High \\
\hline & $\begin{array}{l}\text { Process Related } \\
\text { Outcomes - Mode } \\
\text { of Delivery } \\
\text { (Cesarean } \\
\text { Delivery) }\end{array}$ & $\begin{array}{l}2 \mathrm{SRs}^{45,46} \\
(7,653 \\
\text { patients, } 11 \\
\text { studies) }\end{array}$ & $\begin{array}{l}\text { No difference: There was no } \\
\text { difference in cesarean delivery } \\
\text { rates between amniotomy plus } \\
\text { oxytocin compared with control. }\end{array}$ & High \\
\hline
\end{tabular}




\begin{tabular}{|c|c|c|c|c|}
\hline Category & Outcome & $\begin{array}{l}\text { Study Design } \\
\text { (Sample Size) }\end{array}$ & Conclusion & $\begin{array}{c}\text { SOE } \\
\text { (Rationale) }^{\mathrm{a}}\end{array}$ \\
\hline \multirow[t]{5}{*}{$\begin{array}{l}\text { Adverse } \\
\text { Events }\end{array}$} & $\begin{array}{l}\text { Maternal } \\
\text { Outcomes - } \\
\text { Infection }\end{array}$ & $\begin{array}{l}3 \mathrm{RCTs}^{37} \\
(1,933) \\
2 \mathrm{SRs}^{44-46} \\
(3,475 \\
\text { patients, } 6 \\
\text { studies) }\end{array}$ & $\begin{array}{l}\text { No difference: There was no } \\
\text { difference in risk of infection } \\
\text { between groups. }\end{array}$ & $\begin{array}{l}\text { High } \\
\text { Findings from existing } \\
\text { SR consistent with RCT } \\
\text { evidence }\end{array}$ \\
\hline & $\begin{array}{l}\text { Maternal } \\
\text { Outcomes - } \\
\text { Hemorrhage }\end{array}$ & $\begin{array}{l}2 \mathrm{SRS}^{44-46} \\
(2,674 \\
\text { patients, } 4 \\
\text { studies) }\end{array}$ & $\begin{array}{l}\text { No difference: No difference in } \\
\text { risk of hemorrhage between } \\
\text { groups. }\end{array}$ & High \\
\hline & $\begin{array}{l}\text { Maternal } \\
\text { Outcomes - } \\
\text { Trauma to the } \\
\text { Pelvic Floor }\end{array}$ & $\begin{array}{l}1 \mathrm{RCT}^{36} \\
(283)\end{array}$ & $\begin{array}{l}\text { No difference: One RCT } \\
\text { examined active management } \\
\text { of labor with early amniotomy } \\
\text { and oxytocin as compared with } \\
\text { routine care, there was no } \\
\text { difference in risk of trauma to } \\
\text { the pelvic floor between groups. }\end{array}$ & $\begin{array}{l}\text { Low } \\
\text { (1 study) }\end{array}$ \\
\hline & $\begin{array}{l}\text { Process Related } \\
\text { Outcomes - Mode } \\
\text { of Delivery } \\
\text { (Operative } \\
\text { Vaginal Delivery } \\
\end{array}$ & $\begin{array}{l}1 \mathrm{SR}^{44,46} \\
(5,738 \\
\text { patients, } 9 \\
\text { studies) }\end{array}$ & $\begin{array}{l}\text { No difference: There was no } \\
\text { difference in risk of operative } \\
\text { vaginal delivery between } \\
\text { groups. }\end{array}$ & High \\
\hline & $\begin{array}{l}\text { Process Related } \\
\text { Outcomes - } \\
\text { Parental } \\
\text { Preferences }\end{array}$ & $\begin{array}{l}2 \text { SRs }^{44-46} \\
\text { (2,436 } \\
\text { patients, } 2 \\
\text { studies) }\end{array}$ & $\begin{array}{l}\text { No difference: No difference } \\
\text { between the two groups in } \\
\text { scores of maternal/parental } \\
\text { satisfaction. }\end{array}$ & $\begin{array}{l}\text { Moderate } \\
\text { (Imprecise, varying } \\
\text { metrics) }\end{array}$ \\
\hline
\end{tabular}

${ }^{a}$ Criteria for downgrading SOE are described as Rationale; when these criteria are insufficient for understanding the final SOE, additional explanation is provided.

Abbreviations: $\mathrm{RCT}=$ randomized controlled trial; $\mathrm{SOE}=$ strength of evidence; $\mathrm{SR}=$ systematic review

Table F. Amniotomy plus oxytocin versus control: Evidence summary in parous women

\begin{tabular}{|c|c|c|c|c|}
\hline Category & Outcome & $\begin{array}{l}\text { Study Design } \\
\text { (Sample Size) }\end{array}$ & Conclusion & $\begin{array}{c}\text { SOE } \\
\text { (Rationale) }^{\mathrm{a}}\end{array}$ \\
\hline \multirow[t]{4}{*}{$\begin{array}{l}\text { Intermediate } \\
\text { or Final } \\
\text { Outcomes }\end{array}$} & $\begin{array}{l}\text { Process Related } \\
\text { Outcomes - } \\
\text { Duration of } 1^{\text {st }} \\
\text { Stage Labor }\end{array}$ & $\begin{array}{l}2 \mathrm{SRs}^{45,46} \\
(2,431 \\
\text { patients, } 4 \\
\text { studies) }\end{array}$ & $\begin{array}{l}\text { Improvement with } \\
\text { amniotomy: Amniotomy } \\
\text { decreased the duration of the } \\
\text { first stage of labor compared } \\
\text { with control }\end{array}$ & Moderate (Imprecise) \\
\hline & $\begin{array}{l}\text { Process Related } \\
\text { Outcomes - } \\
\text { Duration of } 2^{\text {nd }} \\
\text { Stage Labor }\end{array}$ & $\begin{array}{l}1 \mathrm{SR}^{45} \\
(2,737 \\
\text { patients, } 5 \\
\text { studies })\end{array}$ & $\begin{array}{l}\text { No difference: No difference in } \\
\text { the duration of second stage of } \\
\text { labor between groups. }\end{array}$ & Moderate (Imprecise) \\
\hline & $\begin{array}{l}\text { Process Related } \\
\text { Outcomes - } \\
\text { Duration of Total } \\
\text { Labor }\end{array}$ & $\begin{array}{l}2 \mathrm{SRS}^{45,46} \\
(4,675 \\
\text { patients, } 7 \\
\text { studies) }\end{array}$ & $\begin{array}{l}\text { Improvement with amniotomy } \\
\text { plus oxytocin: Modest } \\
\text { decrease in duration of labor in } \\
\text { the intervention group as } \\
\text { compared with controls. }\end{array}$ & Moderate (Imprecise) \\
\hline & $\begin{array}{l}\text { Process Related } \\
\text { Outcomes - Mode } \\
\text { of Delivery } \\
\text { (Cesarean } \\
\text { Delivery) }\end{array}$ & $\begin{array}{l}2 \mathrm{SRs}^{45,46} \\
(7,653 \\
\text { patients, } 11 \\
\text { studies) }\end{array}$ & $\begin{array}{l}\text { No difference: No difference in } \\
\text { the rate of cesarean delivery } \\
\text { between groups. }\end{array}$ & Moderate (Imprecise) \\
\hline
\end{tabular}

${ }^{a}$ Criteria for downgrading SOE are described as Rationale; when these criteria are insufficient for understanding the final SOE, additional explanation is provided.

Abbreviations: RCT=randomized controlled trial; SOE=strength of evidence; SR=systematic review 


\section{Key Question 3. Supportive Care}

We identified 64 articles ${ }^{47-110}$ representing 61 individual RCTs that examined the benefits and harms of supportive care measures in women during spontaneous labor. Supportive care measures included interventions such as continuous emotional support, perineal massage, water birth, acupuncture, ambulation and positioning strategies.

Key findings include:

- Supportive care measures during labor encompass a wide variety of interventions and within individual categories of interventions, there is considerable heterogeneity in the nature and timing of the interventions.

- Although supportive care therapies are often seen as increasing parental satisfaction with the birthing process, these outcomes were only assessed in five of the included RCTs with sparse evidence. An earlier SR of 11 studies however did find that women receiving continuous emotional support were less likely to rate their birth experience negatively (moderate SOE).

- Two studies addressing continuous emotional support included in the present review did not show a benefit in reducing $1^{\text {st }}$ or $2^{\text {nd }}$ stage labor duration, although prior SR/MAs of 12 studies (including these two studies) indicated a benefit for total labor duration (moderate SOE).

- Emotional support interventions reduced cesarean deliveries (low SOE for doula support, moderate SOE for continuous emotional support) and instrumental deliveries (moderate SOE).

- There was no difference in rates of cesarean deliveries for women receiving perineal compresses or massage (low SOE), but severe perineal trauma was reduced in nulliparous women (low SOE).

- There was no difference in duration of labor in women using water birth (low SOE).

- Women undergoing acupuncture/acupoint nerve stimulator did not experience differences in labor duration or rates of maternal hemorrhage (low SOE for both outcomes).

- Ambulation was associated with shorter duration of labor (low SOE).

- No differences were found in duration of labor (low SOE) or cesarean delivery rates (moderate SOE) for women using differing positioning interventions. Women in kneeling position were more likely than women in sitting position to have reduced trauma to the pelvic floor (low SOE).

- Administration of intravenous fluids compared with oral intake alone demonstrated a reduction in the duration of labor (low SOE), while not increasing cesarean delivery rates (moderate SOE), maternal hemorrhage (low SOE), or operative vaginal delivery rates (moderate SOE).

Table G summarizes the SOE for continuous emotional support versus control in nulliparous women. Strength of evidence for continuous emotional support versus control in women of mixed parity was rated as insufficient for all outcomes. 
Table G. Continuous emotional support versus control: Evidence summary in nulliparous women

\begin{tabular}{|c|c|c|c|c|}
\hline Category & Outcome & $\begin{array}{l}\text { Study Design } \\
\text { (Sample Size) }\end{array}$ & Conclusion & $\begin{array}{c}\text { SOE } \\
\text { (Rationale) }^{a} \\
\end{array}$ \\
\hline \multirow[t]{5}{*}{$\begin{array}{l}\text { Intermediate } \\
\text { or Final } \\
\text { Outcomes }\end{array}$} & $\begin{array}{l}\text { Process Related } \\
\text { Outcomes - } \\
\text { Duration of } 1^{\text {st }} \\
\text { Stage Labor }\end{array}$ & $\begin{array}{l}2 \mathrm{RCTS}^{79,90} \\
(326)\end{array}$ & $\begin{array}{l}\text { No difference: Good-quality } \\
\text { studies of nulliparous women } \\
\text { found that continuous emotional } \\
\text { support did not reduce duration } \\
\text { of } 1^{\text {st }} \text { stage labor. }\end{array}$ & $\begin{array}{l}\text { Moderate } \\
\text { (Indirect) }\end{array}$ \\
\hline & $\begin{array}{l}\text { Process Related } \\
\text { Outcomes - } \\
\text { Duration of } 2^{\text {nd }} \\
\text { Stage Labor }\end{array}$ & $\begin{array}{l}2 \mathrm{RCTS}^{79,90} \\
(326)\end{array}$ & $\begin{array}{l}\text { No difference: Good-quality } \\
\text { studies of nulliparous women } \\
\text { found that continuous emotional } \\
\text { support did not reduce duration } \\
\text { of } 2^{\text {nd }} \text { stage labor. }\end{array}$ & $\begin{array}{l}\text { Moderate } \\
\text { (Indirect) }\end{array}$ \\
\hline & $\begin{array}{l}\text { Process Related } \\
\text { Outcomes - } \\
\text { Duration of Total } \\
\text { Labor }\end{array}$ & $\begin{array}{l}\mathrm{SR}^{111} \\
(5,366 \\
\text { patients, } 12 \\
\text { studies) }\end{array}$ & $\begin{array}{l}\text { Improvement with continuous } \\
\text { emotional support: Systematic } \\
\text { review of } 12 \text { studies found } \\
\text { shorter total duration of labor }\end{array}$ & $\begin{array}{l}\text { Moderate } \\
\text { (Indirect) }\end{array}$ \\
\hline & $\begin{array}{l}\text { Process Related } \\
\text { Outcomes - Mode } \\
\text { of Delivery } \\
\text { (Cesarean } \\
\text { Delivery) }\end{array}$ & $\begin{array}{l}\text { 2 RCTs }{ }^{70,79} \\
\text { (599) } \\
\text { Doula support: } \\
1 \mathrm{SR}^{111,112} \\
\text { (2,008 } \\
\text { patients, } 5 \\
\text { studies) } \\
\text { Continuous } \\
\text { emotional } \\
\text { support: } \\
1 \text { SR }{ }^{111} \\
\text { (5,366 } \\
\text { patients, } 12 \\
\text { studies) }\end{array}$ & $\begin{array}{l}\text { Improvement with Doula } \\
\text { support: Doula support } \\
\text { reduced cesarean deliveries as } \\
\text { compared to control therapy. } \\
\text { Improvement with continuous } \\
\text { emotional support: } \\
\text { Continuous emotional support } \\
\text { lowered risk of cesarean } \\
\text { delivery (RR } 0.78,95 \% \mathrm{Cl} 0.67 \\
\text { to } 0.91 \text { ) based on SR of } 22 \\
\text { studies. }\end{array}$ & $\begin{array}{l}\text { Low - Doula } \\
\text { (Indirect) } \\
\text { Inconsistency between } \\
\text { SRs and included RCTs } \\
\text { Moderate - Continuous } \\
\text { Emotional Support } \\
\text { (Indirect) }\end{array}$ \\
\hline & $\begin{array}{l}\text { Process Related } \\
\text { Outcomes - Mode } \\
\text { of Delivery } \\
\text { (Instrumental } \\
\text { Delivery) }\end{array}$ & $\begin{array}{l}\text { Doula support: } \\
1 \text { SR }{ }^{111,112} \\
\text { (1,587 } \\
\text { patients, } 4 \\
\text { studies) } \\
\text { Continuous } \\
\text { emotional } \\
\text { support: } \\
1 \text { SR }{ }^{111} \\
\text { (14,118 } \\
\text { patients, } 19 \\
\text { studies) }\end{array}$ & $\begin{array}{l}\text { Improvement with Doula } \\
\text { support: Doula support } \\
\text { reduced risk of instrumental } \\
\text { vaginal delivery } \\
\text { Improvement with continuous } \\
\text { emotional support: } \\
\text { Continuous emotional support } \\
\text { lowered risk of instrumental } \\
\text { vaginal delivery based on SR of } \\
19 \text { studies. }\end{array}$ & $\begin{array}{l}\text { Moderate } \\
\text { (Indirect) }\end{array}$ \\
\hline \multirow[t]{2}{*}{$\begin{array}{l}\text { Adverse } \\
\text { Events }\end{array}$} & $\begin{array}{l}\text { Process Related } \\
\text { Outcomes - } \\
\text { Abnormal Fetal } \\
\text { Heat Tracing }\end{array}$ & $\begin{array}{l}1 \mathrm{RCTs}^{79} \\
(212)\end{array}$ & $\begin{array}{l}\text { No difference: Supportive care } \\
\text { was not associated with } \\
\text { significant differences in fetal } \\
\text { heart tracings. }\end{array}$ & $\begin{array}{l}\text { Low } \\
\text { (Indirect, imprecise, } 1 \\
\text { study) }\end{array}$ \\
\hline & $\begin{array}{l}\text { Process Related } \\
\text { Outcomes - } \\
\text { Parental } \\
\text { Preferences }\end{array}$ & $\begin{array}{l}1 \mathrm{SR}^{111} \\
(11,133 \\
\text { patients, } 11 \\
\text { studies) }\end{array}$ & $\begin{array}{l}\text { Improvement with continuous } \\
\text { emotional support: SR of } 11 \\
\text { studies found women receiving } \\
\text { continuous emotional support } \\
\text { less likely to rate their birth } \\
\text { experience negatively }\end{array}$ & Moderate \\
\hline
\end{tabular}

${ }^{a}$ Criteria for downgrading SOE are described as Rationale; when these criteria are insufficient for understanding the final SOE, additional explanation is provided.

Abbreviations: $\mathrm{CI}=$ confidence interval; hr=hours; RCT=randomized controlled trial; RR=relative risk; SOE=strength of evidence; $\mathrm{SR}=$ systematic review 
Tables H-K summarize the SOE for perineal compresses or massage versus control in nulliparous women and women of mixed parity. In general the SOE was rated as low given evidence from only one study.

Table H. Perineal compresses or massage versus control: Evidence summary in nulliparous women

\begin{tabular}{|c|c|c|c|c|}
\hline Category & Outcome & $\begin{array}{l}\text { Study Design } \\
\text { (Sample Size) }\end{array}$ & Conclusion & $\begin{array}{c}\text { SOE } \\
\text { (Rationale) }^{a}\end{array}$ \\
\hline $\begin{array}{l}\text { Intermediate } \\
\text { or Final } \\
\text { Outcomes }\end{array}$ & $\begin{array}{l}\text { Process Related } \\
\text { Outcomes - Mode } \\
\text { of Delivery } \\
\text { (Cesarean } \\
\text { Delivery) }\end{array}$ & $\begin{array}{l}1 \mathrm{RCT}^{87} \\
(717)\end{array}$ & $\begin{array}{l}\text { No difference: No significant } \\
\text { differences in the proportion of } \\
\text { cesarean deliveries was } \\
\text { reported for the } \\
\text { massage/compress group. }\end{array}$ & $\begin{array}{l}\text { Low } \\
\text { (Indirect, } 1 \text { study) }\end{array}$ \\
\hline $\begin{array}{l}\text { Adverse } \\
\text { Events }\end{array}$ & $\begin{array}{l}\text { Maternal } \\
\text { Outcomes - } \\
\text { Trauma to the } \\
\text { Pelvic Floor }\end{array}$ & $\begin{array}{l}1 \mathrm{RCT}^{87} \\
(717)\end{array}$ & $\begin{array}{l}\text { Improvement with } \\
\text { massage/compress: Severe } \\
\text { perineal trauma (third- and } \\
\text { fourth-degree perineal } \\
\text { laceration) was lower incidence } \\
\text { for the massage/compress } \\
\text { group. }\end{array}$ & $\begin{array}{l}\text { Low } \\
\text { (1 study) }\end{array}$ \\
\hline
\end{tabular}

${ }^{a}$ Criteria for downgrading SOE are described as Rationale; when these criteria are insufficient for understanding the final SOE, additional explanation is provided.

Abbreviations: RCT=randomized controlled trial; SOE=strength of evidence

Table I. Perineal compresses or massage versus control: Evidence summary in women of mixed parity

\begin{tabular}{|c|c|c|c|c|}
\hline Category & Outcome & $\begin{array}{l}\text { Study Design } \\
\text { (Sample Size) }\end{array}$ & Conclusion & $\begin{array}{c}\text { SOE } \\
\text { (Rationale) }^{2}\end{array}$ \\
\hline \multirow[t]{2}{*}{$\begin{array}{l}\text { Intermediate } \\
\text { or Final } \\
\text { Outcomes }\end{array}$} & $\begin{array}{l}\text { Process Related } \\
\text { Outcomes - } \\
\text { Duration of } 2^{\text {nd }} \\
\text { Stage Labor }\end{array}$ & $\begin{array}{l}1 \mathrm{RCT}^{76} \\
(1,211)\end{array}$ & $\begin{array}{l}\text { No difference: Duration of } 2 \text { nd } \\
\text { stage labor was not statistically } \\
\text { significantly different between } \\
\text { the intervention and usual care } \\
\text { groups. }\end{array}$ & $\begin{array}{l}\text { Low } \\
\text { (Indirect, } 1 \text { study) }\end{array}$ \\
\hline & $\begin{array}{l}\text { Process Related } \\
\text { Outcomes - Mode } \\
\text { of Delivery } \\
\text { (Cesarean } \\
\text { Delivery) }\end{array}$ & $\begin{array}{l}1 \mathrm{RCT}^{76} \\
(1,211)\end{array}$ & $\begin{array}{l}\text { No difference: No significant } \\
\text { differences in the proportion of } \\
\text { cesarean deliveries was } \\
\text { reported for the } \\
\text { massage/compress group. }\end{array}$ & $\begin{array}{l}\text { Low } \\
\text { (Indirect, } 1 \text { study) }\end{array}$ \\
\hline $\begin{array}{l}\text { Adverse } \\
\text { Events }\end{array}$ & $\begin{array}{l}\text { Maternal } \\
\text { Outcomes - } \\
\text { Trauma to the } \\
\text { Pelvic Floor }\end{array}$ & $\begin{array}{l}1 \mathrm{RCT}^{76} \\
(1,211)\end{array}$ & $\begin{array}{l}\text { No difference: No significant } \\
\text { differences in perineal trauma } \\
\text { were reported between the } \\
\text { intervention and control groups. }\end{array}$ & $\begin{array}{l}\text { Low } \\
\text { (1 study) }\end{array}$ \\
\hline
\end{tabular}

${ }^{a}$ Criteria for downgrading SOE are described as Rationale; when these criteria are insufficient for understanding the final SOE, additional explanation is provided.

Abbreviations: RCT=randomized controlled trial; SOE=strength of evidence

Table J. Massage during labor versus control: Evidence summary in nulliparous women

\begin{tabular}{|l|l|l|l|l|}
\hline \multicolumn{1}{|c|}{ Category } & \multicolumn{1}{|c|}{ Outcome } & $\begin{array}{l}\text { Study Design } \\
\text { (Sample Size) }\end{array}$ & \multicolumn{1}{c|}{ Conclusion } & \multicolumn{1}{c|}{$\begin{array}{c}\text { SOE } \\
\text { (Rationale) }^{\mathbf{a}}\end{array}$} \\
\hline $\begin{array}{l}\text { Intermediate } \\
\text { or Final } \\
\text { Outcomes }\end{array}$ & $\begin{array}{l}\text { Process Related } \\
\text { Outcomes - } \\
\text { Duration of Total } \\
\text { Labor }\end{array}$ & $\begin{array}{l}\text { RCTs } \\
(123), 57\end{array}$ & $\begin{array}{l}\text { No difference: Total duration of } \\
\text { labor was not significantly } \\
\text { different in the massage group } \\
\text { compared to usual care. }\end{array}$ & $\begin{array}{l}\text { Low } \\
\text { (Indirect, Imprecise) }\end{array}$ \\
\cline { 2 - 5 } & $\begin{array}{l}\text { Process Related } \\
\text { Outcomes - Mode } \\
\text { of Delivery } \\
\text { (Cesarean } \\
\text { Delivery) }\end{array}$ & $\begin{array}{l}\text { 2 RCTs } \\
(123)\end{array}$ & $\begin{array}{l}\text { No difference: The proportion } \\
\text { of cesarean deliveries was not } \\
\text { significantly different between } \\
\text { the massage group and control } \\
\text { group. }\end{array}$ & $\begin{array}{l}\text { Low } \\
\text { (Indirect, Imprecise) }\end{array}$ \\
\hline
\end{tabular}


${ }^{\text {a }}$ Criteria for downgrading SOE are described as Rationale; when these criteria are insufficient for understanding the final SOE, additional explanation is provided.

Abbreviations: RCT=randomized controlled trial; SOE=strength of evidence

Table K. Water birth versus control: Evidence summary in women of mixed parity

\begin{tabular}{|c|c|c|c|c|}
\hline Category & Outcome & $\begin{array}{l}\text { Study Design } \\
\text { (Sample Size) }\end{array}$ & Conclusion & $\begin{array}{c}\text { SOE } \\
\text { (Rationale) }^{\mathrm{a}}\end{array}$ \\
\hline $\begin{array}{l}\text { Intermediate } \\
\text { or Final } \\
\text { Outcomes }\end{array}$ & $\begin{array}{l}\text { Process Related } \\
\text { Outcomes - } \\
\text { Duration of } 2^{\text {nd }} \\
\text { Stage Labor }\end{array}$ & $\begin{array}{l}1 \mathrm{RCT}^{68} \\
(106) \\
1 \mathrm{SR}^{113} \\
\text { (291 patients, } \\
2 \text { studies) }\end{array}$ & $\begin{array}{l}\text { No difference: No difference in } \\
\text { duration of } 2^{\text {nd }} \text { stage labor was } \\
\text { reported. }\end{array}$ & $\begin{array}{l}\text { Low } \\
\text { (Medium risk of bias, } \\
\text { indirect, imprecise) } \\
\text { SOE was increased to } \\
\text { low given findings from } \\
\text { SR which also } \\
\text { demonstrated no } \\
\text { difference between } \\
\text { water birth versus } \\
\text { control }\end{array}$ \\
\hline
\end{tabular}

${ }^{a}$ Criteria for downgrading SOE are described as Rationale; when these criteria are insufficient for understanding the final SOE, additional explanation is provided.

Abbreviations: RCT=randomized controlled trial; SOE=strength of evidence; SR=systematic review

For the studies which compared acupressure versus control, although findings were consistent between studies, the SOE was rated as insufficient for all outcomes given the small number of patients, the potential risk of bias, and the imprecision of the findings.

Tables L and M summarize the SOE for acupuncture/acupoint nerve stimulator versus control therapy. Other than the outcomes listed below, the SOE was rated as insufficient for all other outcomes given inconsistent findings from studies with variability in interventions.

Table L. Acupuncture/acupoint nerve stimulator versus control: Evidence summary in nulliparous women

\begin{tabular}{|c|c|c|c|c|}
\hline Category & Outcome & $\begin{array}{l}\text { Study Design } \\
\text { (Sample Size) }\end{array}$ & Conclusion & $\begin{array}{c}\text { SOE } \\
\text { (Rationale) }^{a}\end{array}$ \\
\hline $\begin{array}{l}\text { Intermediate } \\
\text { or Final } \\
\text { Outcomes }\end{array}$ & $\begin{array}{l}\text { Process Related } \\
\text { Outcomes - } \\
\text { Duration of } 2^{\text {nd }} \\
\text { Stage Labor }\end{array}$ & $\begin{array}{l}4 \\
\text { RCTs } 47,66,104,110 \\
(601)\end{array}$ & $\begin{array}{l}\text { No difference: in } 2^{\text {nd }} \text { stage } \\
\text { labor between the acupuncture } \\
\text { and control groups was } \\
\text { reported. }\end{array}$ & $\begin{array}{l}\text { Low } \\
\text { (Medium risk of bias, } \\
\text { indirect, Imprecise) }\end{array}$ \\
\hline
\end{tabular}

${ }^{a}$ Criteria for downgrading SOE are described as Rationale; when these criteria are insufficient for understanding the final SOE, additional explanation is provided.

Abbreviations: RCT=randomized controlled trial; SOE=strength of evidence

Table M. Acupuncture/acupoint nerve stimulator versus control: Evidence summary in women of mixed parity

\begin{tabular}{|l|l|l|l|l|}
\hline \multicolumn{1}{|c|}{ Category } & \multicolumn{1}{|c|}{ Outcome } & $\begin{array}{l}\text { Study Design } \\
\text { (Sample Size) }\end{array}$ & \multicolumn{1}{c|}{ Conclusion } & \multicolumn{1}{c|}{$\begin{array}{c}\text { SOE } \\
\text { (Rationale) }^{\text {a }}\end{array}$} \\
\hline $\begin{array}{l}\text { Intermediate } \\
\text { or Final } \\
\text { Outcomes }\end{array}$ & $\begin{array}{l}\text { Process Related } \\
\text { Outcomes - } \\
\text { Duration of } 2^{\text {nd }} \\
\text { Stage Labor }\end{array}$ & $\begin{array}{l}2 \text { RCTs } \\
(350)\end{array}$ & $\begin{array}{l}\text { No difference: No significant } \\
\text { difference in 2 } \\
\text { between the acupuncture and } \\
\text { control groups was reported. }\end{array}$ & $\begin{array}{l}\text { Low } \\
\text { (Medium risk of bias, } \\
\text { indirect, imprecise) }\end{array}$ \\
\hline $\begin{array}{l}\text { Adverse } \\
\text { Events }\end{array}$ & $\begin{array}{l}\text { Maternal } \\
\text { Outcomes - } \\
\text { Hemorrhage }\end{array}$ & $\begin{array}{l}1 \mathrm{RCT}^{53} \\
(253)\end{array}$ & $\begin{array}{l}\text { No difference: No significant } \\
\text { difference in hemorrhage was } \\
\text { reported for the intervention } \\
\text { group compared to the control. }\end{array}$ & $\begin{array}{l}\text { Low (High risk of bias, } \\
\text { imprecise) }\end{array}$ \\
\hline
\end{tabular}

${ }^{a}$ Criteria for downgrading SOE are described as Rationale; when these criteria are insufficient for understanding the final SOE, additional explanation is provided.

Abbreviations: RCT=randomized controlled trial; SOE=strength of evidence 
The SOE findings for all outcomes comparing aromatherapy and control treatment was rated as insufficient given the potential risk of bias, small study size, and inconsistent findings. The SOE findings for outcomes comparing Anetheum graveolens seeds (dill) and control treatment was rated as insufficient.

Tables N-P summarize the SOE for ambulation or positioning versus control therapy. Overall the SOE was reduced given the potential risk of bias in the included studies.

Table N. Ambulation versus control: Evidence summary in nulliparous women

\begin{tabular}{|l|l|l|l|l|}
\hline \multicolumn{1}{|c|}{ Category } & \multicolumn{1}{c|}{ Outcome } & $\begin{array}{l}\text { Study Design } \\
\text { (Sample Size) }\end{array}$ & \multicolumn{1}{c|}{ Conclusion } & \multicolumn{1}{c|}{$\begin{array}{c}\text { SOE } \\
\text { (Rationale) }^{\mathbf{a}}\end{array}$} \\
\hline $\begin{array}{l}\text { Intermediate } \\
\text { or Final } \\
\text { Outcomes }\end{array}$ & $\begin{array}{l}\text { Process Related } \\
\text { Outcomes - } \\
\text { Duration of 1 } \\
\text { Stage Labor }\end{array}$ & $\begin{array}{l}2 \mathrm{RCTs}{ }^{77,80} \\
(271)\end{array}$ & $\begin{array}{l}\text { Improvement with } \\
\text { ambulation: 1 good-quality80 } \\
\text { and 1 poor-quality study } \\
\text { that found } \\
\text { with significantly reduced } \\
\text { duration of the first stage and } \\
\text { total duration of labor. }\end{array}$ & $\begin{array}{l}\text { Low } \\
\text { (Medium risk of bias, } \\
\text { indirect, imprecise, } \\
\text { inconsistent with SR) }\end{array}$ \\
\hline
\end{tabular}

${ }^{a}$ Criteria for downgrading SOE are described as Rationale; when these criteria are insufficient for understanding the final SOE, additional explanation is provided.

Abbreviations: RCT=randomized controlled trial; SOE=strength of evidence; SR=systematic review

Table O. Positioning versus control: Evidence summary in nulliparous women

\begin{tabular}{|c|c|c|c|c|}
\hline Category & Outcome & $\begin{array}{l}\text { Study Design } \\
\text { (Sample Size) }\end{array}$ & Conclusion & $\begin{array}{c}\text { SOE } \\
\text { (Rationale) }^{\mathrm{a}}\end{array}$ \\
\hline \multirow[t]{2}{*}{$\begin{array}{l}\text { Intermediate } \\
\text { or Final } \\
\text { Outcomes }\end{array}$} & $\begin{array}{l}\text { Process Related } \\
\text { Outcomes }- \\
\text { Duration of } 1^{\text {st }} \\
\text { Stage Labor }\end{array}$ & $\begin{array}{l}5 \\
\mathrm{RCTS}^{65,71,74,86,91} \\
(798)\end{array}$ & $\begin{array}{l}\text { No difference: None of the } \\
\text { studies examining use of a birth } \\
\text { ball, kneeling, sitting, or semi- } \\
\text { sitting laboring positions found } \\
\text { statistically significant } \\
\text { differences in duration of active } \\
\text { labor. }\end{array}$ & $\begin{array}{l}\text { Low } \\
\text { (High risk of bias, } \\
\text { indirect, imprecise, } \\
\text { inconsistent with SR) }\end{array}$ \\
\hline & $\begin{array}{l}\text { Process Related } \\
\text { Outcomes - Mode } \\
\text { of Delivery } \\
\text { (Cesarean } \\
\text { Delivery) }\end{array}$ & $\begin{array}{l}5 \\
\mathrm{RCTs}^{59,74,96,100,1} \\
01 \\
(4,546) \\
1 \mathrm{SR}^{114} \\
(2,079 \\
\text { patients, } 8 \\
\text { studies) }\end{array}$ & $\begin{array}{l}\text { No difference: No significant } \\
\text { differences were found between } \\
\text { the intervention and control } \\
\text { groups in mode of delivery. }\end{array}$ & $\begin{array}{l}\text { Moderate (Medium risk } \\
\text { of bias, indirect, } \\
\text { imprecise, consistent) } \\
\text { The SOE was } \\
\text { increased given the } \\
\text { support of a SR of } 11 \\
\text { studies. }\end{array}$ \\
\hline $\begin{array}{l}\text { Adverse } \\
\text { Events }\end{array}$ & $\begin{array}{l}\text { Maternal } \\
\text { Outcomes - } \\
\text { Trauma to the } \\
\text { Pelvic Floor }\end{array}$ & $\begin{array}{l}1 \mathrm{RCT}^{74} \\
(271)\end{array}$ & $\begin{array}{l}\text { Improvement with kneeling: } \\
\text { Women in kneeling position } \\
\text { were more likely than women in } \\
\text { sitting position to have an intact } \\
\text { perineum ( } 51 \text { vs. } 37 \% \text { ) and } \\
\text { fewer } 3 \text { rd or } 4 \text { th degree tears ( } 3 \\
\text { vs. } 6 \% \text { ). }\end{array}$ & $\begin{array}{l}\text { Low } \\
\text { (Imprecise, one study) }\end{array}$ \\
\hline
\end{tabular}

${ }^{a}$ Criteria for downgrading SOE are described as Rationale; when these criteria are insufficient for understanding the final SOE, additional explanation is provided.

Abbreviations: RCT=randomized controlled trial; $\mathrm{SOE}=$ strength of evidence; $\mathrm{SR}=$ systematic review 
Table P. Positioning versus control: Evidence summary in women of mixed parity

\begin{tabular}{|l|l|l|l|l|}
\hline \multicolumn{1}{|c|}{ Category } & \multicolumn{1}{|c|}{ Outcome } & $\begin{array}{l}\text { Study Design } \\
\text { (Sample Size) }\end{array}$ & \multicolumn{1}{c|}{ Conclusion } & \multicolumn{1}{c|}{$\begin{array}{c}\text { SOE } \\
\text { (Rationale) }^{\mathbf{a}}\end{array}$} \\
\hline $\begin{array}{l}\text { Intermediate } \\
\text { or Final } \\
\text { Outcomes }\end{array}$ & $\begin{array}{l}\text { Process Related } \\
\text { Outcomes }- \\
\text { Duration of 2 } \\
\text { Stage Labor }\end{array}$ & $\begin{array}{l}\text { RCTs } \\
(1,28,81,98\end{array}$ & $\begin{array}{l}\text { Improvement with } \\
\text { positioning: Second stage of } \\
\text { labor was significantly shorter in } \\
\text { women using either a peanut } \\
\text { ball or a squatting position. }\end{array}$ & $\begin{array}{l}\text { Low } \\
\text { (Medium risk of bias, } \\
\text { indirect, Imprecise) }\end{array}$ \\
\end{tabular}

${ }^{a}$ Criteria for downgrading SOE are described as Rationale; when these criteria are insufficient for understanding the final SOE, additional explanation is provided.

Abbreviations: RCT=randomized controlled trial; SOE=strength of evidence

Table Q summarizes the SOE for nutritional intervention and oral or parenteral hydration intervention in nulliparous women. The SOE was insufficient for outcomes in women of mixed parity.

Table Q. Specific nutritional intervention and oral or parenteral hydration intervention recommendations or limitations: Evidence summary in nulliparous women

\begin{tabular}{|c|c|c|c|c|}
\hline Category & Outcome & $\begin{array}{l}\text { Study Design } \\
\text { (Sample Size) }\end{array}$ & Conclusion & $\begin{array}{c}\text { SOE } \\
\text { (Rationale) }^{a}\end{array}$ \\
\hline \multirow[t]{2}{*}{$\begin{array}{l}\text { Intermediate } \\
\text { or Final } \\
\text { Outcomes }\end{array}$} & $\begin{array}{l}\text { Process Related } \\
\text { Outcomes - } \\
\text { Duration of Total } \\
\text { Labor }\end{array}$ & $\begin{array}{l}3 \mathrm{RCTs}^{55,60,73} \\
(861) \\
1 \mathrm{SR}^{115} \\
(1,781 \\
\text { patients, } 9 \\
\text { studies) }\end{array}$ & $\begin{array}{l}\text { Improvement with } \\
\text { intravenous fluids: } \\
\text { Administration of intravenous } \\
\text { fluids compared with oral intake } \\
\text { alone demonstrated a reduction } \\
\text { in the duration of labor. }\end{array}$ & $\begin{array}{l}\text { Low (Indirect, } \\
\text { inconsistent, imprecise) } \\
\text { The SOE was reduced } \\
\text { given the inconsistency } \\
\text { in the findings of } \\
\text { individual trials and with } \\
\text { the SR and the } \\
\text { variability in hydration } \\
\text { strategies. }\end{array}$ \\
\hline & $\begin{array}{l}\text { Process Related } \\
\text { Outcomes - Mode } \\
\text { of Delivery } \\
\text { (Cesarean } \\
\text { Delivery) }\end{array}$ & $\begin{array}{l}6 \\
\text { RCTs } \\
, 73,61,64,67,69 \\
(1,373)\end{array}$ & $\begin{array}{l}\text { No difference: No significant } \\
\text { differences were found between } \\
\text { groups of women receiving oral } \\
\text { hydration versus high-level } \\
\text { intravenous hydration (OR } 1.26 \text {, } \\
95 \% \mathrm{Cl} 0.08 \text { to } 18.84 \text { ). }\end{array}$ & $\begin{array}{l}\text { Moderate (Indirect, } \\
\text { Imprecise) }\end{array}$ \\
\hline \multirow[t]{2}{*}{$\begin{array}{l}\text { Adverse } \\
\text { Events }\end{array}$} & $\begin{array}{l}\text { Maternal } \\
\text { Outcomes - } \\
\text { Hemorrhage or } \\
\text { Infection }\end{array}$ & $\begin{array}{l}2 \mathrm{RCTS}^{60,69} \\
(539)\end{array}$ & $\begin{array}{l}\text { No difference: No significant } \\
\text { differences in rates of maternal } \\
\text { hemorrhage or infection were } \\
\text { found between groups of } \\
\text { women receiving infusions of } \\
5 \% \text { or } 10 \% \text { dextrose and } \\
\text { normal saline. }\end{array}$ & $\begin{array}{l}\text { Low } \\
\text { (Imprecise) }\end{array}$ \\
\hline & $\begin{array}{l}\text { Process Related } \\
\text { Outcomes - Mode } \\
\text { of Delivery } \\
\text { (Operative } \\
\text { Vaginal Delivery) }\end{array}$ & $\begin{array}{l}5 \mathrm{RCTS}^{55,60,67,73} \\
(1,234)\end{array}$ & $\begin{array}{l}\text { No difference: No difference in } \\
\text { operative vaginal delivery rates } \\
\text { amongst } 5 \text { studies using } \\
\text { varying methods of hydration. }\end{array}$ & $\begin{array}{l}\text { Moderate (Indirect, } \\
\text { Imprecise) }\end{array}$ \\
\hline
\end{tabular}

${ }^{a}$ Criteria for downgrading SOE are described as Rationale; when these criteria are insufficient for understanding the final SOE, additional explanation is provided.

Abbreviations: $\mathrm{CI}=$ confidence interval; $\mathrm{OR}=$ odds ratio; $\mathrm{RCT}=$ randomized controlled trial; $\mathrm{SOE}=$ strength of evidence;

$\mathrm{SR}=$ systematic review 


\section{Key Question 4. Epidural Analgesia}

We identified 26 articles ${ }^{47,104,110,116-138}$ representing 22 individual RCTs that examined the benefits and harms of epidural analgesia (EA) in labor. Key findings included:

- For nulliparous women, a meta-analysis showed no significant differences between EA and combined spinal epidural (CSE) in duration of the first stage of labor (low SOE) or duration of the second stage of labor (low SOE). However, total duration of labor (from time of intervention to delivery) was significantly longer for EA relative to CSE (moderate SOE). There were no differences between EA and CSE in rates of cesarean delivery (moderate SOE).

- For women of mixed parity, there was no difference between EA and CSE for total duration of labor (low SOE), or rates of cesarean delivery (moderate SOE).

- For women of mixed parity, there were no differences between EA and patientcontrolled intravenous analgesia (PCIA) in duration of labor or rates of cesarean delivery (low SOE for both outcomes).

- For nulliparous women, there was no difference in duration of first or second stage labor or rates of cesarean delivery for early versus late EA (moderate SOE for all outcomes).

- For women of mixed parity, there was no evidence of a difference between EA and no EA for the duration of the first stage of labor or rates of cesarean delivery. There was a slight increase in the duration of the second stage for women with EA (moderate SOE for all outcomes).

Tables R and S summarize the SOE for EA versus CSE. In general, meta-analysis of the included studies resulted in low and moderate SOE for major outcomes of interest.

Table R. Epidural analgesia versus combined spinal epidural: Evidence summary in nulliparous women

\begin{tabular}{|c|c|c|c|c|}
\hline Category & Outcome & $\begin{array}{l}\text { Study Design } \\
\text { (Sample Size) }\end{array}$ & Conclusion & $\begin{array}{c}\text { SOE } \\
\text { (Rationale) }^{\mathrm{a}}\end{array}$ \\
\hline \multirow[t]{3}{*}{$\begin{array}{l}\text { Intermediate } \\
\text { or Final } \\
\text { Outcomes }\end{array}$} & $\begin{array}{l}\text { Process Related } \\
\text { Outcomes - } \\
\text { Duration of } 1^{\text {st }} \\
\text { Stage Labor }\end{array}$ & $\begin{array}{l}5 \\
\text { RCTs } 119,123,125,1 \\
31,136 \\
(1,424)\end{array}$ & $\begin{array}{l}\text { No difference: Meta-analysis } \\
\text { showed no significant } \\
\text { differences between EA and } \\
\text { CSE in duration of the first } \\
\text { stage of labor (mean difference } \\
\text { [MD] } 32.7 \text { minutes; } 95 \% \\
\mathrm{Cl}-19.3 \text { to } 84.7 \text { ). }\end{array}$ & $\begin{array}{l}\text { Low } \\
\text { (Medium risk of bias, } \\
\text { indirect, inconsistent, } \\
\text { imprecise) }\end{array}$ \\
\hline & $\begin{array}{l}\text { Process Related } \\
\text { Outcomes - } \\
\text { Duration of } 2^{\text {nd }} \\
\text { Stage Labor }\end{array}$ & $\begin{array}{l}5 \\
\text { RCTs } 119,123,125,1 \\
31,136 \\
(1,424)\end{array}$ & $\begin{array}{l}\text { No difference: Meta-analysis } \\
\text { showed no significant } \\
\text { differences between EA and } \\
\text { CSE in duration of the second } \\
\text { stage of labor (MD }-0.2 \\
\text { minutes; } 95 \% \mathrm{Cl}-21.9 \text { to } 21.6) \text {. }\end{array}$ & $\begin{array}{l}\text { Low } \\
\text { (Medium risk of bias, } \\
\text { indirect, inconsistent, } \\
\text { imprecise) }\end{array}$ \\
\hline & $\begin{array}{l}\text { Process Related } \\
\text { Outcomes - Total } \\
\text { Duration of Labor }\end{array}$ & $\begin{array}{l}5 \\
\text { RCTs }^{119,123,125,1} \\
31,136 \\
(1,424)\end{array}$ & $\begin{array}{l}\text { Worsening with EA: Meta- } \\
\text { analysis showed total duration } \\
\text { of labor (from time of } \\
\text { intervention to delivery) was } \\
\text { significantly longer for EA } \\
\text { relative to CSE, with an MD of } \\
62.0 \text { minutes ( } 95 \% \mathrm{Cl} 7.2 \text { to } \\
116.7) \text {. }\end{array}$ & $\begin{array}{l}\text { Moderate } \\
\text { (Medium risk of bias, } \\
\text { imprecise) }\end{array}$ \\
\hline
\end{tabular}




\begin{tabular}{|c|c|c|c|c|}
\hline Category & Outcome & $\begin{array}{l}\text { Study Design } \\
\text { (Sample Size) }\end{array}$ & Conclusion & $\begin{array}{c}\text { SOE } \\
\text { (Rationale) }^{\mathrm{a}} \\
\end{array}$ \\
\hline & $\begin{array}{l}\text { Process Related } \\
\text { Outcomes - Mode } \\
\text { of Delivery } \\
\text { (Cesarean } \\
\text { Delivery) }\end{array}$ & $\begin{array}{l}5 \\
\text { RCTs }^{119,123,129,1} \\
31,136 \\
(1,604)\end{array}$ & $\begin{array}{l}\text { No difference: Meta-analysis } \\
\text { of the data from } 1604 \text { patients } \\
\text { in these } 5 \text { RCTs showed no } \\
\text { statistically significant difference } \\
\text { in cesarean delivery rates } \\
\text { between EA and CSE (OR } 1.1 \text {; } \\
95 \% \mathrm{Cl} 0.9 \text { to } 1.2 \text { ). }\end{array}$ & $\begin{array}{l}\text { Moderate } \\
\text { (Indirect) }\end{array}$ \\
\hline
\end{tabular}

${ }^{a}$ Criteria for downgrading SOE are described as Rationale; when these criteria are insufficient for understanding the final SOE, additional explanation is provided.

Abbreviations: $\mathrm{CI}=$ confidence interval; $\mathrm{CSE}=$ combined spinal epidural; $\mathrm{EA}=$ epidural analgesia; $\mathrm{MD}=$ mean difference; $\mathrm{OR}=\mathrm{odds}$ ratio; $\mathrm{RCT}=$ randomized controlled trial; $\mathrm{SOE}=$ strength of evidence

Table S. Epidural analgesia versus combined spinal epidural: Evidence summary in women of mixed parity

\begin{tabular}{|c|c|c|c|c|}
\hline Category & Outcome & $\begin{array}{l}\text { Study Design } \\
\text { (Sample Size) }\end{array}$ & Conclusion & $\begin{array}{c}\text { SOE } \\
\text { (Rationale) }^{\mathrm{a}}\end{array}$ \\
\hline \multirow[t]{2}{*}{$\begin{array}{l}\text { Intermediate } \\
\text { or Final } \\
\text { Outcomes }\end{array}$} & $\begin{array}{l}\text { Process Related } \\
\text { Outcomes - Total } \\
\text { Duration of Labor }\end{array}$ & $\begin{array}{l}2 \mathrm{RCTS}^{118,125} \\
(258)\end{array}$ & $\begin{array}{l}\text { No difference: No significant } \\
\text { difference between EA and } \\
\text { CSE for total duration of labor. }\end{array}$ & $\begin{array}{l}\text { Low } \\
\text { (Medium risk of bias, } \\
\text { imprecise) }\end{array}$ \\
\hline & $\begin{array}{l}\text { Process Related } \\
\text { Outcomes - Mode } \\
\text { of Delivery } \\
\text { (Cesarean } \\
\text { Delivery) } \\
\end{array}$ & $\begin{array}{l}4 \\
\mathrm{RCTs}^{118,125,128,1} \\
30 \\
(374)\end{array}$ & $\begin{array}{l}\text { No difference: Meta-analysis } \\
\text { generated an estimate of the } \\
\text { odds ratio of cesarean delivery } \\
\text { associated with CSE relative to } \\
\text { EA of } 0.8 \text { ( } 95 \% \text { Cl: } 0.5 \text { to } 1.3) \text {. }\end{array}$ & $\begin{array}{l}\text { Moderate } \\
\text { (Medium risk of bias) }\end{array}$ \\
\hline $\begin{array}{l}\text { Adverse } \\
\text { Events }\end{array}$ & $\begin{array}{l}\text { Process Related } \\
\text { Outcomes - } \\
\text { Abnormal Fetal } \\
\text { Heart Tracing }\end{array}$ & $\begin{array}{l}2 \mathrm{RCTs}^{118,130} \\
(190)\end{array}$ & $\begin{array}{l}\text { Improvement with EA: CSE } \\
\text { was associated with a higher } \\
\text { proportion of patients with } \\
\text { abnormal fetal heart rate } \\
\text { tracings than EA in one study } \\
\text { and a risk ratio of } 2.28(95 \% \mathrm{Cl} \text { : } \\
0.64 \text { to } 8.16) \text { for an abnormal } \\
\text { fetal heart tracing in another } \\
\text { study. }\end{array}$ & $\begin{array}{l}\text { Low } \\
\text { (Medium risk of bias, } \\
\text { imprecise) }\end{array}$ \\
\hline
\end{tabular}

${ }^{a}$ Criteria for downgrading SOE are described as Rationale; when these criteria are insufficient for understanding the final SOE, additional explanation is provided.

Abbreviations: $\mathrm{CI}=$ confidence interval; $\mathrm{CSE}=$ combined spinal epidural; $\mathrm{EA}=$ =pidural analgesia; $\mathrm{RCT}=$ randomized controlled trial; SOE=strength of evidence

Table T summarizes the SOE for EA versus patient-controlled intravenous analgesia. In general, the SOE was judged insufficient for outcomes given the imprecision of the findings, findings for specific outcomes from just one study, and the non-U.S. settings. Low SOE was reported for duration of labor and cesarean delivery in women with mixed or unspecified parity.

Table T. Epidural analgesia versus patient-controlled intravenous analgesia: Evidence summary in women of mixed parity

\begin{tabular}{|c|c|c|c|c|}
\hline Category & Outcome & $\begin{array}{l}\text { Study Design } \\
\text { (Sample Size) }\end{array}$ & Conclusion & $\begin{array}{c}\text { SOE } \\
\text { (Rationale) }^{\mathrm{a}}\end{array}$ \\
\hline $\begin{array}{l}\text { Intermediate } \\
\text { or Final } \\
\text { Outcomes }\end{array}$ & $\begin{array}{l}\text { Process Related } \\
\text { Outcomes - Total } \\
\text { Duration of Labor }\end{array}$ & $\begin{array}{l}3 \text { RCTs } 47,122,127 \\
(177)\end{array}$ & $\begin{array}{l}\text { No difference: Meta-analysis } \\
\text { did not identify differences in } \\
\text { duration of labor, with the } \\
\text { estimated mean after EA } \\
\text { administration minus duration } \\
\text { after PCIA being }-10.1 \text { minutes } \\
(95 \% \mathrm{Cl}-134.3 \text { to } 114.1) \text {. }\end{array}$ & $\begin{array}{l}\text { Low } \\
\text { (Medium risk of bias, } \\
\text { imprecise, non-U.S. } \\
\text { settings) }\end{array}$ \\
\hline
\end{tabular}




\begin{tabular}{|c|l|l|l|l|}
\hline Category & \multicolumn{1}{|c|}{ Outcome } & $\begin{array}{l}\text { Study Design } \\
\text { (Sample Size) }\end{array}$ & \multicolumn{1}{c|}{ Conclusion } & \multicolumn{1}{c|}{$\begin{array}{c}\text { SOE } \\
\text { (Rationale) }^{\mathbf{a}}\end{array}$} \\
\hline & $\begin{array}{l}\text { Process Related } \\
\text { Outcomes - Mode } \\
\text { of Delivery } \\
\text { (Cesarean } \\
\text { Delivery) }\end{array}$ & $\begin{array}{l}\text { (17) } \\
\text { Del,122,127 }\end{array}$ & $\begin{array}{l}\text { No difference: Meta-analysis } \\
\text { generated an estimate of the } \\
\text { odds ratio for cesarean delivery } \\
\text { of EA relative to PClA of 1.3 } \\
(95 \% \text { Cl 0.3 to 5.6). }\end{array}$ & $\begin{array}{l}\text { Low } \\
\text { (Medium risk of bias, } \\
\text { imprecise, non-U.S. } \\
\text { settings) }\end{array}$ \\
\hline
\end{tabular}

${ }^{\mathrm{a}}$ Criteria for downgrading SOE are described as Rationale; when these criteria are insufficient for understanding the final SOE, additional explanation is provided.

Abbreviations: $\mathrm{CI}=$ confidence interval; EA=epidural analgesia; PCIA=patient-controlled intravenous analgesia;

$\mathrm{RCT}=$ randomized controlled trial; SOE=strength of evidence

The SOE findings for EA versus intravascular tramadol in women of mixed parity was rated as insufficient for all outcomes. Table U summarizes the SOE for early versus late epidural analgesia. The SOE was rated as moderate for all outcomes based on evidence from the SR. The SOE was lowered given that the included studies from the SR spanned 1994 to 2006.

Table U. Early versus late epidural analgesia: Evidence summary in nulliparous women ${ }^{\mathbf{a}}$

\begin{tabular}{|c|c|c|c|c|}
\hline Category & Outcome & $\begin{array}{l}\text { Study Design } \\
\text { (Sample Size) }\end{array}$ & Conclusion & $\begin{array}{c}\text { SOE } \\
\text { (Rationale) }^{\mathrm{a}}\end{array}$ \\
\hline \multirow[t]{3}{*}{$\begin{array}{l}\text { Intermediate } \\
\text { or Final } \\
\text { Outcomes }\end{array}$} & $\begin{array}{l}\text { Process Related } \\
\text { Outcomes }- \\
\text { Duration of } 1^{\text {st }} \\
\text { Stage Labor }\end{array}$ & $\begin{array}{l}1 \mathrm{SR}^{139}(1,739 \\
\text { patients, } 6 \\
\text { studies })\end{array}$ & $\begin{array}{l}\text { No difference: No differences } \\
\text { between early and late } \mathrm{EA} \text { with } \\
\text { an odds ratio of } 0.95(95 \% \mathrm{Cl} \\
0.81 \text { to } 1.10) \text {. }\end{array}$ & Moderate \\
\hline & $\begin{array}{l}\text { Process Related } \\
\text { Outcomes - } \\
\text { Duration of } 2^{\text {nd }} \\
\text { Stage Labor }\end{array}$ & $\begin{array}{l}1 \mathrm{SR}^{139}(1,739 \\
\text { patients, } 6 \\
\text { studies })\end{array}$ & $\begin{array}{l}\text { No difference: No differences } \\
\text { between early and late EA with } \\
\text { a weighted mean difference of } \\
0.52 \text { minutes ( } 95 \% \mathrm{Cl}-5.03 \text { to } \\
6.06 \text { minutes) }\end{array}$ & Moderate \\
\hline & $\begin{array}{l}\text { Process Related } \\
\text { Outcomes - Mode } \\
\text { of Delivery } \\
\text { (Cesarean } \\
\text { Delivery) }\end{array}$ & $\begin{array}{l}1 \mathrm{SR}^{139}(1,739 \\
\text { patients, } 6 \\
\text { studies) }\end{array}$ & $\begin{array}{l}\text { No difference: No differences } \\
\text { between early and late EA } \\
\text { (odds ratio=1.00, } 95 \% \mathrm{Cl} 0.83 \\
\text { to } 1.21 \text { ) }\end{array}$ & Moderate \\
\hline
\end{tabular}

${ }^{a}$ Early epidural was defined as immediate initiation of EA at first request $(<4 \mathrm{~cm})$, and late initiation consisted of delay of EA until the cervix was dilated to at least $4 \mathrm{~cm}$.

${ }^{\mathrm{b}}$ Criteria for downgrading SOE are described as Rationale; when these criteria are insufficient for understanding the final SOE, additional explanation is provided.

Abbreviations: $\mathrm{CI}=$ confidence interval; RCT=randomized controlled trial; SOE=strength of evidence; $\mathrm{SR}=$ systematic review

Strength of evidence was rated as insufficient for all outcomes of these comparisons:

- Routine EA versus analgesia on request

- CSE versus nonpharmacologic pain relief

- EA versus intravenous meperidine

- EA versus low-dose infusion EA

- EA acupuncture point nerve stimulation

- EA versus no EA in nulliparous women

Table V summarizes the SOE for outcomes comparing EA versus no EA in women of mixed parity. The SOE was rated as moderate for major outcomes of labor duration and cesarean delivery based on the findings from a large SR. 
Table V. Epidural analgesia versus no epidural analgesia: Evidence summary in women of mixed parity

\begin{tabular}{|c|c|c|c|c|}
\hline Category & Outcome & $\begin{array}{l}\text { Study Design } \\
\text { (Sample Size) }\end{array}$ & Conclusion & $\begin{array}{c}\text { SOE } \\
\text { (Rationale) }^{\mathrm{a}}\end{array}$ \\
\hline \multirow[t]{3}{*}{$\begin{array}{l}\text { Intermediate } \\
\text { or Final } \\
\text { Outcomes }\end{array}$} & $\begin{array}{l}\text { Process Related } \\
\text { Outcomes }-1^{\text {st }} \\
\text { Stage of Labor }\end{array}$ & $\begin{array}{l}1 \mathrm{RCT}^{47} \\
(120) \\
1 \mathrm{SR}^{140} \\
(2,981 \\
\text { patients, } 11 \\
\text { studies) } \\
\end{array}$ & $\begin{array}{l}\text { No difference: No evidence of } \\
\text { a significant difference between } \\
\text { EA and no EA (MD } 18.51 \\
\text { minutes, } 95 \% \mathrm{Cl}-12.91 \text { to } \\
49.42) \text {. }\end{array}$ & $\begin{array}{l}\text { Moderate } \\
\text { Consistent with SR } \\
\text { findings. }\end{array}$ \\
\hline & $\begin{array}{l}\text { Process Related } \\
\text { Outcomes }-2^{\text {nd }} \\
\text { Stage of Labor }\end{array}$ & $\begin{array}{l}1 \mathrm{RCT}^{47} \\
(120) \\
1 \mathrm{SR}^{140} \\
(4,233 \\
\text { patients, } 13 \\
\text { studies) } \\
\end{array}$ & $\begin{array}{l}\text { Worsening with EA: Women } \\
\text { with epidural analgesia had a } \\
\text { statistically significant longer } \\
\text { second stage of labor (average } \\
\text { MD } 13.66 \text { minutes, } 95 \% \mathrm{Cl} 6.67 \\
\text { to } 20.66 \text { ). }\end{array}$ & $\begin{array}{l}\text { Moderate } \\
\text { Consistent with SR } \\
\text { findings. }\end{array}$ \\
\hline & $\begin{array}{l}\text { Process Related } \\
\text { Outcomes - Mode } \\
\text { of Delivery } \\
\text { (Cesarean } \\
\text { Delivery) }\end{array}$ & $\begin{array}{l}1 \mathrm{RCT}^{47} \\
(120) \\
1 \mathrm{SR}^{140} \\
(8,417 \\
\text { patients, } 27 \\
\text { studies) }\end{array}$ & $\begin{array}{l}\text { No difference: No evidence of } \\
\text { a significant difference in the } \\
\text { risk of caesarean section } \\
\text { overall (RR } 1.10,95 \% \text { Cl } 0.97 \\
\text { to } 1.25 \text { ). }\end{array}$ & $\begin{array}{l}\text { Moderate } \\
\text { Consistent with SR } \\
\text { findings. }\end{array}$ \\
\hline
\end{tabular}

${ }^{a}$ Criteria for downgrading SOE are described as Rationale; when these criteria are insufficient for understanding the final SOE, additional explanation is provided.

Abbreviations: $\mathrm{CI}=$ confidence interval; $\mathrm{EA}=$ epidural analgesia; $\mathrm{MD}=$ mean difference: $\mathrm{RCT}=$ randomized controlled trial;

$\mathrm{RR}=$ relative risk; $\mathrm{SOE}=$ strength of evidence; $\mathrm{SR}=$ systematic review

\section{Key Question 5. Frequency of Cervical Examination}

We identified no RCTs and only one good-quality $\mathrm{SR}^{141}$ that met the inclusion criteria for this KQ. The focus of the SR was to compare different methods of assessing labor progression through the use of vaginal examinations. The objective was to compare digital vaginal examinations for assessing progress of labor to other strategies or different timings. There was insufficient SOE for all outcomes regarding the frequency of cervical examination.

\section{Key Question 6. Intrauterine Pressure Catheters}

We did not identify any RCTs that met the inclusion criteria for this KQ. One good-quality SR addressed the benefits and harms of intrauterine pressure catheters in the diagnosis and management of labor dystocia. ${ }^{142}$ There were no statistically significant differences between intrauterine pressure catheters and external uterine monitoring for the outcomes of mode of delivery, mean time to delivery, neonatal acidemia, or admission to the neonatal intensive care unit (moderate SOE for all outcomes).

Table W summarizes the SOE for intrauterine pressure catheters versus external monitoring. The SOE was rated as moderate for all outcomes assessed given consistent findings from goodquality RCTs included in the SR. 
Table W. Intrauterine pressure catheters versus external monitoring: Evidence summary in women of unspecified parity

\begin{tabular}{|c|c|c|c|c|}
\hline Category & Outcome & $\begin{array}{l}\text { Study Design } \\
\text { (Sample Size) }\end{array}$ & Conclusion & $\begin{array}{c}\text { SOE } \\
\text { (Rationale) }^{\mathrm{a}} \\
\end{array}$ \\
\hline \multirow[t]{2}{*}{$\begin{array}{l}\text { Intermediate } \\
\text { or Final } \\
\text { Outcomes }\end{array}$} & $\begin{array}{l}\text { Process Related } \\
\text { Outcomes - } \\
\text { Duration of Total } \\
\text { Labor }\end{array}$ & $\begin{array}{l}1 \mathrm{SR}^{142}(1,456 \\
\text { patients, } 2 \\
\text { studies) }\end{array}$ & $\begin{array}{l}\text { No difference: No differences } \\
\text { in mean time to delivery with } \\
\text { intrauterine pressure catheters } \\
\text { compared to external } \\
\text { monitoring }\end{array}$ & $\begin{array}{l}\text { Moderate } \\
\text { (Indirect) }\end{array}$ \\
\hline & $\begin{array}{l}\text { Process Related } \\
\text { Outcomes - Mode } \\
\text { of Delivery }\end{array}$ & $\begin{array}{l}1 \mathrm{SR}^{142}(750 \\
\text { patients, } 2 \\
\text { studies })\end{array}$ & $\begin{array}{l}\text { No difference: Comparing } \\
\text { intrauterine pressure catheters } \\
\text { to external monitoring, there } \\
\text { was no difference in delivery by } \\
\text { operative vaginal delivery (RR } \\
1.25,95 \% \mathrm{Cl} 0.91 \text { to } 1.73 \text { ) or by } \\
\text { cesarean deliver (RR } 1.25,95 \% \\
\text { Cl } 0.91 \text { to } 1.71 \text { ). }\end{array}$ & $\begin{array}{l}\text { Moderate } \\
\text { (Indirect) }\end{array}$ \\
\hline \multirow[t]{3}{*}{$\begin{array}{l}\text { Adverse } \\
\text { Events }\end{array}$} & $\begin{array}{l}\text { Maternal } \\
\text { Outcomes - } \\
\text { Infection }\end{array}$ & $\begin{array}{l}1 \mathrm{SR}^{142}(1,456 \\
\text { patients, } 2 \\
\text { studies) }\end{array}$ & $\begin{array}{l}\text { No difference: No differences } \\
\text { in signs of infection in labor in } \\
\text { women with intrauterine } \\
\text { pressure catheters compared to } \\
\text { external monitoring (RR } 0.69 \text {, } \\
95 \% \mathrm{Cl} 0.44 \text { to } 1.08 \text { ). }\end{array}$ & $\begin{array}{l}\text { Moderate } \\
\text { (Indirect) }\end{array}$ \\
\hline & $\begin{array}{l}\text { Neonatal } \\
\text { Outcomes - } \\
\text { Acidemia }\end{array}$ & $\begin{array}{l}1 \mathrm{SR}^{142}(1,456 \\
\text { patients, } 2 \\
\text { studies) }\end{array}$ & $\begin{array}{l}\text { No difference: No differences } \\
\text { in neonatal acidemia }(\mathrm{pH}<7.15) \\
\text { in infants of women with } \\
\text { intrauterine pressure catheters } \\
\text { compared to external } \\
\text { monitoring (RR } 1.31,95 \% \mathrm{Cl} \\
0.95 \text { to } 1.79) \text {. }\end{array}$ & $\begin{array}{l}\text { Moderate } \\
\text { (Indirect) }\end{array}$ \\
\hline & $\begin{array}{l}\text { Neonatal } \\
\text { Outcomes - } \\
\text { Admission to } \\
\text { NICU }\end{array}$ & $\begin{array}{l}1 \mathrm{SR}^{142}(489 \\
\text { patients, } 2 \\
\text { studies) }\end{array}$ & $\begin{array}{l}\text { No difference: No differences } \\
\text { in admission to NICU in infants } \\
\text { of women with intrauterine } \\
\text { pressure catheters compared to } \\
\text { external monitoring (RR } 0.34 \text {, } \\
95 \% \mathrm{Cl} 0.07 \text { to } 1.67) \text {. }\end{array}$ & $\begin{array}{l}\text { Moderate } \\
\text { (Indirect) }\end{array}$ \\
\hline
\end{tabular}

${ }^{a}$ Criteria for downgrading SOE are described as Rationale; when these criteria are insufficient for understanding the final SOE, additional explanation is provided.

Abbreviations: $\mathrm{CI}=$ confidence interval; NICU=neonatal intensive care unit; $\mathrm{RCT}=$ randomized controlled trial; $\mathrm{RR}=$ relative risk; $\mathrm{SOE}=$ strength of evidence; $\mathrm{SR}=$ systematic review

\section{Key Question 7. High-Dose Versus Low-Dose Oxytocin Protocols}

We identified 12 articles $^{36,39,143-152}$ representing 11 individual RCTs that examined the benefits and harms of high-dose versus low-dose oxytocin protocols for women with abnormal labor. Key findings include:

- In nulliparous women, high-dose oxytocin is associated with a lower cesarean delivery rate (moderate SOE) compared with low-dose oxytocin protocols with no difference in maternal hemorrhage (low SOE).

- Early administration of oxytocin is associated with a shorter duration of labor (moderate SOE) but does not affect the overall cesarean delivery rate compared with delayed administration (moderate SOE). There is no difference in adverse events of maternal outcomes of hemorrhage or transfusion (low SOE) or in mode of delivery (low SOE).

- Pulsatile administration of oxytocin is associated with a longer duration of labor compared with continuous administration (low SOE). 
- There is no difference in cesarean delivery rate between women managed with oxytocin and those with expectant management (moderate SOE).

Tables X-AA summarize the SOE for varying oxytocin protocols strategies. For many outcomes the SOE was rated as insufficient or low except where existing SRs were able to add to the evidence base.

Table X. High-dose versus low-dose oxytocin protocols: Evidence summary in nulliparous women

\begin{tabular}{|c|c|c|c|c|}
\hline Category & Outcome & $\begin{array}{l}\text { Study Design } \\
\text { (Sample Size) }\end{array}$ & Conclusion & $\begin{array}{c}\text { SOE } \\
\text { (Rationale) }^{\mathrm{a}}\end{array}$ \\
\hline $\begin{array}{l}\text { Intermediate } \\
\text { or Final } \\
\text { Outcomes }\end{array}$ & $\begin{array}{l}\text { Process Related } \\
\text { Outcomes - Mode } \\
\text { of Delivery } \\
\text { (Cesarean } \\
\text { Delivery) }\end{array}$ & $\begin{array}{l}3 \mathrm{RCTs}^{39,143,152} \\
(1,052) \\
2 \mathrm{SRs}^{153,154} \\
\text { (945 patients, } \\
9 \text { studies) }\end{array}$ & $\begin{array}{l}\text { Improvement with high-dose } \\
\text { oxytocin: High-dose oxytocin } \\
\text { augmentation was associated } \\
\text { with a reduction in the risk of } \\
\text { cesarean section. }\end{array}$ & $\begin{array}{l}\text { Moderate } \\
\text { (inconsistent, } \\
\text { imprecise) } \\
\text { Findings supported by } 2 \\
\text { RCTs and } 2 \text { SRs } \\
\text { increasing SOE. } \\
\text { Inconsistency with a } \\
\text { third study not showing } \\
\text { a difference and } \\
\text { substantial } \\
\text { heterogeneity. }\end{array}$ \\
\hline \multirow[t]{2}{*}{$\begin{array}{l}\text { Adverse } \\
\text { Events }\end{array}$} & $\begin{array}{l}\text { Maternal } \\
\text { Outcomes - } \\
\text { Infection }\end{array}$ & $\begin{array}{l}2 \mathrm{RCTs}^{39,143} \\
(1,052)\end{array}$ & $\begin{array}{l}\text { No difference: No difference in } \\
\text { the rate of maternal infection } \\
\text { between high-and low-dose } \\
\text { oxytocin as part of an active } \\
\text { management of labor protocol } \\
\text { compared to a conventional } \\
\text { management of labor protocol. }\end{array}$ & $\begin{array}{l}\text { Low } \\
\text { (Imprecise) }\end{array}$ \\
\hline & $\begin{array}{l}\text { Maternal } \\
\text { Outcomes - } \\
\text { Hemorrhage }\end{array}$ & $\begin{array}{l}2 \mathrm{RCTs}^{143,152} \\
(1,387)\end{array}$ & $\begin{array}{l}\text { No difference: SOE was low } \\
\text { given imprecise findings from } 2 \\
\text { non-U.S. setting studies. }\end{array}$ & $\begin{array}{l}\text { Low (imprecise, non- } \\
\text { U.S. setting) }\end{array}$ \\
\hline
\end{tabular}

${ }^{a}$ Criteria for downgrading SOE are described as Rationale; when these criteria are insufficient for understanding the final SOE, additional explanation is provided.

Abbreviations: RCT=randomized controlled trial; SOE=strength of evidence; SR=systematic review

Table Y. Early versus delayed oxytocin protocols: Evidence summary in nulliparous women

\begin{tabular}{|c|c|c|c|c|}
\hline Category & Outcome & $\begin{array}{l}\text { Study Design } \\
\text { (Sample Size) }\end{array}$ & Conclusion & $\begin{array}{c}\text { SOE } \\
\text { (Rationale) }^{a}\end{array}$ \\
\hline \multirow[t]{2}{*}{$\begin{array}{l}\text { Intermediate } \\
\text { or Final } \\
\text { Outcomes }\end{array}$} & $\begin{array}{l}\text { Process Related } \\
\text { Outcomes - } \\
\text { Duration of Labor }\end{array}$ & $\begin{array}{l}2 \text { RCTs }^{145,147} \\
(1,042) \\
2 \text { SRs }^{155,156} \\
\text { (2,583 } \\
\text { patients, } 10 \\
\text { studies) }\end{array}$ & $\begin{array}{l}\text { Improvement with early } \\
\text { administration of oxytocin: } \\
\text { shorter duration of labor in early } \\
\text { oxytocin group. }\end{array}$ & $\begin{array}{l}\text { Moderate (non-U.S. } \\
\text { setting, potential risk of } \\
\text { bias) } \\
\text { Consistent with SR } \\
\text { findings }\end{array}$ \\
\hline & $\begin{array}{l}\text { Process Related } \\
\text { Outcomes - Mode } \\
\text { of Delivery } \\
\text { (Cesarean } \\
\text { Delivery) }\end{array}$ & $\begin{array}{l}2 \mathrm{RCTs}^{145,147} \\
(1,042) \\
2 \mathrm{SRs}^{155,156} \\
(2,583 \\
\text { patients, } 10 \\
\text { studies) }\end{array}$ & $\begin{array}{l}\text { No difference: no difference in } \\
\text { mode of delivery given early } \\
\text { oxytocin group. }\end{array}$ & $\begin{array}{l}\text { Moderate (non-U.S. } \\
\text { setting, potential risk of } \\
\text { bias) } \\
\text { Consistent with SR } \\
\text { findings }\end{array}$ \\
\hline $\begin{array}{l}\text { Adverse } \\
\text { Events }\end{array}$ & $\begin{array}{l}\text { Maternal } \\
\text { Outcomes - } \\
\text { Transfusion }\end{array}$ & $\begin{array}{l}2 \mathrm{RCTs}^{145,147} \\
(1,042)\end{array}$ & $\begin{array}{l}\text { No difference: No difference } \\
\text { between women managed with } \\
\text { early versus delayed oxytocin } \\
\text { administration. }\end{array}$ & $\begin{array}{l}\text { Low (non-U.S. setting, } \\
\text { potential risk of bias) }\end{array}$ \\
\hline
\end{tabular}




\begin{tabular}{|c|c|c|c|c|}
\hline Category & Outcome & $\begin{array}{l}\text { Study Design } \\
\text { (Sample Size) }\end{array}$ & Conclusion & $\begin{array}{c}\text { SOE } \\
\text { (Rationale) }^{a}\end{array}$ \\
\hline & $\begin{array}{l}\text { Maternal } \\
\text { Outcomes - } \\
\text { Hemorrhage }\end{array}$ & $\begin{array}{l}2 \text { RCTs }^{145,147} \\
(1,042)\end{array}$ & $\begin{array}{l}\text { No difference: No difference } \\
\text { between women managed with } \\
\text { early versus delayed oxytocin } \\
\text { administration. }\end{array}$ & $\begin{array}{l}\text { Low (non-U.S. setting, } \\
\text { potential risk of bias) }\end{array}$ \\
\hline & $\begin{array}{l}\text { Process Related } \\
\text { Outcomes - Mode } \\
\text { of Delivery } \\
\text { (Instrumental } \\
\text { Delivery) }\end{array}$ & $\begin{array}{l}2 \text { RCTs }^{145,147} \\
(1,042)\end{array}$ & $\begin{array}{l}\text { No difference: No difference } \\
\text { between women managed with } \\
\text { early versus delayed oxytocin } \\
\text { administration. }\end{array}$ & $\begin{array}{l}\text { Low (non-U.S. setting, } \\
\text { potential risk of bias) }\end{array}$ \\
\hline & $\begin{array}{l}\text { Process Related } \\
\text { Outcomes - Mode } \\
\text { of Delivery } \\
\text { (Spontaneous) }\end{array}$ & $\begin{array}{l}2 \mathrm{RCTs}^{145,147} \\
(1,042)\end{array}$ & $\begin{array}{l}\text { No difference: No difference } \\
\text { between women managed with } \\
\text { early versus delayed oxytocin } \\
\text { administration. }\end{array}$ & $\begin{array}{l}\text { Low (non-U.S. setting, } \\
\text { potential risk of bias) }\end{array}$ \\
\hline
\end{tabular}

${ }^{a}$ Criteria for downgrading SOE are described as Rationale; when these criteria are insufficient for understanding the final SOE, additional explanation is provided.

Abbreviations: RCT=randomized controlled trial; RR=relative risk; SOE=strength of evidence; SR=systematic review

Table Z. Pulsatile versus continuous oxytocin protocols: Evidence summary in women of mixed parity

\begin{tabular}{|c|c|c|c|c|}
\hline Category & Outcome & $\begin{array}{l}\text { Study Design } \\
\text { (Sample Size) }\end{array}$ & Conclusion & $\begin{array}{c}\text { SOE } \\
\text { (Rationale) }^{a}\end{array}$ \\
\hline \multirow[t]{2}{*}{$\begin{array}{l}\text { Intermediate } \\
\text { or Final } \\
\text { Outcomes }\end{array}$} & $\begin{array}{l}\text { Process Related } \\
\text { Outcomes - } \\
\text { Duration of } 2 \text { nd } \\
\text { Stage Labor }\end{array}$ & $\begin{array}{l}1 \mathrm{RCT}^{144} \\
(487)\end{array}$ & $\begin{array}{l}\text { No difference: No difference in } \\
\text { the duration of the second } \\
\text { stage of labor among women } \\
\text { managed with pulsatile } \\
\text { compared to continuous } \\
\text { oxytocin for augmentation of } \\
\text { labor. }\end{array}$ & $\begin{array}{l}\text { Low } \\
\text { (Indirect, imprecise) }\end{array}$ \\
\hline & $\begin{array}{l}\text { Process Related } \\
\text { Outcomes - } \\
\text { Duration of Labor }\end{array}$ & $\begin{array}{l}3 \\
\text { RCTs }^{144,148,150} \\
(1,488)\end{array}$ & $\begin{array}{l}\text { Improvement with continuous } \\
\text { oxytocin: Women managed } \\
\text { with pulsatile compared to } \\
\text { continuous oxytocin for } \\
\text { augmentation of labor had a } \\
\text { longer duration of labor. }\end{array}$ & $\begin{array}{l}\text { Low } \\
\text { (Indirect, imprecise, } \\
\text { non-U.S. setting, high } \\
\text { risk of bias) }\end{array}$ \\
\hline $\begin{array}{l}\text { Adverse } \\
\text { Events }\end{array}$ & $\begin{array}{l}\text { Process Related } \\
\text { Outcomes - Mode } \\
\text { of Delivery } \\
\text { (Operative } \\
\text { delivery) }\end{array}$ & $\begin{array}{l}1 \mathrm{RCT}^{144} \\
(500)\end{array}$ & $\begin{array}{l}\text { No difference: No difference in } \\
\text { operative delivery rate between } \\
\text { women managed with pulsatile } \\
\text { compared to continuous } \\
\text { oxytocin for augmentation of } \\
\text { labor. The cesarean delivery } \\
\text { rate was not reported. }\end{array}$ & $\begin{array}{l}\text { Low } \\
\text { (Indirect, imprecise) }\end{array}$ \\
\hline
\end{tabular}

${ }^{a}$ Criteria for downgrading SOE are described as Rationale; when these criteria are insufficient for understanding the final SOE, additional explanation is provided.

Abbreviations: RCT=randomized controlled trial; SOE=strength of evidence

Table AA. Oxytocin versus expectant management: Evidence summary in women of mixed parity

\begin{tabular}{|c|c|c|c|c|}
\hline Category & Outcome & $\begin{array}{l}\text { Study Design } \\
\text { (Sample Size) }\end{array}$ & Conclusion & $\begin{array}{c}\text { SOE } \\
\text { (Rationale) }^{\mathrm{a}}\end{array}$ \\
\hline $\begin{array}{l}\text { Intermediate } \\
\text { or Final } \\
\text { Outcomes }\end{array}$ & $\begin{array}{l}\text { Process Related } \\
\text { Outcomes - Mode } \\
\text { of Delivery } \\
\text { (Cesarean } \\
\text { Delivery) }\end{array}$ & $\begin{array}{l}1 \mathrm{RCT}^{36} \\
(99) \\
\\
2 \mathrm{SRs}^{156,157} \\
\text { (457 patients, } \\
5 \text { studies) }\end{array}$ & $\begin{array}{l}\text { No difference: No difference in } \\
\text { cesarean delivery rate between } \\
\text { women managed with oxytocin } \\
\text { compared to expectant } \\
\text { management. }\end{array}$ & $\begin{array}{l}\text { Moderate } \\
\text { (Imprecise, consistency } \\
\text { with SR } \\
\text { SOE was increased to } \\
\text { moderate given findings } \\
\text { from SRs which also } \\
\text { found no difference in } \\
\text { cesarean delivery rates. }\end{array}$ \\
\hline
\end{tabular}




\begin{tabular}{|l|l|l|l|l|}
\hline Category & \multicolumn{1}{|c|}{ Outcome } & $\begin{array}{l}\text { Study Design } \\
\text { (Sample Size) }\end{array}$ & \multicolumn{1}{c|}{ Conclusion } & \multicolumn{1}{c|}{$\begin{array}{c}\text { SOE } \\
\text { (Rationale) }^{\mathbf{a}}\end{array}$} \\
\hline $\begin{array}{l}\text { Adverse } \\
\text { Events }\end{array}$ & $\begin{array}{l}\text { Process Related } \\
\text { Outcomes - Mode } \\
\text { of Delivery } \\
\text { (Instrumental } \\
\text { Delivery) }\end{array}$ & $\begin{array}{l}1 \mathrm{RCT}{ }^{36} \\
(99)\end{array}$ & $\begin{array}{l}\text { No difference: No difference in } \\
\text { operative vaginal delivery rate } \\
\text { between women managed with } \\
\text { oxytocin compared to expectant } \\
\text { management. }\end{array}$ & $\begin{array}{l}\text { Low } \\
\text { (Imprecise) }\end{array}$ \\
$\begin{array}{l}\text { (138 patients, } \\
\text { 3 studies) }\end{array}$ & $\begin{array}{l}\text { Consistent with SR } \\
\text { findings }\end{array}$ \\
\hline
\end{tabular}

${ }^{a}$ Criteria for downgrading SOE are described as Rationale; when these criteria are insufficient for understanding the final SOE, additional explanation is provided.

Abbreviations: RCT=randomized controlled trial; SOE=strength of evidence; SR=systematic review

\section{Key Question 8. Electronic Fetal Monitoring Versus Intermittent Auscultation}

We were unable to identify any relevant RCTs that met our inclusion criteria for this KQ. We identified 4 potential SRs that compared electronic fetal monitoring with intermittent auscultation, ${ }^{158-161}$ but these were ultimately excluded because the studies included in the SRs utilized interventions that are not currently used in the United States.

\section{Key Question 9. Timing of Pushing in the Second Stage}

We identified six articles ${ }^{162-167}$ representing five RCTs that examined pushing techniques. Key findings include:

- Valsalva/coached and spontaneous/uncoached pushing have similar risks of trauma to the pelvic floor (low SOE).

- There is limited evidence that immediate pushing has a shorter labor duration when compared to delayed pushing in nulliparous women (low SOE).

- There was limited evidence of no difference in neonatal outcomes for immediate versus delayed pushing (low SOE).

Table BB summarizes the SOE for spontaneous pushing versus Valsalva pushing. In general, SOE was judged insufficient for all outcomes, with the exception of the process related outcome of Cesarean delivery.

Table BB. Spontaneous pushing versus Valsalva pushing: Evidence summary in nulliparous women

\begin{tabular}{|l|l|l|l|l|}
\hline \multicolumn{1}{|c|}{ Category } & \multicolumn{1}{|c|}{ Outcome } & $\begin{array}{l}\text { Study Design } \\
\text { (Sample Size) }\end{array}$ & \multicolumn{1}{c|}{ Conclusion } & \multicolumn{1}{c|}{$\begin{array}{c}\text { SOE } \\
\text { (Rationale) }^{\mathbf{a}}\end{array}$} \\
\hline $\begin{array}{l}\text { Intermediate } \\
\text { or Final } \\
\text { Outcomes }\end{array}$ & $\begin{array}{l}\text { Process Related } \\
\text { Outcomes - Mode } \\
\text { of Delivery } \\
\text { (Cesarean } \\
\text { Delivery) }\end{array}$ & $\begin{array}{l}\text { 3 RCT } 163,165,166 \\
(508)\end{array}$ & $\begin{array}{l}\text { No difference: Three RCTs } \\
\text { reported no difference in the } \\
\text { rate of cesarean deliveries } \\
\text { between coached pushing and } \\
\text { uncoached pushing. }\end{array}$ & $\begin{array}{l}\text { Low (Medium risk of } \\
\text { bias, Imprecise) }\end{array}$ \\
\hline
\end{tabular}

${ }^{a}$ Criteria for downgrading SOE are described as Rationale; when these criteria are insufficient for understanding the final SOE, additional explanation is provided.

Abbreviations: RCT=randomized controlled trial; SOE=strength of evidence

Table CC summarizes the SOE for immediate versus delayed pushing. In general, SOE was judged low for all outcomes, given findings from just one study. 
Table CC. Immediate versus delayed pushing: Evidence summary in nulliparous women

\begin{tabular}{|c|c|c|c|c|}
\hline Category & Outcome & $\begin{array}{l}\text { Study Design } \\
\text { (Sample Size) }\end{array}$ & Conclusion & $\begin{array}{c}\text { SOE } \\
\text { (Rationale) }^{\mathrm{a}} \\
\end{array}$ \\
\hline \multirow[t]{2}{*}{$\begin{array}{l}\text { Intermediate } \\
\text { or Final } \\
\text { Outcomes }\end{array}$} & $\begin{array}{l}\text { Process Related } \\
\text { Outcomes - } \\
\text { Duration of Labor } \\
\text { (from intervention } \\
\text { to delivery) }\end{array}$ & $\begin{array}{l}1 \mathrm{RCT}^{167} \\
(2,404)\end{array}$ & $\begin{array}{l}\text { Improvement with immediate } \\
\text { pushing: shorter mean duration } \\
\text { of the second stage of labor in } \\
\text { women randomized to } \\
\text { immediate pushing compared to } \\
\text { delayed pushing. }\end{array}$ & Low (one study) \\
\hline & $\begin{array}{l}\text { Process Related } \\
\text { Outcomes - Mode } \\
\text { of Delivery } \\
\text { (Cesarean } \\
\text { Delivery) } \\
\end{array}$ & $\begin{array}{l}1 \mathrm{RCT}^{167} \\
(2,404)\end{array}$ & $\begin{array}{l}\text { No difference: No difference in } \\
\text { cesarean delivery rate between } \\
\text { women randomized to } \\
\text { immediate pushing compared to } \\
\text { delayed pushing. }\end{array}$ & Low (one study) \\
\hline \multirow[t]{6}{*}{$\begin{array}{l}\text { Adverse } \\
\text { Events }\end{array}$} & $\begin{array}{l}\text { Maternal } \\
\text { Outcomes - } \\
\text { Postpartum } \\
\text { Hemorrhage }\end{array}$ & $\begin{array}{l}1 \mathrm{RCT}^{167} \\
(2,404)\end{array}$ & $\begin{array}{l}\text { Improvement with immediate } \\
\text { pushing: Postpartum } \\
\text { hemorrhage was significantly } \\
\text { greater in the delayed vs the } \\
\text { immediate pushing group. }\end{array}$ & Low (one study) \\
\hline & $\begin{array}{l}\text { Maternal } \\
\text { Outcomes - } \\
\text { Chorioamnionitis }\end{array}$ & $\begin{array}{l}1 \mathrm{RCT}^{167} \\
(2,404)\end{array}$ & $\begin{array}{l}\text { Improvement with immediate } \\
\text { pushing: Chorioamnionitis was } \\
\text { significantly greater in the } \\
\text { delayed vs the immediate } \\
\text { pushing group. }\end{array}$ & Low (one study) \\
\hline & $\begin{array}{l}\text { Process Related } \\
\text { Outcomes - Mode } \\
\text { of Delivery } \\
\text { (Instrumental } \\
\text { Delivery) }\end{array}$ & $\begin{array}{l}1 \mathrm{RCT}^{167} \\
(2,404)\end{array}$ & $\begin{array}{l}\text { No difference: No different in } \\
\text { mode of delivery with delayed } \\
\text { vs immediate pushing. }\end{array}$ & Low (one study) \\
\hline & $\begin{array}{l}\text { Neonatal } \\
\text { Outcomes - } \\
\text { Neonatal Death, } \\
\text { major birth injury, } \\
\text { respiratory } \\
\text { distress transient } \\
\text { tachypnea }\end{array}$ & $\begin{array}{l}1 \mathrm{RCT}^{167} \\
(2,404)\end{array}$ & $\begin{array}{l}\text { No difference: No different in } \\
\text { neonatal death with delayed vs } \\
\text { immediate pushing. }\end{array}$ & Low (one study) \\
\hline & $\begin{array}{l}\text { Neonatal } \\
\text { Outcomes - } \\
\text { Neonatal } \\
\text { Acidemia }\end{array}$ & $\begin{array}{l}1 \mathrm{RCT}^{167} \\
(2,404)\end{array}$ & $\begin{array}{l}\text { Improvement with immediate } \\
\text { pushing: In prespecified } \\
\text { exploratory analyses, a lower } \\
\text { rate of acidemia with immediate } \\
\text { and delayed pushing groups }\end{array}$ & Low (one study) \\
\hline & $\begin{array}{l}\text { Neonatal } \\
\text { Outcomes - } \\
\text { Neonatal } \\
\text { Infection/Sepsis }\end{array}$ & $\begin{array}{l}1 \mathrm{RCT}^{167} \\
(2,404)\end{array}$ & $\begin{array}{l}\text { Improvement with immediate } \\
\text { pushing: The proportion of } \\
\text { suspected sepsis was higher in } \\
\text { the delayed versus immediate } \\
\text { pushing group }\end{array}$ & Low (one study) \\
\hline
\end{tabular}

${ }^{a}$ Criteria for downgrading SOE are described as Rationale; when these criteria are insufficient for understanding the final SOE, additional explanation is provided.

Abbreviations: RCT=randomized controlled trial; SOE=strength of evidence

\section{Discussion}

In general, the findings of the review were consistent with current understanding of the overall strength of evidence for different strategies for management of labor. Estimates of the rate of progress of "normal” labor derived from contemporary data in the United States are quite different from the classic curves described by Friedman. ${ }^{13}$ These differences may be attributable to a number of factors, including secular trends in patient characteristics (e.g., increasing age at first birth and increasing rates of obesity) and increasing use of interventions such as induction of labor or the use of oxytocin to augment labor. More recent data suggest that the transition to 
active labor occurs later in the course of labor than originally described, which is reflected in more recent guidelines suggesting a higher threshold for observing labor duration before intervention with cesarean delivery.

The definition of "normal" labor is fundamental in evaluating the evidence related to managing "abnormal" labor progression, analogous to the threshold value used to define "normal" for a continuous laboratory value. Ideally, the definition would be derived based on data from a large group of women who were followed without intervention and had optimal maternal and neonatal outcomes, but there are obvious practical and ethical barriers to this. , The sensitivity and specificity of the test will vary depending on the choice of threshold, but so will the estimates of the effectiveness of interventions based on that threshold. Comparing results across studies requires a common definition for such "normal" labor and permeates our review.

There is evidence that partograms are useful in low-resource settings, but they have not been shown to improve labor outcomes in high-resource settings. This may be due in part to differences in the data sources for generating labor curves and thresholds. Feasibility and ethical challenges with obtaining a large, contemporary sample of women laboring with minimal to no intervention limits our fundamental scientific understanding of normal labor, normal labor progress, and when durations of labor lead to worse maternal/child outcomes.

In general, our findings that "normal" labor in modern settings is generally longer than earlier guidance are consistent with current guidelines ${ }^{3}$, which are largely informed by the CSL data and encourage allowing longer durations for both first and second stages of labor before intervening with cesarean delivery. However, as noted, over half of women in the "normal" group received augmentation in the Consortium on Safe Labor (CSL) data, and the data are not informative about optimal timing of augmentation. Routine amniotomy is not specifically recommended, although the recommendations note that amniotomy may be helpful in the transition from latent to active labor. Based on the same Cochrane review finding, improved satisfaction and lower cesarean and operative vaginal delivery rates, emotional support is recommended. The potential effect of epidural analgesia on duration of labor is noted as a potential consideration in allowing longer durations before intervention, but there are no recommendations about specific techniques. Cervical exam frequency, intrauterine pressure monitoring, oxytocin dosing protocols, methods for routine fetal monitoring, or timing of pushing in the second labor are not discussed, consistent with the relative paucity of evidence.

The impact of regional anesthesia on the length of the first stage of labor is uncertain, leading to conflicting recommendations from different professional societies. Our findings do not provide greater clarity.

\section{Applicability}

Two broad issues relate to the overall applicability of the available evidence to clinical practice in the United States - one geographic and one temporal. Many of the RCTs meeting our criteria were performed outside of the United States. Aside from issues related to differences in study oversight or reporting, the populations of these studies may differ from U.S. women in labor in terms of health systems, patient preferences and expectations, provider perceptions of risk, availability of resources, and so on. This is particularly relevant to studies that directly compared management strategies based on explicit criteria for defining abnormal labor and studies that attempted to define a "normal" duration of labor (KQ 1). Particularly for studies where the primary outcome is cesarean delivery, factors that affect the threshold for performing cesarean-both the explicit "cutpoint” for duration of labor used and broader factors ranging 
from the relative safety of surgery versus vaginal delivery in low resource settings to cultural expectations to legal concerns - may affect the estimates of effectiveness of an intervention.

A number of studies included the use of a partogram - a graphical comparison of a woman's labor progress compared to a standard-with thresholds for intervention clearly identified. Strength of evidence was judged to be low, with one major factor being a lack of U.S.-based studies. In low-resource settings, the use of a partogram was associated with lower overall cesarean delivery rates compared with labor managed without a partogram, and earlier interventions were associated with lower cesarean delivery rates. In high-resource settings, the use of a partogram that included an assessment of latent phase duration, and which had a threshold for action at 3 hours compared to 4 hours, had higher cesarean delivery rates; but otherwise the use of a partogram compared with no partogram, or other time intervals for action lines, did not affect mode of delivery, duration of labor, indication for cesarean delivery, or complications including postpartum hemorrhage, maternal infection, or neonatal acidemia. Outside of U.S.-based settings, populations, health systems, and management of both prenatal and intrapartum care are quite different - and the impact of these differences on both the relative effectiveness and the absolute difference in outcomes is likely substantial.

Even more fundamentally, use of a tool such as a partogram, or specific interventions such as amniotomy, requires evidence on "normal” labor in order to define requires evidence on "normal” labor in order to define appropriate thresholds for action. The studies we reviewed that attempted to define "normal" labor differed based on parity, the time period in which the studies were conducted, and, among nulliparous women, maternal age. Evidence from the CSL, representing the most recent available large-scale population data ${ }^{19}$ suggest a longer duration of first stage of labor compared to earlier studies, including the National Collaborative Perinatal Project (NCPP). ${ }^{22}$ However, the most striking difference between these two studies was the proportion of women who received oxytocin augmentation (14.6\% in the NCPP cohort from 1959 to 1966 compared with 45.9\% in the CSL cohort from 2002 to 2008).

The CSL population that was used to generate new labor curves consists of women who had spontaneous onset of labor and a vaginal delivery, and thus the labor curves presented provide an estimate of "normal" labor that does not end in a cesarean delivery. Since such a large proportion of women received augmentation, these data do not provide insight into the range of rates of labor progression among women who do not receive augmentation, and cannot provide insight into the relative harms and benefits of augmentation, or the most appropriate thresholds for the timing or dosing of augmentation. The association between a longer duration of the first stage of labor and the greater use of oxytocin among women with a vaginal delivery is consistent with the possibility that greater use of oxytocin may avoid cesarean delivery, but not with observed secular trends in cesarean delivery rates. One would expect that any changes in the threshold for cesarean delivery caused by greater "patience" (allowing a longer duration) and/or "medical management” (greater use of oxytocin) would lead to decreases in cesarean delivery rates.

In summary, evidence suggests that the specific criteria used to define "normal” labor, or a specific threshold for intervention, may affect cesarean delivery rates but not other maternal or neonatal outcomes in some settings. Yet there is no available evidence for the United States. Among women in the United States with spontaneous onset of labor and vaginal delivery, labor progression is slower for women having their first baby compared to women with prior deliveries, but the high proportion of women receiving oxytocin augmentation prevents drawing any inferences about the "normal" labor curve in women with spontaneous onset of labor, no interventions to augment labor, and no adverse maternal or neonatal outcomes. 


\section{Research Recommendations}

We identified several areas of needed future research:

- It would be extremely useful to have separate labor curves derived from contemporary U.S. data for women with spontaneous onset of labor, no augmentation with oxytocin or other pharmacologic agents, and vaginal delivery of healthy baby, stratified by parity, as well as for women with augmented labor. Such labor curves would provide a better understanding of the modern natural course of labor and may provide better information on when to initiate agents to augment labor and when to proceed with cesarean delivery. Such studies could also potentially include laboring women with cesareans for non-labor diagnoses, although the threshold for intervention might be influences by perceptions of the effect of labor duration on the condition leading to the intervention (e.g., women with pre-eclampsia).

- Evaluation of specific labor management strategies (including the use of partograms) derived from contemporary data sources such as the CSL should be a priority. This evaluation should include comparison of different methods for integrating decision support into existing technologies, such as methods and timing of augmenting labor (oxytocin administration, artificial rupture of the membranes), fetal monitoring, tools to monitor uterine contraction strength and frequency, and the impact of supportive therapies (massage, fluids, nutrition, positioning) on mode of delivery. This evaluation would help generate best practice recommendations for safe reduction of the primary cesarean delivery rate while balancing maternal and neonatal outcomes. Given the potential difficulties in recruiting patients into randomized trials, consideration should be given to both high-quality observational studies as well as research designs that combine randomization with allowance for patient preferences. ${ }^{168,169}$

- Given the importance of the labor process to patient preferences and their birthing experience and the lack of evidence about the impact of available interventions on these preferences, the development of tools for estimating patient preferences for both the process and maternal and neonatal outcomes of labor should be a priority. Discrete choice experiments would be one method appropriate for estimating preferences for these complex tradeoffs.

- Comparison of patient preferences of nulliparous to parous women are of great interest as preferences may vary based on prior labor experiences and expectations.

- Studies of these tools/methods should also explore the complexity of decision making that needs to incorporate both maternal and paternal preferences, as well as preferences where parents are acting as surrogates for infants. For example, in a study which elicited preferences for an adverse neonatal outcome with long-term health implications for the purposes of economic analysis, each parent would have preferences that reflect the impact of the condition on their roles as parents, and could provide a preference acting as a surrogate for the child, but the child might have quite different preferences. ${ }^{170-172}$ Validated measures should be incorporated into clinical trials and prospective studies as specific outcomes.

- Encouragement of use of core outcome sets, such as those developed as part of the CROWN (Core Outcomes in Women's Health) initiative. ${ }^{173}$ 


\section{Conclusions}

Dystocia is a common indication for cesarean delivery. Recent data demonstrate that the normal progress of labor with current practice is quite different from curves originally described, although there is still uncertainty about the duration of "normal" labor in the absence of augmentation. Amniotomy and oxytocin decrease duration of labor without increasing cesarean delivery. Emotional support reduces operative delivery rates and patient satisfaction. Further work is needed to identify strategies for management of labor that optimize maternal and neonatal outcomes and patient preferences while minimizing cesarean delivery rates.

\section{References}

1. Monte LM, Ellis RR. Fertility of women in the United States: June 2012. U.S. Census Bureau; July 2014. Available at: http:/www.census.gov/content/dam/Census/ library/publications/2014/demo/p20575.pdf. Accessed August 7, 2018.

2. Neilson J, Lavender T, Quenby S, et al. Obstructed labour: reducing maternal death and disability during pregnancy. Br Med Bull. 2003 December 1, 2003;67(1):191204. doi: 10.1093/bmb/ldg018. PMID: 14711764.

3. American College of Obstetricians \& Gynecologists, Society for Maternal-Fetal Medicine. Obstetric care consensus no. 1: safe prevention of the primary cesarean delivery. Obstet Gynecol. 2014 Mar;123(3):693-711. doi: 10.1097/01.AOG.0000444441.04111.1d. PMID: 24553167.

4. Sheiner E, Levy A, Feinstein U, et al. Risk factors and outcome of failure to progress during the first stage of labor: a populationbased study. Acta Obstet Gynecol Scand. 2002 Mar;81(3):222-6. PMID: 11966478.

5. Rowe-Murray HJ, Fisher JR. Baby friendly hospital practices: cesarean section is a persistent barrier to early initiation of breastfeeding. Birth. 2002 Jun;29(2):124-31. PMID: 12000413.

6. Clark EA, Silver RM. Long-term maternal morbidity associated with repeat cesarean delivery. Am J Obstet Gynecol. 2011 Dec;205(6 Suppl):S2-10. doi: 10.1016/j.ajog.2011.09.028. PMID: 22114995.
7. Hartmann KE, Andrews JC, Jerome RN, et al. Strategies To Reduce Cesarean Birth in Low-Risk Women. Comparative Effectiveness Review No. 80. (Prepared by the Vanderbilt Evidence-based Practice Center under Contract No. 290-2007-10065I.) AHRQ Publication No. 12(13)-EHC128EF. Rockville, MD: Agency for Healthcare Research and Quality. October 2012. Available at: https:/effectivehealthcare.ahrq.gov/topics/ce sarean-birth-2010/research. Accessed August 7, 2018. PMID: 23236638.

8. Clark SL, Garite TJ, Hamilton EF, et al. "Doing something" about the cesarean delivery rate. Am J Obstet Gynecol. 2018 Sep;219(3):267-71. doi: 10.1016/j.ajog.2018.04.044. PMID: 29733840.

9. Betran AP, Torloni MR, Zhang JJ, et al. WHO Statement on Caesarean Section Rates. BJOG. 2016 Apr;123(5):667-70. doi: 10.1111/1471-0528.13526. PMID: 26681211.

10. Birthtools.org. Tools for optimizing the outcomes of labor safely. Available at: http://birthtools.org/Reducing-PrimaryCesareans-NEW. Accessed June 28, 2019.

11. Barber EL, Lundsberg LS, Belanger K, et al. Indications contributing to the increasing cesarean delivery rate. Obstet Gynecol. 2011 Jul;118(1):29-38. doi: 10.1097/AOG.0b013e31821e5f65. PMID: 21646928.

12. Friedman E. The graphic analysis of labor. Am J Obstet Gynecol. 1954 Dec;68(6):1568-75. PMID: 13207246. 
13. Friedman EA. Primigravid labor; a graphicostatistical analysis. Obstet Gynecol. 1955 Dec;6(6):567-89. PMID: 13272981.

14. Agency for Healthcare Research and Quality. Methods Guide for Effectiveness and Comparative Effectiveness Reviews. AHRQ Publication No. 10(14)-EHC063-EF. Rockville, MD: Agency for Healthcare Research and Quality. January 2014. Available at: https://effectivehealthcare.ahrq.gov/topics/ce r-methods-guide/overview. Accessed August 7, 2018.

15. Owens DK, Lohr KN, Atkins D, et al. AHRQ series paper 5: grading the strength of a body of evidence when comparing medical interventions-Agency for Healthcare Research and Quality and the Effective Health Care Program. J Clin Epidemiol. 2010 May;63(5):513-23. PMID: 19595577.

16. Berkman ND, Lohr KN, Ansari M, et al. Grading the Strength of a Body of Evidence When Assessing Health Care Interventions for the Effective Health Care Program of the Agency for Healthcare Research and Quality: An Update. Methods Guide for Comparative Effectiveness Reviews (Prepared by the RTI-UNC Evidence-based Practice Center under Contract No. 2902007-10056-I). AHRQ Publication No. 13(14)-EHC130-EF. Rockville, MD: Agency for Healthcare Research and Quality. November 2013.

https://effectivehealthcare.ahrq.gov/topics/m ethods-guidance-grading-evidence/methods/ Accessed August 7, 2018.

17. Neal JL, Lamp JM, Buck JS, et al. Outcomes of nulliparous women with spontaneous labor onset admitted to hospitals in preactive versus active labor. $\mathrm{J}$ Midwifery Womens Health. 2014 JanFeb;59(1):28-34. doi: 10.1111/jmwh.12160. PMID: 24512265.

18. Frigo MG, Larciprete G, Rossi F, et al. Rebuilding the labor curve during neuraxial analgesia. J Obstet Gynaecol Res. 2011 Nov;37(11):1532-9. doi: 10.1111/j.14470756.2011.01568.x. PMID: 21676079.
19. Zhang J, Landy HJ, Branch DW, et al. Contemporary patterns of spontaneous labor with normal neonatal outcomes. Obstet Gynecol. 2010 Dec;116(6):1281-7. doi: 10.1097/AOG.0b013e3181fdef6e. PMID: 21099592.

20. Cheng YW, Shaffer BL, Bryant AS, et al. Length of the first stage of labor and associated perinatal outcomes in nulliparous women. Obstet Gynecol. 2010

Nov;116(5):1127-35. doi: 10.1097/AOG.0b013e3181f5eaf0. PMID: 20966698.

21. Suzuki R, Horiuchi S, Ohtsu H. Evaluation of the labor curve in nulliparous Japanese women. Am J Obstet Gynecol. 2010 Sep;203(3):226.e1-6. doi: 10.1016/j.ajog.2010.04.014. PMID: 20494329.

22. Zhang J, Troendle J, Mikolajczyk R, et al. The natural history of the normal first stage of labor. Obstet Gynecol. 2010

Apr;115(4):705-10. doi: 10.1097/AOG.0b013e3181d55925. PMID: 20308828.

23. Greenberg MB, Cheng YW, Sullivan M, et al. Does length of labor vary by maternal age? Am J Obstet Gynecol. 2007

Oct;197(4):428.e1-7. doi: 10.1016/j.ajog.2007.06.058. PMID: 17904990.

24. Lavender T, Alfirevic Z, Walkinshaw S. Effect of different partogram action lines on birth outcomes: a randomized controlled trial. Obstet Gynecol. 2006 Aug;108(2):295302. doi: 10.1097/01.AOG.0000226862.78768.5c. PMID: 16880298.

25. Fahdhy M, Chongsuvivatwong V. Evaluation of World Health Organization partograph implementation by midwives for maternity home birth in Medan, Indonesia. Midwifery. 2005 Dec;21(4):301-10. doi: 10.1016/j.midw.2004.12.010. PMID: 16076515.

26. Neal JL, Lowe NK, Caughey AB, et al. Applying a physiologic partograph to Consortium on Safe Labor data to identify opportunities for safely decreasing cesarean births among nulliparous women. Birth. 2018 May 30doi: 10.1111/birt.12358. PMID: 29851163. 
27. Inde Y, Nakai A, Sekiguchi A, et al. Cervical Dilatation Curves of Spontaneous Deliveries in Pregnant Japanese Females. Int J Med Sci. 2018;15(6):549-56. doi: 10.7150/ijms.23505. PMID: 29725244.

28. Kauffman E, Souter VL, Katon JG, et al. Cervical Dilation on Admission in Term Spontaneous Labor and Maternal and Newborn Outcomes. Obstet Gynecol. 2016 Mar;127(3):481-8. doi: 10.1097/aog.0000000000001294. PMID: 26855106.

29. Lee NJ, Neal J, Lowe NK, et al. Comparing Different Partograph Designs for Use in Standard Labor Care: A Pilot Randomized Trial. Matern Child Health J. 2018 Mar;22(3):355-63. doi: 10.1007/s10995017-2366-0. PMID: 28936715.

30. Neal JL, Lowe NK, Phillippi JC, et al. Likelihood of cesarean delivery after applying leading active labor diagnostic guidelines. Birth. 2017 Jun;44(2):128-36. doi: 10.1111/birt.12274. PMID: 28198038.

31. Wood AM, Frey HA, Tuuli MG, et al. Optimal Admission Cervical Dilation in Spontaneously Laboring Women. Am J Perinatol. 2016 Jan;33(2):188-94. doi: 10.1055/s-0035-1563711. PMID: 26344012.

32. Mason BE, Matulich MC, Swanson K, et al. Labor Curves in Multiparous Women Related to Interbirth Intervals. Am J Perinatol. 2018doi: 10.1055/s-00381660469.

33. Tolba SM, Ali SS, Mohammed AM, et al. Management of Spontaneous Labor in Primigravidae: Labor Scale versus WHO Partograph (SLiP Trial) Randomized Controlled Trial. Am J Perinatol. 2018;35(1):48-54. doi: 10.1055/s-00371605575.

34. Lavender T, Cuthbert A, Smyth RM. Effect of partograph use on outcomes for women in spontaneous labour at term and their babies. Cochrane Database Syst Rev. 2018 Aug 6;8:Cd005461. doi: 10.1002/14651858.CD005461.pub5. PMID: 30080256 .
35. Ghafarzadeh M, Moeininasab S, Namdari M. Effect of early amniotomy on dystocia risk and cesarean delivery in nulliparous women: a randomized clinical trial. Arch Gynecol Obstet. 2015 Aug;292(2):321-5. doi: 10.1007/s00404-015-3645-x. PMID: 25666481.

36. Nachum Z, Garmi G, Kadan Y, et al. Comparison between amniotomy, oxytocin or both for augmentation of labor in prolonged latent phase: a randomized controlled trial. Reprod Biol Endocrinol. 2010;8:136. doi: 10.1186/1477-7827-8-136. PMID: 21054896.

37. Mikki N, Wick L, Abu-Asab N, et al. A trial of amniotomy in a Palestinian hospital. J Obstet Gynaecol. 2007 May;27(4):368-73. doi: 10.1080/01443610701327537. PMID: 17654188.

38. Ajadi MA, Kuti O, Orji EO, et al. The effect of amniotomy on the outcome of spontaneous labour in uncomplicated pregnancy. J Obstet Gynaecol. 2006 Oct;26(7):631-4. doi: 10.1080/01443610600903420. PMID: 17071428.

39. Somprasit C, Tanprasertkul C, Kamudhamas A. Reducing cesarean delivery rates: an active management labor program in a setting with limited resources. J Med Assoc Thai. 2005 Jan;88(1):20-5. PMID: 15960212.

40. Abdullah A, Saboohi S, Hashami U. Effects of amniotomy versus spontaneous rupture of membrane on progress of labour and foetal outcome in primigravidae. Journal of the Liaquat University of Medical and Health Sciences. 2010;9(1):33-6.

41. Onah LN, Dim CC, Nwagha UI, et al. Effect of early amniotomy on the outcome of spontaneous labour: a randomized controlled trial of pregnant women in Enugu, Southeast Nigeria. Afr Health Sci. 2015 Dec;15(4):1097-103. doi: 10.4314/ahs.v15i4.7. PMID: 26958009.

42. Ruamsap K, Panichkul P. The Effect of Early Versus Late Amniotomy on The Course of Labor. J Med Assoc Thai. 2017 Feb;100(2):125-32. PMID: 29916231. 
43. Vadivelu M, Rathore S, Benjamin SJ, et al. Randomized controlled trial of the effect of amniotomy on the duration of spontaneous labor. Int J Gynaecol Obstet. 2017 Aug;138(2):152-7. doi: 10.1002/ijgo.12203. PMID: 28485828.

44. Smyth RM, Markham C, Dowswell T. Amniotomy for shortening spontaneous labour. Cochrane Database Syst Rev. 2013;6:Cd006167. doi: 10.1002/14651858.CD006167.pub4. PMID: 23780653 .

45. Brown HC, Paranjothy S, Dowswell T, et al. Package of care for active management in labour for reducing caesarean section rates in low-risk women. Cochrane Database Syst Rev. 2013;9:Cd004907. doi: 10.1002/14651858.CD004907.pub3. PMID: 24043476.

46. Wei S, Wo BL, Qi HP, et al. Early amniotomy and early oxytocin for prevention of, or therapy for, delay in first stage spontaneous labour compared with routine care. Cochrane Database Syst Rev. 2013;8:Cd006794. doi: 10.1002/14651858.CD006794.pub4. PMID: 23926074.

47. Liu Y, Xu M, Che X, et al. Effect of direct current pulse stimulating acupoints of JiaJi (T10-13) and Ciliao (BL 32) with Han's Acupoint Nerve Stimulator on labour pain in women: a randomized controlled clinical study. J Tradit Chin Med. 2015 Dec;35(6):620-5. PMID: 26742304.

48. Akbarzadeh M, Masoudi Z, Zare N, et al. Comparison of the Effects of Maternal Supportive Care and Acupressure (at BL32 Acupoint) on Labor Length and Infant's Apgar Score. Glob J Health Sci. 2015;8(3):48239. doi: 10.5539/gjhs.v8n3p236. PMID: 26493430.

49. Akbarzadeh M, Masoudi Z, Zare N, et al. Comparison of the effects of doula supportive care and acupressure at the BL32 point on the mother's anxiety level and delivery outcome. Iran J Nurs Midwifery Res. 2015 Mar-Apr;20(2):239-46. PMID: 25878703.
50. Asadi N, Maharlouei N, Khalili A, et al. Effects of LI-4 and SP-6 Acupuncture on Labor Pain, Cortisol Level and Duration of Labor. J Acupunct Meridian Stud. 2015 Oct;8(5):249-54. doi: 10.1016/j.jams.2015.08.003. PMID: 26433802.

51. Allameh Z, Tehrani HG, Ghasemi M. Comparing the impact of acupuncture and pethidine on reducing labor pain. Adv Biomed Res. 2015;4:46. doi: 10.4103/22779175.151302. PMID: 25789272.

52. Kaviani M, Maghbool S, Azima S, et al. Comparison of the effect of aromatherapy with Jasminum officinale and Salvia officinale on pain severity and labor outcome in nulliparous women. Iran J Nurs Midwifery Res. 2014 Nov;19(6):666-72. PMID: 25558267.

53. Vixner L, Schytt E, Stener-Victorin E, et al. Acupuncture with manual and electrical stimulation for labour pain: a longitudinal randomised controlled trial. BMC Complement Altern Med. 2014;14:187. doi: 10.1186/1472-6882-14-187. PMID: 24913704.

54. Santhi, Anuratha, Kokilavani. Effectiveness of semi sitting position during 2nd stage of labour on maternal and neonatal outcomes among primigravida. Nurs J India. 2012 Nov-Dec;103(6):272-5. PMID: 23923599.

55. Edwards RK, Reed CA, Villano KS, et al. Effect of hydration on spontaneous labor outcomes in nulliparous pregnant women: a multicenter randomized controlled trial comparing three methods. Am J Perinatol. 2014 Jun;31(6):455-62. doi: 10.1055/s0033-1351661. PMID: 23884718.

56. Silva Gallo RB, Santana LS, Jorge Ferreira $\mathrm{CH}$, et al. Massage reduced severity of pain during labour: a randomised trial. J Physiother. 2013 Jun;59(2):109-16. doi: 10.1016/s1836-9553(13)70163-2. PMID: 23663796.

57. Janssen P, Shroff F, Jaspar P. Massage therapy and labor outcomes: a randomized controlled trial. Int J Ther Massage Bodywork. 2012;5(4):15-20. PMID: 23429706. 
58. Rahmani R, Khakbazan Z, Yavari P, et al. Effect of oral carbohydrate intake on labor progress: randomized controlled trial. Iran J Public Health. 2012;41(11):59-66. PMID: 23304677.

59. Thies-Lagergren L, Kvist LJ, Sandin-Bojo AK, et al. Labour augmentation and fetal outcomes in relation to birth positions: a secondary analysis of an RCT evaluating birth seat births. Midwifery. 2013 Apr;29(4):344-50. doi: 10.1016/j.midw.2011.12.014. PMID: 23084490 .

60. Sharma C, Kalra J, Bagga R, et al. A randomized controlled trial comparing parenteral normal saline with and without $5 \%$ dextrose on the course of labor in nulliparous women. Arch Gynecol Obstet. 2012 Dec;286(6):1425-30. doi: 10.1007/s00404-012-2485-1. PMID: 22865033.

61. Direkvand-Moghadam A, Rezaeian M. Increased intravenous hydration of nulliparas in labor. Int J Gynaecol Obstet. 2012 Sep;118(3):213-5. doi: 10.1016/j.ijgo.2012.03.041. PMID: 22717414.

62. Hamidzadeh A, Shahpourian F, Orak RJ, et al. Effects of LI4 acupressure on labor pain in the first stage of labor. J Midwifery Womens Health. 2012 Mar-Apr;57(2):1338. doi: 10.1111/j.1542-2011.2011.00138.x. PMID: 22432484.

63. Mortazavi SH, Khaki S, Moradi R, et al. Effects of massage therapy and presence of attendant on pain, anxiety and satisfaction during labor. Arch Gynecol Obstet. 2012 Jul;286(1):19-23. doi: 10.1007/s00404-0122227-4. PMID: 22271239.

64. Kavitha A, Chacko KP, Thomas E, et al. A randomized controlled trial to study the effect of IV hydration on the duration of labor in nulliparous women. Arch Gynecol Obstet. 2012 Feb;285(2):343-6. doi: 10.1007/s00404-011-1978-7. PMID: 21748313.
65. Taavoni S, Abdolahian S, Haghani H, et al. Effect of birth ball usage on pain in the active phase of labor: a randomized controlled trial. J Midwifery Womens Health. 2011 Mar-Apr;56(2):137-40. doi: 10.1111/j.1542-2011.2010.00013.x. PMID: 21429078.

66. Ma W, Bai W, Lin C, et al. Effects of Sanyinjiao (SP6) with electroacupuncture on labour pain in women during labour. Complement Ther Med. 2011 Jan;19 Suppl 1:S13-8. doi: 10.1016/j.ctim.2010.09.001. PMID: 21195290.

67. Coco A, Derksen-Schrock A, Coco K, et al. A randomized trial of increased intravenous hydration in labor when oral fluid is unrestricted. Fam Med. 2010 Jan;42(1):52-6. PMID: 20063224.

68. Chaichian S, Akhlaghi A, Rousta F, et al. Experience of water birth delivery in Iran. Arch Iran Med. 2009 Sep;12(5):468-71. PMID: 19722768.

69. Shrivastava VK, Garite TJ, Jenkins SM, et al. A randomized, double-blinded, controlled trial comparing parenteral normal saline with and without dextrose on the course of labor in nulliparas. Am J Obstet Gynecol. 2009 Apr;200(4):379.e1-6. doi: 10.1016/j.ajog.2008.11.030. PMID: 19217592.

70. McGrath SK, Kennell JH. A randomized controlled trial of continuous labor support for middle-class couples: effect on cesarean delivery rates. Birth. 2008 Jun;35(2):92-7. doi: 10.1111/j.1523-536X.2008.00221.x. PMID: 18507579.

71. Miquelutti MA, Cecatti JG, Makuch MY. Upright position during the first stage of labor: a randomised controlled trial. Acta Obstet Gynecol Scand. 2007;86(5):553-8. doi: 10.1080/00016340601185251. PMID: 17464583.

72. Nasir A, Korejo R, Noorani KJ. Child birth in squatting position. J Pak Med Assoc. 2007 Jan;57(1):19-22. PMID: 17319414.

73. Eslamian L, Marsoosi V, Pakneeyat Y. Increased intravenous fluid intake and the course of labor in nulliparous women. Int $\mathrm{J}$ Gynaecol Obstet. 2006 May;93(2):102-5. doi: 10.1016/j.ijgo.2006.01.023. PMID: 16542657. 
74. Ragnar I, Altman D, Tyden T, et al. Comparison of the maternal experience and duration of labour in two upright delivery positions--a randomised controlled trial. BJOG. 2006 Feb;113(2):165-70. doi: 10.1111/j.1471-0528.2005.00824.x. PMID: 16411993.

75. Altman D, Ragnar I, Ekstrom A, et al. Anal sphincter lacerations and upright delivery postures--a risk analysis from a randomized controlled trial. Int Urogynecol J Pelvic Floor Dysfunct. 2007 Feb;18(2):141-6. doi: 10.1007/s00192-006-0123-9. PMID: 16636770 .

76. Albers LL, Sedler KD, Bedrick EJ, et al. Midwifery care measures in the second stage of labor and reduction of genital tract trauma at birth: a randomized trial. J Midwifery Womens Health. 2005 Sep-Oct;50(5):36572. doi: 10.1016/j.jmwh.2005.05.012. PMID: 16154062.

77. Vaijayanthimala M, Judie A. Mobility is an adjuvant approach for intrapartum care - A clinical randomized interventional study. International Journal of Pharmaceutical and Clinical Research. 2014;6(4):356-62.

78. Kashanian M, Shahali S. Effects of acupressure at the Sanyinjiao point (SP6) on the process of active phase of labor in nulliparas women. Journal of Maternal-Fetal and Neonatal Medicine. 2010;23(7):638-41.

79. Bruggemann OM, Parpinelli MA, Osis MJD, et al. Support to woman by a companion of her choice during childbirth: A randomized controlled trial. Reproductive Health. 2007;4.

80. Prabhakar D, George LS, Karkada S. Effectiveness of Ambulation during First Stage of Labour, on the Outcome of Labour among Primigravid Women in Selected Hospitals of Palakkad District, Kerala. International Journal of Nursing Education. 2015;7(1):1-6 p. doi: 10.5958/09749357.2015.00001.X. PMID: 109736286. Language: English. Entry Date: 20150923. Revision Date: 20151008. Publication Type: Journal Article. Journal Subset: Continental Europe.
81. Tussey CM, Botsios E, Gerkin RD, et al. Reducing Length of Labor and Cesarean Surgery Rate Using a Peanut Ball for Women Laboring With an Epidural. Journal of Perinatal Education. 2015 Winter2015;24(1):16-24 9p. doi: 10.1891/1058-1243.24.1.16. PMID: 107772608. Language: English. Entry Date: 20150210. Revision Date: 20150819. Publication Type: Journal Article.

82. Hekmatzadeh SF, Bazarganipour F, Malekzadeh J, et al. A randomized clinical trial of the efficacy of applying a simple protocol of boiled Anethum Graveolens seeds on pain intensity and duration of labor stages. Complement Ther Med.

2014;22(6):970-6 7p. doi: 10.1016/j.ctim.2014.10.007. PMID: 103857382. Language: English. Entry Date: 20150605. Revision Date: 20150710. Publication Type: Journal Article.

83. Shirvani MA, Ganji Z. The influence of cold pack on labour pain relief and birth outcomes: a randomised controlled trial. J Clin Nurs. 2014;23(17/18):2473-80 8p. doi: 10.1111/jocn.12413. PMID: 103978082. Language: English. Entry Date: 20140724. Revision Date: 20150901. Publication Type: Journal Article.

84. Kaviani M, Azima S, Alavi N, et al. The effect of lavender aromatherapy on pain perception and intrapartum outcome in primiparous women. British Journal of Midwifery. 2014;22(2):125-8 4p. PMID: 104020847. Language: English. Entry Date: 20140207. Revision Date: 20150820. Publication Type: Journal Article.

85. Sasitorn P, Boonrueing M, Kitti R, et al. Effect of the Prince of Songkla University Birthing Bed on Duration, Pain, and Comfort Level during Second-Stage Labor in Primiparous Thais. Pacific Rim International Journal of Nursing Research. 2013;17(1):56-67 12p. PMID: 104241027. Language: English. Entry Date: 20130304. Revision Date: 20150819. Publication Type: Journal Article. 
86. Ganapathy T. Childbirth in Supported Sitting Maternal Position. International Journal of Nursing Education. 2012;4(2):8791 5p. PMID: 104394668. Language: English. Entry Date: 20121228. Revision Date: 20150819. Publication Type: Journal Article.

87. Dahlen HG, Homer CS, Cooke M, et al. Perineal outcomes and maternal comfort related to the application of perineal warm packs in the second stage of labor: a randomized controlled trial. Birth: Issues in Perinatal Care. 2007;34(4):282-90 9p. PMID: 105948799. Language: English. Entry Date: 20140221. Revision Date: 20150820. Publication Type: Journal Article.

88. Phumdoung S, Youngvanichsate S, Jongpaiboonpatana $\mathrm{W}$, et al. The effects of the PSU Cat position and music on length of time in the active phase of labor and labor pain. Thai Journal of Nursing Research. 2007;11(2):96-105 10p. PMID: 106181967. Language: English. Entry Date: 20071102.

Revision Date: 20150818. Publication Type: Journal Article.

89. El Hamid, Obaya HE, Gaafar HM. Effect of Acupressure on Labor Pain and Duration of Delivery among Laboring Women Attending Cairo University Hospital. Indian Journal of Physiotherapy \& Occupational Therapy. 2013;7(2):71-6.

90. Yuenyong S, O'Brien B, Jirapeet V. Effects of labor support from close female relative on labor and maternal satisfaction in a Thai setting. J Obstet Gynecol Neonatal Nurs. 2012 Jan;41(1):45-56. doi: 10.1111/j.15526909.2011.01311.x. PMID: 22834721.

91. Taavoni S, Sheikhan F, Abdolahian S, et al. Birth ball or heat therapy? A randomized controlled trial to compare the effectiveness of birth ball usage with sacrum-perineal heat therapy in labor pain management.

Complement Ther Clin Pract. 2016

Aug;24:99-102. doi:

10.1016/j.ctcp.2016.04.001. PMID:

27502808.
92. Yazdkhasti M, Pirak A. The effect of aromatherapy with lavender essence on severity of labor pain and duration of labor in primiparous women. Complement Ther Clin Pract. 2016 Nov;25:81-6. doi: 10.1016/j.ctcp.2016.08.008. PMID: 27863615.

93. Bolbol-Haghighi N, Masoumi SZ, Kazemi F. Effect of Massage Therapy on Duration of Labour: A Randomized Controlled Trial. J Clin Diagn Res. 2016 Apr;10(4):Qc12-5. doi: 10.7860/jcdr/2016/17447.7688. PMID: 27190898.

94. Ahadi Yulghunlu F, Sehhatie Shafaie F, Mirghafourvand M, et al. The effects of intravenous dextrose 5\%, Ringer's solution and oral intake on the duration of labor stages in nulliparous women: A doubleblind, randomized, controlled trial. J Matern Fetal Neonatal Med. 2018 Jun 18:1-151. doi: 10.1080/14767058.2018.1489792. PMID: 29909704.

95. Tanvisut R, Traisrisilp K, Tongsong $\mathrm{T}$. Efficacy of aromatherapy for reducing pain during labor: a randomized controlled trial. Arch Gynecol Obstet. 2018 May;297(5):1145-50. doi: 10.1007/s00404018-4700-1. PMID: 29397442.

96. Moraloglu O, Kansu-Celik H, Tasci Y, et al. The influence of different maternal pushing positions on birth outcomes at the second stage of labor in nulliparous women. J Matern Fetal Neonatal Med. 2017 Jan;30(2):245-9. doi: 10.3109/14767058.2016.1169525. PMID: 27028537.

97. Simarro M, Espinosa JA, Salinas C, et al. A Prospective Randomized Trial of Postural Changes vs Passive Supine Lying during the Second Stage of Labor under Epidural Analgesia. Med Sci (Basel). 2017 Mar 8;5(1)doi: 10.3390/medsci5010005. PMID: 29099021.

98. Zhang H, Huang S, Guo X, et al. A randomised controlled trial in comparing maternal and neonatal outcomes between hands-and-knees delivery position and supine position in China. Midwifery. 2017 Jul;50:117-24. doi: 10.1016/j.midw.2017.03.022. PMID: 28414983. 
99. Fong A, Serra AE, Caballero D, et al. A randomized, double-blinded, controlled trial of the effects of fluid rate and/or presence of dextrose in intravenous fluids on the labor course of nulliparas. Am J Obstet Gynecol. 2017 Aug;217(2):208.e1-.e7. doi: 10.1016/j.ajog.2017.03.010. PMID: 28322776.

100. Gallo RBS, Santana LS, Marcolin AC, et al. Sequential application of nonpharmacological interventions reduces the severity of labour pain, delays use of pharmacological analgesia, and improves some obstetric outcomes: a randomised trial. J Physiother. 2018 Jan;64(1):33-40. doi: 10.1016/j.jphys.2017.11.014. PMID: 29289579.

101. Epidural and Position Trial Collaborative Group. Upright versus lying down position in second stage of labour in nulliparous women with low dose epidural: BUMPES randomised controlled trial. BMJ. 2017 Oct 18;359:j4471. doi: 10.1136/bmj.j4471. PMID: 29046273.

102. Maddady SM, Mohammad-AlizadehCharandabi S, Shafaei FS, et al. Comparing the effects of hot shower and intravenous injection of hyoscine on the pain intensity and duration of active phase of labour in nulliparous women. Journal of Clinical and Diagnostic Research. 2018;12(8):QC07QC11. doi: 10.7860/JCDR/2018/35508.11950.

103. Samadzadeh S, Rezavand N, Yari M, et al. Comparison of Entonox and Transcutaneous Electrical Nerve Stim-ulation (TENS) in labor pain. Journal of Medical and Biomedical Sciences. 2017;6(2):11-6. doi: 10.4314/jmbs.v6i2.2.

104. Wu L, Liu X, Yin Y, et al. Effectiveness of acupuncture versus spinal-epidural anesthesia on labor pain: a randomized controlled trial. J Tradit Chin Med. 2017;37(5):629-35.

105. Wiberg-Itzel E, Wray S, Åkerud H. A randomized controlled trial of a new treatment for labor dystocia. Journal of Maternal-Fetal and Neonatal Medicine. 2018;31(17):2237-44. doi: 10.1080/14767058.2017.1339268.
106. Shafaie FS, Mohaddesi H, Mirghafourvand $\mathrm{M}$, et al. A Randomized, double-blinded, controlled trial comparing parenteral dextrose $5 \%$, Ringer's solution and oral intake on the delivery outcomes in Nulliparas. International Journal of Women's Health and Reproduction Sciences. 2017;5(4):283-9. doi: 10.15296/ijwhr.2017.48.

107. Shahoei R, Shahghebi S, Rezaei M, et al. The effect of transcutaneous electrical nerve stimulation on the severity of labor pain among nulliparous women: A clinical trial. Complement Ther Clin Pract. 2017;28:17680. doi: 10.1016/j.ctcp.2017.05.004. PMID: 124438951. Language: English. Entry Date: 20180330. Revision Date: 20180330. Publication Type: Article.

108. Darsareh F, Nourbakhsh S, Dabiri F. Effect of water immersion on labor outcomes: A randomized clinical trial. Nursing \& Midwifery Studies. 2018;7(3):111-5. doi: 10.4103/nms.nms_18_17. PMID: 130546966. Language: English. Entry Date: 20180710. Revision Date: 20180710. Publication Type: Article. Journal Subset: Continental Europe.

109. İsbir GG, Serçekuş P. The Effects of Intrapartum Supportive Care on Fear of Delivery and Labor Outcomes: A SingleBlind Randomized Controlled Trial. Journal of Nursing Research (Lippincott Williams \& Wilkins). 2017;25(2):112-9. doi: 10.1097/jnr.0000000000000129. PMID: 122434272. Language: English. Entry Date: 20170421. Revision Date: 20170421. Publication Type: Article.

110. Xiao J, Yi W, Wu L. Effects of electroacupuncture on reducing labor pain and complications in the labor analgesia process of combined spinal-epidural analgesia with patient-controlled epidural analgesia. Arch Gynecol Obstet. 2019;299(1):123-8. doi: 10.1007/s00404018-4955-6. PMID: 134079027. Language: English. Entry Date: In Process. Revision Date: 20190117. Publication Type: Journal Article. Journal Subset: Biomedical.

111. Hodnett Ellen D, Gates S, Hofmeyr GJ, et al. Continuous support for women during childbirth. Cochrane Database Syst Rev: John Wiley \& Sons, Ltd; 2013. 
112. Fortier JH, Godwin M. Doula support compared with standard care: Meta-analysis of the effects on the rate of medical interventions during labour for low-risk women delivering at term. Can Fam Physician. 2015;61(6):e284-e92.

113. Cluett ER, Burns E. Immersion in water in labour and birth. Cochrane Database Syst Rev. 2009(2):Cd000111. doi: 10.1002/14651858.CD000111.pub3. PMID: 19370552.

114. Lawrence A, Lewis L, Hofmeyr GJ, et al. Maternal positions and mobility during first stage labour. Cochrane Database Syst Rev. 2013;10:Cd003934. doi:

10.1002/14651858.CD003934.pub4. PMID: 24105444.

115. Dawood F, Dowswell T, Quenby S. Intravenous fluids for reducing the duration of labour in low risk nulliparous women. Cochrane Database Syst Rev. 2013;6:Cd007715. doi: 10.1002/14651858.CD007715.pub2. PMID: 23780639.

116. Genc M, Sahin N, Maral J, et al. Does bupivacaine and fentanyl combination for epidural analgesia shorten the duration of labour? J Obstet Gynaecol. 2015;35(7):6725. doi: 10.3109/01443615.2014.991299. PMID: 25546524.

117. Wassen MM, Smits LJ, Scheepers HC, et al. Routine labour epidural analgesia versus labour analgesia on request: a randomised non-inferiority trial. BJOG. 2015 Feb;122(3):344-50. doi: 10.1111/14710528.12854. PMID: 24849943.

118. Patel NP, El-Wahab N, Fernando R, et al. Fetal effects of combined spinal-epidural vs epidural labour analgesia: a prospective, randomised double-blind study. Anaesthesia. 2014 May;69(5):458-67. doi: 10.1111/anae.12602. PMID: 24738803.

119. Ismail MT, Hassanin MZ. Neuraxial analgesia versus intravenous remifentanil for pain relief in early labor in nulliparous women. Arch Gynecol Obstet. 2012 Dec;286(6):1375-81. doi: 10.1007/s00404012-2459-3. PMID: 22810619.
120. Pascual-Ramirez J, Haya J, Perez-Lopez F, et al. Type of axial analgesia does not influence time to vaginal delivery in a Proportional Hazards Model. Arch Gynecol Obstet. 2012 Oct;286(4):873-80. doi: 10.1007/s00404-012-2360-0. PMID: 22639135.

121. Orange FA, Passini-Jr R, Melo AS, et al. Combined spinal-epidural anesthesia and non-pharmacological methods of pain relief during normal childbirth and maternal satisfaction: a randomized clinical trial. Rev Assoc Med Bras. 2012 Jan-Feb;58(1):112-7. PMID: 22392325.

122. Tveit TO, Seiler S, Halvorsen A, et al. Labour analgesia: a randomised, controlled trial comparing intravenous remifentanil and epidural analgesia with ropivacaine and fentanyl. Eur J Anaesthesiol. 2012 Mar;29(3):129-36. doi: 10.1097/EJA.0b013e32834dfa98. PMID: 22249153.

123. Sweed N, Sabry N, Azab T, et al. Regional versus IV analgesics in labor. Minerva Med. 2011 Oct;102(5):353-61. PMID: 22193345.

124. de Orange FA, Passini R, Jr., Amorim MM, et al. Combined spinal and epidural anaesthesia and maternal intrapartum temperature during vaginal delivery: a randomized clinical trial. Br J Anaesth. 2011 Nov;107(5):762-8. doi: 10.1093/bja/aer218. PMID: 21743067.

125. Pascual-Ramirez J, Haya J, Perez-Lopez FR, et al. Effect of combined spinal-epidural analgesia versus epidural analgesia on labor and delivery duration. Int J Gynaecol Obstet. 2011 Sep;114(3):246-50. doi: 10.1016/j.ijgo.2011.04.004. PMID: 21719012.

126. Wilson MJ, Moore PA, Shennan A, et al. Long-term effects of epidural analgesia in labor: a randomized controlled trial comparing high dose with two mobile techniques. Birth. 2011 Jun;38(2):105-10. doi: 10.1111/j.1523-536X.2010.00466.x. PMID: 21599732. 
127. Douma MR, Middeldorp JM, Verwey RA, et al. A randomised comparison of intravenous remifentanil patient-controlled analgesia with epidural ropivacaine/sufentanil during labour. Int $\mathrm{J}$ Obstet Anesth. 2011 Apr;20(2):118-23. doi: 10.1016/j.ijoa.2010.11.009. PMID: 21376564.

128. Nakamura G, Ganem EM, Rugolo LM, et al. Effects on mother and fetus of epidural and combined spinal-epidural techniques for labor analgesia. Rev Assoc Med Bras. 2009 Jul-Aug;55(4):405-9. PMID: 19750306.

129. Wilson MJ, MacArthur C, Cooper GM, et al. Ambulation in labour and delivery mode: a randomised controlled trial of high-dose vs mobile epidural analgesia. Anaesthesia. 2009 Mar;64(3):266-72. doi: 10.1111/j.1365-2044.2008.05756.x. PMID: 19302638.

130. Abrao KC, Francisco RP, Miyadahira S, et al. Elevation of uterine basal tone and fetal heart rate abnormalities after labor analgesia: a randomized controlled trial. Obstet Gynecol. 2009 Jan;113(1):41-7. doi: 10.1097/AOG.0b013e31818f5eb6. PMID: 19104358.

131. Sezer OA, Gunaydin B. Efficacy of patientcontrolled epidural analgesia after initiation with epidural or combined spinal-epidural analgesia. Int J Obstet Anesth. 2007 Jul;16(3):226-30. doi: 10.1016/j.ijoa.2007.02.007. PMID: 17509869.

132. Nafisi S. Effects of epidural lidocaine analgesia on labor and delivery: a randomized, prospective, controlled trial. BMC Anesthesiol. 2006;6:15. doi: 10.1186/1471-2253-6-15. PMID: 17176461.

133. Ohel G, Gonen R, Vaida S, et al. Early versus late initiation of epidural analgesia in labor: does it increase the risk of cesarean section? A randomized trial. Am J Obstet Gynecol. 2006 Mar;194(3):600-5. doi: 10.1016/j.ajog.2005.10.821. PMID: 16522386.

134. Wong CA, Scavone BM, Peaceman AM, et al. The risk of cesarean delivery with neuraxial analgesia given early versus late in labor. N Engl J Med. 2005 Feb 17;352(7):655-65. doi: 10.1056/NEJMoa042573. PMID: 15716559.
135. Jaitley A, Singh S, Srivastava U, et al. A comparison between epidural and IV tramadol for painless labor and effect on perinatal outcome. Journal of Obstetrics and Gynecology of India. 2011;61(1):42-7.

136. Bhagwat A, Dua C, Saxena K, et al. Comparison of combined spinal epidural technique and low dose epidural technique in progress of labour. Indian J Anaesth. 2008;52(3):282-7.

137. van den Bosch AAS, Goossens M, Bonouvrie K, et al. Maternal quality of life in routine labor epidural analgesia versus labor analgesia on request: results of a randomized trial. Qual Life Res. 2018 Aug;27(8):2027-33. doi: 10.1007/s11136018-1838-z. PMID: 29603114.

138. Shen X, Li Y, Xu S, et al. Epidural Analgesia During the Second Stage of Labor: A Randomized Controlled Trial. Obstet Gynecol. 2017 Nov;130(5):1097103. doi: 10.1097/aog.0000000000002306. PMID: 29016499.

139. Marucci M, Cinnella G, Perchiazzi G, et al. Patient-requested neuraxial analgesia for labor: impact on rates of cesarean and instrumental vaginal delivery. Anesthesiology. 2007 May;106(5):1035-45. doi: 10.1097/01.anes.0000265165.06760.c2. PMID: 17457137.

140. Anim-Somuah M, Smyth RM, Jones L. Epidural versus non-epidural or no analgesia in labour. Cochrane Database Syst Rev. 2011(12):Cd000331. doi: 10.1002/14651858.CD000331.pub3. PMID: 22161362.

141. Downe S, Gyte GM, Dahlen HG, et al. Routine vaginal examinations for assessing progress of labour to improve outcomes for women and babies at term. Cochrane Database Syst Rev. 2013;7:Cd010088. doi: 10.1002/14651858.CD010088.pub2. PMID: 23857468.

142. Bakker JJ, Janssen PF, van Halem K, et al. Internal versus external tocodynamometry during induced or augmented labour. Cochrane Database Syst Rev. 2013;8:Cd006947. doi: 10.1002/14651858.CD006947.pub3. PMID: 23913521. 
143. Kenyon S, Armstrong N, Johnston T, et al. Standard- or high-dose oxytocin for nulliparous women with confirmed delay in labour: quantitative and qualitative results from a pilot randomised controlled trial. BJOG. 2013 Oct;120(11):1403-12. doi: 10.1111/1471-0528.12331. PMID: 23786339.

144. Tribe RM, Crawshaw SE, Seed P, et al. Pulsatile versus continuous administration of oxytocin for induction and augmentation of labor: two randomized controlled trials. Am J Obstet Gynecol. 2012 Mar;206(3):230.e18. doi: 10.1016/j.ajog.2011.11.001. PMID: 22206748.

145. Dencker A, Berg M, Bergqvist L, et al. Early versus delayed oxytocin augmentation in nulliparous women with prolonged labour--a randomised controlled trial. BJOG. 2009 Mar;116(4):530-6. doi:

10.1111/j.1471-0528.2008.01962.x. PMID: 19250364.

146. Bergqvist L, Dencker A, Taft C, et al. Women's experiences after early versus postponed oxytocin treatment of slow progress in first childbirth--a randomized controlled trial. Sex Reprod Healthc. 2012 Jun;3(2):61-5. doi:

10.1016/j.srhc.2012.03.003. PMID: 22578752.

147. Hinshaw K, Simpson S, Cummings S, et al. A randomised controlled trial of early versus delayed oxytocin augmentation to treat primary dysfunctional labour in nulliparous women. BJOG. 2008 Sep;115(10):1289-95; discussion 95-6. doi: 10.1111/j.14710528.2008.01819.x. PMID: 18715415.

148. Palomaki O, Uotila J, Tammela O, et al. A double blind, randomized trial on augmentation of labour with a combination of intravenous propranolol and oxytocin versus oxytocin only. Eur J Obstet Gynecol Reprod Biol. 2006 Mar 1;125(1):44-9. doi: 10.1016/j.ejogrb.2005.06.016. PMID: 16051416.

149. Dy J, Rainey J, Walker MC, et al. Accelerated Titration of Oxytocin in Nulliparous Women with Labour Dystocia: Results of the ACTION Pilot Randomized Controlled Trial. J Obstet Gynaecol Can. 2018 Jun;40(6):690-7. doi: 10.1016/j.jogc.2017.08.046. PMID: 29276166.
150. Liu J, Yi Y, Weiwei X. Effects of Increased Frequency, High Dose, and Pulsatile Oxytocin Regimens on Abnormal Labor Delivery. Med Sci Monit. 2018 Apr 7;24:2063-71. PMID: 29626416.

151. Geeta D, Go R, Sudesh G, et al. Low-dose versus high-dose oxytocin in augmentation of labor: A prospective study. J Indian Med Assoc. 2015;113(10):102.

152. Selin L, Wennerholm UB, Jonsson M, et al. High-dose versus low-dose of oxytocin for labour augmentation: a randomised controlled trial. Women Birth. 2018 Oct 16doi: 10.1016/j.wombi.2018.09.002. PMID: 30341003.

153. Wei SQ, Luo ZC, Qi HP, et al. High-dose vs low-dose oxytocin for labor augmentation: a systematic review. Am J Obstet Gynecol. 2010 Oct;203(4):296-304. doi: 10.1016/j.ajog.2010.03.007. PMID: 20451894.

154. Kenyon S, Tokumasu H, Dowswell T, et al. High-dose versus low-dose oxytocin for augmentation of delayed labour. Cochrane Database Syst Rev. 2013;7:Cd007201. doi: 10.1002/14651858.CD007201.pub3. PMID: 23853046.

155. Wei SQ, Luo ZC, Xu H, et al. The effect of early oxytocin augmentation in labor: a meta-analysis. Obstet Gynecol. 2009 Sep;114(3):641-9. doi: 10.1097/AOG.0b013e3181b11cb8. PMID: 19701046.

156. Bugg GJ, Siddiqui F, Thornton JG. Oxytocin versus no treatment or delayed treatment for slow progress in the first stage of spontaneous labour. Cochrane Database Syst Rev. 2013;6:Cd007123. doi: 10.1002/14651858.CD007123.pub3. PMID: 23794255.

157. Costley PL, East CE. Oxytocin augmentation of labour in women with epidural analgesia for reducing operative deliveries. Cochrane Database Syst Rev. 2012;5:Cd009241. doi: 10.1002/14651858.CD009241.pub2. PMID: 22592738.

158. Lutomski JE, Meaney S, Greene Richard A, et al. Expert systems for fetal assessment in labour. Cochrane Database Syst Rev: John Wiley \& Sons, Ltd; 2015. 
159. Alfirevic Z, Devane D, Gyte Gillian ML. Continuous cardiotocography (CTG) as a form of electronic fetal monitoring (EFM) for fetal assessment during labour.

Cochrane Database Syst Rev: John Wiley \& Sons, Ltd; 2013.

160. East CE, Begg L, Colditz PB, et al. Fetal pulse oximetry for fetal assessment in labour. Cochrane Database Syst Rev. 2014;10:Cd004075. doi: 10.1002/14651858.CD004075.pub4. PMID: 25287809 .

161. Blix E, Brurberg KG, Reierth E, et al. ST waveform analysis versus cardiotocography alone for intrapartum fetal monitoring: A systematic review and meta-analysis of randomized trials. Acta Obstet Gynecol Scand. 2016;95(1):16-27.

162. Yildirim G, Beji NK. Effects of pushing techniques in birth on mother and fetus: a randomized study. Birth. 2008 Mar;35(1):25-30. doi: 10.1111/j.1523536X.2007.00208.x. PMID: 18307484.

163. Bloom SL, Casey BM, Schaffer JI, et al. A randomized trial of coached versus uncoached maternal pushing during the second stage of labor. Am J Obstet Gynecol. 2006 Jan;194(1):10-3. doi: 10.1016/j.ajog.2005.06.022. PMID: 16389004.

164. Schaffer JI, Bloom SL, Casey BM, et al. A randomized trial of the effects of coached vs uncoached maternal pushing during the second stage of labor on postpartum pelvic floor structure and function. Am J Obstet Gynecol. 2005 May;192(5):1692-6. doi: 10.1016/j.ajog.2004.11.043. PMID: 15902179.

165. Vaziri F, Arzhe A, Asadi N, et al. Spontaneous Pushing in Lateral Position versus Valsalva Maneuver During Second Stage of Labor on Maternal and Fetal Outcomes: A Randomized Clinical Trial. Iran Red Crescent Med J. 2016 Oct;18(10):e29279. doi: 10.5812/ircmj.29279. PMID: 28180019.

166. Koyucu RG, Demirci N. Effects of pushing techniques during the second stage of labor: A randomized controlled trial. Taiwan J Obstet Gynecol. 2017 Oct;56(5):606-12. doi: 10.1016/j.tjog.2017.02.005. PMID: 29037544.
167. Cahill AG, Srinivas SK, Tita ATN, et al. Effect of Immediate vs Delayed Pushing on Rates of Spontaneous Vaginal Delivery Among Nulliparous Women Receiving Neuraxial Analgesia: A Randomized Clinical Trial. JAMA. 2018 Oct 9;320(14):1444-54. doi: 10.1001/jama.2018.13986. PMID: 30304425.

168. Walter SD, Turner RM, Macaskill P. Optimising the two-stage randomised trial design when some participants are indifferent in their treatment preferences. Stat Med. 2019 Jun 15;38(13):2317-31. doi: 10.1002/sim.8119. PMID: 30793786.

169. Knox D, Yamamoto T, Baum MA, et al. Design, identification, and sensitivity analysis for patient preference trials. Journal of the American Statistical Association. 2019 Feb 27(just-accepted):1-25.

170. Matza LS, Boye KS, Feeny DH, et al. Impact of caregiver and parenting status on time trade-off and standard gamble utility scores for health state descriptions. Health Qual Life Outcomes. 2014 Apr 9;12:48. doi: 10.1186/1477-7525-12-48. PMID: 24716709.

171. Saigal S, Tyson J. Measurement of quality of life of survivors of neonatal intensive care: critique and implications. Semin Perinatol. 2008 Feb;32(1):59-66. doi: 10.1053/j.semperi.2007.12.007. PMID: 18249241.

172. Goldhaber-Fiebert JD, Brandeau ML. Evaluating Cost-effectiveness of Interventions That Affect Fertility and Childbearing: How Health Effects Are Measured Matters. Med Decis Making. 2015 Oct;35(7):818-46. doi: 10.1177/0272989X15583845. PMID: 25926281.

173. Duffy J, Rolph R, Gale C, et al. Core outcome sets in women's and newborn health: a systematic review. BJOG. 2017 Sep;124(10):1481-9. doi: 10.1111/14710528.14694. PMID: 28421657. 


\section{Introduction}

\section{Background}

\section{Condition}

Approximately 80 percent of American women will eventually have at least one child, ${ }^{1}$ and the majority of these women will undergo labor. "Labor dystocia" (difficult or obstructed labor) ${ }^{2}$ encompasses a variety of concepts, ranging from "abnormally" slow dilation of the cervix or descent of the fetus during active labor ${ }^{3}$ to entrapment of the fetal shoulders after delivery of the head ("shoulder dystocia," an obstetric emergency). For the purposes of this systematic review, we assume that "labor dystocia" refers to "abnormal" labor progression during the latent (up to 4-6 cm dilation) or active phases (from 4-6 cm until full dilation) of the first stage of labor, or during the second stage (from complete cervical dilation until delivery of the baby), although, as discussed below, there have been substantial changes in practice since these "traditional" definitions were developed which raise questions about their generalizability to modern populations. We also limit our review to women in spontaneous labor, with definitions varying somewhat between studies but generally including the onset of spontaneous uterine contractions, and explicitly exclude studies of women undergoing induction, or women with premature rupture of membranes at term in the absence of contractions.

Prolonged labor may increase the risk for maternal and neonatal infection, fetal distress, neonatal hypoxia, uterine rupture, and postpartum hemorrhage; it may also be a marker for increased risk of maternal pelvic floor and genital trauma during delivery (with a subsequent increased risk for future incontinence and pelvic organ prolapse). ${ }^{4}$ Reducing the likelihood of these adverse maternal and neonatal outcomes is the underlying rationale for performing a cesarean delivery for the primary indication of labor dystocia. ${ }^{3}$

However, there is a tradeoff, since cesarean delivery itself increases the risk of maternal hemorrhage, venous thromboembolism, and injury to the bladder and other internal organs, and can affect post-delivery mother-baby interactions. ${ }^{3,5}$ Further, having one cesarean delivery increases the likelihood of having subsequent cesarean deliveries. ${ }^{3} \mathrm{~A}$ woman's risk for abnormal placentation (placenta previa or accreta, each of which is associated with significant maternal and neonatal morbidity and mortality) is directly related to the number of prior cesarean deliveries she has had. ${ }^{6}$

Although there is no consensus on the "optimal" cesarean delivery rate (conceptually, the rate that strikes a balance between benefits and harms for both mother and baby that is considered acceptable to most patients), there is general consensus that current rates in the United States are too high, ${ }^{3,7}$ although whether the factors driving this rate are amenable to evidence-based solutions has been questioned. ${ }^{8}$ There is also growing concern about increases in rates internationally, as reflected by a World Health Organization consensus statement. ${ }^{9}$ Strategies to prevent a woman's first, or primary, caesarean delivery may therefore lead to significant improvements in maternal and neonatal outcomes by reducing both the number of primary and repeat cesareans. ${ }^{3}$ For this reason, the American College of Obstetricians and Gynecologists (ACOG) and the Society for Maternal-Fetal Medicine (SMFM) have issued a joint consensus statement aimed at "preventing the first cesarean delivery,"3 with similar efforts instituted by the American College of Nurse Midwives. ${ }^{10}$ Since abnormalities of labor progression are the single most common cause of primary cesarean delivery in the United 
States, ${ }^{3,11}$ strategies aimed at reducing cesarean delivery for dystocia may have the largest potential impact on overall cesarean rates.

Uncertainty about optimal management of dystocia may play a major role in the welldocumented variation in cesarean delivery rates between hospitals that does not appear to be completely attributable to patient characteristics ${ }^{12}$ (although other factors not directly related to evidence on comparative effectiveness, such as patient and provider preferences, real or perceived malpractice concerns, and local practice norms may also be important factors). Another source of uncertainty is that there are complex tradeoffs between patient preferences for the labor and delivery process, on the one hand, and outcomes on the other. These considerations involve issues related to setting (home, birthing center, hospital), provider (lay midwife, nursemidwife, family physician, obstetrician), and available technology (including analgesia, fetal heart rate monitoring, and measurement of intrauterine pressure). ${ }^{13-15}$ There is also wide variety in the maternal and neonatal outcomes that are reported, and the degree to which patient preferences for both process and outcomes is considered. ${ }^{15-17}$

\section{Diagnosis}

The effective management of labor dystocia is first dependent on the tool used to diagnose the disorder. In the 1950s, Friedman published his observations on the rate of cervical change among a cohort of women in spontaneous labor ${ }^{18}$ and from this constructed labor curves representing the expected rate of cervical change in a population. Deviations from these curves, particularly rates of cervical change slower than expected from the Friedman curve are referred to as protracted or arrest disorders and represent labor dystocia. The Friedman curve has been the primary tool used to diagnose abnormal labor since then, though more recent data from the Consortium on Safe Labor have demonstrated that rates and characteristics of cervical change seen in modern obstetrics are quite different from that represented by the Friedman curve. ${ }^{19}$ Identifying what constitutes normal labor is an important initial step in the management of labor dystocia as it first dictates when various treatment options are initiated. Variation between providers about definitions or perceptions of “abnormal” labor length may contribute to variations in rates of diagnosis.

\section{Prevention and Treatment Strategies}

There are a number of strategies that may either facilitate earlier diagnosis of labor, directly or indirectly (e.g., choice of pain management strategies) prevent a diagnosis of labor dystocia, or accelerate labor progress after a diagnosis of dystocia. Strategies addressed in this report include:

- Use of graphs of cervical dilation versus time ("partograms") to identify patients with slow labor progress, often with an indicator of when intervention is appropriate.

- Timing of the artificial rupture of the amniotic membranes (amniotomy) during labor.

- Various options for maternal positioning, ambulation, and feeding during labor.

- Use of epidural analgesia, or, alternatively, variations in technique (timing, choice of analgesic agents).

- Variations in monitoring labor progress (such as frequency of cervical examination or use of intrauterine pressure catheters) and fetal well-being (fetal heart rate monitoring).

- Variations in strategies for how oxytocin is used during labor augmentation including timing of augmentation relative to labor progress and variation in dosing regimens used. 
- Variations in strategies for reducing the length of the second stage of labor (after cervical dilation is complete but before the baby has delivered), including different approaches to maternal pushing.

The overall goal of treating labor dystocia is to optimize delivery outcomes for mother and child, while attempting to achieve an optimal cesarean delivery rate. As discussed above, the optimal cesarean delivery rate is not known but is the lowest rate that balances benefits and harms to mother and child.

\section{Scope and Key Questions}

\section{Scope of the Review}

The present review evaluates the comparative effectiveness of different strategies for treating labor dystocia in women with otherwise uncomplicated pregnancies. We also limit our review to women in spontaneous labor and exclude those who are undergoing induced labor. In addition, one potential source of uncertainty in the available evidence may be variability in the definitions for different phases of labor, and what constitutes "normal" labor across studies and likely in practice as well. The definition of "normal" may vary across different populations and may depend on whether "normality" is based on a specified quantile of the distribution of rates of cervical change in the first stage of labor or rate of fetal descent in the second stage of labor, or on maternal and neonatal outcomes. ${ }^{20-22}$ The statistical approach used to define "normality,"

primarily in reference to rates of cervical change, has also been the source of controversy. ${ }^{23-25}$ In order to better understand the impact of this variability on the evidence on specific interventions, we also review the evidence on the definition of "normal" labor progression.

We explicitly excluded studies which included women with other potential indications for cesarean section (e.g., multiple pregnancies, prior cesarean) or other conditions which might affect either the likelihood of diagnosis of dystocia (e.g., use of magnesium sulfate in preeclampsia) or lead to contraindications to some interventions (e.g., HIV and amniotomy). We also did not include interventions such as estimation of fetal size or clinical pelvimetry which might affect physician perception of the risk of labor dystocia.

Note that many studies evaluated interventions in nulliparous (women who have not previously given birth) and parous women (women who have previously borne one or more children) separately. Other studies did not indicate the women's parity and were considered to be mixed parity or unspecified parity defined as potentially including both nulliparous and parous women. 


\section{Key Questions}

The specific Key Questions (KQs) addressed in this review are listed below, and Figure 1 displays the analytic framework that guided our work.

- KQ 1: Do delivery outcomes for management of abnormal labor differ based on the criteria used to define protracted or arrested labor at different stages of the labor process?

- KQ 2: What are the benefits and harms of amniotomy in women in spontaneous labor?

- KQ 3: What are the benefits and harms of supportive care measures, including emotional support, ambulation, nutrition, and hydration, during spontaneous labor?

- KQ 4: What are the benefits and harms of epidural analgesia in labor, particularly in terms of the risk of a diagnosis of prolonged labor?

- KQ 5: How does the frequency of cervical examination affect the probability of specific benefits and harms?

- KQ 6: What are the benefits and harms of intrauterine pressure catheters in the diagnosis and management of labor dystocia?

- KQ 7: For women with abnormal labor, what are the relative benefits and harms of high- versus low-dose oxytocin protocols (including nipple stimulation)?

- KQ 8: For women in spontaneous labor undergoing augmentation with oxytocin, what are the relative benefits and harms (in terms of both maternal and neonatal outcomes) of electronic fetal monitoring versus intermittent auscultation?

- KQ 9: For women in the second stage of labor, is there a benefit from delayed or Valsalva pushing for time to delivery or mode of delivery?

Figure 1 depicts the KQs within the context of the populations, interventions, comparators, outcomes, timings, and settings (PICOTS) considered in this review. It illustrates the progression of spontaneous labor, which may be affected by interventions or management strategies performed prior to the diagnosis of abnormal progression; the criteria used to diagnose abnormal progression; and interventions performed after the diagnosis of abnormal progression. 
Figure 1. Analytic framework

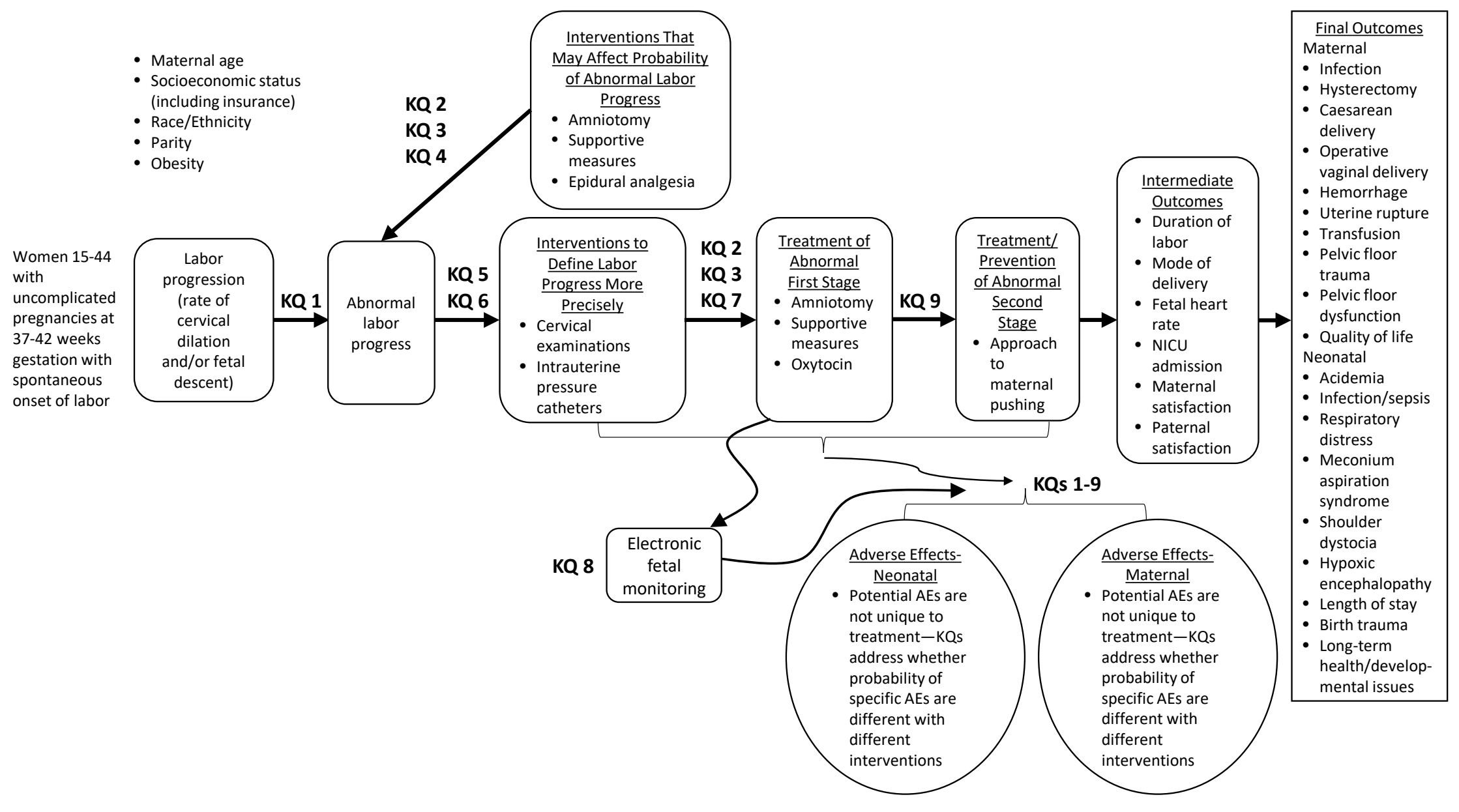

Abbreviations: AEs=adverse effects; KQ=Key Question; NICU=neonatal intensive care unit 


\section{Organization of This Report}

The remainder of the report details our methodology and presents the results of our literature synthesis, with summary tables and strength of evidence grading for major comparisons and outcomes. In the discussion section, we offer our conclusions, summarized findings, and other information that may be relevant to translating this work for clinical practice and future research.

Appendixes provide further details on our methods and the studies we assessed, as follows:

- Appendix A. Exact Search Strings

- Appendix B. Data Abstraction Elements

- Appendix C. List of Included Studies

- Appendix D. List of Excluded Studies

- Appendix E. Characteristics of Included Studies

- Appendix F. A Measurement Tool to Assess Systematic Review (AMSTAR) Quality Assessment for Systematic Reviews

- Appendix G. Risk of Bias Assessment for Included Studies

A list of abbreviations and acronyms is provided at the end of the report. 


\section{Methods}

The methods for this systematic review (SR) follow the Agency for Healthcare Research and Quality (AHRQ) Methods Guide for Effectiveness and Comparative Effectiveness Reviews (hereafter referred to as the Methods Guide) for the Evidence-based Practice Center (EPC) program $^{26}$ and the Preferred Reporting Items for Systematic Reviews and Meta-Analyses (PRISMA) checklist. ${ }^{27}$ See the review protocol $^{28}$ for full details.

\section{Topic Refinement and Review Protocol}

The topic of this report and preliminary Key Questions (KQs) arose through nomination from a professional society and initial development by the Scientific Resource Center for AHRQ's Effective Health Care (EHC) program. During the subsequent topic refinement phase, a panel of Key Informants gave input to the EPC on the KQs to be examined; these KQs were posted on AHRQ's EHC website for public comment in September 2015 for 3 weeks and revised in response to comments. We then drafted a protocol for the SR and recruited a technical expert panel to provide high-level content and methodological expertise throughout the development of the review. The Key Informants and Technical Expert Panel represented members of medical professional societies and clinician/researchers in the areas of obstetrics and gynecology, midwifery, and pediatrics; scientific experts; payers; and patients/consumers. The finalized protocol is posted on the EHC website. ${ }^{28}$ The PROSPERO registration is CRD42016035567.

\section{Literature Search Strategy}

\section{Search Strategy}

To identify relevant published literature, we searched PubMed ${ }^{\circledR}$, Embase $^{\circledR}$, CINAHL $^{\circledR}$, and the Cochrane Database of Systematic Reviews (CDSR), limiting the searches to studies published in English from January 1, 2005, to February 15, 2019. These databases were selected based on internal expert opinion that they would identify most of the relevant literature on this topic and that they reflect the databases used in related SRs, particularly reviews conducted by the Cochrane Pregnancy and Childbirth Group. An experienced search librarian guided all searches. The exact search strings used are given in Appendix A.

We supplemented the electronic searches with a manual search of citations from a set of key primary and review articles. ${ }^{29-57}$ The reference lists for identified key articles were manually searched and cross-referenced against our database, and additional relevant articles not already under consideration were retrieved for screening. All citations were imported into an electronic bibliographical database (EndNote ${ }^{\circledR}$ Version X7; Thomson Reuters, Philadelphia, PA). While the draft report is under peer review, we will update the search and include any eligible studies identified either during that search or through peer or public reviews in the final report.

To identify relevant gray literature, the EPC Scientific Resource Center notified stakeholders that the EPC was interested in receiving information relevant to the KQs. We also searched ClinicalTrials.gov for two purposes: (1) to identify relevant articles from completed studies that may not have appeared through other search strategies and (2) as one mechanism to ascertain publication bias in recent studies. For the latter goal, we sought to identify completed but unpublished studies that could impact the findings of the review. Search terms used for ClinicalTrials.gov are provided in Appendix A We also explored the possibility of publication bias specifically in our quantitative synthesis of the included literature through meta-analysis 
(MA) techniques such as funnel plots when appropriate. Further gray literature assessment included searching the World Health Organization International Clinical Trials Registry Platform search portal and the National Guidelines Clearinghouse to identify potentially relevant study records; we subsequently searched for relevant articles from among the completed studies.

\section{Inclusion and Exclusion Criteria}

We specified our inclusion and exclusion criteria based on the PICOTS (populations, interventions, comparators, outcomes, timing, and settings) identified for each question. Table 1 lists inclusion and exclusion criteria. For the purpose of the review, "uncomplicated pregnancies” excluded populations with either maternal (e.g., hypertension or diabetes) or fetal (e.g., congenital anomalies, growth restriction) conditions which could affect thresholds for intervention.

Table 1. Inclusion and exclusion criteria

\begin{tabular}{|c|c|c|}
\hline $\begin{array}{l}\text { PICOTS } \\
\text { Element }\end{array}$ & Inclusion Criteria & Exclusion Criteria \\
\hline Populations & $\begin{array}{l}\text { KQs 1-5: Women aged 15-44 with uncomplicated } \\
\text { pregnancy at } 37-42 \text { weeks gestation with a singleton } \\
\text { pregnancy with vertex presentation. For the purposes } \\
\text { of this review, women who are undergoing induction of } \\
\text { labor for any indication are excluded, because the } \\
\text { probability of specific outcomes is necessarily different } \\
\text { for them. } \\
\text { KQ 6: Women aged 15-44 with uncomplicated } \\
\text { pregnancy at } 37-42 \text { weeks with suspected } \\
\text { abnormalities of the first stage of labor } \\
\text { KQ 7: Women aged 15-44 with uncomplicated } \\
\text { pregnancy at } 37-42 \text { weeks with a diagnosed } \\
\text { abnormality of the first stage of labor } \\
\text { KQ 8: Women aged 15-44 with uncomplicated } \\
\text { pregnancy at 37-42 weeks gestation with a diagnosed } \\
\text { abnormality of the first stage of labor undergoing } \\
\text { augmentation with oxytocin } \\
\text { KQ 9: Women aged 15-44 with uncomplicated } \\
\text { pregnancies at } 37-42 \text { weeks who have reached } \\
\text { complete cervical dilation (with or without } \\
\text { augmentation); relevant subgroups include women } \\
\text { with and without epidural analgesia } \\
\text { KQs 1-9: Relevant subgroups for all KQs include: } \\
\text { (a) maternal age (particularly adolescents and women } \\
\text { 35-44 years old); (b) parity; (c) maternal race/ethnicity; } \\
\text { (d) maternal socioeconomic status, including insurance } \\
\text { status; and (e) maternal obesity. }\end{array}$ & $\begin{array}{l}\text { - Women <15 or }>44 \\
\text { - } \quad \text { Wears of age } \\
\text { - Women in preterm labor } \\
\text { labor induction for any } \\
\text { indication } \\
\text { - Women with prior history } \\
\text { of cesarean delivery } \\
\text { - Women with } \\
\text { spontaneous rupture of } \\
\text { membranes without } \\
\text { contractions } \\
\text { KQs 6-8: Studies which } \\
\text { do not provide either a } \\
\text { definition of "dystocia," } \\
\text { "prolonged labor," } \\
\text { "arrest of labor," "arrest } \\
\text { of descent," or other } \\
\text { relevant diagnosis within } \\
\text { the Methods section, or } \\
\text { which do not provide a } \\
\text { citation with such a } \\
\text { definition }\end{array}$ \\
\hline
\end{tabular}




\begin{tabular}{|c|c|c|}
\hline $\begin{array}{l}\text { PICOTS } \\
\text { Element }\end{array}$ & Inclusion Criteria & Exclusion Criteria \\
\hline Interventions & $\begin{array}{l}\text { - KQ 1: Definitions of abnormalities of the latent and } \\
\text { active phases of the first stage of labor (up until } \\
\text { complete dilation of the cervix) and of the second } \\
\text { stage of labor (from complete dilation until delivery of } \\
\text { the infant), developed based on data from the Safe } \\
\text { Labor Consortium. } \\
\text { - } \quad \text { KQ 2: Routine amniotomy (artificial rupture of } \\
\text { membranes) } \\
\text { - } \text { KQ 3: Emotional support, ambulation, routine maternal } \\
\text { oxygen supplementation, specific nutritional } \\
\text { recommendations or limitations, specific oral or } \\
\text { parenteral hydration recommendations or limitations, } \\
\text { peanut ball, Lamaze, hypnobirthing, positioning, } \\
\text { acupuncture, hydrotherapy, other nonpharmacologic } \\
\text { interventions identified through the search } \\
\text { - KQ 4: Epidural analgesia } \\
\text { - } \quad \text { KQ 5: Regular cervical examinations (timing may vary) } \\
\text { - } \quad \text { KQ 6: Use of internal pressure catheters for measuring } \\
\text { timing and strength of uterine contractions } \\
\text { - KQ 7: Infusion of low-dose oxytocin } \\
\text { - KQ 8: Electronic fetal monitoring (external or internal) } \\
\text { - } \quad \text { KQ 9: Immediate pushing upon complete dilatation }\end{array}$ & \\
\hline Comparators & $\begin{array}{l}\text { - } \quad \text { KQ 1: Definitions of labor abnormalities based on older } \\
\text { data (Friedman Curve) })^{23,24} \\
\text { - } \quad \text { KQ 2: No amniotomy, amniotomy for specific } \\
\text { indications (e.g., placement of fetal scalp monitor or } \\
\text { intrauterine pressure catheter) } \\
\text { - } \quad \text { KQ 3: Usual care; interventions above compared to } \\
\text { each other } \\
\text { - } \quad \text { KQ 4: No analgesia, other methods of analgesia (e.g., } \\
\text { parenteral narcotics such as morphine or nitrous } \\
\text { oxide), nonpharmacologic methods of pain } \\
\text { management } \\
\text { - } \quad \text { KQ 5: Cervical examination only in the setting of } \\
\text { clinical concern about labor progress; regular cervical } \\
\text { examinations at differing frequencies } \\
\text { - } \quad \text { KQ 6: External tocodynamometry, no monitoring } \\
\text { - KQ 7: High-dose oxytocin; nipple stimulation; maternal } \\
\text { oxygen supplementation as an adjunct to oxytocin; } \\
\text { different formulations of oxytocin } \\
\text { - } \quad \text { KQ 8: Intermittent auscultation of fetal heart rate } \\
\text { - KQ 9: Other specified maternal techniques/approaches } \\
\text { to pushing }\end{array}$ & \\
\hline
\end{tabular}




\begin{tabular}{|c|c|c|c|}
\hline $\begin{array}{l}\text { PICOTS } \\
\text { Element }\end{array}$ & & Inclusion Criteria & Exclusion Criteria \\
\hline Outcomes & $\begin{array}{l}\mathrm{KC} \\
\mathrm{o} \\
\end{array}$ & 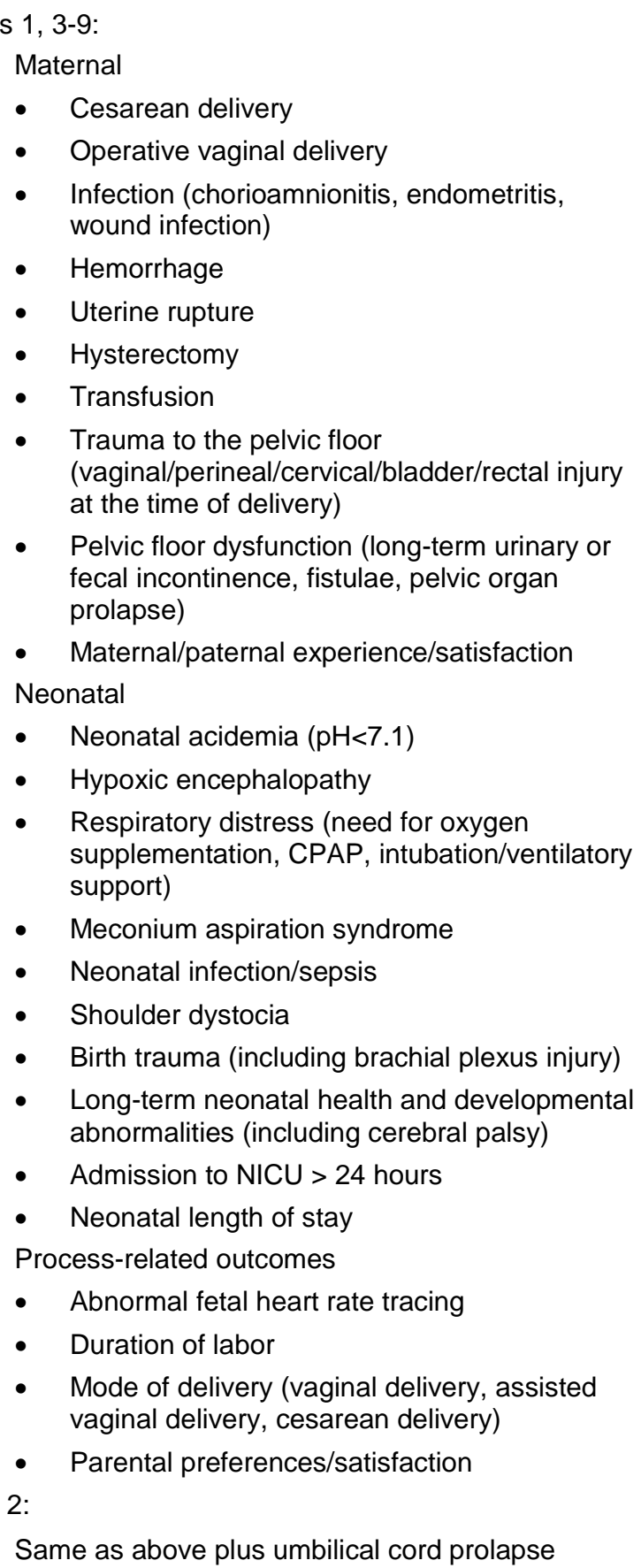 & $\begin{array}{l}\text { For admission to NICU, } \\
\text { studies which did not report } \\
\text { length of stay if indication } \\
\text { distribution was not reported }\end{array}$ \\
\hline Timing & $\begin{array}{l}\mathrm{KC} \\
\mathrm{O}\end{array}$ & $\begin{array}{l}\text { S 1-9: } \\
\text { Short-term: from beginning of spontaneous labor } \\
\text { until discharge home (or equivalent for home } \\
\text { delivery) for mother and infant } \\
\text { Long-term: from discharge onwards }\end{array}$ & \\
\hline
\end{tabular}




\begin{tabular}{|c|c|c|}
\hline $\begin{array}{l}\text { PICOTS } \\
\text { Element }\end{array}$ & Inclusion Criteria & Exclusion Criteria \\
\hline Settings & $\begin{array}{l}\text { KQs 1-9: } \\
\text { o } \\
\text { o } \\
\begin{array}{l}\text { Provation: hospital, birthing center, home } \\
\text { midwife, lay midwife, doula }\end{array}\end{array}$ & \\
\hline Study design & 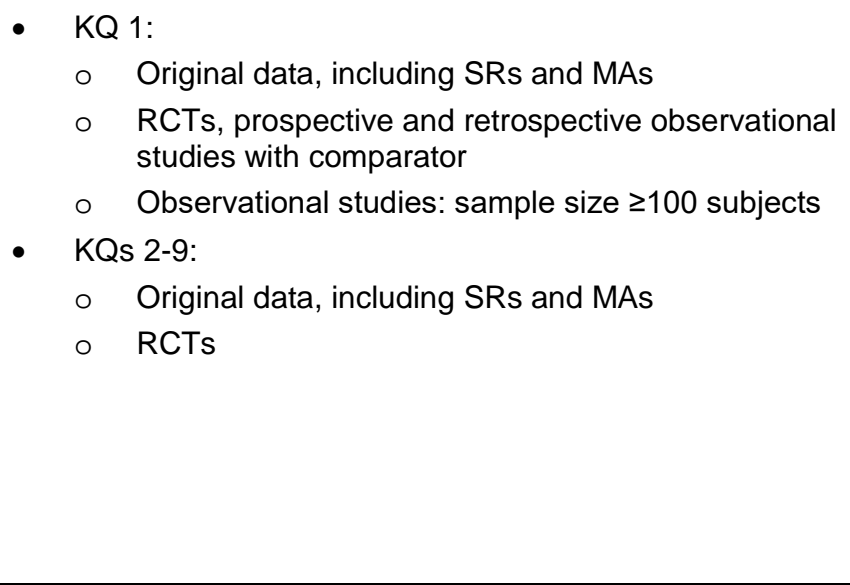 & $\begin{array}{l}\text { Editorials, non-SRs, } \\
\text { letters, case series, case } \\
\text { reports, abstracts only, } \\
\text { retracted/withdrawn } \\
\text { articles } \\
\text { Because observational } \\
\text { studies with <100 } \\
\text { subjects are often } \\
\text { underpowered, they } \\
\text { were excluded. } \\
\text { - SR/MAs were excluded } \\
\text { if they did not provide a } \\
\text { quantitative summary of } \\
\text { results for an outcome of } \\
\text { interest }\end{array}$ \\
\hline Publications & $\begin{array}{l}\text { - KQs 1-9: } \\
\begin{array}{ll}\text { o } & \text { English-language only } \\
\text { o } & \text { Published on or after January } 1,2005^{\mathrm{b}} \\
\text { o } & \text { Relevant methods articles (used for background } \\
& \text { only) }\end{array}\end{array}$ & $\begin{array}{l}\text { - Non-English-language } \\
\text { publications }^{\mathrm{a}}\end{array}$ \\
\hline
\end{tabular}

${ }^{a}$ Non-English language articles were excluded due to (1) the high volume of literature available in English language publications, (2) the focus of our review on applicability to populations in the United States, and (3) the scope of our KQs.

b Through discussion with our Technical Expert Panel, we determined the start date of our search. Given changes in many aspects of practice, there was concern that earlier studies may not be appropriate, and therefore it was limited to 2005 onward. Abbreviations: $\mathrm{CPAP}=$ continuous positive airway pressure; KQ=Key Question; MA=meta-analyses; NICU=neonatal intensive care unit; PICOTS=populations, interventions, comparators, outcomes, timing, settings; RCT=randomized controlled trial; $\mathrm{SR}=$ systematic review

\section{Study Selection}

For citations retrieved from PubMed, Embase, CINAHL, and the Cochrane Database of Systematic Reviews, two reviewers independently screened each title and abstract for potential relevance to the KQs using the prespecified inclusion/exclusion criteria described in Table 1. Articles included by either reviewer underwent full-text screening.

At the full-text screening stage, two reviewers independently reviewed the full text of each article and indicated a decision to include or exclude the article for data abstraction. When paired reviewers arrived at different decisions about whether to include or exclude an article, or about the reason for exclusion, we reconciled the difference through review and discussion among investigators. Articles meeting eligibility criteria were included for data abstraction. At random intervals, quality checks were conducted by senior team members to ensure that screening and abstraction were consistent with inclusion/exclusion criteria and abstraction guidelines. We made screening decisions and abstracted data based on the published literature and available online appendices. We did not contact study authors for additional data. All results were tracked using the DistillerSR data synthesis software program (Evidence Partners Inc., Manotick, ON, Canada). 
Appendix C provides a list of all articles included for data abstraction. Appendix D provides a list of articles excluded at the full-text screening stage, with reasons for exclusion.

\section{Data Extraction}

The research team created data abstraction forms for the KQs that were programmed into DistillerSR software. The abstraction forms were pilot-tested with a sample of included articles to ensure that all relevant data elements were captured and that there was consistency and reproducibility between abstractors. Based on their clinical and methodological expertise, a pair of researchers were assigned to abstract data from each of the eligible articles. One researcher abstracted the data, and the second over-read the article and the accompanying abstraction to check for accuracy and completeness. Disagreements were resolved by consensus or by obtaining a third reviewer's opinion if consensus could not be reached. We linked related publications to avoid duplication of patient cohorts.

We designed the data abstraction forms to collect the data required to evaluate the specified eligibility criteria for inclusion in this review, as well as demographic and other data needed for determining outcomes (intermediate, final, and adverse events outcomes). We paid particular attention to describing the details of the treatment (e.g., frequency of cervical examination, criteria used to diagnose dystocia), patient characteristics (e.g., age, body mass index, parity), and study design (e.g., randomized controlled trial [RCT] versus observational) that may be related to outcomes. In addition, we described comparators carefully, as treatment standards may have changed during the period covered by the review. The safety outcomes were framed to help identify adverse events, including those from drug therapies. Data necessary for assessing quality and applicability, as described in the Methods Guide, ${ }^{26}$ were also abstracted. A complete list of data abstraction elements is provided in Appendix B.

\section{Quality (Risk of Bias) Assessment of Individual Studies}

We assessed methodological quality, or risk of bias, for randomized and nonrandomized individual study designs using a components approach, assessing each study for specific aspects of design or conduct (such as allocation concealment for RCTs, or use of methods to address potential confounding), as detailed in AHRQ's Methods Guide. ${ }^{26}$ Briefly, we rated each study as being of good, fair, or poor quality based on its adherence to well-accepted standard methodologies. For each study, one investigator assigned a summary quality rating, which was then reviewed by a second investigator; disagreements were resolved by consensus or by a third investigator if agreement could not be reached. Table 2 describes the overall study quality assessment ratings. Appendix $G$ presents the risk of bias assessment components for the individual included studies.

Table 2. Definitions of overall quality ratings

\begin{tabular}{|l|l|}
\hline \multicolumn{1}{|c|}{ Quality Rating } & \multicolumn{1}{c|}{ Description } \\
\hline Good (low risk of bias) & $\begin{array}{l}\text { These studies had the least bias, and the results were considered valid. These } \\
\text { studies adhered to the commonly held concepts of high quality, including the } \\
\text { following: a clear description of the population, setting, approaches, and } \\
\text { comparison groups; appropriate measurement of outcomes; appropriate statistical } \\
\text { and analytical methods and reporting; no reporting errors; a low dropout rate; and } \\
\text { clear reporting of dropouts. }\end{array}$ \\
\hline
\end{tabular}




\begin{tabular}{|l|l|}
\hline \multicolumn{1}{|c|}{ Quality Rating } & \multicolumn{1}{c|}{ Description } \\
\hline Fair (moderate risk of bias) & $\begin{array}{l}\text { These studies were susceptible to some bias, but not enough to invalidate the } \\
\text { results. They did not meet all the criteria required for a rating of good quality } \\
\text { because they had some deficiencies, but no flaw was likely to cause major bias. } \\
\text { The study may have been missing information, making it difficult to assess } \\
\text { limitations and potential problems. }\end{array}$ \\
\hline Poor (high risk of bias) & $\begin{array}{l}\text { These studies had significant flaws that might have invalidated the results. They } \\
\text { had serious errors in design, analysis, or reporting; large amounts of missing } \\
\text { information; or discrepancies in reporting. }\end{array}$ \\
\hline
\end{tabular}

The grading was outcome-specific such that a given study that analyzed its primary outcome well but did an incomplete analysis of a secondary outcome could be assigned a different quality grade for each of the two outcomes. Studies of different designs were graded within the context of their respective designs. Thus, RCTs were graded good, fair, or poor, and observational studies were separately graded good, fair, or poor (Appendix G). We acknowledge that one limitation to these standard criteria in settings where patients have strong a priori preferences for certain outcomes or aspects of the process (like labor) may affect willingness to be randomized, and may lead to issues related to generalizability or other biases, although available evidence suggests that there is little impact on internal validity. ${ }^{58}$

We also rated quality for included SRs. Rating was performed using A Measurement Tool to Assess Systematic Review (AMSTAR) for assessing the methodological quality of SRs. ${ }^{59}$ For each study, one investigator assigned a summary quality rating, a second investigator reviewed the rating; disagreements were resolved by consensus or by a third investigator. Reviews were then assigned overall quality scores according to the following categories: ${ }^{60}$

- Good (low risk of bias)—Systematic reviews that have few or no methodological shortcomings and a low risk of bias.

- Fair (moderate risk of bias)—Systematic reviews that have some methodological flaws but the investigators conclude that the flaws will not seriously bias or invalidate the results.

- Poor (high risk of bias)_-Systematic reviews that contain a serious flaw or flaws that, in the judgment of the investigators, are highly likely to bias or invalidate the results.

The AMSTAR quality assessment components for the individual SRs are detailed in Appendix F.

\section{Data Synthesis}

We began by summarizing key features of the included studies for each KQ. To the degree that data were available, we abstracted information on study design; patient characteristics; clinical settings; interventions; and intermediate, final, and adverse event outcomes.

We then determined the feasibility of completing a quantitative synthesis (i.e., meta-analysis, decision analysis, or simulation model). For a meta-analysis, feasibility depends on the volume of relevant literature (requiring at least three relevant studies), conceptual homogeneity of the studies (similar intervention comparisons and outcome definitions), completeness of the reporting of results, and the adequacy and completeness of any existing meta-analyses (MAs). Because there are a large number of existing SRs for this topic, particularly from the Cochrane Collaboration, we considered these results using suggested guidance from the Methods Guide chapter on integrated bodies of evidence, ${ }^{61}$ as outlined in more detail below. As recommended 
there, we based judgments about the benefit of performing a new quantitative synthesis on an assessment of the existing strength of evidence (using the domains of study limitations, consistency, precision, directness, and reporting bias), and on a judgment about the degree to which a new quantitative synthesis would change conclusions about benefit harm/trade-offs, assessment of strength of evidence, substantially improve the precision of the estimate, or provide a more up-to-date estimate reflecting current practice.

When a meta-analysis was appropriate, we used random-effects models to synthesize the available evidence quantitatively. We tested for heterogeneity using graphical displays and test statistics (Q and $\mathrm{I}^{2}$ statistics), while recognizing that the ability of statistical methods to detect heterogeneity may be limited. For comparison, we also performed fixed-effect MAs. We present summary estimates, standard errors, and confidence intervals in the Results chapter. We anticipated that intervention effects might be heterogeneous. We hypothesized that the methodological quality of individual studies, study type, characteristics of the comparator, and patients' underlying clinical presentation would be associated with the intervention effects. When there were sufficient studies, we performed subgroup analyses and/or meta-regression analyses to examine these hypotheses. We performed quantitative and qualitative syntheses separately by study type and discuss their consistency qualitatively.

\section{Strength of the Body of Evidence}

We graded the strength of evidence for each outcome assessed; thus, the strength of evidence for two separate outcomes in a given study may be graded differently. The strength of evidence was assessed using the approach described in AHRQ’s Methods Guide. ${ }^{26,62,63}$ In brief, the approach requires assessment of five domains: study limitations (previously named risk of bias), consistency, directness, precision, and reporting bias, which includes publication bias, outcome reporting, and analysis reporting bias, as described above. Additional domains used when appropriate (most relevant to observational studies) were dose-response association, impact of plausible residual confounders, and strength of association (magnitude of effect). When the body of evidence for a particular outcome included both RCTs and observational studies, we graded each study type separately using design-specific criteria. In considering the overall strength of the entire body of evidence, we considered the extent to which the observational evidence is consistent with RCT data, particularly with regard to direction and magnitude of effect. We also explored the consistency of our findings with recent SRs. Because of the risk of unmeasured confounding, observational studies generally do not contribute to estimates of the magnitude of effect, and judgments about the precision of the effect, when RCT data are available. If there are other issues (such as differences in when and where RCTs were performed compared to observational studies, and how these differences might affect applicability), this would generally lead to increased uncertainty about the magnitude and precision of any treatment effect. ${ }^{64}$ These domains were considered qualitatively, and a summary rating of high, moderate, or low strength of evidence was assigned for each outcome after discussion by two reviewers. In some cases, high, moderate, or low ratings were impossible or imprudent to make, for example, when no evidence was available or when evidence on the outcome was too weak, sparse, or inconsistent to permit any conclusion to be drawn. In these situations, a grade of "insufficient" was assigned. This four-level rating scale consisted of the following definitions: 
- High-We are very confident that the estimate of effect lies close to the true effect for this outcome. The body of evidence has few or no deficiencies. We believe that the findings are stable, i.e., another study would not change the conclusions.

- Moderate-We are moderately confident that the estimate of effect lies close to the true effect for this outcome. The body of evidence has some deficiencies. We believe that the findings are likely to be stable, but some doubt remains.

- Low-We have limited confidence that the estimate of effect lies close to the true effect for this outcome. The body of evidence has major or numerous deficiencies (or both). We believe that additional evidence is needed before concluding either that the findings are stable or that the estimate of effect is close to the true effect.

- Insufficient-We have no evidence, we are unable to estimate an effect, or we have no confidence in the estimate of effect for this outcome. No evidence is available or the body of evidence has unacceptable deficiencies, precluding reaching a conclusion.

As noted above, there is already a large body of SRs, some with MAs, in this area. We used the recommendations outlined in the Methods Guide chapter on integrating existing SRs in incorporating this body of evidence into our review. ${ }^{61}$ Briefly, we confirmed that a given paper was an SR by requiring that the review include an explicit and adequate search, application of predefined eligibility criteria to select studies, risk of bias assessment for included studies, and qualitative or quantitative synthesis of results. Relevance of published reviews meeting these criteria was assessed based on comparability of PICOTS and the extent to which included studies reflect current practice. The quality of relevant existing reviews was graded to determine if the SR was of sufficient quality to inform our evidence base. Key components of this determination included search of multiple sources, use of a generally accepted tool for risk of bias assessment, and sufficient information to assess the strength of the body of evidence that includes the major domains of risk of bias, directness, consistency, precision, and reporting bias (Appendix G). Key aspects of previous reviews described include number and types of studies included, strength of evidence assessment, and overall qualitative or quantitative findings. Newly identified studies are presented separately from the results of existing reviews. Overall strength of evidence findings are based on the primary evidence. Existing SRs were incorporated into the summary SOE when available. Only good- and fair-quality SRs were considered, with heavier weighting to findings from good-quality SRs

\section{Applicability}

We assessed applicability across our KQs using the method described in AHRQ's Methods Guide. $^{26,65}$ In brief, this method uses the PICOTS format as a way to organize information relevant to applicability. The most important issue with respect to applicability is whether the outcomes were different across studies that recruited different populations (e.g., age groups, exclusions for comorbidities) or used different methods to implement the interventions of interest; that is, important characteristics are those that affect baseline (control group) rates of events, intervention group rates of events, or both. We used a checklist applied to each abstracted study to guide the assessment of applicability (Appendix B). For each study, one investigator assigned a summary quality rating, which was then reviewed by a second investigator; disagreements were resolved by consensus or by a third investigator if agreement could not be 
reached. We then used these data across KQs to evaluate the applicability to clinical practice, paying special attention to study eligibility criteria, demographic features of the enrolled population in comparison to the target population, characteristics of the intervention used in comparison with care models currently in use, the possibility of diagnostic tool or treatment intervention learning curves, and clinical relevance and timing of the outcome measures. We summarized issues of applicability qualitatively.

\section{Peer Review and Public Commentary}

Experts in the fields of obstetrics and gynecology, midwifery, pediatrics and neonatology, and methodology, and individuals representing stakeholder and user communities were invited to provide external peer review of the draft report; AHRQ and an associate editor, and members of the TEP were also invited to provide comments. In addition, the draft report was posted on the AHRQ website for public comment from September 5, 2018, through October 10, 2018. We have addressed all reviewer comments, revising the text as appropriate, and documented everything in a disposition of comments report that will be made available 3 months after the Agency posts the final report on the EHC website. A list of peer reviewers submitting comments on the draft report is provided in the front matter of this report. 


\section{Results}

\section{Introduction}

In what follows, we begin by describing the results of our literature searches. We then provide an overall description of the included studies. The remainder of the chapter is organized by Key Question (KQ). Under each of the nine KQs, we begin with a brief description of the included studies, followed by a bulleted list of the key points of the findings and a detailed synthesis of the evidence. The detailed syntheses are organized first by treatment comparison and then by outcome. We conducted quantitative syntheses where possible, as described in the Methods chapter. Each KQ results section concludes with a summary of the strength of evidence for the main findings.

\section{Results of Literature Searches}

Figure 2 depicts the flow of articles through the literature search and screening process. Searches of PubMed, Embase, CINAHL, and the Cochrane Database of Systematic Reviews yielded 14,176 citations, 11,746 of which were unique. Manual searching of gray literature databases and bibliographies of key articles or referral by investigators identified 49 additional citations, for a total of 11,795 citations. No responses were received through public notification to manufacturers of requests for scientific information packets. After applying inclusion/exclusion criteria at the title-and-abstract level, 1,082 full-text articles were retrieved and screened. Of these, 915 were excluded at the full-text screening stage, leaving 167 articles for data abstraction. These 167 articles described 158 unique studies. The relationship of studies to the review questions is as follows: 25 studies relevant to KQ 1, 12 studies relevant to KQ 2, 75 studies relevant to KQ 3, 25 studies relevant to KQ 4, 1 study relevant to KQ 5, 1 study relevant to KQ 6, 17 studies relevant to KQ 7, 1 study relevant to KQ 8, and 7 studies relevant to KQ 9 (some studies were relevant to more than one KQ).

Studies with more than one article are listed in Table 3.

Table 3. Key to primary and companion articles

\begin{tabular}{|c|c|c|}
\hline Study Designation & Primary Abstracted Article & Companion Articles \\
\hline $\begin{array}{l}\text { COMET } \\
\text { (Comparative } \\
\text { Obstetric Mobile } \\
\text { Epidural Trial) }\end{array}$ & Wilson, $2009^{66}$ & Wilson, $2011^{67}$ \\
\hline TREAT Trial & Wassen, $2015^{68}$ & van den Bosch, $2018^{69}$ \\
\hline None & Akbarzadeh, $2015^{70}$ & Akbarzadeh, $2015^{71}$ \\
\hline None & Bloom, $2006^{72}$ & Schaffer, $2005^{73}$ \\
\hline None & Dencker, $2009^{74}$ & Bergqvist, $2012^{75}$ \\
\hline None & de Orange, $2011^{76}$ & Orange, $2012^{77}$ \\
\hline None & Pascual-Ramirez, $2011^{78}$ & Pascual-Ramirez, $2012^{79}$ \\
\hline None & Ragnar, $2006^{80}$ & Altman, $2007^{81}$ \\
\hline None & Shafaie, $2017^{82}$ & Ahadi Yulghunlu, $2018^{83}$ \\
\hline
\end{tabular}


Figure 2. Literature flow diagram

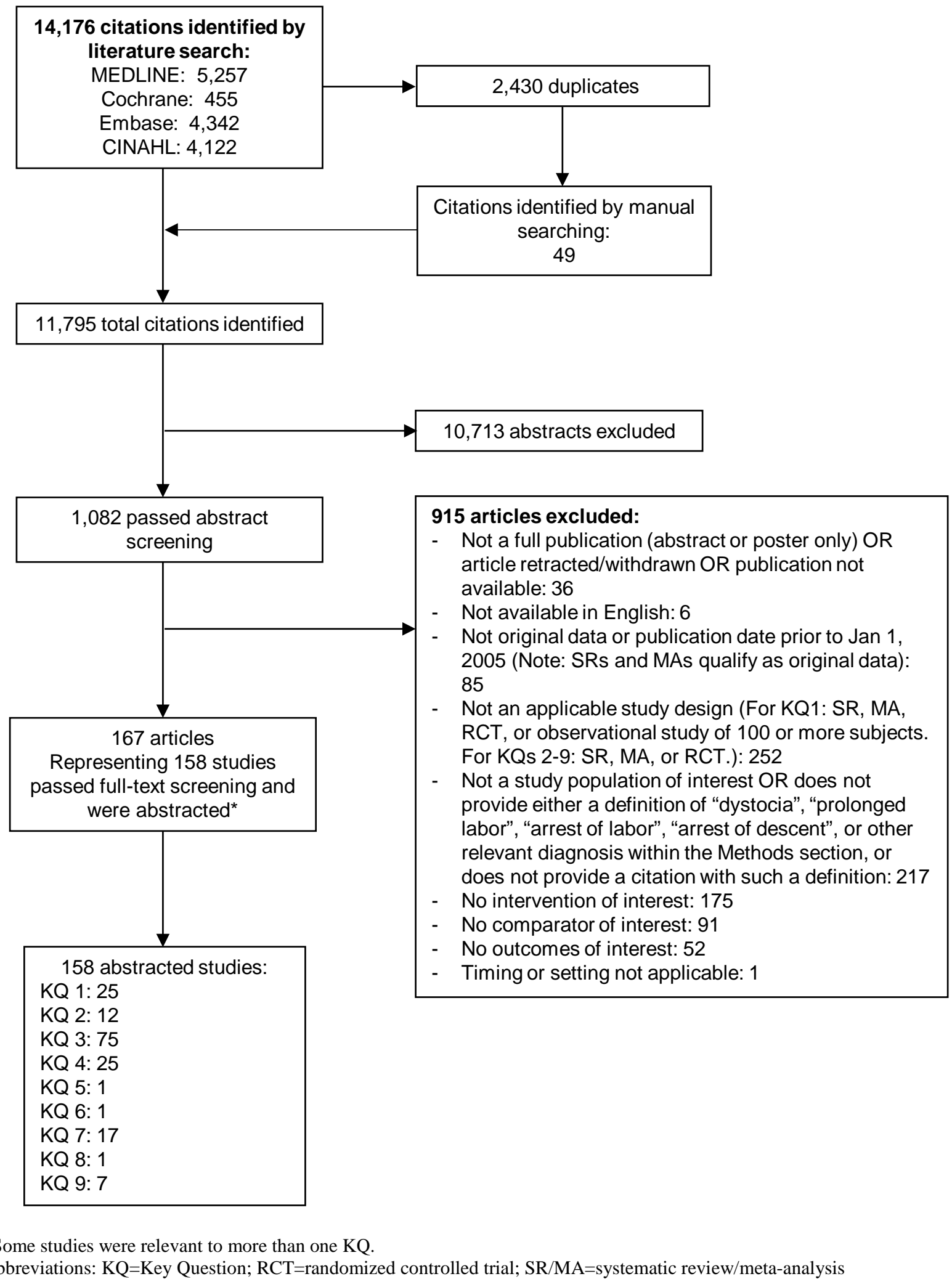

Abbreviations: KQ=Key Question; RCT=randomized controlled trial; SR/MA=systematic review/meta-analysis 


\section{Description of Included Studies}

Overall, we included 158 studies described in 167 publications: 25 studies relevant to KQ 1, 12 studies relevant to KQ 2, 75 studies relevant to KQ 3, 25 studies relevant to KQ 4, 1 study relevant to KQ 5, 1 study relevant to KQ 6, 17 studies relevant to KQ 7, 1 studies relevant to KQ 8, and 7 studies relevant to KQ 9. Of the 158 studies, 122 were RCTs or observational in study design and 36 were SRs. The 122 RCTs/observational studies were conducted wholly or partly in continental Europe or the United Kingdom (26 studies, 21\%), the United States or Canada (24 studies, 19\%), the Middle East (34 studies, 28\%), Asia (26 studies, 21\%), Latin America (7 studies, 6\%), and other locations (Africa [3 studies] and Australia/New Zealand [2 studies], total 4\%). Appendix C provides a detailed listing of included articles. Appendix D provides a complete list of articles excluded at the full-text screening stage, with reasons for exclusion. Further details on the studies included for each KQ are provided in the relevant results sections, below, and in Appendix E. Detailed risk of bias information for each included study is reported in Appendices $\mathrm{F}$ and $\mathrm{G}$.

We searched the ClinicalTrials.gov registry of clinical studies as a mechanism for ascertaining publication bias by identifying studies that have been completed but are as yet unpublished. Among available registries with varying geographic ranges, it is the opinion of the investigators that this widely used, U.S.-based source provided the most relevant information to the populations and interventions of interest in this review. Our search yielded 33 records of completed trials for screening. Manual review identified three of these records as potentially relevant to the KQs. We identified publications (six in total) for all three of these studies, thus finding no indication of publication bias that would impact the results of this review. Five of these publications had been previously identified in our PubMed, Embase, and Cochrane Database of Systematic Reviews searches. The remaining study was a novel publication and was entered into our screening process. Note that we did not compare ClinicalTrials.gov records or protocols listing intended/pre-specified outcomes against published findings.

\section{Key Question 1. Criteria Used To Define Abnormal Labor}

KQ 1 was: Do delivery outcomes for management of abnormal labor differ based on the criteria used to define protracted or arrested labor at different stages of the labor process?

This KQ examined whether labor outcomes among women in spontaneous labor differed based on the criteria used to define abnormal labor. In addition, we sought to determine what constitutes normal labor related to the rate of cervical change and overall duration of labor.

\section{Description of Included Studies}

We identified 19 individual studies that examined whether labor outcomes among women in spontaneous labor differed based on the criteria used to define abnormal labor. ${ }^{21,22,84-98}$ Of the 17

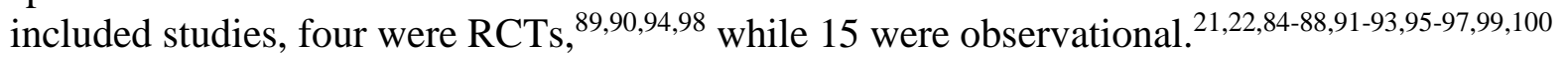
Twelve studies were conducted in the United States, ${ }^{21,22,84,86,88,91,93,95-97,99,100}$ three were conducted in Asia, ${ }^{87,90,92}$ two were conducted in UK/Europe, ${ }^{85,89}$ one study was conducted in Australia/NZ, ${ }^{94}$ and one study was conducted in the Middle East. ${ }^{98}$ All but one study ${ }^{90}$ was conducted in a hospital setting. This lone study was conducted in a maternity home. Seven studies reported government funding, ${ }^{21,22,84,86-88,96}$ two studies reported non-government/nonindustry funding, ${ }^{99,100}$ one study reported a combination of funding from government and nongovernment, non-industry funding, ${ }^{91}$ and nine studies were unclear or did not report the funding 
source. ${ }^{85,89,90,92-95,97,98}$ Fourteen studies were rated as good quality, ${ }^{22,86,88-99}$ three as fair quality, ${ }^{21,85,100}$ and two as poor quality. ${ }^{84,87}$

In addition to the above studies, six systematic reviews (4 good quality, ${ }^{35,101-103} 1$ fair quality, ${ }^{47}$ and 1 poor quality ${ }^{104}$ ) addressed management of abnormal labor based on certain criteria are also discussed below.

\section{Key Points for Criteria Used To Define Abnormal Labor}

\section{Comparisons of pregnancy outcomes based on the criteria used to define abnormal labor}

- Evidence was insufficient regarding rates of cesarean delivery and total duration of labor for different action line partograms.

- No differences were seen in postpartum hemorrhage rates (moderate strength of evidence [SOE]), neonatal acidemia rates (low SOE), or vaginal delivery rates (moderate SOE) between women managed with varying partogram strategies.

- Maternal satisfaction also was not different between partogram strategies (low SOE).

What constitutes normal labor?

- Modern labor curves constructed from the Consortium on Safe Labor (CSL) demonstrate significantly different rates of cervical change, duration of labor, and appearance of the curve (absence or presence of an inflection point) between nulliparous and parous women.

- Modern labor curves constructed from the CSL cohort vary significantly from curves constructed from historical cohorts (Friedman or National Collaborative Perinatal Project [NCPP]), with modern curves suggesting a longer duration of the first stage of labor.

- Maternal age influences the duration of the first and second stage of labor among nulliparous women (older women having longer labors).

\section{Detailed Synthesis for Criteria Used To Define Abnormal Labor}

\section{Pregnancy Outcomes Based on Criteria Used To Define Abnormal Labor}

Four RCTs, ${ }^{89,90,94,98}$ five observational studies, ${ }^{87,91,93,95,96}$ and two good-quality SRs ${ }^{35,102}$ compared outcomes among women in spontaneous labor based on the criteria used to define abnormal labor. None of these directly compared outcomes in women whose labor was managed by the Friedman curve versus the CSL curve, but four studies ${ }^{91,93,95,96}$ compared delivery outcomes based on cervical dilation at time of admission.

\section{Partograms}

In the 1950s, Friedman published his observations of normal labor through graphical representations of changes in cervical dilation. ${ }^{18}$ This work resulted in the use of the Friedman curve as the basis for determining normal labor and the development of partograms. ${ }^{18,105} \mathrm{~A}$ partogram is a graphical representation of a woman's progress in labor. Partograms typically consist of three sections, the first addressing maternal status, the second addressing fetal condition, and the third addressing the progress of labor. The section of the partogram addressing the progress of labor typically contains an alert line which, when crossed, signifies that a 
woman's rate of cervical change is slower than expected. The initial partograms by Philpott and Castle $^{105}$ were constructed with an alert line representing a mean rate of cervical change slower than 10 percent of the population in the active phase of the first stage of labor. ${ }^{102}$ In addition, partograms also include an action line, which initially was positioned 4 hours to the right of the alert line. ${ }^{102}$ The action line serves to help diagnose protracted or arrested labor so that appropriate interventions (e.g., assisted rupture of the membranes, oxytocin augmentation, and/or transfer to a higher level of care) can be administered. The World Health Organization (WHO) developed a partogram that is similar to the Philpott and Castle partogram, with an action line 4 hours to the right of the alert line. ${ }^{106}$ In addition, other groups utilize partograms with action lines 2 or 3 hours to the right of the alert line. We identified four good-quality RCTs, ${ }^{89,90,94,98}$ and one good-quality Cochrane review ${ }^{102}$ addressing labor outcomes among women managed by partograms. Findings from these studies are summarized in Table 4.

Lavender et al. ${ }^{89}$ conducted an RCT at a single site in England comparing outcomes in 2,975 nulliparous women managed with a 2-hour action line partogram versus a 4-hour action line partogram. There were no differences in the overall cesarean delivery rate, indication for cesarean delivery, operative vaginal delivery rate, or rates of neonatal acidemia, postpartum hemorrhage, or maternal satisfaction between the two groups. Women managed on the 2-hour action line partogram demonstrated a significantly shorter duration of labor, reported as the time from randomization to delivery.

Fahdhy et al. ${ }^{90}$ conducted a randomized trial in Indonesia of births managed in a maternity home with a partogram compared to no partogram; randomization was at the level of the midwife, rather than the patient. The trial included both nulliparous and parous women and results were not stratified by parity. Women managed with the partogram had significantly lower cesarean delivery rates, though no differences were seen in postpartum hemorrhage rates or neonatal resuscitation.

Lee et al. ${ }^{94}$ conducted a randomized trial in Brisbane of 99 nulliparous women in spontaneous labor managed with a partogram containing an action line to women managed with a stepped line (dystocia line) partogram. There were no differences in mode of delivery or rates of postpartum hemorrhage, or a composite neonatal outcome between the two interventions. Women managed with the partogram containing the action line had significantly longer duration of labor compared to women managed with the partogram containing the dystocia line (503 vs 291 min, $\mathrm{p}=0.018$ ).

Tolba et al. ${ }^{98}$ conducted a randomized controlled trial in Egypt of 110 nulliparous women in spontaneous labor managed with the WHO partogram compared to women managed with the "Labour Scale.” The Labour Scale is a tool described in $2014^{107}$ that represents a modification to the WHO partogram. The Labour Scale modification included guidelines for labor management as outlined by the National Institute of Clinical Evidence (NICE). Women managed with the Labour Scale and a significantly lower overall cesarean delivery rate compared with women managed with the WHO partogram (3.6\% vs. $18.2 \%$, $\mathrm{p}=0.03$ ), but there was no difference in the mean duration of the active phase of labor between the two groups ( 4.84 vs. 4.40 hours, $\mathrm{p}=0.16$ ).

Neal et al. ${ }^{91}$ also used data from the CSL to determine if the rate of cervical change among women admitted in active labor was associated with mode of delivery. Active labor was defined as an admission cervical dilation of 4 or $5 \mathrm{~cm}$ followed by cervical change of greater than or equal to $1 \mathrm{~cm}$ within 2 hours or an admission cervical examination of greater than or equal to 6 $\mathrm{cm}$. Women admitted in active labor were then divided into those with "physiologic labor progress" or those with "labor dystocia” Physiologic labor progress was defined as falling to the 
left of the dystocia line on the physiologic partograph, ${ }^{108}$ while women with cervical changed falling to the right of the dystocia line were defined as having labor dystocia. Women with labor dystocia, as defined by the physiologic partograph, had a higher rate of cesarean delivery compared to women with physiologic labor progress (20.3\% vs 5.9\%, $\mathrm{p}<0.001)$.

The inconsistency between the findings for these studies for cesarean delivery rates and the duration of labor, and the non-U.S. settings among four of the five, resulted in insufficient SOE.

The Cochrane review by Lavender et al. ${ }^{102}$ addresses the use of partograms in labor outcomes. This review included 11 studies with 9,475 participants and made the following comparisons:

- Partogram versus no partogram

- Partograms with 2-hour versus 4-hour action lines

- Partograms with 2-hour versus 3-hour action lines

- Partograms with 3-hour versus 4-hour action lines

- Partograms with an alert line only versus with both an alert and action line

- Early interventions using a partogram versus late interventions using a partogram

The review planned subgroup analyses by low- and high-resource setting and did not analyze data by parity. In high-resource settings (not explicitly defined in the review), using the partogram compared with not using the partogram, or use of partograms with different action line durations, did not affect overall cesarean delivery rates or indication for cesarean delivery, except that women being managed using a partogram with a 3-hour action line had higher cesarean delivery rates than women managed using a partogram with a 4-hour action line. ${ }^{102}$ In low-resource settings (not explicitly defined in the review), the use of a partogram compared with no partogram did not affect overall cesarean delivery rates. ${ }^{102}$

Women in low-resource settings managed by a partogram with only an alert line had significantly lower cesarean delivery rates compared with women managed by a partogram with both an alert and action line. Similarly, in women in low-resource settings managed by a partogram, those managed with early intervention versus late interventions had lower cesarean delivery rates. In addition, women in high-resource settings managed with a partogram that contained an assessment of latent phase duration had higher over cesarean delivery rates compared to women managed with a partogram that did not include an assessment of latent phase duration. This relationship was primarily driven by an increased cesarean delivery rate for the indication of non-reassuring fetal status in women managed by the partogram with a latent phase (Table 4).

Women in a high-resource setting managed using a partogram with a 2-hour action line compared to women managed using a partogram with stepped dystocia line had similar rates of cesarean delivery. Similarly, women in a high-resource setting managed with a partogram and similar rates of cesarean delivery compared to women managed using a "labour scale."102

The Cochrane review also found that rates of operative vaginal delivery, duration of the first stage of labor, duration of the second stage of labor, rates of neonatal acidemia, maternal infection, or postpartum hemorrhage did not differ based on whether a partogram was used or not, whether the partogram included a 2-hour versus 4-hour action line, a 2-hour versus 3-hour action line, or a 3-hour versus 4-hour action line. ${ }^{102}$ Combined with the RCT evidence, these findings resulted in moderate SOE for these outcomes other than acidemia, which had low SOE based on the findings of one RCT. 
Table 4. Summary of labor outcomes using partograms

\begin{tabular}{|c|c|c|c|c|c|c|c|c|c|c|}
\hline $\begin{array}{l}\text { Study } \\
\text { Quality } \\
\text { Design }\end{array}$ & Int & Com & $\begin{array}{l}\text { Duration } \\
\text { of Labor: } \\
\text { Int (SD) }\end{array}$ & $\begin{array}{l}\text { Duration of } \\
\text { Labor: } \\
\text { Com }\end{array}$ & $\begin{array}{l}\text { Duration of } \\
\text { Labor: } \\
\text { P Value }\end{array}$ & $\begin{array}{c}\text { Cesarean: } \\
\text { Int }\end{array}$ & $\begin{array}{l}\text { Cesarean: } \\
\text { Com }\end{array}$ & $\begin{array}{c}\text { Cesarean: } \\
\text { Difference } \\
(95 \% \mathrm{Cl})\end{array}$ & $\begin{array}{c}\text { Shorter } \\
\text { Labor } \\
\text { Associated } \\
\text { With Lower } \\
\text { Cesarean } \\
\text { Delivery } \\
\text { Rate? }\end{array}$ & Comments \\
\hline $\begin{array}{l}\text { Lavender, } \\
2006^{89} \\
\text { Good } \\
\text { RCT }\end{array}$ & $\begin{array}{l}\text { Partogram } \\
2 \text { hour } \\
\text { action line }\end{array}$ & $\begin{array}{l}\text { Partogram } \\
4 \text { hour } \\
\text { action line }\end{array}$ & $\begin{array}{l}539.6 \\
(260.3) \mathrm{min}\end{array}$ & $\begin{array}{l}566.4 \\
(289.7) \min \end{array}$ & 0.008 & $\begin{array}{l}136 / 1490 \\
(9.1 \%)\end{array}$ & $\begin{array}{l}135 / 1485 \\
(9.1 \%)\end{array}$ & $\begin{array}{l}\text { RR } 1.0 \text { (0.80 to } \\
1.26)\end{array}$ & No & $\begin{array}{l}\text { High-resource } \\
\text { setting }\end{array}$ \\
\hline $\begin{array}{l}\text { Fahdhy, } 2005^{90} \\
\text { Good } \\
\text { RCT }\end{array}$ & Partogram & $\begin{array}{l}\text { No } \\
\text { partogram }\end{array}$ & - & - & - & $\begin{array}{l}24 / 322 \\
(4.9 \%)\end{array}$ & $\begin{array}{l}15 / 304 \\
(7.4 \%)\end{array}$ & $\begin{array}{l}P=0.011, \text { OR } \\
0.64(0.45 \text { to } \\
0.90)\end{array}$ & - & $\begin{array}{l}\text { Low-resource } \\
\text { setting }\end{array}$ \\
\hline $\begin{array}{l}\text { Lee, } 2017^{94} \\
\text { Good } \\
\text { RCT }\end{array}$ & $\begin{array}{l}\text { Partogram } \\
\text { with } \\
\text { dystocia } \\
\text { line }\end{array}$ & $\begin{array}{l}\text { Partogram } \\
\text { with action } \\
\text { line }\end{array}$ & $\begin{array}{l}291 \text { (135 to } \\
539 \text { ) min } \\
\text { Median } \\
\text { (IQR) }\end{array}$ & $\begin{array}{l}503(297 \text { to } \\
665) \text { min } \\
\text { Median } \\
\text { (IQR) }\end{array}$ & 0.018 & 9/50 (18\%) & $8 / 49(16.3 \%)$ & $\begin{array}{l}\text { RR } 1.10 \text { (0.46 to } \\
2.64)\end{array}$ & No & $\begin{array}{l}\text { High-resource } \\
\text { setting }\end{array}$ \\
\hline $\begin{array}{l}\text { Tolba, } 2017^{98} \\
\text { Good } \\
\text { RCT }\end{array}$ & $\begin{array}{l}\text { Labour } \\
\text { Scale }\end{array}$ & $\begin{array}{l}\text { WHO } \\
\text { partogram }\end{array}$ & $\begin{array}{l}4.84(2.51) \\
\mathrm{hr}\end{array}$ & $\begin{array}{l}4.40(1.96) \\
\mathrm{hr}\end{array}$ & 0.16 & $2 / 55$ (3.6\%) & $\begin{array}{l}10 / 55 \\
(18.2 \%)\end{array}$ & $\mathrm{P}=0.03$ & No & $\begin{array}{l}\text { Low-resource } \\
\text { setting }\end{array}$ \\
\hline $\begin{array}{l}\text { Neal, } 2018^{91} \\
\text { Good } \\
\text { Obs }\end{array}$ & $\begin{array}{l}\text { Labor } \\
\text { dystocia as } \\
\text { defined on } \\
\text { the } \\
\text { physiologic } \\
\text { partograph }\end{array}$ & $\begin{array}{l}\text { Physiologic } \\
\text { labor } \\
\text { progress as } \\
\text { defined on } \\
\text { the } \\
\text { physiologic } \\
\text { partograph }\end{array}$ & - & - & - & $\begin{array}{l}164 / 806 \\
(20.3 \%)\end{array}$ & $\begin{array}{l}462 / 7866 \\
(5.9 \%)\end{array}$ & $P<0.001$ & - & $\begin{array}{l}\text { High-resource } \\
\text { setting }\end{array}$ \\
\hline $\begin{array}{l}\text { Lavender, } \\
2018^{102} \\
\text { Good } \\
\text { SR }\end{array}$ & Partogram & $\begin{array}{l}\text { No } \\
\text { partogram }\end{array}$ & - & - & - & $\begin{array}{l}42 / 334 \\
(12.6 \%)\end{array}$ & $\begin{array}{l}71 / 323 \\
(22.0 \%)\end{array}$ & $\begin{array}{l}\text { RR } 0.65 \text { (0.22 to } \\
1.91)\end{array}$ & - & $\begin{array}{l}\text { Low-resource } \\
\text { setting }\end{array}$ \\
\hline $\begin{array}{l}\text { Lavender, } \\
2018^{102} \\
\text { Good } \\
\text { SR }\end{array}$ & Partogram & $\begin{array}{l}\text { No } \\
\text { partogram }\end{array}$ & $\begin{array}{l}\text { First stage: } \\
16.8(7.3) \\
\text { hr } \\
\text { Second } \\
\text { stage: } 2.4 \\
(1.8) \mathrm{hr}\end{array}$ & $\begin{array}{l}\text { First stage: } \\
16.0(7.6) \mathrm{hr} \\
\text { Second } \\
\text { stage: } 2.4 \\
\text { (1.9) } \mathrm{hr}\end{array}$ & $\begin{array}{l}\text { First stage } \\
\text { Mean diff: } \\
0.80 \text { (-0.06, } \\
1.66) \\
\text { Second } \\
\text { stage mean } \\
\text { diff: } 0.0 \\
(-0.21,0.21)\end{array}$ & $\begin{array}{l}125 / 580 \\
(21.5 \%)\end{array}$ & $\begin{array}{l}121 / 576 \\
(21.0 \%)\end{array}$ & $\begin{array}{l}\text { RR } 1.03 \text { (0.82 to } \\
1.28)\end{array}$ & No & $\begin{array}{l}\text { High-resource } \\
\text { setting }\end{array}$ \\
\hline
\end{tabular}




\begin{tabular}{|c|c|c|c|c|c|c|c|c|c|c|}
\hline $\begin{array}{l}\text { Study } \\
\text { Quality } \\
\text { Design }\end{array}$ & Int & Com & $\begin{array}{l}\text { Duration } \\
\text { of Labor: } \\
\text { Int (SD) }\end{array}$ & $\begin{array}{l}\text { Duration of } \\
\text { Labor: } \\
\text { Com }\end{array}$ & $\begin{array}{l}\text { Duration of } \\
\text { Labor: } \\
\text { P Value }\end{array}$ & $\begin{array}{c}\text { Cesarean: } \\
\text { Int }\end{array}$ & $\begin{array}{l}\text { Cesarean: } \\
\text { Com }\end{array}$ & $\begin{array}{l}\text { Cesarean: } \\
\text { Difference } \\
(95 \% \mathrm{Cl})\end{array}$ & $\begin{array}{c}\text { Shorter } \\
\text { Labor } \\
\text { Associated } \\
\text { With Lower } \\
\text { Cesarean } \\
\text { Delivery } \\
\text { Rate? }\end{array}$ & Comments \\
\hline $\begin{array}{l}\text { Lavender, } \\
2018^{102} \\
\text { Good } \\
\text { SR }\end{array}$ & Partogram & $\begin{array}{l}\text { No } \\
\text { partogram }\end{array}$ & - & - & - & $\begin{array}{l}167 / 914 \\
(18.3 \%)\end{array}$ & $\begin{array}{l}192 / 899 \\
(21.4 \%)\end{array}$ & $\begin{array}{l}\text { RR } 0.77 \text { (0.40 to } \\
1.46)\end{array}$ & - & $\begin{array}{l}\text { All subjects } \\
\text { (both low- and } \\
\text { high-resource } \\
\text { settings) }\end{array}$ \\
\hline $\begin{array}{l}\text { Lavender, } \\
2018^{102} \\
\text { Good } \\
\text { SR }\end{array}$ & $\begin{array}{l}\text { Partogram } \\
\text { with Two- } \\
\text { hour action } \\
\text { lime }\end{array}$ & $\begin{array}{l}\text { Partogram } \\
\text { with Four- } \\
\text { hour action } \\
\text { line }\end{array}$ & -- & -- & -- & $\begin{array}{l}40 / 570 \\
(7.0 \%)\end{array}$ & $\begin{array}{l}37 / 578 \\
(6.4 \%)\end{array}$ & $\begin{array}{l}\text { RR } 1.09 \text { (0.71 to } \\
1.68)\end{array}$ & -- & $\begin{array}{l}\text { Low-resource } \\
\text { setting }\end{array}$ \\
\hline $\begin{array}{l}\text { Lavender, } \\
2018^{102} \\
\text { Good } \\
\text { SR }\end{array}$ & $\begin{array}{l}\text { Partogram } \\
\text { with Two- } \\
\text { hour action } \\
\text { line }\end{array}$ & $\begin{array}{l}\text { Partogram } \\
\text { with Four- } \\
\text { hour action } \\
\text { line }\end{array}$ & - & - & - & $\begin{array}{l}\text { Overall: } \\
171 / 1805 \\
(9.5 \%) \\
\text { NRFHT: } \\
51 / 1805 \\
(2.8 \%) \\
\text { Delay: } \\
120 / 1805 \\
(6.6 \%)\end{array}$ & $\begin{array}{l}\text { Overall: } \\
161 / 1796 \\
(9.0 \%) \\
\text { NRFHT: } \\
39 / 1796 \\
(2.2 \%) \\
\text { Delay: } \\
122 / 1796 \\
(6.8 \%)\end{array}$ & $\begin{array}{l}\text { Overall: RR } 1.06 \\
\text { (0.85 to } 1.32) \\
\text { NRFHT: RR } 1.30 \\
\text { (0.86 to } 1.96) \\
\text { Delay: RR } 0.98 \\
\text { (0.77 to } 1.25 \text { ) }\end{array}$ & - & $\begin{array}{l}\text { High-resource } \\
\text { setting }\end{array}$ \\
\hline $\begin{array}{l}\text { Lavender, } \\
2018^{102} \\
\text { Good } \\
\text { SR }\end{array}$ & $\begin{array}{l}\text { Partogram } \\
\text { with Two- } \\
\text { hour action } \\
\text { lime }\end{array}$ & $\begin{array}{l}\text { Partogram } \\
\text { with Four- } \\
\text { hour action } \\
\text { line }\end{array}$ & -- & -- & -- & $\begin{array}{l}\text { Overall: } \\
211 / 2375 \\
(8.9 \%)\end{array}$ & $\begin{array}{l}\text { Overall: } \\
\text { 198/2374 } \\
(8.3 \%)\end{array}$ & $\begin{array}{l}\text { Overall: RR } 1.06 \\
\text { (0.88 to } 1.28)\end{array}$ & -- & $\begin{array}{l}\text { All subjects } \\
\text { (both low- and } \\
\text { high-resource } \\
\text { settings) }\end{array}$ \\
\hline $\begin{array}{l}\text { Lavender, } \\
2018^{102} \\
\text { Good } \\
\text { SR }\end{array}$ & $\begin{array}{l}\text { Partogram } \\
\text { with 2-hour } \\
\text { action line }\end{array}$ & $\begin{array}{l}\text { Partogram } \\
\text { with Three- } \\
\text { hour action } \\
\text { line }\end{array}$ & - & - & - & $\begin{array}{l}\text { Overall: } \\
35 / 315 \\
(11.1 \%) \\
\text { NRFHT: } \\
12 / 315 \\
(3.8 \%) \\
\text { Delay: } \\
23 / 315 \\
(7.3 \%)\end{array}$ & $\begin{array}{l}\text { Overall: } \\
43 / 302 \\
(14.2 \%) \\
\text { NRFHT: } \\
12 / 302 \\
(4.0 \%) \\
\text { Delay: } \\
31 / 302 \\
(10.3 \%)\end{array}$ & $\begin{array}{l}\text { Overall: RR } 0.78 \\
\text { (0.51 to } 1.18) \\
\text { NRFHT: RR } 0.96 \\
\text { (0.44 to } 2.10) \\
\text { Delay: RR } 0.71 \\
\text { (0.42 to } 1.19 \text { ) }\end{array}$ & - & $\begin{array}{l}\text { High-resource } \\
\text { setting }\end{array}$ \\
\hline $\begin{array}{l}\text { Lavender, } \\
2018^{102} \\
\text { Good } \\
\text { SR }\end{array}$ & $\begin{array}{l}\text { Partogram } \\
\text { with 3-hour } \\
\text { action line }\end{array}$ & $\begin{array}{l}\text { Partogram } \\
\text { with 4-hour } \\
\text { action line }\end{array}$ & - & - & - & $\begin{array}{l}\text { Overall: } \\
43 / 302 \\
(14.2 \%) \\
\text { NRFHT: } \\
12 / 302 \\
(4.0 \%) \\
\text { Delay: } \\
31 / 302 \\
(10.3 \%)\end{array}$ & $\begin{array}{l}\text { Overall: } \\
26 / 311 \\
\text { (8.4\%) } \\
\text { NRFHT: } \\
\text { 7/311 (2.2\%) } \\
\text { Delay: } \\
\text { 19/311 } \\
(6.1 \%)\end{array}$ & $\begin{array}{l}\text { Overall: RR } 1.70 \\
\text { (1.07 to } 2.70) \\
\text { NRFHT: RR } 1.77 \\
\text { (0.70 to } 4.42) \\
\text { Delay: RR } 1.68 \\
\text { (0.97 to } 2.91 \text { ) }\end{array}$ & - & $\begin{array}{l}\text { High-resource } \\
\text { setting }\end{array}$ \\
\hline
\end{tabular}




\begin{tabular}{|c|c|c|c|c|c|c|c|c|c|c|}
\hline $\begin{array}{l}\text { Study } \\
\text { Quality } \\
\text { Design }\end{array}$ & Int & Com & $\begin{array}{l}\text { Duration } \\
\text { of Labor: } \\
\text { Int (SD) }\end{array}$ & $\begin{array}{l}\text { Duration of } \\
\text { Labor: } \\
\text { Com }\end{array}$ & $\begin{array}{l}\text { Duration of } \\
\text { Labor: } \\
\text { P Value }\end{array}$ & $\begin{array}{c}\text { Cesarean: } \\
\text { Int }\end{array}$ & $\begin{array}{l}\text { Cesarean: } \\
\text { Com }\end{array}$ & $\begin{array}{l}\text { Cesarean: } \\
\text { Difference } \\
(95 \% \mathrm{Cl})\end{array}$ & $\begin{array}{c}\text { Shorter } \\
\text { Labor } \\
\text { Associated } \\
\text { With Lower } \\
\text { Cesarean } \\
\text { Delivery } \\
\text { Rate? }\end{array}$ & Comments \\
\hline $\begin{array}{l}\text { Lavender, } \\
2018^{102} \\
\text { Good } \\
\text { SR }\end{array}$ & $\begin{array}{l}\text { Partogram } \\
\text { with Alert } \\
\text { line only }\end{array}$ & $\begin{array}{l}\text { Partogram } \\
\text { with Alert } \\
\text { and Action } \\
\text { line }\end{array}$ & - & - & - & $\begin{array}{l}\text { Overall: } \\
55 / 344 \\
(16.0 \%)\end{array}$ & $\begin{array}{l}\text { Overall: } \\
82 / 350 \\
(23.4 \%)\end{array}$ & $\begin{array}{l}\text { Overall: RR } 0.68 \\
(0.50 \text { to } 0.93)\end{array}$ & - & $\begin{array}{l}\text { Low-resource } \\
\text { setting }\end{array}$ \\
\hline $\begin{array}{l}\text { Lavender, } \\
2018^{102} \\
\text { Good } \\
\text { SR }\end{array}$ & $\begin{array}{l}\text { Partogram } \\
\text { and Early } \\
\text { Intervention }\end{array}$ & $\begin{array}{l}\text { Partogram } \\
\text { and Late } \\
\text { Intervention }\end{array}$ & - & - & - & $\begin{array}{l}\text { Overall: } \\
55 / 344 \\
(16.0 \%)\end{array}$ & $\begin{array}{l}\text { Overall: } \\
82 / 350 \\
(23.4 \%)\end{array}$ & $\begin{array}{l}\text { Overall: RR } 0.68 \\
\text { (0.50 to } 0.93)\end{array}$ & - & $\begin{array}{l}\text { Low-resource } \\
\text { setting }\end{array}$ \\
\hline $\begin{array}{l}\text { Lavender, } \\
2018^{102} \\
\text { Good } \\
\text { SR } \\
\end{array}$ & $\begin{array}{l}\text { Partogram } \\
\text { and Early } \\
\text { Intervention }\end{array}$ & $\begin{array}{l}\text { Partogram } \\
\text { and Late } \\
\text { Intervention }\end{array}$ & - & - & - & $\begin{array}{l}\text { Overall: } \\
171 / 1490 \\
(11.5 \%)\end{array}$ & $\begin{array}{l}\text { Overall: } \\
\text { 161/1485 } \\
(10.8 \%)\end{array}$ & $\begin{array}{l}\text { Overall: RR } 1.06 \\
\text { (0.85 to } 1.32)\end{array}$ & - & $\begin{array}{l}\text { High-resource } \\
\text { setting }\end{array}$ \\
\hline $\begin{array}{l}\text { Lavender, } \\
2018^{102} \\
\text { Good } \\
\text { SR }\end{array}$ & $\begin{array}{l}\text { Partogram } \\
\text { and Early } \\
\text { Intervention }\end{array}$ & $\begin{array}{l}\text { Partogram } \\
\text { and Late } \\
\text { Intervention }\end{array}$ & - & - & - & $\begin{array}{l}\text { Overall: } \\
226 / 2149 \\
(10.5 \%)\end{array}$ & $\begin{array}{l}\text { Overall: } \\
243 / 2146 \\
(11.3 \%)\end{array}$ & $\begin{array}{l}\text { Overall: RR } 0.94 \\
\text { (0.67 to } 1.31)\end{array}$ & - & $\begin{array}{l}\text { All subjects } \\
\text { (both low- and } \\
\text { high-resource } \\
\text { settings) }\end{array}$ \\
\hline $\begin{array}{l}\text { Lavender, } \\
2018^{102} \\
\text { Good } \\
\text { SR }\end{array}$ & $\begin{array}{l}\text { Partogram } \\
\text { with latent } \\
\text { phase }\end{array}$ & $\begin{array}{l}\text { Partogram } \\
\text { without } \\
\text { latent } \\
\text { phase }\end{array}$ & - & - & - & $\begin{array}{l}\text { Overall: } \\
83 / 350 \\
\text { (23.7\%) } \\
\text { NRFHT: } \\
65 / 350 \\
(18.6 \%) \\
\text { Delay: } \\
12 / 350 \\
(3.4 \%)\end{array}$ & $\begin{array}{l}\text { Overall: } \\
38 / 393 \\
(9.7 \%) \\
\text { NRFHT: } \\
15 / 393 \\
(3.8 \%) \\
\text { Delay: } \\
10 / 393 \\
(2.5 \%)\end{array}$ & $\begin{array}{l}\text { Overall: RR } 2.45 \\
\text { (1.72 to } 3.50) \\
\text { NRFHT: RR } 4.87 \\
\text { (2.83 to } 8.37) \\
\text { Delay: RR } 1.35 \\
\text { (0.59 to } 3.08 \text { ) }\end{array}$ & - & $\begin{array}{l}\text { High-resource } \\
\text { setting }\end{array}$ \\
\hline $\begin{array}{l}\text { Lavender, } \\
2018^{102} \\
\text { Good } \\
\text { SR }\end{array}$ & $\begin{array}{l}\text { Partogram } \\
\text { with 2-hour } \\
\text { action line }\end{array}$ & $\begin{array}{l}\text { Partogram } \\
\text { with } \\
\text { stepped } \\
\text { dystocia } \\
\text { line }\end{array}$ & - & - & - & $9 / 50(18 \%)$ & $8 / 49(16.3 \%)$ & $\begin{array}{l}\text { RR } 1.10 \text { (0.46 to } \\
2.62)\end{array}$ & - & $\begin{array}{l}\text { High-resource } \\
\text { setting } \\
\text { (includes only } \\
\text { a single study) }\end{array}$ \\
\hline $\begin{array}{l}\text { Lavender, } \\
2018^{102} \\
\text { Good } \\
\text { SR }\end{array}$ & Partogram & $\begin{array}{l}\text { Labour } \\
\text { scale }\end{array}$ & - & - & - & $5 / 61(8.2 \%)$ & $\begin{array}{l}12 / 61 \\
(19 / 7 \%)\end{array}$ & $\begin{array}{l}\text { RR } 0.42 \text { (0.16 to } \\
1.11)\end{array}$ & - & $\begin{array}{l}\text { High-resource } \\
\text { setting } \\
\text { (includes only } \\
\text { a single study) }\end{array}$ \\
\hline
\end{tabular}

Abbreviations: -=not reported; CI=confidence interval; Com=comparator; hr=hour; Int=intervention; IQR=interquartile range; NRFHT=Nonreassuring Fetal Heart Rate Tracing; $\mathrm{RCT}=$ randomized controlled trial; $\mathrm{RR}=$ relative risk; $\mathrm{SD}=$ standard deviation; $\mathrm{SR}=$ systematic review 


\section{Hoppe-University of Washington Cohort}

Hoppe et al. conducted a retrospective cohort study of women in spontaneous labor at the University of Washington to determine if women with long duration of active labor as defined by the Consortium on Safe Labor (CSL) labor curves would exhibit higher rates of delivery outcomes compared to women with shorter duration of active labor. ${ }^{100}$ Women with active labors lasting longer than the CSL $95^{\text {th }}$ percentile and women whose active labor progressed longer than the median and up to the $95^{\text {th }}$ percentile were compared to women with active labor shorter than the CSL median. Women with duration of active labor lasting longer than both the $95^{\text {th }}$ percentile and longer than the median and up to the $95^{\text {th }}$ percentile had higher odds of cesarean delivery compared to women whose labor lasted shorter than the CSL median labor duration (odds ratio[OR] 6.8 [95\% confidence interval (CI) 3.9, 11.7] and OR 3.1 [95\% CI 1.8, 5.5] for $>95^{\text {th }}$ percentile and between the median and $95^{\text {th }}$ percentile, respectively). Women with active phase of labor greater than the $95^{\text {th }}$ percentile of women in the CSL cohort were also more likely to have postpartum hemorrhage (OR 1.6 [95\% CI 1.0, 2.7]) and women with an active phase greater than the median and up to the $95^{\text {th }}$ percentile where more likely to develop chorioamnionitis (OR 2.5 [95\% CI 1.1, 5.9]) compared to women with active labor lasting shorter than the CSL median. There were no differences in the proportion of neonates with an Apgar score less than 7 or risk for being admitted to the intensive care nursery based on duration of labor as defined by the CSL labor curves.

\section{Cervical Dilation at Admission and Delivery Outcomes}

Following publication of the CSL demonstrating that modern labor curves may differ from those originally described by Friedman, a number of studies have looked at delivery outcomes based on the definition used for active labor and whether cervical dilation at time of admission is associated with mode of delivery and other labor outcomes.

Wood et al. ${ }^{96}$ conducted a secondary analysis of data collected as part of a prospective cohort study of women presenting in spontaneous labor at the Barnes-Jewish Hospital in St. Louis. Women admitted at less than $6 \mathrm{~cm}$ dilated were compared to women admitted with cervical dilation of greater than or equal to $6 \mathrm{~cm}$. Outcomes were stratified by parity and the study included 2,033 women. Among nulliparous women, there was no significant difference in the overall cesarean delivery rate among women admitted with a cervical dilation less than $6 \mathrm{~cm}$ compared to those admitted with a cervical dilation greater than or equal to $6 \mathrm{~cm}(16.8 \%$ vs. $7.1 \%$, relative risk [RR] 2.35, 0.90 to 6.13$)$. In contrast, among parous women, women admitted with cervical dilation less than $6 \mathrm{~cm}$ had a significantly overall increased rate of cesarean delivery compared to women admitted at greater than $6 \mathrm{~cm}(11.0 \%$ vs. $2.5 \%$, RR 4.36, 1.80 to 10.52). There were no differences in the cesarean delivery rate for arrest of dilation between the two groups in either nulliparous or parous women.

Kauffman et al. ${ }^{93}$ performed a retrospective cohort study of women in spontaneous labor delivering in 14 Washington State hospitals to determine if cervical dilation at time of admission was associated with labor outcomes. Women with cervical dilation less than $4 \mathrm{~cm}$ were compared to women with cervical dilation greater than or equal to $4 \mathrm{~cm}$. Data were stratified by parity. Among nulliparous women, women admitted with cervical dilation less than $4 \mathrm{~cm}$ had an increased overall cesarean delivery rate compared to women admitted in spontaneous labor at 4 $\mathrm{cm}$ or greater (21.8\% vs. $14.5 \%$, RR $1.50,1.32$ to1.70). There were no differences in rates of operative vaginal delivery or transfusion between the two groups. Among parous women admitted with cervical dilation less than $4 \mathrm{~cm}$ a higher overall cesarean delivery rate was 
demonstrated compared to parous women admitted with cervical dilation greater than or equal to $4 \mathrm{~cm}$ (3.7\% vs. 1.9\%, RR 1.95, 1.47 to 2.57). Parous women admitted at less than $4 \mathrm{~cm}$ cervical dilation had higher operative vaginal delivery rates (4.4\% vs. 2.8\%, RR $1.62,1.11$ to 2.37 ) but no differences in rate of transfusion compared to parous women admitted at greater than or equal to $4 \mathrm{~cm}$.

Neal et al. ${ }^{95}$ conducted a good-quality retrospective cohort of women in spontaneous labor managed at the Ohio State University Wexner Medical Center to determine if the definition used for active labor affected labor outcomes among nulliparous women in spontaneous labor. The definitions for active labor were based on those of (1) Freidman, ${ }^{18}$ (2) the NICE guidelines, ${ }^{109}$ and (3) the American College of Obstetricians and Gynecologists and the Society for MaternalFetal Medicine. ${ }^{110}$ Women admitted prior to active labor had higher overall cesarean delivery rates compared to women admitted in active labor regardless by which definition was used to diagnose active labor (Friedman 13.8\% vs 7.0\%, $\mathrm{p}<0.001$; NICE guidelines $16.9 \%$ vs 6.7\%, $\mathrm{p}<0.001 ;$ ACOG/SMFM $13.4 \%$ vs. 9.7\%, $\mathrm{p}<0.05$ ). There were also significant differences in the rate of a composite adverse maternal outcome that included fever during labor and postpartum hemorrhage among women admitted prior to active labor compared to those admitted in active labor (Friedman $8.9 \%$ vs $3.7 \%$, $\mathrm{p}<0.01$; NICE guidelines $10.7 \%$ vs $5.5 \%$, $\mathrm{p}<0.001$; and ACOG/SMFM $8.6 \%$ vs 3.9\%, $\mathrm{p}<0.01)$.

\section{Suzuki Cohort}

An observational study conducted in Japan by Suzuki et al. ${ }^{87}$ compared duration of the first stage of labor among 2,369 nulliparous women having a vaginal delivery following spontaneous labor from 4 sites with published data from the Friedman and CSL cohorts. Women in the Suzuki study had a mean (standard deviation [SD]) duration of first stage of labor of 12.3 (7.7) hours compared with 13.3 (7.6) hours in the Friedman data. The CSL data for the duration of the first stage of labor was 7.3 (95\% CI 3.3 to 13.7) hours in the CSL datasets. The operative vaginal delivery rates varied significantly between the 3 cohorts (3.5\% vs. $51.2 \%$ vs. $13.0 \%$ in the Suzuki, Friedman, and CSL cohorts, respectively). In addition, the Suzuki study compared the time it took to change from one centimeter dilation to the next centimeter dilation during the first stage of labor to similar data obtained from the CSL study in nulliparous women. In both studies, the rate of cervical change increased with advancing cervical dilation, though the rate of change in the Japanese cohort was slower than in the CSL cohort, resulting in a longer duration of the first stage of labor (Table 5).

Table 5. Median time intervals (hours) by cervical dilation in nulliparous women, Japanese cohort (Suzuki study) versus CSL (Zhang study)

\begin{tabular}{|c|c|c|}
\hline Cervical Dilation, $\mathbf{c m}$ & Suzuki Study $\left.{ }^{\mathbf{8 7}} \mathbf{( 9 5 \%} \mathbf{C l}\right)$ & CSL Zhang Study $\left.{ }^{\mathbf{2 1}} \mathbf{( 9 5 \%} \mathbf{~ C l}\right)$ \\
\hline 2 to 3 & $7.5(2.7$ to 21.0$)$ & $3.2(0.6$ to 15.0$)$ \\
\hline 3 to 4 & $6.2(2.2$ to 17.7$)$ & $2.7(0.6$ to 10.1$)$ \\
\hline 4 to 5 & $4.8(1.5$ to 15.7$)$ & $0.8(0.4$ to 6.6$)$ \\
\hline 5 to 6 & $3.3(1.0$ to 10.7$)$ & $0.6(0.2$ to 3.1$)$ \\
\hline 6 to 7 & $2.6(0.7$ to 9.3$)$ & $0.5(0.1$ to 1.5$)$ \\
\hline 7 to 8 & $1.8(0.5$ to 6.8$)$ & $0.4(0.1$ to 1.3$)$ \\
\hline 8 to 9 & $1.0(0.2$ to 4.4$)$ & $0.4(0.1$ to 1.4$)$ \\
\hline
\end{tabular}

Abbreviations: $\mathrm{CI}=$ confidence interval; $\mathrm{cm}=$ centimeter; $\mathrm{CSL}=$ Consortium on Safe Labor 


\section{Active Management of Labor}

The active management of labor was first described by O'Driscoll and colleagues ${ }^{111}$ based on their experience in the National Maternity Hospital in Dublin and was originally designed to allow for a shorter duration of labor and reduce the number of prolonged labors, but more recently it has also been applied to help lower cesarean delivery rates. The originally described active management of labor includes the following interventions: one-to-one nursing support during labor, routine use of amniotomy, intravenous oxytocin, strict diagnosis of labor, strict monitoring of the progress of labor (typically with use of a partogram), strict criteria for the diagnosis of protracted or arrested labor, and peer review of assisted deliveries. ${ }^{35}$ We identified one Cochrane Review that addressed the use of a package of care for the active management of labor. ${ }^{35}$ The review included 7 studies with 5,390 subjects. The authors planned to stratify results by parity, but all of the included studies only included nulliparous women. The overall cesarean delivery rate did not differ between women receiving active management of labor and women receiving usual care when all studies were included. In 1 of the 7 studies, approximately onethird of the subjects were excluded post-randomization, as randomization occurred at 30 weeks and many women developed reasons for exclusion following this. ${ }^{112}$ In sensitivity analysis that excluded this study, active management of labor resulted in significantly lower cesarean delivery rates and shorter duration of labor when compared with usual care (Table 6). ${ }^{35}$ Active management of labor was also associated with shorter duration of time from admission to delivery and the first stage of labor compared to usual care. The second stage of labor was not different between the two groups (Table 6). Active management of labor did not affect rates of operative vaginal delivery, postpartum hemorrhage, maternal satisfaction, or maternal infection. 
Table 6. Labor outcomes by active management of labor

\begin{tabular}{|c|c|c|c|c|c|c|c|c|c|c|}
\hline $\begin{array}{l}\text { Study } \\
\text { Quality }\end{array}$ & Int & Com & $\begin{array}{l}\text { Duration of } \\
\text { Labor: } \\
\text { Int }\end{array}$ & $\begin{array}{l}\text { Duration of } \\
\text { Labor: } \\
\text { Com }\end{array}$ & $\begin{array}{c}\text { Duration of } \\
\text { Labor: } \\
\text { P Value } \\
(95 \% \mathrm{Cl})\end{array}$ & $\begin{array}{c}\text { Cesarean: } \\
\text { Int }\end{array}$ & $\begin{array}{l}\text { Cesarean: } \\
\text { Com }\end{array}$ & $\begin{array}{c}\text { Cesarean: } \\
\text { Difference } \\
(95 \% \mathrm{Cl})\end{array}$ & $\begin{array}{c}\text { Shorter } \\
\text { Labor } \\
\text { Associated } \\
\text { With Lower } \\
\text { Cesarean } \\
\text { Delivery } \\
\text { Rate? } \\
\end{array}$ & Comments \\
\hline $\begin{array}{l}\text { Brown, } \\
2013^{35} \\
\text { Good }\end{array}$ & $\begin{array}{l}\text { Active } \\
\text { management } \\
\text { of labor }\end{array}$ & $\begin{array}{l}\text { Routine } \\
\text { care }\end{array}$ & - & - & - & $\begin{array}{l}\text { Overall: } \\
343 / 2573 \\
(13.3 \%)\end{array}$ & $\begin{array}{l}\text { Overall: } \\
416 / 2817 \\
(14.8 \%)\end{array}$ & $\begin{array}{l}\text { Overall: RR } \\
0.88 \text { (0.77 to } \\
1.01)\end{array}$ & 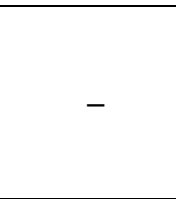 & $\begin{array}{l}\text { All studies } \\
\text { including } 1 \text { with } \\
\text { high number of } \\
\text { post- } \\
\text { randomization } \\
\text { exclusions }\end{array}$ \\
\hline $\begin{array}{l}\text { Brown, } \\
2013^{35} \\
\text { Good }\end{array}$ & $\begin{array}{l}\text { Active } \\
\text { management } \\
\text { of labor }\end{array}$ & $\begin{array}{l}\text { Routine } \\
\text { care }\end{array}$ & $\begin{array}{l}\text { Admission to } \\
\text { delivery: } 7.7(1.9) \\
\text { hr } \\
\text { First stage: } 6.8 \\
(2.3) \text { hr } \\
\text { Second stage: } \\
0.86(0.43) \mathrm{hr}\end{array}$ & $\begin{array}{l}\text { Admission to } \\
\text { delivery: } 9.4 \\
\text { (1.7) hr } \\
\text { First stage: } \\
8.3(1.9) \mathrm{hr} \\
\text { Second } \\
\text { stage: } 0.89 \\
(0.44) \mathrm{hr}\end{array}$ & $\begin{array}{l}\text { Difference in } \\
\text { admission to } \\
\text { delivery: - } \\
1.69(-2.08 \\
\text { to }-1.31) \mathrm{hr} \\
\text { Difference in } \\
\text { first stage: - } \\
1.56(-2.17 \\
\text { to }-0.96) \mathrm{hr} \\
\text { Difference in } \\
\text { second } \\
\text { stage: }-0.02 \\
(-0.06 \text { to } \\
0.02) \mathrm{hr}\end{array}$ & $\begin{array}{l}\text { Overall: } \\
146 / 1564 \\
(9.3 \%)\end{array}$ & $\begin{array}{l}\text { Overall: } \\
240 / 1911 \\
(12.5 \%)\end{array}$ & $\begin{array}{l}\text { Overall: RR } \\
0.77 \text { (0.63 to } \\
0.94)\end{array}$ & Yes & $\begin{array}{l}\text { Sensitivity } \\
\text { analysis with } 1 \\
\text { study excluded } \\
\text { (high-post } \\
\text { randomization } \\
\text { exclusion rate) }\end{array}$ \\
\hline
\end{tabular}

Abbreviations: -=not reported; CI=confidence interval; Com=comparator; hr=hour; Int=intervention; RR=relative risk 


\section{What Constitutes Normal Duration of Labor?}

Eight observational studies ${ }^{21,22,84,86,88,92,97,99}$ and three fair-quality systematic reviews/metaanalyses (SR/MAs) ${ }^{47,101,103}$ addressed the question of what constitutes normal duration of labor. The populations studied varied based on parity and whether labor was augmented, both of which may affect the duration of labor. Furthermore, the CSL investigators performed a subgroup analysis to determine the progression of labor among women receiving oxytocin augmentation. ${ }^{99}$

\section{National Collaborative Perinatal Project, the Consortium on Safe Labor, and the Inde Cohort}

The NCPP and the CSL were two large observational studies that both addressed duration of labor. The NCPP was a large observational study conducted at 12 sites between 1959 and 1966 and included 54,304 singleton pregnancies that delivered at 20 weeks or later. ${ }^{22}$ Of these, labor outcomes were reported for 26,838 parturients with singleton gestation, spontaneous onset of labor, and who completed the first stage of labor. ${ }^{22}$ In contrast, the CSL was a large observational study conducted at 19 sites between 2002 and 2008, with 87 percent of the births occurring between 2005 and 2007. ${ }^{21}$ The CSL included 62,415 subjects who had spontaneous onset of labor and a vaginal delivery. The rate of labor augmentation differed significantly between the two cohorts. Within the NCPP cohort, 14.6 percent of women received oxytocin augmentation ( $20 \%$ of nulliparous, $12 \%$ of parous 1 , and $12 \%$ or parous $2+$ ), ${ }^{22}$ while 45.9 percent of women in the CSL cohort received oxytocin augmentation (47\% of nulliparous, $45 \%$ of parous 1 , and $45 \%$ of parous $2+){ }^{21}$

Unlike the nulliparous labor curve of Friedman, which demonstrates a clear inflection point at which the rate of cervical dilation changes dramatically (transition from latent to active phase of labor) during the course of the first stage of labor, neither the NCPP or CSL nulliparous labor curves demonstrate a clear inflection point at which the rate of cervical dilation changes. ${ }^{18,19,21,22}$ In contrast, the labor curves for parous women in both the NCPP and CSL cohorts demonstrate an inflection point at which the rate of cervical dilation changes. In the NCPP cohort, the inflection point for Parous 1 women occurred at $5.5 \mathrm{~cm}$, while for Parous 2+ women, the inflection point occurred at $5 \mathrm{~cm}$ dilation. ${ }^{22}$ In the CSL cohort, the inflection point occurred at 6 cm cervical dilation for both Parous 1 and Parous $2+$ women. ${ }^{21}$

Inde et al. ${ }^{92}$ conducted an observational retrospective cohort study of women admitted in spontaneous labor who progressed to have a spontaneous vaginal delivery at six hospitals in Japan with the goal of creating normal labor curves for their population. Within their population, the study found that the labor curve for nulliparous women had an inflection point occurring at six centimeters, above which the rate of cervical change increased. Parous women, both with one prior or more than one prior delivery, demonstrated an inflection point at $5 \mathrm{~cm}$, above which the rate of cervical change increased. The mean $\left(95^{\text {th }}\right.$ percentile) duration of labor differed significantly $(\mathrm{p}<0.001)$ for women in the cohort by parity; 8.48 (20.0), 4.4 (10.4), and 4.0 (10.1) hours for nulliparous, parous 1 and parous $2+$ women, respectively.

There were significant differences in maternal characteristics between the three cohorts, including maternal age, race/ethnicity, body mass index, cervical dilation at admission, and/or rate of oxytocin augmentation. The extent to which differences in these patient characteristics contributed to the observed differences in labor curves is unclear.

Oladapo et al. ${ }^{101}$ conducted an SR that included seven observational studies and 99,971 women to determine the expected rate of cervical change among women in spontaneous labor. 
Results were stratified by parity. They found that the rate of cervical changes at approximately 5 to $6 \mathrm{~cm}$ dilation among nulliparous and parous women. The NCPP, CSL, Inde, and Oladapo datasets all reported the time it took to change from one centimeter dilation to the next centimeter dilation during the first stage of labor (Table 7). 
Table 7. Median time intervals (hours) by cervical dilation and parity from one cervical dilation score to the next, all cohorts

\begin{tabular}{|c|c|c|c|c|c|c|c|c|c|c|c|}
\hline $\begin{array}{l}\text { Cervical Dilation, } \\
\mathbf{c m}\end{array}$ & $\begin{array}{c}\text { NCPP } \\
\text { Cohort }^{22} \\
\text { Parity } 0\end{array}$ & $\begin{array}{c}\text { NCPP } \\
\text { Cohort } \\
\text { Parity } 1\end{array}$ & $\begin{array}{c}\text { NCPP } \\
\text { Cohort } \\
\text { Parity 2+ }\end{array}$ & $\begin{array}{c}\text { CSL } \\
\text { Cohort }{ }^{21} \\
\text { Parity } 0\end{array}$ & $\begin{array}{c}\text { CSL } \\
\text { Cohort } \\
\text { Parity } 1 \\
\end{array}$ & $\begin{array}{c}\text { CSL } \\
\text { Cohort } \\
\text { Parity 2+ }\end{array}$ & $\begin{array}{l}\text { Inde et } \\
\text { Cohort }{ }^{92} \\
\text { Parity } 0\end{array}$ & $\begin{array}{c}\text { Inde } \\
\text { Cohort } \\
\text { Parity } 1\end{array}$ & $\begin{array}{c}\text { Inde } \\
\text { Cohort } \\
\text { Parity 2+ }\end{array}$ & $\begin{array}{c}\text { Oladapo } \\
\text { SR }^{101} \\
\text { Parity } 0\end{array}$ & $\begin{array}{c}\text { Oladapo } \\
\text { SR } \\
\text { Parity 1+ }\end{array}$ \\
\hline $3-4$ & $1.2(6.6)$ & - & - & $1.8(8.1)$ & - & - & $2.2(8.0)$ & $0.9(4.0)$ & $0.8(4.5)$ & 2.0 & 2.4 \\
\hline $4-5$ & $0.9(4.5)$ & $0.7(3.3)$ & $0.7(3.5)$ & $1.3(6.4)$ & $1.4(7.3)$ & $1.4(7.0)$ & $1.8(5.8)$ & $0.5(2.2)$ & $0.5(2.4)$ & 1.5 & 1.2 \\
\hline $5-6$ & $0.6(2.6)$ & $0.4(1.6)$ & $0.4(1.6)$ & $0.8(3.2)$ & $0.8(3.4)$ & $0.8(3.4)$ & $1.3(4.7)$ & $0.4(2.2)$ & $0.3(2.1)$ & 0.9 & 0.7 \\
\hline $6-7$ & $0.5(1.8)$ & $0.4(1.2)$ & $0.3(1.2)$ & $0.6(2.2)$ & $0.5(1.9)$ & $0.5(1.8)$ & $1.1(3.1)$ & $0.3(1.7)$ & $0.3(1.7)$ & 0.7 & 0.4 \\
\hline $7-8$ & $0.4(1.4)$ & $0.3(0.8)$ & $0.3(0.7)$ & $0.5(1.6)$ & $0.4(1.3)$ & $0.4(1.2)$ & $1.0(3.3)$ & $0.3(1.7)$ & $0.3(1.5)$ & 0.6 & 0.4 \\
\hline $8-9$ & $0.4(1.3)$ & $0.3(0.7)$ & $0.2(0.6)$ & $0.5(1.4)$ & $0.3(1.0)$ & $0.3(0.9)$ & $0.8(2.2)$ & $0.3(1.3)$ & $0.2(1.0)$ & 0.5 & 0.3 \\
\hline $9-10$ & $0.4(1.2)$ & $0.2(0.5)$ & $0.2(0.5)$ & $0.5(1.8)$ & $0.3(0.9)$ & $0.3(0.8)$ & $0.5(2.2)$ & $0.2(1.2)$ & $0.2(1.2)$ & 0.5 & 0.3 \\
\hline
\end{tabular}

Abbreviations: $\mathrm{cm}=$ centimeter; $\mathrm{CSL}=$ Consortium on Safe Labor; NCPP=National Collaborative Perinatal Project 
The time from admission to $10 \mathrm{~cm}$ cervical dilation based on the cervical dilation at the time of admission among nulliparous women was reported for each of the three cohorts. The median $\left(95^{\text {th }}\right.$ percentile) time from admission to delivery within the NCPP cohort was 6.3 (20.7), 4.5 (16.2), 3.2 (14.2), and 2.1 (9.3) hours for women admitted at 2-2.5 cm, 3-3.5 cm, 4-4.5 cm, and 5-5.5 cm cervical dilation, respectively. ${ }^{22}$ For nulliparous women in the CSL cohort, the median ( $95^{\text {th }}$ percentile) time from admission to delivery was 8.4 (20.0), 6.9 (17.4), 5.3 (16.4), and 3.8 (12.7) hours for women admitted at 2-2.5 cm, 3-3.5 cm, 4-4.5 cm, and 5-5.5 cm cervical dilation, respectively. ${ }^{21}$ For nulliparous women in the Inde cohort, the median $\left(95^{\text {th }}\right.$ percentile) time from admission to delivery was 6.7 (16.8), 5.1 (13.5), 3.7 (10.2), and 3.0 (8.9) hours for women admitted at $2 \mathrm{~cm}, 3 \mathrm{~cm}, 4 \mathrm{~cm}$, and $5 \mathrm{~cm}$ cervical dilation, respectively. Among nulliparous women included in the Oladapo SR, the median ( $95^{\text {th }}$ percentile) time from admission to delivery was 7.8, 6.4, 4.9, and 3.4 hours for women admitted at $2 \mathrm{~cm}, 3 \mathrm{~cm}, 4 \mathrm{~cm}$, and $5 \mathrm{~cm}$ cervical dilation, respectively.

\section{Consortium on Safe Labor Subgroup Analysis; Oxytocin Augmentation}

Zhang et al conducted a subgroup analysis of the CSL dataset to determine the progress of labor among women requiring oxytocin augmentation during labor. ${ }^{99}$ For this analysis, they included women within the CSL cohort with a non-anomalous singleton gestation in the vertex presentation at 37 weeks or greater who had a vaginal delivery and for whom oxytocin data was available. The group conducted two analyses: (1) duration of labor for progressing from one centimeter to the next centimeter dilation when oxytocin was started at the beginning of the interval (Table 8) and (2) duration of labor for progressing from one centimeter to the next when the oxytocin infusion rate reached the highest dose prior to the start of the cervical dilation interval studies (Table 9). The authors found that as labor progressed, the time required to change from one centimeter to the next became shorter when oxytocin was started later in labor. In addition, once the maximal required infusion rate was achieved, the rate of cervical dilation progressed more quickly the later in labor that the maximal rate was achieved.

Table 8. Duration of labor in hours for cervical dilation to the next centimeter with oxytocin starting at the beginning of the interval ${ }^{a}$

\begin{tabular}{|c|c|c|c|c|}
\hline $\begin{array}{c}\text { Starting } \\
\text { Oxytocin at the } \\
\text { Interval }\end{array}$ & N Nulliparous & $\begin{array}{c}\text { Nulliparous } \\
\mathbf{5 0}^{\text {th }} \begin{array}{c}\text { Percentile } \\
\mathbf{9 5}^{\text {th }} \mathbf{)}\end{array}\end{array}$ & N Parous & $\begin{array}{c}\text { Parous } \\
\mathbf{5 0}^{\text {th }} \text { Percentile } \\
\mathbf{( 9 5}^{\text {th }} \mathbf{)}\end{array}$ \\
\hline $4-5 \mathrm{~cm}$ & 740 & $2.9(8.8)$ & 850 & $3.1(10.1)$ \\
\hline $5-6 \mathrm{~cm}$ & 460 & $1.7(5.8)$ & 646 & $1.9(8.0)$ \\
\hline $6-7 \mathrm{~cm}$ & 319 & $1.4(5.2)$ & 445 & $1.3(6.1)$ \\
\hline $7-8 \mathrm{~cm}$ & 221 & $1.1(5.0)$ & 316 & $1.0(4.6)$ \\
\hline $8-9 \mathrm{~cm}$ & 139 & $1.5(6.4)$ & 219 & $0.9(3.8)$ \\
\hline $9-10 \mathrm{~cm}$ & 105 & $1.8(5.5)$ & 150 & $0.7(2.9)$ \\
\hline $6-10 \mathrm{~cm}$ & 319 & $2.1(6.0)$ & 445 & $1.7(6.20)$ \\
\hline
\end{tabular}

${ }^{a}$ Interval-censored regression 
Table 9. Duration of labor in hours for cervical dilation to the next centimeter with oxytocin reaching the highest dose before the start of the interval ${ }^{\mathrm{a}}$

\begin{tabular}{|c|c|c|c|c|}
\hline $\begin{array}{c}\text { Starting } \\
\text { Oxytocin at the } \\
\text { Interval }\end{array}$ & N Nulliparous & $\begin{array}{c}\text { Nulliparous } \\
\mathbf{5 0}^{\text {th }} \text { Percentile } \\
\left.\mathbf{9 5}^{\text {th }}\right)\end{array}$ & N Parous & $\begin{array}{c}\text { Parous } \\
\mathbf{5 0}^{\text {th }} \text { Percentile } \\
\mathbf{9 5}^{\text {th }} \mathbf{)}\end{array}$ \\
\hline $4-5 \mathrm{~cm}$ & 967 & $0.7(2.4)$ & 551 & $0.6(1.9)$ \\
\hline $5-6 \mathrm{~cm}$ & 1596 & $0.5(1.5)$ & 1188 & $0.4(1.1)$ \\
\hline $6-7 \mathrm{~cm}$ & 2126 & $0.4(1.0)$ & 1848 & $0.3(0.8)$ \\
\hline $7-8 \mathrm{~cm}$ & 2533 & $0.4(1.0)$ & 2434 & $0.3(0.6)$ \\
\hline $8-9 \mathrm{~cm}$ & 2917 & $0.4(0.9)$ & 2958 & $0.2(0.5)$ \\
\hline $9-10 \mathrm{~cm}$ & 3200 & $0.5(1.6)$ & 3362 & $0.2(0.6)$ \\
\hline $6-10 \mathrm{~cm}$ & 2127 & $0.5(1.5)$ & 1855 & $0.4(0.9)$ \\
\hline $\begin{array}{c}2^{\text {nd }} \text { stage without } \\
\text { epidural analgesia }\end{array}$ & 89 & $0.5(2.2)$ & 212 & $0.1(0.4)$ \\
\hline $\begin{array}{c}2^{\text {nd }} \text { stage with } \\
\text { epidural analgesia }\end{array}$ & 3340 & $1.2(3.1)$ & 3452 & $0.4(1.1)$ \\
\hline
\end{tabular}

a Interval-censored regression

\section{Interbirth Interval and Labor Curve}

In a fair-quality observational study, ${ }^{97}$ labor curves were constructed for parous women presenting to the Prentice Women's Hospital to determine if the interbirth interval, the time between the prior and current birth affected the shape of the labor curve. Women were divided into one of three groups, by duration of the interbirth interval; less than 59 months, 60 to 119 months, and greater than or equal to 120 months. The mean duration of labor for each of the three groups was not reported. Summary labor curves for each of the three groups were constructed and equations fitting the curves were reported where cervical dilation is expressed by; 1$) \mathrm{cm}=4.67 * e^{(0.079 * \text { time })}$ for the interbirth interval group of less than 59 months, 2$) \mathrm{cm}=$ $4.94 * e^{(0.079 * \text { time })}$ for the interbirth interval group of 60 to 119 months, and 3$) \mathrm{cm}=4.87 * e^{(0.090 * \text { time })}$ for the interbirth interval group of greater than or equal to 120 months. The mean rate of cervical dilation for each of the three groups was $0.57,0.52$, and $0.78 \mathrm{~cm}$ per hour, respectively, with women in the longer interbirth interval demonstrating significantly slower rates of cervical change.

\section{Frigo Italian Cohort and the Abalos SR}

Frigo et al ${ }^{85}$ conducted a fair-quality observational cohort of nulliparous women in spontaneous labor who delivered vaginally to determine the duration of the first stage and second stage of labor, with the ultimate goal of constructing labor curves for their population and then comparing those curves to the curves published by Friedman and the CSL. All women in the Frigo cohort received regional analgesia and were assigned in an alternating fashion to combined spinal plus epidural analgesia or to epidural analgesia alone. The mean duration of the first stage of labor in their population was 4 hours and 30 minutes (SD 1.52 hours), and the mean duration of the second stage of labor was 1 hour and 10 minutes (SD 0.43 hours). Oxytocin augmentation was received in 55.9 percent of the study population. Within this cohort, women with combined spinal plus epidural analgesia had significantly shorter mean (SD) duration of the first (4.01 [1.43] vs. 4.60 [1.39] hours, $p=0.043$ ) and second (1.05 [0.38] vs. 1.15 [0.35] hours, $p=0.036)$ stages of labor compared to women receiving epidural analgesia alone (Table 10).

Finally, Abalos et al. ${ }^{103}$ conducted an SR of 37 studies including 208,000 women to determine the median duration of the first and second stages of labor. Among nulliparous women, the median ( $95^{\text {th }}$ percentile) duration of the first stage of labor ranged from 3.7 to 5.9 
hours (14.5 to 16.7 hours) when active labor was considered to begin at $4 \mathrm{~cm}$ cervical dilation and ranged from 3.8 to 4.3 hours (11.3 to 12.7 hours) when active labor was considered to begin at $5 \mathrm{~cm}$ cervical dilation.

Table 10. Duration of labor and oxytocin augmentation in the Frigo, Friedman, and CSL cohorts

\begin{tabular}{|l|l|l|l|}
\hline \multicolumn{1}{|c|}{ Outcome } & \multicolumn{1}{|c|}{ Frigo Cohort $^{85}$} & \multicolumn{1}{|c|}{ Friedman Cohort $^{19}$} & \multicolumn{1}{c|}{ CSL Cohort $^{\mathbf{2 1}}$} \\
\hline $\begin{array}{l}\text { Mean (SD) Duration of first } \\
\text { stage, hours }\end{array}$ & $4.50(1.5)$ & 4.35 & 5.50 \\
\hline $\begin{array}{l}\text { Mean (SD) Duration of } \\
\text { second stage, hours }\end{array}$ & $1.10(0.4)$ & 0.39 & 0.53 \\
\hline $\begin{array}{l}\text { Oxytocin augmentation, \% of } \\
\text { study population }\end{array}$ & 55.9 & 50 & 45.9 \\
\hline
\end{tabular}

Abbreviation: $\mathrm{CSL}=$ Consortium on Safe Labor; SD=standard deviation

\section{Labor Outcomes by Duration of Labor and Maternal Age}

A large, single-center observational study ${ }^{86}$ of 10,661 nulliparous women in spontaneous labor assessed delivery outcomes based on the duration of labor. The duration of the first stage of labor was divided into 3 categories: $<5^{\text {th }}$ percentile, $5^{\text {th }}$ to $95^{\text {th }}$ percentile, and $>95^{\text {th }}$ percentile. Mode of delivery and rates of postpartum hemorrhage, chorioamnionitis, and endometritis varied by duration of the first stage of labor (Table 11). The incidence of third or fourth degree perineal laceration, neonatal acidemia, neonatal sepsis, shoulder dystocia, or birth trauma was not influenced by duration of the first stage of labor. In variable analysis, mode of delivery (overall adjusted odds ratio [aOR] 0.62 [95\% CI, 0.45 to 0.84 ] for cesarean delivery and aOR 2.28 [95\% CI, 1.92 to 2.72] for first stage duration for the $<5^{\text {th }}$ percentile and $>95^{\text {th }}$ percentile compared to the $5^{\text {th }}$ to $95^{\text {th }}$ percentile, respectively) and chorioamnionitis (aOR 0.31 [95\% CI, 0.17 to 0.56 ] and aOR 1.58 [95\% CI, 1.25 to 1.98 ] for first stage duration for the $<5^{\text {th }}$ percentile and $>95^{\text {th }}$ percentile compared to the $5^{\text {th }}$ to $95^{\text {th }}$ percentile, respectively) remained significantly different based on duration of the first stage of labor.

Table 11. Maternal outcomes by duration of the first stage of labor

\begin{tabular}{|c|c|c|c|c|}
\hline Outcome & $\begin{array}{c}<5^{\text {th }} \text { Percentile } \\
(0-2.8 \text { Hours) } n=525\end{array}$ & $\begin{array}{c}5^{\text {th }} \text { to } 95^{\text {th }} \\
\text { Percentile } \\
(2.8-30 \text { Hours }) \\
n=9,611\end{array}$ & $\begin{array}{c}>95^{\text {th }} \text { Percentile } \\
\text { (>30 Hours) } \\
n=525\end{array}$ & P Value \\
\hline $\begin{array}{l}\text { Mode of delivery, } \% \\
\text { spontaneous vaginal }\end{array}$ & 80.6 & 72.9 & 63.8 & $<0.001$ \\
\hline $\begin{array}{l}\text { Mode of delivery, \% } \\
\text { operative vaginal }\end{array}$ & 17.4 & 21.0 & 22.6 & $<0.001$ \\
\hline $\begin{array}{l}\text { Mode of delivery, \% } \\
\text { cesarean }\end{array}$ & 2.0 & 6.1 & 13.5 & $<0.001$ \\
\hline $\begin{array}{l}\text { Postpartum } \\
\text { hemorrhage, } \%\end{array}$ & 8.6 & 9.8 & 14.0 & 0.004 \\
\hline Chorioamnionitis, \% & 2.9 & 12.5 & 23.5 & $<0.001$ \\
\hline Endometritis, \% & 1.0 & 2.4 & 3.2 & 0.04 \\
\hline
\end{tabular}

The duration of labor is affected by maternal age. A single-center observational study of 31,976 women demonstrated that the duration of the first and second stage of labor is associated with maternal age. ${ }^{88}$ In multivariable analysis including only those women in spontaneous labor (excludes women who were induced), older nulliparous women demonstrated significantly 
longer first stage of labor compared to younger women, though this relationship was not seen among parous women. Older nulliparous and parous women had longer adjusted duration of the second stage of labor compared to younger women (Table 12).

Table 12. Duration of labor (minutes) by maternal age ${ }^{a}$

\begin{tabular}{|c|c|c|c|c|c|c|}
\hline $\begin{array}{l}\text { Parity and } \\
\text { Stage of } \\
\text { Labor }\end{array}$ & $<20$ Yrs & 20-24 Yrs & 25-29 Yrs & 30-34 Yrs & 35-39 Yrs & $\geq 40$ Yrs \\
\hline $\begin{array}{l}\text { Nulliparous } \\
\text { first stage }\end{array}$ & $\begin{array}{c}550 \\
\text { (170 to } 1400)\end{array}$ & $\begin{array}{c}555 \\
\text { (170 to } 1423)\end{array}$ & $\begin{array}{c}595 \\
\text { (180 to } 1445)\end{array}$ & $\begin{array}{c}630 \\
\text { (180 to 1590) }\end{array}$ & $\begin{array}{c}660 \\
\text { (180 to 1734) }\end{array}$ & $\begin{array}{c}585 \\
\text { (200 to } 1740)\end{array}$ \\
\hline $\begin{array}{l}\text { Nulliparous } \\
\text { second stage }\end{array}$ & $\begin{array}{c}51 \\
\text { (10 to 232) } \\
\end{array}$ & $\begin{array}{c}65 \\
\text { (12 to } 245) \\
\end{array}$ & $\begin{array}{c}89 \\
\text { (15 to 282) } \\
\end{array}$ & $\begin{array}{c}118 \\
\text { (19 to 317) } \\
\end{array}$ & $\begin{array}{c}127 \\
\text { (21 to 336) } \\
\end{array}$ & $\begin{array}{c}148 \\
\text { (21 to 381) } \\
\end{array}$ \\
\hline $\begin{array}{l}\text { Parous } \\
\text { first stage }\end{array}$ & $\begin{array}{c}368 \\
\text { (117 to } 1080)\end{array}$ & $\begin{array}{c}365 \\
\text { (103 to 1080) }\end{array}$ & $\begin{array}{c}355 \\
\text { (95 to } 1075) \\
\end{array}$ & $\begin{array}{c}345 \\
\text { (90 to } 1080)\end{array}$ & $\begin{array}{c}345 \\
\text { (90 to } 1110) \\
\end{array}$ & $\begin{array}{c}343 \\
\text { (80 to 1098) }\end{array}$ \\
\hline $\begin{array}{l}\text { Parous } \\
\text { second stage }\end{array}$ & 16 (3 to 120$)$ & 15 (3 to 128$)$ & 18 (3 to 160$)$ & 20 (3 to 191) & 24 (4 to 221$)$ & 26 (3 to 197) \\
\hline
\end{tabular}

a Data are median duration of labor (95\% confidence interval) in minutes. Includes women who were induced (range 12.7 to $19.7 \%)$.

Abbreviations: yrs=years

\section{Labor Duration by Initial Rate of Cervical Change at Admission}

An observational study of 216 nulliparous women compared the duration of labor and mode of delivery based on the initial rate of cervical change at the time of admission. ${ }^{84}$ Women with an initial rate of cervical change of $<0.5 \mathrm{~cm}$ per hour in the first 4 hours were defined as being in pre-labor, and women with an initial rate of cervical change of $>0.5 \mathrm{~cm}$ per hour were defined as being in active labor. Women in active labor were less likely to be delivered by cesarean deliver and had shorter duration of labor from admission to $10 \mathrm{~cm}$ compared to women in admitted in pre-labor.

A fair-quality SR of 18 studies including 7009 nulliparous women by the same lead author ${ }^{47}$ demonstrated that the mean (SD) duration of the active phase of labor in nulliparous women was 6.0 (2.0) hours, with an associated mean (SD) rate of cervical change of $1.2(0.5) \mathrm{cm}$ per hour.

\section{Strength of Evidence for Criteria Used To Define Abnormal Labor}

Table 13 summarizes the SOE for the use of partograms described above. In general, the SOE was reduced for outcomes because of inconsistences between studies (which may be related to variation in the definitions used to build the partograms), and because the evidence was largely based on studies from non-U.S. settings (and several focused on low-resource settings). This is largely because of questions related to whether differences in the characteristics of patients, providers, or settings between U.S. and non-U.S. settings affect the generalizability of the results to the US. 
Table 13. Partogram use: Strength of evidence for major outcomes and adverse events

\begin{tabular}{|c|c|c|c|c|}
\hline Category & Outcome & $\begin{array}{l}\text { Study Design } \\
\text { (Sample Size) }\end{array}$ & Conclusion & $\begin{array}{c}\text { SOE } \\
\text { (Rationale) }^{a} \\
\end{array}$ \\
\hline \multirow[t]{4}{*}{$\begin{array}{l}\text { Intermediate } \\
\text { or Final } \\
\text { Outcomes }\end{array}$} & $\begin{array}{l}\text { Process Related } \\
\text { Outcomes - Mode } \\
\text { of Delivery } \\
\text { (Cesarean } \\
\text { Delivery) }\end{array}$ & $\begin{array}{l}\begin{array}{l}\text { 4 RCTs } \\
(3,810,90,94,98\end{array} \\
1 \text { Obs }^{91} \\
(8,672) \\
1 \text { SR }^{102} \\
(1,813 \\
\text { patients, } 3 \\
\text { studies) }\end{array}$ & $\begin{array}{l}\text { Inconclusive: Inconsistent } \\
\text { findings from } 4 \text { studies } \\
\text { combined with non-U.S. } \\
\text { settings resulted in insufficient } \\
\text { SOE. }\end{array}$ & $\begin{array}{l}\text { Insufficient } \\
\text { (Indirect [non-U.S. } \\
\text { setting], Inconsistent) } \\
\text { SR evidence also was } \\
\text { inconsistent between } \\
\text { low and high-resource } \\
\text { settings. }\end{array}$ \\
\hline & $\begin{array}{l}\text { Process Related } \\
\text { Outcomes - } \\
\text { Operative Vaginal } \\
\text { Delivery }\end{array}$ & $\begin{array}{l}\mathrm{RCT}^{89} \\
(1,929) \\
1 \mathrm{SR}^{102} \\
(1,813 \\
\text { patients, } 3 \\
\text { studies) }\end{array}$ & $\begin{array}{l}\text { No difference: No difference in } \\
\text { operative vaginal delivery rates } \\
\text { between women managed with } \\
\text { varying partogram strategies. }\end{array}$ & $\begin{array}{l}\text { Moderate } \\
\text { (non-U.S. setting) } \\
\text { Findings consistent with } \\
\text { SR }\end{array}$ \\
\hline & $\begin{array}{l}\text { Process Related } \\
\text { Outcomes - } \\
\text { Parental } \\
\text { Preferences }\end{array}$ & $\begin{array}{l}1 \mathrm{RCT}^{89} \\
(1,929)\end{array}$ & $\begin{array}{l}\text { No difference: An RCT in the } \\
\text { UK demonstrated no difference } \\
\text { in maternal satisfaction scores } \\
\text { between women managed with } \\
\text { a two-hour action line } \\
\text { partogram compared to women } \\
\text { managed with a four-hour } \\
\text { action line partogram. }\end{array}$ & $\begin{array}{l}\text { Low } \\
\text { (non-U.S. setting, } 1 \\
\text { study) }\end{array}$ \\
\hline & $\begin{array}{l}\text { Process Related } \\
\text { Outcomes - Mode } \\
\text { of Delivery } \\
\text { (Cesarean } \\
\text { Delivery) }\end{array}$ & $\begin{array}{l}\begin{array}{l}\text { 4 RCTs } \\
(3,810,90,94,98\end{array} \\
1 \text { Obs }^{91} \\
(8,672) \\
1 \mathrm{SR}^{102} \\
(1,813 \\
\text { patients, } 3 \\
\text { studies) }\end{array}$ & $\begin{array}{l}\text { Inconclusive: Inconsistent } \\
\text { findings from } 4 \text { studies } \\
\text { combined with non-U.S. } \\
\text { settings resulted in insufficient } \\
\text { SOE. }\end{array}$ & $\begin{array}{l}\text { Insufficient } \\
\text { (Indirect [non-U.S. } \\
\text { setting], Inconsistent) } \\
\text { SR evidence also was } \\
\text { inconsistent between } \\
\text { low and high-resource } \\
\text { settings. }\end{array}$ \\
\hline \multirow[t]{3}{*}{$\begin{array}{l}\text { Adverse } \\
\text { Events }\end{array}$} & $\begin{array}{l}\text { Maternal } \\
\text { Outcomes - } \\
\text { Hemorrhage }\end{array}$ & $\begin{array}{l}3 \mathrm{RCTS}^{89,90,94} \\
(3,700)\end{array}$ & $\begin{array}{l}\text { No difference: No difference } \\
\text { postpartum hemorrhage rates } \\
\text { among women managed with } \\
\text { varying partogram strategies. }\end{array}$ & $\begin{array}{l}\text { Moderate (non-U.S. } \\
\text { setting) }\end{array}$ \\
\hline & $\begin{array}{l}\text { Neonatal } \\
\text { Outcomes - } \\
\text { Respiratory } \\
\text { Distress }\end{array}$ & $\begin{array}{l}1 \mathrm{RCT}^{90} \\
(626)\end{array}$ & $\begin{array}{l}\text { Inconclusive: SOE was rated } \\
\text { as insufficient given findings } \\
\text { from } 1 \text { study in non-U.S. low } \\
\text { resource setting. }\end{array}$ & $\begin{array}{l}\text { Insufficient } \\
\text { (non-U.S. setting, } 1 \\
\text { small study) }\end{array}$ \\
\hline & $\begin{array}{l}\text { Neonatal } \\
\text { Outcomes - } \\
\text { Acidemia }\end{array}$ & $\begin{array}{l}1 \mathrm{RCT}^{89} \\
(1,929)\end{array}$ & $\begin{array}{l}\text { No difference: No difference in } \\
\text { neonatal acidemia rates } \\
\text { between women managed with } \\
\text { varying partogram strategies. }\end{array}$ & $\begin{array}{l}\text { Low } \\
\text { (non-U.S. setting, } 1 \\
\text { study) }\end{array}$ \\
\hline
\end{tabular}

${ }^{a}$ Criteria for downgrading SOE are described as Rationale; when these criteria are insufficient for understanding the final SOE, additional explanation is provided.

Abbreviations: Obs=observational; RCT=randomized controlled trial; SOE=strength of evidence; $\mathrm{SR}=$ systematic review

\section{Key Question 2. Amniotomy}

KQ 2 was: What are the benefits and harms of amniotomy in women in spontaneous labor? 


\section{Description of Included Studies}

We identified nine RCTs that examined the benefits and harms of amniotomy ( \pm oxytocin) in women in spontaneous labor. ${ }^{113-121}$ Of these, four studies were conducted in the Middle East, ${ }^{113-}$ 115,118 three were conducted in Asia, ${ }^{117,120,121}$ and two were conducted in Africa. ${ }^{116,119}$ All but one study ${ }^{118}$ were conducted in a hospital setting. The lone exception was a study conducted in an obstetrics and gynecology unit. All nine studies were unclear about or did not report their funding source. Six studies were rated as good quality, ${ }^{114-117,119,121}$ and three studies were rated as fair quality. ${ }^{113,118,120}$

Comparisons of interest were amniotomy versus an alternative control treatment without amniotomy (eight studies ${ }^{113-116,118-121}$ ) and amniotomy plus oxytocin versus control treatment (two studies ${ }^{114,117}$ ). Several studies evaluated timing of amniotomy and varied in their definitions though most assumed early amniotomy was defined as receiving amniotomy at 4-5 cm cervical dilation.

In terms of parity, four studies reported results for nulliparous women only; ${ }^{113,117,118,120}$ one reported results for nulliparous and parous women separately (with no analysis of combined results); ${ }^{115}$ one reported results for nulliparous and parous women combined and for each of the parity subgroups; ${ }^{114}$ and three reported results for women of unspecified parity. ${ }^{116,119,121}$ We were able to combine results across parity subgroups for some dichotomous outcomes of interest; we report those below.

In addition to the above studies, three good-quality SRs addressed the benefits and harms of amniotomy. ${ }^{35,122,123}$ All three SR/MAs examined the role of amniotomy, with or without oxytocin, to prevent labor dystocia, ${ }^{122}$ shorten spontaneous labor, ${ }^{123}$ or prevent cesarean delivery $^{35}$ in spontaneous labor. Wei et al. performed a meta-analysis to estimate the effects of amniotomy plus oxytocin for prevention of, or therapy for, delay in labor progress on the cesarean delivery rate and on indicators of maternal and neonatal morbidity. Smyth et al. ${ }^{123}$ compared amniotomy alone to intention to preserve the membranes to shorten the duration of labor. The primary objective of the analysis performed by Brown et al. ${ }^{35}$ was to determine whether a predefined package of interventions during childbirth such as "active management of labor" reduces the cesarean delivery rate in low-risk women and improves women's satisfaction. Several of the studies included in our review overlapped with studies included in these three reviews.

\section{Key Points for Amniotomy}

\section{Amniotomy versus control treatment}

- Amniotomy decreases the total duration of labor in nulliparous women (moderate SOE) and those with unspecified parity (low SOE).

- There was no difference in the rate of cesarean delivery for early amniotomy versus control in women with unspecified parity (moderate SOE)

- There were no differences in rates of maternal infection, hemorrhage, or trauma to the pelvic floor (moderate SOE) for early amniotomy versus control.

\section{Amniotomy plus oxytocin versus control treatment}

- Routine amniotomy plus oxytocin decrease the duration of labor and has a similar effect in both nulliparous and parous women (high SOE). 
- Routine amniotomy plus oxytocin do not differ compared to control treatment in cesarean delivery rates in both nulliparous and parous women (high SOE).

\section{Detailed Synthesis for Amniotomy}

\section{Amniotomy Versus Control Treatment}

Amniotomy is the practice of rupturing the amniotic sac during the course of labor and may be performed for a variety of indications. For the purpose of preventing labor dystocia, amniotomy is performed early in the labor process although the optimal timing is an area of active debate. Across included studies, amniotomy has been compared to various control treatments. The specific control treatment was described across all studies as care according to the obstetric providers' discretion without intentional amniotomy in the absence of other indications (such as direct monitoring of fetal heart rate or intrauterine pressure).

\section{Results in Nulliparous Women for Amniotomy}

Five RCTs examined amniotomy versus control treatment in nulliparous women. ${ }^{113-115,118,120}$

\section{Duration of Labor and Cesarean Delivery Rates for Amniotomy}

Four studies ${ }^{113-115,118}$ demonstrated a statistically significant decrease in the total duration of labor in women randomized to amniotomy (moderate SOE) and one fair-quality trial found that the duration of labor was not statistically different amongst the two groups (Table 14). ${ }^{120}$ One fair-quality trial ${ }^{113}$ also demonstrated a significantly decreased cesarean delivery rate in women randomized to amniotomy. Another fair-quality trial ${ }^{120}$ demonstrated an increase in the number of cesarean deliveries in women randomized to amniotomy. The remaining three studies, showed no significant differences in cesarean delivery rates between groups. The SOE was rated as insufficient given inconsistent and imprecise findings. 
Table 14. Amniotomy versus control in nulliparous women-total duration of labor and cesarean delivery rates

\begin{tabular}{|c|c|c|c|c|c|c|c|c|c|c|}
\hline $\begin{array}{l}\text { Study } \\
\text { Quality }\end{array}$ & Int & Com & $\begin{array}{l}\text { Duration of } \\
\text { Labor: } \\
\text { Int }\end{array}$ & $\begin{array}{l}\text { Duration of } \\
\text { Labor: } \\
\text { Com }\end{array}$ & $\begin{array}{l}\text { Duration } \\
\text { of Labor: } \\
P \text { Value }\end{array}$ & $\begin{array}{l}\text { Cesarean: } \\
\text { Int (\%) }\end{array}$ & $\begin{array}{c}\text { Cesarean: } \\
\text { Com (\%) }\end{array}$ & $\begin{array}{l}\text { Cesarean: } \\
\text { P Value }\end{array}$ & $\begin{array}{c}\text { Shorter Labor } \\
\text { Associated } \\
\text { With Lower } \\
\text { Cesarean } \\
\text { Delivery Rate? }\end{array}$ & Comments \\
\hline $\begin{array}{l}\text { Abdullah, } \\
2010^{118} \\
\text { Fair }\end{array}$ & $\begin{array}{l}\text { Routine } \\
\text { amniotomy } \\
\mathrm{N}=100\end{array}$ & $\begin{array}{l}\text { Amniotomy } \\
\text { for specific } \\
\text { indications } \\
N=100\end{array}$ & $\begin{array}{l}399.6 \min \\
\pm 84.6\end{array}$ & $\begin{array}{l}456 \text { min } \\
\pm 104.4\end{array}$ & $<0.001$ & $8(8 \%)$ & $10(10 \%)$ & 0.62 & No & $\begin{array}{l}\text { Duration of } \\
\text { labor defined } \\
\text { as time from } \\
\text { enrollment to } \\
\text { delivery }\end{array}$ \\
\hline $\begin{array}{l}\text { Ghafarzadeh, } \\
2015^{113} \\
\text { Fair }\end{array}$ & $\begin{array}{l}\text { Routine } \\
\text { amniotomy } \\
\text { at }<4 \mathrm{~cm} \\
\mathrm{~N}=150\end{array}$ & $\begin{array}{l}\text { Amniotomy } \\
\text { for specific } \\
\text { indications } \\
N=150\end{array}$ & $450 \min \pm 42$ & $504 \min \pm 60$ & $<0.001$ & $17(11.3 \%)$ & $59(39.3 \%)$ & $\begin{array}{l}<0.0001 \\
\text { aOR } 0.183 \text { (95\% } \\
\text { Cl, } 0.099 \text { to } \\
0.338) \text { - adjusted } \\
\text { for BMI, age, } \\
\text { gestational age, } \\
\text { neonatal weight, } \\
\text { cervical dilation, } \\
\text { cervical } \\
\text { effacement }\end{array}$ & Yes & $\begin{array}{l}\text { Duration of } \\
\text { labor defined } \\
\text { as onset of } \\
\text { uterine } \\
\text { contractions } \\
\text { until } 1 \mathrm{hr} \text { after } \\
\text { expulsion of } \\
\text { placenta }\end{array}$ \\
\hline $\begin{array}{l}\text { Mikki, } 2007^{115} \\
\text { Good }\end{array}$ & $\begin{array}{l}\text { Amniotomy } \\
\text { shortly } \\
\text { after } \\
\text { admission } \\
\mathrm{N}=74\end{array}$ & $\begin{array}{l}\text { Routine } \\
\text { care/ } \\
\text { amniotomy } \\
\text { if indicated } \\
\mathrm{N}=83\end{array}$ & $\begin{array}{l}231 \text { min } \\
\pm 110\end{array}$ & $\begin{array}{l}291 \text { min } \\
\pm 138\end{array}$ & $<0.001$ & - & - & $\begin{array}{l}\text { Unadjusted OR } \\
0.52(95 \% \mathrm{Cl} 0.12 \\
\text { to } 2.2) ; \mathrm{p}=0.48\end{array}$ & No & $\begin{array}{l}\text { Duration of } \\
\text { labor defined } \\
\text { as time from } \\
\text { randomization } \\
\text { to full dilation }\end{array}$ \\
\hline $\begin{array}{l}\text { Nachum, } \\
2010^{114} \\
\text { Good }\end{array}$ & $\begin{array}{l}\text { Amniotomy } \\
\mathrm{N}=21\end{array}$ & $\begin{array}{l}\text { No } \\
\text { intervention } \\
\mathrm{N}=23\end{array}$ & $\begin{array}{l}629 \min \\
\pm 338\end{array}$ & $\begin{array}{l}740 \min \\
\pm 294\end{array}$ & 0.25 & 2 (9.5\%) & $0(0 \%)$ & 0.22 & - & $\begin{array}{l}\text { Duration of } \\
\text { labor defined } \\
\text { as time from } \\
\text { enrollment until } \\
\text { delivery }\end{array}$ \\
\hline $\begin{array}{l}\text { Ruamsap, } \\
2017^{120} \\
\text { Fair }\end{array}$ & $\begin{array}{l}\text { Early } \\
\text { amniotomy } \\
\mathrm{N}=60\end{array}$ & $\begin{array}{l}\text { Late/ } \\
\text { Selective } \\
\text { amniotomy } \\
\mathrm{N}=60\end{array}$ & $\begin{array}{l}241.5 \text { min } \\
\text { (125 to } 454)\end{array}$ & $\begin{array}{l}244.50 \text { min } \\
\text { (55 to } 768 \text { ) }\end{array}$ & 0.763 & $26(43.3 \%)$ & $12(20 \%)$ & 0.006 & No & $\begin{array}{l}\text { Duration of } \\
\text { labor defined } \\
\text { as time from } \\
\text { enrollment to } \\
\text { delivery }\end{array}$ \\
\hline
\end{tabular}

Abbreviations: aOR=adjusted odds ratio; BMI=body mass index; Com=comparator; $\mathrm{CI}=$ confidence interval; cm=centimeter; hr=hour; Int=intervention; min=minute; $\mathrm{N}=$ number; $\mathrm{OR}=$ odds ratio 


\section{Maternal Outcomes After Amniotomy}

In two good quality RCTs ${ }^{114,115}$ and one fair quality RCT ${ }^{120}$, there was no evidence of increased risk of infection or maternal hemorrhage associated with amniotomy (moderate SOE). In one good quality RCT comparing amniotomy shortly after admission $(\mathrm{N}=74)$ to control treatment $(\mathrm{N}=83)$, there were no cases of maternal fever in the intervention group, and 1 case (1.2\%) of maternal fever in the control group. There was 1 case of postpartum hemorrhage in the intervention group (1.4\%) compared to 2 cases in the comparator group (2.4\%). ${ }^{115}$

In another good quality RCT, comparing amniotomy $(\mathrm{N}=21)$ to unrandomized women whose labor progressed spontaneously without intervention ( $N=23)$, there were 3 cases $(14 \%)$ of intrapartum fever/antibiotic use in the intervention group, as compared with 0 cases $(0 \%)$ in the control group $(p=0.10)$. There were no cases of postpartum hemorrhage in either group. ${ }^{114}$

One fair quality RCT comparing early amniotomy $(\mathrm{N}=60)$ to late amniotomy $(\mathrm{N}=60)$, there were no cases of postpartum infection among the two groups. ${ }^{120}$

Three good-quality studies described trauma to the pelvic floor, as outlined in Table 15. There was no evidence of increased risk of pelvic floor trauma in either group (moderate SOE).

Table 15. Amniotomy versus control in nulliparous women-trauma to the pelvic floor

\begin{tabular}{|c|c|c|c|c|c|c|}
\hline $\begin{array}{l}\text { Study } \\
\text { Quality }\end{array}$ & Intervention & Comparator & $\begin{array}{l}\text { Specific } \\
\text { Outcome }\end{array}$ & $\begin{array}{c}\text { Results } \\
\text { Intervention } \\
(\%)\end{array}$ & $\begin{array}{c}\text { Results } \\
\text { Comparator } \\
(\%)\end{array}$ & P Value \\
\hline $\begin{array}{l}\text { Abdullah, } \\
2010^{118} \\
\text { Fair }\end{array}$ & $\begin{array}{l}\text { Amniotomy } \\
\mathrm{N}=100\end{array}$ & $\begin{array}{l}\text { Amniotomy } \\
\text { for specific } \\
\text { indications } \\
\mathrm{N}=100\end{array}$ & Episiotomy & $53(53 \%)$ & $61(61 \%)$ & 0.25 \\
\hline $\begin{array}{l}\text { Mikki, } \\
2007^{115} \\
\text { Good }\end{array}$ & $\begin{array}{l}\text { Amniotomy } \\
\text { shortly after } \\
\text { admission } \\
\mathrm{N}=74\end{array}$ & $\begin{array}{l}\text { Routine care/ } \\
\text { amniotomy if } \\
\text { indicated } \\
\mathrm{N}=83\end{array}$ & Episiotomy & $54(74.0 \%)$ & $59(72.0 \%)$ & 0.78 \\
\hline $\begin{array}{l}\text { Mikki, } \\
2007^{115} \\
\text { Good }\end{array}$ & $\begin{array}{l}\text { Amniotomy } \\
\text { shortly after } \\
\text { admission } \\
\mathrm{N}=74\end{array}$ & $\begin{array}{l}\text { Routine care/ } \\
\text { amniotomy if } \\
\text { indicated } \\
\mathrm{N}=83\end{array}$ & $\begin{array}{l}\text { Tears (not } \\
\text { further } \\
\text { specified) }\end{array}$ & $11(15.1 \%)$ & $19(22.9 \%)$ & 0.21 \\
\hline $\begin{array}{l}\text { Nachum, } \\
2010^{114} \\
\text { Good }\end{array}$ & $\begin{array}{l}\text { Amniotomy } \\
\mathrm{N}=21\end{array}$ & $\begin{array}{l}\text { No } \\
\text { intervention } \\
\mathrm{N}=23\end{array}$ & $\begin{array}{l}\text { Anal } \\
\text { sphincter tear }\end{array}$ & $0(0 \%)$ & $0(0 \%)$ & NS \\
\hline
\end{tabular}

Abbreviations: NS=not significant

\section{Neonatal Outcomes After Amniotomy}

In one good quality RCT comparing amniotomy shortly after admission ( $\mathrm{N}=74)$ to control treatment $(\mathrm{N}=83),{ }^{115}$ there were no cases of neonatal fever in either group (insufficient SOE). In a fair quality RCT comparing early amniotomy $(\mathrm{N}=60)$ to late amniotomy $(\mathrm{N}=60)$, there were 2 (3.33\%) admission to the ICU for the early amniotomy group and 0 for the late amniotomy group, which was not statistically significant. There were $8(13.33 \%)$ cases of meconium-stained amniotic fluid in the early amniotomy group as compared to $10(16.67 \%)$ in the late amniotomy group, also reported to not be statistically significant. ${ }^{120}$

\section{Process-Related Outcomes After Amniotomy}

In a small good quality RCT, comparing amniotomy $(\mathrm{N}=21)$ to control treatment $(\mathrm{N}=23)$ maternal satisfaction was reported by patients on a scale of 1-5. Women randomized to 
amniotomy reported a lower average maternal satisfaction score $(4.4 \pm 0.9)$, compared to control treatment $(5.0 \pm 0.2)$ (insufficient SOE). ${ }^{114}$

\section{Results in Parous Women for Amniotomy}

Two good-quality RCTs compared amniotomy to control treatment in parous women. ${ }^{114,115}$

\section{Duration of Labor and Cesarean Delivery Rates for Amniotomy}

One study demonstrated a decreased total duration of labor in parous women randomized to amniotomy versus control treatment. A second good quality study did not demonstrate this difference (insufficient SOE). There was no difference in cesarean delivery rates between groups in the second study (insufficient SOE).

The first study was a good quality RCT, comparing amniotomy $(\mathrm{N}=266)$ to control treatment $(\mathrm{N}=267)$ in parous women, there was a significantly decreased total duration of labor in the intervention group (133 \pm 71 minutes) as compared with the comparison group (172 \pm 106 minutes) ( $<<0.001) .{ }^{115}$ Rates of cesarean delivery were not reported for this study.

The second good quality RCT, compared amniotomy $(\mathrm{N}=49)$ to unrandomized women whose labor progressed spontaneously without intervention $(\mathrm{N}=47)$ in parous women, there was no difference in the total duration of labor in the intervention group (352 \pm 320 minutes) as compared with the comparison group (376 \pm 232 minutes; $\mathrm{p}=0.67$ ). The rate of cesarean was similar in both groups in this study. There were no cesarean deliveries in the intervention group, and 1 cesarean delivery in the intervention group (2\%). ${ }^{114}$

\section{Maternal Outcomes After Amniotomy}

In two good quality RCTs, there was no evidence of increased risk of infection, maternal hemorrhage or pelvic floor trauma associated with amniotomy as compared with control treatment in parous women (moderate SOE). ${ }^{114,115}$

In one good quality RCT comparing amniotomy shortly after admission $(\mathrm{N}=266)$ to control treatment $(\mathrm{N}=267)$ in parous women, there was 1 case $(0.4 \%)$ of maternal fever in the intervention group, and 0 cases $(0 \%)$ in the control group. There were 2 cases $(0.7 \%)$ of postpartum hemorrhage in the intervention group and 2 cases $(0.7 \%)$ in the comparison group. In regards to pelvic floor trauma, there were 8 cases of episiotomy $(3.0 \%)$ in the intervention group and 14 cases of comparison group (5.3\%). Lacerations were reported in $29.0 \%$ of women in the intervention group and in $33.7 \%$ of women in the comparison group. ${ }^{115}$

In another good quality RCT, comparing amniotomy $(\mathrm{N}=49)$ to unrandomized women whose labor progressed spontaneously without intervention $(\mathrm{N}=47)$ in parous women, there was 1 case (2\%) of maternal fever/antibiotic use in the intervention group, as compared with 0 cases ( $0 \%)$ in the control group. There were no cases of postpartum hemorrhage in either group. Pelvic floor trauma was reported as rates of anal sphincter tear. There were no cases of anal sphincter tear reported in either group. ${ }^{114}$

\section{Neonatal Outcomes After Amniotomy}

In one good quality RCT comparing amniotomy shortly after admission ( $\mathrm{N}=266)$ to control treatment $(\mathrm{N}=267)$ in parous women, there were no cases of neonatal fever in the intervention group (0\%) and 1 case $(0.4 \%)$ in the comparison group. ${ }^{115}$ 


\section{Process-Related Outcomes After Amniotomy}

In a good quality RCT, comparing amniotomy $(\mathrm{N}=49)$ to control treatment $(\mathrm{N}=47)$ maternal satisfaction was reported by parous women on a scale of 1-5. Parous women randomized to amniotomy reported a similar average score $(4.9 \pm 0.4)$ as compared to control treatment $(5.0 \pm 0.0 ; \mathrm{p}=0.087){ }^{114}$

\section{Results in Women of Mixed or Unspecified Parity for Amniotomy}

Four good-quality RCTs compared amniotomy to control treatment in women of unspecified $^{116}$ or mixed ${ }^{114,119,121}$ parity. In addition, we combined nulliparous and parous results (reported separately, without a combined analysis), where possible, for dichotomous outcomes from a third good-quality trial. ${ }^{115}$

\section{Duration of Labor and Cesarean Delivery Rates for Amniotomy}

One RCT reported outcomes for a group of women of unspecified parity. ${ }^{116}$ Low-risk women who presented in labor were randomized to amniotomy $(n=58)$ versus control treatment $(n=59)$. In this study, control treatment was defined as monitoring with a partogram until delivery, with labor augmentation if progress was not considered satisfactory. Augmentation consisted of the use of intravenous oxytocin infusion in the control group, and amniotomy was considered after 1 hour or more. Mean total duration of labor $( \pm$ SD) was significantly shorter in women randomized to amniotomy (208.27 \pm 22.52 minutes) versus control treatment $(292.07 \pm 23.41$ minutes; $\mathrm{p}<0.05)$. There was also a statistically significant $(\mathrm{p}<0.05)$ decrease in the duration of the first stage of labor (randomization to full cervical dilation) in the intervention group (mean 182.17 \pm SD 19.70 minutes) versus controls (mean 265.02 \pm SD 20.40 minutes). There was no significant difference in the duration of the second stage of labor. There was no significant difference in cesarean delivery rates between the two groups (1.5\% in both).

A second $\mathrm{RCT}^{114}$ examined delivery outcomes in women who were randomized to amniotomy $(n=70)$ as compared to a control group $(n=70)$. In this case, the control group was composed of unrandomized women whose labor progressed spontaneously without intervention. Results were reported for nulliparous and parous women combined and for each of the parity subgroups. For the combined population, there were no significant differences between treatment groups in total duration of labor. Mean total duration of labor ( \pm SD) was $431 \pm 346$ minutes in women randomized to amniotomy. Mean total duration of labor ( \pm SD) was $498 \pm 306$ minutes in women randomized to control $(\mathrm{p}=0.23)$. There was no significant difference in cesarean rate between treatment groups (intervention 2.8\%, control 1.4\%) (low SOE).

Another $\mathrm{RCT}^{119}$ compared delivery outcomes of 214 women randomly assigned to receive early amniotomy $(n=107)$ versus a control group whose membranes were conserved $(n=107)$. Women randomized to receive amniotomy received amniotomy at $4-5 \mathrm{~cm}$ cervical dilation. The total duration of labor was statistically lower for women randomly assigned to receive early amniotomy (279.4 \pm 53.7 minutes) as compared to the control group (354.4 \pm 67.5 minutes). The duration of labor for nulliparous women was also statistically lower for those women assigned to receive early amniotomy was $287.1 \pm 66.54$ minutes compared to $358.6 \pm 60.64$ minutes for women in the control group. The rate of emergency cesarean delivery was not statistically significant among the two group.

The last RCT in this group, ${ }^{121}$ reported the outcomes for women randomly assigned to receive amniotomy $(\mathrm{N}=143)$ compared to conservative management $(\mathrm{N}=144)$, in which patients did not receive amniotomy unless medically indicated. The median duration of labor was reported to be statistically shorter for women who were randomized to receive amniotomy (235 
with interquartile range 117-355) compared to conservative management (364 with interquartile range 201-580). The cesarean delivery rate among the two group was not statistically significant.

\section{Maternal Outcomes After Amniotomy}

In two good quality RCTs, there was no significant increased risk of infection, maternal hemorrhage, or pelvic floor trauma associated with amniotomy as compared with control treatment in a mixed group (parous and nulliparous) of women. ${ }^{114,115}$ SOE was moderate for all three outcomes.

In one good quality RCT comparing amniotomy shortly after admission $(\mathrm{N}=340)$ to control treatment $(\mathrm{N}=350)$ in nulliparous and parous women, there was 1 case $(0.3 \%)$ of maternal fever in the intervention group, and 1 case $(0.3 \%)$ in the control group. There were 3 cases $(0.9 \%)$ of postpartum hemorrhage in the intervention group and 4 cases (1.1\%) in the comparison group. In regards to pelvic floor trauma, there were 62 cases of episiotomy (18.2\%) in the intervention group and 72 cases (20.9\%) in the comparison group. Lacerations were reported in $25.9 \%$ of women in the intervention group and in $31.1 \%$ of women in the comparison group. ${ }^{115}$

In another good quality RCT, comparing amniotomy $(\mathrm{N}=70)$ to unrandomized women whose labor progressed spontaneously without intervention $(\mathrm{N}=70)$ in nulliparous and parous women, there were 3 cases (4\%) of intrapartum fever and 1 case (1\%) of postpartum fever in the intervention group, as compared with 0 cases of intrapartum or postpartum fever in the control group. There were no cases of postpartum hemorrhage in either group. Pelvic floor trauma was reported as rates of anal sphincter tear. There were no cases of anal sphincter tear reported in either group. ${ }^{114}$

One good quality RCT that compared amniotomy to conservative management recorded one case of cord prolapse $(0.7 \%)$ in the amniotomy group and zero in the conservative management group. Although not statistically significant, the trial showed an increase number of postpartum hemorrhage, 8 (5.6\%), for women in the conservative management group opposed to women who received amniotomy, 4 (2.8\%). The occurrence of postpartum fever for women in the conservative management, reported as 7 (4.9\%), group was statistically higher than that of women who received amniotomy, which was $1(0.7 \%) .{ }^{121}$

\section{Neonatal Outcomes After Amniotomy}

In one good quality RCT comparing amniotomy shortly after admission $(\mathrm{N}=340)$ to control treatment $(\mathrm{N}=350)$ in the composite results of nulliparous and parous women, there were no cases of neonatal fever in the intervention group ( $0 \%)$ and 1 case $(0.3 \%)$ in the comparison group (low SOE). ${ }^{115}$ One study that compared receiving early amniotomy ( $\left.\mathrm{N}=107\right)$ to allowing membranes to remain intact $(\mathrm{N}=107)$ found no statistical difference for Newborn Special Care Unit admission across the two groups. In addition, the trial found no statistically significant difference between birth weight for the amniotomy group ( $3.2 \pm 0.493 \mathrm{~kg})$ and the control group $(3.1 \pm 0.418 \mathrm{~kg}){ }^{119}$

\section{Process-Related Outcomes After Amniotomy}

In a good quality RCT, comparing amniotomy $(\mathrm{N}=70)$ to control treatment $(\mathrm{N}=70)$, maternal satisfaction was reported by a mixed population (parous and nulliparous) women on a scale of 15. Women randomized to amniotomy reported a similar average maternal satisfaction score (4.7 $\pm 0.6)$ as compared to control treatment $(5.0 \pm 0.1) .{ }^{114}$ 


\section{Relevant Systematic Reviews/Meta-Analyses for Amniotomy}

A single Cochrane good-quality review ${ }^{123}$ compared amniotomy alone to control treatment to shorten the duration of labor. The objective of this review was to determine the effectiveness and safety of amniotomy alone for routinely shortening all spontaneous labor. The study included singleton pregnancies regardless of parity or gestation at trial entry in spontaneous labor. This meta-analysis included RCTs comparing amniotomy alone versus intention to preserve the membranes. This review included 15 studies, randomizing a total of 5583 women. One of these 15 studies was also included in our review. ${ }^{116}$ The remaining 14 included studies were excluded because of date of publication (prior to January 1, 2005). There was no evidence that amniotomy shortened the duration of labor. There was no reduction in the duration of the first stage of labor (MD -20.43 minutes; 95\% CI, -95.93 to 55.06) or increased the risk of cesarean delivery (RR 1.27; $95 \%$ CI, 0.99 to 1.63). These findings were also seen in subgroups of nulliparous women only or parous women only. There were no statistically significant differences in risk for other maternal or neonatal adverse outcomes.

\section{Strength of Evidence for Amniotomy}

Tables 16-18 summarize the SOE for the comparison of amniotomy versus control treatment.

Table 16. Early amniotomy versus control: Evidence profile in nulliparous women

\begin{tabular}{|c|c|c|c|c|}
\hline Category & Outcome & $\begin{array}{l}\text { Study Design } \\
\text { (Sample Size) }\end{array}$ & Conclusion & $\begin{array}{c}\text { SOE } \\
\text { (Rationale) }^{a}\end{array}$ \\
\hline \multirow[t]{2}{*}{$\begin{array}{l}\text { Intermediate } \\
\text { or Final } \\
\text { Outcomes }\end{array}$} & $\begin{array}{l}\text { Process Related } \\
\text { Outcomes - } \\
\text { Duration of Total } \\
\text { Labor }\end{array}$ & $\begin{array}{l}\text { 5 RCTs } \text { R }^{113-} \\
115,118,120 \\
(1,593) \\
1 \text { SR }(379 \\
\text { patients, } 4 \\
\text { studies) }\end{array}$ & $\begin{array}{l}\text { Improvement with early } \\
\text { amniotomy: All trials } \\
\text { demonstrated a decrease in the } \\
\text { duration of labor in women } \\
\text { randomized to early amniotomy. }\end{array}$ & $\begin{array}{l}\text { Moderate } \\
\text { (Medium risk of bias, } \\
\text { Inconsistent, Indirect) } \\
\text { SOE was reduced } \\
\text { given inconsistency } \\
\text { with existing SR which } \\
\text { found no difference in } \\
\text { less contemporary } \\
\text { RCTs }\end{array}$ \\
\hline & $\begin{array}{l}\text { Process Related } \\
\text { Outcomes - Mode } \\
\text { of Delivery } \\
\text { (Cesarean } \\
\text { Delivery) }\end{array}$ & $\begin{array}{l}\text { 5 RCTs's } 113- \\
115,118,120 \\
(1,593) \\
1 \text { SR }(2,674 \\
\text { patients, } 6 \\
\text { studies })^{123} \\
\end{array}$ & $\begin{array}{l}\text { Inconclusive: SOE was } \\
\text { insufficient given inconsistent } \\
\text { and imprecise findings from } \\
\text { studies of varying quality. }\end{array}$ & $\begin{array}{l}\text { Insufficient (Medium } \\
\text { risk of bias, Indirect, } \\
\text { inconsistent, imprecise) } \\
\text { Existing SR did not } \\
\text { resolve inconsistency in } \\
\text { findings }\end{array}$ \\
\hline \multirow[t]{4}{*}{$\begin{array}{l}\text { Adverse } \\
\text { Events }\end{array}$} & $\begin{array}{l}\text { Maternal } \\
\text { Outcomes - } \\
\text { Infection }\end{array}$ & $\begin{array}{l}3 \\
\text { RCTs } 114,115,120 \\
(1,593)\end{array}$ & $\begin{array}{l}\text { No difference: Two good } \\
\text { quality RCTs and one fair- } \\
\text { quality RCT support no } \\
\text { increased risk of infection }\end{array}$ & Moderate (imprecise) \\
\hline & $\begin{array}{l}\text { Maternal } \\
\text { Outcomes - } \\
\text { Trauma to pelvic } \\
\text { floor } \\
\end{array}$ & $\begin{array}{l}3 \\
\text { RCTs } 114,115,118 \\
(437)\end{array}$ & $\begin{array}{l}\text { No difference: Three good } \\
\text { quality RCTs support no } \\
\text { evidence of increased risk of } \\
\text { pelvic floor trauma }\end{array}$ & Moderate (imprecise) \\
\hline & $\begin{array}{l}\text { Neonatal } \\
\text { Outcomes - } \\
\text { Infection }\end{array}$ & $\begin{array}{l}\text { 1 RCT }^{115} \\
\text { (157) }\end{array}$ & $\begin{array}{l}\text { Inconclusive: SOE was } \\
\text { insufficient given imprecise } \\
\text { findings from } 1 \text { small study }\end{array}$ & $\begin{array}{l}\text { Insufficient } \\
\text { (Imprecise, } 1 \text { small } \\
\text { study) }\end{array}$ \\
\hline & $\begin{array}{l}\text { Neonatal } \\
\text { Outcomes - NICU } \\
\text { admissions }\end{array}$ & $\begin{array}{l}1 \mathrm{RCT}^{120} \\
(120)\end{array}$ & $\begin{array}{l}\text { Inconclusive: SOE was } \\
\text { insufficient given imprecise } \\
\text { findings from } 1 \text { small study }\end{array}$ & $\begin{array}{l}\text { Insufficient } \\
\text { (Imprecise, } 1 \text { small } \\
\text { study) }\end{array}$ \\
\hline
\end{tabular}




\begin{tabular}{|c|c|c|c|c|}
\hline Category & Outcome & $\begin{array}{l}\text { Study Design } \\
\text { (Sample Size) }\end{array}$ & Conclusion & $\begin{array}{c}\text { SOE } \\
\text { (Rationale) }^{a}\end{array}$ \\
\hline & $\begin{array}{l}\text { Neonatal } \\
\text { Outcomes - } \\
\text { Meconium-stained } \\
\text { fluid }\end{array}$ & $\begin{array}{l}1 \mathrm{RCT}^{120} \\
(120)\end{array}$ & $\begin{array}{l}\text { Inconclusive: SOE was } \\
\text { insufficient given imprecise } \\
\text { findings from } 1 \text { small study }\end{array}$ & $\begin{array}{l}\text { Insufficient } \\
\text { (Imprecise, } 1 \text { small } \\
\text { study) }\end{array}$ \\
\hline & $\begin{array}{l}\text { Process Related } \\
\text { Outcomes - } \\
\text { Parental } \\
\text { Satisfaction }\end{array}$ & $\begin{array}{l}1 \mathrm{RCT}^{114} \\
(44)\end{array}$ & $\begin{array}{l}\text { Inconclusive: SOE was } \\
\text { insufficient given imprecise } \\
\text { findings from } 1 \text { small study }\end{array}$ & $\begin{array}{l}\text { Insufficient } \\
\text { (Imprecise, } 1 \text { small } \\
\text { study) }\end{array}$ \\
\hline
\end{tabular}

${ }^{a}$ Criteria for downgrading SOE are described as Rationale; when these criteria are insufficient for understanding the final SOE, additional explanation is provided.

Abbreviations: RCT=randomized controlled trial; SOE=strength of evidence; SR=systematic review

Table 17. Early amniotomy versus control: Evidence profile in women with unspecified parity

\begin{tabular}{|c|c|c|c|c|}
\hline Category & Outcome & $\begin{array}{l}\text { Study Design } \\
\text { (Sample Size) }\end{array}$ & Conclusion & $\begin{array}{c}\text { SOE } \\
\text { (Rationale) }^{\mathrm{a}} \\
\end{array}$ \\
\hline \multirow[t]{2}{*}{$\begin{array}{l}\text { Intermediate } \\
\text { or Final } \\
\text { Outcomes }\end{array}$} & $\begin{array}{l}\text { Process Related } \\
\text { Outcomes - } \\
\text { Duration of Total } \\
\text { Labor }\end{array}$ & $\begin{array}{l}4 \\
\mathrm{RCTS} \\
21 \\
(912)\end{array}$ & $\begin{array}{l}\text { Improvement with early } \\
\text { amniotomy: Three studies } \\
\text { suggest shorter duration of total } \\
\text { labor with early amniotomy. } \\
\text { One study from the middle east } \\
\text { did not find a difference. }\end{array}$ & $\begin{array}{l}\text { Low (Indirect, } \\
\text { inconsistent) }\end{array}$ \\
\hline & $\begin{array}{l}\text { Process Related } \\
\text { Outcomes - Mode } \\
\text { of Delivery } \\
\text { (Cesarean } \\
\text { Delivery) }\end{array}$ & 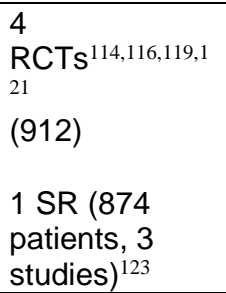 & $\begin{array}{l}\text { No difference: There was no } \\
\text { difference in the rate of } \\
\text { cesarean delivery between } \\
\text { women randomized to early } \\
\text { amniotomy versus control. }\end{array}$ & $\begin{array}{l}\text { Moderate } \\
\text { (Indirect, consistent) } \\
\text { Existing SR was } \\
\text { consistent with RCT } \\
\text { findings }\end{array}$ \\
\hline \multirow[t]{6}{*}{$\begin{array}{l}\text { Adverse } \\
\text { Events }\end{array}$} & $\begin{array}{l}\text { Maternal } \\
\text { Outcomes - } \\
\text { Infection }\end{array}$ & $\begin{array}{l}2 \mathrm{RCTs}^{114,115} \\
(973)\end{array}$ & $\begin{array}{l}\text { No difference: There was no } \\
\text { evidence of increased risk of } \\
\text { infection associated with early } \\
\text { amniotomy versus control. }\end{array}$ & Moderate (Imprecise) \\
\hline & $\begin{array}{l}\text { Maternal } \\
\text { Outcomes - } \\
\text { Hemorrhage }\end{array}$ & $\begin{array}{l}2 \mathrm{RCTs}^{114,115} \\
(973)\end{array}$ & $\begin{array}{l}\text { No difference: There was no } \\
\text { evidence of increased risk of } \\
\text { maternal hemorrhage } \\
\text { associated with early } \\
\text { amniotomy. }\end{array}$ & Moderate (Imprecise) \\
\hline & $\begin{array}{l}\text { Maternal } \\
\text { Outcomes - } \\
\text { Trauma to Pelvic } \\
\text { Floor }\end{array}$ & $\begin{array}{l}3 \\
\text { RCTs } 114,115,118 \\
(683)\end{array}$ & $\begin{array}{l}\text { No difference: There was no } \\
\text { evidence of increased risk of } \\
\text { trauma to the pelvic floor } \\
\text { associated with early } \\
\text { amniotomy. }\end{array}$ & $\begin{array}{l}\text { Moderate } \\
\text { (Medium risk of bias) }\end{array}$ \\
\hline & $\begin{array}{l}\text { Neonatal } \\
\text { Outcomes - } \\
\text { Infection }\end{array}$ & $\begin{array}{l}1 \mathrm{RCT}^{115} \\
(690)\end{array}$ & $\begin{array}{l}\text { No difference: There was no } \\
\text { evidence of increased risk of } \\
\text { neonatal infection associated } \\
\text { with early amniotomy. }\end{array}$ & $\begin{array}{l}\text { Low } \\
\text { (1 study) }\end{array}$ \\
\hline & $\begin{array}{l}\text { Process Related } \\
\text { Outcomes - Mode } \\
\text { of Delivery } \\
\text { (Operative } \\
\text { Vaginal Delivery) } \\
\end{array}$ & $\begin{array}{l}3 \\
\text { RCTs } 114,116,118 \\
(611)\end{array}$ & $\begin{array}{l}\text { No difference: There was no } \\
\text { evidence of increased risk of } \\
\text { operative vaginal delivery } \\
\text { associated with early } \\
\text { amniotomy. }\end{array}$ & $\begin{array}{l}\text { Low } \\
\text { (Indirect, imprecise) }\end{array}$ \\
\hline & $\begin{array}{l}\text { Process Related } \\
\text { Outcomes - } \\
\text { Parental } \\
\text { Satisfaction }\end{array}$ & $\begin{array}{l}1 \mathrm{RCT}^{114} \\
(273)\end{array}$ & $\begin{array}{l}\text { Inconclusive: SOE was } \\
\text { insufficient given imprecise } \\
\text { findings from } 1 \text { small study }\end{array}$ & $\begin{array}{l}\text { Insufficient } \\
\text { (Imprecise, } 1 \text { small } \\
\text { study) }\end{array}$ \\
\hline
\end{tabular}

${ }^{a}$ Criteria for downgrading SOE are described as Rationale; when these criteria are insufficient for understanding the final SOE, additional explanation is provided.

Abbreviations: RCT=randomized controlled trial; SOE=strength of evidence; SR=systematic review 
Table 18. Early amniotomy versus control: Evidence profile in parous women

\begin{tabular}{|c|c|c|c|c|}
\hline Category & Outcome & $\begin{array}{l}\text { Study Design } \\
\text { (Sample Size) }\end{array}$ & Conclusion & $\begin{array}{c}\text { SOE } \\
\text { (Rationale) }^{\mathrm{a}} \\
\end{array}$ \\
\hline \multirow[t]{3}{*}{$\begin{array}{l}\text { Intermediate } \\
\text { or Final } \\
\text { Outcomes }\end{array}$} & $\begin{array}{l}\text { Process Related } \\
\text { Outcomes - } \\
\text { Duration of Total } \\
\text { Labor }\end{array}$ & $\begin{array}{l}2 \text { RCTs } 114,115 \\
(973) \\
1 \text { SR (386 } \\
\text { patients, } 3 \\
\text { studies) }^{123}\end{array}$ & $\begin{array}{l}\text { Inconclusive: SOE was } \\
\text { insufficient given conflicting } \\
\text { evidence from available studies. }\end{array}$ & $\begin{array}{l}\text { Insufficient (Indirect, } \\
\text { inconsistent, imprecise) } \\
\text { Existing SR did not } \\
\text { resolve inconsistency }\end{array}$ \\
\hline & $\begin{array}{l}\text { Process Related } \\
\text { Outcomes - Mode } \\
\text { of Delivery } \\
\text { (Cesarean } \\
\text { Delivery) }\end{array}$ & $\begin{array}{l}1 \mathrm{RCT}^{114} \\
(533) \\
1 \text { SR }(1,473 \\
\text { patients, } 2 \\
\text { studies) }\end{array}$ & $\begin{array}{l}\text { Inconclusive: SOE was } \\
\text { insufficient given imprecise } \\
\text { findings from } 1 \text { study. }\end{array}$ & $\begin{array}{l}\text { Insufficient } \\
\text { (Indirect, imprecise) } \\
\text { Existing SR did not } \\
\text { resolve inconsistency }\end{array}$ \\
\hline & $\begin{array}{l}\text { Process Related } \\
\text { Outcomes - } \\
\text { Parental } \\
\text { Satisfaction }\end{array}$ & $\begin{array}{l}1 \mathrm{RCT}^{114} \\
(273)\end{array}$ & $\begin{array}{l}\text { Inconclusive: SOE was } \\
\text { insufficient given imprecise } \\
\text { findings from } 1 \text { small study }\end{array}$ & $\begin{array}{l}\text { Insufficient } \\
\text { (Imprecise, } 1 \text { small } \\
\text { study) }\end{array}$ \\
\hline
\end{tabular}

${ }^{a}$ Criteria for downgrading SOE are described as Rationale; when these criteria are insufficient for understanding the final SOE, additional explanation is provided.

Abbreviations: RCT=randomized controlled trial; SOE=strength of evidence; SR=systematic review

\section{Amniotomy Plus Oxytocin Versus Control Treatment}

Labor management with amniotomy is often combined with latent use of oxytocin in labor protocols. Two RCTs examined amniotomy plus oxytocin in this context. One of the two studies reported results for nulliparous and parous women combined and for each of the parity subgroups. ${ }^{114}$ The other reported results only for nulliparous women. ${ }^{117}$

A good quality $\mathrm{RCT}^{114}$ examined delivery outcomes in women who were randomized to amniotomy $(n=16)$ as compared to a control group $(n=20)$. In this case, the control group was composed of (unrandomized) women whose labor progressed spontaneously without intervention.

A second $\mathrm{RCT}^{117}$ compared an active management of labor protocol to control treatment for nulliparous women in spontaneous labor in a low resource setting. Active management was defined as amniotomy within 1 hour of admission, frequent vaginal exams, and routine administration of high dose oxytocin if cervical dilation fell below a rate of $1 \mathrm{~cm} /$ hour. Control treatment was conventional care at the discretion of the provider. Of note, while patients in the intervention group received oxytocin more frequently than those in the comparison group $(\mathrm{p}<0.05), 47 \%$ of patients in the comparison group received oxytocin.

Two relevant good-quality SRs were identified. ${ }^{35,122}$ Wei et al. ${ }^{122}$ performed a meta-analysis to estimate the effects of amniotomy plus oxytocin for prevention of, or therapy for, delay in labor progress on the cesarean delivery rate and on indicators of maternal and neonatal morbidity. The SR/MA included 14 trials, randomizing a total of 8033 women. Two of these 14 studies are also included in our review. ${ }^{114,117}$ The remaining 12 studies were excluded from our included studies because of date of publication (prior to January 1, 2005). Given the overlap of our two included studies with the SR, and given the high-quality of SR/MA from a trusted source (Cochrane) we considered the findings of this entire SR/MA in the rating of the SOE. The results of SR/MA by Brown et al is summarized in detail in KQ $1 .^{35}$ 


\section{Results in Nulliparous Women for Amniotomy Plus Oxytocin}

\section{Duration of Labor and Cesarean Delivery Rates for Amniotomy Plus Oxytocin}

In two good-quality RCTs of nulliparous women, the first stage and total duration of labor was shortened in women randomized to amniotomy plus oxytocin as compared to control treatment. ${ }^{14,117}$ These findings were also supported by a good-quality SR discussed below and the combined evidence resulted in a high SOE.

\section{Maternal Outcomes After Amniotomy Plus Oxytocin}

Two good quality RCTs reported maternal outcomes including infection, hemorrhage and pelvic floor trauma and identified no increased risk of maternal adverse outcomes in nulliparous women randomized to amniotomy with oxytocin as compared to control treatment. In nulliparous women, amniotomy and oxytocin does not significantly increase the risk of adverse maternal outcomes as compared with control treatment.

In a good quality RCT, comparing amniotomy $(\mathrm{N}=16)$ to unrandomized women whose labor progressed spontaneously without intervention $(\mathrm{N}=23)$ in nulliparous women, there were no cases of intrapartum, postpartum fever, antibiotic use, postpartum hemorrhage or anal sphincter tear in either group. ${ }^{114}$

Another good quality RCT compared amniotomy and oxytocin protocol $(\mathrm{n}=320)$ to control treatment $(\mathrm{n}=640)$ for nulliparous women in spontaneous labor in a low resource setting. There were 26 cases (8.1\%) of maternal fever in the intervention group, and 53 cases (8.3\%) in the comparison group. There were no cases of postpartum hemorrhage in either group. ${ }^{117}$

\section{Neonatal Outcomes After Amniotomy Plus Oxytocin}

There was very little information on neonatal adverse outcomes in this subgroup. A good quality RCT, comparing amniotomy and oxytocin protocol $(n=320)$ to control treatment $(n=640)$ for nulliparous women in spontaneous labor in a low resource setting, reported no cases of chorioamnionitis in the intervention group, and 6 cases (0.9\%) in the comparison group. The difference was not statistically significant. ${ }^{117}$

\section{Process-Related Outcomes After Amniotomy Plus Oxytocin}

In a good quality RCT, comparing amniotomy $(\mathrm{N}=16)$ to control treatment $(\mathrm{N}=23)$, maternal satisfaction was reported by parous women on a scale of 1-5. Parous women randomized to amniotomy reported a similar average score $(4.8 \pm 0.5)$ as compared to control treatment (5.0 \pm $0.2 ; \mathrm{p}=0.15) .{ }^{114}$

\section{Results in Parous Women for Amniotomy Plus Oxytocin}

\section{Duration of Labor and Cesarean Delivery Rates for Amniotomy Plus Oxytocin}

One good-quality RCT ${ }^{114}$ examined amniotomy and oxytocin $(n=55)$ versus control treatment $(\mathrm{N}=47)$ in parous women. There was a statistically significant decrease in the total duration of labor in the intervention group $(279 \pm 201$ minutes) compared with the control group (376 \pm 232 minutes; $\mathrm{p}=0.03$ ). There was no significant difference in cesarean delivery rates. The cesarean rate in the intervention group was $0.02 \%$ and $0.04 \%$ in the comparison group. 


\section{Maternal Outcomes After Amniotomy Plus Oxytocin}

One good-quality RCT ${ }^{114}$ examined amniotomy and oxytocin $(n=55)$ versus control treatment $(\mathrm{N}=47)$ in parous women. There were no cases of intrapartum fever, postpartum fever or antibiotic use in either group. There were 3 cases $(6 \%)$ of postpartum hemorrhage in the intervention group, there were no cases in the comparison group $(\mathrm{p}=0.25)$. There were no cases of anal sphincter tear in either group.

\section{Neonatal Outcomes After Amniotomy Plus Oxytocin}

No data was available on neonatal adverse outcomes for parous women in spontaneous labor randomized to amniotomy and oxytocin as compared with control treatment.

\section{Process-Related Outcomes After Amniotomy Plus Oxytocin}

In a good quality RCT, comparing amniotomy $(\mathrm{N}=55)$ to control treatment $(\mathrm{N}=47)$, maternal satisfaction was reported by parous women on a scale of 1-5. Parous women randomized to amniotomy reported a similar average score $(4.9 \pm 0.5)$ as compared to control treatment (5.0 \pm $0.0 ; \mathrm{p}=0.14) .{ }^{114}$

\section{Results in Women of Mixed or Unspecified Parity for Amniotomy Plus Oxytocin}

A single study reported results for amniotomy plus oxytocin versus control treatment in women of mixed parity. ${ }^{114}$

\section{Duration of Labor and Cesarean Delivery Rates for Amniotomy Plus Oxytocin}

In one good-quality RCT examining women of mixed parity, ${ }^{114}$ there was a statistically significant difference in the total duration of labor for women randomized to amniotomy plus oxytocin ( $\mathrm{n}=71 ; 312+/-245$ minute) as compared with control treatment ( $\mathrm{n}=70 ; 498+/-306$ minutes; $\mathrm{p}<0.001)$. There was no difference in cesarean delivery rates between the two treatment groups (1\% in both groups). ${ }^{114}$

\section{Maternal Outcomes After Amniotomy Plus Oxytocin}

One good-quality RCT examined the risks of adverse maternal outcomes in women of mixed parity randomized to amniotomy plus oxytocin $(\mathrm{N}=71)$ compared to control $(\mathrm{N}=70)$. There was no increased risk of adverse maternal outcomes in either group. There were no cases of intrapartum fever, postpartum fever, or antibiotic use in this subgroup. There were 3 cases of postpartum hemorrhage (4\%) in the intervention group as compared to 0 cases in the comparison group. This difference was not statistically significant. There were no cases of anal sphincter injury in either group. ${ }^{114}$

\section{Neonatal Outcomes After Amniotomy Plus Oxytocin}

No data were available on neonatal adverse outcomes for women of mixed parity in spontaneous labor randomized to amniotomy and oxytocin as compared with control treatment.

\section{Process-Related Outcomes After Amniotomy Plus Oxytocin}

In a good quality RCT, comparing amniotomy $(\mathrm{N}=71)$ to control treatment $(\mathrm{N}=70)$, maternal satisfaction was reported by parous women on a scale of 1-5. Parous women randomized to amniotomy reported a similar average score $(4.9 \pm 0.5)$ as compared to control treatment (5.0 \pm $0.1 ; \mathrm{p}=.10)^{114}$ 


\section{Relevant Systematic Reviews/Meta-Analyses for Amniotomy Plus Oxytocin}

Wei et al. ${ }^{122}$ performed a meta-analysis to estimate the effects of amniotomy plus oxytocin for prevention of, or therapy for, delay in labor progress on the cesarean delivery rate and on indicators of maternal and neonatal morbidity. The SR/MA included 14 trials, randomizing a total of 8033 women. Two of these 14 studies represent the two included studies in our review. ${ }^{114,117}$ The remaining 12 included studies were excluded from our report because of date of publication (prior to January 1, 2005). Again, given the quality of the SR/MA and alignment with our interventions of interest, we incorporated the findings in to our SOE ratings. Studies included unselected pregnant women in spontaneous labor and pregnant women in spontaneous labor with a delay in the first stage of labor. The length of first stage of labor was shortened in the amniotomy plus oxytocin group compared with the expectant management group (mean difference [MD] -1.57 hours; 95\% CI, -2.14 to -1.01). Amniotomy plus oxytocin was also associated with a reduction in the total duration of labor (MD -1.28 hours; 95\% CI, -1.97 to 0.59). The cesarean delivery rate was reduced in 11 trials looking at prevention of dystocia (11 trials, 7653 women, average RR 0.87; 95\% CI, 0.77 to 0.99). In women who were randomized to amniotomy plus oxytocin, the time from admission to giving birth was reduced (MD 1.3 hours; 95\% CI, -1.97 to -0.59$)$.

\section{Strength of Evidence for Amniotomy Plus Oxytocin}

Tables 19-21 summarize the SOE for the comparison of amniotomy plus oxytocin versus control treatment. In general, the SOE was judged as moderate or high based on existing SR/MAs.

Table 19. Amniotomy plus oxytocin versus control: Evidence profile in nulliparous women

\begin{tabular}{|c|c|c|c|c|}
\hline Category & Outcome & $\begin{array}{l}\text { Study Design } \\
\text { (Sample Size) }\end{array}$ & Conclusion & $\begin{array}{c}\text { SOE } \\
\text { (Rationale) }^{\mathrm{a}}\end{array}$ \\
\hline \multirow[t]{4}{*}{$\begin{array}{l}\text { Intermediate } \\
\text { or Final } \\
\text { Outcomes }\end{array}$} & $\begin{array}{l}\text { Process Related } \\
\text { Outcomes }- \\
\text { Duration of } 1^{\text {st }} \\
\text { Stage Labor }\end{array}$ & $\begin{array}{l}2 \mathrm{SRs}^{35,122} \\
(2,431 \\
\text { patients, } 4 \\
\text { studies) }\end{array}$ & $\begin{array}{l}\text { Improvement with amniotomy } \\
\text { plus oxytocin: Amniotomy plus } \\
\text { oxytocin decreased the duration } \\
\text { of the first stage of labor. }\end{array}$ & High \\
\hline & $\begin{array}{l}\text { Process Related } \\
\text { Outcomes - } \\
\text { Duration of } 2^{\text {nd }} \\
\text { Stage Labor }\end{array}$ & $\begin{array}{l}1 \mathrm{SR}^{35} \\
(2,737 \\
\text { patients, } 5 \\
\text { studies) }\end{array}$ & $\begin{array}{l}\text { No difference: There was no } \\
\text { difference in the duration of } \\
\text { second stage of labor between } \\
\text { groups. }\end{array}$ & Moderate (Imprecise) \\
\hline & $\begin{array}{l}\text { Process Related } \\
\text { Outcomes - } \\
\text { Duration of Total } \\
\text { Labor }\end{array}$ & $\begin{array}{l}2 \mathrm{SRS}^{35,122} \\
(4,675 \\
\text { patients, } 7 \\
\text { studies) }\end{array}$ & $\begin{array}{l}\text { Improvement with amniotomy } \\
\text { plus oxytocin: The duration of } \\
\text { labor was shortened in women } \\
\text { randomized to amniotomy plus } \\
\text { oxytocin as compared to routine } \\
\text { care. }\end{array}$ & High \\
\hline & $\begin{array}{l}\text { Process Related } \\
\text { Outcomes - Mode } \\
\text { of Delivery } \\
\text { (Cesarean } \\
\text { Delivery) }\end{array}$ & $\begin{array}{l}2 \mathrm{SRs}^{35,122} \\
(7,653 \\
\text { patients, } 11 \\
\text { studies) }\end{array}$ & $\begin{array}{l}\text { No difference: There was no } \\
\text { difference in cesarean delivery } \\
\text { rates between amniotomy plus } \\
\text { oxytocin compared with control. }\end{array}$ & High \\
\hline
\end{tabular}

${ }^{a}$ Criteria for downgrading SOE are described as Rationale; when these criteria are insufficient for understanding the final SOE, additional explanation is provided.

Abbreviations: $\mathrm{SOE}=$ strength of evidence; $\mathrm{SR}=$ systematic review 
Table 20. Amniotomy plus oxytocin versus control: Evidence profile in women with unspecified parity

\begin{tabular}{|c|c|c|c|c|}
\hline Category & Outcome & $\begin{array}{l}\text { Study Design } \\
\text { (Sample Size) }\end{array}$ & Conclusion & $\begin{array}{c}\text { SOE } \\
\text { (Rationale) }^{a}\end{array}$ \\
\hline \multirow[t]{4}{*}{$\begin{array}{l}\text { Intermediate } \\
\text { or Final } \\
\text { Outcomes }\end{array}$} & $\begin{array}{l}\text { Process Related } \\
\text { Outcomes }- \\
\text { Duration of } 1^{\text {st }} \\
\text { Stage Labor }\end{array}$ & $\begin{array}{l}2 \text { SRs }^{35,122} \\
(2,431 \\
\text { patients, } 4 \\
\text { studies) }\end{array}$ & $\begin{array}{l}\text { Improvement with amniotomy } \\
\text { plus oxytocin: Amniotomy plus } \\
\text { oxytocin decreased the duration } \\
\text { of the first stage of labor. }\end{array}$ & High \\
\hline & $\begin{array}{l}\text { Process Related } \\
\text { Outcomes - } \\
\text { Duration of } 2^{\text {nd }} \\
\text { Stage Labor }\end{array}$ & $\begin{array}{l}1 \mathrm{SR}^{35} \\
(2,737 \\
\text { patients, } 5 \\
\text { studies) }\end{array}$ & $\begin{array}{l}\text { No difference: There was no } \\
\text { difference in the duration of the } \\
\text { second stage of labor in the } \\
\text { amniotomy plus oxytocin group } \\
\text { as compared with control. }\end{array}$ & Moderate (Imprecise) \\
\hline & $\begin{array}{l}\text { Process Related } \\
\text { Outcomes - } \\
\text { Duration of Total } \\
\text { Labor }\end{array}$ & $\begin{array}{l}2 \mathrm{SRs}^{35,122} \\
(4,675 \\
\text { patients, } 7 \\
\text { studies) }\end{array}$ & $\begin{array}{l}\text { Improvement with amniotomy } \\
\text { plus oxytocin: Amniotomy plus } \\
\text { oxytocin decreased the total } \\
\text { duration of labor. }\end{array}$ & High \\
\hline & $\begin{array}{l}\text { Process Related } \\
\text { Outcomes - Mode } \\
\text { of Delivery } \\
\text { (Cesarean } \\
\text { Delivery) }\end{array}$ & $\begin{array}{l}2 \text { SRs }^{35,122} \\
\text { (7,653 } \\
\text { patients, } 11 \\
\text { studies) }\end{array}$ & $\begin{array}{l}\text { No difference: There was no } \\
\text { difference in cesarean delivery } \\
\text { rates between amniotomy plus } \\
\text { oxytocin compared with control. }\end{array}$ & High \\
\hline \multirow[t]{5}{*}{$\begin{array}{l}\text { Adverse } \\
\text { Events }\end{array}$} & $\begin{array}{l}\text { Maternal } \\
\text { Outcomes - } \\
\text { Infection }\end{array}$ & $\begin{array}{l}3 \mathrm{RCTs}^{115} \\
(1,933) \\
2 \mathrm{SRs}^{35,122,123} \\
(3,475 \\
\text { patients, } 6 \\
\text { studies) }\end{array}$ & $\begin{array}{l}\text { No difference: There was no } \\
\text { difference in risk of infection } \\
\text { between groups. }\end{array}$ & $\begin{array}{l}\text { High } \\
\text { Findings from existing } \\
\text { SR consistent with RCT } \\
\text { evidence }\end{array}$ \\
\hline & $\begin{array}{l}\text { Maternal } \\
\text { Outcomes - } \\
\text { Hemorrhage }\end{array}$ & $\begin{array}{l}2 \text { SRs }^{35,122,123} \\
(2,674 \\
\text { patients, } 4 \\
\text { studies) }\end{array}$ & $\begin{array}{l}\text { No difference: No difference in } \\
\text { risk of hemorrhage between } \\
\text { groups. }\end{array}$ & High \\
\hline & $\begin{array}{l}\text { Maternal } \\
\text { Outcomes - } \\
\text { Trauma to the } \\
\text { Pelvic Floor }\end{array}$ & $\begin{array}{l}1 \mathrm{RCT}^{114} \\
(283)\end{array}$ & $\begin{array}{l}\text { No difference: One RCT } \\
\text { examined active management } \\
\text { of labor with early amniotomy } \\
\text { and oxytocin as compared with } \\
\text { routine care, there was no } \\
\text { difference in risk of trauma to } \\
\text { the pelvic floor between groups. }\end{array}$ & $\begin{array}{l}\text { Low } \\
\text { (1 study) }\end{array}$ \\
\hline & $\begin{array}{l}\text { Process Related } \\
\text { Outcomes - Mode } \\
\text { of Delivery } \\
\text { (Operative } \\
\text { Vaginal Delivery } \\
\end{array}$ & $\begin{array}{l}1 \mathrm{SR}^{122,123} \\
(5,738 \\
\text { patients, } 9 \\
\text { studies) }\end{array}$ & $\begin{array}{l}\text { No difference: There was no } \\
\text { difference in risk of operative } \\
\text { vaginal delivery between } \\
\text { groups. }\end{array}$ & High \\
\hline & $\begin{array}{l}\text { Process Related } \\
\text { Outcomes - } \\
\text { Parental } \\
\text { Preferences }\end{array}$ & $\begin{array}{l}2 \mathrm{SRs}^{35,122,123} \\
(2,436 \\
\text { patients, } 2 \\
\text { studies) }\end{array}$ & $\begin{array}{l}\text { No difference: No difference } \\
\text { between the two groups in } \\
\text { scores of maternal/parental } \\
\text { satisfaction. }\end{array}$ & $\begin{array}{l}\text { Moderate } \\
\text { (Imprecise, varying } \\
\text { metrics) }\end{array}$ \\
\hline
\end{tabular}

${ }^{a}$ Criteria for downgrading SOE are described as Rationale; when these criteria are insufficient for understanding the final SOE, additional explanation is provided.

Abbreviations: RCT=randomized controlled trial; SOE=strength of evidence; $\mathrm{SR}=$ systematic review 
Table 21. Amniotomy plus oxytocin versus control: Evidence profile in parous women

\begin{tabular}{|c|c|c|c|c|}
\hline Category & Outcome & $\begin{array}{l}\text { Study Design } \\
\text { (Sample Size) }\end{array}$ & Conclusion & $\begin{array}{c}\text { SOE } \\
\text { (Rationale) }^{a}\end{array}$ \\
\hline \multirow[t]{4}{*}{$\begin{array}{l}\text { Intermediate } \\
\text { or Final } \\
\text { Outcomes }\end{array}$} & $\begin{array}{l}\text { Process Related } \\
\text { Outcomes }- \\
\text { Duration of } 1^{\text {st }} \\
\text { Stage Labor }\end{array}$ & $\begin{array}{l}2 \mathrm{SRS}^{35,122} \\
(2,431 \\
\text { patients, } 4 \\
\text { studies) }\end{array}$ & $\begin{array}{l}\text { Improvement with } \\
\text { amniotomy: Amniotomy } \\
\text { decreased the duration of the } \\
\text { first stage of labor compared } \\
\text { with control }\end{array}$ & Moderate (Imprecise) \\
\hline & $\begin{array}{l}\text { Process Related } \\
\text { Outcomes - } \\
\text { Duration of } 2^{\text {nd }} \\
\text { Stage Labor }\end{array}$ & $\begin{array}{l}1 \mathrm{SR}^{35} \\
(2,737 \\
\text { patients, } 5 \\
\text { studies) }\end{array}$ & $\begin{array}{l}\text { No difference: No difference in } \\
\text { the duration of second stage of } \\
\text { labor between groups. }\end{array}$ & Moderate (Imprecise) \\
\hline & $\begin{array}{l}\text { Process Related } \\
\text { Outcomes - } \\
\text { Duration of Total } \\
\text { Labor }\end{array}$ & $\begin{array}{l}2 \mathrm{SRs}^{35,122} \\
\text { (4,675 } \\
\text { patients, } 7 \\
\text { studies) }\end{array}$ & $\begin{array}{l}\text { Improvement with amniotomy } \\
\text { plus oxytocin: Modest } \\
\text { decrease in duration of labor in } \\
\text { the intervention group as } \\
\text { compared with controls. }\end{array}$ & Moderate (Imprecise) \\
\hline & $\begin{array}{l}\text { Process Related } \\
\text { Outcomes - Mode } \\
\text { of Delivery } \\
\text { (Cesarean } \\
\text { Delivery) }\end{array}$ & $\begin{array}{l}2 \mathrm{SRs}^{35,122} \\
(7,653 \\
\text { patients, } 11 \\
\text { studies) }\end{array}$ & $\begin{array}{l}\text { No difference: No difference in } \\
\text { the rate of cesarean delivery } \\
\text { between groups. }\end{array}$ & Moderate (Imprecise) \\
\hline
\end{tabular}

${ }^{a}$ Criteria for downgrading SOE are described as Rationale; when these criteria are insufficient for understanding the final SOE, additional explanation is provided.

Abbreviations: $\mathrm{SOE}=$ strength of evidence; $\mathrm{SR}=$ systematic review

\section{Key Question 3. Supportive Care}

KQ 3 was: What are the benefits and harms of supportive care measures, including emotional support, ambulation, nutrition, and hydration, during spontaneous labor?

\section{Description of Included Studies}

We identified 64 articles ${ }^{70,71,80-83,124-181}$ representing 61 individual RCTs that examined the benefits and harms of supportive care measures in women during spontaneous labor. Supportive care measures included interventions such as continuous emotional support, perineal massage, water birth, acupuncture, ambulation and positioning strategies.

Of the 61 included studies, 25 were conducted in the Middle East, ${ }^{70,82,125-127,133,136-}$ 138,140,143,147,148,151,155-157,162,164-166,174,175,178,179 15 were conducted in Asia, 124,129,135,139,141,150,153,158,159,161,163,167,170,176,181 7 were conducted in the United States, ${ }^{130,142,144,145,149,154,171} 4$ were conducted in Latin America, ${ }^{131,146,152,172} 8$ were conducted in UK/Europe ${ }^{80,128,134,168,169,173,177,180}$ one was conducted in Australia/NZ, ${ }^{160}$ and one was conducted in Canada. ${ }^{132}$ All but three studies ${ }^{129,131,172}$ were conducted in a hospital setting. These three studies were conducted in birthing centers. Eleven studies reported government funding, ${ }^{82,124,130,141,145,149,152,172,173,176,181} 21$ reported nongovernment, nonindustry funding, ${ }^{70,126,127,132,133,136,138,140,142,151,153,155-158,161,163,164,167,171,172 ~ a n d ~ t w o ~ r e p o r t e d ~ a ~ m i x t u r e ~ o f ~}$ funding from government and non-government sources. ${ }^{128,177}$ Twenty seven studies were unclear or did not report the funding source. $80,125,129,131,134,135,137,139,143,144,146-148,150,154,159,160,162,165,166,168-$ 170,174,175,178,180 Finally, of the 60 included studies, 23 were rated as good quality, ${ }^{80,131,132,135,139,141,142,144-146,148,149,151-153,160,163,165-167,171-173} 31$ as fair quality, ${ }^{82,124,125,128-}$ 130,133,134,136,137,140,143,147,154-158,162,164,168-170,174-181 and 7 as poor quality. ${ }^{70,126,127,138,150,159,161}$

In addition to the above studies, 14 SRs that addressed the benefits and harms of supportive care measures are also discussed below. Four were rated as fair quality, ${ }^{182-185}$ while 10 reviews were rated as good quality..$^{34,36,38,45,48,50,52,54,186,187}$ 


\section{Key Points for Supportive Care}

- Supportive care measures during labor encompass a wide variety of interventions and within individual categories of interventions, there is considerable heterogeneity in the nature and timing of the interventions.

- Although supportive care therapies are often seen as increasing parental satisfaction with the birthing process, these outcomes were only assessed in five of the included RCTs with sparse evidence. An earlier SR of 11 studies however did find that women receiving continuous emotional support were less likely to rate their birth experience negatively (moderate SOE).

- Two studies addressing continuous emotional support included in the present review did not show a benefit in reducing $1^{\text {st }}$ or $2^{\text {nd }}$ stage labor duration, although prior SR/MAs of 12 studies (including these two studies) indicated a benefit for total labor duration (moderate SOE).

- Emotional support interventions reduced cesarean deliveries (low SOE for doula support, moderate SOE for continuous emotional support) and instrumental deliveries (moderate SOE).

- There was no difference in rates of cesarean deliveries for women receiving perineal compresses or massage (low SOE), but severe perineal trauma was reduced in nulliparous women (low SOE).

- There was no difference in duration of labor in women using water birth (low SOE)

- Women undergoing acupuncture/acupoint nerve stimulator did not experience differences in labor duration or rates of maternal hemorrhage (low SOE for both outcomes).

- Ambulation was associated with shorter duration of labor (low SOE).

- No differences were found in duration of labor (low SOE) or cesarean delivery rates (moderate SOE) for women using differing positioning interventions. Women in kneeling position were more likely than women in sitting position to have reduced trauma to the pelvic floor (low SOE).

- Administration of intravenous fluids compared with oral intake alone demonstrated a reduction in the duration of labor (low SOE), while not increasing cesarean delivery rates (moderate SOE), maternal hemorrhage (low SOE), or operative vaginal delivery rates (moderate SOE). 


\section{Detailed Synthesis for Supportive Care}

The supportive care interventions as compared with control treatment were:

- Continuous emotional support

- Perineal compresses or massage

- Massage during labor

- Water birth

- Acupressure

- Acupuncture

- Aromatherapy

- Anetheum graveolens seeds

- Ambulation and positioning strategies

- Specific nutritional intervention and oral or parenteral hydration intervention recommendations or limitations

- Transcutaneous electrical nerve stimulation (TENS)

- Oral bicarbonate

- Hyoscine or hot shower

- Assessment and support during early labor

Below we detail each of these comparisons in terms of the included studies, outcomes assessed, and strength of evidence. Within each comparison we discuss findings in nulliparous women, in parous women, and then in women of mixed or unspecified parity.

\section{Continuous Emotional Support Versus Control Treatment}

Results for this intervention were reported for nulliparous women in three studies ${ }^{145,152,163}$ and for a mixed population of women in two studies (three articles). ${ }^{70,71,180}$ Three relevant goodquality SR/MAs were identified. ${ }^{52,54,187}$

\section{Results in Nulliparous Women}

Three studies ${ }^{145,152,163}$ examined the effects of continuous emotional support during labor provided by either a doula ${ }^{145}$ or a relative or companion of the patient's choosing. ${ }^{152,163}$ All three studies were good quality. ${ }^{145,152,163}$

\section{Duration of Labor and Cesarean Delivery Rates for Continuous Emotional Support}

No significant difference in duration of labor was reported in the two primary studies reporting on this outcome. ${ }^{152,163}$ The duration of first-stage labor was nonsignificantly shorter in the companion arm [( 3.4 vs. 3.8 hours, $p=0.123)^{152}$ and (4.48 vs. 5.02 hours, $\left.p=0.09\right)^{163}$ ] The duration of second-stage labor was non-significantly longer in the companion arm in both studies [(18 vs. 16.2 minutes, $p=0.368) ;{ }^{152}$ (58 vs. 50.1 minutes, $\left.p=0.26\right)^{163}$ ]. These findings were also included in the SR discussed below and based on that larger set of studies we found a moderate strength of evidence that there was an overall reduction in duration of labor for women receiving emotional support.

Cesarean deliveries were reported significantly less often in the doula arm in one study (13.4\% vs. $25.0 \%$, $\mathrm{p}=0.002),{ }^{145}$ whereas a similar proportion of cesarean deliveries was reported in both treatment arms in another study (10.5\% in the continuous support arm vs. $11.2 \%$ in the 
control arm, RR 0.93 , 95\% CI 0.43 to 2.02). ${ }^{152}$ Based on these findings in combination with the SR evidence discussed below we rated the SOE as low for a reduction in cesarean deliveries with doula support.

\section{Neonatal Outcomes for Continuous Emotional Support}

No significant difference was reported for altered fetal heart rate in one study (RR 1.18, 95\% CI 0.84 to 1.66) (low SOE). ${ }^{152}$

\section{Results in Women of Mixed or Unspecified Parity}

\section{Duration of Labor and Cesarean Delivery Rates for Continuous Emotional Support}

One poor-quality study reported in two separate articles, ${ }^{70,71}$ and one fair-quality study ${ }^{180}$ evaluated duration of labor. One study evaluated the duration of labor in a mixed population of 150 nulliparous and parous women receiving continuous emotional support from a doula or receiving usual care. The duration of labor in the doula group was significantly shorter than the control group for first-stage labor (157 vs. 281 minutes, $\mathrm{p}<0.001)$ and second-stage labor (58.9 vs. 128.4 minutes, $\mathrm{p}<0.001){ }^{70}$ The second study of 63 primiparous or parous women reported shorter duration of labor in the group of women receiving continuous support from a midwifery student than the women receiving usual care (8.0 hours vs 12.7 hours, $\mathrm{p}<0.001) .{ }^{180}$ Given the small sizes and the poor/fair quality of the studies, the evidence was rated as insufficient for all outcomes assessed.

\section{Relevant Systematic Reviews/Meta-Analyses for Continuous Emotional Support}

We identified two good-quality SR/MAs that addressed either doula support ${ }^{52}$ or continuous emotional support ${ }^{54}$ during labor. Doula support compared with standard care was associated with a significantly reduced risk of cesarean delivery (OR 0.68, 95\% CI 0.47 to 0.99 ) based on 2008 women across 5 studies (low SOE) and reduced risk of instrumental vaginal delivery (OR $0.54,95 \%$ CI 0.35 to 0.92 ) based on 1587 women across 4 studies (moderate SOE). ${ }^{52}$ One study included in the present review was included in this SR. ${ }^{145}$

Continuous emotional support was associated with a shorter total duration of labor (mean difference -0.58 hours, 95\% CI -0.85 to -0.31 ) based on 5366 women across 12 studies (moderate SOE). ${ }^{54}$ It also was associated with a lower risk of cesarean delivery (RR 0.78, 95\% CI 0.67 to 0.91 ) based on 15,175 women across 22 studies (moderate SOE), a lower risk on instrumental vaginal delivery (RR 0.90, 95\% CI 0.85 to 0.96) based on 14,118 women across 19 studies (moderate SOE), and a higher risk of spontaneous vaginal delivery (RR 1.08 95\% CI 1.04 to 1.12 ) based on 14,119 women across 19 studies. ${ }^{54}$ Women receiving continuous emotional support were also less likely to rate their birth experience negatively (RR 0.69, 95\% CI 0.59 to 0.79), based on 11,133 women across 11 studies (moderate SOE). ${ }^{54}$ No significant differences were observed for trauma to the pelvic floor or neonatal admission to special care nursery. ${ }^{54}$

An update of the 2013 systematic review of continuous emotional support ${ }^{54}$ was published in 2017. ${ }^{187}$ Continuous emotional support was associated with a shorter duration of labor (mean difference -0.69 hour, $95 \%$ CI -1.04 to -0.34 ) based on 5,429 women across 13 studies. It also was associated with a lower risk of cesarean delivery (RR 0.75, 95\% CI 0.64 to 0.88 ) based on 15347 women across 24 studies, a lower risk of instrumental vaginal birth (RR 0.90, 95\% CI 
0.85 to 0.96 ) based on 14,118 women across 19 studies, and a higher likelihood of spontaneous vaginal birth (RR 1.08, 95\% CI 1.04 to 1.12) based on 14,369 women across 21 studies.

Five of the studies included in the present review were included in the SR/MAs of continuous emotional support. ${ }^{70,145,152,163,180}$

\section{Strength of Evidence for Continuous Emotional Support}

Tables 22 and 23 summarize the SOE for the above outcomes in nulliparous and mixed parity women.

Table 22. Continuous emotional support versus control: Evidence profile in nulliparous women

\begin{tabular}{|c|c|c|c|c|}
\hline Category & Outcome & $\begin{array}{l}\text { Study Design } \\
\text { (Sample Size) }\end{array}$ & Conclusion & $\begin{array}{c}\text { SOE } \\
\text { (Rationale) }^{\mathrm{a}} \\
\end{array}$ \\
\hline \multirow[t]{5}{*}{$\begin{array}{l}\text { Intermediate } \\
\text { or Final } \\
\text { Outcomes }\end{array}$} & $\begin{array}{l}\text { Process Related } \\
\text { Outcomes - } \\
\text { Duration of } 1^{\text {st }} \\
\text { Stage Labor }\end{array}$ & $\begin{array}{l}2 \mathrm{RCTs}^{152,163} \\
(326)\end{array}$ & $\begin{array}{l}\text { No difference: Good-quality } \\
\text { studies of nulliparous women } \\
\text { found that continuous emotional } \\
\text { support did not reduce duration } \\
\text { of } 1^{\text {st }} \text { stage labor. }\end{array}$ & $\begin{array}{l}\text { Moderate } \\
\text { (Indirect) }\end{array}$ \\
\hline & $\begin{array}{l}\text { Process Related } \\
\text { Outcomes - } \\
\text { Duration of } 2^{\text {nd }} \\
\text { Stage Labor }\end{array}$ & $\begin{array}{l}2 \mathrm{RCTs}^{152,163} \\
(326)\end{array}$ & $\begin{array}{l}\text { No difference: Good-quality } \\
\text { studies of nulliparous women } \\
\text { found that continuous emotional } \\
\text { support did not reduce duration } \\
\text { of } 2^{\text {nd }} \text { stage labor. }\end{array}$ & $\begin{array}{l}\text { Moderate } \\
\text { (Indirect) }\end{array}$ \\
\hline & $\begin{array}{l}\text { Process Related } \\
\text { Outcomes - } \\
\text { Duration of Total } \\
\text { Labor }\end{array}$ & $\begin{array}{l}1 \mathrm{SR}^{54} \\
(5,366 \\
\text { patients, } 12 \\
\text { studies) }\end{array}$ & $\begin{array}{l}\text { Improvement with continuous } \\
\text { emotional support: Systematic } \\
\text { review of } 12 \text { studies found } \\
\text { shorter total duration of labor }\end{array}$ & $\begin{array}{l}\text { Moderate } \\
\text { (Indirect) }\end{array}$ \\
\hline & $\begin{array}{l}\text { Process Related } \\
\text { Outcomes - Mode } \\
\text { of Delivery } \\
\text { (Cesarean } \\
\text { Delivery) }\end{array}$ & $\begin{array}{l}\text { 2 RCTs } \\
\text { (599) } \\
\text { Doula support: } \\
1 \text { SR } \\
\text { ( } 2,008 \\
\text { patients, } 5 \\
\text { studies) } \\
\text { Continuous } \\
\text { emotional } \\
\text { support: } \\
1 \text { SR } \\
\text { (5,366 } \\
\text { patients, } 12 \\
\text { studies) }\end{array}$ & $\begin{array}{l}\text { Improvement with Doula } \\
\text { support: Doula support } \\
\text { reduced cesarean deliveries as } \\
\text { compared to control therapy. } \\
\text { Improvement with continuous } \\
\text { emotional support: } \\
\text { Continuous emotional support } \\
\text { lowered risk of cesarean } \\
\text { delivery (RR } 0.78,95 \% \mathrm{Cl} 0.67 \\
\text { to } 0.91 \text { ) based on SR of } 22 \\
\text { studies. }\end{array}$ & $\begin{array}{l}\text { Low - Doula } \\
\text { (Indirect) } \\
\text { Inconsistency between } \\
\text { SRs and included RCTs } \\
\text { Moderate - Continuous } \\
\text { Emotional Support } \\
\text { (Indirect) }\end{array}$ \\
\hline & $\begin{array}{l}\text { Process Related } \\
\text { Outcomes - Mode } \\
\text { of Delivery } \\
\text { (Instrumental } \\
\text { Delivery) }\end{array}$ & $\begin{array}{l}\text { Doula support: } \\
1 \text { SR }{ }^{52,54} \\
\text { (1,587 } \\
\text { patients, } 4 \\
\text { studies) } \\
\text { Continuous } \\
\text { emotional } \\
\text { support: } \\
1 \mathrm{SR}^{54} \\
\text { (14,118 } \\
\text { patients, } 19 \\
\text { studies) }\end{array}$ & $\begin{array}{l}\text { Improvement with Doula } \\
\text { support: Doula support } \\
\text { reduced risk of instrumental } \\
\text { vaginal delivery } \\
\text { Improvement with continuous } \\
\text { emotional support: } \\
\text { Continuous emotional support } \\
\text { lowered risk of instrumental } \\
\text { vaginal delivery based on SR of } \\
19 \text { studies. }\end{array}$ & $\begin{array}{l}\text { Moderate } \\
\text { (Indirect) }\end{array}$ \\
\hline
\end{tabular}




\begin{tabular}{|c|c|c|c|c|}
\hline Category & Outcome & $\begin{array}{l}\text { Study Design } \\
\text { (Sample Size) }\end{array}$ & Conclusion & $\begin{array}{c}\text { SOE } \\
\text { (Rationale) }^{a}\end{array}$ \\
\hline \multirow[t]{2}{*}{$\begin{array}{l}\text { Adverse } \\
\text { Events }\end{array}$} & $\begin{array}{l}\text { Process Related } \\
\text { Outcomes - } \\
\text { Abnormal Fetal } \\
\text { Heat Tracing }\end{array}$ & $\begin{array}{l}1 \mathrm{RCTS}^{152} \\
(212)\end{array}$ & $\begin{array}{l}\text { No difference: Supportive care } \\
\text { was not associated with } \\
\text { significant differences in fetal } \\
\text { heart tracings. }\end{array}$ & $\begin{array}{l}\text { Low } \\
\text { (Indirect, imprecise, } 1 \\
\text { study) }\end{array}$ \\
\hline & $\begin{array}{l}\text { Process Related } \\
\text { Outcomes - } \\
\text { Parental } \\
\text { Preferences }\end{array}$ & $\begin{array}{l}1 \mathrm{SR}^{54} \\
(11,133 \\
\text { patients, } 11 \\
\text { studies) }\end{array}$ & $\begin{array}{l}\text { Improvement with continuous } \\
\text { emotional support: SR of } 11 \\
\text { studies found women receiving } \\
\text { continuous emotional support } \\
\text { less likely to rate their birth } \\
\text { experience negatively }\end{array}$ & Moderate \\
\hline
\end{tabular}

${ }^{a}$ Criteria for downgrading SOE are described as Rationale; when these criteria are insufficient for understanding the final SOE, additional explanation is provided.

Abbreviations: $\mathrm{CI}=$ confidence interval; hr=hours; RCT=randomized controlled trial; RR=relative risk; SOE=strength of evidence; SR=systematic review

Table 23. Continuous emotional support versus control: Evidence profile in women of mixed parity

\begin{tabular}{|c|c|c|c|c|}
\hline Category & Outcome & $\begin{array}{l}\text { Study Design } \\
\text { (Sample Size) }\end{array}$ & Conclusion & $\begin{array}{c}\text { SOE } \\
\text { (Rationale) }^{a}\end{array}$ \\
\hline \multirow[t]{4}{*}{$\begin{array}{l}\text { Intermediate } \\
\text { or Final } \\
\text { Outcomes }\end{array}$} & $\begin{array}{l}\text { Process Related } \\
\text { Outcomes - } \\
\text { Duration of } 1^{\text {st }} \\
\text { Stage Labor }\end{array}$ & $\begin{array}{l}1 \mathrm{RCT}^{70} \\
(150)\end{array}$ & $\begin{array}{l}\text { Inconclusive: SOE was } \\
\text { insufficient given } 1 \text { small study } \\
\text { with high risk of bias. }\end{array}$ & $\begin{array}{l}\text { Insufficient } \\
\text { (High risk of bias, } \\
\text { Indirect, imprecise) }\end{array}$ \\
\hline & $\begin{array}{l}\text { Process Related } \\
\text { Outcomes - } \\
\text { Duration of } 2^{\text {nd }} \\
\text { Stage Labor }\end{array}$ & $\begin{array}{l}1 \mathrm{RCT}^{70} \\
(150)\end{array}$ & $\begin{array}{l}\text { Inconclusive: SOE was } \\
\text { insufficient given } 1 \text { small study } \\
\text { with high risk of bias. }\end{array}$ & $\begin{array}{l}\text { Insufficient } \\
\text { (High risk of bias, } \\
\text { Indirect, imprecise) }\end{array}$ \\
\hline & $\begin{array}{l}\text { Process Related } \\
\text { Outcomes - } \\
\text { Duration of Total } \\
\text { Labor }\end{array}$ & $\begin{array}{l}2 \mathrm{RCTs}^{70,180} \\
(213)\end{array}$ & $\begin{array}{l}\text { Inconclusive: SOE was } \\
\text { insufficient given two small } \\
\text { studies with high risk of bias }\end{array}$ & $\begin{array}{l}\text { Insufficient } \\
\text { (High risk of bias, } \\
\text { Indirect, imprecise) }\end{array}$ \\
\hline & $\begin{array}{l}\text { Process Related } \\
\text { Outcomes - } \\
\text { Duration of } 1^{\text {st }} \\
\text { Stage Labor }\end{array}$ & $\begin{array}{l}1 \mathrm{RCT}^{70} \\
(150)\end{array}$ & $\begin{array}{l}\text { Inconclusive: SOE was } \\
\text { insufficient given } 1 \text { small study } \\
\text { with high risk of bias. }\end{array}$ & $\begin{array}{l}\text { Insufficient } \\
\text { (High risk of bias, } \\
\text { Indirect, imprecise) }\end{array}$ \\
\hline
\end{tabular}

${ }^{a}$ Criteria for downgrading SOE are described as Rationale; when these criteria are insufficient for understanding the final SOE, additional explanation is provided.

Abbreviations: $\mathrm{RCT}=$ randomized controlled trial; $\mathrm{RR}=$ relative risk; $\mathrm{SOE}=$ strength of evidence

\section{Perineal Compresses or Massage Versus Control Treatment}

Results for this intervention were reported for nulliparous women in two studies (one good quality) ${ }^{160}$ and one fair quality ${ }^{156}$ ) and for a mixed population of women in one good-quality study. ${ }^{149}$ No relevant SR/MAs were identified.

\section{Results in Nulliparous Women}

Two studies, assessed the effects of perineal compresses or massage on labor outcomes, including duration of labor, cesarean delivery rate, and incidence of perineal trauma. The interventions were warm compresses applied to the perineum during second-stage labor ${ }^{160}$ or cold compresses applied to the body during first-stage labor and to the perineum during secondstage labor. ${ }^{156}$ 


\section{Duration of Labor and Cesarean Delivery Rates for Perineal Compresses or Massage}

Warm compresses or perineal massage showed no statistically significant difference in duration of second-stage labor (82.09 vs. 86.64 minutes, $\mathrm{p}=0.35$ ), ${ }^{160}$ whereas a statistically significant shortening of both first-stage (190.44 vs. 273.91 minutes, $\mathrm{p}<0.001)$ and second-stage (32.12 vs. 41.15 minutes) labor was reported with cold compresses. ${ }^{156}$ Given the inconsistent findings for second-stage labor and to small number of patients in the fair-quality study for firststage labor, both these outcomes were rates as insufficient SOE. The proportion of cesarean deliveries was not significantly different for women who had warm compresses applied to the perineum (12/360 in the intervention group vs. 8/357 in the control group, $\mathrm{p}=0.64)$ (low SOE).

\section{Maternal Outcomes for Perineal Compresses or Massage}

Severe perineal trauma (third- and fourth-degree perineal laceration) was reported in one study, with a significantly lower incidence in the intervention group (4.2\% vs. 8.7\%, OR 2.16, 95\% CI 1.15 to 4.10). ${ }^{160}$ A significantly lower rate of urinary incontinence at 3 months in the intervention care group was also reported $(9.7 \%$ vs. 22.4, $\mathrm{p}=0.0001) .{ }^{160}$ Strength of evidence was rated as low for both outcomes.

\section{Results in Women of Mixed or Unspecified Parity}

One good-quality study compared compresses applied to the perineum versus perineal massage versus control treatment in a population comprised on nulliparous and parous women. ${ }^{149}$

\section{Duration of Labor and Cesarean Delivery Rates for Perineal Compresses or Massage}

The duration of second-stage labor was not statistically significantly different between the intervention groups (41 minutes for warm compresses, 33 minutes for perineal massage, and 36 minutes for control treatment). ${ }^{149}$ Spontaneous vaginal delivery occurred in $96.0 \%$ of the warm compress group, $99.3 \%$ of the perineal massage group, and $98.5 \%$ of the control group. ${ }^{149}$ The SOE was rated as low for both outcomes.

\section{Maternal Outcomes for Perineal Compresses or Massage}

Third- or fourth-degree perineal trauma was reported for $0.7 \%$ of the warm compress group, $1.3 \%$ of the perineal massage group, and 1.5\% of the control group (p value not reported) low SOE). ${ }^{149}$

\section{Relevant Systematic Reviews/Meta-Analyses for Perineal Massage}

We identified one fair-quality systematic review that examined perineal trauma and mode of delivery comparing women who had perineal massage to usual care. ${ }^{184}$ One study described above $^{149}$ was included in the meta-analysis. Severe perineal trauma (third or fourth degree lacerations) was reported for nulliparous women in three studies with a total of 340 women and for parous women in two studies with a total of 2,147 women. The relative risk for nulliparous women was 0.09 (95\% CI 0.01-1.62) based no events in the perineal massage group (0/170) vs. 5 events among 170 women in the control group. The reported relative risk for the parous women was 1.06 (95\% CI 0.59-1.92), however this appears to be an error. The reported number of controls in the total column $(\mathrm{N}=2036)$ does not equal the total of the individual studies $(\mathrm{N}=1036)$. Based on data from the two individual studies, the event rate for the controls should 
be 30/1036 (2.9\%) not 30/2036 (1.5\%) as reported in the meta-analysis. The event rate in the women receiving perineal massage was 17/1111 (1.5\%). Conclusions about parous women cannot be made due to the apparent erroneous data. Mode of delivery was not significantly different between women who had perineal massage versus usual care.

\section{Strength of Evidence for Perineal Compresses or Massage}

Tables 24 and 25 summarize the SOE for the above studies. In general the SOE was rated as low given evidence from only one study.

Table 24. Perineal compresses or massage versus control: Evidence profile in nulliparous women

\begin{tabular}{|c|c|c|c|c|}
\hline Category & Outcome & $\begin{array}{l}\text { Study Design } \\
\text { (Sample Size) }\end{array}$ & Conclusion & $\begin{array}{c}\text { SOE } \\
\text { (Rationale) }^{a}\end{array}$ \\
\hline \multirow[t]{3}{*}{$\begin{array}{l}\text { Intermediate } \\
\text { or Final } \\
\text { Outcomes }\end{array}$} & $\begin{array}{l}\text { Process Related } \\
\text { Outcomes - } \\
\text { Duration of } 2^{\text {nd }} \\
\text { Stage Labor }\end{array}$ & $\begin{array}{l}1 \mathrm{RCT}^{156} \\
(64)\end{array}$ & $\begin{array}{l}\text { Inconclusive: SOE was rated } \\
\text { as insufficient given findings } \\
\text { from } 1 \text { small study with medium } \\
\text { risk of bias. }\end{array}$ & $\begin{array}{l}\text { Insufficient } \\
\text { (Medium risk of bias, } \\
\text { indirect, } 1 \text { small study) }\end{array}$ \\
\hline & $\begin{array}{l}\text { Process Related } \\
\text { Outcomes - Mode } \\
\text { of Delivery } \\
\text { (Cesarean } \\
\text { Delivery) }\end{array}$ & $\begin{array}{l}2 \mathrm{RCTs}^{156,160} \\
\text { (781) }\end{array}$ & $\begin{array}{l}\text { Inconclusive: SOE was rated } \\
\text { as insufficient given } \\
\text { inconsistent findings from } 2 \\
\text { studies with medium risk of } \\
\text { bias. }\end{array}$ & $\begin{array}{l}\text { Insufficient (Medium } \\
\text { risk of bias, } \\
\text { Inconsistent, imprecise) }\end{array}$ \\
\hline & $\begin{array}{l}\text { Process Related } \\
\text { Outcomes - Mode } \\
\text { of Delivery } \\
\text { (Cesarean } \\
\text { Delivery) }\end{array}$ & $\begin{array}{l}1 \mathrm{RCT}^{160} \\
(717)\end{array}$ & $\begin{array}{l}\text { No difference: No significant } \\
\text { differences in the proportion of } \\
\text { cesarean deliveries was } \\
\text { reported for the } \\
\text { massage/compress group. }\end{array}$ & $\begin{array}{l}\text { Low } \\
\text { (Indirect, } 1 \text { study) }\end{array}$ \\
\hline $\begin{array}{l}\text { Adverse } \\
\text { Events }\end{array}$ & $\begin{array}{l}\text { Maternal } \\
\text { Outcomes - } \\
\text { Trauma to the } \\
\text { Pelvic Floor }\end{array}$ & $\begin{array}{l}1 \mathrm{RCT}^{160} \\
(717)\end{array}$ & $\begin{array}{l}\text { Improvement with } \\
\text { massage/compress: Severe } \\
\text { perineal trauma (third- and } \\
\text { fourth-degree perineal } \\
\text { laceration) was lower incidence } \\
\text { for the massage/compress } \\
\text { group. }\end{array}$ & $\begin{array}{l}\text { Low } \\
\text { (1 study) }\end{array}$ \\
\hline
\end{tabular}

${ }^{a}$ Criteria for downgrading SOE are described as Rationale; when these criteria are insufficient for understanding the final SOE, additional explanation is provided.

Abbreviations: $\mathrm{CI}=$ confidence interval; $\mathrm{OR}=$ odds ratio; $\mathrm{RCT}=$ randomized controlled trial; $\mathrm{SOE}=$ strength of evidence

Table 25. Perineal compresses or massage versus control: Evidence profile in women of mixed parity

\begin{tabular}{|c|c|c|c|c|}
\hline Category & Outcome & $\begin{array}{l}\text { Study Design } \\
\text { (Sample Size) }\end{array}$ & Conclusion & $\begin{array}{c}\text { SOE } \\
\text { (Rationale) }^{\mathrm{a}}\end{array}$ \\
\hline \multirow[t]{2}{*}{$\begin{array}{l}\text { Intermediate } \\
\text { or Final } \\
\text { Outcomes }\end{array}$} & $\begin{array}{l}\text { Process Related } \\
\text { Outcomes - } \\
\text { Duration of } 2^{\text {nd }} \\
\text { Stage Labor }\end{array}$ & $\begin{array}{l}1 \mathrm{RCT}^{149} \\
(1,211)\end{array}$ & $\begin{array}{l}\text { No difference: Duration of } 2 \text { nd } \\
\text { stage labor was not statistically } \\
\text { significantly different between } \\
\text { the intervention and usual care } \\
\text { groups. }\end{array}$ & $\begin{array}{l}\text { Low } \\
\text { (Indirect, } 1 \text { study) }\end{array}$ \\
\hline & $\begin{array}{l}\text { Process Related } \\
\text { Outcomes - Mode } \\
\text { of Delivery } \\
\text { (Cesarean } \\
\text { Delivery) }\end{array}$ & $\begin{array}{l}1 \mathrm{RCT}^{149} \\
(1,211)\end{array}$ & $\begin{array}{l}\text { No difference: No significant } \\
\text { differences in the proportion of } \\
\text { cesarean deliveries was } \\
\text { reported for the } \\
\text { massage/compress group. }\end{array}$ & $\begin{array}{l}\text { Low } \\
\text { (Indirect, } 1 \text { study) }\end{array}$ \\
\hline $\begin{array}{l}\text { Adverse } \\
\text { Events }\end{array}$ & $\begin{array}{l}\text { Maternal } \\
\text { Outcomes - } \\
\text { Trauma to the } \\
\text { Pelvic Floor }\end{array}$ & $\begin{array}{l}1 \mathrm{RCT}^{149} \\
(1,211)\end{array}$ & $\begin{array}{l}\text { No difference: No significant } \\
\text { differences in perineal trauma } \\
\text { were reported between the } \\
\text { intervention and control groups. }\end{array}$ & $\begin{array}{l}\text { Low } \\
\text { (1 study) }\end{array}$ \\
\hline
\end{tabular}

${ }^{a}$ Criteria for downgrading SOE are described as Rationale; when these criteria are insufficient for understanding the final SOE, additional explanation is provided.

Abbreviations: RCT=randomized controlled trial; SOE=strength of evidence 


\section{Massage During Labor Versus Control Treatment}

Results for massage during labor versus control treatment were reported for nulliparous women in three studies. ${ }^{131,132,138}$ and in women of mixed parity in one study. ${ }^{166}$ No relevant SR/MAs were identified.

\section{Results in Nulliparous Women}

Three studies, two good quality ${ }^{131,132}$ and one poor quality, ${ }^{138}$ evaluated the effects of massage during labor. The duration and timing of the intervention varied between studies ranging from 30 minutes of massage ${ }^{131}$ up to 5 hours of massage. ${ }^{132}$

\section{Duration of Labor and Cesarean Delivery Rates for Massage During Labor}

Duration of labor (first- or second-stage or total duration) was not significantly different between the massage and control groups in the two good-quality studies (Table 26). ${ }^{131,132}$ The poor-quality study reported that the active phase of labor was 3.1 hours shorter in the massage group $(p<0.001) .{ }^{138}$ Based on these findings the SOE was rated as insufficient for the duration of $1^{\text {st }}$ stage labor and for $2^{\text {nd }}$ stage but low for the total duration of labor.

Additionally, the proportion of cesarean deliveries was not significantly different between the massage groups and control groups in the two studies reporting this outcome (low SOE).

Table 26. Effects of massage during labor versus control treatment

\begin{tabular}{|c|c|c|c|c|c|c|c|c|}
\hline $\begin{array}{l}\text { Study } \\
\text { Quality }\end{array}$ & Int & Com & $\begin{array}{l}\text { Duration } \\
\text { of Labor: } \\
\text { Int }\end{array}$ & $\begin{array}{l}\text { Duration } \\
\text { of Labor: } \\
\text { Com }\end{array}$ & $\begin{array}{c}\text { Duration } \\
\text { of Labor: } \\
\text { P Value }\end{array}$ & $\begin{array}{c}\text { Cesarean: } \\
\text { Int }\end{array}$ & $\begin{array}{l}\text { Cesarean: } \\
\text { Com }\end{array}$ & $\begin{array}{c}\text { Cesarean: } \\
\text { P Value }\end{array}$ \\
\hline $\begin{array}{l}\text { Silva } \\
\text { Gallo, } \\
2013^{131} \\
\text { Good }\end{array}$ & $\begin{array}{l}\text { Massage } \\
\text { ( } 30 \text { min) } \\
\text { adjunct to } \\
\text { usual } \\
\text { care } \\
\mathrm{N}=23\end{array}$ & $\begin{array}{l}\text { Usual } \\
\text { care } \\
\mathrm{N}=23\end{array}$ & $\begin{array}{l}\text { Total } \\
\text { duration } \\
6.8 \mathrm{hr} \\
(1.6)\end{array}$ & $\begin{array}{l}\text { Total } \\
\text { duration } \\
5.7 \mathrm{hr} \\
(1.5)\end{array}$ & $\begin{array}{l}\text { Mean } \\
\text { difference } \\
(95 \% \mathrm{Cl}) \\
1.1(0.2 \text { to } \\
2.0)\end{array}$ & $6 / 23$ & $4 / 23$ & $\begin{array}{l}\text { RR 1.5, } \\
95 \% \mathrm{Cl} 0.5 \\
\text { to } 4.6\end{array}$ \\
\hline $\begin{array}{l}\text { Janssen, } \\
2012^{132} \\
\text { Good }\end{array}$ & $\begin{array}{l}\text { Massage } \\
\text { (up to } 5 \\
\text { hr) } \\
\text { adjunct to } \\
\text { usual } \\
\text { care } \\
\mathrm{N}=37\end{array}$ & $\begin{array}{l}\text { Usual } \\
\text { care } \\
\mathrm{N}=40\end{array}$ & $\begin{array}{l}1^{\text {st }} \text { stage } \\
897.4 \text { min } \\
(507.4) \\
2^{\text {nd }} \text { stage } \\
136.0 \text { min } \\
(89.6)\end{array}$ & $\begin{array}{l}1^{\text {st }} \text { stage } \\
788.6 \text { min } \\
(336.8) \\
2^{\text {nd }} \text { stage } \\
125.0 \text { min } \\
(81.7)\end{array}$ & $\begin{array}{l}0.28 \\
0.36\end{array}$ & 9/37 & $7 / 40$ & 0.71 \\
\hline $\begin{array}{l}\text { Mortazavi, } \\
2012^{138} \\
\text { Poor }\end{array}$ & $\begin{array}{l}\text { Massage } \\
\text { (30 min } x \\
\text { 3) adjunct } \\
\text { to usual } \\
\text { care } \\
\mathrm{N}=40\end{array}$ & $\begin{array}{l}\text { Usual } \\
\text { care } \\
\mathrm{N}=40\end{array}$ & $\begin{array}{l}\text { Active } \\
\text { phase } \\
2.6 \mathrm{hr} \\
(0.95)\end{array}$ & $\begin{array}{l}\text { Active } \\
\text { phase } \\
5.7 \mathrm{hr} \\
(1.89)\end{array}$ & $<0.001$ & - & - & - \\
\hline
\end{tabular}

Abbreviations: $\mathrm{CI}=$ confidence interval; Com=comparator; hr=hours; Int=intervention; $\min =$ minutes; $\mathrm{RR}=$ relative risk

\section{Results in Women of Mixed Parity}

One good quality study ${ }^{166}$ of 100 women of mixed parity evaluated the effect of at least 30 minutes of massage on duration of labor and type of delivery. Women receiving massage had statistically significantly shorter first stage labor (8.96 vs. 11.46 hours, $\mathrm{p}<0.0001$ ) and second stage labor (49.29 vs 64.14 minutes, $\mathrm{p}=0.0003$ ). There were fewer cesarean deliveries in the massage group than the control group (1/50 vs. 3/50) but the differences were not statistically significant. 


\section{Strength of Evidence for Massage During Labor}

Tables 27 and 28 summarize the SOE for the effects of massage during labor.

Table 27. Massage during labor versus control: Evidence profile in nulliparous women

\begin{tabular}{|c|c|c|c|c|}
\hline Category & Outcome & $\begin{array}{l}\text { Study Design } \\
\text { (Sample Size) }\end{array}$ & Conclusion & $\begin{array}{c}\text { SOE } \\
\text { (Rationale) }^{a}\end{array}$ \\
\hline \multirow[t]{4}{*}{$\begin{array}{l}\text { Intermediate } \\
\text { or Final } \\
\text { Outcomes }\end{array}$} & $\begin{array}{l}\text { Process Related } \\
\text { Outcomes - } \\
\text { Duration of } 1^{\text {st }} \\
\text { Stage Labor }\end{array}$ & $\begin{array}{l}2 \mathrm{RCTs}^{132,138} \\
(197)\end{array}$ & $\begin{array}{l}\text { Inconclusive: SOE was } \\
\text { insufficient given inconsistent } \\
\text { and imprecise findings from } 2 \\
\text { studies. }\end{array}$ & $\begin{array}{l}\text { Insufficient (Medium } \\
\text { risk of bias, indirect, } \\
\text { Inconsistent, imprecise) }\end{array}$ \\
\hline & $\begin{array}{l}\text { Process Related } \\
\text { Outcomes - } \\
\text { Duration of } 2^{\text {nd }} \\
\text { Stage Labor }\end{array}$ & $\begin{array}{l}1 \mathrm{RCT}^{132} \\
(77)\end{array}$ & $\begin{array}{l}\text { Inconclusive: SOE was } \\
\text { insufficient given imprecise } \\
\text { findings from } 1 \text { small study. }\end{array}$ & $\begin{array}{l}\text { Insufficient } \\
\text { (Indirect, Imprecise, } 1 \\
\text { small study) }\end{array}$ \\
\hline & $\begin{array}{l}\text { Process Related } \\
\text { Outcomes - } \\
\text { Duration of Total } \\
\text { Labor }\end{array}$ & $\begin{array}{l}2 \mathrm{RCTs}^{131,132} \\
(123)\end{array}$ & $\begin{array}{l}\text { No difference: Total duration of } \\
\text { labor was not significantly } \\
\text { different in the massage group } \\
\text { compared to usual care. }\end{array}$ & $\begin{array}{l}\text { Low } \\
\text { (Indirect, Imprecise) }\end{array}$ \\
\hline & $\begin{array}{l}\text { Process Related } \\
\text { Outcomes - Mode } \\
\text { of Delivery } \\
\text { (Cesarean } \\
\text { Delivery) } \\
\end{array}$ & $\begin{array}{l}2 \mathrm{RCTs}^{131,132} \\
(123)\end{array}$ & $\begin{array}{l}\text { No difference: The proportion } \\
\text { of cesarean deliveries was not } \\
\text { significantly different between } \\
\text { the massage group and control } \\
\text { group. }\end{array}$ & $\begin{array}{l}\text { Low } \\
\text { (Indirect, Imprecise) }\end{array}$ \\
\hline
\end{tabular}

${ }^{a}$ Criteria for downgrading SOE are described as Rationale; when these criteria are insufficient for understanding the final SOE, additional explanation is provided.

Abbreviations: RCT=randomized controlled trial; SOE=strength of evidence

Table 28. Massage during labor versus control: Evidence profile in women of mixed parity

\begin{tabular}{|c|c|c|c|c|}
\hline Category & Outcome & $\begin{array}{l}\text { Study Design } \\
\text { (Sample Size) }\end{array}$ & Conclusion & $\begin{array}{c}\text { SOE } \\
\text { (Rationale) }^{\mathrm{a}}\end{array}$ \\
\hline \multirow[t]{3}{*}{$\begin{array}{l}\text { Intermediate } \\
\text { or Final } \\
\text { Outcomes }\end{array}$} & $\begin{array}{l}\text { Process Related } \\
\text { Outcomes }- \\
\text { Duration of } 1^{\text {st }} \\
\text { Stage Labor }\end{array}$ & $\begin{array}{l}1 \mathrm{RCT}^{166} \\
(100)\end{array}$ & $\begin{array}{l}\text { Inconclusive: SOE was } \\
\text { insufficient given imprecise } \\
\text { findings from } 1 \text { small study. }\end{array}$ & $\begin{array}{l}\text { Insufficient } \\
\text { (Indirect, Imprecise, } 1 \\
\text { small study) }\end{array}$ \\
\hline & $\begin{array}{l}\text { Process Related } \\
\text { Outcomes - } \\
\text { Duration of } 2^{\text {nd }} \\
\text { Stage Labor }\end{array}$ & $\begin{array}{l}1 \mathrm{RCT}^{166} \\
(100)\end{array}$ & $\begin{array}{l}\text { Inconclusive: SOE was } \\
\text { insufficient given imprecise } \\
\text { findings from } 1 \text { small study. }\end{array}$ & $\begin{array}{l}\text { Insufficient } \\
\text { (Indirect, Imprecise, } 1 \\
\text { small study) }\end{array}$ \\
\hline & $\begin{array}{l}\text { Process Related } \\
\text { Outcomes - Mode } \\
\text { of Delivery } \\
\text { (Cesarean } \\
\text { Delivery) }\end{array}$ & $\begin{array}{l}1 \mathrm{RCT}^{166} \\
(100)\end{array}$ & $\begin{array}{l}\text { Inconclusive: SOE was } \\
\text { insufficient given imprecise } \\
\text { findings from } 1 \text { small study. }\end{array}$ & $\begin{array}{l}\text { Insufficient } \\
\text { (Indirect, Imprecise, } 1 \\
\text { small study) }\end{array}$ \\
\hline
\end{tabular}

${ }^{a}$ Criteria for downgrading SOE are described as Rationale; when these criteria are insufficient for understanding the final SOE, additional explanation is provided.

Abbreviations: RCT=randomized controlled trial; SOE=strength of evidence

\section{Water Immersion Versus Control Treatment}

Two studies reported outcomes for women laboring in a warm bath. ${ }^{143,179}$ In one study, the women were immersed in water during active labor until cervical dilation reached $(4 \mathrm{~cm}$ to $10 \mathrm{~cm})$ and then had usual care for delivery, ${ }^{179}$ and in the other, the women were immersed in water during both labor and delivery. ${ }^{143}$ Results for this intervention were reported for nulliparous women in one study ${ }^{179}$ and in women of mixed parity in the other study. ${ }^{143}$ One relevant goodquality SR/meta-analysis was also identified. ${ }^{48}$ 


\section{Results in Nulliparous Women}

One RCT of fair quality assessed labor outcomes among 90 women who were immersed in water during active labor ( $4 \mathrm{~cm}$ to $10 \mathrm{~cm}$ dilation) and then received usual care for delivery compared to 90 women who received usual care throughout labor and delivery. ${ }^{179}$ First-stage active labor was significantly longer in the intervention group than the usual care group (232.95 vs. 165.81 minutes, $\mathrm{p}<.001$ ). There was no difference in the duration of second stage labor (48.40 vs. 48.00 minutes, $\mathrm{p}=0.631$ ). There also was no difference in mode of delivery, with cesarean sections in $2.2 \%$ of the intervention group and $3.3 \%$ of the usual care group $(\mathrm{p}=.902)$. Satisfaction with birth was significantly higher in the intervention group than the control group (8.85 vs. 5.08 on a 10 -point scale, $\mathrm{p}<0.001$ ).

\section{Results in Women of Mixed or Unspecified Parity}

One RCT of fair quality assessed labor outcomes among 106 women giving birth in a warm water bath compared with conventional deliveries. ${ }^{143}$ First-stage active labor was significantly shorter in the water birth group (114.4 vs. 186 minutes, $\mathrm{p}=0.004)$, whereas no difference was observed in duration of second-stage labor (20.9 vs. 20.6 minutes, $\mathrm{p}=0.9$ ). All water births were vaginal deliveries compared with $79.2 \%$ in the conventional group.

\section{Relevant Systematic Reviews/Meta-Analyses for Water Birth}

We identified one good-quality SR/meta-analysis that addressed the effects of immersion in water on labor outcomes. ${ }^{48}$ Analyses that were restricted to women in spontaneous labor included 1 to 3 studies, with 60 to 291 women included in different analyses. No statistically significant differences were observed in length of first- or second-stage labor, cesarean deliveries, hemorrhage, perineal trauma, neonatal ICU admission, or neonatal sepsis. Based on one study within that meta analysis, women who gave birth in water immersion were less likely to report being dissatisfied with their birth experience (RR $0.24,95 \%$ CI 0.07 to 0.80 ). One study included in the present review was also included in the SR/meta-analysis. ${ }^{143}$ A 2018 update of this systematic review stated that they were not able to perform planned sub-group analyses of spontaneous versus induced labor due to lack of data relating to sub-groups. ${ }^{188}$

Given the findings of this sole fair-quality RCT and the combined evidence from the SR we rated the SOE for total duration of labor as low for no difference between water birth and control and insufficient for the outcome of cesarean delivery for women of mixed parity.

\section{Strength of Evidence for Water Birth}

Tables 29 and 30 summarize the SOE for water birth compared to control therapy.

Table 29. Water birth versus control: Evidence profile in nulliparous women

\begin{tabular}{|l|l|l|l|l|}
\hline \multicolumn{1}{|c|}{ Category } & \multicolumn{1}{|c|}{ Outcome } & $\begin{array}{l}\text { Study Design } \\
\text { (Sample Size) }\end{array}$ & \multicolumn{1}{c|}{ Conclusion } & \multicolumn{1}{c|}{$\begin{array}{c}\text { SOE } \\
\text { (Rationale) }^{\mathbf{a}}\end{array}$} \\
\hline $\begin{array}{l}\text { Intermediate } \\
\text { or Final } \\
\text { Outcomes }\end{array}$ & $\begin{array}{l}\text { Process Related } \\
\text { Outcomes - Total } \\
\text { Duration of Labor }\end{array}$ & $\begin{array}{l}1 \mathrm{RCT} \mathrm{T}^{179} \\
(90)\end{array}$ & $\begin{array}{l}\text { Inconclusive: SOE was } \\
\text { insufficient given imprecise } \\
\text { findings from 1 small study. }\end{array}$ & $\begin{array}{l}\text { Insufficient } \\
\text { (Indirect, Imprecise, 1 } \\
\text { small study) }\end{array}$ \\
\cline { 2 - 6 } & $\begin{array}{l}\text { Process Related } \\
\text { Outcomes - Mode } \\
\text { of Delivery } \\
\text { (Cesarean } \\
\text { Delivery) }\end{array}$ & $\begin{array}{l}1 \mathrm{RCT}^{179} \\
(90)\end{array}$ & $\begin{array}{l}\text { Inconclusive: SOE was } \\
\text { insufficient given imprecise } \\
\text { findings from 1 small study. }\end{array}$ & $\begin{array}{l}\text { Insufficient } \\
\text { Indirect, Imprecise, 1 }_{\text {small study) }}\end{array}$ \\
\end{tabular}

${ }^{a}$ Criteria for downgrading SOE are described as Rationale; when these criteria are insufficient for understanding the final SOE, additional explanation is provided.

Abbreviations: RCT=randomized controlled trial; SOE=strength of evidence; SR=systematic review 
Table 30. Water birth versus control: Evidence profile in women of mixed parity

\begin{tabular}{|c|c|c|c|c|}
\hline Category & Outcome & $\begin{array}{l}\text { Study Design } \\
\text { (Sample Size) }\end{array}$ & Conclusion & $\begin{array}{c}\text { SOE } \\
\text { (Rationale) }^{a}\end{array}$ \\
\hline \multirow[t]{2}{*}{$\begin{array}{l}\text { Intermediate } \\
\text { or Final } \\
\text { Outcomes }\end{array}$} & $\begin{array}{l}\text { Process Related } \\
\text { Outcomes - } \\
\text { Duration of } 2^{\text {nd }} \\
\text { Stage Labor }\end{array}$ & $\begin{array}{l}1 \mathrm{RCT}^{143} \\
(106) \\
1 \mathrm{SR}^{48} \\
\text { (291 patients, } \\
2 \text { studies) }\end{array}$ & $\begin{array}{l}\text { No difference: No difference in } \\
\text { duration of } 2^{\text {nd }} \text { stage labor was } \\
\text { reported. }\end{array}$ & $\begin{array}{l}\text { Low } \\
\text { (Medium risk of bias, } \\
\text { indirect, imprecise) } \\
\text { SOE was increased to } \\
\text { low given findings from } \\
\text { SR which also } \\
\text { demonstrated no } \\
\text { difference between } \\
\text { water birth versus } \\
\text { control }\end{array}$ \\
\hline & $\begin{array}{l}\text { Process Related } \\
\text { Outcomes - Mode } \\
\text { of Delivery } \\
\text { (Cesarean } \\
\text { Delivery) }\end{array}$ & $\begin{array}{l}\text { 1 RCT } 143 \\
(106)\end{array}$ & $\begin{array}{l}\text { Inconclusive: SOE was rated } \\
\text { as insufficient given imprecise } \\
\text { findings in } 1 \text { study with potential } \\
\text { risk of bias. }\end{array}$ & $\begin{array}{l}\text { Insufficient (Medium } \\
\text { risk of bias, Indirect, } \\
\text { imprecise, } 1 \text { study) }\end{array}$ \\
\hline
\end{tabular}

${ }^{a}$ Criteria for downgrading SOE are described as Rationale; when these criteria are insufficient for understanding the final SOE, additional explanation is provided.

Abbreviations: RCT=randomized controlled trial; SOE=strength of evidence; SR=systematic review

\section{Acupressure Versus Control Treatment}

Results for this intervention were reported for nulliparous women in two studies ${ }^{151,162}$ and for women of unspecified parity in two studies. ${ }^{70,137}$ One study was judged to be good quality, ${ }^{151}$ two fair quality, ${ }^{137,162}$ and one poor quality. ${ }^{70}$ No relevant SR/MAs were identified.

\section{Results in Nulliparous Women}

\section{Duration of Labor and Cesarean Delivery Rates for Acupressure}

One good-quality ${ }^{151}$ and one fair-quality ${ }^{162}$ study assessed duration of labor in nulliparous women. Each measure of duration of labor was significantly shorter for the acupressure group compared with the control group: active phase (4.2 vs. 7.4 hours, $\mathrm{p}=0.0001),{ }^{151}$ total first-stage (6.02 vs. 9.45 hours, $p=0.002){ }^{162}$ and second-stage ( 23.42 vs. 34.89 minutes, $\left.p=0.04\right) .{ }^{162}$ Given the small size of the studies, the imprecision in the findings, and the potential risk of bias the strength of evidence for all duration of labor outcomes was rated as insufficient. One goodquality study reported a smaller proportion of cesarean deliveries in the acupressure group compared with the control group (6/60 vs. 25/60, p=0.0001) (insufficient SOE). ${ }^{151}$

\section{Results in Women of Mixed or Unspecified Parity}

\section{Duration of Labor and Cesarean Delivery Rates for Acupressure}

One fair-quality ${ }^{137}$ and one poor-quality ${ }^{70}$ study assessed duration of labor in mixed populations of nulliparous and parous women. Each study reported a statistically significantly shorter duration of first-stage labor (161.7 vs. 281.0 minutes, $\mathrm{p}<0.0001^{70}$ and 146.4 vs. 185.4 minutes, $\mathrm{p}<0.001^{137}$ and second-stage labor (56.1 vs. 128.4 minutes, $\mathrm{p}<0.0001^{70}$ and 20.51 vs. $28.5 \mathrm{~min}, \mathrm{p}=0.038 .{ }^{137}$ The lower quality of these included studies and the imprecision of the findings resulted in a insufficient strength of evidence rating for these outcomes.

In the fair-quality study, women in the acupressure group were significantly more satisfied with the birth process than those in the control group (5.76 [0.63] vs. 5.36 [1.08], respectively) (insufficient SOE). ${ }^{137}$ 


\section{Strength of Evidence for Acupressure}

Tables 31 and 32 summarize the SOE for available outcomes within this comparison. Although findings were consistent between studies, the SOE was rated as insufficient for all outcomes given the small number of patients, the potential risk of bias, and the imprecision of the findings.

Table 31. Acupressure versus control: Evidence profile in nulliparous women

\begin{tabular}{|c|c|c|c|c|}
\hline Category & Outcome & $\begin{array}{l}\text { Study Design } \\
\text { (Sample Size) }\end{array}$ & Conclusion & $\begin{array}{c}\text { SOE } \\
\text { (Rationale) }^{\mathrm{a}}\end{array}$ \\
\hline \multirow[t]{4}{*}{$\begin{array}{l}\text { Intermediate } \\
\text { or Final } \\
\text { Outcomes }\end{array}$} & $\begin{array}{l}\text { Process Related } \\
\text { Outcomes - } \\
\text { Duration of } 1^{\text {st }} \\
\text { Stage Labor }\end{array}$ & $\begin{array}{l}1 \mathrm{RCT}^{162} \\
(100)\end{array}$ & $\begin{array}{l}\text { Inconclusive: SOE was } \\
\text { insufficient given potential risk } \\
\text { of bias, imprecise findings, and } \\
\text { only one study }\end{array}$ & $\begin{array}{l}\text { Insufficient } \\
\text { (Medium risk of bias, } \\
\text { indirect, imprecise, } 1 \\
\text { study) }\end{array}$ \\
\hline & $\begin{array}{l}\text { Process Related } \\
\text { Outcomes }- \\
\text { Duration of } 2^{\text {nd }} \\
\text { Stage Labor }\end{array}$ & $\begin{array}{l}1 \mathrm{RCT}^{162} \\
(100)\end{array}$ & $\begin{array}{l}\text { Inconclusive: SOE was } \\
\text { insufficient given potential risk } \\
\text { of bias, imprecise findings, and } \\
\text { only one study. }\end{array}$ & $\begin{array}{l}\text { Insufficient } \\
\text { (Medium risk of bias, } \\
\text { indirect, Imprecise, } 1 \\
\text { study) }\end{array}$ \\
\hline & $\begin{array}{l}\text { Process Related } \\
\text { Outcomes - } \\
\text { Duration of Total } \\
\text { Labor }\end{array}$ & $\begin{array}{l}2 \mathrm{RCTs}^{151,162} \\
(220)\end{array}$ & $\begin{array}{l}\text { Inconclusive: SOE was } \\
\text { insufficient given potential risk } \\
\text { of bias, imprecise findings, and } \\
\text { small study size }\end{array}$ & $\begin{array}{l}\text { Insufficient } \\
\text { (Medium risk of bias, } \\
\text { indirect, Imprecise) }\end{array}$ \\
\hline & $\begin{array}{l}\text { Process Related } \\
\text { Outcomes - Mode } \\
\text { of Delivery } \\
\text { (Cesarean } \\
\text { Delivery) }\end{array}$ & $\begin{array}{l}1 \mathrm{RCT}^{151} \\
(120)\end{array}$ & $\begin{array}{l}\text { Inconclusive: SOE was } \\
\text { insufficient given imprecise } \\
\text { findings from only one study }\end{array}$ & $\begin{array}{l}\text { Insufficient } \\
\text { (Indirect, Imprecise, } 1 \\
\text { study) }\end{array}$ \\
\hline
\end{tabular}

${ }^{a}$ Criteria for downgrading SOE are described as Rationale; when these criteria are insufficient for understanding the final SOE, additional explanation is provided.

Abbreviations: RCT=randomized controlled trial; SOE=strength of evidence

Table 32. Acupressure versus control: Evidence profile in women of mixed parity

\begin{tabular}{|c|c|c|c|c|}
\hline Category & Outcome & $\begin{array}{l}\text { Study Design } \\
\text { (Sample Size) }\end{array}$ & Conclusion & $\begin{array}{c}\text { SOE } \\
\text { (Rationale) }^{a}\end{array}$ \\
\hline \multirow[t]{3}{*}{$\begin{array}{l}\text { Intermediate } \\
\text { or Final } \\
\text { Outcomes }\end{array}$} & $\begin{array}{l}\text { Process Related } \\
\text { Outcomes - } \\
\text { Duration of } 1^{\text {st }} \\
\text { Stage Labor }\end{array}$ & $\begin{array}{l}2 \mathrm{RCTs}^{70,137} \\
(250)\end{array}$ & $\begin{array}{l}\text { Inconclusive: SOE was } \\
\text { insufficient given potential risk } \\
\text { of bias, imprecise findings, and } \\
\text { small studies }\end{array}$ & $\begin{array}{l}\text { Insufficient } \\
\text { (High risk of bias, } \\
\text { indirect, Imprecise) }\end{array}$ \\
\hline & $\begin{array}{l}\text { Process Related } \\
\text { Outcomes - } \\
\text { Duration of } 2^{\text {nd }} \\
\text { Stage Labor }\end{array}$ & $\begin{array}{l}2 \mathrm{RCTS}^{70,137} \\
(250)\end{array}$ & $\begin{array}{l}\text { Inconclusive: SOE was } \\
\text { insufficient given potential risk } \\
\text { of bias, imprecise findings, and } \\
\text { small studies }\end{array}$ & $\begin{array}{l}\text { Insufficient } \\
\text { (High risk of bias, } \\
\text { indirect, Imprecise) }\end{array}$ \\
\hline & $\begin{array}{l}\text { Process Related } \\
\text { Outcomes - } \\
\text { Duration of Total } \\
\text { Labor }\end{array}$ & $\begin{array}{l}2 \mathrm{RCTS}^{70,137} \\
(250)\end{array}$ & $\begin{array}{l}\text { Inconclusive: SOE was } \\
\text { insufficient given potential risk } \\
\text { of bias, imprecise findings, and } \\
\text { small studies }\end{array}$ & $\begin{array}{l}\text { Insufficient } \\
\text { (High risk of bias, } \\
\text { indirect, imprecise) }\end{array}$ \\
\hline
\end{tabular}

${ }^{a}$ Criteria for downgrading SOE are described as Rationale; when these criteria are insufficient for understanding the final SOE, additional explanation is provided.

Abbreviations: RCT=randomized controlled trial; SOE=strength of evidence

\section{Acupuncture Versus Control Treatment}

Seven studies reported on the effects of acupuncture ${ }^{125,126,128,141,176,181}$ or acupoint nerve stimulator ${ }^{124}$ on labor outcomes. Results were reported for nulliparous women in four studies ${ }^{125,128,176,181}$ and for women of mixed parity in three studies. ${ }^{124,126,141}$ One study was good quality, ${ }^{141}$ four were fair quality, ${ }^{124,125,128,176,181}$ and one was poor quality. ${ }^{126}$ Comparisons included sham acupuncture ${ }^{125,141}$, no analgesia or available standard of care. ${ }^{124,126,128,141}$ and no 
analgesia or combined spinal-epidural anesthesia. ${ }^{176}$ One study compared both acupuncture and electroacupuncture with control treatment. ${ }^{128}$ another compared electroacupuncture to sham acupuncture and control treatment ${ }^{141}$ and another compared combined spinal epidural anesthesia with patient-controlled epidural anesthesia with and without electroacupuncture. ${ }^{181}$ One relevant good-quality SR/meta-analysis was identified. ${ }^{45}$

\section{Results in Nulliparous Women}

\section{Duration of Labor and Cesarean Delivery Rates for Acupuncture}

Results were not consistent across studies or within one study in regard to the duration of labor. The acupuncture group had a significantly shorter duration of first-stage labor when compared with sham acupuncture ( 130 vs. 250 minutes, $\mathrm{p}=0.001$ ) but no difference in secondstage labor ( 36 vs. 35 minutes, $\mathrm{p}=0.739$ ) in one study. ${ }^{125} \mathrm{~A}$ second study found no significant difference in total duration of labor between the acupuncture and control group (619 vs. 615 minutes, hazard ratio $1.03,95 \% 0.75$ to 1.41 ), but a significantly shorter duration of labor in the electroacupuncture group (500 vs. 615 minutes, HR 1.44, 95\% 1.06 to 1.97 ). ${ }^{128}$ The third study found no significant difference in duration of active stage labor between the acupuncture and control groups ( 3.0 vs. 3.3 hours, $\mathrm{p}>0.05$ ), both of which were significantly shorter than the combined spinal-epidural anesthesia group ( 4.5 hours, $\mathrm{p}<0.05){ }^{176}$ There were no significant differences between the acupuncture, control and combined spinal-epidural analgesia in the duration of $2^{\text {nd }}$ stage ( 0.9 hour, 0.8 hour, 0.9 hour, respectively, $\left.\mathrm{p}>0.05\right)$ or $3^{\text {rd }}$ stage $(0.2$ hour, 0.2 hour, 0.2 hour, $\mathrm{p}>0.05$ ) labor. The fourth study found a statistically significantly shorter duration of first stage labor and third stage labor in the epidural anesthesia plus electroacupuncture group compared to the epidural alone group (260.00 vs 362.50 minutes, $\mathrm{p}=0.00$ for first stage, 6.00 vs 8.00 minutes, $\mathrm{p}=0.02$ for third stage), but no difference in second stage labor ( 81.50 vs. 92.50 minutes, $\mathrm{p}=0.90) .{ }^{181}$ Given the inconsistency of findings and variability in interventions, the SOE was rated as insufficient for the duration of first stage and total duration of labor. The consistency of findings for second stage resulted in a low SOE rating for no difference.

The proportion of cesarean deliveries was smaller, but not significantly different for the acupuncture (8.4\%, OR $0.64,95 \%$ CI 0.23 to 1.79 ) or electroacupuncture (5.7\%, OR $0.41,95 \%$ CI 0.14 to 1.26 ) groups compared with the control group (13.3\%). ${ }^{128}$ Cesarean deliveries were also lower but not significantly different in the epidural anesthesia plus electroacupuncture group versus epidural anesthesia alone $(1.64 \%$ versus $9.1 \%, \mathrm{p}=0.07) .{ }^{181}$ In the other study, the cesarean delivery rates were lowered in the intervention groups as compared to control therapy. ${ }^{124}$ Given the inconsistency in findings the SOE was rated as insufficient.

\section{Maternal Outcomes for Acupuncture}

Perineal trauma (third or fourth degree laceration) was not significantly different in the acupuncture group (5.3\%, OR 1.19, 95\% CI 0.28 to 5.16) or electroacupuncture group (4.9\%, OR 0.92 , 95\% CI 0.21 to 3.92) compared with the control group (5.6\%) (insufficient SOE). ${ }^{128}$ 


\section{Results in Women of Mixed or Unspecified Parity}

\section{Duration of Labor and Cesarean Delivery Rates for Acupuncture}

One study reported a significantly shorter duration of active-phase labor ${ }^{126}$ in the acupuncture group, whereas the other two studies found no significant differences in duration of the firststage, the second-stage, or total duration of labor when comparing the acupuncture group with the control group or with a sham acupuncture group (insufficient SOE for first stage labor, low SOE for no difference in second stage labor duration). ${ }^{124,141}$ In one fair-quality study, acupuncture was associated with a significant reduction in cesarean deliveries (1/30 vs. 8/30, $\mathrm{p}<0.05$ ) (insufficient SOE). ${ }^{124}$ Table 33 shows results for these studies.

\section{Maternal Outcomes for Acupuncture}

Postpartum hemorrhage was not significantly different between the acupuncture and control groups, with one study reporting severe hemorrhage in $8.0 \%$ of the control group and $4.0 \%$ of the acupuncture group $(\mathrm{p}=0.537),{ }^{126}$ and another study stating no significant differences in postpartum hemorrhage without reporting specific data. ${ }^{141}$ 
Table 33. Effects of acupuncture versus control treatment

\begin{tabular}{|c|c|c|c|c|c|c|c|c|}
\hline $\begin{array}{l}\text { Study } \\
\text { Quality }\end{array}$ & Int & Com & $\begin{array}{l}\text { Duration of Labor: } \\
\text { Int }\end{array}$ & $\begin{array}{l}\text { Duration of Labor: } \\
\text { Com }\end{array}$ & $\begin{array}{c}\text { Duration of } \\
\text { Labor: } \\
\text { P Value }\end{array}$ & $\begin{array}{c}\text { Cesarean: } \\
\text { Int }\end{array}$ & $\begin{array}{l}\text { Cesarean: } \\
\text { Com }\end{array}$ & $\begin{array}{c}\text { Cesarean: } \mathbf{P} \\
\text { Value }\end{array}$ \\
\hline $\begin{array}{l}\text { Allameh, } \\
2015^{126} \\
\text { Poor }\end{array}$ & $\begin{array}{l}\text { Acupuncture } \\
\text { adjunct to } \\
\text { usual care } \\
\mathrm{N}=27\end{array}$ & $\begin{array}{l}\text { Usual care } \\
\mathrm{N}=28\end{array}$ & $\begin{array}{l}\text { Active phase } \\
175.8 \mathrm{~min}\end{array}$ & $\begin{array}{l}\text { Active phase } \\
243.77 \mathrm{~min}\end{array}$ & $\begin{array}{l}\text { Mean difference } \\
<0.001\end{array}$ & $2 / 27$ & $3 / 28$ & 0.67 \\
\hline \multirow[t]{2}{*}{ Liu, $2015^{124}$} & $\begin{array}{l}\text { Acupuncture } \\
\mathrm{N}=30\end{array}$ & $\begin{array}{l}\text { No analgesic } \\
\text { intervention/e } \\
\text { xpectant } \\
\text { management } \\
\mathrm{N}=30\end{array}$ & $\begin{array}{l}1^{\text {st }} \text { stage } \\
430.1 \mathrm{~min}(119.8)\end{array}$ & $\begin{array}{l}1^{\text {st }} \text { stage } \\
439.6 \text { min }(200.3)\end{array}$ & 0.82 & $1 / 30$ & $8 / 30$ & 0.011 \\
\hline & $\begin{array}{l}\text { Acupuncture } \\
\mathrm{N}=30\end{array}$ & $\begin{array}{l}\text { No analgesic } \\
\text { intervention/e } \\
\text { xpectant } \\
\text { management } \\
\mathrm{N}=30\end{array}$ & $\begin{array}{l}2^{\text {nd }} \text { stage } \\
43.3 \text { min }(17.5)\end{array}$ & $\begin{array}{l}2^{\text {nd }} \text { stage } \\
46.3 \text { min }(20.6)\end{array}$ & 0.54 & - & - & - \\
\hline \multirow[t]{4}{*}{ Ma, $2011^{141}$} & $\begin{array}{l}\text { Electro- } \\
\text { acupuncture } \\
\text { adjunct to } \\
\text { usual care } \\
\mathrm{N}=92\end{array}$ & $\begin{array}{l}\text { Usual care } \\
N=100\end{array}$ & $\begin{array}{l}1^{\text {st }} \text { stage latent } \\
219.60 \text { min } \\
(130.19)\end{array}$ & $\begin{array}{l}1^{\text {st }} \text { stage latent } \\
244.20 \text { min } \\
(164.76)\end{array}$ & 0.25 & - & - & - \\
\hline & $\begin{array}{l}\text { Sham } \\
\text { acupuncture } \\
\text { adjunct to } \\
\text { usual care } \\
\mathrm{N}=94\end{array}$ & $\begin{array}{l}\text { Usual care } \\
\mathrm{N}=100\end{array}$ & $\begin{array}{l}1^{\text {st }} \text { stage latent } \\
246.60 \mathrm{~min} \\
(161.54)\end{array}$ & $\begin{array}{l}1^{\text {st }} \text { stage latent } \\
244.20 \mathrm{~min} \\
(164.76)\end{array}$ & 0.92 & - & - & - \\
\hline & $\begin{array}{l}\text { Electro- } \\
\text { acupuncture } \\
\text { adjunct to } \\
\text { usual care } \\
\mathrm{N}=92\end{array}$ & $\begin{array}{l}\text { Usual care } \\
\mathrm{N}=100\end{array}$ & $\begin{array}{l}1^{\text {st }} \text { stage active } \\
186.05 \mathrm{~min}(99.66)\end{array}$ & $\begin{array}{l}1^{\text {st }} \text { stage active } \\
161.03 \text { min }(87.23)\end{array}$ & 0.06 & - & - & - \\
\hline & $\begin{array}{l}\text { Sham } \\
\text { acupuncture } \\
\text { adjunct to } \\
\text { usual care } \\
\mathrm{N}=94\end{array}$ & $\begin{array}{l}\text { Usual care } \\
\mathrm{N}=100\end{array}$ & $\begin{array}{l}1^{\text {st }} \text { stage active } \\
196.76 \text { min } \\
(100.91)\end{array}$ & $\begin{array}{l}1^{\text {st }} \text { stage active } \\
161.03 \min (87.23)\end{array}$ & 0.009 & - & - & - \\
\hline
\end{tabular}




\begin{tabular}{|c|c|c|c|c|c|c|c|c|}
\hline $\begin{array}{l}\text { Study } \\
\text { Quality }\end{array}$ & Int & Com & $\begin{array}{l}\text { Duration of Labor: } \\
\text { Int }\end{array}$ & $\begin{array}{l}\text { Duration of Labor: } \\
\text { Com }\end{array}$ & $\begin{array}{c}\text { Duration of } \\
\text { Labor: } \\
\text { P Value }\end{array}$ & $\begin{array}{l}\text { Cesarean: } \\
\text { Int }\end{array}$ & $\begin{array}{l}\text { Cesarean: } \\
\text { Com }\end{array}$ & $\begin{array}{c}\text { Cesarean: } P \\
\text { Value }\end{array}$ \\
\hline & $\begin{array}{l}\text { Electro- } \\
\text { acupuncture } \\
\text { adjunct to } \\
\text { usual care } \\
\mathrm{N}=92\end{array}$ & $\begin{array}{l}\text { Usual care } \\
\mathrm{N}=100\end{array}$ & $\begin{array}{l}2^{\text {nd }} \text { stage } \\
30.65 \text { min }(19.40)\end{array}$ & $\begin{array}{l}2^{\text {nd }} \text { stage } \\
31.92 \text { min (19.99) }\end{array}$ & 0.66 & - & - & - \\
\hline & $\begin{array}{l}\text { Sham } \\
\text { acupuncture } \\
\text { adjunct to } \\
\text { usual care } \\
\mathrm{N}=94\end{array}$ & $\begin{array}{l}\text { Usual care } \\
N=100\end{array}$ & $\begin{array}{l}2^{\text {nd }} \text { stage } \\
30.02 \text { min } \\
(19.39)\end{array}$ & $\begin{array}{l}2^{\text {nd }} \text { stage } \\
31.92 \text { min (19.99) }\end{array}$ & 0.50 & - & - & - \\
\hline & $\begin{array}{l}\text { Electro- } \\
\text { acupuncture } \\
\text { adjunct to } \\
\text { usual care } \\
\mathrm{N}=116\end{array}$ & $\begin{array}{l}\text { Usual care } \\
N=100\end{array}$ & $\begin{array}{l}\text { Total duration } \\
443.44 \text { min } \\
(176.88)\end{array}$ & $\begin{array}{l}\text { Total duration } \\
444.21 \text { min } \\
(193.34)\end{array}$ & 0.97 & - & - & - \\
\hline & $\begin{array}{l}\text { Sham } \\
\text { acupuncture } \\
\text { adjunct to } \\
\text { usual care } \\
\mathrm{N}=117\end{array}$ & $\begin{array}{l}\text { Usual care } \\
\mathrm{N}=100\end{array}$ & $\begin{array}{l}\text { Total duration } \\
480.85 \text { min } \\
(206.80)\end{array}$ & $\begin{array}{l}\text { Total duration } \\
444.21 \text { min } \\
(193.34)\end{array}$ & 0.16 & - & - & - \\
\hline \multirow[t]{2}{*}{ Xiao, 2019181} & $\begin{array}{l}\text { CSEA plus } \\
\text { patient- } \\
\text { controlled } \\
\text { epidural } \\
\text { anesthesia } \\
\text { plus electro- } \\
\text { acupuncture } \\
\mathrm{N}=60\end{array}$ & $\begin{array}{l}\text { CSEA plus } \\
\text { patient- } \\
\text { controlled } \\
\text { epidural } \\
\text { anesthesia } \\
\mathrm{N}=60\end{array}$ & $\begin{array}{l}1^{\text {st }} \text { stage }(3-10 \mathrm{~cm}) \\
260.00 \mathrm{~min} \\
(236.25)\end{array}$ & $\begin{array}{l}1^{\text {st }} \text { stage }(3-10 \mathrm{~cm}) \\
362.50 \mathrm{~min} \\
(355.00)\end{array}$ & 0.00 & $1 / 60$ & $6 / 60$ & 0.07 \\
\hline & $\begin{array}{l}\text { CSEA plus } \\
\text { patient- } \\
\text { controlled } \\
\text { epidural } \\
\text { anesthesia } \\
\text { plus electro- } \\
\text { acupuncture } \\
\mathrm{N}=60\end{array}$ & $\begin{array}{l}\text { CSEA plus } \\
\text { patient- } \\
\text { controlled } \\
\text { epidural } \\
\text { anesthesia } \\
\mathrm{N}=60\end{array}$ & $\begin{array}{l}2^{\text {nd }} \text { stage } \\
81.50 \mathrm{~min}(127.50)\end{array}$ & $\begin{array}{l}2^{\text {nd }} \text { stage } \\
92.50 \text { min }(81.00)\end{array}$ & 0.90 & - & - & - \\
\hline
\end{tabular}




\begin{tabular}{|c|c|c|c|c|c|c|c|c|}
\hline $\begin{array}{l}\text { Study } \\
\text { Quality }\end{array}$ & Int & Com & $\begin{array}{c}\text { Duration of Labor: } \\
\text { Int }\end{array}$ & $\begin{array}{l}\text { Duration of Labor: } \\
\text { Com }\end{array}$ & $\begin{array}{l}\text { Duration of } \\
\text { Labor: } \\
\text { P Value }\end{array}$ & $\begin{array}{c}\text { Cesarean: } \\
\text { Int }\end{array}$ & $\begin{array}{l}\text { Cesarean: } \\
\text { Com }\end{array}$ & $\begin{array}{l}\text { Cesarean: } P \\
\text { Value }\end{array}$ \\
\hline & $\begin{array}{l}\text { CSEA plus } \\
\text { patient- } \\
\text { controlled } \\
\text { epidural } \\
\text { anesthesia } \\
\text { plus electro- } \\
\text { acupuncture } \\
\mathrm{N}=60\end{array}$ & $\begin{array}{l}\text { CSEA plus } \\
\text { patient- } \\
\text { controlled } \\
\text { epidural } \\
\text { anesthesia } \\
\mathrm{N}=60\end{array}$ & $\begin{array}{l}\text { 3rd stage } \\
6.00 \min (3.75)\end{array}$ & $\begin{array}{l}2^{\text {nd }} \text { stage } \\
8.00 \text { min }(4.75)\end{array}$ & 0.02 & - & - & - \\
\hline
\end{tabular}

Abbreviations: -=not reported; Com=comparator; CSEA= combined spinal-epidural anesthesia; Int=intervention; min=minute 


\section{Relevant Systematic Reviews/Meta-Analyses for Acupuncture}

We identified one good-quality SR/MA that examined the effects of acupuncture on labor outcomes. ${ }^{45}$ Analyses that were restricted to women in spontaneous labor included 1 to 3 studies, with 128 to 448 women in the various analyses of mode of delivery. No statistically significant differences were observed in the proportion of cesarean deliveries, assisted vaginal births, or spontaneous vaginal births. None of these studies were included in our review given their publication date. They also did not analyze findings by parity.

\section{Strength of Evidence for Acupuncture}

Tables 34 and 35 summarize the SOE for acupuncture/acupoint nerve stimulator versus control therapy. In general, the SOE was rated as insufficient given inconsistent findings from studies with variability in interventions.

Table 34. Acupuncture/acupoint nerve stimulator versus control: Evidence profile in nulliparous women

\begin{tabular}{|c|c|c|c|c|}
\hline Category & Outcome & $\begin{array}{l}\text { Study Design } \\
\text { (Sample Size) }\end{array}$ & Conclusion & $\begin{array}{c}\text { SOE } \\
\text { (Rationale) }^{a}\end{array}$ \\
\hline \multirow[t]{4}{*}{$\begin{array}{l}\text { Intermediate } \\
\text { or Final } \\
\text { Outcomes }\end{array}$} & $\begin{array}{l}\text { Process Related } \\
\text { Outcomes - } \\
\text { Duration of } 1^{\text {st }} \\
\text { Stage Labor }\end{array}$ & $\begin{array}{l}6 \mathrm{RCTS}^{124-} \\
126,141,176,181 \\
(775)\end{array}$ & $\begin{array}{l}\text { Inconclusive: given } \\
\text { inconsistency in findings, } \\
\text { variability in interventions, and } \\
\text { potential risk of bias within the } \\
\text { studies. }\end{array}$ & $\begin{array}{l}\text { Insufficient (High risk of } \\
\text { bias, indirect, } \\
\text { inconsistent, imprecise) }\end{array}$ \\
\hline & $\begin{array}{l}\text { Process Related } \\
\text { Outcomes - } \\
\text { Duration of } 2^{\text {nd }} \\
\text { Stage Labor }\end{array}$ & $\begin{array}{l}4 \\
\text { RCTs } \\
81 \\
(601)\end{array}$ & $\begin{array}{l}\text { No difference: in } 2^{\text {nd }} \text { stage } \\
\text { labor between the acupuncture } \\
\text { and control groups was } \\
\text { reported. }\end{array}$ & $\begin{array}{l}\text { Low } \\
\text { (Medium risk of bias, } \\
\text { indirect, Imprecise) }\end{array}$ \\
\hline & $\begin{array}{l}\text { Process Related } \\
\text { Outcomes - } \\
\text { Duration of Total } \\
\text { Labor }\end{array}$ & $\begin{array}{l}3 \\
\text { RCTs }^{125,128,141} \\
(602)\end{array}$ & $\begin{array}{l}\text { Inconclusive: SOE was } \\
\text { insufficient given inconsistency } \\
\text { in findings, variability in } \\
\text { interventions, and potential risk } \\
\text { of bias within the studies. }\end{array}$ & $\begin{array}{l}\text { Insufficient (Medium } \\
\text { risk of bias, indirect, } \\
\text { inconsistent, imprecise) }\end{array}$ \\
\hline & $\begin{array}{l}\text { Process Related } \\
\text { Outcomes - Mode } \\
\text { of Delivery } \\
\text { (Cesarean } \\
\text { Delivery) } \\
\end{array}$ & $\begin{array}{l}3 \\
\text { RCTs } s^{124,128,181} \\
(493)\end{array}$ & $\begin{array}{l}\text { Inconclusive: SOE was } \\
\text { insufficient given inconsistency } \\
\text { in findings, variability in } \\
\text { interventions, and potential risk } \\
\text { of bias within the studies. }\end{array}$ & $\begin{array}{l}\text { Insufficient (Medium } \\
\text { risk of bias, indirect, } \\
\text { inconsistent, imprecise) }\end{array}$ \\
\hline $\begin{array}{l}\text { Adverse } \\
\text { Events }\end{array}$ & $\begin{array}{l}\text { Maternal } \\
\text { Outcomes - } \\
\text { Trauma to the } \\
\text { Pelvic Floor }\end{array}$ & $\begin{array}{l}1 \mathrm{RCT}^{128} \\
(253)\end{array}$ & $\begin{array}{l}\text { Inconclusive: SOE was rated } \\
\text { as insufficient given findings } \\
\text { from } 1 \text { study with medium risk } \\
\text { of bias. }\end{array}$ & $\begin{array}{l}\text { Insufficient (Medium } \\
\text { risk of bias, Imprecise, } \\
1 \text { study) }\end{array}$ \\
\hline
\end{tabular}

${ }^{a}$ Criteria for downgrading SOE are described as Rationale; when these criteria are insufficient for understanding the final SOE, additional explanation is provided.

Abbreviations: RCT=randomized controlled trial; SOE=strength of evidence

Table 35. Acupuncture/acupoint nerve stimulator versus control: Evidence profile in women of mixed parity

\begin{tabular}{|l|l|l|l|l|}
\hline \multicolumn{1}{|c|}{ Category } & \multicolumn{1}{|c|}{ Outcome } & $\begin{array}{l}\text { Study Design } \\
\text { (Sample Size) }\end{array}$ & \multicolumn{1}{c|}{ Conclusion } & \multicolumn{1}{c|}{$\begin{array}{c}\text { SOE } \\
\text { (Rationale) }^{\mathbf{a}}\end{array}$} \\
\hline $\begin{array}{l}\text { Intermediate } \\
\text { or Final } \\
\text { Outcomes }\end{array}$ & $\begin{array}{l}\text { Process Related } \\
\text { Outcomes }-\end{array}$ & $\begin{array}{l}4 \text { RCTs } \\
\text { Duration of } 1^{\text {st }} \\
\text { Stage Labor }\end{array}$ & $\begin{array}{l}\text { Inconclusive: Results were } \\
\text { inconsistent as to the effects of } \\
\text { manual or electroacupuncture } \\
\text { with a shorter duration reported } \\
\text { in some but not all studies }\end{array}$ & $\begin{array}{l}\text { Insufficient (Medium } \\
\text { risk of bias, indirect, } \\
\text { inconsistent, imprecise) }\end{array}$ \\
\hline
\end{tabular}




\begin{tabular}{|c|c|c|c|c|}
\hline Category & Outcome & $\begin{array}{l}\text { Study Design } \\
\text { (Sample Size) }\end{array}$ & Conclusion & $\begin{array}{c}\text { SOE } \\
\text { (Rationale) }^{\mathrm{a}}\end{array}$ \\
\hline & $\begin{array}{l}\text { Process Related } \\
\text { Outcomes - } \\
\text { Duration of } 2^{\text {nd }} \\
\text { Stage Labor }\end{array}$ & $\begin{array}{l}2 \mathrm{RCTS}^{124,141} \\
(350)\end{array}$ & $\begin{array}{l}\text { No difference: No significant } \\
\text { difference in } 2^{\text {nd }} \text { stage labor } \\
\text { between the acupuncture and } \\
\text { control groups was reported. }\end{array}$ & $\begin{array}{l}\text { Low } \\
\text { (Medium risk of bias, } \\
\text { indirect, imprecise) }\end{array}$ \\
\hline & $\begin{array}{l}\text { Process Related } \\
\text { Outcomes - } \\
\text { Duration of Total } \\
\text { Labor }\end{array}$ & $\begin{array}{l}3 \\
\text { RCTs }^{125,128,141} \\
(602)\end{array}$ & $\begin{array}{l}\text { Inconclusive: Results were } \\
\text { inconsistent as to the effects of } \\
\text { manual or electroacupuncture } \\
\text { on total duration labor, with a } \\
\text { shorter duration reported in only } \\
1 \text { study. SOE was rated as } \\
\text { insufficient. }\end{array}$ & $\begin{array}{l}\text { Insufficient (Medium } \\
\text { risk of bias, indirect, } \\
\text { Inconsistent, imprecise) }\end{array}$ \\
\hline & $\begin{array}{l}\text { Process Related } \\
\text { Outcomes - Mode } \\
\text { of Delivery } \\
\text { (Cesarean } \\
\text { Delivery) }\end{array}$ & $\begin{array}{l}2 \mathrm{RCTs}^{124,128} \\
(373)\end{array}$ & $\begin{array}{l}\text { Inconclusive: SOE was rated } \\
\text { as insufficient given findings } \\
\text { from } 1 \text { study with medium risk } \\
\text { of bias. }\end{array}$ & $\begin{array}{l}\text { Insufficient (Medium } \\
\text { risk of bias, indirect, } \\
\text { imprecise) }\end{array}$ \\
\hline $\begin{array}{l}\text { Adverse } \\
\text { Events }\end{array}$ & $\begin{array}{l}\text { Maternal } \\
\text { Outcomes - } \\
\text { Hemorrhage }\end{array}$ & $\begin{array}{l}1 \mathrm{RCT}^{128} \\
(253)\end{array}$ & $\begin{array}{l}\text { No difference: No significant } \\
\text { difference in hemorrhage was } \\
\text { reported for the intervention } \\
\text { group compared to the control. }\end{array}$ & $\begin{array}{l}\text { Low (High risk of bias, } \\
\text { imprecise) }\end{array}$ \\
\hline
\end{tabular}

${ }^{a}$ Criteria for downgrading SOE are described as Rationale; when these criteria are insufficient for understanding the final SOE, additional explanation is provided.

Abbreviations: RCT=randomized controlled trial; SOE=strength of evidence

\section{Aromatherapy Versus Control Treatment}

Aromatherapy was compared to control therapy for nulliparous women in four studies, two good quality, ${ }^{165,167}$ one fair quality ${ }^{157}$ and one poor quality. ${ }^{127}$ No relevant SR/MAs were identified.

\section{Results in Nulliparous Women}

\section{Duration of Labor and Cesarean Delivery Rates for Aromatherapy}

Four studies addressed duration of first stage labor ${ }^{127,157,165,167}$ and three addressed duration of second stage labor. ${ }^{157,165,167}$ Aromatherapy was not associated with a significantly shorter firststage labor in three of the studies (Table 36). ${ }^{157,165,167}$ In the fourth study, salvia aromatherapy was associated with a significantly shorter duration of first-stage labor $(p=0.001)$ whereas there was no significant difference between jasmine aromatherapy and placebo. No significant differences in second stage labor were reported in two studies, ${ }^{165,167}$ whereas the third study reported a significantly shorter second stage labor with salvia aromatherapy than either jasmine aromatherapy or placebo. ${ }^{157}$

No significant difference in the proportion of cesarean deliveries was reported in two studies. ${ }^{127,167}$

In the fair-quality study, women were more "content” (51.2\%) compared with those in the control group $(23.8 \%)(\mathrm{p}<0.001)$ (insufficient SOE). ${ }^{157}$ 
Table 36. Effects of aromatherapy versus control treatment

\begin{tabular}{|c|c|c|c|c|c|c|c|c|}
\hline $\begin{array}{l}\text { Study } \\
\text { Quality }\end{array}$ & Int & Com & $\begin{array}{l}\text { Duration of } \\
\text { Labor: Int }\end{array}$ & $\begin{array}{l}\text { Duration of } \\
\text { Labor: Com }\end{array}$ & $\begin{array}{c}\text { Duration of } \\
\text { Labor: } \\
\text { P Value }\end{array}$ & Cesarean: Int & Cesarean: Com & $\begin{array}{l}\text { Cesarean: } \\
\text { P Value }\end{array}$ \\
\hline \multirow[t]{4}{*}{$\begin{array}{l}\text { Kaviani, } 2014^{127} \\
\text { Poor }\end{array}$} & $\begin{array}{l}\text { Aromatherapy } \\
\text { (Salvia) } \\
\mathrm{N}=46\end{array}$ & $\begin{array}{l}\text { Aromatherapy } \\
\text { (Jasmine) } \mathrm{N}=48\end{array}$ & $\begin{array}{l}\text { 1st stage labor } \\
460.3 \text { min }(65.5)\end{array}$ & $\begin{array}{l}\text { 1st stage labor } \\
493.6 \text { min } \\
(59.8)\end{array}$ & $\begin{array}{l}0.001 \\
\text { (salvia vs } \\
\text { other groups) }\end{array}$ & 6/52 (11.5\%) & $4 / 52(7.7 \%)$ & 0.6 \\
\hline & $\begin{array}{l}\text { Aromatherapy } \\
\text { (Salvia) } \\
\mathrm{N}=46\end{array}$ & $\begin{array}{l}\text { Placebo } \\
\text { (distilled water) } \\
\mathrm{N}=45\end{array}$ & $\begin{array}{l}\text { 1st stage labor } \\
460.3 \text { min (65.5) }\end{array}$ & $\begin{array}{l}\text { 1st stage labor } \\
509.3 \text { min } \\
(60.1)\end{array}$ & $\begin{array}{l}0.4 \\
\text { (jasmine vs } \\
\text { placebo) }\end{array}$ & 6/52 (11.5\%) & $7 / 52$ (13.5\%) & 0.6 \\
\hline & $\begin{array}{l}\text { Aromatherapy } \\
\text { (Salvia) } \\
\mathrm{N}=46\end{array}$ & $\begin{array}{l}\text { Aromatherapy } \\
\text { (Jasmine) } N=48\end{array}$ & $\begin{array}{l}\text { 2nd stage labor } \\
44.3 \mathrm{~min}(7.6)\end{array}$ & $\begin{array}{l}\text { 2nd stage labor } \\
46 \min (7.2)\end{array}$ & $\begin{array}{l}0.003 \\
\text { (salvia vs } \\
\text { other groups) }\end{array}$ & - & - & - \\
\hline & $\begin{array}{l}\text { Aromatherapy } \\
\text { (Salvia) } \\
\mathrm{N}=46\end{array}$ & $\begin{array}{l}\text { Placebo } \\
\text { (distilled water) } \\
\mathrm{N}=45\end{array}$ & $\begin{array}{l}\text { 2nd stage labor } \\
44.3 \min (7.6)\end{array}$ & $\begin{array}{l}\text { 2nd stage labor } \\
49.83 \text { min } \\
(8.6)\end{array}$ & - & - & - & - \\
\hline $\begin{array}{l}\text { Kaviani, } 2014^{157} \\
\text { Fair }\end{array}$ & $\begin{array}{l}\text { Aromatherapy } \\
\text { (lavender) } \\
\mathrm{N}=80\end{array}$ & $\begin{array}{l}\text { Placebo } \\
\text { (distilled water) } \\
\mathrm{N}=80\end{array}$ & $\begin{array}{l}1^{\text {st }} \text { stage labor } \\
3.6 \mathrm{hrs} \\
(1.39)\end{array}$ & $\begin{array}{l}1^{\text {st }} \text { stage labor } \\
3.9 \mathrm{hrs}(0.5)\end{array}$ & NS & - & - & - \\
\hline \multirow[t]{2}{*}{$\begin{array}{l}\text { Tanvisut, } \\
2018^{167}\end{array}$} & $\begin{array}{l}\text { Aromatherapy } \\
\text { (Jasmine, } \\
\text { geranium rose, } \\
\text { citrus or lavender) } \\
\mathrm{N}=52\end{array}$ & $\begin{array}{l}\text { Usual care } \\
\mathrm{N}=52\end{array}$ & $\begin{array}{l}1^{\text {st }} \text { stage labor } \\
775.6 \text { min } \\
(334.9)\end{array}$ & $\begin{array}{l}1^{\text {st }} \text { stage labor } \\
669.7 \mathrm{~min} \\
(463.7)\end{array}$ & 0.205 & - & - & - \\
\hline & $\begin{array}{l}\text { Aromatherapy } \\
\text { (Jasmine, } \\
\text { geranium rose, } \\
\text { citrus or lavender) } \\
\mathrm{N}=52\end{array}$ & $\begin{array}{l}\text { Usual care } \\
N=52\end{array}$ & $\begin{array}{l}2^{\text {nd }} \text { stage labor } \\
30.2 \text { min } \\
(28.1)\end{array}$ & $\begin{array}{l}2^{\text {nd }} \text { stage labor } \\
23.6 \text { min } \\
(20.4)\end{array}$ & 0.201 & $4 / 52(7.7 \%)$ & $6 / 52$ (11.5\%) & 0.506 \\
\hline \multirow[t]{2}{*}{$\begin{array}{l}\text { Yazdkhasti, } \\
2016^{165}\end{array}$} & $\begin{array}{l}\text { Lavender essence } \\
\mathrm{N}=60\end{array}$ & $\begin{array}{l}\text { Placebo } \\
\text { (distilled water) } \\
\mathrm{N}=59\end{array}$ & $\begin{array}{l}1^{\text {st }} \text { stage active } \\
170.2 \min (91.08)\end{array}$ & $\begin{array}{l}1^{\text {st }} \text { stage active } \\
181.5 \text { min } \\
(93.6)\end{array}$ & 0.5 & - & - & - \\
\hline & $\begin{array}{l}\text { Lavender essence } \\
\mathrm{N}=60\end{array}$ & $\begin{array}{l}\text { Placebo } \\
\text { (distilled water) } \\
\mathrm{N}=59\end{array}$ & $\begin{array}{l}2^{\text {nd }} \text { stage } \\
59.4 \text { min } \\
(34.4)\end{array}$ & $\begin{array}{l}2^{\text {nd }} \text { stage } \\
48.66 \text { min } \\
(23.5)\end{array}$ & 0.6 & - & - & - \\
\hline
\end{tabular}

Abbreviations: -=not reported; Int=intervention; Com=comparator; NS=not significant 


\section{Strength of Evidence for Aromatherapy}

Table 37 summarizes the SOE for outcomes comparing aromatherapy and control treatment. Given the potential risk of bias, small study size, and inconsistent findings, the SOE was rated as insufficient for all outcomes.

Table 37. Aromatherapy versus control: Evidence profile in nulliparous women

\begin{tabular}{|c|c|c|c|c|}
\hline Category & Outcome & $\begin{array}{l}\text { Study Design } \\
\text { (Sample Size) }\end{array}$ & Conclusion & $\begin{array}{c}\text { SOE } \\
\text { (Rationale) }^{\mathrm{a}}\end{array}$ \\
\hline \multirow[t]{3}{*}{$\begin{array}{l}\text { Intermediate } \\
\text { or Final } \\
\text { Outcomes }\end{array}$} & $\begin{array}{l}\text { Process Related } \\
\text { Outcomes }- \\
\text { Duration of } 1^{\text {st }} \\
\text { Stage Labor }\end{array}$ & $\begin{array}{l}4 \\
\mathrm{RCTS} \\
67 \\
(522)\end{array}$ & $\begin{array}{l}\text { Inconclusive: SOE was rated } \\
\text { as insufficient given } \\
\text { inconsistent findings among } \\
\text { studies with potential risk of } \\
\text { bias. }\end{array}$ & $\begin{array}{l}\text { Insufficient (High risk of } \\
\text { bias, indirect, } \\
\text { inconsistent, imprecise) }\end{array}$ \\
\hline & $\begin{array}{l}\text { Process Related } \\
\text { Outcomes - } \\
\text { Duration of } 2^{\text {nd }} \\
\text { Stage Labor }\end{array}$ & $\begin{array}{l}3 \\
\text { RCTs } 127,165,167 \\
(362)\end{array}$ & $\begin{array}{l}\text { Inconclusive: SOE was rated } \\
\text { as insufficient given } \\
\text { inconsistent findings among } \\
\text { types of aromatherapy from } 1 \\
\text { study with high potential risk of } \\
\text { bias. }\end{array}$ & $\begin{array}{l}\text { Insufficient (High risk of } \\
\text { bias, indirect, } \\
\text { imprecise) }\end{array}$ \\
\hline & $\begin{array}{l}\text { Process Related } \\
\text { Outcomes - Mode } \\
\text { of Delivery } \\
\text { (Cesarean } \\
\text { Delivery) }\end{array}$ & $\begin{array}{l}2 \mathrm{RCTs}^{127,167} \\
(260)\end{array}$ & $\begin{array}{l}\text { Inconclusive: SOE was rated } \\
\text { as insufficient findings from } 1 \\
\text { study with high potential risk of } \\
\text { bias. }\end{array}$ & $\begin{array}{l}\text { Insufficient (High risk of } \\
\text { bias, indirect, } \\
\text { Imprecise) }\end{array}$ \\
\hline
\end{tabular}

${ }^{a}$ Criteria for downgrading SOE are described as Rationale; when these criteria are insufficient for understanding the final SOE, additional explanation is provided.

Abbreviations: RCT=randomized controlled trial; SOE=strength of evidence

\section{Anetheum Graveolens (Dill) Seeds Versus Control Treatment}

Results for this intervention were reported for nulliparous and parous women in one study. ${ }^{155}$ No relevant SR/MAs were identified.

\section{Results in Nulliparous Women}

One fair-quality RCT evaluated the effect of consumption of a boiled extract of Anetheum graveolens $L$. (dill) seeds at the start of active-phase labor on duration of labor. ${ }^{155}$ Statistically significantly shorter durations of labor were reported for the intervention group for both firststage (192.01 vs. 397.71 minutes, $\mathrm{p}=0.001$ ) and second-stage labor ( $23.10 \mathrm{vs.} 39$ minutes, $\mathrm{p}=0.001$ ). Given that the findings are from one small fair-quality study the SOE was rated as insufficient.

\section{Results in Parous Women}

The same fair-quality study ${ }^{155}$ reported outcomes for parous women. Duration of first-stage labor was statistically significantly shorter in the intervention group (145 vs. 279.69 minutes, $\mathrm{p}=0.001$ ), whereas differences for second-stage labor were not significant (12.50 vs. 16.56 minutes, $\mathrm{p}=0.12$ ). Again given that the findings are from one small fair-quality study the SOE was rated as insufficient.

\section{Strength of Evidence for Anetheum Graveolens (Dill) Seeds}

Tables 38 and 39 summarize the SOE for dill seeds versus control treatment. 
Table 38. Anetheum graveolens seeds versus control: Evidence profile in nulliparous women

\begin{tabular}{|c|c|c|c|c|}
\hline Category & Outcome & $\begin{array}{l}\text { Study Design } \\
\text { (Sample Size) }\end{array}$ & Conclusion & $\begin{array}{c}\text { SOE } \\
\text { (Rationale) }^{\mathrm{a}} \\
\end{array}$ \\
\hline \multirow[t]{2}{*}{$\begin{array}{l}\text { Intermediate } \\
\text { or Final } \\
\text { Outcomes }\end{array}$} & $\begin{array}{l}\text { Process Related } \\
\text { Outcomes - } \\
\text { Duration of } 1^{\text {st }} \\
\text { Stage Labor }\end{array}$ & $\begin{array}{l}1 \mathrm{RCT}^{155} \\
(103)\end{array}$ & $\begin{array}{l}\text { Inconclusive: SOE was rated } \\
\text { as insufficient given imprecise } \\
\text { findings from } 1 \text { small study with } \\
\text { potential risk of bias. }\end{array}$ & $\begin{array}{l}\text { Insufficient (Medium } \\
\text { risk of bias, indirect, } \\
\text { imprecise, } 1 \text { study) }\end{array}$ \\
\hline & $\begin{array}{l}\text { Process Related } \\
\text { Outcomes - } \\
\text { Duration of } 2^{\text {nd }} \\
\text { Stage Labor }\end{array}$ & $\begin{array}{l}1 \mathrm{RCT}^{155} \\
(103)\end{array}$ & $\begin{array}{l}\text { Inconclusive: SOE was rated } \\
\text { as insufficient given imprecise } \\
\text { findings from } 1 \text { small study with } \\
\text { potential risk of bias. }\end{array}$ & $\begin{array}{l}\text { Insufficient } \\
\text { (Medium risk of bias, } \\
\text { indirect, imprecise, } 1 \\
\text { study) }\end{array}$ \\
\hline
\end{tabular}

${ }^{a}$ Criteria for downgrading SOE aredescribed as Rationale; when these criteria are insufficient for understanding the final SOE, additional explanation is provided.

Table 39. Anetheum graveolens seeds versus control: Evidence profile in women of mixed parity

\begin{tabular}{|c|c|c|c|c|}
\hline Category & Outcome & $\begin{array}{l}\text { Study Design } \\
\text { (Sample Size) }\end{array}$ & Conclusion & $\begin{array}{c}\text { SOE } \\
\text { (Rationale) }^{a}\end{array}$ \\
\hline \multirow[t]{2}{*}{$\begin{array}{l}\text { Intermediate } \\
\text { or Final } \\
\text { Outcomes }\end{array}$} & $\begin{array}{l}\text { Process Related } \\
\text { Outcomes - } \\
\text { Duration of } 1^{\text {st }} \\
\text { Stage Labor }\end{array}$ & $\begin{array}{l}1 \mathrm{RCT}^{155} \\
(103)\end{array}$ & $\begin{array}{l}\text { Inconclusive: SOE was rated } \\
\text { as insufficient given imprecise } \\
\text { findings from } 1 \text { small study with } \\
\text { potential risk of bias. }\end{array}$ & $\begin{array}{l}\text { Insufficient } \\
\text { (Medium risk of bias, } \\
\text { indirect, imprecise, } 1 \\
\text { study) }\end{array}$ \\
\hline & $\begin{array}{l}\text { Process Related } \\
\text { Outcomes - } \\
\text { Duration of } 2^{\text {nd }} \\
\text { Stage Labor }\end{array}$ & $\begin{array}{l}1 \mathrm{RCT}^{155} \\
(103)\end{array}$ & $\begin{array}{l}\text { Inconclusive: SOE was rated } \\
\text { as insufficient given imprecise } \\
\text { findings from } 1 \text { small study with } \\
\text { potential risk of bias. }\end{array}$ & $\begin{array}{l}\text { Insufficient } \\
\text { (Medium risk of bias, } \\
\text { indirect, imprecise, } 1 \\
\text { study) }\end{array}$ \\
\hline
\end{tabular}

${ }^{a}$ Criteria for downgrading SOE are described as Rationale; when these criteria are insufficient for understanding the final SOE, additional explanation is provided.

Abbreviations: RCT=randomized controlled trial; SOE=strength of evidence

\section{Ambulation and Positioning Strategies Versus Control Treatment}

Sixteen studies examined the effects of ambulation and positioning strategies during labor on labor outcomes. ${ }^{80,129,134,140,146,147,150,153,154,158,159,161,164,169,170,172 ~ F o u r ~ o f ~ t h e s e ~ s t u d i e s ~ w e r e ~ r a t e d ~ a s ~}$ good-quality $^{80,146,153,172}$ and nine studies were rated as fair quality. ${ }^{129,134,140,147,154,158,164,169,170}$ Three studies were judged to be of poor quality ${ }^{150,159,161}$ due to unclear and inconsistent reporting, discrepant participant numbers, and poor control group/usual care definitions.

Results were reported for nulliparous women in 12 studies. $^{80,129,134,140,146,150,153,158,159,161,164,172}$ Table 40 shows results for these studies.

Results were reported for a mixed population of women in four studies. ${ }^{147,154,169,170}$ Two relevant good-quality SR/MAs were identified. ${ }^{34,50}$

\section{Results in Nulliparous Women}

One good-quality study ${ }^{153}$ and one poor-quality study ${ }^{150}$ examined the effects of ambulation (moving, swaying, rocking, etc.) compared with being confined to bed. Ten studies examined positioning using various methods: angle of the head of the birthing bed, ${ }^{129}$ birth seat, ${ }^{134}$ birth ball, ${ }^{140,164}$ peanut ball, ${ }^{159}$ upright position, ${ }^{146,173}$ kneeling position, ${ }^{80}$ squatting position ${ }^{168}$ and the Prince of Songkla University (PSU) birthing bed. ${ }^{158,161}$ One study compared a combination of strategies used in sequence - birth ball, lumbosacral massage and warm shower- to usual care. ${ }^{172}$

\section{Duration of Labor and Cesarean Delivery Rates for Ambulation and Positioning Strategies \\ Ambulation during first-stage labor was associated with significant reduction in labor

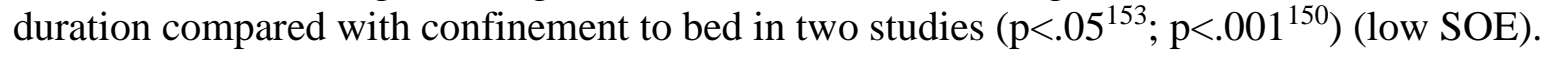


Studies investigating upright laboring positions demonstrated heterogeneity in both interventions and comparators, and reported outcomes were mixed. Statistically significantly shorter second stage labor in the intervention group was reported in two studies, ${ }^{159,168}$ statistically significantly longer duration in two studies ${ }^{80,173}$ and no significant difference in one study. ${ }^{146}$ One study comparing a semi-sitting (head of bed at 45 degrees) position to a supine position found significant differences in duration of second-stage labor $(\mathrm{p}<.05) .{ }^{129}$ Using a birth seat, which may help maintain an upright position, was found to significantly reduce duration of second-stage labor $(\mathrm{p}<.001)$ compared with all other positions in one study. ${ }^{134}$ By comparison, two studies compared use of a birth ball, which may also help maintain an upright position, with reclining in bed and/or heat therapy and did not find significant differences in duration of active-phase labor. ${ }^{140,164}$ A study that evaluated a combination of interventions (birth ball, massage and warm shower) reported a significantly shorter second stage labor in the intervention group than the control group, but no significant difference in total duration of labor. ${ }^{172}$ The strength of evidence was rated as low for duration of the first stage of labor given the potential risk of bias in two studies and the heterogeneity in interventions. Given the inconsistency in findings the SOE was rated as insufficient for the duration of second stage labor.

Two studies investigated lying positions using a bed with several optional adjustments (PSU bed; head and foot of bed angles, lumbar support, leg placement, etc.). ${ }^{158,161}$ One study found statistically significant lower duration of second-stage labor in the intervention group compared with lying with the head of the bed at 45, 60, and 15 degrees, ${ }^{158}$ and the other found significant differences between groups using the PSU bed and those in traditional beds. ${ }^{161} \mathrm{SOE}$ was rated as insufficient for all interventions other than ambulation during the first stage of labor.

Of the twelve studies with nulliparous participants, six reported cesarean delivery outcomes. ${ }^{80,134,150,168,172,173}$ Four studies found lower numbers of cesarean deliveries in intervention groups, ${ }^{80,134,150,172}$ though only one poor quality study showed a statistically significant difference $(\mathrm{p}<0.01) .{ }^{150}$ One study reported the same number of cesarean deliveries in the intervention and control groups ${ }^{168}$ and one reported non-significantly higher rates of cesarean deliveries in the control group ${ }^{173}$ Given the potential high risk of bias, the SOE was rated as insufficient for ambulation. The SOE was rated as moderate for positioning given the consistent findings of the included studies and the support of the meta analysis discussed below.

\section{Maternal Outcomes for Ambulation and Positioning Strategies}

Two good-quality studies reported maternal outcomes. ${ }^{80,173}$ In one study a kneeling position was associated with non-significant reductions in pelvic floor trauma (vaginal laceration, sphincter rupture, third- and fourth-degree perineal tears). ${ }^{80}$ In a second study, no significant difference in perineal tear severity or postpartum hemorrhage was found between upright vs. lying down position during second stage labor. ${ }^{173}$ (low SOE).

\section{Neonatal Outcomes for Ambulation and Positioning Strategies}

Two good quality ${ }^{172,173}$ and two poor-quality studies ${ }^{150,159}$ reported neonatal outcomes. In one good-quality study, metabolic acidosis (cord artery $\mathrm{pH}<7.05$ ) in the upright position group was less frequent but not significantly different than the control group (6/1556 vs. 17/1537, RR 0.35, $95 \%$ CI 0.10 to 1.18$)$. The other good quality study reported non-significant differences in shoulder dystocia (0/40 in the intervention group and $1 / 40$ in the usual care group). ${ }^{172}$ Abnormal fetal heart rate tracing data were reported without significance values in two studies. ${ }^{150,159}$ The study using a movement intervention found 0.9 percent of the experimental group and 1.9 percent of the control group experienced abnormal fetal heart rate (FHR) tracing, ${ }^{150}$ and a study 
investigating a supported sitting versus supine position showed 7 of 100 individuals in the experimental group with abnormal FHR tracing compared to 13 of 100 individuals in the control group. ${ }^{159}$ Given the potential risk of bias in these studies, the SOE was rated as insufficient.

\section{Process-Related Outcomes for Ambulation and Positioning Strategies}

One good quality ${ }^{172}$ and two poor-quality studies ${ }^{150,159}$ reported on parental preferences. ${ }^{150,159}$ In the good quality study, satisfaction with the overall labor experience was higher in the combination intervention group than the usual care group (3.6 vs. 2.0 on a 4-point scale, difference 1.6, 95\% CI 1.2 to 2.0), as was satisfaction with duration of labor and pain severity during labor, while satisfaction with the quality of care received was not significantly different between the groups. In one of the poor-quality studies, ${ }^{150}$ in the intervention group, 23.6 percent of mothers rated their satisfaction level as "moderate" while 76.4 percent rated it as "high." In the control group, 11.4 percent rated satisfaction as "low," 26.7 percent as "moderate," and 61.9 percent as "high" $(\mathrm{p}<0.01)$. In comparing a supported sitting position with a supine position, 93 percent of those women in the sitting (experimental) group expressed a higher preference for assigned position for next childbirth, compared with 61 percent of women in the supine position. ${ }^{150} 92$ percent of women in the supported sitting position agreed that the assigned position was more comfortable for giving birth, compared with 54 percent in the supine group. In the second poor-quality study, ${ }^{159} 93$ percent of women stated a higher preference of the supporting sitting position for their next childbirth, compared with 61 percent in the supine position. Given the high risk of bias in these two studies the SOE was rated as insufficient. 
Table 40. Effects of ambulation versus control treatment

\begin{tabular}{|c|c|c|c|c|c|c|c|c|c|c|}
\hline $\begin{array}{l}\text { Study } \\
\text { Quality }\end{array}$ & Int & Com & $\begin{array}{l}\text { Duration of } \\
\text { Labor: } \\
\text { Int }\end{array}$ & $\begin{array}{l}\text { Duran of } \\
\text { Labor: } \\
\text { Com }\end{array}$ & $\begin{array}{l}\text { Duration of } \\
\text { Labor: } \\
\text { P Value }\end{array}$ & $\begin{array}{c}\text { Cesarean: } \\
\text { Int }\end{array}$ & $\begin{array}{l}\text { Cesarean: } \\
\text { Com }\end{array}$ & $\begin{array}{l}\text { Cesarean: } \\
\text { P Value }\end{array}$ & $\begin{array}{c}\text { Shorter } \\
\text { Labor } \\
\text { Associated } \\
\text { With Lower } \\
\text { Cesarean } \\
\text { Delivery } \\
\text { Rate? }\end{array}$ & Comments \\
\hline $\begin{array}{l}\text { Epidural and } \\
\text { Position Trial } \\
\text { Collaborative } \\
\text { Group, } \\
2017^{173} \\
\text { Good }\end{array}$ & $\begin{array}{l}\text { Any upright } \\
\text { position } \\
\text { during } 2^{\text {nd }} \\
\text { stage labor } \\
\mathrm{N}=1556\end{array}$ & $\begin{array}{l}\text { Lying down } \\
\text { position } \\
\text { during } 2^{\text {nd }} \\
\text { stage labor } \\
\mathrm{N}=1537\end{array}$ & $\begin{array}{l}\text { Median } \\
\text { duration of } \\
2^{\text {nd }} \text { stage } \\
\text { labor } 149 \\
\text { minutes } \\
\text { (IQR } 100 \text { to } \\
\text { 197) }\end{array}$ & $\begin{array}{l}\text { Median } \\
\text { duration of } \\
2^{\text {nd }} \text { stage } \\
\text { labor } 141 \\
\text { minutes } \\
\text { (IQR } 95 \text { to } \\
\text { 188) }\end{array}$ & 0.01 & $\begin{array}{l}158 / 1556 \\
(10.2 \%)\end{array}$ & $\begin{array}{l}127 / 1537 \\
(8.3 \%)\end{array}$ & $\begin{array}{l}\text { RR } 1.23 \\
(95 \% \mathrm{Cl} 0.92- \\
1.64)\end{array}$ & $\begin{array}{l}\text { Shorter } 2^{\text {nd }} \\
\text { stage labor } \\
\text { and lower } \\
\text { cesarean rate } \\
\text { in control } \\
\text { group }\end{array}$ & - \\
\hline $\begin{array}{l}\text { Gallo, } 2018^{172} \\
\text { Fair }\end{array}$ & $\begin{array}{l}\text { Birth ball for } \\
40 \text { min, then } \\
\text { massage for } \\
40 \text { min, then } \\
\text { warm } \\
\text { shower for } \\
40 \text { min } \\
N=40\end{array}$ & $\begin{array}{l}\text { Usual care } \\
\mathrm{N}=40\end{array}$ & $\begin{array}{l}\text { Total } \\
\text { duration of } \\
\text { labor } 373 \\
\text { min (154) } \\
2^{\text {nd }} \text { stage } \\
\text { labor } 19 \text { min } \\
(12)\end{array}$ & $\begin{array}{l}\text { Total } \\
\text { duration of } \\
\text { labor } 445 \\
\text { min (189) } \\
2^{\text {nd }} \text { stage } \\
\text { labor } 37 \text { min } \\
(35)\end{array}$ & $\begin{array}{l}-72(-148 \text { to } \\
5) \\
-18(-30 \\
\text { to }-5)\end{array}$ & $5 / 40(13 \%)$ & $10 / 40(25 \%)$ & $\begin{array}{l}\text { RR 0.50 } \\
(95 \% \text { Cl 0.19- } \\
1.33)\end{array}$ & - & - \\
\hline $\begin{array}{l}\text { Ganapathy, } \\
2012^{159} \\
\text { Poor }\end{array}$ & $\begin{array}{l}\text { HOB } \\
\text { elevated to } \\
60^{\circ} \text { in } 2^{\text {nd }} \\
\text { stage of } \\
\text { labor } \\
(\mathrm{N}=100)\end{array}$ & $\begin{array}{l}\text { Flat supine } \\
(\mathrm{N}=100)\end{array}$ & $\begin{array}{l}2^{\text {nd }} \text { stage: } 56 \\
\text { min }\end{array}$ & $67 \mathrm{~min}$ & $<0.05$ & $\begin{array}{l}\text { Only } \\
\text { "instrumental } \\
\text { deliveries" } \\
\text { reported }\end{array}$ & - & - & - & - \\
\hline $\begin{array}{l}\text { Miquelutti, } \\
2007^{146} \\
\text { Good }\end{array}$ & $\begin{array}{l}\text { Information } \\
\text { and } \\
\text { encourage- } \\
\text { ment for } \\
\text { upright } \\
\text { position } \\
\text { during } 1^{\text {st }} \\
\text { stage }\end{array}$ & $\begin{array}{l}\text { Free to } \\
\text { move as } \\
\text { desired } \\
\text { (usual care) } \\
\mathrm{N}=53\end{array}$ & $\begin{array}{l}1^{\text {st }} \text { stage: } \\
\text { Median=390 } \\
\text { min (NR) } \\
n=35 \\
2^{\text {nd }} \text { stage: } \\
29.5 \text { min }\end{array}$ & $\begin{array}{l}\text { Median=325 } \\
\min (N R) \\
n=42\end{array}$ & 0.76 & $\begin{array}{l}\text { NR: only } \\
\text { "normal } \\
\text { delivery" } \\
\text { reported }\end{array}$ & - & - & - & $\begin{array}{l}\text { "Normal" } \\
\text { delivery RR: } \\
\text { Intervention } \\
0.85 \text { (0.63 to } \\
1.14)\end{array}$ \\
\hline
\end{tabular}




\begin{tabular}{|c|c|c|c|c|c|c|c|c|c|c|}
\hline $\begin{array}{l}\text { Study } \\
\text { Quality }\end{array}$ & Int & Com & $\begin{array}{l}\text { Duration of } \\
\text { Labor: } \\
\text { Int }\end{array}$ & $\begin{array}{l}\text { Duran of } \\
\text { Labor: } \\
\text { Com }\end{array}$ & $\begin{array}{l}\text { Duration of } \\
\text { Labor: } \\
\text { P Value }\end{array}$ & $\begin{array}{c}\text { Cesarean: } \\
\text { Int }\end{array}$ & $\begin{array}{l}\text { Cesarean: } \\
\text { Com }\end{array}$ & $\begin{array}{l}\text { Cesarean: } \\
\text { P Value }\end{array}$ & $\begin{array}{c}\text { Shorter } \\
\text { Labor } \\
\text { Associated } \\
\text { With Lower } \\
\text { Cesarean } \\
\text { Delivery } \\
\text { Rate? }\end{array}$ & Comments \\
\hline $\begin{array}{l}\text { Moraloglu, } \\
2017^{168} \\
\text { Fair }\end{array}$ & $\begin{array}{l}\text { Squatting } \\
\text { position } \\
\text { during } 2^{\text {nd }} \\
\text { stage labor } \\
(\mathrm{N}=50)\end{array}$ & $\begin{array}{l}\text { Supine at } 45 \\
\text { degree } \\
\text { during } 2^{\text {nd }} \\
\text { stage labor } \\
(\mathrm{N}=50)\end{array}$ & $\begin{array}{l}2^{\text {nd }} \text { stage } \\
\text { labor } \\
21.02 \text { min } \\
(5.60) \\
\\
3^{\text {rd }} \text { stage } \\
\text { labor } \\
6.18 \text { min } \\
(1.77)\end{array}$ & $\begin{array}{l}2^{\text {nd }} \text { stage } \\
\text { labor } \\
55.40 \text { min } \\
(6.91) \\
3^{\text {rd }} \text { stage } \\
\text { labor } \\
5.92 \text { min } \\
(1.60)\end{array}$ & $\begin{array}{l}<0.001 \\
\text { NS }\end{array}$ & $1 / 51(2 \%)$ & $1 / 51(2 \%)$ & NS & - & - \\
\hline \multirow[t]{3}{*}{$\begin{array}{l}\text { Phumdoung, } \\
2007^{161} \\
\text { Poor }\end{array}$} & $\begin{array}{l}\text { PSU Cat } \\
\text { position } \\
\text { (alternate } \\
\text { with high } \\
\text { head) } \\
(\mathrm{N}=40)\end{array}$ & $\begin{array}{l}\text { PSU Cat } \\
\text { (alternate } \\
\text { with supine) } \\
(\mathrm{N}=40)\end{array}$ & $\begin{array}{l}\text { Time in } \\
\text { active } \\
\text { phase: } \\
212.38 \text { min } \\
(114.54)\end{array}$ & $\begin{array}{l}289.88 \text { min } \\
(106.68)\end{array}$ & $\begin{array}{l}<0.001 \\
\text { (between- } \\
\text { group } \\
\text { differences) }\end{array}$ & - & - & - & - & $\begin{array}{l}\text { Music } \\
\text { therapy } \\
\text { group } \\
\text { removed for } \\
\mathrm{N} ; 1 \\
\text { cesarean } \\
\text { delivery in } \\
\text { entire group } \\
\text { (arm NR) }\end{array}$ \\
\hline & $\begin{array}{l}\text { PSU Cat } \\
\text { position } \\
\text { (alternate } \\
\text { with high } \\
\text { head) } \\
(\mathrm{N}=40)\end{array}$ & $\begin{array}{l}\text { High head } \\
\text { position } \\
(\mathrm{N}=41)\end{array}$ & $\begin{array}{l}\text { Time in } \\
\text { active } \\
\text { phase: } \\
212.38 \text { min } \\
(114.54)\end{array}$ & $\begin{array}{l}208.29 \text { min } \\
(82.10)\end{array}$ & $\begin{array}{l}<0.001 \\
\text { (between- } \\
\text { group } \\
\text { differences) }\end{array}$ & - & - & - & - & - \\
\hline & $\begin{array}{l}\text { PSU Cat } \\
\text { position } \\
\text { (alternate } \\
\text { with high } \\
\text { head) } \\
(\mathrm{N}=40)\end{array}$ & $\begin{array}{l}\text { Supine } \\
\text { position } \\
(\mathrm{N}=43)\end{array}$ & $\begin{array}{l}\text { Time in } \\
\text { active } \\
\text { phase: } \\
212.38 \text { min } \\
(114.54)\end{array}$ & $\begin{array}{l}379.74 \text { min } \\
(126.59)\end{array}$ & $\begin{array}{l}<0.001 \\
\text { (between- } \\
\text { group } \\
\text { differences) }\end{array}$ & - & - & - & - & $\begin{array}{l}\text { Supine } \\
\text { group had } \\
\text { longer labor } \\
\text { duration } \\
\text { than all } \\
\text { other groups } \\
\text { (significance } \\
\text { NR) }\end{array}$ \\
\hline $\begin{array}{l}\text { Prabhakar, } \\
2015^{153} \\
\text { Good }\end{array}$ & $\begin{array}{l}\text { Ambulation } \\
\text { for } 1-1.5 \mathrm{hr} \\
\text { with rest } \\
\text { periods } \\
(\mathrm{N}=30)\end{array}$ & $\begin{array}{l}\text { Confined to } \\
\text { bed most of } \\
\text { the time } \\
(\mathrm{N}=30)\end{array}$ & $\begin{array}{l}\text { Duration: } \\
575.27 \mathrm{~min} \\
(79.33)\end{array}$ & $\begin{array}{l}617.20 \mathrm{~min} \\
(62.3)\end{array}$ & 0.027 & $\begin{array}{l}\text { Only } \\
\text { "normal" vs. } \\
\text { "abnormal" } \\
\text { reported }\end{array}$ & - & - & - & - \\
\hline
\end{tabular}




\begin{tabular}{|c|c|c|c|c|c|c|c|c|c|c|}
\hline $\begin{array}{l}\text { Study } \\
\text { Quality }\end{array}$ & Int & Com & $\begin{array}{l}\text { Duration of } \\
\text { Labor: } \\
\text { Int }\end{array}$ & $\begin{array}{l}\text { Duran of } \\
\text { Labor: } \\
\text { Com }\end{array}$ & $\begin{array}{l}\text { Duration of } \\
\text { Labor: } \\
\text { P Value }\end{array}$ & $\begin{array}{c}\text { Cesarean: } \\
\text { Int }\end{array}$ & $\begin{array}{l}\text { Cesarean: } \\
\text { Com }\end{array}$ & $\begin{array}{l}\text { Cesarean: } \\
\text { P Value }\end{array}$ & $\begin{array}{c}\text { Shorter } \\
\text { Labor } \\
\text { Associated } \\
\text { With Lower } \\
\text { Cesarean } \\
\text { Delivery } \\
\text { Rate? } \\
\end{array}$ & Comments \\
\hline $\begin{array}{l}\text { Ragnar, } \\
2006^{80} \\
\text { Good }\end{array}$ & $\begin{array}{l}\text { Kneeling } \\
\text { position, } \\
\text { leaning } \\
\text { toward } \mathrm{HOB} \\
(\mathrm{N}=138)\end{array}$ & $\begin{array}{l}\text { Sitting } \\
\text { position, } \\
\text { HOB at } 60^{\circ} \\
(\mathrm{N}=133)\end{array}$ & $\begin{array}{l}2^{\text {nd }} \text { stage }= \\
48.5 \mathrm{~min} \\
(27.6) \\
\\
\text { Total labor } \\
\text { duration= } \\
9.4 \mathrm{hr}(5.8) \\
\end{array}$ & $\begin{array}{l}41 \mathrm{~min} \\
(23.4) \\
9.1 \mathrm{hr}(4.6)\end{array}$ & $\begin{array}{l}0.017 \\
0.64\end{array}$ & 0 & 2 & 0.15 & $\begin{array}{l}\text { Yes; } \\
\text { significance } \\
\text { NR }\end{array}$ & - \\
\hline $\begin{array}{l}\text { Santhi, } \\
2012^{129} \\
\text { Fair }\end{array}$ & $\begin{array}{l}\text { Semi-sitting } \\
\text { position: } \\
\text { HOB at } 45^{\circ} \\
\text { during } 2^{\text {nd }} \\
\text { stage labor } \\
\mathrm{N}=25\end{array}$ & $\begin{array}{l}\text { Supine } \\
\text { position } \\
\qquad N=25\end{array}$ & $\begin{array}{c}\text { Mean } \\
\text { duration of } \\
2^{\text {nd }} \text { stage: } 33 \\
\text { min (SD NR) }\end{array}$ & $\begin{array}{c}59 \min (S D \\
N R)\end{array}$ & $<.05$ & - & - & - & - & - \\
\hline $\begin{array}{l}\text { Sasitorn, } \\
2013^{158} \\
\text { Fair }\end{array}$ & $\begin{array}{l}\text { PSU birthing } \\
\text { bed without } \\
\text { the holding } \\
\text { bar }(\mathrm{N}=60)\end{array}$ & $\begin{array}{l}\text { PSU birthing } \\
\text { bed with the } \\
\text { holding bar } \\
(\mathrm{N}=60) \\
\text { Usual } \\
\text { birthing bed } \\
\text { with HOB at } \\
45-60^{\circ} \\
(\mathrm{N}=60) \\
\text { Usual } \\
\text { birthing bed } \\
\text { with } \mathrm{HOB} \text { at } \\
15^{\circ}(\mathrm{N}=60)\end{array}$ & $\begin{array}{l}2^{\text {nd }} \text { stage: } \\
17.63 \mathrm{~min} \\
(9.70)\end{array}$ & $\begin{array}{l}16.58 \mathrm{~min} \\
(8.47) \\
\\
24.18 \mathrm{~min} \\
(14.20) \\
\\
31.63 \mathrm{~min} \\
(14.22)\end{array}$ & $<0.001$ & - & - & - & - & $\begin{array}{l}\text { Both PSU } \\
\text { groups had } \\
\text { significantly } \\
\text { lower } \\
\text { duration of } \\
2^{\text {nd }} \text { stage }\end{array}$ \\
\hline $\begin{array}{l}\text { Taavoni, } \\
2011^{140} \\
\text { Fair }\end{array}$ & $\begin{array}{l}\begin{array}{l}\text { Birth } \\
\text { ball/Peanut } \\
\text { ball }\end{array} \\
\mathrm{N}=\mathrm{NR} \\
\text { (Total } \mathrm{N} \\
\text { enrolled= } \\
62 \text { ) }\end{array}$ & $\begin{array}{l}\text { Reclining on } \\
\text { bed }\end{array}$ & $\begin{array}{l}\text { Active } \\
\text { phase: } 1.78 \\
\mathrm{hr}(0.58) \\
(\mathrm{N}=\mathrm{NR})\end{array}$ & $\begin{array}{l}1.67 \mathrm{hr} \\
(0.98) \\
(\mathrm{N}=\mathrm{NR})\end{array}$ & 0.605 & - & - & - & Unknown & - \\
\hline $\begin{array}{l}\text { Taavoni, } \\
2016^{164} \\
\text { Fair }\end{array}$ & $\begin{array}{l}\text { Birth ball for } \\
30 \text { min } \\
\text { during active } \\
\text { labor } \\
(\mathrm{N}=30)\end{array}$ & $\begin{array}{l}\text { Heat applied } \\
\text { to sacral and } \\
\text { perineal } \\
\text { area for } 30 \\
\text { min during } \\
\text { active labor } \\
(\mathrm{N}=30)\end{array}$ & $\begin{array}{l}1^{\text {st }} \text { stage } \\
\text { active labor } \\
1.78 \mathrm{hr} \\
(0.58)\end{array}$ & $\begin{array}{l}1^{\text {st }} \text { stage } \\
\text { active labor } \\
1.95 \mathrm{hr} \\
(0.01)\end{array}$ & 0.562 & - & - & - & - & - \\
\hline
\end{tabular}




\begin{tabular}{|c|c|c|c|c|c|c|c|c|c|c|}
\hline $\begin{array}{l}\text { Study } \\
\text { Quality }\end{array}$ & Int & Com & $\begin{array}{l}\text { Duration of } \\
\text { Labor: } \\
\text { Int }\end{array}$ & $\begin{array}{l}\text { Duran of } \\
\text { Labor: } \\
\text { Com }\end{array}$ & $\begin{array}{l}\text { Duration of } \\
\text { Labor: } \\
\text { P Value }\end{array}$ & $\begin{array}{c}\text { Cesarean: } \\
\text { Int }\end{array}$ & $\begin{array}{l}\text { Cesarean: } \\
\text { Com }\end{array}$ & $\begin{array}{l}\text { Cesarean: } \\
\text { P Value }\end{array}$ & $\begin{array}{c}\text { Shorter } \\
\text { Labor } \\
\text { Associated } \\
\text { With Lower } \\
\text { Cesarean } \\
\text { Delivery } \\
\text { Rate? }\end{array}$ & Comments \\
\hline & $\begin{array}{l}\text { Birth ball for } \\
30 \text { min } \\
\text { during active } \\
\text { labor } \\
(\mathrm{N}=30)\end{array}$ & $\begin{array}{l}\text { Usual care } \\
(\mathrm{N}=30)\end{array}$ & $\begin{array}{l}1^{\text {st }} \text { stage } \\
\text { active labor } \\
1.78 \mathrm{hr} \\
(0.58)\end{array}$ & $\begin{array}{l}1^{\text {st }} \text { stage } \\
\text { active labor } \\
1.67 \mathrm{hr} \\
(0.98)\end{array}$ & 0.562 & - & - & - & - & - \\
\hline $\begin{array}{l}\text { Thies- } \\
\text { Lagergren, } \\
2013^{134} \\
\text { Fair }\end{array}$ & $\begin{array}{l}\text { Birth seat } \\
(N=500)\end{array}$ & $\begin{array}{l}\text { Mother's } \\
\text { choice of } \\
\text { birth position } \\
\text { (including } \\
\text { birth seat) } \\
(\mathrm{N}=502)\end{array}$ & $\begin{array}{l}1^{\text {st }} \\
\text { stage }=444 \\
\min (236) \\
2^{\text {nd }} \text { stage }= \\
38 \text { min (25) } \\
3^{\text {rd }} \text { stage }= \\
14 \text { min }(15)\end{array}$ & $\begin{array}{l}455 \min \\
(228) \\
44 \min (27) \\
13 \min (15)\end{array}$ & $\begin{array}{l}0.494 \\
0.001 \\
0.620\end{array}$ & $\begin{array}{l}n=23 \\
4.6 \%\end{array}$ & $\begin{array}{l}n=29 \\
5.8 \%\end{array}$ & 0.39 & $\begin{array}{l}\text { Shorter } 2^{\text {nd }} \\
\text { stage in } \\
\text { intervention } \\
\text { group } \\
\text { consistent } \\
\text { with lower } \\
\text { cesarean } \\
\text { delivery rate }\end{array}$ & - \\
\hline $\begin{array}{l}\text { Vaijayanthim } \\
\text { ala, } 2014^{150} \\
\text { Poor }\end{array}$ & $\begin{array}{l}\text { Movement } \\
\text { during labor } \\
\text { (walking, } \\
\text { rocking, } \\
\text { swaying on } \\
\text { a birthball, } \\
\text { etc.) } \\
\text { discussed/ } \\
\text { encouraged } \\
\text { ( } \mathrm{N}=106)\end{array}$ & $\begin{array}{l}\text { Control } \\
\text { (movement } \\
\text { during labor } \\
\text { not } \\
\text { discussed) } \\
(\mathrm{N}=105)\end{array}$ & $\begin{array}{l}<12 \mathrm{hr}: 53 \\
(50 \%) \\
12-14 \mathrm{hr}: 21 \\
(19.8 \%) \\
\\
>14 \mathrm{hr}: \\
32(30.2 \%)\end{array}$ & $\begin{array}{l}24(22.9 \%) \\
29(27.6 \%) \\
52(49.5 \%)\end{array}$ & 0.001 & $14(13.3 \%)$ & $21(21.1 \%)$ & $<0.01$ & Yes & - \\
\hline
\end{tabular}

Abbreviations: Com=comparator; $\mathrm{HOB}=$ head of bed; Int=intervention; min=minutes; $\mathrm{NR}=$ =not reported; NS=not significant; $\mathrm{RR}=$ =relative risk; $\mathrm{SD}=$ standard deviation 


\section{Results in Women of Mixed or Unspecified Parity}

Three fair-quality studies examined the effects of ambulation and positioning in populations of unclear parity. ${ }^{147,154,170}$ One compared a squatting position with a supine position in secondstage labor ${ }^{147}$, another compared a hands-and-knees position with a supine position in secondstage labor ${ }^{170}$ and the third compared use of a peanut ball after an epidural to a control group. ${ }^{154}$

\section{Duration of Labor and Cesarean Delivery Rates for Ambulation and Positioning Strategies}

Two studies found statistically significant reductions in duration of labor. Women using a squatting position experienced shorter second-stage labor $(\mathrm{p}<0.05),{ }^{147}$ while women using a peanut ball had reductions in duration of first and second stages of labor $(\mathrm{p}=0.006$ and $\mathrm{p}<0.001$, respectively). ${ }^{154}$ The third study reported significantly longer second stage labor in the women in the hands-and-knees position than the control group (45.3 minutes vs. 32.1 minutes, $\mathrm{p}<0.001$ ) but significantly shorter third stage labor ( 9.2 minutes vs. 11.0 minutes, $p=0.0080 .{ }^{170}$ Given findings from just one study regarding the first stage labor duration, the SOE was rated as insufficient. The consistent findings across the two studies resulted in a low SOE rating for the second stage labor duration outcome.

In all three studies, intervention groups had lower rates of cesarean delivery, with statistically significant differences in the peanut ball study $(\mathrm{p}=0.011)^{154}$ and the hands-and-knees delivery study $(\mathrm{p}=0.015)^{170}$ (insufficient SOE).

\section{Maternal Outcomes for Ambulation and Positioning Strategies}

One study reported data on pelvic floor trauma and hemorrhage, showing non-significant differences in periurethral tears, second- and third-degree perineal tears, and postpartum hemorrhage between groups laboring in a squatting position versus a seated position. ${ }^{147} \mathrm{~A}$ second study also reported non-significant differences in second degree perineal tears comparing handsand-knees delivery to supine delivery ${ }^{170}$ (insufficient SOE).

\section{Neonatal Outcomes for Ambulation and Positioning Strategies}

Two studies reported on shoulder dystocia by delivery position. ${ }^{147,170}$ Shoulder dystocia was reported for two neonates in the control group using a seated position for labor, versus no reports of shoulder dystocia in the squatting position group. ${ }^{147}$ There also were no instances of shoulder dystocia in the hands-and-knees delivery group versus 4 in the supine delivery group $(p=0.60) .{ }^{170}$

\section{Process-Related Outcomes for Ambulation and Positioning Strategies}

Nonsignificant differences were reported between groups of women using a peanut ball and the control group in numbers of forceps and vacuum deliveries. ${ }^{154}$ Eleven percent of the group using a squatting position had forceps delivery compared with 24 percent in the supine group $(\mathrm{p}<0.05)$ (insufficient SOE).

\section{Relevant Systematic Reviews/Meta-Analyses for Ambulation and Positioning Strategies}

We identified two good-quality SR/MAs that examined the effects of ambulation and positioning during labor on labor outcomes, with mixed parity groupings. One assessed the effects of various upright positions (including ambulation, sitting, kneeling, and standing) compared to recumbent positions (including supine). ${ }^{34}$ Analyses of up to 11 studies indicated 
reduced duration of first-stage labor for women in upright positions (MD -1.43, 95\% CI -2.35 to -0.50). These findings were inconsistent with our primary studies which demonstrated no difference (low SOE).

Consistent with our included studies, this meta-analysis also supported no difference in cesarean delivery rates (RR $0.70,95 \%$ CI 0.49 to 1.01 ) (moderate SOE). There were no significant differences for other outcomes for mothers or babies. In spite of methodological and quality heterogeneity, sensitivity analyses of higher quality studies supported the main findings.

A second review examined whether encouraging women to adopt an upright position or ambulate during first-stage labor reduced the duration of this stage. ${ }^{50}$ Analyses of 5 studies with between 68 and 1024 participants found non-statistically significant reductions in favor of upright position/ambulation in duration of first-stage labor in nulliparous women (WMD -0.52 hours, 95\% CI -2.13 to 1.09) and parous women (WMD -0.54 hours, 95\% CI -1.75 to 0.671). Other outcomes, including mode of delivery, maternal, and neonatal outcomes, were not affected.

\section{Strength of Evidence for Ambulation and Positioning Strategies}

Tables 41-43 summarize the SOE for ambulation or positioning versus control therapy. Overall the SOE was reduced given the potential risk of bias in the included studies.

Table 41. Ambulation versus control: Evidence profile in nulliparous women

\begin{tabular}{|c|c|c|c|c|}
\hline Category & Outcome & $\begin{array}{l}\text { Study Design } \\
\text { (Sample Size) }\end{array}$ & Conclusion & $\begin{array}{c}\text { SOE } \\
\text { (Rationale) }^{a}\end{array}$ \\
\hline \multirow[t]{2}{*}{$\begin{array}{l}\text { Intermediate or } \\
\text { Final } \\
\text { Outcomes }\end{array}$} & $\begin{array}{l}\text { Process Related } \\
\text { Outcomes - } \\
\text { Duration of } 1^{\text {st }} \\
\text { Stage Labor }\end{array}$ & $\begin{array}{l}2 \mathrm{RCTS}^{150,153} \\
(271)\end{array}$ & $\begin{array}{l}\text { Improvement with } \\
\text { ambulation: } 1 \text { good-quality }{ }^{153} \\
\text { and } 1 \text { poor-quality study }{ }^{150} \\
\text { found that ambulation was } \\
\text { associated with significantly } \\
\text { reduced duration of the first } \\
\text { stage and total duration of } \\
\text { labor. }\end{array}$ & $\begin{array}{l}\text { Low } \\
\text { (Medium risk of bias, } \\
\text { indirect, imprecise, } \\
\text { inconsistent with SR) }\end{array}$ \\
\hline & $\begin{array}{l}\text { Process Related } \\
\text { Outcomes - } \\
\text { Mode of Delivery } \\
\text { (Cesarean } \\
\text { Delivery) }\end{array}$ & $\begin{array}{l}1 \mathrm{RCT}^{150} \\
(211)\end{array}$ & $\begin{array}{l}\text { Inconclusive: The SOE was } \\
\text { rated as insufficient given } \\
\text { findings from } 1 \text { study with high } \\
\text { risk of bias. }\end{array}$ & $\begin{array}{l}\text { Insufficient } \\
\text { (High risk of bias, } \\
\text { indirect, imprecise, } 1 \\
\text { study) }\end{array}$ \\
\hline \multirow[t]{2}{*}{$\begin{array}{l}\text { Adverse } \\
\text { Events }\end{array}$} & $\begin{array}{l}\text { Neonatal } \\
\text { Outcomes - } \\
\text { Abnormal Fetal } \\
\text { Heart Tracing }\end{array}$ & $\begin{array}{l}1 \mathrm{RCT}^{150} \\
(211)\end{array}$ & $\begin{array}{l}\text { Inconclusive: The SOE was } \\
\text { rated as insufficient given } \\
\text { findings from on1e study with } \\
\text { high risk of bias. }\end{array}$ & $\begin{array}{l}\text { Insufficient } \\
\text { (High risk of bias, } \\
\text { indirect, imprecise, } 1 \\
\text { study) }\end{array}$ \\
\hline & $\begin{array}{l}\text { Process Related } \\
\text { Outcomes - } \\
\text { Parental } \\
\text { Preferences }\end{array}$ & $\begin{array}{l}\text { 1 RCT150 } \\
(211)\end{array}$ & $\begin{array}{l}\text { Inconclusive: The SOE was } \\
\text { rated as insufficient given } \\
\text { findings from } 1 \text { study with high } \\
\text { risk of bias. }\end{array}$ & $\begin{array}{l}\text { Insufficient } \\
\text { (High risk of bias, } \\
\text { indirect, imprecise, } 1 \\
\text { study) }\end{array}$ \\
\hline
\end{tabular}

${ }^{\mathrm{a}}$ Criteria for downgrading SOE are described as Rationale; when these criteria are insufficient for understanding the final SOE, additional explanation is provided.

Abbreviations: RCT=randomized controlled trial; $\mathrm{SOE}=$ strength of evidence; $\mathrm{SR}=$ systematic review 
Table 42. Positioning versus control: Evidence profile in nulliparous women

\begin{tabular}{|c|c|c|c|c|}
\hline Category & Outcome & $\begin{array}{l}\text { Study Design } \\
\text { (Sample Size) }\end{array}$ & Conclusion & $\begin{array}{c}\text { SOE } \\
\text { (Rationale) }^{a}\end{array}$ \\
\hline \multirow[t]{3}{*}{$\begin{array}{l}\text { Intermediate } \\
\text { or Final } \\
\text { Outcomes }\end{array}$} & $\begin{array}{l}\text { Process Related } \\
\text { Outcomes }- \\
\text { Duration of } 1^{\text {st }} \\
\text { Stage Labor }\end{array}$ & $\begin{array}{l}5 \\
\text { RCTs } \\
9,164 \\
(798)\end{array}$ & $\begin{array}{l}\text { No difference: None of the } \\
\text { studies examining use of a birth } \\
\text { ball, kneeling, sitting, or semi- } \\
\text { sitting laboring positions found } \\
\text { statistically significant } \\
\text { differences in duration of active } \\
\text { labor. }\end{array}$ & $\begin{array}{l}\text { Low } \\
\text { (High risk of bias, } \\
\text { indirect, imprecise, } \\
\text { inconsistency with SR) }\end{array}$ \\
\hline & $\begin{array}{l}\text { Process Related } \\
\text { Outcomes - } \\
\text { Duration of } 2^{\text {nd }} \\
\text { Stage Labor }\end{array}$ & $\begin{array}{l}10 \\
\mathrm{RCTS}^{80,129,134,14} \\
6,158,159,161,168,172,1 \\
73 \\
(5,307)\end{array}$ & $\begin{array}{l}\text { Inconclusive: Given the } \\
\text { inconsistency, imprecision, and } \\
\text { potential risk of bias, the SOE } \\
\text { was rated as insufficient. }\end{array}$ & $\begin{array}{l}\text { Insufficient (High risk of } \\
\text { bias, indirect, } \\
\text { Inconsistent, imprecise) }\end{array}$ \\
\hline & $\begin{array}{l}\text { Process Related } \\
\text { Outcomes - Mode } \\
\text { of Delivery } \\
\text { (Cesarean } \\
\text { Delivery) }\end{array}$ & $\begin{array}{l}5 \\
\mathrm{RCTS}^{80,134,168,17} \\
(4,173 \\
(4,546) \\
1 \mathrm{SR}^{34} \\
(2,079 \\
\text { patients, } 8 \\
\text { studies) }\end{array}$ & $\begin{array}{l}\text { No difference: No significant } \\
\text { differences were found between } \\
\text { the intervention and control } \\
\text { groups in mode of delivery. }\end{array}$ & $\begin{array}{l}\text { Moderate (Medium risk } \\
\text { of bias, indirect, } \\
\text { imprecise, consistent) } \\
\text { The SOE was } \\
\text { increased given the } \\
\text { support of a SR of } 11 \\
\text { studies. }\end{array}$ \\
\hline \multirow[t]{2}{*}{$\begin{array}{l}\text { Adverse } \\
\text { Events }\end{array}$} & $\begin{array}{l}\text { Maternal } \\
\text { Outcomes - } \\
\text { Trauma to the } \\
\text { Pelvic Floor }\end{array}$ & $\begin{array}{l}1 \mathrm{RCT}^{80} \\
(271)\end{array}$ & $\begin{array}{l}\text { Improvement with kneeling: } \\
\text { Women in kneeling position } \\
\text { were more likely than women in } \\
\text { sitting position to have an intact } \\
\text { perineum ( } 51 \text { vs. } 37 \% \text { ) and } \\
\text { fewer } 3 \text { rd or } 4 \text { th degree tears ( } 3 \\
\text { vs. } 6 \% \text { ). }\end{array}$ & $\begin{array}{l}\text { Low } \\
\text { (Imprecise, one study) }\end{array}$ \\
\hline & $\begin{array}{l}\text { Neonatal } \\
\text { Outcomes - } \\
\text { Abnormal Fetal } \\
\text { Heart Tracing } \\
\end{array}$ & $\begin{array}{l}1 \mathrm{RCT}^{159} \\
(200)\end{array}$ & $\begin{array}{l}\text { Inconclusive: The SOE was } \\
\text { rated as insufficient given } \\
\text { findings from one study with } \\
\text { high risk of bias. }\end{array}$ & $\begin{array}{l}\text { Insufficient } \\
\text { (High risk of bias, } \\
\text { indirect, Imprecise) }\end{array}$ \\
\hline
\end{tabular}

${ }^{a}$ Criteria for downgrading SOE are described as Rationale; when these criteria are insufficient for understanding the final SOE, additional explanation is provided.

Abbreviations: RCT=randomized controlled trial; SOE=strength of evidence; SR=systematic review

Table 43. Ambulation/positioning versus control: Evidence profile in women of mixed parity

\begin{tabular}{|c|c|c|c|c|}
\hline Category & Outcome & $\begin{array}{l}\text { Study Design } \\
\text { (Sample Size) }\end{array}$ & Conclusion & $\begin{array}{c}\text { SOE } \\
\text { (Rationale) }^{\mathrm{a}} \\
\end{array}$ \\
\hline \multirow[t]{3}{*}{$\begin{array}{l}\text { Intermediate } \\
\text { or Final } \\
\text { Outcomes }\end{array}$} & $\begin{array}{l}\text { Process Related } \\
\text { Outcomes - } \\
\text { Duration of } 1^{\text {st }} \\
\text { Stage Labor }\end{array}$ & $\begin{array}{l}1 \mathrm{RCT}^{154} \\
(201)\end{array}$ & $\begin{array}{l}\text { Inconclusive: SOE was } \\
\text { insufficient given potential risk } \\
\text { of bias and findings from } 1 \\
\text { study. }\end{array}$ & $\begin{array}{l}\text { Insufficient } \\
\text { (Medium risk of bias, } \\
\text { indirect, Imprecise, } \\
\text { o1ne study) }\end{array}$ \\
\hline & $\begin{array}{l}\text { Process Related } \\
\text { Outcomes - } \\
\text { Duration of } 2^{\text {nd }} \\
\text { Stage Labor }\end{array}$ & $\begin{array}{l}3 \\
\text { RCTs } 147,154,170 \\
(1,287)\end{array}$ & $\begin{array}{l}\text { Improvement with } \\
\text { positioning: Second stage of } \\
\text { labor was significantly shorter } \\
\text { in women using either a peanut } \\
\text { ball or a squatting position. }\end{array}$ & $\begin{array}{l}\text { Low } \\
\text { (Medium risk of bias, } \\
\text { indirect, Imprecise) }\end{array}$ \\
\hline & $\begin{array}{l}\text { Process Related } \\
\text { Outcomes - Mode } \\
\text { of Delivery } \\
\text { (Cesarean } \\
\text { Delivery) }\end{array}$ & $\begin{array}{l}3 \\
\text { RCTs }^{147,154,170} \\
(1,287)\end{array}$ & $\begin{array}{l}\text { Inconclusive: SOE was rated } \\
\text { as insufficient given potential } \\
\text { risk of bias and } 2 \text { studies where } \\
\text { only } 1 \text { demonstrated statistical } \\
\text { significance. }\end{array}$ & $\begin{array}{l}\text { Insufficient (Medium } \\
\text { risk of bias, indirect, } \\
\text { Inconsistent, imprecise) }\end{array}$ \\
\hline
\end{tabular}




\begin{tabular}{|c|c|c|c|c|}
\hline Category & Outcome & $\begin{array}{l}\text { Study Design } \\
\text { (Sample Size) }\end{array}$ & Conclusion & $\begin{array}{c}\text { SOE } \\
\text { (Rationale) }^{\mathrm{a}}\end{array}$ \\
\hline \multirow[t]{4}{*}{$\begin{array}{l}\text { Adverse } \\
\text { Events }\end{array}$} & $\begin{array}{l}\text { Maternal } \\
\text { Outcomes - } \\
\text { Trauma to the } \\
\text { Pelvic Floor }\end{array}$ & $\begin{array}{l}2 \text { RCTs }^{147,170} \\
(1,086)\end{array}$ & $\begin{array}{l}\text { Inconclusive: SOE was } \\
\text { insufficient given potential risk } \\
\text { of bias and findings with } \\
\text { heterogeneous interventions. }\end{array}$ & $\begin{array}{l}\text { Insufficient } \\
\text { (Medium risk of bias, } \\
\text { Imprecise) }\end{array}$ \\
\hline & $\begin{array}{l}\text { Maternal } \\
\text { Outcomes - } \\
\text { Hemorrhage }\end{array}$ & $\begin{array}{l}\text { 1 RCT }{ }^{147} \\
(200)\end{array}$ & $\begin{array}{l}\text { Inconclusive: SOE was } \\
\text { insufficient given potential risk } \\
\text { of bias and findings from } 1 \\
\text { study. }\end{array}$ & $\begin{array}{l}\text { Insufficient } \\
\text { (Medium risk of bias, } \\
\text { Imprecise, } 1 \text { study) }\end{array}$ \\
\hline & $\begin{array}{l}\text { Neonatal } \\
\text { Outcomes - } \\
\text { Shoulder Dystocia }\end{array}$ & $\begin{array}{l}\text { 2 RCTs }{ }^{147,170} \\
(1,086)\end{array}$ & $\begin{array}{l}\text { Inconclusive: SOE was } \\
\text { insufficient given potential risk } \\
\text { of bias and findings with } \\
\text { heterogeneous interventions. }\end{array}$ & $\begin{array}{l}\text { Insufficient } \\
\text { (Medium risk of bias, } \\
\text { Imprecise) }\end{array}$ \\
\hline & $\begin{array}{l}\text { Process Related } \\
\text { Outcomes - Mode } \\
\text { of Delivery } \\
\text { (Operative Vaginal } \\
\text { Delivery) }\end{array}$ & $\begin{array}{l}1 \mathrm{RCT}^{154} \\
(142)\end{array}$ & $\begin{array}{l}\text { Inconclusive: SOE was } \\
\text { insufficient given potential risk } \\
\text { of bias and findings from } 1 \\
\text { study. }\end{array}$ & $\begin{array}{l}\text { Insufficient } \\
\text { (Medium risk of bias, } \\
\text { indirect, Imprecise, } 1 \\
\text { study) }\end{array}$ \\
\hline
\end{tabular}

${ }^{a}$ Criteria for downgrading SOE are described as Rationale; when these criteria are insufficient for understanding the final SOE, additional explanation is provided.

Abbreviations: RCT=randomized controlled trial; SOE=strength of evidence

\section{Specific Nutritional Intervention and Oral or Parenteral Hydration Intervention Recommendations or Limitations Versus Control Treatment}

Ten studies, described in 11 papers, examined the effects of specific nutritional intervention ${ }^{133}$ and oral or parenteral hydration intervention recommendations or limitations on labor outcomes. $^{82,83,130,135,136,139,142,144,148,171}$ One good-quality study compared oral with parenteral hydration, ${ }^{139}$ another good-quality study compared combined oral and parenteral hydration to discretionary parenteral and oral hydration, ${ }^{142}$ and one fair quality study compared oral and parenteral hydration combined to oral hydration alone. ${ }^{82,83}$ Three good-quality studies compared parenteral hydration of normal saline and dextrose to normal saline alone. ${ }^{135,144,171}$ Three good-quality ${ }^{139,142,148}$ and one fair-quality study ${ }^{136}$ examined the effects of varying hydration volumes using Lactated Ringer's solution. One fair-quality study examined the effects of parenteral hydration using D5LR, a Lactated Ringer's solution containing a 5 percent dextrose injection. ${ }^{130}$

Six good-quality ${ }^{135,139,142,144,148,171}$ and two fair-quality ${ }^{82,130,136}$ studies examined the effects of oral and parenteral hydration recommendations and limitations on labor outcomes in nulliparous women. Table 44 shows results for these studies.

One fair-quality study examined the effects of oral carbohydrate intake on women of mixed parity. ${ }^{133}$ Two relevant good-quality SR/MAs were identified. ${ }^{36,38}$ 


\section{Results in Nulliparous Women}

\section{Duration of Labor and Cesarean Delivery Rates for Specific Nutritional Intervention and Oral or Parenteral Hydration Intervention Recommendations or Limitations}

The five studies examining the effects of intravenous hydration with a Lactated Ringer's (LR) solution were divided in significant findings. ${ }^{82,83,136,139,142,148}$ Different rates of intravenous hydration with LR was found to significantly decrease $(\mathrm{p}<.001)$ duration of active labor compared to oral hydration only in one fair-quality study, ${ }^{136}$ yet had no significant effects when oral hydration was unrestricted in two good-quality studies. ${ }^{139,142}$ When compared with a lower volume of LR solution $(125 \mathrm{ml} / \mathrm{hr})$ in one study, a higher volume $(250 \mathrm{ml} / \mathrm{hr})$ resulted in a shorter mean duration of labor $(\mathrm{p}=.001){ }^{148}$

One study described in two articles ${ }^{82,83}$ comparing intravenous LR, intravenous 5 percent dextrose and oral intake reported significantly shorter total duration of labor in the LR and 5 percent dextrose groups as compared to the oral groups and significantly shorter duration in the 5 percent dextrose group than the LR group. Second stage labor was longer in the LR group than the dextrose or oral group. ${ }^{83}$ D5LR at $125 \mathrm{ml} / \mathrm{hr}$ and $250 \mathrm{ml} / \mathrm{hr}$ with limited oral intake was not found to significantly reduce labor duration compared to a rate of $25 \mathrm{ml} / \mathrm{hr}$ and ad libitum oral hydration. ${ }^{130}$ However, a 5 percent intravenous dextrose (D5) solution was associated with reductions in second-stage labor $(\mathrm{p}=0.01)$ and time from fluid initiation to delivery $(\mathrm{p}=0.02) .{ }^{144}$ Infusion of a dextrose and saline solution was associated with significantly decreased overall labor duration $(\mathrm{p}=0.0) .{ }^{135}$ When combined with the SR evidence discussed below we rated the SOE as low for a reduction in total duration of labor. The SOE was reduced given the inconsistency in the findings from the individual trials and the variability in interventions assessed.

Eight studies reported cesarean delivery rates. ${ }^{82,83,130,136,139,142,144,148,171}$ While infusions of LR at both 125 and $250 \mathrm{ml} / \mathrm{hr}$ did not result in significantly fewer cesarean deliveries, there was a trend in that direction with increased hydration $\left(\mathrm{p}=0.1^{148}\right)$. Parenteral $\mathrm{D} 5 \mathrm{LR},{ }^{130}$ intravenous solutions of 5 percent and 10 percent dextrose, ${ }^{144}$ or dextrose 5 percent or 2.5 percent ${ }^{171}$ resulted in significant differences in rate of cesarean delivery compared to normal saline ( $\mathrm{p}=0.309,{ }^{130}$ $\mathrm{p}=0.21^{144}$ and $\left.\mathrm{p}=0.46^{171}\right)$. No significant differences were noted when comparing $250 \mathrm{ml} / \mathrm{hr} \mathrm{LR}$ to unrestricted oral hydration $\left(\mathrm{p}=0.30^{142}\right)$, LR at $125 \mathrm{ml} / \mathrm{hr}, 250 \mathrm{ml} / \mathrm{hr}$, and oral hydration $\left(\mathrm{p}=0.824^{139}\right)$, LR at 60,120 , and $240 \mathrm{ml} / \mathrm{hr}$ with oral hydration $\left(\mathrm{p}=0.58^{136}\right)$; LR with 5 percent dextrose or oral intake (p not reported). ${ }^{82,83}$

Meta-analysis of the data from three RCTs ${ }^{136,139,142}$ with moderate heterogeneity $\left(\mathrm{I}^{2}=67.1 \%\right.$, $\mathrm{Q}=6.1, \mathrm{p}=0.048$ ) showed no significant difference in cesarean delivery rates (OR 1.26, 95\% CI 0.08 to 18.84) for women receiving high levels of intravenous hydration (either 240 or 250 $\mathrm{ml} / \mathrm{hr}$ ) compared to those with ad libitum oral hydration only (Figure 3) (moderate SOE). These findings were supported by the two SRs discussed below. 
Figure 3. Forest plot of cesarean delivery rate for oral hydration versus high-level intravenous hydration (number of events)

\section{C-section Rate (Oral vs. High)}

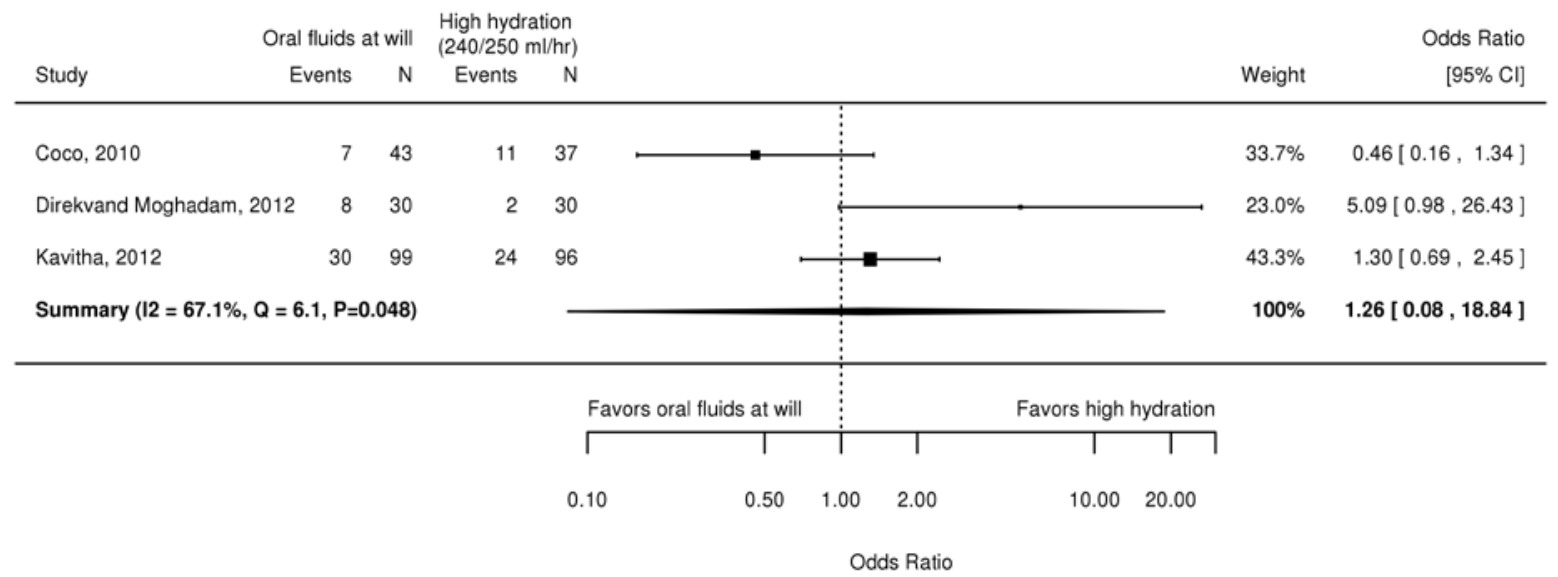

Abbreviations: $\mathrm{CI}=$ confidence interval 


\section{Maternal Outcomes for Specific Nutritional Intervention and Oral or Parenteral Hydration Intervention Recommendations or Limitations}

Three good-quality studies reported maternal outcomes. ${ }^{135,144,171}$ All found that intravenous dextrose solution was not significantly associated with lower rates of chorioamniotis (infection) or postpartum hemorrhage compared to normal saline alone (low SOE).

\section{Neonatal Outcomes for Specific Nutritional Intervention and Oral or Parenteral Hydration Intervention Recommendations or Limitations}

One good-quality study reported neonatal outcomes. Statistical significance was not found for participants experiencing abnormal fetal heart rate tracing in one study comparing 5 percent and 10 percent dextrose solutions to normal saline (5\% arm, 2/94 individuals; 10\% arm, 8/98 individuals; control/normal saline arm: 2/97 individuals). ${ }^{144}$

\section{Process-Related Outcomes for Specific Nutritional Intervention and Oral or Parenteral Hydration Intervention Recommendations or Limitations}

Five studies reported other process-related outcomes. Intravenous dextrose and normal saline solution was associated with a significantly lower number of participants experiencing prolonged labor $(\mathrm{p}=0.009)$ compared to normal saline alone, but not with number of operative vaginal deliveries, though intervention groups experienced fewer $(\mathrm{p}=0.1) .{ }^{135}$ Number of operative vaginal deliveries were not significantly different between arms receiving infusions of LR at 125 or $250 \mathrm{ml} / \mathrm{hr}$ compared with unrestricted oral fluids and LR at $25 \mathrm{ml} / \mathrm{hr} .{ }^{130}$ Differences in incidence of prolonged labor were not noted when comparing intravenous LR at rates of 125 and $250 \mathrm{ml} / \mathrm{hr}$ with oral hydration. ${ }^{139}$ No significant differences in vacuum extractions were noted with increased intravenous hydration (moderate SOE). ${ }^{142,148}$ 
Table 44. Effects of specific nutritional intervention and oral or parenteral hydration intervention

\begin{tabular}{|c|c|c|c|c|c|c|c|c|c|c|}
\hline $\begin{array}{l}\text { Study } \\
\text { Quality }\end{array}$ & Int & Com & $\begin{array}{l}\text { Duration of } \\
\text { Labor: } \\
\text { Int }\end{array}$ & $\begin{array}{l}\text { Duration of } \\
\text { Labor: } \\
\text { Com }\end{array}$ & $\begin{array}{l}\text { Duration } \\
\text { of Labor: } \\
\mathrm{P} \text { Value }\end{array}$ & $\begin{array}{c}\text { Cesarean: } \\
\text { Int }\end{array}$ & $\begin{array}{l}\text { Cesarean: } \\
\text { Com }\end{array}$ & $\begin{array}{c}\text { Cesarean: } \\
\text { P Value }\end{array}$ & $\begin{array}{c}\text { Shorter } \\
\text { Labor } \\
\text { Associated } \\
\text { With Lower } \\
\text { Cesarean } \\
\text { Delivery } \\
\text { Rate? } \\
\end{array}$ & Comments \\
\hline \multirow[t]{3}{*}{$\begin{array}{l}\text { Coco, } 2010^{142} \\
\text { Good }\end{array}$} & \multirow{3}{*}{$\begin{array}{l}\text { LR } 250 @ \\
250 \mathrm{ml} / \mathrm{hr} \\
\text { plus } \\
\text { unrestricte } \\
\text { d oral } \\
\text { fluids } \\
(\mathrm{N}=37)\end{array}$} & \multirow{3}{*}{$\begin{array}{l}\text { LR at } \\
\text { provider's } \\
\text { discretion } \\
\text { plus } \\
\text { unrestricted } \\
\text { oral fluids } \\
\text { (usual care) } \\
\text { (N=43) }\end{array}$} & $\begin{array}{l}1^{\text {st }} \text { stage } \\
\text { (mean hr; } \\
\text { vaginal } \\
\text { deliveries } \\
\text { only): } 7.9\end{array}$ & $\begin{array}{l}1^{\text {st }} \text { stage (mean } \\
\text { hr; vaginal } \\
\text { deliveries only): } \\
8.0\end{array}$ & 0.90 & 11 & 7 & 0.30 & - & - \\
\hline & & & $\begin{array}{l}2^{\text {nd }} \text { stage } \\
\text { (mean hr; } \\
\text { vaginal } \\
\text { deliveries } \\
\text { only):1.6 }\end{array}$ & $\begin{array}{l}2^{\text {nd }} \text { stage (mean } \\
\text { hr; vaginal } \\
\text { deliveries } \\
\text { only):1.4 }\end{array}$ & 0.49 & 11 & 7 & 0.30 & - & - \\
\hline & & & $\begin{array}{l}\text { Total (mean } \\
\text { hr; vaginal } \\
\text { deliveries } \\
\text { only):9.5 }\end{array}$ & $\begin{array}{l}\text { Total (mean hr; } \\
\text { vaginal } \\
\text { deliveries } \\
\text { only): } 9.4\end{array}$ & 0.92 & 11 & 7 & 0.30 & - & - \\
\hline \multirow[t]{2}{*}{$\begin{array}{l}\text { Direkvand- } \\
\text { Moghadam, } \\
2012^{136}\end{array}$} & $\begin{array}{l}\text { LR } 60 \\
\mathrm{ml} / \mathrm{hr} \\
(\mathrm{N}=24)\end{array}$ & $\begin{array}{l}\text { LR } 120 \\
\mathrm{ml} / \mathrm{hr} \\
(\mathrm{N}=26)\end{array}$ & $\begin{array}{l}\text { Active phase } \\
\text { of } 1^{\text {st }} \text { phase: } \\
237.8 \text { min } \\
(36.4) \\
2^{\text {nd }} \text { phase: } \\
54.8 \text { min } \\
(16.2) \\
3^{\text {rd }} \text { phase: } 6.2 \\
\text { min }(2.9)\end{array}$ & $\begin{array}{l}\text { Active phase of } \\
1^{\text {st }} \text { phase: } 231.7 \\
\text { min }(43.5) \\
2^{\text {nd }} \text { phase: } 51.3 \\
\text { min (11.9) } \\
3^{\text {rd }} \text { phase: } 6.1 \\
\min (4.0)\end{array}$ & $\begin{array}{l}0.5949 \\
0.3857 \\
0.9204\end{array}$ & 20 & 13.3 & 0.0167 & - & $\begin{array}{l}\text { NR } \\
\text { significant } \\
\text { between LR } \\
\text { arms }\end{array}$ \\
\hline & $\begin{array}{l}\text { LR } 60 \\
\mathrm{ml} / \mathrm{hr} \\
(\mathrm{N}=24)\end{array}$ & $\begin{array}{l}\text { LR } 240 \\
\mathrm{ml} / \mathrm{hr} \\
(\mathrm{N}=28)\end{array}$ & $\begin{array}{l}\text { Active phase } \\
\text { of } 1^{\text {st }} \text { phase: } \\
237.8 \text { min } \\
(36.4) \\
2^{\text {nd }} \text { phase: } \\
54.8 \text { min } \\
(16.2) \\
3^{\text {rd }} \text { phase: } 6.2 \\
\text { min }(2.9)\end{array}$ & $\begin{array}{l}\text { Active phase of } \\
1^{\text {st }} \text { phase: } 206.2 \\
\text { min (38.3) } \\
2^{\text {nd }} \text { phase: } 49.8 \\
\text { min (11.4) } \\
3^{\text {rd }} \text { phase: } 5.7 \\
\text { min }(2.7)\end{array}$ & $<0.001$ & - & 6.7 & - & - & $\begin{array}{l}\text { NR } \\
\text { significant } \\
\text { between LR } \\
\text { arms }\end{array}$ \\
\hline
\end{tabular}




\begin{tabular}{|c|c|c|c|c|c|c|c|c|c|c|}
\hline $\begin{array}{l}\text { Study } \\
\text { Quality }\end{array}$ & Int & Com & $\begin{array}{l}\text { Duration of } \\
\text { Labor: } \\
\text { Int }\end{array}$ & $\begin{array}{l}\text { Duration of } \\
\text { Labor: } \\
\text { Com }\end{array}$ & $\begin{array}{l}\text { Duration } \\
\text { of Labor: } \\
\text { P Value }\end{array}$ & $\begin{array}{c}\text { Cesarean: } \\
\text { Int }\end{array}$ & $\begin{array}{c}\text { Cesarean: } \\
\text { Com }\end{array}$ & $\begin{array}{l}\text { Cesarean: } \\
\text { P Value }\end{array}$ & $\begin{array}{c}\text { Shorter } \\
\text { Labor } \\
\text { Associated } \\
\text { With Lower } \\
\text { Cesarean } \\
\text { Delivery } \\
\text { Rate? } \\
\end{array}$ & Comments \\
\hline & $\begin{array}{l}\text { LR } 60 \\
\mathrm{ml} / \mathrm{hr} \\
(\mathrm{N}=24)\end{array}$ & $\begin{array}{l}\text { Oral fluids } \\
\text { at will } \\
(\mathrm{N}=22)\end{array}$ & $\begin{array}{l}\text { Active phase } \\
\text { of } 1^{\text {st }} \text { phase: } \\
237.8 \text { min } \\
(36.4) \\
2^{\text {nd }} \text { phase: } \\
54.8 \text { min } \\
(16.2) \\
3^{\text {rd }} \text { phase: } 6.2 \\
\text { min }(2.9)\end{array}$ & $\begin{array}{l}\text { Active phase of } \\
1^{\text {st }} \text { phase: } 252.3 \\
\text { min }(40.9) \\
2^{\text {nd }} \text { phase: } 64.3 \\
\text { min (13.9) } \\
3^{\text {rd }} \text { phase: } 6.9 \\
\text { min (3.6) }\end{array}$ & 0.01 & 26.6 & - & 0.58 & - & $\begin{array}{l}\text { NR } \\
\text { significant } \\
\text { between LR } \\
\text { arms }\end{array}$ \\
\hline \multirow[t]{2}{*}{$\begin{array}{l}\text { Edwards, } \\
2014^{130}\end{array}$} & $\begin{array}{l}125 \mathrm{ml} / \mathrm{hr} \\
\mathrm{D} 5 \mathrm{LR} \\
(\mathrm{N}=105)\end{array}$ & $\begin{array}{l}250 \mathrm{ml} / \mathrm{hr} \\
\mathrm{D} 5 \mathrm{LR} \\
(\mathrm{N}=105)\end{array}$ & $\begin{array}{l}\text { Total duration: } \\
11.6 \mathrm{hr}(5.9) \\
1^{\text {st }} \text { stage: } 10.2 \\
\text { hr }(5.6)\end{array}$ & $\begin{array}{l}\text { Total duration: } \\
11.4 \mathrm{hr}(5.5) \\
1^{\text {st }} \text { stage: } 10.3 \mathrm{hr} \\
(5.2)\end{array}$ & 0.998 & 23 & 18 & 0.309 & - & - \\
\hline & $\begin{array}{l}125 \mathrm{ml} / \mathrm{hr} \\
\text { D5LR } \\
(\mathrm{N}=105)\end{array}$ & $\begin{array}{l}25 \mathrm{ml} / \mathrm{hr} \\
\mathrm{D} 5 \mathrm{LR} \\
(\mathrm{N}=105)\end{array}$ & $\begin{array}{l}\text { Total duration: } \\
11.6 \mathrm{hr}(5.9) \\
1^{\text {st }} \text { stage: } 10.2 \\
\mathrm{hr}(5.6)\end{array}$ & $\begin{array}{l}\text { Total duration } \\
\text { (hr): } 11.5(5.9) \\
1^{\text {st }} \text { stage (hr): } 9.9 \\
(5.7)\end{array}$ & 0.671 & 23 & 17 & 0.3605 & - & - \\
\hline $\begin{array}{l}\text { Eslamian, } \\
2006^{148} \\
\text { Good }\end{array}$ & $\begin{array}{l}\text { LR } \\
125 \mathrm{ml} / \mathrm{hr} \\
(\mathrm{N}=153)\end{array}$ & $\begin{array}{l}\text { LR } 250 \\
\mathrm{ml} / \mathrm{hr} \\
(\mathrm{N}=147)\end{array}$ & $\begin{array}{l}1^{\text {st }} \text { stage: } 367 \\
\text { min (105) } \\
2^{\text {nd }} \text { stage: } \\
18.52 \text { min } \\
(10) \\
\text { Total: } 386 \text { min } \\
(110)\end{array}$ & $\begin{array}{l}1^{\text {st }} \text { stage: } 236 \\
\text { min }(86) \\
2^{\text {nd }} \text { stage: } 16.55 \\
\text { min }(7) \\
\text { Total: } 253 \text { min } \\
(97)\end{array}$ & $\begin{array}{l}0.0001 \\
0.08 \\
0.001\end{array}$ & 10 & 1 & 0.1 & $\begin{array}{l}\text { Yes. But } \\
\text { cesarean } \\
\text { delivery } \\
\text { difference is } \\
\mathrm{NS} \text { ("trend } \\
\text { toward a } \\
\text { lower } \\
\text { frequency of } \\
\text { cesarean } \\
\text { deliveries") }\end{array}$ & - \\
\hline \multirow[t]{2}{*}{$\begin{array}{l}\text { Fong, } 2017^{171} \\
\text { Good }\end{array}$} & $\begin{array}{l}5 \% \\
\text { Dextrose } \\
\text { in normal } \\
\text { saline } \\
125 \mathrm{ml} / \mathrm{hr} \\
(\mathrm{N}=66)\end{array}$ & $\begin{array}{l}2.5 \% \\
\text { Dextrose in } \\
\text { normal } \\
\text { saline } \\
250 \mathrm{ml} / \mathrm{hr} \\
(\mathrm{N}=66)\end{array}$ & $\begin{array}{l}1^{\text {st }} \text { stage } \\
471.7 \text { min } \\
(324.3) \\
2^{\text {nd }} \text { stage } \\
107.6 \text { min } \\
(92.9) \\
\text { Total: } \\
609.8 \text { min } \\
(401.1) \\
\end{array}$ & $\begin{array}{l}1^{\text {st }} \text { stage } \\
501.6 \text { min } \\
(368.7) \\
2^{\text {nd }} \text { stage } \\
106.2 \\
(96.2) \\
\text { Total: } \\
577.9 \text { min } \\
(336.1)\end{array}$ & $\begin{array}{l}0.83 \\
0.93 \\
0.92\end{array}$ & $\begin{array}{l}- \\
- \\
26 / 92 \\
(28.3 \%)\end{array}$ & $\begin{array}{l}- \\
- \\
24 / 90 \\
(26.7 \%)\end{array}$ & $\begin{array}{l}- \\
- \\
0.46\end{array}$ & - & - \\
\hline & $\begin{array}{l}5 \% \\
\text { Dextrose } \\
\text { in normal } \\
\text { saline } \\
125 \mathrm{ml} / \mathrm{hr}\end{array}$ & $\begin{array}{l}\text { Normal } \\
\text { saline } \\
250 \mathrm{ml} / \mathrm{hr} \\
(\mathrm{N}=73)\end{array}$ & $\begin{array}{l}1^{\text {st }} \text { stage } \\
471.7 \text { min } \\
(324.3) \\
2^{\text {nd }} \text { stage } \\
107.6 \text { min }\end{array}$ & $\begin{array}{l}1^{\text {st }} \text { stage } \\
509.6 \text { min } \\
(345.1) \\
2^{\text {nd }} \text { stage } \\
98.0 \text { min }\end{array}$ & - & - & - & - & - & - \\
\hline
\end{tabular}




\begin{tabular}{|c|c|c|c|c|c|c|c|c|c|c|}
\hline $\begin{array}{l}\text { Study } \\
\text { Quality }\end{array}$ & Int & Com & $\begin{array}{l}\text { Duration of } \\
\text { Labor: } \\
\text { Int }\end{array}$ & $\begin{array}{l}\text { Duration of } \\
\text { Labor: } \\
\text { Com }\end{array}$ & $\begin{array}{l}\text { Duration } \\
\text { of Labor: } \\
\mathrm{P} \text { Value }\end{array}$ & $\begin{array}{c}\text { Cesarean: } \\
\text { Int }\end{array}$ & $\begin{array}{l}\text { Cesarean: } \\
\text { Com }\end{array}$ & $\begin{array}{l}\text { Cesarean: } \\
\text { P Value }\end{array}$ & $\begin{array}{c}\text { Shorter } \\
\text { Labor } \\
\text { Associated } \\
\text { With Lower } \\
\text { Cesarean } \\
\text { Delivery } \\
\text { Rate? }\end{array}$ & Comments \\
\hline & $(\mathrm{N}=66)$ & & $\begin{array}{l}\text { (92.9) } \\
\text { Total: } \\
609.8 \text { min } \\
(401.1)\end{array}$ & $\begin{array}{l}(67.3) \\
\text { Total: } \\
607.6 \text { min } \\
(358.6)\end{array}$ & & & $\begin{array}{l}19 / 92 \\
(20.7 \%)\end{array}$ & & & \\
\hline \multirow{2}{*}{$\begin{array}{l}\text { Kavitha, } \\
2012^{139} \\
\text { Good }\end{array}$} & $\begin{array}{l}\text { Oral } \\
\text { hydration } \\
(\mathrm{N}=99)\end{array}$ & $\begin{array}{l}\text { LR } 125 \\
\mathrm{ml} / \mathrm{hr} \\
(\mathrm{N}=98)\end{array}$ & $\begin{array}{l}\text { Active labor: } \\
391.3 \mathrm{~min} \\
\text { (211) }\end{array}$ & $\begin{array}{l}\text { Active labor: } \\
363.1 \text { min (172) }\end{array}$ & 0.203 & $30.6 \%$ & $31 \%$ & 0.824 & - & - \\
\hline & $\begin{array}{l}\text { Oral } \\
\text { hydration } \\
(\mathrm{N}=99)\end{array}$ & $\begin{array}{l}\text { LR } 250 \\
\mathrm{ml} / \mathrm{hr} \\
(\mathrm{N}=96)\end{array}$ & $\begin{array}{l}\text { Active labor: } \\
391.3 \text { min } \\
\text { (211) }\end{array}$ & $\begin{array}{l}\text { Active labor } \\
\text { (min): } 343 \text { min } \\
\text { (171) }\end{array}$ & 0.203 & $30.6 \%$ & $25 \%$ & 0.824 & - & - \\
\hline $\begin{array}{l}\text { Sharma, } \\
2012^{135} \\
\text { Good }\end{array}$ & $\begin{array}{l}\text { Normal } \\
\text { saline with } \\
\text { dextrose } \\
\text { alternating } \\
\text { with } \\
\text { normal } \\
\text { saline at } \\
175 \mathrm{ml} / \mathrm{hr} \\
(\mathrm{N}=122)\end{array}$ & $\begin{array}{l}\text { Normal } \\
\text { saline at } \\
175 \mathrm{ml} / \mathrm{hr} \\
(\mathrm{N}=121)\end{array}$ & $\begin{array}{l}\text { Total duration: } \\
297.8 \text { min } \\
(154.4)\end{array}$ & $\begin{array}{l}473.8 \min \\
(220.5)\end{array}$ & 0.000 & - & - & - & - & - \\
\hline $\begin{array}{l}\text { Shrivastava, } \\
2009^{144} \\
\text { Good }\end{array}$ & $\begin{array}{l}5 \% \\
\text { dextrose } \\
\text { in normal } \\
\text { saline } \\
(\mathrm{N}=76)\end{array}$ & $\begin{array}{l}10 \% \\
\text { dextrose in } \\
\text { normal } \\
\text { saline } \\
(\mathrm{N}=72)\end{array}$ & $\begin{array}{l}\text { Median } \\
\text { Min from fluid } \\
\text { initiation to } \\
\text { complete } \\
\text { cervical } \\
\text { dilation: } 299 \\
\text { (82-1091) } \\
2^{\text {nd }} \text { stage: } 69 \\
\text { (17-227) } \\
\text { Min from fluid } \\
\text { initiation to } \\
\text { delivery: } 392 \\
\text { (100-1157) }\end{array}$ & $\begin{array}{l}\text { Median } \\
\text { Min from fluid } \\
\text { initiation to } \\
\text { complete } \\
\text { cervical dilation: } \\
328 \text { (61-672) } \\
2^{\text {nd }} \text { stage: } 62 \\
(14-191) \\
\text { Min from fluid } \\
\text { initiation to } \\
\text { delivery: } 393 \\
\text { (97-827) }\end{array}$ & $\begin{array}{l}0.1 \\
0.01 \\
0.02\end{array}$ & 18 & 24 & 0.21 & - & - \\
\hline
\end{tabular}




\begin{tabular}{|c|c|c|c|c|c|c|c|c|c|c|}
\hline $\begin{array}{l}\text { Study } \\
\text { Quality }\end{array}$ & Int & Com & $\begin{array}{l}\text { Duration of } \\
\text { Labor: } \\
\text { Int }\end{array}$ & $\begin{array}{l}\text { Duration of } \\
\text { Labor: } \\
\text { Com }\end{array}$ & $\begin{array}{l}\text { Duration } \\
\text { of Labor: } \\
\text { P Value }\end{array}$ & $\begin{array}{c}\text { Cesarean: } \\
\text { Int }\end{array}$ & $\begin{array}{l}\text { Cesarean: } \\
\text { Com }\end{array}$ & $\begin{array}{l}\text { Cesarean: } \\
\text { P Value }\end{array}$ & $\begin{array}{c}\text { Shorter } \\
\text { Labor } \\
\text { Associated } \\
\text { With Lower } \\
\text { Cesarean } \\
\text { Delivery } \\
\text { Rate? }\end{array}$ & Comments \\
\hline & $\begin{array}{l}5 \% \\
\text { dextrose } \\
\text { in normal } \\
\text { saline } \\
(\mathrm{N}=76)\end{array}$ & $\begin{array}{l}\text { normal } \\
\text { saline } \\
\text { (control) } \\
(\mathrm{N}=84)\end{array}$ & $\begin{array}{l}\text { Median } \\
\text { Min from fluid } \\
\text { initiation to } \\
\text { complete } \\
\text { cervical } \\
\text { dilation: } 299 \\
\text { (82-1091) } \\
2^{\text {nd }} \text { stage: } 69 \\
\text { (17-227) } \\
\text { Min from fluid } \\
\text { initiation to } \\
\text { delivery: } 392 \\
\text { (100-1157) }\end{array}$ & $\begin{array}{l}\text { Median } \\
\text { Min from fluid } \\
\text { initiation to } \\
\text { complete } \\
\text { cervical dilation: } \\
360 \text { (95-1203) } \\
2^{\text {nd }} \text { stage: } 106 \\
(24-266) \\
\text { Min from fluid } \\
\text { initiation to } \\
\text { delivery: } 464 \\
(185-1336)\end{array}$ & $\begin{array}{l}0.1 \\
0.01 \\
0.02\end{array}$ & 18 & 14 & 0.21 & - & - \\
\hline $\begin{array}{l}\text { Ahadi } \\
\text { Yulghunlu, } \\
2018^{83} \\
\text { and Shafaie, } \\
2017^{82} \\
\text { Fair }\end{array}$ & $\begin{array}{l}\mathrm{LR} \\
125 \mathrm{ml} / \mathrm{hr} \\
(\mathrm{N}=63)\end{array}$ & $\begin{array}{l}5 \% \\
\text { Dextrose } \\
(\mathrm{N}=65)\end{array}$ & $\begin{array}{l}1^{\text {st }} \text { stage } \\
\text { active } \\
276.7 \mathrm{~min} \\
(91.3)\end{array}$ & $\begin{array}{l}1^{\text {st }} \text { stage active } \\
150.6 \text { min }(78.5)\end{array}$ & $\begin{array}{l}\text { LR vs. Dex } \\
<0.001 \\
\text { Dex vs oral } \\
<0.001 \\
\text { LR vs oral } \\
0.965\end{array}$ & $4 / 67$ & $2 / 67$ & 0.002 & - & - \\
\hline
\end{tabular}

Abbreviations: -=not reported; Com=comparator; D5LR=lactated Ringer's 5\% dextrose; hr=hours; Int=intervention; IQR=interquartile range; LR=lactated ringer's solution; min=minutes; $\mathrm{NR}=$ not reported; NS=not significant 


\section{Results in Women of Mixed or Unspecified Parity}

\section{Duration of Labor and Cesarean Delivery Rates for Specific Nutritional Intervention and Oral or Parenteral Hydration Intervention Recommendations or Limitations}

Oral carbohydrate intake was associated with a significant decrease in duration of secondstage labor compared to water only ( $\mathrm{p}=0.04){ }^{133}$ Differences in third-stage and overall duration were not statistically significant ( $\mathrm{p}=0.1$ and 0.3 , respectively). Oral carbohydrate intake was not associated with significant differences in rates of cesarean delivery $(\mathrm{p}=0.9)$. These findings were all rated as insufficient SOE given imprecise findings from one fair-quality study.

\section{Process-Related Outcomes for Specific Nutritional Intervention and Oral or Parenteral Hydration Intervention Recommendations or Limitations}

Oral carbohydrate intake was not associated with significant differences between rates of spontaneous, instrumental vaginal, or caesarian delivery ( $\mathrm{p}=0.9$ ) (insufficient SOE). ${ }^{133}$

\section{Relevant Systematic Reviews/Meta-Analyses for Specific Nutritional Intervention and Oral or Parenteral Hydration Intervention Recommendations or Limitations}

We identified SR/MAs (three good-quality and two fair-quality) that examined the effects of specific nutritional intervention and oral or parenteral hydration intervention recommendations or limitations on labor outcomes. ${ }^{36,38,182,183,185}$ Three of the reviews examined the impact of food or carbohydrate consumption during labor, ${ }^{36,182,185}$ while the other two examined the impact of intravenous fluids. ${ }^{38,183}$

One systematic review investigated the harms and benefits of oral food and fluid restriction with and without intravenous hydration. ${ }^{36}$ Analyses included 4 pertinent studies (one excluded due to including labor induction) with between 60 and 328 patients, all women with low risk of complications. No statistically significant differences were observed in cesarean delivery rates, duration of labor, or any outcomes, indicating insufficient evidence for oral fluid restrictions.

A second review (fair quality) compared food or oral carbohydrate solution intake to ice chips or water. ${ }^{185}$ Less restrictive food intake was associated with a significantly shorter duration of labor (-16.01 minutes, 95\% CI -24.91 to -7.12) based on 9 studies with 3,675 participants. Other outcomes of interest including cesarean delivery and admission to NICU did not differ significantly between the intervention and control group. This review included one of the individual studies described above. ${ }^{133}$

The third review (fair quality) focused only on carbohydrate supplementation during labor. ${ }^{182}$ Four of the six studies (698 women total) included in this systematic review were also included in the review described above. ${ }^{185}$ There was no difference in the total duration of active labor (3.15 minutes, 95\% CI -35.64 to 41.95). There also was no significant difference in cesarean births (RR 1.15 , $95 \%$ CI 0.83 to 1.61 ).

The first of the reviews focused on intravenous fluids during labor examined whether routine administration of intravenous fluids reduced the duration of labor or affected maternal or neonatal health. ${ }^{38}$ Analyses of nine studies revealed some decrease in labor duration in some studies. This meta analysis included three of our primary RCTs. ${ }^{136,139,142}$ No differences in rate of cesarean delivery or neonatal outcomes (when reported) were noted. 
Another fair-quality review assessed intravenous fluid infusion rate, regardless of the fluid used, on labor outcomes in nulliparous women. ${ }^{183}$ Higher infusion rate $(250 \mathrm{ml} / \mathrm{hr} \mathrm{vs} 125 \mathrm{ml} / \mathrm{h}$ ) was associated with reduced risk for cesarean delivery, $12.5 \%$ vs $18.1 \%$, RR $0.70,95 \%$ CI $0.53-$ 0.92 based on 7 studies with a total of 1215 women. Total duration of labor was significantly shorter in the high infusion groups (-64.38 minutes, 95\% CI -121.88 to -6.88) based on six studies with 1155 women. Second stage labor was also significantly shorter (-2.80 minutes, 95\% CI -4.49 to -1.10) based on four studies with 899 women. Chorioamnionitis, postpartum hemorrhage and NICU admission did not differ significantly between the intervention groups. This review included four of the individual studies described above. ${ }^{130,136,139,148}$

Heterogeneity in quality and methodology across studies precludes recommendation of routine parenteral hydration in laboring women.

\section{Strength of Evidence for Specific Nutritional Intervention and Oral or Parenteral Hydration Intervention Recommendations or Limitations}

Tables 45 and 46 summarize the SOE for nutritional, oral, or parenteral hydration interventions in nulliparous or mixed parity women.

Table 45. Specific nutritional intervention and oral or parenteral hydration intervention recommendations or limitations: Evidence profile in nulliparous women

\begin{tabular}{|c|c|c|c|c|}
\hline Category & Outcome & $\begin{array}{l}\text { Study Design } \\
\text { (Sample Size) }\end{array}$ & Conclusion & $\begin{array}{c}\text { SOE } \\
\text { (Rationale) }^{a}\end{array}$ \\
\hline \multirow[t]{2}{*}{$\begin{array}{l}\text { Intermediate } \\
\text { or Final } \\
\text { Outcomes }\end{array}$} & $\begin{array}{l}\text { Process Related } \\
\text { Outcomes - } \\
\text { Duration of Total } \\
\text { Labor }\end{array}$ & $\begin{array}{l}3 \\
\text { RCTs }^{130,135,148} \\
(861) \\
1 \mathrm{SR}^{38} \\
(1,781 \\
\text { patients, } 9 \\
\text { studies) }\end{array}$ & $\begin{array}{l}\text { Improvement with } \\
\text { intravenous fluids: } \\
\text { Administration of intravenous } \\
\text { fluids compared with oral intake } \\
\text { alone demonstrated a reduction } \\
\text { in the duration of labor. }\end{array}$ & $\begin{array}{l}\text { Low (Indirect, } \\
\text { inconsistent, imprecise) } \\
\text { The SOE was reduced } \\
\text { given the inconsistency } \\
\text { in the findings of } \\
\text { individual trials and with } \\
\text { the SR and the } \\
\text { variability in hydration } \\
\text { strategies. }\end{array}$ \\
\hline & $\begin{array}{l}\text { Process Related } \\
\text { Outcomes - Mode } \\
\text { of Delivery } \\
\text { (Cesarean } \\
\text { Delivery) }\end{array}$ & $\begin{array}{l}6 \\
\text { RCTs }^{130,136,139,1} \\
42,144,148 \\
(1,373)\end{array}$ & $\begin{array}{l}\text { No difference: No significant } \\
\text { differences were found between } \\
\text { groups of women receiving oral } \\
\text { hydration versus high-level } \\
\text { intravenous hydration (OR } 1.26 \text {, } \\
95 \% \mathrm{Cl} 0.08 \text { to } 18.84 \text { ) }\end{array}$ & $\begin{array}{l}\text { Moderate (Indirect, } \\
\text { Imprecise) }\end{array}$ \\
\hline \multirow[t]{3}{*}{$\begin{array}{l}\text { Adverse } \\
\text { Events }\end{array}$} & $\begin{array}{l}\text { Maternal } \\
\text { Outcomes - } \\
\text { Hemorrhage or } \\
\text { Infection }\end{array}$ & $\begin{array}{l}2 \mathrm{RCTs}^{135,144} \\
(539)\end{array}$ & $\begin{array}{l}\text { No difference: No significant } \\
\text { differences in rates of maternal } \\
\text { hemorrhage or infection were } \\
\text { found between groups of } \\
\text { women receiving infusions of } \\
5 \% \text { or } 10 \% \text { dextrose and } \\
\text { normal saline. }\end{array}$ & $\begin{array}{l}\text { Low } \\
\text { (Imprecise) }\end{array}$ \\
\hline & $\begin{array}{l}\text { Neonatal } \\
\text { Outcomes - } \\
\text { Abnormal Fetal } \\
\text { Heart Tracing }\end{array}$ & $\begin{array}{l}1 \mathrm{RCT}^{144} \\
(289)\end{array}$ & $\begin{array}{l}\text { Inconclusive: SOE was } \\
\text { insufficient given imprecise } \\
\text { findings from } 1 \text { study. }\end{array}$ & $\begin{array}{l}\text { Insufficient } \\
\text { (Indirect, Imprecise, } 1 \\
\text { study) }\end{array}$ \\
\hline & $\begin{array}{l}\text { Process Related } \\
\text { Outcomes - Mode } \\
\text { of Delivery } \\
\text { (Operative } \\
\text { Vaginal Delivery) }\end{array}$ & $\begin{array}{l}5 \\
\text { RCTs } \\
48 \\
(1,234), 135,142,1\end{array}$ & $\begin{array}{l}\text { No difference: No difference in } \\
\text { operative vaginal delivery rates } \\
\text { amongst } 5 \text { studies using } \\
\text { varying methods of hydration. }\end{array}$ & $\begin{array}{l}\text { Moderate (Indirect, } \\
\text { Imprecise) }\end{array}$ \\
\hline
\end{tabular}

${ }^{\text {a }}$ Criteria for downgrading SOE are described as Rationale; when these criteria are insufficient for understanding the final SOE, additional explanation is provided.

Abbreviations: $\mathrm{CI}=$ confidence interval; $\mathrm{OR}=$ odds ratio; $\mathrm{RCT}=$ randomized controlled trial; $\mathrm{SOE}=$ strength of evidence 
Table 46. Specific nutritional intervention and oral or parenteral hydration intervention recommendations or limitations: Evidence profile in women of mixed parity

\begin{tabular}{|c|c|c|c|c|}
\hline Category & Outcome & $\begin{array}{l}\text { Study Design } \\
\text { (Sample Size) }\end{array}$ & Conclusion & $\begin{array}{c}\text { SOE } \\
\text { (Rationale) }^{\mathrm{a}}\end{array}$ \\
\hline \multirow[t]{4}{*}{$\begin{array}{l}\text { Intermediate } \\
\text { or Final } \\
\text { Outcomes }\end{array}$} & $\begin{array}{l}\text { Process Related } \\
\text { Outcomes - } \\
\text { Duration of } 2^{\text {nd }} \\
\text { Stage Labor }\end{array}$ & $\begin{array}{l}1 \mathrm{RCT}^{133} \\
(177)\end{array}$ & $\begin{array}{l}\text { Inconclusive: SOE was } \\
\text { insufficient given imprecise } \\
\text { findings from } 1 \text { study with } \\
\text { potential risk of bias. }\end{array}$ & $\begin{array}{l}\text { Insufficient (Medium risk } \\
\text { of bias, indirect, } \\
\text { Imprecise, } 1 \text { study) }\end{array}$ \\
\hline & $\begin{array}{l}\text { Process Related } \\
\text { Outcomes - } \\
\text { Duration of Total } \\
\text { Labor }\end{array}$ & $\begin{array}{l}\text { 1 } \mathrm{RCT}^{133} \\
(177)\end{array}$ & $\begin{array}{l}\text { Inconclusive: SOE was } \\
\text { insufficient given imprecise } \\
\text { findings from } 1 \text { study with } \\
\text { potential risk of bias. }\end{array}$ & $\begin{array}{l}\text { Insufficient (Medium risk } \\
\text { of bias, indirect, } \\
\text { Imprecise, } 1 \text { study) }\end{array}$ \\
\hline & $\begin{array}{l}\text { Process Related } \\
\text { Outcomes - Mode } \\
\text { of Delivery } \\
\text { (Cesarean } \\
\text { Delivery) }\end{array}$ & $\begin{array}{l}\text { 1 RCT } \mathrm{RCT}^{133} \\
(177)\end{array}$ & $\begin{array}{l}\text { Inconclusive: SOE was } \\
\text { insufficient given imprecise } \\
\text { findings from } 1 \text { study with } \\
\text { potential risk of bias. }\end{array}$ & $\begin{array}{l}\text { Insufficient (Medium risk } \\
\text { of bias, indirect, } \\
\text { Imprecise, } 1 \text { study) }\end{array}$ \\
\hline & $\begin{array}{l}\text { Process Related } \\
\text { Outcomes - Mode } \\
\text { of Delivery } \\
\text { (Operative } \\
\text { Vaginal Delivery) }\end{array}$ & $\begin{array}{l}1 \mathrm{RCT}^{133} \\
(177)\end{array}$ & $\begin{array}{l}\text { Inconclusive: SOE was } \\
\text { insufficient given imprecise } \\
\text { findings from one study with } \\
\text { potential risk of bias. }\end{array}$ & Insufficient (Imprecise) \\
\hline
\end{tabular}

${ }^{a}$ Criteria for downgrading SOE are described as Rationale; when these criteria are insufficient for understanding the final SOE, additional explanation is provided.

Abbreviations: RCT=randomized controlled trial; SOE=strength of evidence

\section{TENS Versus Control Treatment}

Two studies reported on the effects of transcutaneous electrical nerve stimulation (TENS) on labor outcomes. ${ }^{175,178}$ Results were reported for nulliparous women in one study ${ }^{178}$ and for women of mixed parity in the other study. ${ }^{175}$ Both studies were fair quality. ${ }^{175,178}$ One study compared TENS to an inactive TENS unit or usual care ${ }^{178}$ and the other compared TENS, Entonox (nitrous oxide) or the combination of the two. ${ }^{175}$

\section{Results in Nulliparous Women}

\section{Duration of Labor for TENS}

The duration of first-stage labor was significantly shorter in the women using the TENS unit than those with the inactive unit or usual care (Table 47). ${ }^{178}$ The duration of second or third-stage labor was not significantly different between the groups.

\section{Maternal Outcomes for TENS}

Maternal hemorrhage (500-1000ml blood loss) was not significantly different across the treatment groups, occurring in 10\% of the TENS group, $10 \%$ of the inactive TENS group and $16.7 \%$ of the usual care group, $\mathrm{p}=0.66 .^{178}$

\section{Results in Women of Mixed or Unspecified Parity}

\section{Duration of Labor}

The duration of first-stage labor was not significantly different between the Entonox group and the TENS plus Entonox group, but was significantly longer in the TENS group (Table 47). ${ }^{175}$ 
Table 47. Effects of TENS versus control treatment

\begin{tabular}{|c|c|c|c|c|c|}
\hline $\begin{array}{l}\text { Study } \\
\text { Quality }\end{array}$ & Int & Com & $\begin{array}{l}\text { Duration of } \\
\text { Labor: Int }\end{array}$ & $\begin{array}{l}\text { Duration of } \\
\text { Labor: Com }\end{array}$ & $\begin{array}{l}\text { Duration } \\
\text { of Labor: } \\
\text { P Value }\end{array}$ \\
\hline \multirow[t]{6}{*}{ Shahoei, $2017^{178}$} & \multirow[t]{2}{*}{$\begin{array}{l}\text { TENS } \\
\mathrm{N}=30\end{array}$} & $\begin{array}{l}\text { Inactive TENS } \\
\mathrm{N}=30\end{array}$ & \multirow[t]{2}{*}{$\begin{array}{l}1^{\text {st }} \text { Stage } \\
158.42 \text { min } \\
(136.64)\end{array}$} & $\begin{array}{l}1^{\text {st }} \text { Stage } \\
262.5 \mathrm{~min} \\
(125.23)\end{array}$ & \multirow[t]{2}{*}{$<0.0002$} \\
\hline & & $\begin{array}{l}\text { Usual care } \\
N=30\end{array}$ & & $\begin{array}{l}1^{\text {st }} \text { Stage } \\
257.16 \mathrm{~min} \\
(114.10)\end{array}$ & \\
\hline & \multirow[t]{2}{*}{$\begin{array}{l}\text { TENS } \\
\mathrm{N}=30\end{array}$} & $\begin{array}{l}\text { Inactive TENS } \\
\mathrm{N}=30\end{array}$ & \multirow[t]{2}{*}{$\begin{array}{l}2^{\text {nd }} \text { Stage } \\
43 \min (29.37)\end{array}$} & $\begin{array}{l}2^{\text {nd }} \text { Stage } \\
57.5 \\
(41.39)\end{array}$ & \multirow[t]{2}{*}{0.12} \\
\hline & & $\begin{array}{l}\text { Usual care } \\
N=30\end{array}$ & & $\begin{array}{l}2^{\text {nd }} \text { Stage } \\
44.03 \\
(29.17) \\
\end{array}$ & \\
\hline & \multirow[t]{2}{*}{$\begin{array}{l}\text { TENS } \\
\mathrm{N}=30\end{array}$} & $\begin{array}{l}\text { Inactive TENS } \\
\mathrm{N}=30\end{array}$ & \multirow[t]{2}{*}{$\begin{array}{l}3^{\text {rd }} \text { Stage } \\
11.6 \min (4.2)\end{array}$} & $\begin{array}{l}3^{\text {rd }} \text { Stage } \\
13.27 \mathrm{~min}(8.7)\end{array}$ & \multirow[t]{2}{*}{0.29} \\
\hline & & $\begin{array}{l}\text { Usual care } \\
\mathrm{N}=30\end{array}$ & & $\begin{array}{l}3^{\text {rd }} \text { Stage } \\
13.00 \mathrm{~min} \\
(10.87)\end{array}$ & \\
\hline \multirow{2}{*}{$\begin{array}{l}\text { Samadzadeh, } \\
2017^{175} \\
\text { Fair }\end{array}$} & \multirow[t]{2}{*}{$\begin{array}{l}\text { TENS } \\
\mathrm{N}=40\end{array}$} & $\begin{array}{l}\text { Entonox } \\
\mathrm{N}=40\end{array}$ & \multirow[t]{2}{*}{$\begin{array}{l}1^{\text {st }} \text { stage } \\
300.1 \min (224.8)\end{array}$} & $\begin{array}{l}1^{\text {st }} \text { stage } \\
228.5 \text { min }(92.4)\end{array}$ & \multirow[t]{2}{*}{$\begin{array}{l}\text { Not } \\
\text { reported }\end{array}$} \\
\hline & & $\begin{array}{l}\text { TENS \& Entonox } \\
\mathrm{N}=40\end{array}$ & & $\begin{array}{l}1^{\text {st }} \text { stage } \\
214.6 \mathrm{~min}(151.4)\end{array}$ & \\
\hline
\end{tabular}

Abbreviations: Com=comparator; Int=intervention; min=minute; TENS=transcutaneous electrical nerve stimulation

\section{Oral Bicarbonate Versus Control Treatment}

One fair-quality RCT examined the effect of oral bicarbonate on labor outcomes in women with labor dystocia. ${ }^{177}$ Two hundred nulliparous women who had labor dystocia, defined as crossing the action line on a partogram or labor arrest for $\geq 2$ hours, were randomized to receive an oral bicarbonate solution followed by oxytocin administration in 1 hour or immediate oxytocin administration.

\section{Results in Nulliparous Women}

Duration of labor, as defined by the proportion of women with active time of delivery $>12$ hours, was not significantly different between the women receiving bicarbonate in advance of oxytocin administration and those receiving immediate oxytocin ( $49 \%$ vs. $40 \%, p=0.2)$. There also was no difference in the proportion of women with cesarean delivery (8.9\% vs. $8.1 \%$, $\mathrm{p}=0.8)$. Post-partum hemorrhage was reported in none of the women receiving bicarbonate and oxytocin and in 16.2 percent of the women receiving oxytocin only (p-value not reported).

\section{Hyoscine or Hot Shower Versus Control Treatment}

One fair-quality RCT examined the effect of intravenous injections of hyoscine or a hot shower versus usual care on labor outcomes. ${ }^{174}$ A total of 162 nulliparous women were randomized, with women in the intervention groups either receiving the hyoscine injection or taking a 20-minute hot shower at $4 \mathrm{~cm}$ and $7 \mathrm{~cm}$ cervical dilation.

\section{Results in Nulliparous Women}

Duration of active labor, as defined by the time from $4 \mathrm{~cm}$ dilation to full dilation, was significantly longer in the usual care group (312.6 minutes) than either the hyoscine group (221.2 
minutes) or the hot shower group (201.9 minutes) ( $\mathrm{p}<0.001$ for hot shower vs. usual care; $\mathrm{p}=0.003$ for hyoscine vs. usual care; $\mathrm{p}=0.522$ for hyoscine vs. hot shower). The number of cesarean deliveries was the same in each group (5/53 in the hyoscine group, 5/55 in the hot shower group, and 5/54 in the usual care group).

\section{Assessment and Support During Early Labor Versus Control Treatment}

We identified one systematic review that compared assessment and support interventions during early labor versus control treatments. ${ }^{186}$ The interventions evaluated in the review were assessment versus direct admission in early labor ( 1 study), home support versus telephone triage (3 studies) and one-to-one structured care versus usual care (1 study).

Assessment during early labor as compared to direct admission was associated with shorter duration of labor in hospital (-5.20 hours, 95\% CI -7.06 to -3.34) and higher maternal satisfaction score (16.0, 95\% CI 7.53 to 24.47), but no significant difference in rate of cesarean section (RR $0.72,95 \%$ CI 0.30 to 1.72 ).

Home support versus telephone triage was associated with no significant difference in rate of cesarean section (RR 1.05, 95\% CI 0.95 to 1.17) or neonatal admission to special care unit (RR 0.84, 95\% CI 0.50 to 1.42$)$. A higher maternal satisfaction score (3.47, 95\% CI 1.00 to 5.94) for the intervention was reported in one study.

One-on-one structured care versus usual care showed no significant differences in rate of cesarean section (RR 0.93 , 95\% CI 0.84 to 1.02 ) or neonatal admission to special care unit (RR $0.98,95 \%$ CI 0.80 to 1.21$)$.

\section{Key Question 4. Epidural Analgesia}

KQ 4 was: What are the benefits and harms of epidural analgesia in labor, particularly in terms of the risk of a diagnosis of prolonged labor?

In this Key Question, we focus on the evidence on the effect of specific methods for analgesia during labor, particularly various approaches to regional analgesia using epidural or other methods, on the duration of labor and the risk of cesarean delivery. If certain characteristics of labor analgesia (e.g., type of analgesia, timing, dosage) increase the duration of labor, then it is plausible that this increased duration would be associated with an increased risk of cesarean delivery for dystocia.

\section{Description of Included Studies}

We identified 26 articles $66-69,76-79,124,176,181,189-203$ representing 22 individual RCTs that examined the benefits and harms of epidural analgesia in labor. Four studies were each described in two publications, as follows:

- de Orange, 2011: Primary report ${ }^{76}$ and a companion paper $^{77}$

- $\quad$ Pascual-Ramirez, 2011: Primary report $^{78}$ and a companion paper $^{79}$

- Wilson, 2009: Primary report ${ }^{66}$ and a companion paper ${ }^{67}$

- Wassen, 2015: Primary report ${ }^{68}$ and a companion paper ${ }^{69}$

However, while the companion papers for Pascual-Ramirez, 2011, and Wilson, 2009, individually met inclusion criteria, they did not provide additional unique information on 
outcomes of interest to this review beyond the information provided in the primary report. The companion paper for de Orange, 2011 is cited where relevant under "Detailed Synthesis" below.

Of the 22 included studies, 8 were conducted in UK/Europe, ${ }^{66,68,78,189,190,192,194,197} 6$ were conducted in Asia, ${ }^{124,176,181,201-203} 3$ were conducted in the Middle East, ${ }^{191,198,199} 3$ were conducted in Latin America, ${ }^{76,195,196} 1$ was conducted in Africa, ${ }^{193}$ and 1 was conducted in the United States. ${ }^{200}$ Fifteen studies were conducted in a hospital, $68,78,124,176,181,189,191-193,196,198-200,202,203$ while 7 studies were unclear or reported other settings. ${ }^{66,76,190,194,195,197,201}$ Five studies reported government funding, ${ }^{66,124,176,181,199}$ two reported nongovernment, nonindustry funding, ${ }^{198,200}$ and 1 reported a mixture of funding from government and nongovernment sources. ${ }^{190}$ Fourteen studies were unclear or did not report the funding source. ${ }^{68,76,78,189,191-197,201-203}$ Finally, of the 22 included studies, 8 studies were rated as good quality, ${ }^{68,76,78,191,199,200,202,203} 11$ as fair quality, ${ }^{66,124,176,181,189,190,192,195-198}$ and 3 as poor quality. ${ }^{193,194,201}$

\section{Key Points for Epidural Analgesia}

- For nulliparous women, a meta-analysis showed no significant differences between epidural analgesia (EA) and combined spinal epidural (CSE) in duration of the first stage of labor (low SOE) or duration of the second stage of labor (low SOE). However, total duration of labor (from time of intervention to delivery) was significantly longer for EA relative to CSE (moderate SOE). There were no differences between EA and CSE in rates of cesarean delivery (moderate SOE).

- For women of mixed parity, there was no difference between EA and CSE for total duration of labor (low SOE), or rates of cesarean delivery (moderate SOE).

- For women of mixed parity, there were no differences between EA and patient-controlled intravenous analgesia (PCIA) in duration of labor or rates of cesarean delivery (low SOE for both outcomes).

- For nulliparous women, there was no difference in duration of first or second stage labor or rates of cesarean delivery for early versus late EA (moderate SOE for all outcomes)

- For women of mixed parity, there was no evidence of a difference between EA and no EA for the duration of the first stage of labor or rates of cesarean delivery. There was a slight increase in the duration of the second stage for women with EA (moderate SOE for all outcomes).

\section{Detailed Synthesis for Epidural Analgesia}

Comparisons of interest were:

- Epidural analgesia versus combined spinal epidural analgesia

- Epidural analgesia versus patient-controlled intravenous analgesia

- Epidural analgesia versus intravascular tramadol

- Early versus late epidural analgesia

- Routine epidural analgesia versus analgesia on request

- Combined spinal epidural analgesia versus nonpharmacologic pain relief

- Epidural analgesia versus intravenous meperidine

- Epidural analgesia versus low-dose infusion epidural analgesia

- Epidural analgesia versus acupuncture point nerve stimulation

- Epidural analgesia versus no epidural analgesia 


\section{Epidural Analgesia Versus Combined Spinal Epidural Analgesia}

Of the 22 included studies, 9 RCTs representing 1,251 patients compared EA with CSE, which involves both epidural and spinal analgesia. ${ }^{66,78,190,191,193,195-197,202}$ Of these nine RCTs, four were conducted in UK/Europe, ${ }^{66,78,190,197}$ two were conducted in Asia or the Middle East, ${ }^{191,202}$ and three were conducted in Latin America or Africa. ${ }^{193,195,196}$ One RCT reported funding from a government agency, ${ }^{66}$ one reported a mixture of funding from government and nongovernment sources, ${ }^{190}$ and the remaining seven were unclear or did not report the funding source. Three RCTs were rated as good quality, ${ }^{78,191,202}$ five were rated as fair, ${ }^{66,190,195-197}$ and one was rated as poor quality. ${ }^{193}$

Of the nine RCTs that compared EA with CSE, five included only nulliparous women. ${ }^{6,191,193,197,202}$ and one included both nulliparous and parous women but reported duration of labor results separately for the $52.8 \%$ of the patient population who were nulliparous. ${ }^{78}$ The remaining three RCTs included mixed parity populations, with the following proportion of nulliparous women in each study: $68.7 \%,{ }^{190} 82.5 \%,{ }^{195}$ and $68.8 \% .{ }^{196}$ None of the studies reported findings specifically for parous women.

No SR/MAs were identified that were relevant to this comparison.

\section{Results in Nulliparous Women}

\section{Duration of Labor and Cesarean Delivery Rates for Epidural Analgesia Versus Combined Spinal Epidural Analgesia}

Six of the nine RCTs that compared EA with CSE reported duration of labor, ${ }^{78}$ cesarean delivery rates, ${ }^{66}$ or both ${ }^{191,193,197,202}$ in nulliparous women. Table 48 shows results for these studies; outcomes are described following the table. 
Table 48. Effects of epidural analgesia versus combined spinal epidural in nulliparous women

\begin{tabular}{|c|c|c|c|c|c|c|c|c|c|}
\hline $\begin{array}{l}\text { Study } \\
\text { Quality }\end{array}$ & $\begin{array}{c}\text { Int } \\
N\end{array}$ & $\underset{N}{C o m}$ & $\begin{array}{l}\text { Duration of } \\
\text { Labor: } \\
\text { Int }\end{array}$ & $\begin{array}{c}\text { Duration of Labor: } \\
\text { Com }\end{array}$ & $\begin{array}{c}\text { Duration of Labor: } \\
\text { P Value }\end{array}$ & $\begin{array}{l}\text { Cesarean: } \\
\text { Int }\end{array}$ & $\begin{array}{l}\text { Cesarean: } \\
\text { Com }\end{array}$ & $\begin{array}{l}\text { Cesarean: } \\
\text { P Value }\end{array}$ & $\begin{array}{c}\text { Shorter Labor } \\
\text { Associated With } \\
\text { Lower Cesarean } \\
\text { Delivery Rate? }\end{array}$ \\
\hline $\begin{array}{l}\text { Bhagwat, } \\
2008^{202} \\
\text { Good }\end{array}$ & $\begin{array}{l}\mathrm{EA} \\
30\end{array}$ & $\begin{array}{l}\text { CSE } \\
30\end{array}$ & $\begin{array}{l}\text { Stage 1: } 193 \mathrm{~min} \\
\pm 12 \\
\text { Stage 2: } 30 \mathrm{~min} \pm \\
7\end{array}$ & $\begin{array}{l}\text { Stage 1: } 118 \min \pm \\
26 \\
\text { Stage 2: } 19 \min \pm 21\end{array}$ & $\begin{array}{l}\text { Stage 1: }<0.001 \\
\text { Stage 2: } 0.409\end{array}$ & $2(6.7 \%)$ & $2(6.7 \%)$ & 1 & No \\
\hline $\begin{array}{l}\text { Ismail, } \\
2012^{191} \\
\text { Good }\end{array}$ & $\begin{array}{l}\text { EA } \\
380\end{array}$ & $\begin{array}{l}\text { CSE } \\
380\end{array}$ & $\begin{array}{l}\text { Stage 1, latent } \\
\text { phase: } 468 \mathrm{~min} \\
\pm 54 \\
\text { Stage 1, active } \\
\text { phase: } 113 \mathrm{~min} \\
\pm 42 \\
\text { Stage } 2: 60 \mathrm{~min} \\
\pm 30 \\
\text { Total: } 648 \mathrm{~min} \\
\pm 234\end{array}$ & $\begin{array}{l}\text { Stage } 1 \text {, latent } \\
\text { phase: } 396 \text { min } \pm 42 \\
\text { Stage } 1 \text {, active } \\
\text { phase: } 93 \text { min } \pm 24 \\
\text { Stage } 2: 48 \text { min } \pm 18 \\
\text { Total: } 582 \text { min } \pm 180\end{array}$ & $\begin{array}{l}\text { Stage } 1, \text { latent } \\
\text { phase: }<0.0001 \\
\text { Stage } 1, \text { active } \\
\text { phase: }<0.0001 \\
\text { Stage } 2:<0.0001 \\
\text { Total: }<0.0001\end{array}$ & $95(25.0 \%)$ & $87(22.9 \%)$ & 0.50 & No \\
\hline $\begin{array}{l}\text { Pascual- } \\
\text { Ramirez, } \\
2011^{78} \\
\text { Good }\end{array}$ & $\begin{array}{l}\text { EA } \\
34 \\
33 \\
33\end{array}$ & $\begin{array}{l}\text { CSE } \\
30 \\
29 \\
29\end{array}$ & $\begin{array}{l}\text { Stage 1: } 237 \mathrm{~min} \\
\pm 109 \\
\text { Stage 2: } 48 \mathrm{~min} \\
\pm 32 \\
\text { Total: } 282 \mathrm{~min} \\
\pm 113\end{array}$ & $\begin{array}{l}\text { Stage 1: } 239 \mathrm{~min} \\
\pm 142 \\
\text { Stage 2: } 51 \mathrm{~min} \pm 34 \\
\text { Total: } 185 \mathrm{~min} \pm 145\end{array}$ & $\begin{array}{l}\text { Stage 1: } 0.94 \\
\text { Stage 2: } 0.76 \\
\text { Total: } 0.91\end{array}$ & - & - & - & No \\
\hline $\begin{array}{l}\text { Sezer, } \\
2007^{197} \\
\text { Fair }\end{array}$ & $\begin{array}{l}\text { EA } \\
20\end{array}$ & $\begin{array}{l}\text { CSE } \\
20\end{array}$ & $\begin{array}{l}\text { Stage 1: } 204 \mathrm{~min} \\
\pm 66 \\
\text { Stage 2: } 66 \mathrm{~min} \\
\pm 48 \\
\text { Total: } 270 \mathrm{~min} \\
\pm 73\end{array}$ & $\begin{array}{l}\text { Stage 1: } 225 \mathrm{~min} \\
\pm 129 \\
\text { Stage 2: } 56 \min \pm 27 \\
\text { Total: } 299 \min \pm 138\end{array}$ & $\begin{array}{l}\text { Stage 1: } 0.52 \\
\text { Stage 2: } 0.42 \\
\text { Total: } 0.41\end{array}$ & $4(20.0 \%)$ & $4(20.0 \%)$ & 1 & No \\
\hline $\begin{array}{l}\text { Sweed, } \\
2011^{193} \\
\text { Poor }\end{array}$ & $\begin{array}{l}\text { EA } \\
20\end{array}$ & $\begin{array}{l}\text { CSE } \\
20\end{array}$ & $\begin{array}{l}\text { Stage 1: } 236 \mathrm{~min} \\
\pm 113 \\
\text { Stage 2: } 41 \mathrm{~min} \\
\pm 33\end{array}$ & $\begin{array}{l}\text { Stage 1: } 163 \mathrm{~min} \\
\pm 97 \\
\text { Stage 2: } 66 \mathrm{~min} \pm 40\end{array}$ & $\begin{array}{l}\text { Stage 1: } 0.03 \\
\text { Stage 2: } 0.049\end{array}$ & $1(5.0 \%)$ & $0(0 \%)$ & 0.31 & No \\
\hline $\begin{array}{l}\text { Wilson, } \\
2009^{66} \\
\text { Fair }\end{array}$ & $\begin{array}{l}\text { EA } \\
353\end{array}$ & $\begin{array}{l}\text { CSE } \\
351\end{array}$ & - & - & - & $98(27.8 \%)$ & $99(28.2 \%)$ & 0.91 & - \\
\hline
\end{tabular}

Abbreviations: -=not reported; CI=confidence interval; Com=comparator; CSE=combined spinal epidural; EA=epidural analgesia; Int=intervention; Min=minutes; N=number of patients/participants; $\mathrm{SD}=$ standard deviation 
Five of the nine RCTs that compared EA with CSE reported either mean time from randomization or initiation of the analgesia intervention to delivery, or duration of both the first and second stages of labor ${ }^{78,191,193,197,202}$ in nulliparous women (Table 48). Three of these RCTs were rated as good quality, ${ }^{78,191,202}$ one as fair, ${ }^{197}$ and one as poor. ${ }^{193}$ These 5 RCTs represented 962 patients. Four studies included only nulliparous patients, ${ }^{191,193,197,202}$ and one ${ }^{78}$ reported findings for duration of labor separately for the subset of patients who were nulliparous.

Meta-analysis of the data from these RCTs showed no significant differences between EA and CSE in duration of the first stage of labor (MD 32.7 minutes; 95\% CI -19.3 to 84.7) (Figure 4, low SOE) or duration of the second stage of labor (MD -0.2 minutes; 95\% CI -21.9 to 21.6) (Figure 5, low SOE). However, total duration of labor (from time of intervention to delivery) was significantly longer for EA relative to CSE, with an MD of 62.0 minutes (95\% CI 7.2 to 116.7) (Figure 6, moderate SOE).

Figure 4. Epidural analgesia versus combined spinal epidural in nulliparous women-duration of first stage of labor (minutes)

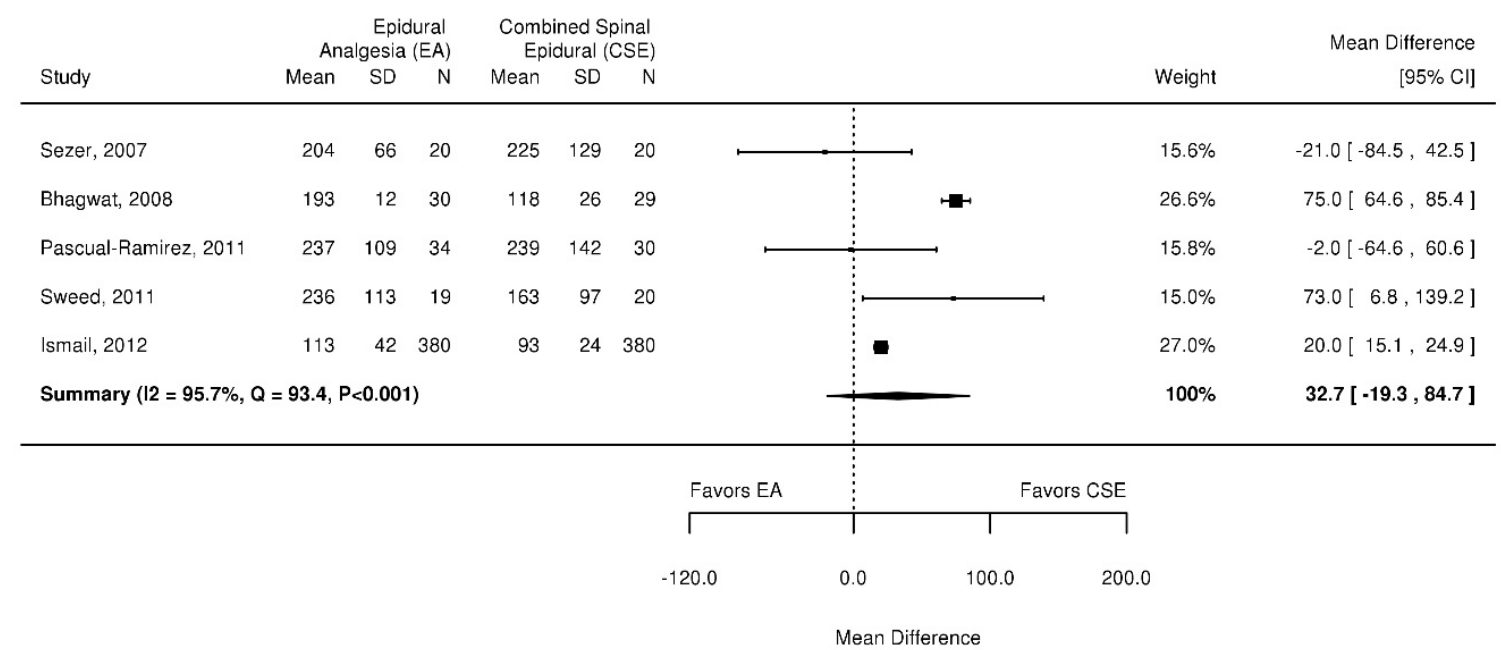

Abbreviations: $\mathrm{CI}=$ confidence interval; $\mathrm{CSE}=$ combined spinal epidural; $\mathrm{EA}=$ epidural analgesia; $\mathrm{N}=$ number of participants; $\mathrm{SD}=$ standard deviation 
Figure 5. Epidural analgesia versus combined spinal epidural in nulliparous women-duration of second stage of labor (minutes)

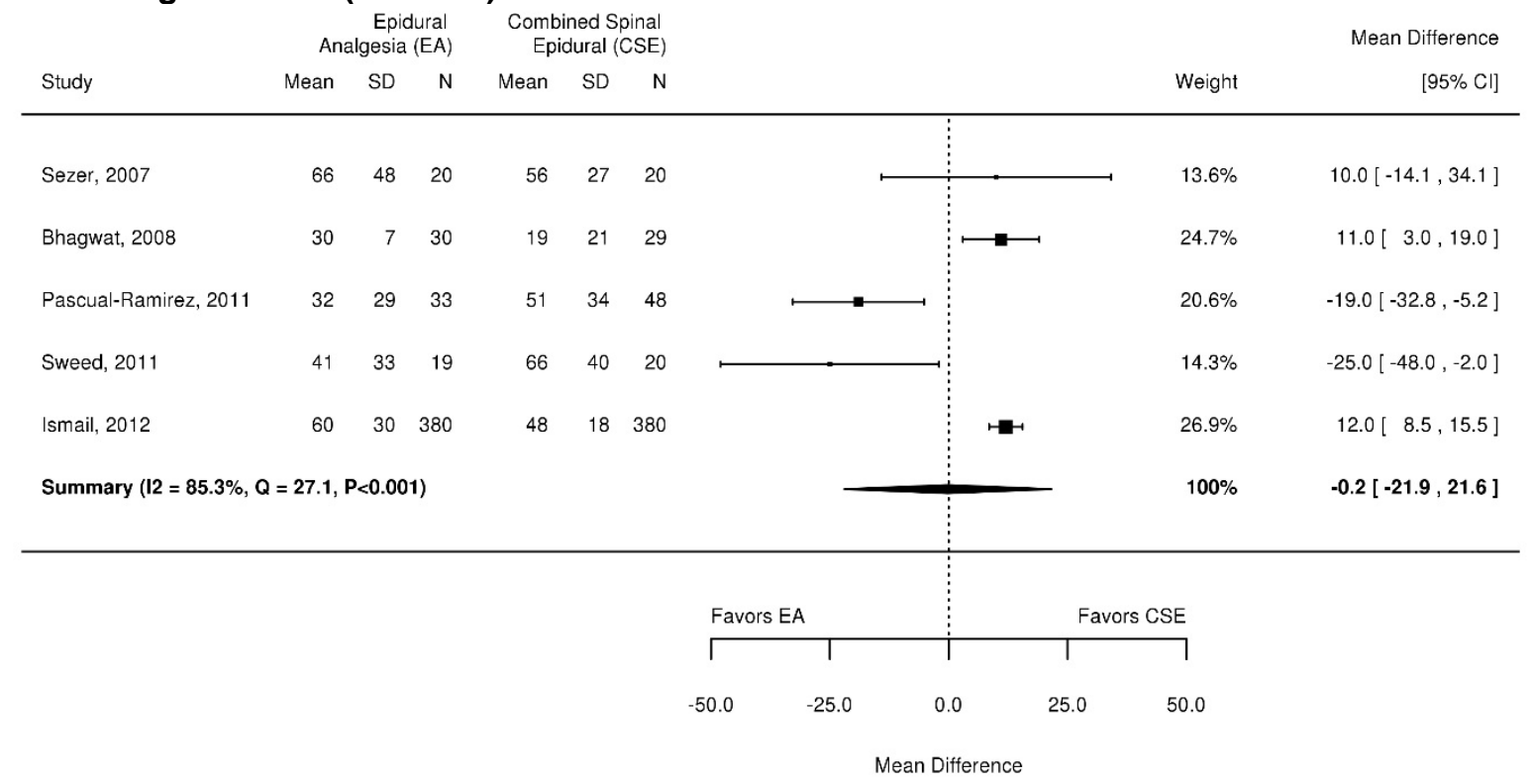

Abbreviations: $\mathrm{CI}=$ confidence interval; $\mathrm{CSE}=$ combined spinal epidural; $\mathrm{EA}=$ =pidural analgesia; $\mathrm{N}=$ number of participants; $\mathrm{SD}=$ standard deviation

Figure 6. Epidural analgesia versus combined spinal epidural in nulliparous women-total duration of labor (minutes)

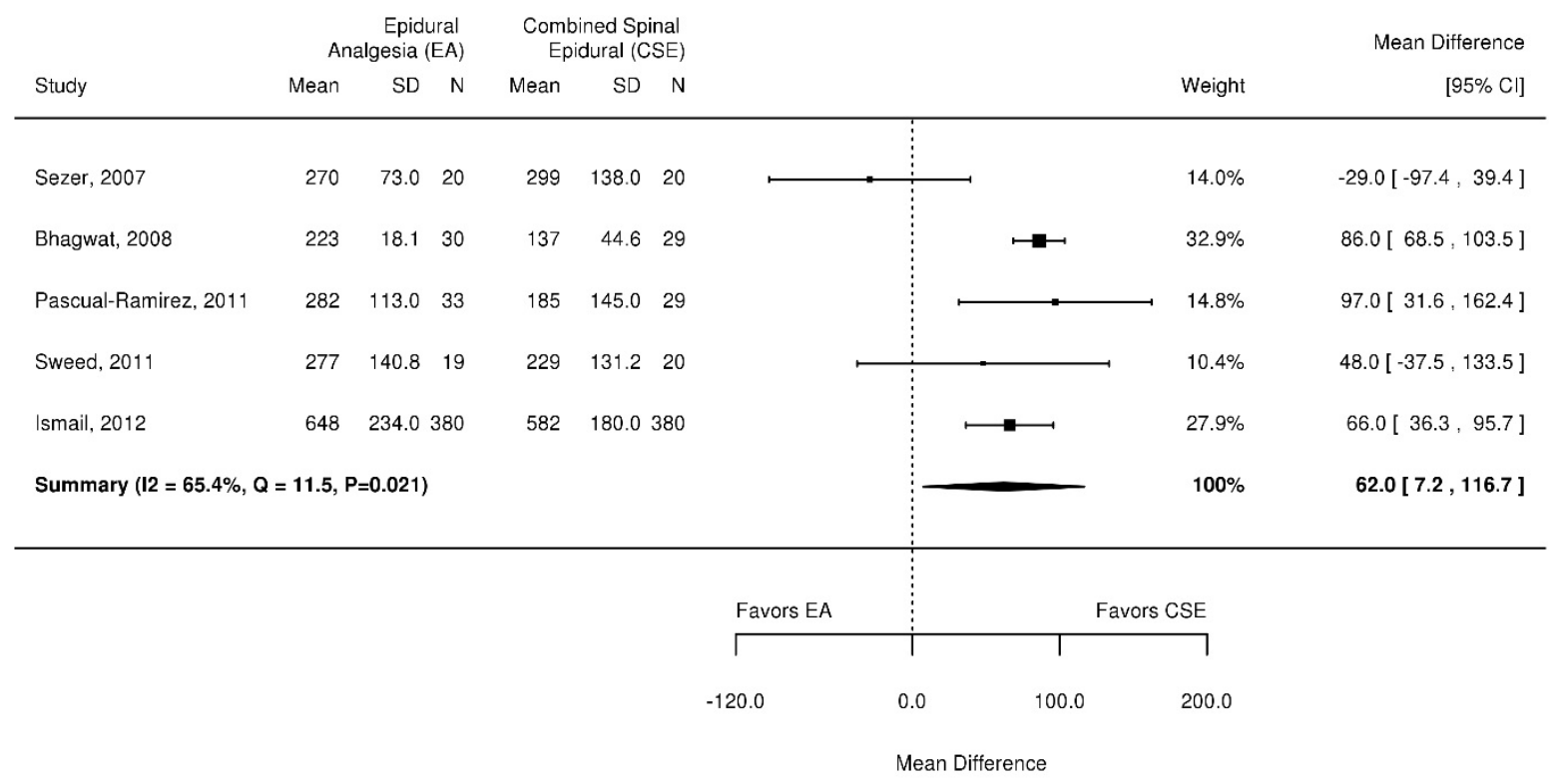

Abbreviations: $\mathrm{CI}=$ confidence interval; $\mathrm{CSE}=$ combined spinal epidural; EA=epidural analgesia; $\mathrm{N}=$ number of participants; $\mathrm{SD}=$ standard deviation 
Five RCTs compared cesarean delivery rates associated with EA versus CSE among nulliparous women. ${ }^{66,191,193,197,202}$ (Table 48). Two of these RCTs were rated as good quality, ${ }^{191,202}$ two as fair, ${ }^{66,197}$ and one as poor. ${ }^{193}$ Meta-analysis of the data from 1604 patients in these 5 RCTs showed no statistically significant difference in cesarean delivery rates between EA and CSE (odds ratio [OR] 1.1; 95\% CI 0.9 to 1.2) (Figure 7, moderate SOE).

Figure 7. Epidural analgesia versus combined spinal epidural in nulliparous women-cesarean delivery rates (number of events)

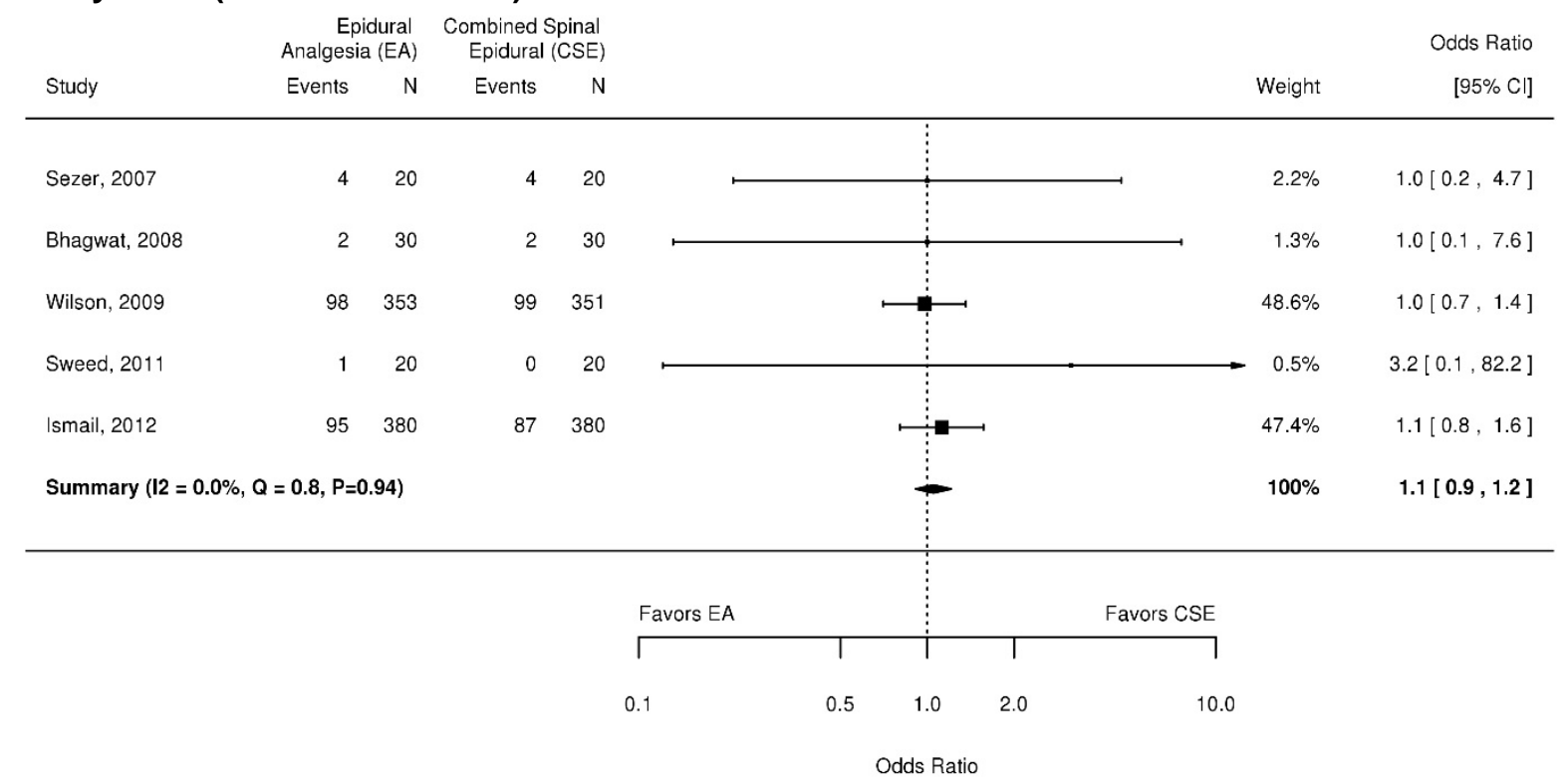

Abbreviations: $\mathrm{CI}=$ confidence interval; $\mathrm{CSE}=$ combined spinal epidural; $\mathrm{EA}=$ epidural analgesia; $\mathrm{N}=$ number of participants; $\mathrm{SD}=$ standard deviation

\section{Process-Related Outcomes for Epidural Analgesia Versus Combined Spinal Epidural Analgesia}

A good-quality RCT involving 1,140 patients assessed maternal overall satisfaction with analgesia 24 hours after delivery using a using a 4-point verbal scale ranging from very satisfied to very dissatisfied (1=very dissatisfied, 2=dissatisfied, 3=satisfied, 4=very satisfied). ${ }^{191}$ Mean maternal satisfaction scores (SD) associated with each of the 3 study interventions were $2.8(0.8)$ for EA, 3.9 (0.6) for CSE, and 3.0 (0.7) for patient-controlled intravenous analgesia $(\mathrm{p}<0.001$ for the 3-way comparison).

\section{Results in Women of Mixed or Unspecified Parity}

\section{Duration of Labor and Cesarean Delivery Rates for Epidural Analgesia Versus Combined Spinal Epidural Analgesia}

Four RCTs compared EA with CSE in women with mixed parity. The proportion of nulliparous women in each of these studies was as follows: 68.8 percent, ${ }^{196} 82.5$ percent, ${ }^{195} 52.8$ percent, ${ }^{78}$ and 68.7 percent. ${ }^{190}$ Table 49 shows results for these studies; the two outcomes are described following the table. 
Table 49. Effects of epidural analgesia versus combined spinal epidural in women of mixed or unspecified parity

\begin{tabular}{|c|c|c|c|c|c|c|c|c|c|}
\hline $\begin{array}{l}\text { Study } \\
\text { Quality }\end{array}$ & $\stackrel{\text { Int }}{N}$ & $\underset{N}{C o m}$ & $\begin{array}{l}\text { Duration of } \\
\text { Labor: } \\
\text { Int }\end{array}$ & $\begin{array}{l}\text { Duration of } \\
\text { Labor: } \\
\text { Com }\end{array}$ & $\begin{array}{l}\text { Duration of } \\
\text { Labor: } \\
\text { P Value }\end{array}$ & $\begin{array}{c}\text { Cesarean: } \\
\text { Int }\end{array}$ & $\begin{array}{l}\text { Cesarean: } \\
\text { Com }\end{array}$ & $\begin{array}{c}\text { Cesarean: } \\
\text { P Value }\end{array}$ & $\begin{array}{c}\text { Shorter Labor } \\
\text { Associated With } \\
\text { Lower Cesarean } \\
\text { Delivery Rate? }\end{array}$ \\
\hline $\begin{array}{l}\text { Abrao, } \\
2009^{196} \\
\text { Fair }\end{array}$ & $\begin{array}{l}\text { EA } \\
36\end{array}$ & $\begin{array}{l}\text { CSE } \\
41\end{array}$ & - & - & - & $13(36 \%)$ & $13(32 \%)$ & 0.68 & No \\
\hline $\begin{array}{l}\text { Nakamura, } \\
2009^{195} \\
\text { Fair }\end{array}$ & $\begin{array}{l}\text { EA } \\
20\end{array}$ & $\begin{array}{l}\text { CSE } \\
20\end{array}$ & - & - & - & $5(25 \%)$ & $6(30 \%)$ & 0.72 & No \\
\hline $\begin{array}{l}\text { Pascual- } \\
\text { Ramirez, } \\
2011^{78} \\
\text { Good }\end{array}$ & $\begin{array}{l}\text { EA } \\
63 \\
62 \\
62\end{array}$ & $\begin{array}{l}\text { CSE } \\
58 \\
57 \\
57\end{array}$ & $\begin{array}{l}\text { Stage 1: } 204 \\
\text { min } \pm 109 \\
\text { Stage 2: } 42 \\
\text { min } \pm 32 \\
\text { Total: } 246 \text { min } \\
\pm 112\end{array}$ & $\begin{array}{l}\text { Stage 1: } 212 \mathrm{~min} \\
\pm 133 \\
\text { Stage 2: } 43 \mathrm{~min} \\
\pm 34 \\
\text { Total: } 255 \mathrm{~min} \\
\pm 144\end{array}$ & $\begin{array}{l}\text { Stage 1: } 0.85 \\
\text { Stage 2: } 0.60 \\
\text { Total: } 0.77\end{array}$ & $10(14.1 \%)$ & $15(21.1 \%)$ & 0.27 & No \\
\hline $\begin{array}{l}\text { Patel, } 2014^{190} \\
\text { Fair }\end{array}$ & $\begin{array}{l}\text { EA } \\
53\end{array}$ & $\begin{array}{l}\text { CSE } \\
62\end{array}$ & $\begin{array}{l}\text { Total: Median } \\
431 \text { min (IQR } \\
283 \text { to } 589 \text { ) } \\
\end{array}$ & $\begin{array}{l}\text { Total: Median } 462 \\
\text { min (IQR } 291 \text { to } \\
611 \text { ) }\end{array}$ & NS & $9(17.0 \%)$ & $14(22.6 \%)$ & 0.45 & No \\
\hline
\end{tabular}

Abbreviations: -=not reported; CI=confidence interval; Com=comparator; $\mathrm{CSE}=$ combined spinal epidural; EA=epidural analgesia; Int=intervention; IQR=interquartile range; Min=minutes; $\mathrm{N}=$ number of patients/participants; NS=not significant 
A single, good-quality study involving 144 patients of mixed parity reported duration of labor in the comparison of EA versus CSE. ${ }^{78}$ In this study, mean duration of the first stage of labor was 204 minutes $(S D=109)$ for EA compared with 212 minutes $(S D=133)$ for $C S E$ $(\mathrm{p}=0.85)$, and mean duration of the second stage of labor was 42 minutes $(\mathrm{SD}=32)$ for $\mathrm{EA}$ compared with 43 minutes $(S D=34)$ for $\operatorname{CSE}(\mathrm{p}=0.60)$. SOE was rated as insufficient for both outcomes. Mean time for total duration of labor was 246 minutes $(S D=112)$ for $E A$, versus 255 minutes ( $\mathrm{SE}=144)$ for $\mathrm{CSE}(\mathrm{p}=0.77)$. A fair-quality study involving 115 patients also found no difference in median duration of total labor between EA and CSE (low SOE). ${ }^{190}$ All four RCTs that compared EA with CSE in a mixed parity population reported cesarean delivery rates. ${ }^{78,190,195,196}$ Meta-analysis of these data involving 374 patients of mixed parity generated an estimate of the odds ratio of cesarean delivery associated with CSE relative to EA of 0.8 (95\% CI: 0.5 to 1.3 ) (Figure 8, moderate SOE).

Figure 8. Epidural analgesia versus combined spinal epidural in women of mixed or unspecified parity-cesarean delivery rates (number of events)

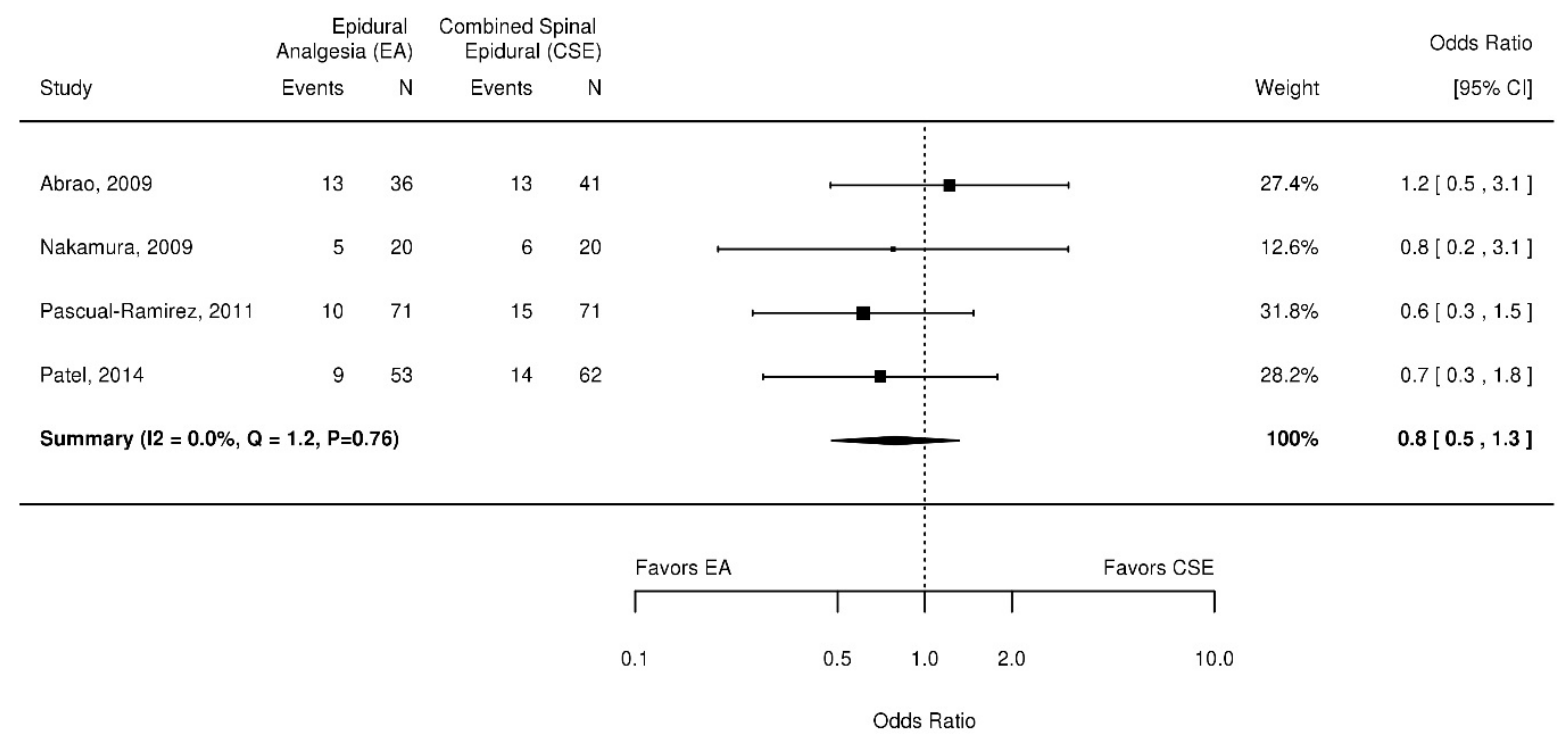

Abbreviations: $\mathrm{CI}=$ confidence interval; $\mathrm{CSE}=$ combined spinal epidural; $\mathrm{EA}=$ epidural analgesia; $\mathrm{N}=$ number of participants; $\mathrm{SD}=$ standard deviation

\section{Neonatal Outcomes for Epidural Analgesia Versus Combined Spinal Epidural Analgesia}

Neither EA nor CSE was associated with neonatal intensive care admissions in the single, fair-quality RCT involving 115 patients that compared EA with CSE and reported this outcome (insufficient SOE). ${ }^{190}$

\section{Process-Related Outcomes for Epidural Analgesia Versus Combined Spinal Epidural Analgesia}

CSE was found to be associated with a higher proportion of patients with abnormal fetal heart rate tracings than EA in a fair-quality RCT involving 77 patients ( $31.7 \%$ vs. 5.6\%, respectively; $\mathrm{p}<0.01) .{ }^{196}$ In another fair-quality RCT involving 115 patients, ${ }^{190}$ an abnormal fetal heart tracing pattern was noted in $13 \%$ of patients in the CSE arm, compared with $6 \%$ in the EA 
group. This corresponds to a risk ratio of 2.28 (95\% CI 0.64 to 8.16) of CSE relative to EA (low SOE).

Another good-quality RCT involving 144 patients assessed maternal satisfaction with analgesia at three different time points: initially; during stage 1 of labor; and during stage 2 of labor. ${ }^{78}$ The median maternal satisfaction score of 1 for initial satisfaction was statistically lower (indicating a higher level of satisfaction) for EA compared with CSE with the median score of 2 $(p=0.005)$. There were no statistically significant between-group differences in satisfaction with analgesia during either the first or second stages of labor (insufficient SOE).

\section{Strength of Evidence for Epidural Analgesia Versus Combined Spinal Epidural Analgesia}

Tables 50 and 51 summarize the SOE for the comparison of EA versus CSE. In general, meta analysis of the included studies allowed low and moderate SOE for major outcomes of interest.

Table 50. Epidural analgesia versus combined spinal epidural: Evidence profile in nulliparous women

\begin{tabular}{|c|c|c|c|c|}
\hline Category & Outcome & $\begin{array}{l}\text { Study Design } \\
\text { (Sample Size) }\end{array}$ & Conclusion & $\begin{array}{c}\text { SOE } \\
\text { (Rationale) }^{\mathrm{a}}\end{array}$ \\
\hline \multirow[t]{4}{*}{$\begin{array}{l}\text { Intermediate } \\
\text { or Final } \\
\text { Outcomes }\end{array}$} & $\begin{array}{l}\text { Process Related } \\
\text { Outcomes - } \\
\text { Duration of } 1^{\text {st }} \\
\text { Stage Labor }\end{array}$ & $\begin{array}{l}5 \\
\text { RCTs } \\
7,202,191,193,19 \\
(1,424)\end{array}$ & $\begin{array}{l}\text { No difference: Meta-analysis } \\
\text { showed no significant } \\
\text { differences between EA and } \\
\text { CSE in duration of the first } \\
\text { stage of labor (mean difference } \\
\text { [MD] } 32.7 \text { minutes; } 95 \% \\
\mathrm{Cl}-19.3 \text { to } 84.7 \text { ). }\end{array}$ & $\begin{array}{l}\text { Low } \\
\text { (Medium risk of bias, } \\
\text { indirect, inconsistent, } \\
\text { imprecise) }\end{array}$ \\
\hline & $\begin{array}{l}\text { Process Related } \\
\text { Outcomes - } \\
\text { Duration of } 2^{\text {nd }} \\
\text { Stage Labor }\end{array}$ & $\begin{array}{l}5 \\
\mathrm{RCTs}^{78,191,193,19} \\
7,202 \\
(1,424)\end{array}$ & $\begin{array}{l}\text { No difference: Meta-analysis } \\
\text { showed no significant } \\
\text { differences between EA and } \\
\text { CSE in duration of the second } \\
\text { stage of labor (MD }-0.2 \\
\text { minutes; } 95 \% \mathrm{Cl}-21.9 \text { to } 21.6) \text {. }\end{array}$ & $\begin{array}{l}\text { Low } \\
\text { (Medium risk of bias, } \\
\text { indirect, inconsistent, } \\
\text { imprecise) }\end{array}$ \\
\hline & $\begin{array}{l}\text { Process Related } \\
\text { Outcomes - Total } \\
\text { Duration of Labor }\end{array}$ & $\begin{array}{l}5 \\
\text { RCTs } \\
7,202,191,193,19 \\
(1,424)\end{array}$ & $\begin{array}{l}\text { Worsening with EA: Meta- } \\
\text { analysis showed total duration } \\
\text { of labor (from time of } \\
\text { intervention to delivery) was } \\
\text { significantly longer for EA } \\
\text { relative to CSE, with an MD of } \\
62.0 \text { minutes ( } 95 \% \mathrm{Cl} 7.2 \text { to } \\
116.7) \text {. }\end{array}$ & $\begin{array}{l}\text { Moderate } \\
\text { (Medium risk of bias, } \\
\text { imprecise) }\end{array}$ \\
\hline & $\begin{array}{l}\text { Process Related } \\
\text { Outcomes - Mode } \\
\text { of Delivery } \\
\text { (Cesarean } \\
\text { Delivery) }\end{array}$ & $\begin{array}{l}5 \\
\text { RCTs } \\
7,202,191,193,19 \\
(1,604)\end{array}$ & $\begin{array}{l}\text { No difference: Meta-analysis } \\
\text { of the data from } 1604 \text { patients } \\
\text { in these } 5 \text { RCTs showed no } \\
\text { statistically significant difference } \\
\text { in cesarean delivery rates } \\
\text { between EA and CSE (OR 1.1; } \\
95 \% \mathrm{Cl} 0.9 \text { to } 1.2 \text { ). }\end{array}$ & $\begin{array}{l}\text { Moderate } \\
\text { (Indirect) }\end{array}$ \\
\hline $\begin{array}{l}\text { Adverse } \\
\text { Events }\end{array}$ & $\begin{array}{l}\text { Process Related } \\
\text { Outcomes - } \\
\text { Parental } \\
\text { Preferences }\end{array}$ & $\begin{array}{l}1 \mathrm{RCT}^{191} \\
(1,140)\end{array}$ & $\begin{array}{l}\text { Inconclusive: SOE was } \\
\text { insufficient given imprecise } \\
\text { findings from one study }\end{array}$ & $\begin{array}{l}\text { Insufficient } \\
\text { (imprecise, one study) }\end{array}$ \\
\hline
\end{tabular}

${ }^{a}$ Criteria for downgrading SOE are described as Rationale; when these criteria are insufficient for understanding the final SOE, additional explanation is provided.

Abbreviations: $\mathrm{CI}=$ confidence interval; $\mathrm{CSE}=$ combined spinal epidural; $\mathrm{EA}=$ =pidural analgesia; $\mathrm{MD}=$ mean difference; $\mathrm{OR}=\mathrm{odds}$ ratio; $\mathrm{RCT}=$ randomized controlled trial; $\mathrm{SOE}=$ strength of evidence 
Table 51. Epidural analgesia versus combined spinal epidural: Evidence profile in women of mixed parity

\begin{tabular}{|c|c|c|c|c|}
\hline Category & Outcome & $\begin{array}{l}\text { Study Design } \\
\text { (Sample Size) }\end{array}$ & Conclusion & $\begin{array}{c}\text { SOE } \\
\text { (Rationale) }^{\mathrm{a}}\end{array}$ \\
\hline \multirow[t]{4}{*}{$\begin{array}{l}\text { Intermediate } \\
\text { or Final } \\
\text { Outcomes }\end{array}$} & $\begin{array}{l}\text { Process Related } \\
\text { Outcomes - } \\
\text { Duration of } 1^{\text {st }} \\
\text { Stage Labor }\end{array}$ & $\begin{array}{l}1 \mathrm{RCT}^{78} \\
(144)\end{array}$ & $\begin{array}{l}\text { Inconclusive: SOE was } \\
\text { insufficient given imprecise } \\
\text { findings from one small study }\end{array}$ & $\begin{array}{l}\text { Insufficient } \\
\text { (Indirect, imprecise, one } \\
\text { study) }\end{array}$ \\
\hline & $\begin{array}{l}\text { Process Related } \\
\text { Outcomes - } \\
\text { Duration of } 2^{\text {nd }} \\
\text { Stage Labor }\end{array}$ & $\begin{array}{l}1 \mathrm{RCT}^{78} \\
(144)\end{array}$ & $\begin{array}{l}\text { Inconclusive: SOE was } \\
\text { insufficient given imprecise } \\
\text { findings from one small study }\end{array}$ & $\begin{array}{l}\text { Insufficient } \\
\text { (Indirect, imprecise, one } \\
\text { study) }\end{array}$ \\
\hline & $\begin{array}{l}\text { Process Related } \\
\text { Outcomes - Total } \\
\text { Duration of Labor }\end{array}$ & $\begin{array}{l}2 \mathrm{RCTs}^{78,190} \\
(258)\end{array}$ & $\begin{array}{l}\text { No difference: No significant } \\
\text { difference between EA and } \\
\text { CSE for total duration of labor. }\end{array}$ & $\begin{array}{l}\text { Low } \\
\text { (Medium risk of bias, } \\
\text { imprecise) }\end{array}$ \\
\hline & $\begin{array}{l}\text { Process Related } \\
\text { Outcomes - Mode } \\
\text { of Delivery } \\
\text { (Cesarean } \\
\text { Delivery) }\end{array}$ & $\begin{array}{l}4 \\
\mathrm{RCTs} \\
6 \\
(374)\end{array}$ & $\begin{array}{l}\text { No difference: Meta-analysis } \\
\text { generated an estimate of the } \\
\text { odds ratio of cesarean delivery } \\
\text { associated with CSE relative to } \\
\text { EA of } 0.8 \text { ( } 95 \% \mathrm{Cl} \text { : } 0.5 \text { to } 1.3) \text {. }\end{array}$ & $\begin{array}{l}\text { Moderate } \\
\text { (Medium risk of bias) }\end{array}$ \\
\hline \multirow[t]{3}{*}{$\begin{array}{l}\text { Adverse } \\
\text { Events }\end{array}$} & $\begin{array}{l}\text { Neonatal } \\
\text { Outcomes - } \\
\text { Admission to } \\
\text { NICU }\end{array}$ & $\begin{array}{l}1 \mathrm{RCT}^{190} \\
(115)\end{array}$ & $\begin{array}{l}\text { Inconclusive: SOE was } \\
\text { insufficient given imprecise } \\
\text { findings from one small study }\end{array}$ & $\begin{array}{l}\text { Insufficient } \\
\text { (Medium risk of bias, } \\
\text { imprecise, one small } \\
\text { study) }\end{array}$ \\
\hline & $\begin{array}{l}\text { Process Related } \\
\text { Outcomes - } \\
\text { Abnormal Fetal } \\
\text { Heart Tracing }\end{array}$ & $\begin{array}{l}2 \mathrm{RCTs}^{190,196} \\
(190)\end{array}$ & $\begin{array}{l}\text { Improvement with EA: CSE } \\
\text { was associated with a higher } \\
\text { proportion of patients with } \\
\text { abnormal fetal heart rate } \\
\text { tracings than EA in one study } \\
\text { and a risk ratio of } 2.28 \text { ( } 95 \% \mathrm{Cl} \text { : } \\
0.64 \text { to } 8.16) \text { for an abnormal } \\
\text { fetal heart tracing in another } \\
\text { study. }\end{array}$ & $\begin{array}{l}\text { Low } \\
\text { (Medium risk of bias, } \\
\text { imprecise) }\end{array}$ \\
\hline & $\begin{array}{l}\text { Process Related } \\
\text { Outcomes - } \\
\text { Parental } \\
\text { Preferences }\end{array}$ & $\begin{array}{l}1 \mathrm{RCT}^{78} \\
(142)\end{array}$ & $\begin{array}{l}\text { Inconclusive: SOE was } \\
\text { insufficient given imprecise } \\
\text { findings from one small study }\end{array}$ & $\begin{array}{l}\text { Insufficient } \\
\text { (Imprecise, one small } \\
\text { study) }\end{array}$ \\
\hline
\end{tabular}

${ }^{a}$ Criteria for downgrading SOE are described as Rationale; when these criteria are insufficient for understanding the final SOE, additional explanation is provided.

Abbreviations: $\mathrm{CI}=$ confidence interval; $\mathrm{CSE}=$ combined spinal epidural; $\mathrm{EA}=$ =pidural analgesia; $\mathrm{RCT}=$ randomized controlled trial; SOE=strength of evidence

\section{Epidural Analgesia Versus Patient-Controlled Intravenous Analgesia}

Results for the comparison of EA and combined PCIA were reported for nulliparous women in one study ${ }^{191}$ and for a mixed population of women in three studies. ${ }^{124,192,194}$ We also identified one good-quality SR/meta-analysis relevant to this comparison. ${ }^{33}$

\section{Results in Nulliparous Women}

\section{Duration of Labor and Cesarean Delivery Rates for Epidural Analgesia Versus Patient-Controlled Intravenous Analgesia}

A single, good-quality RCT conducted in Egypt compared duration of labor and cesarean delivery rates associated with EA in comparison with both PCIA with remifentanil and CSE in 1140 nulliparous women. ${ }^{191}$ Duration of labor did not appear to be different between these two groups. Mean duration of labor in hours for EA compared with PCIA were, respectively, 10.8 $(\mathrm{SD}=3.9)$ versus $10.3(\mathrm{SD}=3.5)$ for total labor duration; $7.8(\mathrm{SD}=0.9)$ versus $7.7(\mathrm{SD}=0.8)$ for 
duration of the latent phase of the first stage; $1.88(\mathrm{SD}=0.7)$ versus $1.80(\mathrm{SD}=0.6)$ for duration of the active phase of the first stage; and $1.0(\mathrm{SD}=0.5)$ versus $0.95(\mathrm{SD}=0.4)$ for duration of the second stage. The cesarean delivery rate was $25.0 \%$ in both groups. Given findings from one RCT in a non-U.S. setting the SOE was rated as insufficient for all outcomes.

\section{Process-Related Outcomes for Epidural Analgesia Versus Patient-Controlled Intravenous Analgesia}

The RCT by Ismail et al. ${ }^{191}$ assessed maternal overall satisfaction with analgesia 24 hours after delivery was assessed using a using a 4-point verbal scale ranging from very satisfied to very dissatisfied (1: very dissatisfied, 2: dissatisfied, 3: satisfied, 4: very satisfied). ${ }^{191}$ Statistical significance testing for the EA versus PCIA comparison was not reported, but the mean maternal satisfaction score of $2.8(\mathrm{SD}=0.8)$ for EA was similar to the satisfaction score of $3.0(\mathrm{SD}=0.7)$ for PCIA (insufficient SOE).

\section{Results in Women of Mixed or Unspecified Parity}

Three RCTs compared EA with PCIA among women with mixed or unspecified parity. One was a fair-quality study conducted in Norway involving 23 nulliparous and 16 parous women, ${ }^{192}$ one was a fair-quality study conducted in China involving 120 patients of unclear parity, ${ }^{124}$ and one was a poor-quality RCT conducted in The Netherlands involving 12 nulliparous and 14 parous patients. ${ }^{194}$ Results were not reported separately by parity. Table 52 shows results for these studies. 


\begin{tabular}{|c|c|c|c|c|c|c|c|c|c|}
\hline $\begin{array}{l}\text { Study } \\
\text { Quality }\end{array}$ & $\stackrel{\text { Int }}{N}$ & $\underset{N}{\text { Com }}$ & $\begin{array}{l}\text { Duration of } \\
\text { Labor: } \\
\text { Int }\end{array}$ & $\begin{array}{l}\text { Duration of } \\
\text { Labor: } \\
\text { Com }\end{array}$ & $\begin{array}{l}\text { Duration of } \\
\text { Labor: } \\
\text { P Value }\end{array}$ & $\begin{array}{c}\text { Cesarean: } \\
\text { Int }\end{array}$ & $\begin{array}{l}\text { Cesarean: } \\
\text { Com }\end{array}$ & $\begin{array}{l}\text { Cesarean: } \\
\text { P Value }\end{array}$ & $\begin{array}{c}\text { Shorter Labor } \\
\text { Associated With } \\
\text { Lower Cesarean } \\
\text { Delivery Rate? }\end{array}$ \\
\hline $\begin{array}{l}\text { Douma, } \\
2011^{194} \\
\text { Poor }\end{array}$ & $\begin{array}{l}\text { EA } \\
10\end{array}$ & $\begin{array}{l}\mathrm{PCIA} \\
10\end{array}$ & $\begin{array}{l}\text { Stage 1: } 410 \mathrm{~min} \\
\pm 173 \\
\text { Stage 2: } 32 \mathrm{~min} \\
\pm 14\end{array}$ & $\begin{array}{l}\text { Stage 1: } 488 \mathrm{~min} \\
\pm 277 \\
\text { Stage 2: } 71 \mathrm{~min} \\
\pm 40\end{array}$ & $\begin{array}{l}\text { Stage 1: } 0.42 \\
\text { Stage 2: } 0.009\end{array}$ & $2(20 \%)$ & $1(10 \%)$ & 0.53 & No \\
\hline $\begin{array}{l}\text { Liu, 2015 } \\
\text { Fair }\end{array}$ & $\begin{array}{l}\mathrm{EA} \\
\mathrm{N}=30\end{array}$ & $\begin{array}{l}\mathrm{PCIA} \\
30\end{array}$ & $\begin{array}{l}\text { Stage 1: } 423 \mathrm{~min} \\
\pm 181 \\
\text { Stage 2: } 61 \mathrm{~min} \\
\pm 29\end{array}$ & $\begin{array}{l}\text { Stage 1: } 425 \mathrm{~min} \\
\pm 199 \\
\text { Stage 2: } 46 \mathrm{~min} \\
\pm 9\end{array}$ & $\begin{array}{l}\text { Stage 1: } 0.97 \\
\text { Stage 2: } 0.03\end{array}$ & $2(6.7 \%)$ & $2(6.7 \%)$ & 1 & No \\
\hline $\begin{array}{l}\text { Tveit, } 2012^{192} \\
\text { Fair }\end{array}$ & $\begin{array}{l}\text { EA } \\
20\end{array}$ & $\begin{array}{l}\mathrm{PClA} \\
17\end{array}$ & $\begin{array}{l}\text { Stage 1: } 360 \mathrm{~min} \\
\pm 186 \\
\text { Stage 2: } 42 \mathrm{~min} \\
\pm 32\end{array}$ & $\begin{array}{l}\text { Stage 1: } 359 \mathrm{~min} \\
\pm 188 \\
\text { Stage } 2: 51 \mathrm{~min} \\
\pm 34\end{array}$ & $\begin{array}{l}\text { Stage 1: } 0.98 \\
\text { Stage 2: } 0.41\end{array}$ & $3(15.0 \%)$ & $1(5.9 \%)$ & 0.37 & No \\
\hline
\end{tabular}

Abbreviations: Com=comparator; EA=epidural analgesia; Int=intervention; min=minutes; $\mathrm{N}=$ number of patients/participants; PCIA=patient-controlled intravenous analgesia 
Meta-analysis of these 3 RCTs did not identify differences in duration of labor between these two strategies for analgesia, with the estimated mean difference in total duration of labor after EA administration minus duration after PCIA being -10.1 minutes (95\% CI -134.3 to 114.1) (Figure 9). Given the potential risk of bias in all of the included studies and their non-U.S. settings, the SOE was rated as low.

Figure 9. Epidural analgesia versus patient-controlled intravenous analgesia in women of mixed or unspecified parity-total duration of labor (minutes)

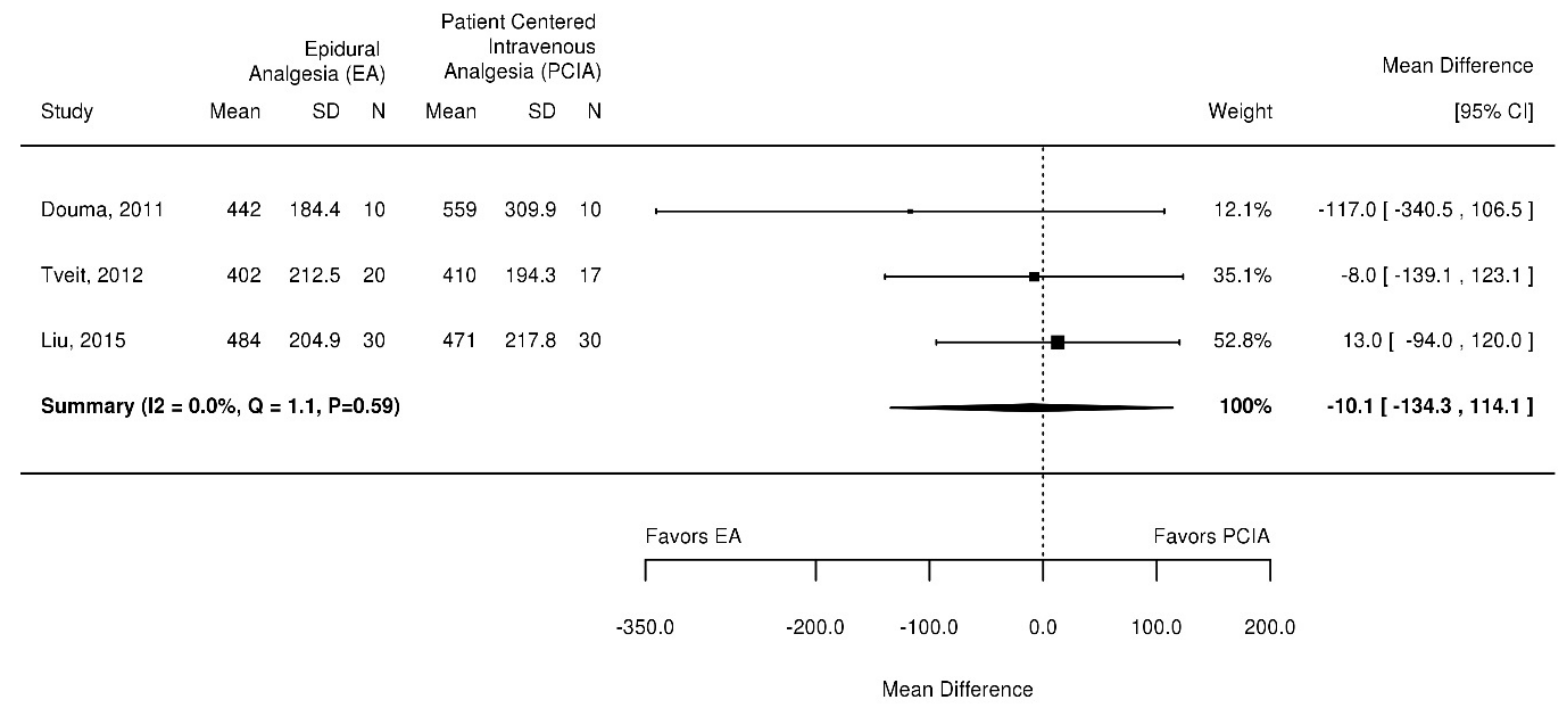

Abbreviations: $\mathrm{CI}=$ confidence interval; EA=epidural analgesia; $\mathrm{N}=$ number of participants; $\mathrm{PCIA}=$ patient-controlled intravenous analgesia; $\mathrm{SD}=$ standard deviation

Meta-analysis of the three RCTs that compared EA with PCIA ${ }^{124,192,194}$ generated an estimate of the odds ratio for cesarean delivery of EA relative to PCIA of 1.3 (95\% CI 0.3 to 5.6) (Figure 10). This suggests that there is no statistically significant difference in cesarean delivery rates between these two interventions. Again given potential risk of bias, non-U.S. setting, and the imprecision of the findings the SOE was rated as low. 
Figure 10. Epidural analgesia versus patient-controlled intravenous analgesia in women of mixed or unspecified parity-cesarean delivery rates (number of events)

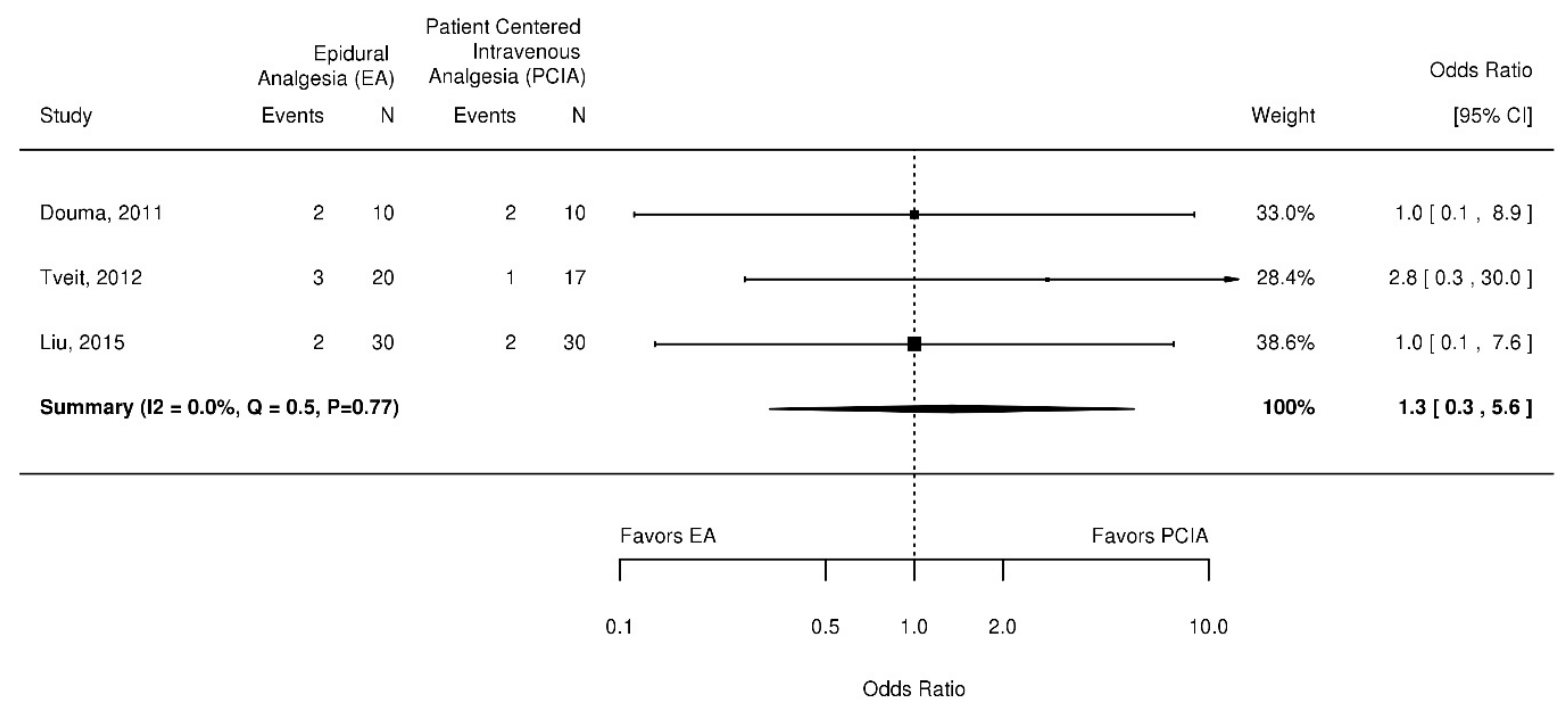

Abbreviations: $\mathrm{CI}=$ confidence interval; $\mathrm{EA}=$ epidural analgesia; $\mathrm{N}=$ number of participants; $\mathrm{PCIA}=$ patient-controlled intravenous analgesia; $\mathrm{SD}=$ standard deviation

\section{Process-Related Outcomes for Epidural Analgesia Versus Patient-Controlled Intravenous Analgesia}

In the RCT by Tveit et al., ${ }^{192}$ abnormal fetal heart rate tracings were present in one of 20 patients in the EA group and 2 of 17 patients in the PCIA group. In the same RCT, one of 20 patients in the EA group and none of the 17 patients in the PCIA group delivered a baby with congenital hip displacement. Maternal self-reports of satisfaction with analgesia were similar between the two intervention groups. The SOE was rated as insufficient given imprecise findings in this single small study.

\section{Relevant Systematic Reviews/Meta-Analyses for Epidural Analgesia Versus Patient-Controlled Intravenous Analgesia}

A good-quality SR and meta-analysis published in 2014, with a final search date of November 29, 2012, reviewed and synthesized the findings from published RCTs that compared EA with PCIA with the analgesic medication remifentanil. ${ }^{33}$ Parity of the women included in the studies was not reported. Of the five RCTs included in that SR, three are also included in our review. ${ }^{191,192,194}$ We excluded the remaining two studies that were included in the SR by Liu et al. because they did not report outcomes of interest and therefore the findings of the SR do not add to our included evidence and findings.

Two other good-quality reviews, one a Cochrane review ${ }^{204}$ and the other an independent review, ${ }^{205}$ included 9 trials, but the 6 not included in this review included women who were undergoing induction of labor, and results were not reported separately and therefore did not impact our strength of evidence ratings. 


\section{Strength of Evidence for Epidural Analgesia Versus Patient-Controlled Intravenous Analgesia}

Tables 53 and 54 summarize the SOE for the comparison of EA versus CSE. In general, the strength of evidence was judged insufficient for outcomes given the imprecision of the findings, findings for specific outcomes from just one study, and the non-U.S. settings. Low SOE was reported for duration of labor and cesarean delivery in women with mixed or unspecified parity.

Table 53. Epidural analgesia versus patient-controlled intravenous analgesia: Evidence profile in nulliparous women

\begin{tabular}{|c|c|c|c|c|}
\hline Category & Outcome & $\begin{array}{l}\text { Study Design } \\
\text { (Sample Size) }\end{array}$ & Conclusion & $\begin{array}{c}\text { SOE } \\
\text { (Rationale) }^{a}\end{array}$ \\
\hline \multirow[t]{4}{*}{$\begin{array}{l}\text { Intermediate } \\
\text { or Final } \\
\text { Outcomes }\end{array}$} & $\begin{array}{l}\text { Process Related } \\
\text { Outcomes - } \\
\text { Duration of } 1^{\text {st }} \\
\text { Stage Labor }\end{array}$ & $\begin{array}{l}1 \mathrm{RCT}^{191} \\
(1,140)\end{array}$ & $\begin{array}{l}\text { Inconclusive: SOE was } \\
\text { insufficient given imprecise } \\
\text { findings from one study } \\
\text { performed in a non-U.S. setting. }\end{array}$ & $\begin{array}{l}\text { Insufficient } \\
\text { (Imprecise, one study, } \\
\text { non-U.S. setting) }\end{array}$ \\
\hline & $\begin{array}{l}\text { Process Related } \\
\text { Outcomes - } \\
\text { Duration of } 2^{\text {nd }} \\
\text { Stage Labor }\end{array}$ & $\begin{array}{l}1 \mathrm{RCT}^{191} \\
(1,140)\end{array}$ & $\begin{array}{l}\text { Inconclusive: SOE was } \\
\text { insufficient given imprecise } \\
\text { findings from one study } \\
\text { performed in a non-U.S. setting. }\end{array}$ & $\begin{array}{l}\text { Insufficient } \\
\text { (Imprecise, one study, } \\
\text { non-U.S. setting) }\end{array}$ \\
\hline & $\begin{array}{l}\text { Process Related } \\
\text { Outcomes - Total } \\
\text { Duration of Labor }\end{array}$ & $\begin{array}{l}1 \mathrm{RCT}^{191} \\
(1,140)\end{array}$ & $\begin{array}{l}\text { Inconclusive: SOE was } \\
\text { insufficient given imprecise } \\
\text { findings from one study } \\
\text { performed in a non-U.S. setting. }\end{array}$ & $\begin{array}{l}\text { Insufficient } \\
\text { (Imprecise, one study, } \\
\text { non-U.S. setting) }\end{array}$ \\
\hline & $\begin{array}{l}\text { Process Related } \\
\text { Outcomes - Mode } \\
\text { of Delivery } \\
\text { (Cesarean } \\
\text { Delivery) }\end{array}$ & $\begin{array}{l}1 \mathrm{RCT}^{191} \\
(1,140)\end{array}$ & $\begin{array}{l}\text { Inconclusive: SOE was } \\
\text { insufficient given imprecise } \\
\text { findings from one study } \\
\text { performed in a non-U.S. setting. }\end{array}$ & $\begin{array}{l}\text { Insufficient } \\
\text { (Imprecise, one study, } \\
\text { non-U.S. setting) }\end{array}$ \\
\hline $\begin{array}{l}\text { Adverse } \\
\text { Events }\end{array}$ & $\begin{array}{l}\text { Process Related } \\
\text { Outcomes - } \\
\text { Parental } \\
\text { Preferences }\end{array}$ & $\begin{array}{l}1 \mathrm{RCT}^{191} \\
(1,140)\end{array}$ & $\begin{array}{l}\text { Inconclusive: SOE was } \\
\text { insufficient given imprecise } \\
\text { findings from one study } \\
\text { performed in a non-U.S. setting. }\end{array}$ & $\begin{array}{l}\text { Insufficient } \\
\text { (Imprecise, one study, } \\
\text { non-U.S. setting) }\end{array}$ \\
\hline
\end{tabular}

${ }^{a}$ Criteria for downgrading SOE are described as Rationale; when these criteria are insufficient for understanding the final SOE, additional explanation is provided.

Abbreviations: RCT=randomized controlled trial; SOE=strength of evidence

Table 54. Epidural analgesia versus patient-controlled intravenous analgesia: Evidence profile in women of mixed parity

\begin{tabular}{|c|c|c|c|c|}
\hline Category & Outcome & $\begin{array}{l}\text { Study Design } \\
\text { (Sample Size) }\end{array}$ & Conclusion & $\begin{array}{c}\text { SOE } \\
\text { (Rationale) }^{a}\end{array}$ \\
\hline \multirow[t]{2}{*}{$\begin{array}{l}\text { Intermediate } \\
\text { or Final } \\
\text { Outcomes }\end{array}$} & $\begin{array}{l}\text { Process Related } \\
\text { Outcomes - Total } \\
\text { Duration of Labor }\end{array}$ & $\begin{array}{l}3 \\
\text { RCTs }^{124,192,194} \\
(177)\end{array}$ & $\begin{array}{l}\text { No difference: Meta-analysis } \\
\text { did not identify differences in } \\
\text { duration of labor, with the } \\
\text { estimated mean after EA } \\
\text { administration minus duration } \\
\text { after } \mathrm{PClA} \text { being }-10.1 \text { minutes } \\
(95 \% \mathrm{Cl}-134.3 \text { to } 114.1) \text {. }\end{array}$ & $\begin{array}{l}\text { Low } \\
\text { (Medium risk of bias, } \\
\text { imprecise, non-U.S. } \\
\text { settings) }\end{array}$ \\
\hline & $\begin{array}{l}\text { Process Related } \\
\text { Outcomes - Mode } \\
\text { of Delivery } \\
\text { (Cesarean } \\
\text { Delivery) } \\
\end{array}$ & $\begin{array}{l}3 \\
\text { RCTs } 124,192,194 \\
(17)\end{array}$ & $\begin{array}{l}\text { No difference: Meta-analysis } \\
\text { generated an estimate of the } \\
\text { odds ratio for cesarean delivery } \\
\text { of EA relative to PCIA of } 1.3 \\
(95 \% \mathrm{Cl} 0.3 \text { to } 5.6) \text {. }\end{array}$ & $\begin{array}{l}\text { Low } \\
\text { (Medium risk of bias, } \\
\text { imprecise, non-U.S. } \\
\text { settings) }\end{array}$ \\
\hline $\begin{array}{l}\text { Adverse } \\
\text { Events }\end{array}$ & $\begin{array}{l}\text { Process Related } \\
\text { Outcomes - } \\
\text { Abnormal Fetal } \\
\text { Heart Tracing }\end{array}$ & $\begin{array}{l}1 \mathrm{RCT}^{192} \\
(37)\end{array}$ & $\begin{array}{l}\text { Inconclusive: SOE was } \\
\text { insufficient given imprecise } \\
\text { findings from one small study } \\
\text { performed in a non-U.S. setting. }\end{array}$ & $\begin{array}{l}\text { Insufficient } \\
\text { (Imprecise, one study, } \\
\text { non-U.S. setting) }\end{array}$ \\
\hline
\end{tabular}




\begin{tabular}{|c|l|l|l|l|}
\hline Category & \multicolumn{1}{|c|}{ Outcome } & $\begin{array}{l}\text { Study Design } \\
\text { (Sample Size) }\end{array}$ & \multicolumn{1}{c|}{ Conclusion } & \multicolumn{1}{c|}{$\begin{array}{c}\text { SOE } \\
\text { (Rationale) }^{\mathbf{a}}\end{array}$} \\
\hline & $\begin{array}{l}\text { Process Related } \\
\text { Outcomes }- \\
\text { Parental } \\
\text { Preferences }\end{array}$ & $\begin{array}{l}1 \mathrm{RCT} \mathrm{T}^{192} \\
(37)\end{array}$ & $\begin{array}{l}\text { Inconclusive: SOE was } \\
\text { insufficient given imprecise } \\
\text { findings from one small study } \\
\text { performed in a non-U.S. setting. }\end{array}$ & $\begin{array}{l}\text { Insufficient } \\
\text { (Imprecise, one study, } \\
\text { non-U.S. setting) }\end{array}$ \\
\hline
\end{tabular}

${ }^{a}$ Criteria for downgrading SOE are described as Rationale; when these criteria are insufficient for understanding the final SOE, additional explanation is provided.

Abbreviations: $\mathrm{CI}=$ confidence interval; EA=epidural analgesia; PCIA=patient-controlled intravenous analgesia;

RCT=randomized controlled trial; SOE=strength of evidence

\section{Epidural Analgesia Versus Intravascular Tramadol}

Results for this comparison were reported for women of mixed parity in one study. ${ }^{201}$ No relevant SR/MAs were identified.

\section{Results in Women of Mixed or Unspecified Parity}

A poor-quality RCT $(\mathrm{N}=90)$ conducted in India compared epidural tramadol plus bupivacaine versus intravenous tramadol in a mixed parity population. ${ }^{201}$ The only outcome of interest reported concerned parental preferences.

Process-Related Outcomes for Epidural Analgesia Versus Intravascular Tramadol

The distribution of responses for parturient satisfaction ("poor," "average," "good," "excellent”) favored the epidural group $(\mathrm{p}<0.05)$. Given the high risk of bias, small size, and non-U.S. setting the SOE was rated as insufficient.

\section{Strength of Evidence for Epidural Analgesia Versus Intravascular Tramadol}

Table 55 summarizes the SOE for the comparison of EA versus intravascular tramadol.

Table 55. Epidural analgesia versus intravascular tramadol: Evidence profile in women of mixed parity

\begin{tabular}{|l|l|l|l|l|}
\hline \multicolumn{1}{|c|}{ Category } & \multicolumn{1}{|c|}{ Outcome } & $\begin{array}{l}\text { Study Design } \\
\text { (Sample Size) }\end{array}$ & \multicolumn{1}{c|}{ Conclusion } & \multicolumn{1}{c|}{$\begin{array}{c}\text { SOE } \\
\text { (Rationale) }^{\mathbf{a}}\end{array}$} \\
\hline $\begin{array}{l}\text { Intermediate } \\
\text { or Final } \\
\text { Outcomes }\end{array}$ & $\begin{array}{l}\text { Process Related } \\
\text { Outcomes - } \\
\text { Parental } \\
\text { Preferences }\end{array}$ & $\begin{array}{l}1 \mathrm{RCT} 201 \\
(90)\end{array}$ & $\begin{array}{l}\text { Inconclusive: SOE was } \\
\text { insufficient given imprecise } \\
\text { findings from one small study } \\
\text { performed in a non-U.S. setting. }\end{array}$ & $\begin{array}{l}\text { Insufficient } \\
\text { Imph risk of bias, } \\
\text { Imon-U.S. setting) }\end{array}$ \\
\hline
\end{tabular}

${ }^{a}$ Criteria for downgrading SOE are described as Rationale; when these criteria are insufficient for understanding the final SOE, additional explanation is provided.

Abbreviations: RCT=randomized controlled trial; SOE=strength of evidence

\section{Early Versus Late Epidural Analgesia}

Results for this comparison were reported in two good-quality RCTs. ${ }^{199,200}$ One relevant good-quality SR/meta-analysis was also identified. ${ }^{49}$ All three of these studies focused exclusively on nulliparous women. Although the specifics of the EA protocols differed, in all studies early initiation was defined as EA initiated before the cervix was dilated to $4-5 \mathrm{~cm}$.

\section{Results in Nulliparous Women}

\section{Duration of Labor and Cesarean Delivery Rates for Early Versus Late Epidural Analgesia}

A good-quality RCT conducted in Israel compared early with late initiation of EA in 449 nulliparous women. ${ }^{199}$ Early initiation of EA consisted of immediate initiation of EA at first 
request $(<4 \mathrm{~cm})$, and late initiation consisted of delay of EA until the cervix was dilated to at least $4 \mathrm{~cm}$. Mean duration (SD) of the first stage of labor from time of randomization was significantly shorter for early (5.9 hours [2.9]) vs. late (6.6 hours [3.5]; $p=0.04$ ) initiation of EA. Mean duration (SD) of the second stage of labor did not differ between early (95 minutes [59]) vs. late (105 minutes [64]; $\mathrm{p}=0.12$ ) initiation of EA. Cesarean delivery rates did not differ between the two groups. Early initiation of EA was associated with a 13\% cesarean delivery rate, compared with $11 \%$ for late initiation $(\mathrm{p}=0.77){ }^{199}$

Another good-quality RCT conducted in the United States randomly allocated 750 nulliparous women to intrathecal fentanyl (using a spinal-epidural technique) at the first request for analgesia and epidural analgesia at the second request for analgesia (early EA) versus systemic hydromorphone at the first request for analgesia and epidural analgesia at either cervical dilatation of $4.0 \mathrm{~cm}$ or greater or at the third request for analgesia (late EA). ${ }^{200}$ Relative to late EA, early EA was associated with a shorter median time to vaginal delivery with a mean difference of 81 minutes (95\% CI 28 to 123) and a shorter duration of the first stage of labor with a mean difference of 81 minutes (95\% CI 35 to 123). Mean duration of the second stage of labor, however, did not differ between the two groups, with a mean difference of 11 minutes (95\% CI 6 to 21). The cesarean delivery rate of $17.8 \%$ associated with early EA was not statistically different from the rate of $20.7 \%$ associated with late EA $(p=0.31)$.

\section{Relevant Systematic Reviews/Meta-Analyses for Early Versus Late Epidural Analgesia}

A good-quality SR published in 2007 evaluated the effects that different timing of initiation of regional analgesia has on labor outcomes in nulliparous women. ${ }^{49}$ The review identified and included 9 eligible RCTs involving a total of 3320 patients. Meta-analysis of 8 of these RCTs involving a total of 2980 patients generated an estimated pooled OR of 1.0 (95\% CI 0.82 to 1.23) for cesarean delivery for early neuraxial analgesia relative to control interventions. The duration of labor was no different between interventions. The two RCTs included in our review and summarized above were included in this SR. The remaining 7 RCTs were published prior to the earliest eligible publication date for our review. Given the overlap of this SR with our included studies and the high quality of this SR, our SOE ratings emphasize the findings of the SR. The SOE was lowered, however, given that the included studies from the SR spanned 1994-2006 and may not reflect contemporary clinical practice strategies. Note though that the findings from the later studies included in our review as individual RCTs aligned with the findings of the SR.

\section{Strength of Evidence for Early Versus Late Epidural Analgesia}

Table 56 summarizes the SOE for early versus late epidural analgesia. The SOE was rated as moderate for all outcomes based on evidence from the good-quality SR.

\section{Table 56. Early versus late epidural analgesia: Evidence profile in nulliparous women ${ }^{\mathrm{a}}$}

\begin{tabular}{|c|c|c|c|c|}
\hline Category & Outcome & $\begin{array}{l}\text { Study Design } \\
\text { (Sample Size) }\end{array}$ & Conclusion & $\begin{array}{c}\text { SOE } \\
\text { (Rationale) }^{a}\end{array}$ \\
\hline $\begin{array}{l}\text { Intermediate } \\
\text { or Final } \\
\text { Outcomes }\end{array}$ & $\begin{array}{l}\text { Process Related } \\
\text { Outcomes }- \\
\text { Duration of } 1^{\text {st }} \\
\text { Stage Labor }\end{array}$ & $\begin{array}{l}1 \mathrm{SR}^{49}(1,739 \\
\text { patients, } 6 \\
\text { studies })\end{array}$ & $\begin{array}{l}\text { No difference: No differences } \\
\text { between early and late EA with } \\
\text { an odds ratio of } 0.95(95 \% \mathrm{Cl} \\
0.81 \text { to } 1.10) \text {. }\end{array}$ & Moderate \\
\hline
\end{tabular}




\begin{tabular}{|c|c|c|c|c|}
\hline Category & Outcome & $\begin{array}{l}\text { Study Design } \\
\text { (Sample Size) }\end{array}$ & Conclusion & $\begin{array}{c}\text { SOE } \\
\text { (Rationale) }^{a}\end{array}$ \\
\hline & $\begin{array}{l}\text { Process Related } \\
\text { Outcomes - } \\
\text { Duration of } 2^{\text {nd }} \\
\text { Stage Labor }\end{array}$ & $\begin{array}{l}1 \mathrm{SR}^{49}(1,739 \\
\text { patients, } 6 \\
\text { studies })\end{array}$ & $\begin{array}{l}\text { No difference: No differences } \\
\text { between early and late EA with } \\
\text { a weighted mean difference of } \\
0.52 \text { minutes ( } 95 \% \mathrm{Cl}-5.03 \text { to } \\
6.06 \text { minutes) }\end{array}$ & Moderate \\
\hline & $\begin{array}{l}\text { Process Related } \\
\text { Outcomes - Mode } \\
\text { of Delivery } \\
\text { (Cesarean } \\
\text { Delivery) }\end{array}$ & $\begin{array}{l}1 \mathrm{SR}^{49}(1,739 \\
\text { patients, } 6 \\
\text { studies })\end{array}$ & $\begin{array}{l}\text { No difference: No differences } \\
\text { between early and late EA } \\
\text { (odds ratio=1.00, } 95 \% \mathrm{Cl} 0.83 \\
\text { to } 1.21 \text { ) }\end{array}$ & Moderate \\
\hline
\end{tabular}

${ }^{a}$ Early epidural was defined as immediate initiation of EA at first request $(<4 \mathrm{~cm})$, and late initiation consisted of delay of EA until the cervix was dilated to at least $4 \mathrm{~cm}$.

${ }^{\mathrm{b}}$ Criteria for downgrading SOE are described as Rationale; when these criteria are insufficient for understanding the final SOE, additional explanation is provided.

Abbreviations: $\mathrm{CI}=$ confidence interval; $\mathrm{EA}=$ =arly epidural; $\mathrm{RCT}=$ randomized controlled trial; $\mathrm{SOE}=$ strength of evidence;

$\mathrm{SR}=$ systematic review

\section{Routine Epidural Analgesia Versus Analgesia on Request}

Results for this comparison were reported for women of mixed parity in one study. ${ }^{68}$. Results for changes in quality-of-life between antepartum and 6 weeks postpartum from this same study were reported in a subsequent publication. ${ }^{69}$ No relevant SR/MAs were identified.

\section{Results in Women of Mixed or Unspecified Parity}

A good-quality RCT conducted in The Netherlands compared routine EA with analgesia on request in the form of intramuscular opiates or EA at the first or second request for pain relief after opiates. ${ }^{68}$ Of the 233 patients randomized to routine EA and the 255 women randomized to analgesia on request, 115 (49\%) and 122 (48\%), respectively, were nulliparous.

\section{Duration of Labor and Cesarean Delivery Rates for Routine Epidural Analgesia Versus Analgesia on Request}

Median duration of the second stage of labor did not differ between EA (20 minutes; IQR, 10 to 50) compared with analgesia on request (19 minutes; IQR, 8.0 to 45). This corresponds to a difference in means of 2.0 (95\% CI -3.2 to 7.1$).{ }^{68}$ In the EA group, 44 patients (19\% of all patients randomized to EA) underwent cesarean delivery versus 39 patients in the analgesia on request group (15\% of all patients randomized to analgesia on request). This corresponds to a between-group difference in percentage of 3.6 (95\% CI -3.1 to 10.3). ${ }^{68}$ Given the imprecision in findings from one study the SOE was rated as insufficient.

\section{Maternal Outcomes for Early Versus Late Epidural Analgesia}

The maternal outcomes reported in this study were postpartum hemorrhage and trauma to the pelvic floor (perineal laceration). There was no difference in the percentage of patients who experienced postpartum hemorrhage of greater than $1000 \mathrm{~mL}$ of blood loss between women in the EA group (6.0\%) versus women in the analgesia-on-request group (4.3\%). This corresponds to a difference in percentage of -0.6 (95\% CI -3.5 to 2.4). ${ }^{68}$

There was no difference in the percentage of patients who experienced third- or fourthdegree perineal laceration between women in the EA group $(0.9 \%)$ versus women in the analgesia-on-request group (1.6\%). This corresponds to a difference in percentage of -0.7 (95\% CI -2.6 to 1.2). ${ }^{68}$ Again the SOE was rated as insufficient given the findings from this one study. 
A later publication from this study reported on change in generic quality-of-life between antepartum and 6 weeks postpartum, as measured by the Short Form 36 (SF-36) and found no difference in either overall score or scores on individual subscales $(n=488)$. Again the SOE was rated as insufficient given the findings from this one study. ${ }^{69}$

\section{Neonatal Outcomes for Early Versus Late Epidural Analgesia}

Delivery was complicated by shoulder dystocia in 5 patients $(2.1 \%)$ in the EA group versus 8 patients (3.1\%) in the analgesia-on-request group. This corresponds to a difference in percentage of -1.0 (95\% CI: -3.8 to 1.8 ) (insufficient SOE). ${ }^{68}$

\section{Strength of Evidence for Early Versus Late Epidural Analgesia}

Table 57 summarizes the SOE for early versus late epidural analgesia. The SOE was rated as insufficient for all outcomes.

Table 57. Routine epidural analgesia versus analgesia on request: Evidence profile in women of mixed parity

\begin{tabular}{|c|c|c|c|c|}
\hline Category & Outcome & $\begin{array}{l}\text { Study Design } \\
\text { (Sample Size) }\end{array}$ & Conclusion & $\begin{array}{c}\text { SOE } \\
\text { (Rationale) }^{a}\end{array}$ \\
\hline \multirow[t]{2}{*}{$\begin{array}{l}\text { Intermediate } \\
\text { or Final } \\
\text { Outcomes }\end{array}$} & $\begin{array}{l}\text { Process Related } \\
\text { Outcomes }-2^{\text {nd }} \\
\text { Stage of Labor }\end{array}$ & $\begin{array}{l}1 \mathrm{RCT}^{68} \\
(603)\end{array}$ & $\begin{array}{l}\text { Inconclusive: SOE was } \\
\text { insufficient given imprecise } \\
\text { findings from one study } \\
\text { performed in a non-U.S. setting. }\end{array}$ & $\begin{array}{l}\text { Insufficient } \\
\text { (Imprecision, one study, } \\
\text { non-U.S. setting) }\end{array}$ \\
\hline & $\begin{array}{l}\text { Process Related } \\
\text { Outcomes - Mode } \\
\text { of Delivery } \\
\text { (Cesarean } \\
\text { Delivery) }\end{array}$ & $\begin{array}{l}1 \mathrm{RCT}^{68} \\
(603)\end{array}$ & $\begin{array}{l}\text { Inconclusive: SOE was } \\
\text { insufficient given imprecise } \\
\text { findings from one study } \\
\text { performed in a non-U.S. setting. }\end{array}$ & $\begin{array}{l}\text { Insufficient } \\
\text { (Imprecision, one study, } \\
\text { non-U.S. setting) }\end{array}$ \\
\hline \multirow[t]{4}{*}{$\begin{array}{l}\text { Adverse } \\
\text { Events }\end{array}$} & $\begin{array}{l}\text { Maternal } \\
\text { Outcomes - } \\
\text { Trauma to the } \\
\text { Pelvic Floor }\end{array}$ & $\begin{array}{l}1 \mathrm{RCT}^{68} \\
(603)\end{array}$ & $\begin{array}{l}\text { Inconclusive: SOE was } \\
\text { insufficient given imprecise } \\
\text { findings from one study } \\
\text { performed in a non-U.S. setting. }\end{array}$ & $\begin{array}{l}\text { Insufficient } \\
\text { (Imprecision, one study, } \\
\text { non-U.S. setting) }\end{array}$ \\
\hline & $\begin{array}{l}\text { Maternal } \\
\text { Outcomes - } \\
\text { Hemorrhage }\end{array}$ & $\begin{array}{l}1 \mathrm{RCT}^{68} \\
(603)\end{array}$ & $\begin{array}{l}\text { Inconclusive: SOE was } \\
\text { insufficient given imprecise } \\
\text { findings from one study } \\
\text { performed in a non-U.S. setting. }\end{array}$ & $\begin{array}{l}\text { Insufficient } \\
\text { (Imprecision, one study, } \\
\text { non-U.S. setting) }\end{array}$ \\
\hline & $\begin{array}{l}\text { Maternal } \\
\text { Outcomes-Quality } \\
\text { of life }\end{array}$ & $\begin{array}{l}1 \mathrm{RCT}^{69} \\
(488)\end{array}$ & $\begin{array}{l}\text { Inconclusive: SOE was } \\
\text { insufficient given imprecise } \\
\text { findings from one study } \\
\text { performed in a non-U.S. setting. }\end{array}$ & $\begin{array}{l}\text { Insufficient } \\
\text { (imprecision, one study, } \\
\text { non-U.S. setting) }\end{array}$ \\
\hline & $\begin{array}{l}\text { Neonatal } \\
\text { Outcomes - } \\
\text { Shoulder Dystocia }\end{array}$ & $\begin{array}{l}1 \mathrm{RCT}^{68} \\
(603)\end{array}$ & $\begin{array}{l}\text { Inconclusive: SOE was } \\
\text { insufficient given imprecise } \\
\text { findings from one study } \\
\text { performed in a non-U.S. setting. }\end{array}$ & $\begin{array}{l}\text { Insufficient } \\
\text { (Imprecision, one study, } \\
\text { non-U.S. setting) }\end{array}$ \\
\hline
\end{tabular}

${ }^{a}$ Criteria for downgrading SOE are described as Rationale; when these criteria are insufficient for understanding the final SOE, additional explanation is provided.

Abbreviations: RCT=randomized controlled trial; SOE=strength of evidence

\section{Combined Spinal Epidural Analgesia Versus Nonpharmacologic Pain Relief}

Results for this comparison were reported for women of mixed parity in one study, which was described in two papers. ${ }^{76,77}$ No relevant SR/MAs were identified. 


\section{Results in Women of Mixed or Unspecified Parity}

A good-quality RCT conducted in Brazil randomized 35 patients of mixed parity to CSE and 35 patients to only nonpharmacologic methods of pain relief during delivery. Patients in both groups received continuous support throughout labor, including assistance provided by a doula, the use of exercise balls, massage, and music therapy. ${ }^{76}$

\section{Duration of Labor and Cesarean Delivery Rates for Combined Spinal Epidural Analgesia Versus Nonpharmacologic Pain Relief}

Median duration of the first stage of labor was significantly shorter among patients who received CSE (180 minutes; IQR, 90 to 240) versus patients who received nonpharmacologic care only (265 minutes; IQR, 160 to 365; p=0.01). Median duration of the second stage of labor was not different between CSE and nonpharmacologic care (30 minutes; IQR, 20 to 47.5 vs. 30 minutes; IQR, 20 to 50, respectively; $\mathrm{p}=0.97) .{ }^{76}$ Of the 35 patients randomized to CSE, 4 (11\%) delivered via cesarean delivery compared with 7 of 35 patients (21\%) randomized to nonpharmacologic care only $(\mathrm{p}=0.23) .{ }^{76} \mathrm{SOE}$ was rated as insufficient for all outcomes given findings from one small study.

\section{Process-Related Outcomes for Combined Spinal Epidural Analgesia Versus Nonpharmacologic Pain Relief}

This study reported two process-related outcomes, abnormal fetal heart rate tracings and maternal satisfaction. There was no between-group difference in the rate of abnormal fetal heart rate tracings (6\% for CSE vs. 9\% for nonpharmacologic care only; $p=0.5$ ) (insufficient SOE).

Maternal satisfaction was significantly greater for CSE than for nonpharmacologic care only, with $97 \%$ of the patients in the CSE group reporting satisfaction with the method of pain control versus $69 \%$ in the nonpharmacologic care group $(\mathrm{p}=0.001)$, and $94 \%$ versus $71 \%(\mathrm{p}=0.01)$, respectively, reporting satisfaction with delivery (insufficient SOE) ${ }^{77}$

\section{Strength of Evidence for Combined Spinal Epidural Analgesia Versus Nonpharmacologic Pain Relief}

Table 58 summarizes the SOE for combined spinal epidural analgesia versus nonpharmacologic pain relief. The SOE was rated as insufficient for all outcomes.

Table 58. Strength of evidence for combined spinal epidural analgesia versus nonpharmacologic pain relief in women of mixed parity

\begin{tabular}{|c|l|l|l|l|}
\hline \multicolumn{1}{|c|}{ Category } & \multicolumn{1}{|c|}{ Outcome } & $\begin{array}{l}\text { Study Design } \\
\text { (Sample Size) }\end{array}$ & \multicolumn{1}{c|}{ Conclusion } & \multicolumn{1}{c|}{$\begin{array}{c}\text { SOE } \\
\text { (Rationale) }\end{array}$} \\
\hline $\begin{array}{l}\text { Intermediate } \\
\text { or Final } \\
\text { Outcomes }\end{array}$ & $\begin{array}{l}\text { Process Related } \\
\text { Outcomes }-1^{\text {st }} \\
\text { Stage of Labor }\end{array}$ & $\begin{array}{l}1 \mathrm{RCT} 76 \\
(70)\end{array}$ & $\begin{array}{l}\text { Inconclusive: SOE was } \\
\text { insufficient given imprecise } \\
\text { findings from one small study } \\
\text { performed in a non-U.S. setting. }\end{array}$ & $\begin{array}{l}\text { Insufficient } \\
\text { (Imprecision, one study, } \\
\text { non-U.S. setting) }\end{array}$ \\
\cline { 2 - 6 } & $\begin{array}{l}\text { Process Related } \\
\text { Outcomes - 2nd } \\
\text { Stage of Labor }\end{array}$ & $\begin{array}{l}1 \mathrm{RCT}^{76} \\
(70)\end{array}$ & $\begin{array}{l}\text { Inconclusive: SOE was } \\
\text { insufficient given imprecise } \\
\text { findings from one small study } \\
\text { performed in a non-U.S. setting. }\end{array}$ & $\begin{array}{l}\text { Insufficient } \\
\text { (Imprecision, one study, } \\
\text { non-U.S. setting) }\end{array}$ \\
\cline { 2 - 6 } & $\begin{array}{l}\text { Process Related } \\
\text { Outcomes - Mode } \\
\text { of Delivery } \\
\text { (Cesarean } \\
\text { Delivery) }\end{array}$ & $\begin{array}{l}1 \mathrm{RCT}{ }^{76} \\
(70)\end{array}$ & $\begin{array}{l}\text { Inconclusive: SOE was } \\
\text { insufficient given imprecise } \\
\text { findings from one small study } \\
\text { performed in a non-U.S. setting. }\end{array}$ & $\begin{array}{l}\text { Insufficient } \\
\text { (Imprecision, one study, } \\
\text { non-U.S. setting) }\end{array}$ \\
\hline
\end{tabular}




\begin{tabular}{|l|l|l|l|l|}
\hline \multicolumn{1}{|c|}{ Category } & \multicolumn{1}{|c|}{ Outcome } & $\begin{array}{l}\text { Study Design } \\
\text { (Sample Size) }\end{array}$ & \multicolumn{1}{c|}{ Conclusion } & \multicolumn{1}{c|}{$\begin{array}{c}\text { SOE } \\
\text { (Rationale) }^{\mathbf{a}}\end{array}$} \\
\hline $\begin{array}{l}\text { Adverse } \\
\text { Events }\end{array}$ & $\begin{array}{l}\text { Process Related } \\
\text { Outcomes - } \\
\text { Abnormal Fetal } \\
\text { Heart Tracing }\end{array}$ & $\begin{array}{l}\text { RCT } \\
(70)\end{array}$ & $\begin{array}{l}\text { Inconclusive: SOE was } \\
\text { insufficient given imprecise } \\
\text { findings from one small study } \\
\text { performed in a non-U.S. setting. }\end{array}$ & $\begin{array}{l}\text { Insufficient } \\
\text { (Imprecision, one study, } \\
\text { non-U.S. setting) }\end{array}$ \\
\cline { 2 - 6 } & $\begin{array}{l}\text { Process Related } \\
\text { Outcomes - } \\
\text { Parental } \\
\text { Preferences }\end{array}$ & $\begin{array}{l}1 \mathrm{RCT}^{76} \\
\mathrm{(70)}\end{array}$ & $\begin{array}{l}\text { Inconclusive: SOE was } \\
\text { insufficient given imprecise } \\
\text { findings from one small study } \\
\text { performed in a non-U.S. setting. }\end{array}$ & $\begin{array}{l}\text { Insufficient } \\
\text { (Imprecision, one study, } \\
\text { non-U.S. setting) }\end{array}$ \\
\hline
\end{tabular}

${ }^{a}$ Criteria for downgrading SOE are described as Rationale; when these criteria are insufficient for understanding the final SOE, additional explanation is provided.

Abbreviations: RCT=randomized controlled trial; SOE=strength of evidence

\section{Epidural Analgesia Versus Intravenous Meperidine}

Results for this comparison were reported for nulliparous women in one study. ${ }^{198}$ No relevant SR/MAs were identified.

\section{Results in Nulliparous Women}

A fair-quality RCT conducted in Iran randomized 395 nulliparous women to EA (n=197) or a single dose of intravenous meperidine $(n=198) .{ }^{198}$ Given findings from one study in a non-U.S. setting with medium risk of bias the SOE was rated as insufficient for all outcomes.

\section{Duration of Labor and Cesarean Delivery Rates for Epidural Analgesia Versus Intravenous Meperidine}

There were no significant between-group differences ( $\mathrm{p}$ values reported as not significant) in either the mean duration of the active phase of the first stage of labor (2.5 hours [SD 1.4] for EA versus 2.4 hours [SD 1.6] for meperidine) or the second stage of labor (1.0 hours [SD 0.7] for EA versus 0.9 hours [SD 0.7] for meperidine). ${ }^{198}$ There were no significant between-group differences (p values reported as not significant) in rates of cesarean delivery for dystocia (4\% for EA vs. 4\% for meperidine) or for bradycardia (8\% for EA vs. 5\% for meperidine). ${ }^{198}$

\section{Neonatal Outcomes for Epidural Analgesia Versus Intravenous Meperidine}

There were no admissions to the neonatal intensive care unit associated with either EA or meperidine. ${ }^{198}$

\section{Strength of Evidence for Epidural Analgesia Versus Intravenous Meperidine}

Table 59 summarizes the SOE for epidural analgesia versus intravenous meperidine. The SOE was rated as insufficient for all outcomes.

Table 59. Epidural analgesia versus intravenous meperidine: Evidence profile in nulliparous women

\begin{tabular}{|c|l|l|l|l|}
\hline \multicolumn{1}{|c|}{ Category } & \multicolumn{1}{|c|}{ Outcome } & $\begin{array}{l}\text { Study Design } \\
\text { (Sample Size) }\end{array}$ & \multicolumn{1}{c|}{ Conclusion } & \multicolumn{1}{c|}{$\begin{array}{c}\text { SOE } \\
\text { (Rationale) }^{\mathbf{a}}\end{array}$} \\
\hline $\begin{array}{l}\text { Intermediate } \\
\text { or Final } \\
\text { Outcomes }\end{array}$ & $\begin{array}{l}\text { Process Related } \\
\text { Outcomes }-1^{\text {st }} \\
\text { Stage of Labor } \\
(395)\end{array}$ & $\begin{array}{l}\text { Inconclusive: SOE was } \\
\text { insufficient given imprecise } \\
\text { findings from one study } \\
\text { performed in a non-U.S. setting. }\end{array}$ & $\begin{array}{l}\text { Insufficient } \\
\text { (Imprecision, one study, } \\
\text { non-U.S. setting) }\end{array}$ \\
\cline { 2 - 5 } & $\begin{array}{l}\text { Process Related } \\
\text { Outcomes }-2^{\text {nd }} \\
\text { Stage of Labor }\end{array}$ & $\begin{array}{l}1 \mathrm{RCT}{ }^{198} \\
(395)\end{array}$ & $\begin{array}{l}\text { Inconclusive: SOE was } \\
\text { insufficient given imprecise } \\
\text { findings from one study } \\
\text { performed in a non-U.S. setting. }\end{array}$ & $\begin{array}{l}\text { Insufficient } \\
\text { (Imprecision, one study, } \\
\text { non-U.S. Setting) }\end{array}$ \\
\hline
\end{tabular}




\begin{tabular}{|l|l|l|l|l|}
\hline Category & \multicolumn{1}{|c|}{ Outcome } & $\begin{array}{l}\text { Study Design } \\
\text { (Sample Size) }\end{array}$ & \multicolumn{1}{c|}{ Conclusion } & \multicolumn{1}{c|}{$\begin{array}{c}\text { SOE } \\
\text { (Rationale) }^{\mathbf{a}}\end{array}$} \\
\hline & $\begin{array}{l}\text { Process Related } \\
\text { Outcomes - Mode } \\
\text { of Delivery } \\
\text { (Cesarean } \\
\text { Delivery) }\end{array}$ & $\begin{array}{l}\text { RCT } 198 \\
(395)\end{array}$ & $\begin{array}{l}\text { Inconclusive: SOE was } \\
\text { insufficient given imprecise } \\
\text { findings from one study } \\
\text { performed in a non-U.S. setting. }\end{array}$ & $\begin{array}{l}\text { Insufficient } \\
\text { (Imprecision, one study, } \\
\text { non-U.S. setting) }\end{array}$ \\
\hline $\begin{array}{l}\text { Adverse } \\
\text { Events }\end{array}$ & $\begin{array}{l}\text { Neonatal } \\
\text { Outcomes - NICU } \\
\text { Admissions }\end{array}$ & $\begin{array}{l}1 \mathrm{RCT}^{198} \\
(395)\end{array}$ & $\begin{array}{l}\text { Inconclusive: SOE was } \\
\text { insufficient given imprecise } \\
\text { findings from one study } \\
\text { performed in a non-U.S. setting. }\end{array}$ & $\begin{array}{l}\text { Insufficient } \\
\text { (Imprecision, one study, } \\
\text { non-U.S. setting) }\end{array}$ \\
\hline
\end{tabular}

${ }^{a}$ Criteria for downgrading SOE are described as Rationale; when these criteria are insufficient for understanding the final SOE, additional explanation is provided.

Abbreviations: NICU=neonatal intensive care unit; RCT=randomized controlled trial; SOE=strength of evidence 


\section{Epidural Analgesia Versus Low-Dose Infusion Epidural Analgesia}

Results for this comparison were reported for nulliparous women in one study ${ }^{66}$ No relevant SR/MAs were identified.

\section{Results in Nulliparous Women}

A fair-quality RCT conducted in the UK randomized 1052 nulliparous women to EA $(n=253)$, CSE $(n=351)$, or low dose infusion EA $(n=350)$ to allow for ambulation during labor. ${ }^{66}$ Results for the comparison of EA versus low-dose infusion EA are reported below. Cesarean delivery rate was the only outcome of interest reported. Given the imprecise findings from only one study performed in a non-U.S. setting the SOE was rated as insufficient.

\section{Cesarean Delivery Rates for Epidural Analgesia Versus Low-Dose Infusion Epidural Analgesia}

Rates of cesarean delivery did not appear to differ between EA (27\%) and low-dose infusion EA (29\%) (p value not reported). ${ }^{66}$

\section{Strength of Evidence for Epidural Analgesia Versus Low-Dose Infusion Epidural Analgesia}

Table 60 summarizes the SOE for epidural analgesia versus low-dose infusion epidural analgesia. The SOE was rated as insufficient for all outcomes.

Table 60. Epidural analgesia versus low-dose infusion epidural analgesia: Evidence profile in nulliparous women

\begin{tabular}{|l|l|l|l|l|}
\hline \multicolumn{1}{|c|}{ Category } & \multicolumn{1}{|c|}{ Outcome } & $\begin{array}{l}\text { Study Design } \\
\text { (Sample Size) }\end{array}$ & \multicolumn{1}{c|}{ Conclusion } & \multicolumn{1}{c|}{$\begin{array}{c}\text { SOE } \\
\text { (Rationale) }^{\mathbf{a}}\end{array}$} \\
\hline $\begin{array}{l}\text { Intermediate } \\
\text { Or Final } \\
\text { Outcomes }\end{array}$ & $\begin{array}{l}\text { Process Related } \\
\text { Outcomes - Mode } \\
\text { of Delivery } \\
\text { (Cesarean } \\
\text { Delivery) }\end{array}$ & $\begin{array}{l}\text { Inconclusive: SOE was } \\
(1,052)\end{array}$ & $\begin{array}{l}\text { insufficient given imprecise } \\
\text { findings from one study } \\
\text { performed in a non-U.S. setting. }\end{array}$ & $\begin{array}{l}\text { Insufficient } \\
\text { (Imprecision, one study, } \\
\text { non-U.S. setting) }\end{array}$ \\
\hline
\end{tabular}

${ }^{a}$ Criteria for downgrading SOE are described as Rationale; when these criteria are insufficient for understanding the final SOE, additional explanation is provided.

Abbreviations: RCT=randomized controlled trial; SOE=strength of evidence

\section{Epidural Analgesia Versus Acupuncture}

Results for this comparison were reported for nulliparous women in two studies ${ }^{176,181}$ and women of unspecified parity in one study. ${ }^{124}$ No relevant SR/MAs were identified.

\section{Results in Nulliparous Women}

In one fair-quality RCT conducted in China, 131 nulliparous women were randomized to continuous spinal EA ( $n=45)$, acupuncture $(n=43)$, or no analgesia $(n=43)$; formal comparisons were only made between acupuncture and epidural, and acupuncture and control. ${ }^{176}$. The second fair quality RCT randomized 127 nulliparous women to continuous spinal EA with patientcontrolled EA alone $(n=66)$ or continuous spinal EA and patient-controlled EA plus electroacupuncture $(n=61)$. Given findings from two small studies in a non-U.S. setting, and differences in the comparisons, the SOE was rated as insufficient for all outcomes. 


\section{Duration of Labor and Cesarean Delivery Rates for Epidural Analgesia Versus Acupuncture}

In the study of Wu et al, mean duration (SD) of the active first stage of labor in women randomized to EA was 4.5 hours (2.3) compared to 3.0 hours (1.0) in women randomized to acupuncture $(\mathrm{p}<0.05)$. There were no significant differences reported for duration of second stage of labor. Mode of delivery was not reported. ${ }^{176}$

In the study of Xiao et al, which evaluated electroacupuncture as an adjunct to epidural alone, median duration (interquartile range) of the first stage was 260 minutes (236 minutes) in the electroacupuncture group and 362 minutes (355 minutes) for the epidural only group $(p<0.05)$. Second stage of labor was not significantly different between groups (median 81 minutes with electroacupuncture, 92 minutes without). Cesarean section rates were also lower with electroacupuncture, but low overall numbers limited power $(1.6 \%$ vs $9.1 \%, \mathrm{p}=0.07)$. Use of oxytocin was significantly lower with electroacupuncture $(16.7 \% \text { vs } 50 \% \text {, } p<0.05)^{181}$

\section{Maternal Outcomes for Epidural Analgesia Versus Acupuncture}

In the Wu et al study, the mean (SD) volume of estimated blood loss was significantly higher with EA-320.0 (85.6) ml--compared to acupuncture--273.7 (53.6) ml—but the clinical significance of this difference was not reported. ${ }^{176}$

\section{Neonatal Outcomes for Epidural Analgesia Versus Acupuncture}

In the Wu study, although the authors reported "neonatal asphyxia" (defined as Apgar less than 7), they did not specify whether these were 1 or 5 minute Apgar scores. There was no difference in incidence $\left(11.1 \%\right.$ in the epidural group vs $9.3 \%$ in the acupuncture group. ${ }^{176}$ Xiao et al. did not report an incidence for neonatal asphyxia; median cord blood $\mathrm{pH}$ and 1 and 5 minute Apgar scores were identical between the two groups.

\section{Strength of Evidence for Epidural Analgesia Versus Acupuncture}

Table 61 summarizes the SOE for epidural analgesia versus acupuncture. The SOE was rated as insufficient for all outcomes.

Table 61. Epidural analgesia versus acupuncture point nerve stimulation: Evidence profile in nulliparous women

\begin{tabular}{|c|c|c|c|c|}
\hline Category & Outcome & $\begin{array}{l}\text { Study Design } \\
\text { (Sample Size) }\end{array}$ & Conclusion & $\begin{array}{c}\text { SOE } \\
\text { (Rationale) }^{a}\end{array}$ \\
\hline \multirow[t]{2}{*}{$\begin{array}{l}\text { Intermediate } \\
\text { or Final } \\
\text { Outcomes }\end{array}$} & $\begin{array}{l}\text { Process Related } \\
\text { Outcomes }-1^{\text {st }} \\
\text { Stage of Labor }\end{array}$ & $\begin{array}{l}2 \mathrm{RCTs}^{176}, 181 \\
(258)\end{array}$ & $\begin{array}{l}\text { Inconclusive: SOE was } \\
\text { insufficient given imprecise } \\
\text { findings from two studies } \\
\text { performed in a non-U.S. setting. }\end{array}$ & $\begin{array}{l}\text { Insufficient } \\
\text { (Imprecision, two } \\
\text { studies, non-U.S. } \\
\text { setting) }\end{array}$ \\
\hline & $\begin{array}{l}\text { Process Related } \\
\text { Outcomes }-2^{\text {nd }} \\
\text { Stage of Labor }\end{array}$ & $\begin{array}{l}2 \mathrm{RCTs}^{176}, 181 \\
(258)\end{array}$ & $\begin{array}{l}\text { Inconclusive: SOE was } \\
\text { insufficient given imprecise } \\
\text { findings from two studies } \\
\text { performed in a non-U.S. setting. }\end{array}$ & $\begin{array}{l}\text { Insufficient } \\
\text { (Imprecision, two } \\
\text { studies, non-U.S. } \\
\text { setting) }\end{array}$ \\
\hline \multirow[t]{2}{*}{$\begin{array}{l}\text { Adverse } \\
\text { Events }\end{array}$} & $\begin{array}{l}\text { Maternal } \\
\text { Outcomes - } \\
\text { Hemorrhage }\end{array}$ & $\begin{array}{l}1 \mathrm{RCT}^{176} \\
(131)\end{array}$ & $\begin{array}{l}\text { Inconclusive: SOE was } \\
\text { insufficient given imprecise } \\
\text { findings from one study } \\
\text { performed in a non-U.S. setting. }\end{array}$ & $\begin{array}{l}\text { Insufficient } \\
\text { (Imprecision, one study, } \\
\text { non-U.S. setting) }\end{array}$ \\
\hline & $\begin{array}{l}\text { Neonatal } \\
\text { Outcomes - } \\
\text { Hypoxia }\end{array}$ & $\begin{array}{l}2 \mathrm{RCTs}^{176}, 181 \\
(258)\end{array}$ & $\begin{array}{l}\text { Inconclusive: SOE was } \\
\text { insufficient given imprecise } \\
\text { findings from two studies } \\
\text { performed in a non-U.S. setting. }\end{array}$ & $\begin{array}{l}\text { Insufficient } \\
\text { (Imprecision, two } \\
\text { studies, non-U.S. } \\
\text { setting) }\end{array}$ \\
\hline
\end{tabular}


${ }^{\text {a }}$ Criteria for downgrading SOE are described as Rationale; when these criteria are insufficient for understanding the final SOE, additional explanation is provided.

Abbreviations: RCT=randomized controlled trial; SOE=strength of evidence

\section{Results in Women of Mixed or Unspecified Parity}

In a fair-quality RCT conducted in China, 120 patients of unspecified parity were randomized to EA $(n=30)$, PCIA $(n=30)$, acupuncture point nerve stimulation $(n=30)$, or no analgesia $(n=30){ }^{124}$ Results for the comparison of EA versus acupuncture point nerve stimulation are reported below. Given findings from one small study in non-U.S. setting, the SOE was rated as insufficient for all outcomes.

\section{Duration of Labor and Cesarean Delivery Rates for Epidural Analgesia Versus Acupuncture Point Nerve Stimulation}

Mean duration (SD) of the first stage of labor associated with EA was 423 minutes (181) compared with 430 minutes (120) for acupuncture point nerve stimulation. Mean duration (SD) of the second stage of labor was 61 minutes (29) for EA versus 43 minutes (18) for acupuncture point nerve stimulation. Statistical significance testing for these two comparisons was not reported. ${ }^{124}$ Two of the 30 patients (6.7\%) randomized to receive EA delivered via cesarean delivery, compared with 1 of the 30 patients (3.3\%) in the acupuncture point nerve stimulation group (p value not reported). ${ }^{124}$

\section{Maternal Outcomes for Epidural Analgesia Versus Acupuncture Point Nerve Stimulation}

The only maternal outcome reported in this study was postpartum hemorrhage. The mean volume of postpartum blood loss (SD) was estimated to be $125 \mathrm{~mL}$ (24) for the patients in the EA group, compared with $127 \mathrm{~mL}$ (23) in the acupuncture point nerve stimulation group (p value not reported). ${ }^{124}$

\section{Neonatal Outcomes for Epidural Analgesia Versus Acupuncture Point Nerve Stimulation}

Neonatal hypoxia (not described further in the original report) occurred in 1 of 30 patients (3.3\%) in the EA group and 2 of 30 (6.7\%) in the acupuncture point nerve stimulation group (p value not reported). ${ }^{124}$

\section{Strength of Evidence for Epidural Analgesia Versus Acupuncture Point Nerve Stimulation}

Table 62 summarizes the SOE for epidural analgesia acupuncture point nerve stimulation. The SOE was rated as insufficient for all outcomes.

Table 62. Epidural analgesia versus acupuncture point nerve stimulation: Evidence profile in women of mixed parity

\begin{tabular}{|l|l|l|l|l|}
\hline \multicolumn{1}{|c|}{ Category } & \multicolumn{1}{|c|}{ Outcome } & $\begin{array}{l}\text { Study Design } \\
\text { (Sample Size) }\end{array}$ & \multicolumn{1}{c|}{ Conclusion } & \multicolumn{1}{c|}{$\begin{array}{c}\text { SOE } \\
\text { (Rationale) }^{\mathbf{a}}\end{array}$} \\
\hline $\begin{array}{l}\text { Intermediate or } \\
\text { Final Outcomes }\end{array}$ & $\begin{array}{l}\text { Process Related } \\
\text { Outcomes }-1^{\text {st }} \\
\text { Stage of Labor }\end{array}$ & $\begin{array}{l}1 \mathrm{RCT} \text { 124 } \\
(120)\end{array}$ & $\begin{array}{l}\text { Inconclusive: SOE } \\
\text { was insufficient given } \\
\text { imprecise findings from } \\
\text { one study performed in } \\
\text { a non-U.S. setting. }\end{array}$ & $\begin{array}{l}\text { Insufficient } \\
\text { (Imprecision, one study, } \\
\text { non-U.S. setting) }\end{array}$ \\
\hline
\end{tabular}




\begin{tabular}{|c|c|c|c|c|}
\hline Category & Outcome & $\begin{array}{l}\text { Study Design } \\
\text { (Sample Size) }\end{array}$ & Conclusion & $\begin{array}{c}\text { SOE } \\
\text { (Rationale) }^{a}\end{array}$ \\
\hline & $\begin{array}{l}\text { Process Related } \\
\text { Outcomes }-2^{\text {nd }} \\
\text { Stage of Labor }\end{array}$ & $\begin{array}{l}1 \mathrm{RCT}^{124} \\
(120)\end{array}$ & $\begin{array}{l}\text { Inconclusive: SOE } \\
\text { was insufficient given } \\
\text { imprecise findings from } \\
\text { one study performed in } \\
\text { a non-U.S. setting. }\end{array}$ & $\begin{array}{l}\text { Insufficient } \\
\text { (Imprecision, one study, } \\
\text { non-U.S. setting) }\end{array}$ \\
\hline & $\begin{array}{l}\text { Process Related } \\
\text { Outcomes - Mode of } \\
\text { Delivery (Cesarean } \\
\text { Delivery) }\end{array}$ & $\begin{array}{l}1 \mathrm{RCT}^{124} \\
(120)\end{array}$ & $\begin{array}{l}\text { Inconclusive: SOE } \\
\text { was insufficient given } \\
\text { imprecise findings from } \\
\text { one study performed in } \\
\text { a non-U.S. setting. }\end{array}$ & $\begin{array}{l}\text { Insufficient } \\
\text { (Imprecision, one study, } \\
\text { non-U.S. setting) }\end{array}$ \\
\hline \multirow[t]{2}{*}{ Adverse Events } & $\begin{array}{l}\text { Maternal Outcomes } \\
\text { - Hemorrhage }\end{array}$ & $\begin{array}{l}1 \mathrm{RCT}^{124} \\
(120)\end{array}$ & $\begin{array}{l}\text { Inconclusive: SOE } \\
\text { was insufficient given } \\
\text { imprecise findings from } \\
\text { one study performed in } \\
\text { a non-U.S. setting. }\end{array}$ & $\begin{array}{l}\text { Insufficient } \\
\text { (Imprecision, one study, } \\
\text { non-U.S. setting) }\end{array}$ \\
\hline & $\begin{array}{l}\text { Neonatal Outcomes } \\
\text { - Hypoxia }\end{array}$ & $\begin{array}{l}1 \mathrm{RCT}^{124} \\
(120)\end{array}$ & $\begin{array}{l}\text { Inconclusive: SOE } \\
\text { was insufficient given } \\
\text { imprecise findings from } \\
\text { one study performed in } \\
\text { a non-U.S. setting. }\end{array}$ & $\begin{array}{l}\text { Insufficient } \\
\text { (Imprecision, one study, } \\
\text { non-U.S. setting) }\end{array}$ \\
\hline
\end{tabular}

${ }^{a}$ Criteria for downgrading SOE are described as Rationale; when these criteria are insufficient for understanding the final SOE, additional explanation is provided.

Abbreviations: RCT=randomized controlled trial; SOE=strength of evidence

\section{Epidural Analgesia Versus No Epidural Analgesia}

Results for this comparison were reported for nulliparous women in two studies ${ }^{189,203}$ and for women of unspecified parity in another. ${ }^{124}$ One relevant good-quality SR/meta-analysis that included studies of both nulliparous and parous women was identified. ${ }^{43}$

\section{Results in Nulliparous Women}

A fair-quality RCT conducted in Turkey randomly allocated 50 nulliparous patients each to vaginal delivery with EA (bupivacaine and fentanyl) or with no EA (1\% lidocaine). ${ }^{189}$ Three patients in the EA group and 2 in the no-EA group underwent cesarean delivery and were thus excluded from the study. Duration of labor was the only outcome of interest reported.

A good-quality RCT conducted in China randomly allocated 400 nulliparous women in spontaneous labor with an epidural in place to either continued epidural analgesia (ropivacaine and sufentanil) or placebo during the second stage of labor. Duration of second stage, mode of delivery, and neonatal Apgar scores were reported. ${ }^{203}$

\section{Duration of Labor and Mode of Delivery for Epidural Analgesia Versus No Epidural Analgesia}

Mean duration (SD) of the active phase of the first stage of labor was significantly shorter in the EA group (218 minutes [166]) than in the no-EA group (259 minutes [158]; p=0.048). However, mean duration of the second stage of labor was significantly longer in the EA group (29.6 minutes [43.0]) than in the no-EA group (24.8 minutes [35.3]; $\mathrm{p}=0.043) .{ }^{189}$ Given findings from one study in a non-U.S. setting with medium risk of bias, the SOE was rated as insufficient.

Mean duration (SD) of the second stage did not differ between women allocated to epidural (52 minutes [25]) or placebo (51 minutes [27]). Mode of delivery also did not differ significantly, but the number of non-vaginal deliveries was quite low (2 cesarean sections in the epidural group vs 0 in the placebo group, 5 forceps deliveries in the epidural group vs 2 in the 
placebo group). Given findings from one study in a non-U.S. setting with substantial imprecision, the SOE was rated as insufficient. ${ }^{203}$

\section{Neonatal Outcomes for Epidural Analgesia Versus No Epidural Analgesia}

Apgar scores less than 9 at 5 minutes did not differ, but the number of events was, again, quite low (0 in the placebo group, 3 in the epidural group). Given findings from one study in a non-U.S. setting with substantial imprecision, the SOE was rated as insufficient.

\section{Results in Women of Mixed or Unspecified Parity}

In a fair-quality RCT conducted in China, 120 patients of unspecified parity were randomized to EA $(n=30)$, PCIA ( $n=30)$, acupuncture point nerve stimulation $(n=30)$, or no analgesia $(n=30) .{ }^{124}$ In this section we focus only on the EA versus no EA groups.

\section{Duration of Labor and Cesarean Delivery Rates for Epidural Analgesia Versus No Epidural Analgesia \\ Mean duration (SD) of the first stage of labor associated with EA was 423 minutes (181), compared with 440 minutes (200) for no analgesia $(\mathrm{p}=0.73)$. Mean duration (SD) of the second stage of labor was 61 minutes (29) for EA versus 46 minutes (21) for no analgesia $(p=0.02){ }^{124}$ Two of the 30 patients (6.7\%) randomized to receive EA delivered via cesarean delivery, compared with 8 of the 30 patients $(27 \%)$ in the no-analgesia group $(p=0.036) .{ }^{124}$}

\section{Maternal Outcomes for Epidural Analgesia Versus No Epidural Analgesia}

The only maternal outcome reported in this study was postpartum hemorrhage. The mean volume of postpartum blood loss (SD) was estimated to be $125 \mathrm{~mL}$ (24) for the patients in the EA group, compared with $140 \mathrm{~mL}(29)$ in the no-analgesia group $(\mathrm{p}=0.03){ }^{124}$

\section{Neonatal Outcomes for Epidural Analgesia Versus No Epidural Analgesia}

Neonatal hypoxia (not described further in the original report) occurred in 1 of 30 patients (3.3\%) in the EA group and 2 of $30(6.7 \%)$ in the no analgesia group $(p=0.55){ }^{124}$

\section{Relevant Systematic Reviews/Meta-Analyses for Epidural Analgesia Versus No Epidural Analgesia}

A good-quality SR published in 2011 summarized and synthesized data from eligible RCTs that compared EA with non-epidural analgesia or no analgesia in labor. ${ }^{43}$ The authors of that review identified and included 38 studies involving 9,658 patients of mixed parity. Neither of the two RCTs that compared EA with no analgesia that met our eligibility criteria were included in this SR because of publication date eligibility criteria. Similar to our included study, results of MAs reported in this SR suggest that relative to non-epidural analgesia or no analgesia in labor, the duration of the first stage of labor associated with EA is not significantly longer (MD 18.51 minutes, 95\% CI -12.91 to 49.42), but that the duration of the second stage of labor is slightly longer with EA (MD 13.66 minutes, 95\% CI 6.67 to 20.66). Different from our included study, the pooled RR for cesarean deliveries associated with EA relative to nonepidural or no analgesia was estimated to be 1.10 (95\% CI 0.97 to 1.25) demonstrating no difference. These findings are from studies with mixed parity. 


\section{Strength of Evidence for Epidural Analgesia Versus No Epidural Analgesia}

Tables 63 and 64 summarize the SOE for outcomes comparing epidural analgesia versus no epidural analgesia. The SOE was rated as moderate for major outcomes of labor duration and cesarean delivery based on the findings from a large SR.

Table 63. Epidural analgesia versus no epidural analgesia: Evidence profile in nulliparous women

\begin{tabular}{|c|c|c|c|c|}
\hline Category & Outcome & $\begin{array}{l}\text { Study Design } \\
\text { (Sample Size) }\end{array}$ & Conclusion & $\begin{array}{c}\text { SOE } \\
\text { (Rationale) }^{\mathrm{a}}\end{array}$ \\
\hline \multirow[t]{2}{*}{$\begin{array}{l}\text { Intermediate } \\
\text { or Final } \\
\text { Outcomes }\end{array}$} & $\begin{array}{l}\text { Process Related } \\
\text { Outcomes }-1^{\text {st }} \\
\text { Stage of Labor }\end{array}$ & $\begin{array}{l}1 \mathrm{RCT}^{189} \\
(100)\end{array}$ & $\begin{array}{l}\text { Inconclusive: SOE was } \\
\text { insufficient given imprecise } \\
\text { findings from one study } \\
\text { performed in a non-U.S. setting } \\
\text { with medium risk of bias. }\end{array}$ & $\begin{array}{l}\text { Insufficient } \\
\text { (Medium risk of bias, } \\
\text { imprecision, one study, } \\
\text { non-U.S. setting) }\end{array}$ \\
\hline & $\begin{array}{l}\text { Process Related } \\
\text { Outcomes }-2^{\text {nd }} \\
\text { Stage of Labor }\end{array}$ & $\begin{array}{l}2 \mathrm{RCTS}^{189,203} \\
(500)\end{array}$ & $\begin{array}{l}\text { Inconclusive: SOE was } \\
\text { insufficient given imprecise } \\
\text { findings from two studies } \\
\text { performed in a non-U.S. setting } \\
\text { with medium risk of bias. }\end{array}$ & $\begin{array}{l}\text { Insufficient } \\
\text { (Medium risk of bias, } \\
\text { imprecision, two } \\
\text { studies, non-U.S. } \\
\text { setting) }\end{array}$ \\
\hline $\begin{array}{l}\text { Adverse } \\
\text { Events }\end{array}$ & $\begin{array}{l}\text { Neonatal } \\
\text { outcomes }- \text { Apgar } \\
\text { score }<9 \text { at } 5 \\
\text { minutes }\end{array}$ & $1 \mathrm{RCT}^{203}$ & $\begin{array}{l}\text { Inconclusive: SOE was } \\
\text { insufficient given imprecise } \\
\text { findings from one study } \\
\text { performed in a non-U.S. setting }\end{array}$ & $\begin{array}{l}\text { Insufficient } \\
\text { (Medium risk of bias, } \\
\text { imprecision, one study, } \\
\text { non-U.S. setting) }\end{array}$ \\
\hline
\end{tabular}

${ }^{a}$ Criteria for downgrading SOE are described as Rationale; when these criteria are insufficient for understanding the final SOE, additional explanation is provided.

Abbreviations: RCT=randomized controlled trial; SOE=strength of evidence

Table 64. Epidural analgesia versus no epidural analgesia: Evidence profile in women of mixed parity

\begin{tabular}{|c|c|c|c|c|}
\hline Category & Outcome & $\begin{array}{l}\text { Study Design } \\
\text { (Sample Size) }\end{array}$ & Conclusion & $\begin{array}{c}\text { SOE } \\
\text { (Rationale) }^{a}\end{array}$ \\
\hline \multirow[t]{3}{*}{$\begin{array}{l}\text { Intermediate } \\
\text { or Final } \\
\text { Outcomes }\end{array}$} & $\begin{array}{l}\text { Process Related } \\
\text { Outcomes }-1^{\text {st }} \\
\text { Stage of Labor }\end{array}$ & $\begin{array}{l}1 \mathrm{RCT}^{124} \\
(120) \\
1 \mathrm{SR}^{43} \\
(2,981 \\
\text { patients, } 11 \\
\text { studies) }\end{array}$ & $\begin{array}{l}\text { No difference: No evidence of } \\
\text { a significant difference between } \\
\text { EA and no EA (MD } 18.51 \\
\text { minutes, } 95 \% \mathrm{Cl}-12.91 \text { to } \\
49.42) \text {. }\end{array}$ & $\begin{array}{l}\text { Moderate } \\
\text { Consistent with SR } \\
\text { findings. }\end{array}$ \\
\hline & $\begin{array}{l}\text { Process Related } \\
\text { Outcomes }-2^{\text {nd }} \\
\text { Stage of Labor }\end{array}$ & $\begin{array}{l}1 \mathrm{RCT}^{124} \\
(120) \\
1 \mathrm{SR}^{43} \\
(4,233 \\
\text { patients, } 13 \\
\text { studies) }\end{array}$ & $\begin{array}{l}\text { Worsening with EA: Women } \\
\text { with epidural analgesia had a } \\
\text { statistically significant longer } \\
\text { second stage of labor (average } \\
\text { MD } 13.66 \text { minutes, } 95 \% \text { Cl } 6.67 \\
\text { to 20.66). }\end{array}$ & $\begin{array}{l}\text { Moderate } \\
\text { Consistent with SR } \\
\text { findings. }\end{array}$ \\
\hline & $\begin{array}{l}\text { Process Related } \\
\text { Outcomes - Mode } \\
\text { of Delivery } \\
\text { (Cesarean } \\
\text { Delivery) }\end{array}$ & $\begin{array}{l}1 \mathrm{RCT}^{124} \\
(120) \\
1 \mathrm{SR}^{43} \\
(8,417 \\
\text { patients, } 27 \\
\text { studies) }\end{array}$ & $\begin{array}{l}\text { No difference: No evidence of } \\
\text { a significant difference in the } \\
\text { risk of caesarean section } \\
\text { overall (RR } 1.10,95 \% \text { Cl } 0.97 \\
\text { to } 1.25 \text { ). }\end{array}$ & $\begin{array}{l}\text { Moderate } \\
\text { Consistent with SR } \\
\text { findings. }\end{array}$ \\
\hline $\begin{array}{l}\text { Adverse } \\
\text { Events }\end{array}$ & $\begin{array}{l}\text { Maternal } \\
\text { Outcomes - } \\
\text { Hemorrhage }\end{array}$ & $\begin{array}{l}1 \mathrm{RCT}^{124} \\
(120)\end{array}$ & $\begin{array}{l}\text { Inconclusive: SOE was } \\
\text { insufficient given imprecise } \\
\text { findings from } 1 \text { study performed } \\
\text { in a non-U.S. setting with } \\
\text { medium risk of bias. }\end{array}$ & $\begin{array}{l}\text { Insufficient } \\
\text { (Medium risk of bias, } \\
\text { imprecision, } 1 \text { study, } \\
\text { non-U.S. setting) }\end{array}$ \\
\hline
\end{tabular}




\begin{tabular}{|c|l|l|l|l|}
\hline Category & \multicolumn{1}{|c|}{ Outcome } & $\begin{array}{l}\text { Study Design } \\
\text { (Sample Size) }\end{array}$ & \multicolumn{1}{c|}{ Conclusion } & \multicolumn{1}{c|}{$\begin{array}{c}\text { SOE } \\
\text { (Rationale) }^{\mathbf{a}}\end{array}$} \\
\hline & $\begin{array}{l}\text { Neonatal } \\
\text { Outcomes }- \\
\text { Hypoxia }\end{array}$ & $\begin{array}{l}1 \mathrm{RCT} \mathrm{CT}^{124} \\
(120)\end{array}$ & $\begin{array}{l}\text { Inconclusive: SOE was } \\
\text { insufficient given imprecise } \\
\text { findings from 1 study performed } \\
\text { in a non-U.S. setting with } \\
\text { medium risk of bias. }\end{array}$ & $\begin{array}{l}\text { Insufficient } \\
\text { (Medium risk of bias, } \\
\text { imprecision, 1 study, } \\
\text { non-U.S. setting) }\end{array}$ \\
\hline
\end{tabular}

${ }^{\mathrm{a}}$ Criteria for downgrading SOE are described as Rationale; when these criteria are insufficient for understanding the final SOE, additional explanation is provided.

Abbreviations: $\mathrm{CI}=$ confidence interval; $\mathrm{EA}=$ epidural analgesia; $\mathrm{MD}=$ mean difference: $\mathrm{RCT}=$ randomized controlled trial;

$\mathrm{RR}=$ relative risk; $\mathrm{SOE}=$ strength of evidence; $\mathrm{SR}=$ systematic review

\section{Key Question 5. Frequency of Cervical Examination}

KQ 5 was: How does the frequency of cervical examination affect the probability of specific benefits and harms?

\section{Description of Included Studies}

We identified no RCTs and only one good-quality $\mathrm{SR}^{206}$ that met the inclusion criteria for this KQ. The focus of the SR was to compare different methods of assessing labor progression through the use of vaginal examinations. The objective was to compare digital vaginal examinations for assessing progress of labor to other strategies or different timings.

\section{Key Point for Frequency of Cervical Examination}

- There was insufficient SOE for all outcomes regarding the frequency of cervical examination.

\section{Detailed Synthesis for Frequency of Cervical Examination}

We identified one good-quality SR ${ }^{206}$ which included two studies comparing the effects of vaginal examinations versus other strategies or different timings on the progression of labor and maternal and neonatal health outcomes. Only one of the studies included was relevant to this KQ: an RCT of 150 women undergoing routine vaginal examinations every 2 hours compared to every 4 hours. ${ }^{207}$ The authors of the SR considered this study to be of poor quality due to the lack of description regarding allocation concealment in the randomization process and participants being excluded from the study after randomization who developed exclusion criteria prior to labor. The included study did not meet our inclusion criteria due to date of publication (1996).

The main outcomes were mode of birth, length of labor, incidence of maternal or neonatal infection requiring antibiotics, maternal satisfaction with intrapartum care, and hemorrhage. There was no difference between every-2-hour and every-4-hour examinations for cesarean deliver (RR 0.77; 95\% CI, 0.36 to 1.64), spontaneous vaginal birth (RR 0.98; 95\% CI, 0.80 to 1.21 ), and operative vaginal birth (RR 1.44; $95 \% \mathrm{CI}, 0.66$ to 3.17). The mean difference in length of labor was -6.00 minutes ( $95 \% \mathrm{CI},-88.70$ to 76.70 ). There were no data on the incidence of maternal or infant infection requiring antibiotics or maternal satisfaction in labor (SOE insufficient for all outcomes). 


\section{Strength of Evidence for Frequency of Cervical Examination}

Table 65 summarizes the SOE for the findings described above. All outcomes had insufficient SOE.

Table 65. Cervical examination versus other strategies: Evidence profile in women of unspecified parity

\begin{tabular}{|l|l|l|l|l|}
\hline \multicolumn{1}{|c|}{ Category } & \multicolumn{1}{|c|}{ Outcome } & $\begin{array}{l}\text { Study Design } \\
\text { (Sample Size) }\end{array}$ & \multicolumn{1}{c|}{ Conclusion } & \multicolumn{1}{c|}{$\begin{array}{c}\text { SOE } \\
\text { (Rationale) }^{\mathrm{a}}\end{array}$} \\
\hline $\begin{array}{l}\text { Intermediate } \\
\text { or Final } \\
\text { Outcomes }\end{array}$ & $\begin{array}{l}\text { Process Related } \\
\text { Outcomes - } \\
\text { Duration of Total } \\
\text { Labor }\end{array}$ & $1 \mathrm{RCT}^{206}(150)$ & $\begin{array}{l}\text { Inconclusive: SOE was } \\
\text { insufficient given evidence from } \\
1 \text { older poor-quality study with } \\
\text { imprecise findings. }\end{array}$ & $\begin{array}{l}\text { Insufficient (High risk of } \\
\text { bias, Imprecise, } 1 \\
\text { study) }\end{array}$ \\
\cline { 2 - 5 } & $\begin{array}{l}\text { Process Related } \\
\text { Outcomes - Mode } \\
\text { of Delivery } \\
\text { (Cesarean } \\
\text { Delivery) }\end{array}$ & $1 \mathrm{RCT}^{206}(150)$ & $\begin{array}{l}\text { Inconclusive: SOE was } \\
\text { insufficient given evidence from } \\
1 \text { older poor-quality study with } \\
\text { imprecise findings. }\end{array}$ & $\begin{array}{l}\text { Insufficient (High risk of } \\
\text { bias, Imprecise, } 1 \\
\text { study) }\end{array}$ \\
\end{tabular}

${ }^{a}$ Criteria for downgrading SOE are described as Rationale; when these criteria are insufficient for understanding the final SOE, additional explanation is provided.

Abbreviations: RCT=randomized controlled trial; SOE=strength of evidence; SR=systematic review

\section{Key Question 6. Intrauterine Pressure Catheters}

KQ 6 was: What are the benefits and harms of intrauterine pressure catheters in the diagnosis and management of labor dystocia?

\section{Description of Included Studies}

We did not identify any RCTs that met the inclusion criteria for this KQ. Below we describe results from one good-quality SR that addressed the benefits and harms of intrauterine pressure catheters in the diagnosis and management of labor dystocia. ${ }^{37}$

\section{Key Point for Intrauterine Pressure Catheters}

- There were no statistically significant differences between intrauterine pressure catheters and external uterine monitoring for the outcomes of mode of delivery, mean time to delivery, neonatal acidemia, or admission to the NICU (moderate SOE for all outcomes).

\section{Detailed Synthesis for Intrauterine Pressure Catheters}

A good-quality SR included 3 good-quality RCTs comparing the use of intrauterine pressure catheters versus external monitoring in women being induced or augmented in labor. One study $(n=150)$ was restricted to women in spontaneous labor with a diagnosis of dystocia while the other two included both augmented and induced labors; one of these reported results by indication for oxytocin (500 women were augmented). We summarize here the pooled subgroup analyses for this population. The primary studies were not included in our review because of date of publication.

Maternal outcomes included the process outcomes of mode of delivery and duration of labor in addition to risk of infection. In the pooled analyses, internal monitoring increased the proportion of operative vaginal deliveries (OR 1.25, 95\% CI 1.02 to 1.53); cesarean delivery rates were also higher with internal monitoring, but not significantly (OR 1.25, 95\% CI 0.91 to 1.21) Of note, there was statistically significant evidence of heterogeneity in results comparing 
the augmented to the induced subgroups. There was no significant difference in the mean time to delivery in women with augmented labor who had an intrauterine pressure catheter $(296.84$ minutes) versus external fetal monitoring (297.19 minutes) in the one study that reported this outcome $(\mathrm{p}=0.99)$; median times to delivery in both studies were also similar. There were no differences for signs of infection in labor for women with internal versus external tocodynamometry (RR 0.69; 95\% CI, 0.44 to 1.08 ).

Neonatal outcomes were not reported for the relevant subgroups.

\section{Strength of Evidence for Intrauterine Pressure Catheters}

Table 66 summarizes the SOE for the findings described above. The SOE was rated as moderate for all outcomes assessed given consistent findings from good-quality RCTs.

Table 66. Intrauterine pressure catheters versus external monitoring: Evidence profile in women of unspecified parity

\begin{tabular}{|c|c|c|c|c|}
\hline Category & Outcome & $\begin{array}{l}\text { Study Design } \\
\text { (Sample Size) }\end{array}$ & Conclusion & $\begin{array}{c}\text { SOE } \\
\text { (Rationale) }^{a}\end{array}$ \\
\hline \multirow[t]{2}{*}{$\begin{array}{l}\text { Intermediate } \\
\text { or Final } \\
\text { Outcomes }\end{array}$} & $\begin{array}{l}\text { Process Related } \\
\text { Outcomes - } \\
\text { Duration of Total } \\
\text { Labor }\end{array}$ & $\begin{array}{l}1 \mathrm{SR}^{37}(1,456 \\
\text { patients, } 2 \\
\text { studies })\end{array}$ & $\begin{array}{l}\text { No difference: No differences } \\
\text { in mean time to delivery with } \\
\text { intrauterine pressure catheters } \\
\text { compared to external } \\
\text { monitoring }\end{array}$ & $\begin{array}{l}\text { Moderate } \\
\text { (Indirect) }\end{array}$ \\
\hline & $\begin{array}{l}\text { Process Related } \\
\text { Outcomes - Mode } \\
\text { of Delivery }\end{array}$ & $\begin{array}{l}1 \mathrm{SR}^{37}(750 \\
\text { patients, } 2 \\
\text { studies) }\end{array}$ & $\begin{array}{l}\text { No difference: Comparing } \\
\text { intrauterine pressure catheters } \\
\text { to external monitoring, there } \\
\text { was no difference in delivery by } \\
\text { operative vaginal delivery (RR } \\
1.25,95 \% \mathrm{Cl} 0.91 \text { to } 1.73 \text { ) or by } \\
\text { cesarean deliver (RR } 1.25,95 \% \\
\text { Cl } 0.91 \text { to } 1.71 \text { ). }\end{array}$ & $\begin{array}{l}\text { Moderate } \\
\text { (Indirect) }\end{array}$ \\
\hline \multirow[t]{3}{*}{$\begin{array}{l}\text { Adverse } \\
\text { Events }\end{array}$} & $\begin{array}{l}\text { Maternal } \\
\text { Outcomes - } \\
\text { Infection }\end{array}$ & $\begin{array}{l}1 \mathrm{SR}^{37}(1,456 \\
\text { patients, } 2 \\
\text { studies })\end{array}$ & $\begin{array}{l}\text { No difference: No differences } \\
\text { in signs of infection in labor in } \\
\text { women with intrauterine } \\
\text { pressure catheters compared to } \\
\text { external monitoring (RR } 0.69 \text {, } \\
95 \% \mathrm{Cl} 0.44 \text { to } 1.08 \text { ). }\end{array}$ & $\begin{array}{l}\text { Moderate } \\
\text { (Indirect) }\end{array}$ \\
\hline & $\begin{array}{l}\text { Neonatal } \\
\text { Outcomes - } \\
\text { Acidemia }\end{array}$ & $\begin{array}{l}1 \mathrm{SR}^{37}(1,456 \\
\text { patients, } 2 \\
\text { studies) }\end{array}$ & $\begin{array}{l}\text { No difference: No differences } \\
\text { in neonatal acidemia }(\mathrm{pH}<7.15) \\
\text { in infants of women with } \\
\text { intrauterine pressure catheters } \\
\text { compared to external } \\
\text { monitoring (RR } 1.31,95 \% \mathrm{Cl} \\
0.95 \text { to } 1.79) \text {. }\end{array}$ & $\begin{array}{l}\text { Moderate } \\
\text { (Indirect) }\end{array}$ \\
\hline & $\begin{array}{l}\text { Neonatal } \\
\text { Outcomes - } \\
\text { Admission to } \\
\text { NICU }\end{array}$ & $\begin{array}{l}1 \mathrm{SR}^{37}(489 \\
\text { patients, } 2 \\
\text { studies) }\end{array}$ & $\begin{array}{l}\text { No difference: No differences } \\
\text { in admission to NICU in infants } \\
\text { of women with intrauterine } \\
\text { pressure catheters compared to } \\
\text { external monitoring (RR 0.34, } \\
95 \% \mathrm{CI} 0.07 \text { to } 1.67 \text { ). }\end{array}$ & $\begin{array}{l}\text { Moderate } \\
\text { (Indirect) }\end{array}$ \\
\hline
\end{tabular}

${ }^{a}$ Criteria for downgrading SOE are described as Rationale; when these criteria are insufficient for understanding the final SOE, additional explanation is provided.

Abbreviations: $\mathrm{CI}=$ confidence interval; $\mathrm{NICU}=$ neonatal intensive care unit; $\mathrm{RCT}=$ randomized controlled trial; $\mathrm{RR}=\mathrm{relative}$ risk; $\mathrm{SOE}=$ strength of evidence; $\mathrm{SR}=$ systematic review 


\section{Key Question 7. High-Dose Versus Low-Dose Oxytocin Protocols}

KQ 7 was: For women with abnormal labor, what are the relative benefits and harms of highversus low-dose oxytocin protocols (including nipple stimulation)?

In this Key Question, we review the evidence on the effect on specific approaches to oxytocin augmentation, including dose, method of administration (pulsatile vs. continuous), and timing of administration relative to phase of labor. Note that how high and low dose oxytocin is defined varies between studies and so we have listed each study's specific protocol within the text.

\section{Description of Included Studies}

We identified 12 articles $^{74,75,114,117,208-215}$ representing 11 individual RCTs that examined the benefits and harms of high-dose versus low-dose oxytocin protocols for women with abnormal labor. Of the 11 included studies, 6 were conducted in UK/Europe, ${ }^{74,208-211,215} 3$ were conducted in Asia, ${ }^{117,213,214}$ one was conducted in Canada, ${ }^{212}$ and one was conducted in the Middle East. ${ }^{114}$ All eleven studies were conducted in a hospital setting. Four studies reported government funding, ${ }^{74,208-210}$ two reported non-government, non-industry funding, ${ }^{211,213}$ one reported a combination of government and non-government, non-industry funding, ${ }^{212}$ and four were unclear or did not report the funding source. ${ }^{114,117,214,215}$ Finally, of the eleven included studies, seven were rated as good quality, ${ }^{114,117,208-211,215}$ three were rated as fair quality, ${ }^{74,212,214}$ and one was rated as poor quality. ${ }^{213}$

Of the 11 studies, 6 RCTs ${ }^{117,208,212-215}$ and 3 SR/MAs ${ }^{216-218}$ addressed high-dose versus lowdose oxytocin protocols for women with abnormal labor. Two RCTs ${ }^{74,210}$ and two SR/MAs ${ }^{219,220}$ addressed the timing of oxytocin augmentation following a diagnosis of abnormal labor. Two RCTs $^{209,213}$ studied the effect of pulsatile oxytocin infusions and another ${ }^{211}$ the use of adjuvant beta-blockade with oxytocin. One SR/MA studied the effect of oxytocin augmentation with regional analgesia, ${ }^{221}$ and one SR/MA ${ }^{220}$ and two RCTs ${ }^{114,218}$ compared oxytocin with no oxytocin in women with abnormal labor.

In addition to the above studies, five good-quality systematic reviews $216,217,219-221$ and one fair-quality systematic review ${ }^{218}$ addressed the benefits and harms of oxytocin protocols are also discussed below.

\section{Key Points for High-Dose Versus Low-Dose Oxytocin Protocols}

- In nulliparous women, high-dose oxytocin is associated with a lower cesarean delivery rate (moderate SOE) compared with low-dose oxytocin protocols with no difference in maternal hemorrhage (low SOE).

- Early administration of oxytocin is associated with a shorter duration of labor (moderate SOE) but does not affect the overall cesarean delivery rate compared with delayed administration (moderate SOE). There is no difference in adverse events of maternal outcomes of hemorrhage or transfusion (low SOE) or in mode of delivery (low SOE).

- Pulsatile administration of oxytocin is associated with a longer duration of labor compared with continuous administration (low SOE).

- There is no difference in cesarean delivery rate between women managed with oxytocin compared to expectant management (moderate SOE). 


\section{Detailed Synthesis for High-Dose Versus Low-Dose Oxytocin Protocol}

Oxytocin is a peptide and powerful uterotonic agent that is synthesized in the hypothalamus and secreted in a pulsatile fashion from the posterior pituitary. The synthetic version of oxytocin, Pitocin, is identical to the naturally-occurring hormone and is commonly used in obstetrics for induction and augmentation of labor. Due to its short serum half-life and narrow therapeutic range, oxytocin is given as a continuous intravenous infusion and begun at a low rate and then incrementally increased until a regular contraction pattern is achieved. Intravenous oxytocin dosing protocols are typically classified as either low-dose or high-dose based on the initial starting dose and by the interval of dose increase (Table 67). ${ }^{222}$

Table 67. Low-dose and high-dose oxytocin infusion protocols

\begin{tabular}{|l|c|c|c|}
\hline Regimen & $\begin{array}{c}\text { Starting Dose } \\
(\mathbf{m U / m i n})\end{array}$ & $\begin{array}{c}\text { Incremental Increase } \\
(\mathbf{m U / m i n})\end{array}$ & Dosage Interval (min) \\
\hline Low-dose & $0.5-2$ & $1-2$ & $15-40$ \\
\hline High-dose & 4 or higher & $3-6$ & $15-40$ \\
\hline
\end{tabular}

Abbreviations: $\mathrm{mU} / \mathrm{min}=$ milliunits per minute; min=minutes

\section{High-Dose Versus Low-Dose Oxytocin for Abnormal Labor}

\section{Results in Nulliparous Women}

\section{Duration of Labor and Cesarean Delivery Rates for High-Dose Versus Low-Dose Oxytocin}

We identified four RCTs $s^{117,208,212,215}$ and three SR/MAs ${ }^{216-218}$ that compared high-dose versus low-dose oxytocin protocols for nulliparous women with abnormal labor. One good-quality RCT $^{117}$ consisted of 960 nulliparous women in spontaneous labor in Thailand and compared active management versus conventional management of labor. The active management included early rupture of the membranes and a high-dose oxytocin infusion protocol (starting at 6 $\mathrm{mU} / \mathrm{min}$, increasing by $2 \mathrm{mU} / \mathrm{min}$ every 30 minutes to a maximal rate of $40 \mathrm{mU} / \mathrm{min}$ or to five contractions in 10 minutes). The specifics of the low-dose oxytocin protocol were not provided.

Women receiving the high-dose oxytocin protocol had a shorter duration of the first stage of labor but no difference in the duration of the second stage of labor compared with women receiving the conventional protocol, but there was no difference in mode of delivery or indication for cesarean or rates of maternal fever or chorioamnionitis between the two groups. ${ }^{117}$ (Table 68).

In a second good-quality RCT ${ }^{215}$, high-dose $(6.6 \mathrm{mU} / \mathrm{min}$ with incremental increases of $6.6 \mathrm{mU} / \mathrm{min})$ oxytocin was compared to low-dose $(3.3 \mathrm{mU} / \mathrm{min}$ with incremental increases of $3.3 \mathrm{mU} / \mathrm{min}$ ) oxytocin in 1295 nulliparous women in Sweden with delayed labor. This study found no difference in cesarean delivery rate between groups, but the high-dose group had shorter labors and more instances of tachysystole.

In a third good-quality RCT, ${ }^{208}$ high-dose oxytocin was compared to a standard protocol among nulliparous women in the UK with spontaneous onset of labor and labor complicated by dystocia. This study was a feasibility pilot RCT. Duration of labor was not reported, but there were no differences in mode of delivery or indication for cesarean. ${ }^{208}$ (Table 68).

In another feasibility pilot RCT (fair-quality) conducted in Canada, ${ }^{212} 79$ nulliparous women with labor dystocia were randomized to low-dose ( $2 \mathrm{mU} / \mathrm{min}$ with dosage increases of $2 \mathrm{mU} / \mathrm{min}$ ) 
and high-dose ( $4 \mathrm{mU} / \mathrm{min}$ with dosage increases of $4 \mathrm{mU} / \mathrm{min})$ oxytocin infusion regimens. The high-dose group received a greater maximum oxytocin infusion than the low-dose group, but there were no significant differences in duration of labor or mode of delivery ${ }^{212}$ (Table 68). 
Table 68. Labor outcomes by high- and low-dose oxytocin protocols in nulliparous women

\begin{tabular}{|c|c|c|c|c|c|c|c|c|c|c|}
\hline $\begin{array}{l}\text { Study } \\
\text { Design } \\
\text { Quality }\end{array}$ & Int & Com & $\begin{array}{l}\text { Duration of } \\
\text { Labor: } \\
\text { Int }\end{array}$ & $\begin{array}{l}\text { Duration of } \\
\text { Labor: } \\
\text { Com }\end{array}$ & $\begin{array}{l}\text { Duration of } \\
\text { Labor: } \\
\text { P Value }\end{array}$ & $\begin{array}{c}\text { Cesarean: } \\
\text { Int }\end{array}$ & $\begin{array}{l}\text { Cesarean: } \\
\text { Com }\end{array}$ & $\begin{array}{l}\text { Cesarean: } \\
\text { P Value }\end{array}$ & $\begin{array}{c}\text { Shorter } \\
\text { Labor } \\
\text { Associated } \\
\text { With Lower } \\
\text { Cesarean } \\
\text { Delivery } \\
\text { Rate? }\end{array}$ & Comments \\
\hline $\begin{array}{l}\text { Dy, } 2018^{212} \\
\text { RCT } \\
\text { Fair }\end{array}$ & $\begin{array}{l}\text { High-dose } \\
\text { oxytocin } \\
(4 \mathrm{mU} / \mathrm{min} \\
\text { with } \\
4 \mathrm{mU} / \mathrm{min} \\
\text { increments) }\end{array}$ & $\begin{array}{l}\text { Low-dose } \\
\text { oxytocin } \\
\text { (2mU/min } \\
\text { with } \\
2 \mathrm{mU} / \mathrm{min} \\
\text { increments) }\end{array}$ & $\begin{array}{l}\text { Second } \\
\text { stage: } 1.4 \\
\text { hr (SD: } 4.3 \\
\text { hr) }\end{array}$ & $\begin{array}{l}\text { Second } \\
\text { stage: } 2.1 \\
\text { hr (SD: } 1.6 \\
\text { hr) }\end{array}$ & $\begin{array}{l}\text { RR }-0.72(- \\
2.3 \text { to } 0.90) \\
p=0.38\end{array}$ & $6 / 40(15 \%)$ & $10 / 39(25.6 \%)$ & $\begin{array}{l}0.59(0.24, \\
1.45) \\
p=0.25\end{array}$ & Unknown & - \\
\hline $\begin{array}{l}\text { Kenyon, } \\
2013^{217} \\
\text { SR } \\
\text { Good }\end{array}$ & $\begin{array}{l}\text { High-dose } \\
\text { oxytocin }\end{array}$ & $\begin{array}{l}\text { Low-dose } \\
\text { oxytocin }\end{array}$ & $\begin{array}{l}\text { Oxytocin to } \\
\text { delivery: } 7.8 \\
\text { hr (2.7) }\end{array}$ & $\begin{array}{l}\text { Oxytocin to } \\
\text { delivery: } \\
11.3 \mathrm{hr} \\
(6.1)\end{array}$ & $\begin{array}{l}\text { Mean } \\
\text { difference: } \\
-3.50 \mathrm{hr} \\
(-6.38 \\
\text { to }-0.62)\end{array}$ & $\begin{array}{l}\text { Overall (all } \\
\text { subjects): } \\
43 / 320 \\
(13.4 \%) \\
\text { Overall } \\
\text { (nulliparous): } \\
30 / 138 \\
(21.7 \%) \\
\text { Overall } \\
\text { (parous): } 8 / 82 \\
\text { (9.7\%) }\end{array}$ & $\begin{array}{l}\text { Overall (all } \\
\text { subjects): } \\
71 / 324 \text { (21.9\%) } \\
\text { Overall } \\
\text { (nulliparous): } \\
\text { 48/162 (29.6\%) } \\
\text { Overall } \\
\text { (parous) 14/62 } \\
\text { (22.6\%) }\end{array}$ & $\begin{array}{l}\text { Overall (all } \\
\text { subjects): RR } \\
0.62(0.44 \text { to } \\
0.86 \text { ) } \\
\text { Overall } \\
\text { (nulliparous): } \\
\text { RR } 0.71 \text { ( } 0.47 \\
\text { to } 1.06 \text { ) } \\
\text { Overall } \\
\text { (parous): RR } \\
0.43(0.19 \text { to } \\
0.97 \text { ) }\end{array}$ & Yes & - \\
\hline $\begin{array}{l}\text { Kenyon, } \\
2013^{208} \\
\text { RCT } \\
\text { Good }\end{array}$ & $\begin{array}{l}\text { High-dose } \\
\text { oxytocin }\end{array}$ & $\begin{array}{l}\text { Low-dose } \\
\text { oxytocin }\end{array}$ & - & - & - & $17 / 47(36.2 \%)$ & 15/47 (31.9\%) & 0.66 & - & - \\
\hline $\begin{array}{l}\text { Selin, } 2018^{215} \\
\text { RCT } \\
\text { Good }\end{array}$ & $\begin{array}{l}\text { High-dose } \\
\text { oxytocin } \\
(6.6 \mathrm{mU} / \mathrm{min} \\
\text { with } \\
6.6 \mathrm{mU} / \mathrm{min} \\
\text { increments) }\end{array}$ & $\begin{array}{l}\text { Low-dose } \\
\text { oxytocin } \\
\text { (3.3mU/min } \\
\text { with } \\
3.3 \mathrm{mU} / \mathrm{min} \\
\text { increments) }\end{array}$ & $\begin{array}{l}\text { Active } \\
\text { phase to } \\
\text { birth: } 744 \\
\text { min (209) }\end{array}$ & $\begin{array}{l}\text { Active } \\
\text { phase to } \\
\text { birth: } 768 \\
\text { min (196) }\end{array}$ & $\begin{array}{l}\text { Mean } \\
\text { difference: - } \\
23.4 \text { min } \\
\text { 95\% Cl: - } \\
45.3 ;-1.5) \\
\text { p=0.021 }\end{array}$ & $\begin{array}{l}80 / 647 \\
(12.4 \%)\end{array}$ & $80 / 648(12.3 \%)$ & $\begin{array}{l}\text { Mean } \\
\text { difference: } 0.0 \\
(95 \% \mathrm{Cl}:-3.7 ; \\
3.8) \\
\mathrm{p}=1.00\end{array}$ & No & - \\
\hline
\end{tabular}




\begin{tabular}{|c|c|c|c|c|c|c|c|c|c|c|}
\hline $\begin{array}{l}\text { Study } \\
\text { Design } \\
\text { Quality }\end{array}$ & Int & Com & $\begin{array}{l}\text { Duration of } \\
\text { Labor: } \\
\text { Int }\end{array}$ & $\begin{array}{l}\text { Duration of } \\
\text { Labor: } \\
\text { Com }\end{array}$ & $\begin{array}{l}\text { Duration of } \\
\text { Labor: } \\
\text { P Value }\end{array}$ & $\begin{array}{c}\text { Cesarean: } \\
\text { Int }\end{array}$ & $\begin{array}{l}\text { Cesarean: } \\
\text { Com }\end{array}$ & $\begin{array}{l}\text { Cesarean: } \\
\text { P Value }\end{array}$ & $\begin{array}{c}\text { Shorter } \\
\text { Labor } \\
\text { Associated } \\
\text { With Lower } \\
\text { Cesarean } \\
\text { Delivery } \\
\text { Rate? }\end{array}$ & Comments \\
\hline $\begin{array}{l}\text { Somprasit, } \\
2005^{117} \\
\text { RCT } \\
\text { Good }\end{array}$ & $\begin{array}{l}\text { Early } \\
\text { AROM, 2- } \\
\text { hour } \\
\text { vaginal } \\
\text { exams with } \\
\text { high-dose } \\
\text { oxytocin } \\
\text { given if } \\
\text { dilated <1 } \\
\mathrm{cm}\end{array}$ & $\begin{array}{l}\text { No protocol } \\
\text { for initiating/ } \\
\text { stopping } \\
\text { oxytocin, } \\
\text { vaginal } \\
\text { exams as } \\
\text { indicated }\end{array}$ & $\begin{array}{l}\text { First stage: } \\
538.0 \mathrm{~min} \\
(242.9)\end{array}$ & $\begin{array}{l}\text { First stage: } \\
589.4 \text { min } \\
(263.8)\end{array}$ & 0.0036 & $\begin{array}{l}38 / 320 \\
(11.9 \%)\end{array}$ & $94 / 640(14.7 \%)$ & 0.23 & $\begin{array}{l}\text { Trend } \\
\text { toward } \\
\text { lower } \\
\text { cesarean } \\
\text { delivery } \\
\text { rate with } \\
\text { shorter } \\
\text { labor }\end{array}$ & $\begin{array}{l}\text { Low-resource } \\
\text { setting }\end{array}$ \\
\hline $\begin{array}{l}\text { Wei, } 2010 \\
(\mathrm{SR})^{216} \\
\text { RCT } \\
\text { Good }\end{array}$ & $\begin{array}{l}\text { High-dose } \\
\text { oxytocin }\end{array}$ & $\begin{array}{l}\text { Low-dose } \\
\text { oxytocin }\end{array}$ & $\begin{array}{l}\text { Labor } \\
\text { duration } \\
\text { >12 hr: } \\
75 / 741 \\
(10.1 \%)\end{array}$ & $\begin{array}{l}\text { Labor } \\
\text { duration > } \\
12 \mathrm{hr} \\
156 / 763 \\
(20.4 \%)\end{array}$ & $\begin{array}{l}\text { RR } 0.46 \\
(0.30 \text { to } \\
0.70)\end{array}$ & $\begin{array}{l}361 / 2748 \\
(13.1 \%)\end{array}$ & $\begin{array}{l}405 / 2675 \\
(15.1 \%)\end{array}$ & $\begin{array}{l}\text { RR } 0.85 \text { (0.75- } \\
0.97)\end{array}$ & Yes & - \\
\hline
\end{tabular}

Abbreviations: -=not reported; AROM=artificial rupture of membranes; CI=confidence interval; Com=comparator; hr=hours; Int=intervention; min=minutes; RCT=randomized controlled trial; $\mathrm{RR}=$ relative risk; $\mathrm{SR}=$ systematic review 


\section{Maternal Outcomes}

There was no significant difference in maternal pelvic floor trauma or hemorrhage ${ }^{208}$ or fever/infection ${ }^{117,208,215}$ between high- and low-dose protocols in the studies that reported it, although the Kenyon study was not powered to detect differences.

\section{Neonatal Outcomes}

There was no significant difference in the incidence of neonatal respiratory distress, or neonatal length of stay, in the one study which reported this outcome, but it was not powered to detect differences. ${ }^{208}$

\section{Strength of Evidence for High-Dose Versus Low-Dose Oxytocin in Nulliparous Women}

Table 69 summarizes the SOE for the high-dose versus low-dose oxytocin protocols described above. In general, the SOE was inconclusive given imprecise findings other than for mode of delivery.

Table 69. High-dose versus low-dose oxytocin protocols: Evidence profile in nulliparous women

\begin{tabular}{|c|c|c|c|c|}
\hline Category & Outcome & $\begin{array}{l}\text { Study Design } \\
\text { (Sample Size) }\end{array}$ & Conclusion & $\begin{array}{c}\text { SOE } \\
\left(^{(R a t i o n a l e)}\right)^{a} \\
\end{array}$ \\
\hline \multirow[t]{3}{*}{$\begin{array}{l}\text { Intermediate } \\
\text { or Final } \\
\text { Outcomes }\end{array}$} & $\begin{array}{l}\text { Process Related } \\
\text { Outcomes - } \\
\text { Duration of } 1^{\text {st }} \\
\text { Stage Labor }\end{array}$ & $\begin{array}{l}2 \text { RCTs }^{117,208} \\
(1,052)\end{array}$ & $\begin{array}{l}\text { Inconclusive: SOE was } \\
\text { insufficient given imprecise and } \\
\text { inconsistent findings from } 2 \\
\text { studies. }\end{array}$ & $\begin{array}{l}\text { Insufficient } \\
\text { (Inconsistent, } \\
\text { imprecise, non-U.S. } \\
\text { setting) }\end{array}$ \\
\hline & $\begin{array}{l}\text { Process Related } \\
\text { Outcomes - } \\
\text { Duration of } 2^{\text {nd }} \\
\text { Stage Labor }\end{array}$ & $\begin{array}{l}3 \\
\text { RCTs }{ }^{117,208,215} \\
(2,315)\end{array}$ & $\begin{array}{l}\text { Inconclusive: SOE was } \\
\text { insufficient given imprecise and } \\
\text { inconsistent findings from } 3 \\
\text { studies. }\end{array}$ & $\begin{array}{l}\text { Insufficient } \\
\text { (Inconsistent, } \\
\text { imprecise, non-U.S. } \\
\text { setting) }\end{array}$ \\
\hline & $\begin{array}{l}\text { Process Related } \\
\text { Outcomes - Mode } \\
\text { of Delivery } \\
\text { (Cesarean } \\
\text { Delivery) }\end{array}$ & $\begin{array}{l}3 \\
\text { RCTs }^{117,208,215} \\
(1,052) \\
2 \text { SRs }^{216,217} \\
\text { (945 patients, } \\
9 \text { studies) }\end{array}$ & $\begin{array}{l}\text { Improvement with high-dose } \\
\text { oxytocin: High-dose oxytocin } \\
\text { augmentation was associated } \\
\text { with a reduction in the risk of } \\
\text { cesarean section. }\end{array}$ & $\begin{array}{l}\text { Moderate } \\
\text { (inconsistent, } \\
\text { imprecise) } \\
\text { Findings supported by } 2 \\
\text { RCTs and } 2 \text { SRs } \\
\text { increasing SOE. } \\
\text { Inconsistency with a } \\
\text { third study not showing } \\
\text { a difference and } \\
\text { substantial } \\
\text { heterogeneity. }\end{array}$ \\
\hline \multirow[t]{3}{*}{$\begin{array}{l}\text { Adverse } \\
\text { Events }\end{array}$} & $\begin{array}{l}\text { Maternal } \\
\text { Outcomes - } \\
\text { Trauma to the } \\
\text { Pelvic Floor }\end{array}$ & $\begin{array}{l}1 \mathrm{RCT}^{208} \\
(92)\end{array}$ & $\begin{array}{l}\text { Inconclusive: SOE was } \\
\text { insufficient given imprecise and } \\
\text { finding from } 1 \text { small pilot study }\end{array}$ & $\begin{array}{l}\text { Insufficient (imprecise, } \\
\text { non-U.S. setting, } 1 \\
\text { small study) }\end{array}$ \\
\hline & $\begin{array}{l}\text { Maternal } \\
\text { Outcomes - } \\
\text { Infection }\end{array}$ & $\begin{array}{l}2 \mathrm{RCTs}^{117,208} \\
(1,052)\end{array}$ & $\begin{array}{l}\text { No difference: No difference in } \\
\text { the rate of maternal infection } \\
\text { between high-and low-dose } \\
\text { oxytocin as part of an active } \\
\text { management of labor protocol } \\
\text { compared to a conventional } \\
\text { management of labor protocol. }\end{array}$ & $\begin{array}{l}\text { Low } \\
\text { (Imprecise) }\end{array}$ \\
\hline & $\begin{array}{l}\text { Maternal } \\
\text { Outcomes - } \\
\text { Hemorrhage }\end{array}$ & $\begin{array}{l}2 \mathrm{RCTs}^{208,215} \\
(1,387)\end{array}$ & $\begin{array}{l}\text { No difference: SOE was low } \\
\text { given imprecise findings from } 2 \\
\text { non-U.S. setting studies. }\end{array}$ & $\begin{array}{l}\text { Low (imprecise, non- } \\
\text { U.S. setting) }\end{array}$ \\
\hline
\end{tabular}




\begin{tabular}{|c|c|c|c|c|}
\hline Category & Outcome & $\begin{array}{l}\text { Study Design } \\
\text { (Sample Size) }\end{array}$ & Conclusion & $\begin{array}{c}\text { SOE } \\
\text { (Rationale) }^{\mathrm{a}}\end{array}$ \\
\hline & $\begin{array}{l}\text { Neonatal } \\
\text { Outcomes - } \\
\text { Respiratory } \\
\text { Distress }\end{array}$ & $\begin{array}{l}1 \mathrm{RCT}^{208} \\
(92)\end{array}$ & $\begin{array}{l}\text { Inconclusive: SOE was } \\
\text { insufficient given imprecise and } \\
\text { finding from } 1 \text { small pilot study. }\end{array}$ & $\begin{array}{l}\text { Insufficient (imprecise, } \\
\text { non-U.S. setting, } 1 \\
\text { small study) }\end{array}$ \\
\hline & $\begin{array}{l}\text { Neonatal } \\
\text { Outcomes - } \\
\text { Neonatal Length } \\
\text { of Stay }\end{array}$ & $\begin{array}{l}1 \mathrm{RCT}^{208} \\
(92)\end{array}$ & $\begin{array}{l}\text { Inconclusive: SOE was } \\
\text { insufficient given imprecise and } \\
\text { finding from } 1 \text { small pilot study. }\end{array}$ & $\begin{array}{l}\text { Insufficient (imprecise, } \\
\text { non-U.S. setting, } 1 \\
\text { small study) }\end{array}$ \\
\hline
\end{tabular}

${ }^{a}$ Criteria for downgrading SOE are described as Rationale; when these criteria are insufficient for understanding the final SOE, additional explanation is provided.

Abbreviations: RCT=randomized controlled trial; SOE=strength of evidence; SR=systematic review

\section{Results in Parous Women}

\section{Duration of Labor and Cesarean Delivery Rates for High-Dose Versus Low-Dose Oxytocin}

We identified two RCTs (one fair quality, ${ }^{214}$ one poor quality ${ }^{213}$ ) that compared high-dose and low-dose oxytocin in parous women.

The fair-quality study, ${ }^{214}$ compared low-dose $(1 \mathrm{mU} / \mathrm{min}$, increased by $1 \mathrm{mU} / \mathrm{min}$ every 20 minutes) and high-dose (5mU/min increased by $5 \mathrm{mU} / \mathrm{min}$ every 20 minutes) oxytocin infusions in a total of 211 parous women in India with slow-progressing spontaneous labor. The duration of labor was significantly reduced in the high-dose group, but there was no difference in cesarean section rates between the groups (Table 70). ${ }^{214}$

In the second study, rated as poor-quality, ${ }^{213} 900$ parous women with arrested labor progress in China were randomized into five groups: oxytocin regimens of $1 \mathrm{mU} / \mathrm{min}$ (initial dose $2 \mathrm{mU} / \mathrm{min}$ ), $4 \mathrm{mU} / \mathrm{min}$ (initial dose $8 \mathrm{mU} / \mathrm{min}$ ), $16 \mathrm{mU} / \mathrm{min}$ (continuous infusion), $5 \mathrm{mU} / \mathrm{min}$ quarter-hourly, and pulsatile administration with a syringe pump. Outcomes of the pulsatile administration regimen compared to the continuous infusion regimen are in the pulsatile oxytocin section, below. The continuous infusion and $1 \mathrm{mU} / \mathrm{min}$ groups had similar rates of instrument-facilitated delivery, which were higher than the rates of instrument-facilitated delivery for the $4 \mathrm{mU} / \mathrm{min}$ and $5 \mathrm{mU} / \mathrm{min}$ quarter-hourly regimens. The continuous infusion had the highest rate of uterine hyperstimulation. Maternal and child deaths and Apgar scores under 7 were also measured, but differences were not statistically significant (Table 70). 
Table 70. Labor outcomes by high- and low-dose oxytocin protocols in parous women

\begin{tabular}{|c|c|c|c|c|c|c|c|c|c|c|}
\hline $\begin{array}{l}\text { Study } \\
\text { Design } \\
\text { Quality }\end{array}$ & Int & Com & $\begin{array}{l}\text { Duration of } \\
\text { Labor: } \\
\text { Int }\end{array}$ & $\begin{array}{l}\text { Duration of } \\
\text { Labor: } \\
\text { Com }\end{array}$ & $\begin{array}{l}\text { Duration of } \\
\text { Labor: } \\
\text { P Value }\end{array}$ & $\begin{array}{l}\text { Cesarean: } \\
\text { Int }\end{array}$ & $\begin{array}{l}\text { Cesarean: } \\
\text { Com }\end{array}$ & $\begin{array}{l}\text { Cesarean: } \\
\text { P Value }\end{array}$ & $\begin{array}{c}\text { Shorter } \\
\text { Labor } \\
\text { Associated } \\
\text { With Lower } \\
\text { Cesarean } \\
\text { Delivery } \\
\text { Rate? }\end{array}$ & Comments \\
\hline $\begin{array}{l}\text { Geeta, } 2015^{214} \\
\text { RCT } \\
\text { Fair }\end{array}$ & $\begin{array}{l}\text { High-dose } \\
\text { oxytocin } \\
\text { (starting at } \\
5 \mathrm{mU} / \mathrm{min} \text { ) }\end{array}$ & $\begin{array}{l}\text { Low-dose } \\
\text { oxytocin } \\
\text { (starting at } \\
\text { 1mU/min) }\end{array}$ & $\begin{array}{l}4.88 \mathrm{hr} \text { (SD: } \\
1.00 \mathrm{hr})\end{array}$ & $\begin{array}{l}6.86 \mathrm{hr} \text { (SD: } \\
0.99 \mathrm{hr})\end{array}$ & $p<0.05$ & $\begin{array}{l}29 / 110 \\
(26.36 \%)\end{array}$ & $\begin{array}{l}28 / 101 \\
(27.72 \%)\end{array}$ & $p=0.95$ & $\begin{array}{l}\text { Unknown/ } \\
\text { No }\end{array}$ & - \\
\hline $\begin{array}{l}\text { Liu, } 2018^{213} \\
\text { RCT } \\
\text { Poor }\end{array}$ & $\begin{array}{l}\text { High-dose } \\
\text { oxytocin: } \\
4 \mathrm{mU} / \mathrm{min} \\
\text { (initial } \\
8 \mathrm{mU} / \mathrm{min} \\
\text { dose), } \\
5 \mathrm{mU} / \mathrm{min} \\
\text { quarter- } \\
\text { hourly. }\end{array}$ & $\begin{array}{l}\text { low-dose: } \\
1 \mathrm{mU} / \mathrm{min} \\
\text { (initial } \\
2 \mathrm{mU} / \mathrm{min} \\
\text { dose) }\end{array}$ & $\begin{array}{l}\text { Infusion to } \\
\text { delivery: } \\
4 \mathrm{mU} / \mathrm{min} \text { : } \\
\sim 10 \text { hours; } \\
5 \mathrm{mU} / \mathrm{min} \\
\text { quarter- } \\
\text { hourly: } \\
\sim 10.5 \text { hours } \\
\text { First stage } \\
\text { of labor to } \\
\text { delivery: } \\
4 \mathrm{mU} / \mathrm{min}: \\
\sim 8.4 \text { hours; } \\
5 \mathrm{mU} / \mathrm{min} \\
\text { quarter- } \\
\text { hourly: } ~ \\
\text { hours }\end{array}$ & $\begin{array}{l}\text { Infusion to } \\
\text { delivery: } \\
\sim 10.4 \text { hours } \\
\text { First stage } \\
\text { of labor to } \\
\text { delivery: } \\
\sim 8.2 \text { hours }\end{array}$ & $\begin{array}{l}\text { Infusion to } \\
\text { delivery: } \\
5 \mathrm{mU} / \mathrm{min} \\
\text { quarter- } \\
\text { hourly } \\
\text { compared } \\
\text { to } 4 \mathrm{mU} / \mathrm{min} \text { : } \\
\mathrm{p}<0.0001 \\
1 \mathrm{mU} / \mathrm{min} \\
\text { compared } \\
\text { to } 4 \mathrm{mU} / \mathrm{min} \text { : } \\
\mathrm{p}=0.0103 \\
\text { First stage } \\
\text { of labor to } \\
\text { delivery: all } \\
\text { of these } \\
\text { groups: } \\
\mathrm{p} \geq 0.05\end{array}$ & $\begin{array}{l}5 \mathrm{mU} / \mathrm{min} \\
\text { quarter-hourly: } \\
5 / 162(3 \%) \\
4 \mathrm{mU} / \mathrm{min}: \\
6 / 162(4 \%)\end{array}$ & $\begin{array}{l}1 \mathrm{mU} / \mathrm{min}: \\
13 / 162(8 \%)\end{array}$ & $\begin{array}{l}\text { 4mU/min } \\
\text { compared to } \\
1 \mathrm{mU} / \mathrm{min}: \\
\mathrm{p}=0.0078 \\
5 \mathrm{mU} / \mathrm{min} \\
\text { quarter-hourly } \\
\text { compared to } \\
4 \mathrm{mU} / \mathrm{min}: \\
\mathrm{p}=0.3188\end{array}$ & Unknown & - \\
\hline
\end{tabular}

Abbreviations: -=not reported; Com=comparator; hr=hours; Int=intervention; min=minutes; RCT=randomized controlled trial; SD=standard deviation 


\section{Maternal Outcomes}

In the poor-quality study there was no significant difference in maternal deaths (insufficient $\mathrm{SOE}){ }^{213}$

\section{Neonatal Outcomes}

In the poor-quality study there was no significant difference in neonatal deaths or Apgar scores less than 7 (insufficient SOE). ${ }^{213}$

\section{Relevant Systematic Reviews/Meta-Analyses for Dosage of Oxytocin}

Two SR/MAs analyzed the effect of high-dose oxytocin protocols on labor outcomes among women with dystocia. Wei et al. ${ }^{216}$ conducted an SR/MA of 10 studies including 5,423 women with labor dystocia. The studies included both nulliparous and parous women, though results were not stratified by parity. High-dose oxytocin was associated with an overall lower risk for cesarean delivery and associated higher rate of spontaneous vaginal delivery. High-dose oxytocin was associated with lower rates of labor duration greater than 12 hours but higher rates of uterine tachysystole. There were no differences in the rate of postpartum hemorrhage, need for maternal transfusion, uterine atony, uterine rupture, shoulder dystocia, chorioamnionitis, nonreassuring fetal heart rate tracings, fetal distress, meconium aspiration, neonatal acidemia, or maternal satisfaction were seen between the two groups (Table 68).

In the second SR/MA, Kenyon et al. conducted a Cochrane review ${ }^{217}$ addressing high-dose versus low-dose oxytocin protocols for augmentation of abnormal labor. Their review included 4 studies with 644 subjects. High-dose oxytocin was associated with a lower overall cesarean delivery rate and with a higher rate of spontaneous vaginal delivery and shorter duration of labor. Subgroup analysis based on parity demonstrated that lower cesarean delivery rates were seen only in parous women, while nulliparous women had lower but nonsignificant cesarean delivery rates. One of the four studies was judged to be at high risk of bias. When that study was removed from the analysis, the overall cesarean delivery rate among all subjects was no longer significantly different between the two oxytocin-dosing protocols. There were no differences in maternal satisfaction, chorioamnionitis, postpartum hemorrhage, emergent delivery for nonreassuring fetal status, or neonatal acidemia between the two oxytocin-dosing protocols.

\section{Strength of Evidence for High-Dose Versus Low-Dose Oxytocin in Parous Women}

Table 71 summarizes the SOE for the high-dose versus low-dose oxytocin protocols described above. The SOE was insufficient for all outcomes given findings from studies with high risk of bias performed in non-U.S. settings.

Table 71. High-dose versus low-dose oxytocin protocols: Evidence profile in parous women

\begin{tabular}{|l|l|l|l|l|}
\hline \multicolumn{1}{|c|}{ Category } & \multicolumn{1}{|c|}{ Outcome } & $\begin{array}{l}\text { Study Design } \\
\text { (Sample Size) }\end{array}$ & \multicolumn{1}{c|}{ Conclusion } & \multicolumn{1}{c|}{$\begin{array}{c}\text { SOE } \\
\text { (Rationale) }^{\mathbf{a}}\end{array}$} \\
\hline $\begin{array}{l}\text { Intermediate } \\
\text { or Final } \\
\text { Outcomes }\end{array}$ & $\begin{array}{l}\text { Process Related } \\
\text { Outcomes - } \\
\text { Duration of Labor }\end{array}$ & $\begin{array}{l}\text { RCTs,214 } \\
(1,111)\end{array}$ & $\begin{array}{l}\text { Inconclusive: SOE was } \\
\text { insufficient given imprecise and } \\
\text { inconsistent findings from 2 } \\
\text { studies in non-U.S. settings with } \\
\text { potential risk of bias. }\end{array}$ & $\begin{array}{l}\text { Insufficient (imprecise, } \\
\text { inconsistent, non-U.S. } \\
\text { setting, high risk of } \\
\text { bias) }\end{array}$ \\
\hline
\end{tabular}




\begin{tabular}{|c|c|c|c|c|}
\hline Category & Outcome & $\begin{array}{l}\text { Study Design } \\
\text { (Sample Size) }\end{array}$ & Conclusion & $\begin{array}{c}\text { SOE } \\
\text { (Rationale) }^{a}\end{array}$ \\
\hline & $\begin{array}{l}\text { Process Related } \\
\text { Outcomes - Mode } \\
\text { of Delivery } \\
\text { (Cesarean } \\
\text { Delivery) } \\
\end{array}$ & $\begin{array}{l}2 \text { RCTs }^{213,214} \\
(1,111)\end{array}$ & $\begin{array}{l}\text { Inconclusive: SOE was } \\
\text { insufficient given imprecise } \\
\text { findings from } 2 \text { studies in non- } \\
\text { U.S. settings with potential risk } \\
\text { of bias. }\end{array}$ & $\begin{array}{l}\text { Insufficient (imprecise, } \\
\text { non-U.S. setting, high } \\
\text { risk of bias) }\end{array}$ \\
\hline \multirow[t]{2}{*}{$\begin{array}{l}\text { Adverse } \\
\text { Events }\end{array}$} & $\begin{array}{l}\text { Maternal } \\
\text { Outcomes - } \\
\text { Death }\end{array}$ & $\begin{array}{l}1 \mathrm{RCT}^{213} \\
(900)\end{array}$ & $\begin{array}{l}\text { Inconclusive: SOE was } \\
\text { insufficient given imprecise } \\
\text { findings from } 1 \text { study in non- } \\
\text { U.S. settings with high risk of } \\
\text { bias. }\end{array}$ & $\begin{array}{l}\text { Insufficient (imprecise, } \\
\text { non-U.S. setting, high } \\
\text { risk of bias) }\end{array}$ \\
\hline & $\begin{array}{l}\text { Neonatal } \\
\text { Outcomes - } \\
\text { Death }\end{array}$ & $\begin{array}{l}1 \mathrm{RCT}^{213} \\
(900)\end{array}$ & $\begin{array}{l}\text { Inconclusive: SOE was } \\
\text { insufficient given imprecise } \\
\text { findings from } 1 \text { study in non- } \\
\text { U.S. settings with high risk of } \\
\text { bias. }\end{array}$ & $\begin{array}{l}\text { Insufficient (imprecise, } \\
\text { non-U.S. setting, high } \\
\text { risk of bias) }\end{array}$ \\
\hline
\end{tabular}

${ }^{a}$ Criteria for downgrading SOE are described as Rationale; when these criteria are insufficient for understanding the final SOE, additional explanation is provided.

Abbreviations: RCT=randomized controlled trial; SOE=strength of evidence

\section{Timing of Oxytocin Administration}

\section{Results in Nulliparous Women}

\section{Duration of Labor and Cesarean Delivery Rates for High-Dose Versus Low-Dose Oxytocin}

Two RCTs ${ }^{74,210}$ (one good quality and one fair quality) addressed the timing of oxytocin augmentation following a diagnosis of abnormal labor in nulliparous women. Dencker et al. ${ }^{74}$ conducted an fair-quality RCT of early (following no progress 1 hour after amniotomy, oxytocin infusion was administered within 20 minutes) versus delayed (postponement of oxytocin augmentation for 3 hours) oxytocin administration for augmentation of labor in nulliparous women. The study was conducted at 2 sites in Sweden and included 630 women. There were no significant differences in mode of delivery between the two groups, but early administration of oxytocin was associated with a shorter duration of labor from randomization to delivery. There were no differences in duration of the second stage of labor or rates of postpartum hemorrhage, need for transfusion, anal sphincter laceration, or neonatal acidosis between the two groups (Table 72).

Hinshaw et al. ${ }^{210}$ conducted an good-quality RCT of early (within 20 minutes of randomization) versus delayed (withheld for a period of 8 hours unless intervention became clinically indicated) oxytocin administration for labor augmentation in nulliparous women. The study was conducted at 12 sites in the UK and included 412 women. There were no differences in rates of cesarean delivery between the two groups, but again duration of labor from randomization to delivery was shorter in the early oxytocin group. There were no differences in the rates of postpartum hemorrhage, need for transfusion, neonatal death or infection, or maternal satisfaction between the two groups (Table 72). 
Table 72. Labor outcomes by timing of oxytocin administration in nulliparous women

\begin{tabular}{|c|c|c|c|c|c|c|c|c|c|c|}
\hline $\begin{array}{c}\text { Study } \\
\text { Design } \\
\text { Quality }\end{array}$ & Int & Com & $\begin{array}{l}\text { Duration of } \\
\text { Labor: } \\
\text { Int }\end{array}$ & $\begin{array}{l}\text { Duration of } \\
\text { Labor: } \\
\text { Com }\end{array}$ & $\begin{array}{l}\text { Duration } \\
\text { of Labor: } \\
\text { P Value }\end{array}$ & $\begin{array}{c}\text { Cesarean: } \\
\text { Int }\end{array}$ & $\begin{array}{l}\text { Cesarean: } \\
\text { Com }\end{array}$ & $\begin{array}{l}\text { Cesarean: } \\
\text { P Value }\end{array}$ & $\begin{array}{c}\text { Shorter Labor } \\
\text { Associated } \\
\text { With Lower } \\
\text { Cesarean } \\
\text { Delivery Rate? }\end{array}$ & Comments \\
\hline $\begin{array}{l}\text { Dencker, } \\
2009^{74} \\
\text { RCT } \\
\text { Fair }\end{array}$ & $\begin{array}{l}\text { Early } \\
\text { administration } \\
\text { of oxytocin }\end{array}$ & $\begin{array}{l}\text { Delayed } \\
\text { administration } \\
\text { of oxytocin }\end{array}$ & $\begin{array}{l}\text { Random- } \\
\text { ization to } \\
\text { delivery: } 5.2 \\
\text { hr (2.8) } \\
\text { Second } \\
\text { stage: } 1.7 \\
\text { hr (1.2) }\end{array}$ & $\begin{array}{l}\text { Random- } \\
\text { ization to } \\
\text { delivery: } 6.7 \\
\text { hr (3.2) } \\
\text { Second } \\
\text { stage: } 1.8 \\
\text { hr (1.3) }\end{array}$ & $\begin{array}{l}\text { Randomiz } \\
\text { ation to } \\
\text { delivery: } \\
\text { p<0.001 } \\
\text { Second } \\
\text { stage: } \\
p=0.68\end{array}$ & $\begin{array}{l}\text { Overall: } \\
29 / 314 \\
(9.2 \%)\end{array}$ & $\begin{array}{l}\text { Overall: } \\
34 / 316 \\
(10.8 \%)\end{array}$ & $\begin{array}{l}\text { Overall: RR } \\
0.8 \text { (0.5 to } \\
1.4)\end{array}$ & No & - \\
\hline $\begin{array}{l}\text { Hinshaw, } \\
2008^{210} \\
\text { RCT } \\
\text { Good }\end{array}$ & $\begin{array}{l}\text { Early } \\
\text { administration } \\
\text { of oxytocin }\end{array}$ & $\begin{array}{l}\text { Delayed } \\
\text { administration } \\
\text { of oxytocin }\end{array}$ & $\begin{array}{l}\text { Random- } \\
\text { ization to } \\
\text { delivery: } 5 \\
\text { hr } 52 \text { min } \\
\text { (IQR 3:52 } \\
\text { to 8:02) }\end{array}$ & $\begin{array}{l}\text { Random- } \\
\text { ization to } \\
\text { delivery: } 9 \\
\text { hr } 8 \text { min } \\
\text { (IQR 5:06 } \\
\text { to 13:16) }\end{array}$ & $P<0.001$ & $\begin{array}{l}\text { Overall: } \\
\text { 28/208 } \\
(13.5 \%) \\
\text { NRFHT: } \\
\text { 4/208 (1.9\%) } \\
\text { Delay: } \\
21 / 208 \\
(10.1 \%)\end{array}$ & $\begin{array}{l}\text { Overall: } \\
\text { 28/204 } \\
\text { (13.7\%) } \\
\text { NRFHT: } \\
\text { 6/204 (2.9\%) } \\
\text { Delay: } \\
\text { 17/204 } \\
(8.3 \%)\end{array}$ & $\begin{array}{l}\text { Overall: RR } \\
0.98 \text { (0.6 to } \\
1.7) \\
\text { NRFHT: Not } \\
\text { provided but } \\
\text { NS } \\
\text { Delay: RR } \\
1.23 \text { (0.6 to } \\
2.4) \\
\end{array}$ & No & - \\
\hline $\begin{array}{l}\text { Wei, } \\
2009^{219} \\
\text { SR/MA } \\
\text { Good }\end{array}$ & $\begin{array}{l}\text { Early } \\
\text { administration } \\
\text { of oxytocin }\end{array}$ & $\begin{array}{l}\text { Delayed } \\
\text { administration } \\
\text { of oxytocin }\end{array}$ & - & - & $\begin{array}{l}\text { Admission } \\
\text { to delivery: } \\
\text { Mean } \\
\text { difference } \\
-1.36 \mathrm{hr} \\
(-2.82 \text { to } \\
0.09)\end{array}$ & $\begin{array}{l}\text { Overall: } \\
153 / 1010 \\
(15.1 \%)\end{array}$ & $\begin{array}{l}\text { Overall: } \\
167 / 973 \\
(17.2 \%)\end{array}$ & $\begin{array}{l}\text { Overall: RR } \\
0.87(0.71 \text { to } \\
1.06)\end{array}$ & No & - \\
\hline $\begin{array}{l}\text { Bugg, } \\
2013^{220} \\
\text { SR/MA } \\
\text { Good }\end{array}$ & $\begin{array}{l}\text { Early } \\
\text { administration } \\
\text { of oxytocin }\end{array}$ & $\begin{array}{l}\text { Delayed } \\
\text { administration } \\
\text { of oxytocin }\end{array}$ & $\begin{array}{l}\text { Randomizat } \\
\text { ion to } \\
\text { delivery: } \\
5.26 \mathrm{hr} \\
(0.89)\end{array}$ & $\begin{array}{l}\text { Randomizat } \\
\text { ion to } \\
\text { delivery: } \\
7.50 \mathrm{hr} \\
(1.39)\end{array}$ & $\begin{array}{l}\text { Randomiz } \\
\text { ation to } \\
\text { delivery: } \\
\text { Mean } \\
\text { difference } \\
-2.20 \mathrm{hr} \\
(-3.29 \\
\text { to }-1.10) \\
\end{array}$ & $\begin{array}{l}\text { Overall: } \\
\text { 74/610 } \\
(12.1 \%)\end{array}$ & $\begin{array}{l}\text { Overall: } \\
76 / 590 \\
(12.9 \%)\end{array}$ & $\begin{array}{l}\text { Overall: RR } \\
0.88(0.66 \text { to } \\
1.19)\end{array}$ & No & - \\
\hline
\end{tabular}

Abbreviations: -=not reported; Com=comparator; hr=hours; Int=intervention; IQR=interquartile range; NRFHT=nonreassuring fetal heart rate tracing; NS=not significant; $\mathrm{RCT}=$ randomized controlled trial; $\mathrm{RR}=$ relative risk; SR/MA=systematic review/meta analysis 


\section{Maternal Outcomes}

In the two studies described above, there were no significant differences in postpartum hemorrhage or need for transfusion. ${ }^{74,210}$ In the Dencker study, there were no differences in anal sphincter laceration, ${ }^{74}$ and in the Hinshaw et al study no difference in maternal satisfaction. ${ }^{210}$ Hinshaw et al. ${ }^{210}$ conducted an RCT of early (within 20 minutes of randomization) versus delayed (withheld for a period of 8 hours unless intervention became clinically indicated) oxytocin administration for labor augmentation in nulliparous women. The study was conducted at 12 sites in the UK and included 412 women. There were no differences in rates of cesarean delivery between the two groups, but again duration of labor from randomization to delivery was shorter in the early oxytocin group. There were no differences in the rates of postpartum hemorrhage, need for transfusion, neonatal death or infection, or maternal satisfaction between the two groups (Table 72).

\section{Neonatal Outcomes}

There were no significant differences in neonatal death or infection ${ }^{210}$ or acidosis $^{74}$ in the included studies.

\section{Relevant Systematic Reviews/Meta-Analyses for Timing of Oxytocin}

Wei et al. ${ }^{219}$ conducted a meta-analysis on early oxytocin administration for augmentation of labor that included 9 studies and 1,983 women. Early oxytocin augmentation was defined as immediate oxytocin administration when dystocia was identified. The studies included both nulliparous and parous women, though results were not stratified by parity. Early administration of oxytocin was associated with a higher rate of spontaneous vaginal delivery but similar to our included RCTs no differences in rate of cesarean delivery or operative vaginal delivery. Early administration was associated with uterine tachysystole, but there were no differences in the duration of labor (admission to delivery) or rates of postpartum hemorrhage, need for transfusion, maternal fever or chorioamnionitis, or fetal distress (Table 72).

Bugg et al. conducted a Cochrane review ${ }^{220}$ addressing early versus delayed (delayed use by one hour or more) administration of oxytocin for labor augmentation. They identified 8 studies including 1388 women. The studies included both nulliparous and parous women, though results were not stratified by parity. Both our included RCTs were also included in this SR. Early administration of oxytocin was associated with a shorter duration of labor from randomization to delivery, but there were no differences in mode of delivery or rates of uterine tachysystole, postpartum hemorrhage, or maternal satisfaction between the two groups (Table 72).

Gaucher et al. ${ }^{218}$ completed an fair-quality SR of studies evaluating oxytocin regimens for women with dystocia, but many descriptive studies were included, and they were not evaluated separately. Several included studies addressed immediate v. delayed oxytocin (delayed by 2+, 3, or 8 hours), and the authors concluded that early administration of oxytocin can reduce duration of labor as compared to delayed administration in dystocia during the active phase of labor. 


\section{Strength of Evidence for Timing of Oxytocin}

Table 73 summarizes the SOE for the timing of oxytocin described above. The SOE was moderate for outcomes informed both by individual RCTs and existing SRs.

Table 73. Early versus delayed oxytocin protocols: Evidence profile in nulliparous women

\begin{tabular}{|c|c|c|c|c|}
\hline Category & Outcome & $\begin{array}{l}\text { Study Design } \\
\text { (Sample Size) }\end{array}$ & Conclusion & $\begin{array}{c}\text { SOE } \\
\text { (Rationale) }^{a}\end{array}$ \\
\hline \multirow[t]{2}{*}{$\begin{array}{l}\text { Intermediate } \\
\text { or Final } \\
\text { Outcomes }\end{array}$} & $\begin{array}{l}\text { Process Related } \\
\text { Outcomes - } \\
\text { Duration of Labor }\end{array}$ & $\begin{array}{l}2 \mathrm{RCTs}^{74,210} \\
(1,042) \\
2 \mathrm{SRs}^{219,220} \\
(2,583 \\
\text { patients, } 10 \\
\text { studies) }\end{array}$ & $\begin{array}{l}\text { Improvement with early } \\
\text { administration of oxytocin: } \\
\text { shorter duration of labor in early } \\
\text { oxytocin group. }\end{array}$ & $\begin{array}{l}\text { Moderate (non-U.S. } \\
\text { setting, potential risk of } \\
\text { bias) } \\
\text { Consistent with SR } \\
\text { findings }\end{array}$ \\
\hline & $\begin{array}{l}\text { Process Related } \\
\text { Outcomes - Mode } \\
\text { of Delivery } \\
\text { (Cesarean } \\
\text { Delivery) }\end{array}$ & $\begin{array}{l}2 \mathrm{RCTS}^{74,210} \\
(1,042) \\
2 \mathrm{SRs}^{219,220} \\
(2,583 \\
\text { patients, } 10 \\
\text { studies) } \\
\end{array}$ & $\begin{array}{l}\text { No difference: no difference in } \\
\text { mode of delivery given early } \\
\text { oxytocin group. }\end{array}$ & $\begin{array}{l}\text { Moderate (non-U.S. } \\
\text { setting, potential risk of } \\
\text { bias) } \\
\text { Consistent with SR } \\
\text { findings }\end{array}$ \\
\hline \multirow[t]{7}{*}{$\begin{array}{l}\text { Adverse } \\
\text { Events }\end{array}$} & $\begin{array}{l}\text { Maternal } \\
\text { Outcomes - } \\
\text { Trauma to the } \\
\text { Pelvic Floor }\end{array}$ & $\begin{array}{l}1 \mathrm{RCT}^{74} \\
(630)\end{array}$ & $\begin{array}{l}\text { Inconclusive: SOE was } \\
\text { insufficient given findings from } \\
\text { one non-U.S. study with } \\
\text { potential risk of bias }\end{array}$ & $\begin{array}{l}\text { Insufficient } \\
\text { (Imprecise, non-U.S. } \\
\text { setting, risk of bias, one } \\
\text { study) }\end{array}$ \\
\hline & $\begin{array}{l}\text { Maternal } \\
\text { Outcomes - } \\
\text { Transfusion }\end{array}$ & $\begin{array}{l}2 \mathrm{RCTS}^{74,210} \\
(1,042)\end{array}$ & $\begin{array}{l}\text { No difference: No difference } \\
\text { between women managed with } \\
\text { early versus delayed oxytocin } \\
\text { administration. }\end{array}$ & $\begin{array}{l}\text { Low (non-U.S. setting, } \\
\text { potential risk of bias) }\end{array}$ \\
\hline & $\begin{array}{l}\text { Maternal } \\
\text { Outcomes - } \\
\text { Hemorrhage }\end{array}$ & $\begin{array}{l}2 \mathrm{RCTs}^{74,210} \\
(1,042)\end{array}$ & $\begin{array}{l}\text { No difference: No difference } \\
\text { between women managed with } \\
\text { early versus delayed oxytocin } \\
\text { administration. }\end{array}$ & $\begin{array}{l}\text { Low (non-U.S. setting, } \\
\text { potential risk of bias) }\end{array}$ \\
\hline & $\begin{array}{l}\text { Neonatal } \\
\text { Outcomes - } \\
\text { Neonatal } \\
\text { Infection/Sepsis }\end{array}$ & $\begin{array}{l}1 \mathrm{RCT}^{210} \\
(412)\end{array}$ & $\begin{array}{l}\text { Inconclusive: SOE was } \\
\text { insufficient given imprecise } \\
\text { findings from one non-U.S. } \\
\text { study }\end{array}$ & $\begin{array}{l}\text { Insufficient } \\
\text { (Imprecise, non-U.S. } \\
\text { setting, one study) }\end{array}$ \\
\hline & $\begin{array}{l}\text { Neonatal } \\
\text { Outcomes - } \\
\text { Neonatal } \\
\text { Acidemia }\end{array}$ & $\begin{array}{l}1 \mathrm{RCT}^{74} \\
(630)\end{array}$ & $\begin{array}{l}\text { Inconclusive: SOE was } \\
\text { insufficient given findings from } \\
\text { one non-U.S. study with } \\
\text { potential risk of bias }\end{array}$ & $\begin{array}{l}\text { Insufficient } \\
\text { (Imprecise, non-U.S. } \\
\text { setting, risk of bias, one } \\
\text { study) }\end{array}$ \\
\hline & $\begin{array}{l}\text { Process Related } \\
\text { Outcomes - Mode } \\
\text { of Delivery } \\
\text { (Instrumental } \\
\text { Delivery) }\end{array}$ & $\begin{array}{l}2 \mathrm{RCTs}^{74,210} \\
(1,042)\end{array}$ & $\begin{array}{l}\text { No difference: No difference } \\
\text { between women managed with } \\
\text { early versus delayed oxytocin } \\
\text { administration. }\end{array}$ & $\begin{array}{l}\text { Low (non-U.S. setting, } \\
\text { potential risk of bias) }\end{array}$ \\
\hline & $\begin{array}{l}\text { Process Related } \\
\text { Outcomes - Mode } \\
\text { of Delivery } \\
\text { (Spontaneous) }\end{array}$ & $\begin{array}{l}2 \mathrm{RCTs}^{74,210} \\
(1,042)\end{array}$ & $\begin{array}{l}\text { No difference: No difference } \\
\text { between women managed with } \\
\text { early versus delayed oxytocin } \\
\text { administration. }\end{array}$ & $\begin{array}{l}\text { Low (non-U.S. setting, } \\
\text { potential risk of bias) }\end{array}$ \\
\hline
\end{tabular}

${ }^{a}$ Criteria for downgrading SOE are described as Rationale; when these criteria are insufficient for understanding the final SOE, additional explanation is provided.

Abbreviations: RCT=randomized controlled trial; SOE=strength of evidence; SR=systematic review 


\section{Pulsatile Oxytocin Administration and Adjuvants to Oxytocin}

Endogenous oxytocin is released in a pulsatile fashion from the pituitary gland. In contrast, oxytocin is most commonly given as a continuous intravenous infusion for both induction and augmentation of labor.

\section{Results in Women of Mixed Parity}

Duration of Labor and Cesarean Delivery Rates for Oxytocin Administration and Adjuvants to Oxytocin

Tribe et al. ${ }^{209}$ conducted an RCT of pulsatile versus continuous oxytocin for augmentation of labor. The trial was conducted at two sites in the UK and included 500 women. The trial included both nulliparous and parous women and results were not stratified by parity. Pulsatile oxytocin was associated with longer duration of labor compared with continuous infusion. Fewer women delivered vaginally within 24 hours in the pulsatile group, but overall cesarean delivery rates were not reported. There was no difference in the rate of neonatal infection, hypoxic ischemic encephalopathy or neonatal seizures between the two groups (Table 74).

Labor is a high catecholamine state and endogenous catecholamines may interfere with uterine contractility as beta2-adrenergic receptor agonists are known tocolytic agents. Palomaki et al. ${ }^{211}$ conducted an RCT of combined propanol (beta adrenergic receptor antagonist) plus oxytocin compared with oxytocin alone for augmentation of labor. The trial was conducted at a single site in Finland and included 107 women. Both nulliparous and parous women were included and the results were not stratified by parity. There were no differences in mode of delivery or duration of labor between the two groups (Table 74).

Liu et al. ${ }^{213}$ compared several oxytocin regimens in their RCT, as described in the high-dose vs. low-dose section, above. One group was assigned a pulsatile regimen, which was primarily compared to the group receiving the $16 \mathrm{mU} / \mathrm{min}$ continuous infusion. The duration of labor was longest with pulsatile administration, though that regimen also had the lowest rate of uterine hyperstimulation. The pulsatile administration group had the lowest rate of failed vaginal birth within 24 hours of instrument-facilitated delivery (Table 74). 
Table 74. Labor outcomes with pulsatile oxytocin or with adjuvants in women of mixed parity

\begin{tabular}{|c|c|c|c|c|c|c|c|c|c|c|}
\hline $\begin{array}{l}\text { Study } \\
\text { Design } \\
\text { Quality }\end{array}$ & Int & Com & $\begin{array}{l}\text { Duration of } \\
\text { Labor: } \\
\text { Int }\end{array}$ & $\begin{array}{l}\text { Duration of } \\
\text { Labor: } \\
\text { Com }\end{array}$ & $\begin{array}{l}\text { Duration of } \\
\text { Labor: } \\
\text { P Value }\end{array}$ & $\begin{array}{l}\text { Cesarean: } \\
\text { Int }\end{array}$ & $\begin{array}{l}\text { Cesarean: } \\
\text { Com }\end{array}$ & $\begin{array}{l}\text { Cesarean: } \\
\text { P Value }\end{array}$ & $\begin{array}{l}\text { Shorter Labor } \\
\text { Associated } \\
\text { With Lower } \\
\text { Cesarean } \\
\text { Delivery Rate? }\end{array}$ & Comments \\
\hline $\begin{array}{l}\text { Tribe, } \\
2012^{209} \\
\text { RCT } \\
\text { Good }\end{array}$ & $\begin{array}{l}\text { Pulsatile } \\
\text { oxytocin }\end{array}$ & $\begin{array}{l}\text { Continuous } \\
\text { oxytocin }\end{array}$ & $\begin{array}{l}\text { Infusion to } \\
\text { delivery: } 9.61 \\
\text { hr (95\% } \mathrm{Cl} \\
8.95 \text { to } 10.27) \\
\text { First and } \\
\text { second stage } \\
\text { of labor: } 15.79 \\
\text { hr (95\% Cl } \\
14.93 \text { to } \\
16.65)\end{array}$ & $\begin{array}{l}\text { Infusion to } \\
\text { delivery: } 7.17 \\
\text { hr (95\% Cl } \\
6.58 \text { to } 7.77) \\
\text { First stage } \\
\text { and second } \\
\text { stage of } \\
\text { labor: } 14.06 \\
\text { hr (95\% Cl } \\
13.20 \text { to } \\
14.92)\end{array}$ & $\begin{array}{l}\text { Infusion to } \\
\text { delivery: RR } \\
2.4 \text { (1.6 to } \\
3.3) \\
\text { First and } \\
\text { second } \\
\text { stage of } \\
\text { labor: RR } \\
1.7(0.5 \text { to } \\
2.9)\end{array}$ & $\begin{array}{l}\text { Failed } \\
\text { vaginal } \\
\text { delivery in } \\
24 \text { hours: } \\
119 / 251 \\
(47.4 \%)\end{array}$ & $\begin{array}{l}\text { Failed } \\
\text { vaginal } \\
\text { delivery in } 24 \\
\text { hours: } \\
93 / 249 \\
(37.3 \%)\end{array}$ & $\begin{array}{l}\text { Failed } \\
\text { vaginal } \\
\text { delivery in } 24 \\
\text { hours: } 1.27 \\
(1.03 \text { to } 1.56)\end{array}$ & Unknown & $\begin{array}{l}\text { Overall } \\
\text { cesarean } \\
\text { delivery rates } \\
\text { were not } \\
\text { reported in the } \\
\text { study. }\end{array}$ \\
\hline $\begin{array}{l}\text { Palomki, } \\
2006^{211} \\
\text { RCT } \\
\text { Good }\end{array}$ & $\begin{array}{l}\text { Oxytocin } \\
\text { plus } \\
\text { propranolol }\end{array}$ & $\begin{array}{l}\text { Oxytocin } \\
\text { alone }\end{array}$ & $\begin{array}{l}\text { Duration of } \\
\text { augmented } \\
\text { labor: } 185 \text { min } \\
\text { Total duration } \\
\text { of labor (first, } \\
\text { second and } \\
\text { third stage): } \\
810 \text { min }\end{array}$ & $\begin{array}{l}\text { Duration of } \\
\text { augmented } \\
\text { labor: } 223 \\
\text { min } \\
\text { Total } \\
\text { duration of } \\
\text { labor (first, } \\
\text { second, third } \\
\text { stage): } 768 \\
\text { min }\end{array}$ & $\begin{array}{l}\text { Duration of } \\
\text { augmented } \\
\text { labor: } \\
p=0.217 \\
\text { Total } \\
\text { duration } n \text { of } \\
\text { labor (first, } \\
\text { second, third } \\
\text { stage): } \\
p=0.486\end{array}$ & $\begin{array}{l}\text { Overall: } \\
6 / 55 \\
(10.9 \%)\end{array}$ & $\begin{array}{l}\text { Overall: } 2 / 52 \\
(3.8 \%)\end{array}$ & $\begin{array}{l}\text { Overall: } \\
p=0.154\end{array}$ & No & - \\
\hline $\begin{array}{l}\text { Liu, } \\
2018^{213} \\
\text { RCT } \\
\text { Poor }\end{array}$ & $\begin{array}{l}\text { Pulsatile } \\
\text { oxytocin } \\
\text { (pulses of } \\
1 / 8 \text { the } \\
\text { continuous } \\
\text { infusion) }\end{array}$ & $\begin{array}{l}\text { Continuous } \\
\text { oxytocin } \\
\text { (16mU/min) }\end{array}$ & $\begin{array}{l}\text { Infusion to } \\
\text { delivery: } \sim 16 \\
\text { hours. first } \\
\text { stage of labor } \\
\text { to delivery: } \sim 9 \\
\text { hours }\end{array}$ & $\begin{array}{l}\text { Infusion to } \\
\text { delivery: } ~ 10 \\
\text { hours. first } \\
\text { stage of } \\
\text { labor to } \\
\text { delivery: } \\
\sim 8.2 \text { hours }\end{array}$ & $\begin{array}{l}\text { Infusion to } \\
\text { delivery: } \\
p<0.0001 \text {. } \\
\text { first stage of } \\
\text { labor to } \\
\text { delivery: } \\
p<0.0001\end{array}$ & $\begin{array}{l}\text { Cesarean: } \\
1 / 162(1 \%) \\
\text { Failed } \\
\text { vaginal } \\
\text { delivery in } \\
24 \text { hours: } \\
12 / 162(7 \%)\end{array}$ & $\begin{array}{l}\text { Cesarean: } \\
\text { 15/162 (9\%) } \\
\text { Failed } \\
\text { vaginal } \\
\text { delivery in } 24 \\
\text { hours: } \\
40 / 162 \\
(25 \%)\end{array}$ & $\begin{array}{l}\text { Cesarean: } \\
\mathrm{p}=0.0001 \\
\\
\text { Failed } \\
\text { vaginal } \\
\text { delivery in } 24 \\
\text { hours: } \\
\mathrm{p}<0.0001\end{array}$ & Unknown & - \\
\hline
\end{tabular}

Abbreviations: -=not reported; CI=confidence interval; Com=comparator; hr=hours; Int=intervention; min=minutes; RCT=randomized controlled trial; RR=relative risk 


\section{Maternal Outcomes}

In the study Liu et al., ${ }^{213}$ the pulsatile regimen had the lowest rate of postpartum hemorrhage.

\section{Neonatal Outcomes}

In the study of Tribe et al., ${ }^{209}$ there was no difference in the rate of neonatal infection, hypoxic ischemic encephalopathy or neonatal seizures between the two groups (Table 74).

\section{Strength of Evidence for Pulsatile Oxytocin Protocols in Women of Mixed Parity}

Table 75 summarizes the SOE for pulsatile oxytocin protocols described above. In general, the SOE was rated as low or insufficient given imprecise findings from non-U.S. settings.

Table 75. Pulsatile versus continuous oxytocin protocols: Evidence profile in women of mixed parity

\begin{tabular}{|c|c|c|c|c|}
\hline Category & Outcome & $\begin{array}{l}\text { Study Design } \\
\text { (Sample Size) }\end{array}$ & Conclusion & $\begin{array}{c}\text { SOE } \\
\text { (Rationale) }^{\mathrm{a}}\end{array}$ \\
\hline \multirow[t]{2}{*}{$\begin{array}{l}\text { Intermediate } \\
\text { or Final } \\
\text { Outcomes }\end{array}$} & $\begin{array}{l}\text { Process Related } \\
\text { Outcomes - } \\
\text { Duration of } 2 \text { nd } \\
\text { Stage Labor }\end{array}$ & $\begin{array}{l}1 \mathrm{RCT}^{209} \\
(487)\end{array}$ & $\begin{array}{l}\text { No difference: No difference in } \\
\text { the duration of the second } \\
\text { stage of labor among women } \\
\text { managed with pulsatile } \\
\text { compared to continuous } \\
\text { oxytocin for augmentation of } \\
\text { labor. }\end{array}$ & $\begin{array}{l}\text { Low } \\
\text { (Indirect, Imprecise) }\end{array}$ \\
\hline & $\begin{array}{l}\text { Process Related } \\
\text { Outcomes - } \\
\text { Duration of Labor }\end{array}$ & $\begin{array}{l}3 \\
\text { RCTs } \\
(1,489), 211,213\end{array}$ & $\begin{array}{l}\text { Improvement with continuous } \\
\text { oxytocin: Women managed } \\
\text { with pulsatile compared to } \\
\text { continuous oxytocin for } \\
\text { augmentation of labor had a } \\
\text { longer duration of labor. }\end{array}$ & $\begin{array}{l}\text { Low } \\
\text { (Indirect, imprecise, } \\
\text { non-U.S. setting, high } \\
\text { risk of bias) }\end{array}$ \\
\hline \multirow[t]{3}{*}{$\begin{array}{l}\text { Adverse } \\
\text { Events }\end{array}$} & $\begin{array}{l}\text { Maternal } \\
\text { Outcomes - } \\
\text { Postpartum } \\
\text { hemorrhage }\end{array}$ & $\begin{array}{l}1 \mathrm{RCT}^{213} \\
(900)\end{array}$ & $\begin{array}{l}\text { Inconclusive: SOE was } \\
\text { insufficient given imprecise } \\
\text { findings from } 1 \text { study in non- } \\
\text { U.S. settings with high risk of } \\
\text { bias }\end{array}$ & $\begin{array}{l}\text { Insufficient (imprecise, } \\
\text { non-U.S. setting, high } \\
\text { risk of bias) }\end{array}$ \\
\hline & $\begin{array}{l}\text { Process Related } \\
\text { Outcomes - Mode } \\
\text { of Delivery } \\
\text { (Operative } \\
\text { delivery) }\end{array}$ & $\begin{array}{l}1 \mathrm{RCT}^{209} \\
(500)\end{array}$ & $\begin{array}{l}\text { No difference: No difference in } \\
\text { operative delivery rate between } \\
\text { women managed with pulsatile } \\
\text { compared to continuous } \\
\text { oxytocin for augmentation of } \\
\text { labor. The cesarean delivery } \\
\text { rate was not reported. }\end{array}$ & $\begin{array}{l}\text { Low } \\
\text { (Indirect, imprecise) }\end{array}$ \\
\hline & $\begin{array}{l}\text { Process Related } \\
\text { Outcomes - Mode } \\
\text { of Delivery } \\
\text { (Instrumental } \\
\text { Delivery) }\end{array}$ & $\begin{array}{l}1 \mathrm{RCT}^{211} \\
(107)\end{array}$ & $\begin{array}{l}\text { Inconclusive: SOE was } \\
\text { insufficient given imprecise } \\
\text { findings from } 1 \text { small study. }\end{array}$ & $\begin{array}{l}\text { Insufficient (Imprecise, } \\
1 \text { small study) }\end{array}$ \\
\hline
\end{tabular}

${ }^{a}$ Criteria for downgrading SOE are described as Rationale; when these criteria are insufficient for understanding the final SOE, additional explanation is provided.

Abbreviations: RCT=randomized controlled trial; SOE=strength of evidence 


\section{Oxytocin Versus Expectant Management}

\section{Results in Women of Mixed Parity}

\section{Duration of Labor and Cesarean Delivery Rates for Oxytocin Versus Expectant Management}

We identified one good quality RCT ${ }^{114}$ and two good quality systematic reviews ${ }^{220,221}$ comparing various methods for labor augmentation. In Nachum et al. ${ }^{114}$ there were three intervention arms: amniotomy alone, amniotomy with oxytocin, and oxytocin alone. The control arm included expectant management. The results of the amniotomy and amniotomy plus oxytocin augmentation compared with expectant management are presented in KQ 2. There was no difference in mode of delivery, duration of the first stage of labor, or duration of the second stage of labor. There were no differences or rates of postpartum hemorrhage, anal sphincter laceration or postpartum fever between women receiving oxytocin alone compared to women in the expectant management group. Women managed with oxytocin had greater mean satisfaction scores compared with the expectantly managed group (4.7 [0.6] vs. 5.0 [0.1], $\mathrm{p}<0.05$ after posthoc testing) on a five-point scale from absolutely not satisfied (1) to absolutely satisfied (5). The study included both nulliparous and parous women and results were not stratified by parity.

\section{Maternal Outcomes}

Nachum et al. ${ }^{114}$ found that there were no significant differences in rates of postpartum hemorrhage, anal sphincter laceration or postpartum fever between women receiving oxytocin alone compared to women in the expectant management group. Women managed with oxytocin had greater mean satisfaction scores compared with the expectantly managed group (4.7 [0.6] vs. 5.0 [0.1], $\mathrm{p}<0.05$ after post-hoc testing) on a five-point scale from absolutely not satisfied (1) to absolutely satisfied (5).

\section{Relevant Systematic Reviews for Oxytocin Versus Expectant Management}

There were two good-quality SRs that addressed oxytocin expectant for augmentation of labor. ${ }^{220,221}$ One review was in the setting of concomitant regional analgesia ${ }^{221}$ and the other was a Cochrane review on the effect of oxytocin augmentation versus expectant management for labor dystocia. ${ }^{220}$ Costley et al. performed an SR/MA of oxytocin augmentation versus expectant management in women with epidural analgesia. ${ }^{221}$ The review included two studies involving 319 nulliparous women. There were no differences in mode of delivery of rates of postpartum hemorrhage between the two groups. Bugg et al. conducted a Cochrane review that included 8 studies with 1388 subjects on the use of oxytocin versus expectant management for labor dystocia as well as the use of early or delayed oxytocin administration. ${ }^{220}$ The studies included both nulliparous and parous women and results were not stratified by parity. Of the eight studies, three (138 subjects) compared oxytocin administration with expectant management. There was no difference in cesarean delivery or operative vaginal delivery between the two groups (Table 76). 
Table 76. Labor outcomes with oxytocin compared to expectant management in women of mixed parity

\begin{tabular}{|c|c|c|c|c|c|c|c|c|c|c|}
\hline $\begin{array}{l}\text { Study } \\
\text { Quality }\end{array}$ & Int & Com & $\begin{array}{l}\text { Duration of } \\
\text { Labor: } \\
\text { Int }\end{array}$ & $\begin{array}{l}\text { Duration of } \\
\text { Labor: Com }\end{array}$ & $\begin{array}{l}\text { Duration of } \\
\text { Labor: } \\
\text { P Value }\end{array}$ & $\begin{array}{l}\text { Cesarean: } \\
\text { Int }\end{array}$ & $\begin{array}{l}\text { Cesarean: } \\
\text { Com }\end{array}$ & $\begin{array}{l}\text { Cesarean: } \\
\text { P Value }\end{array}$ & $\begin{array}{c}\text { Shorter } \\
\text { Labor } \\
\text { Associated } \\
\text { With Lower } \\
\text { Cesarean } \\
\text { Delivery } \\
\text { Rate? } \\
\end{array}$ & Comments \\
\hline $\begin{array}{l}\text { Costley, } \\
2012^{221} \\
\text { SR/MA } \\
\text { Good }\end{array}$ & $\begin{array}{c}\text { Oxytocin } \\
\text { augmentation }\end{array}$ & $\begin{array}{l}\text { No intervention/ } \\
\text { Expectant } \\
\text { management }\end{array}$ & - & - & - & - & - & $\begin{array}{c}\text { Overall: RR } \\
0.95(0.42 \text { to } \\
2.12)\end{array}$ & - & $\begin{array}{l}\text { Women } \\
\text { with } \\
\text { epidural } \\
\text { analgesia }\end{array}$ \\
\hline $\begin{array}{l}\text { Bugg, } \\
2013^{220} \\
\text { SR/MA } \\
\text { Good }\end{array}$ & $\begin{array}{c}\text { Oxytocin } \\
\text { augmentation }\end{array}$ & $\begin{array}{l}\text { No intervention/ } \\
\text { Expectant } \\
\text { management }\end{array}$ & - & - & - & $\begin{array}{c}\text { Overall: } \\
8 / 65 \\
(12.3 \%)\end{array}$ & $\begin{array}{l}\text { Overall: } \\
\text { 10/73 } \\
(13.7 \%)\end{array}$ & $\begin{array}{c}\text { Overall: RR } \\
0.84(0.36 \text { to } \\
1.96)\end{array}$ & - & - \\
\hline $\begin{array}{l}\text { Nachum, } \\
2010^{114} \\
\text { RCT } \\
\text { Good }\end{array}$ & $\begin{array}{c}\text { Oxytocin } \\
\text { augmentation }\end{array}$ & $\begin{array}{l}\text { No intervention/ } \\
\text { Expectant } \\
\text { management }\end{array}$ & $\begin{array}{l}\text { Random- } \\
\text { ization to } \\
\text { delivery: } 494 \text { min } \\
\text { (327) } \\
\text { First stage: } 463 \\
\text { min (313) } \\
\text { Active phase: } \\
103 \text { min (89) } \\
\text { Second stage: } \\
\quad 31 \text { min (46) }\end{array}$ & $\begin{array}{l}\text { Random- } \\
\text { ization to } \\
\text { delivery: } 498 \\
\text { min (306) } \\
\text { First stage: } \\
460 \text { min (285) } \\
\text { Active phase: } \\
127 \text { min (96) } \\
\text { Second stage: } \\
38 \text { min (54) }\end{array}$ & $\begin{array}{l}\text { Random- } \\
\text { ization to } \\
\text { delivery: } \\
p=0.94 \\
\text { First stage: } \\
p=0.95 \\
\text { Active } \\
\text { phase: } \\
p=0.12 \\
\text { Second } \\
\text { stage: } \\
p=0.41 \\
\end{array}$ & $\begin{array}{c}\text { Overall: } \\
2 / 72(2.8 \%)\end{array}$ & $\begin{array}{c}\text { Overall: } 1 / 70 \\
(1.4 \%)\end{array}$ & Overall: $p=0.9$ & No & - \\
\hline
\end{tabular}

Abbreviations: -=not reported; Com=comparator; hr=hours; Int=intervention; RCT=randomized controlled trial; RR=relative risk; SR/MA=systematic review/meta analysis 


\section{Strength of Evidence for Oxytocin Versus Expectant Management}

Table 77 summarizes the SOE for oxytocin versus expectant management.

Table 77. Oxytocin versus expectant management: Evidence profile in women of mixed parity

\begin{tabular}{|c|c|c|c|c|}
\hline Category & Outcome & $\begin{array}{l}\text { Study Design } \\
\text { (Sample Size) }\end{array}$ & Conclusion & $\begin{array}{c}\text { SOE } \\
\text { (Rationale) }^{\mathrm{a}}\end{array}$ \\
\hline \multirow[t]{2}{*}{$\begin{array}{l}\text { Intermediate } \\
\text { or Final } \\
\text { Outcomes }\end{array}$} & $\begin{array}{l}\text { Process Related } \\
\text { Outcomes - } \\
\text { Duration of Labor } \\
\text { (from intervention } \\
\text { to delivery) }\end{array}$ & $\begin{array}{l}1 \mathrm{RCT}^{114} \\
(99)\end{array}$ & $\begin{array}{l}\text { Inconclusive: SOE was } \\
\text { insufficient given imprecise } \\
\text { findings from } 1 \text { small study. }\end{array}$ & $\begin{array}{l}\text { Insufficient (Imprecise, } \\
1 \text { small study) }\end{array}$ \\
\hline & $\begin{array}{l}\text { Process Related } \\
\text { Outcomes - Mode } \\
\text { of Delivery } \\
\text { (Cesarean } \\
\text { Delivery) }\end{array}$ & $\begin{array}{l}\text { 1 RCT }^{114} \\
(99) \\
2 \text { SRs }^{220,221} \\
\text { (457 patients, } \\
5 \text { studies) }\end{array}$ & $\begin{array}{l}\text { No difference: No difference in } \\
\text { cesarean delivery rate between } \\
\text { women managed with oxytocin } \\
\text { compared to expectant } \\
\text { management. }\end{array}$ & $\begin{array}{l}\text { Moderate } \\
\text { (Imprecise, consistency } \\
\text { with SR } \\
\text { SOE was increased to } \\
\text { moderate given findings } \\
\text { from SRs which also } \\
\text { found no difference in } \\
\text { cesarean delivery rates. }\end{array}$ \\
\hline $\begin{array}{l}\text { Adverse } \\
\text { Events }\end{array}$ & $\begin{array}{l}\text { Process Related } \\
\text { Outcomes - Mode } \\
\text { of Delivery } \\
\text { (Instrumental } \\
\text { Delivery) }\end{array}$ & $\begin{array}{l}\text { 1 } \mathrm{RCT}^{114} \\
(99) \\
1 \mathrm{SR}^{220} \\
\text { (138 patients, } \\
3 \text { studies) }\end{array}$ & $\begin{array}{l}\text { No difference: No difference in } \\
\text { operative vaginal delivery rate } \\
\text { between women managed with } \\
\text { oxytocin compared to expectant } \\
\text { management. }\end{array}$ & $\begin{array}{l}\text { Low } \\
\text { (Imprecise) } \\
\text { Consistent with SR } \\
\text { findings }\end{array}$ \\
\hline
\end{tabular}

${ }^{a}$ Criteria for downgrading SOE are described as Rationale; when these criteria are insufficient for understanding the final SOE, additional explanation is provided.

Abbreviations: RCT=randomized controlled trial; SOE=strength of evidence; SR=systematic review

\section{Key Question 8. Electronic Fetal Monitoring Versus Intermittent Auscultation}

KQ 8 was: For women in spontaneous labor undergoing augmentation with oxytocin, what are the relative benefits and harms (in terms of both maternal and neonatal outcomes) of electronic fetal monitoring versus intermittent auscultation?

\section{Description of Included Studies}

We were unable to identify any relevant RCTs that met our inclusion criteria at this time. We identified 4 potential SRs that had comparisons of electronic fetal monitoring to intermittent auscultation, ${ }^{31,51,55,56}$ but these were ultimately excluded because the studies included in the reviews evaluated interventions that are not currently used in the United States. We did identify one $\mathrm{SR}^{223}$ that had included studies on the comparisons of electronic fetal monitoring to intermittent auscultation.

\section{Key Point for Electronic Fetal Monitoring Versus Intermittent Auscultation}

- There was insufficient SOE for all outcomes regarding electronic fetal monitoring versus intermittent auscultation 


\section{Detailed Synthesis for Electronic Fetal Monitoring Versus Intermittent Auscultation}

We identified one SR by Martis et al. ${ }^{223}$ that examined electronic fetal monitoring versus intermittent auscultation. This SR included three studies comparing the effect of electronic fetal monitoring versus intermittent auscultation on maternal and neonatal health outcomes. All three studies were conducted in Africa and included a total of 6,241 women and 6,241 babies. Two of the three studies (3,242 women and 3,242 babies) were included in the quantitative synthesis (meta-analysis) since the other study was found to have questionable data reporting. The authors of the review considered both of the studies in the meta-analysis to be of high risk for performance bias due to inability to blind. One of the included studies in the meta-analysis did not meet our inclusion criteria because of the 1994 publication date. Two comparisons were made in this review, intermittent electronic fetal monitoring with Pinard and Doppler ultrasonography with routine Pinard.

There were no differences in intermittent electronic fetal monitoring versus routine Pinard for the outcomes of low Apgar scores at 5 minutes or perinatal mortality. Neonatal seizures were reduced in the electronic fetal monitoring group (RR 0.05, 95\% CI 0.00 to 0.89). This outcome include 633 infants and was considered to have very low quality evidence. No outcomes on mortality, morbidity, cerebral palsy, or neurosensory disability. Of the maternal outcomes, higher rates of cesarean section were found among the electronic fetal monitoring group (RR 2.92, 95\% CI 1.78 to 4.80). This outcome included 633 women and was judged to have moderate quality evidence compared to routine Pinard. No differences were found with instrumental vaginal births. No outcomes related to maternal mortality, instrumental vaginal birth for fetal distress and or acidosis, analgesia in labor, mobility or restriction during labor, and postnatal depression.

When comparing Doppler ultrasound versus routine Pinard, no differences were found between groups for Apgar scores, perinatal mortality, or neonatal seizures. Outcomes related to cord blood acidosis, composite of mortality and serious morbidity, cerebral palsy, neurosensory disability were not reported. Of the maternal outcomes, women allocated to the Doppler ultrasonography had higher rates of cesarean section for fetal distress compared to routine Pinard (RR 2.71, 95\% CI 1.64 to 4.48). This outcome included 627 women and was judged to be moderate quality evidence. There was no difference in instrumental vaginal births between groups. No other maternal outcomes were reported.

\section{Key Question 9. Timing of Pushing in the Second Stage}

KQ 9 was: For women in the second stage of labor, is there a benefit from delayed or Valsalva pushing for time to delivery or mode of delivery?

\section{Description of Included Studies}

We identified six articles ${ }^{72,73,224-227}$ representing five RCTs that examined pushing techniques among 605 nulliparous women. Two fair-quality RCTs were conducted in the UK/Europe, ${ }^{224,226}$ one fair-quality RCT was conducted in the Middle East, ${ }^{225}$ and two good-quality RCTs were conducted in the United States. ${ }^{72,227}$ Two studies reported government funding, ${ }^{72,224}$ one reported university internal funding, ${ }^{225}$ one reported a combination of government and non-government funding, ${ }^{227}$ and one did not report a funding source or it was unclear. ${ }^{226}$

In addition, we identified two SRs that met our inclusion criteria. ${ }^{228,229}$ Of the above RCTs, three $^{72,73,224}$ were identified in the 2016 SR by Barasinski et al., ${ }^{229}$ and four were identified in the 
2017 SR by Lemos et al. ${ }^{228}$ The original RCT by Koyucu et al. ${ }^{226}$ was not included in the Lemos et al. SR, most likely because of its later publication date.

\section{Key Points for Timing of Pushing}

- Valsalva/coached and spontaneous/uncoached pushing have similar rates of cesarean delivery (low SOE).

- There is limited evidence that immediate pushing has a shorter labor duration when compared to delayed pushing in nulliparous women (low SOE).

- There was limited evidence of no difference in neonatal outcomes for immediate versus delayed pushing (low SOE).

\section{Detailed Synthesis for Timing of Pushing}

\section{Coached Pushing Versus Uncoached Pushing}

Results for this intervention were reported for nulliparous women in four studies. ${ }^{72,224-226}$ No relevant SR/MAs were identified.

\section{Results in Nulliparous Women}

Four RCTs compared pushing techniques (coached/Valsalva pushing versus spontaneous or uncoached pushing) among nulliparous women without epidural analgesia.

\section{Duration of Labor and Cesarean Delivery Rates for Coached Pushing Versus Uncoached Pushing}

One study ${ }^{224}$ demonstrated a statistically significant increase in the length of the second stage of labor in women randomized to Valsalva pushing (40.8 vs. 50.1 minutes, $\mathrm{p}=0.045$ ) (Table 78). The cesarean delivery rate for women after randomization was not reported for this study. In contrast, the other three studies ${ }^{72,225,226}$ demonstrated that coached/Valsalva technique was associated with a shorter duration of the second stage compared with uncoached pushing (spontaneous or Valsalva). SOE was rated as insufficient for duration of labor given inconsistent and imprecise findings. There was no difference in rate of cesarean deliveries among these studies (low SOE). 
Table 78. Duration of labor and cesarean delivery rates for spontaneous pushing versus Valsalva pushing

\begin{tabular}{|c|c|c|c|c|c|c|c|c|c|c|}
\hline $\begin{array}{l}\text { Study } \\
\text { Quality }\end{array}$ & Int & Comp & $\begin{array}{l}\text { Duration } \\
\text { of Labor: } \\
\text { Int }\end{array}$ & $\begin{array}{l}\text { Duration } \\
\text { of Labor: } \\
\text { Com }\end{array}$ & $\begin{array}{c}\text { Duration } \\
\text { of } \\
\text { Labor: P } \\
\text { Value }\end{array}$ & $\begin{array}{l}\text { Cesarean: } \\
\text { Int }\end{array}$ & $\begin{array}{l}\text { Cesarean: } \\
\text { Com }\end{array}$ & $\begin{array}{l}\text { Cesarean: } \\
\text { P Value }\end{array}$ & $\begin{array}{l}\text { Shorter } \\
\text { Labor } \\
\text { Associated } \\
\text { With } \\
\text { Lower } \\
\text { Cesarean } \\
\text { Delivery } \\
\text { Rate? }\end{array}$ & Comments \\
\hline $\begin{array}{l}\text { Bloom, } 2006^{72} \\
\text { Good }\end{array}$ & $\begin{array}{l}\text { Coached } \\
\text { Pushing } \\
N=163\end{array}$ & $\begin{array}{l}\text { Un-coached } \\
\text { Pushing } \\
\mathrm{N}=157\end{array}$ & $\begin{array}{l}\text { Duration } \\
46.3 \text { min } \\
\pm 41.5\end{array}$ & $\begin{array}{l}\text { Duration } \\
59.1 \text { min } \\
\pm 49.1\end{array}$ & 0.014 & $1(<1 \%)$ & $5(3 \%)$ & 0.109 & No & \\
\hline $\begin{array}{l}\text { Koyucu, } \\
2017^{226} \\
\text { Fair }\end{array}$ & $\begin{array}{l}\text { Spontaneous } \\
\text { Pushing } \\
\text { Group N=40 }\end{array}$ & $\begin{array}{l}\text { Valsalva } \\
\text { Pushing with } \\
\text { Instruction } \\
\mathrm{N}=40\end{array}$ & $\begin{array}{l}\text { Duration } \\
63.2 \text { min } \\
(\mathrm{SD}=21.3)\end{array}$ & $\begin{array}{l}\text { Duration } \\
46.6 \mathrm{~min} \\
(\mathrm{SD}=23.4)\end{array}$ & 0.001 & -- & -- & -- & -- & $\begin{array}{l}\text { All patients had } \\
\text { vaginal delivery in } \\
\text { cephalic position }\end{array}$ \\
\hline $\begin{array}{l}\text { Yildirim, } \\
2008^{224} \\
\text { Fair }\end{array}$ & $\begin{array}{l}\text { Valsalva } \\
\text { Pushing } \\
\mathrm{N}=50\end{array}$ & $\begin{array}{l}\text { Spontaneous } \\
\text { Pushing } \\
\mathrm{N}=50\end{array}$ & $\begin{array}{l}\text { Duration } \\
50.1 \text { min } \\
\pm 26.3\end{array}$ & $\begin{array}{l}\text { Duration } \\
40.8 \text { min } \\
\pm 19.1\end{array}$ & 0.045 & - & - & - & Unknown & - \\
\hline $\begin{array}{l}\text { Vaziri, } 2016^{225} \\
\text { Fair }\end{array}$ & $\begin{array}{l}\text { Spontaneous } \\
\text { Pushing in } \\
\text { Lateral } \\
\text { Position } \\
\mathrm{N}=35\end{array}$ & $\begin{array}{l}\text { Valsalva } \\
\text { Pushing in } \\
\text { Supine } \\
\text { Position } \\
N=34\end{array}$ & $\begin{array}{l}\text { Duration } \\
76.32 \text { min } \\
(\mathrm{SD}=8.26)\end{array}$ & $\begin{array}{l}\text { Duration } \\
64.56 \\
(S D=15.24)\end{array}$ & $<0.001$ & $1(<1 \%)$ & $2(1 \%)$ & - & NA & - \\
\hline
\end{tabular}

Abbreviations: -=not reported; Com=comparator; Int=intervention; min=minutes; NA=not applicable; $\mathrm{RR}=$ relative risk; $\mathrm{SD}=$ standard deviation 


\section{Maternal Outcomes for Coached Pushing Versus Uncoached Pushing}

While evidence is limited, there was no statistically significant increase in the incidence of maternal adverse outcomes including forceps delivery or perineal lacerations (Table 79). ${ }^{72,224}$ The companion study also showed no difference in the incidence of urodynamic stress incontinence (low SOE). ${ }^{73}$ One study demonstrated a statistically significant increase in postpartum hemoglobin among the intervention group of spontaneous pushing. ${ }^{226}$ There were no data on maternal infection or maternal satisfaction.

Table 79. Maternal adverse outcomes for spontaneous pushing versus Valsalva pushing

\begin{tabular}{|c|c|c|c|c|c|c|}
\hline $\begin{array}{l}\text { Study } \\
\text { Quality }\end{array}$ & Intervention & Comparator & Outcome & $\begin{array}{c}\text { Results: } \\
\text { Intervention }\end{array}$ & Results: Comparator & P Value \\
\hline \multirow{2}{*}{$\begin{array}{l}\text { Yildirim, } \\
2008^{224}\end{array}$} & \multirow{2}{*}{$\begin{array}{l}\text { Valsalva } \\
\text { pushing } \\
\mathrm{N}=50\end{array}$} & \multirow{2}{*}{$\begin{array}{l}\text { Spontaneous } \\
\text { pushing } \\
\mathrm{N}=50\end{array}$} & $2^{\text {nd }}$ Degree & $6(12 \%)$ & $4(8 \%)$ & 0.167 \\
\hline & & & Cervical tear & $2(4 \%)$ & $0(0 \%)$ & 0.495 \\
\hline \multirow{3}{*}{$\begin{array}{l}\text { Bloom, } \\
2006^{72}\end{array}$} & \multirow{3}{*}{$\begin{array}{l}\text { Coached } \\
\text { pushing } \\
\mathrm{N}=163\end{array}$} & \multirow{3}{*}{$\begin{array}{l}\text { Uncoached } \\
\text { pushing } \\
\mathrm{N}=157\end{array}$} & Forceps & $6(4 \%)$ & $7(5 \%)$ & 0.725 \\
\hline & & & 3rd Degree & $12(7 \%)$ & $13(8 \%)$ & 0.73 \\
\hline & & & 4th Degree & $6(4 \%)$ & $2(1 \%)$ & 0.087 \\
\hline \multirow{3}{*}{$\begin{array}{l}\text { Koyucu, } \\
2017^{226}\end{array}$} & \multirow{9}{*}{$\begin{array}{l}\text { Spontaneous } \\
\text { pushing } \\
\mathrm{N}=40\end{array}$} & \multirow{9}{*}{$\begin{array}{l}\text { Valsalva } \\
\text { pushing } \\
\mathrm{N}=40\end{array}$} & Episiotomy & $34(85 \%)$ & $35(87.5 \%)$ & 0.745 \\
\hline & & & $1^{\text {st }}$ degree & $3(7.5 \%)$ & $2(5 \%)$ & 0.236 \\
\hline & & & $2^{\text {nd }}$ degree & $3(7.5 \%)$ & $3(7.5 \%)$ & - \\
\hline \multirow[t]{6}{*}{ Fair } & & & $\begin{array}{l}2^{\text {nd }} \text { degree } \\
\text { with } \\
\text { episiotomy }\end{array}$ & $24(60.0 \%)$ & $16(40.0 \%)$ & - \\
\hline & & & $\begin{array}{l}\text { Extended } \\
\text { episiotomy }\end{array}$ & $10(25.0 \%)$ & $18(45.0 \%)$ & - \\
\hline & & & $3^{\text {rd }}$ degree & -- & $1(2.5 \%)$ & - \\
\hline & & & $\begin{array}{l}\text { Cervical } \\
\text { lacerations }\end{array}$ & $1(2.5 \%)$ & $4(10.0 \%)$ & - \\
\hline & & & $\begin{array}{l}\text { Postpartum } \\
\text { haemaglobin }\end{array}$ & $\begin{array}{l}9.87 \\
(S D=1.05)\end{array}$ & $9.10(\mathrm{SD}=1.0)$ & 0.001 \\
\hline & & & $\begin{array}{l}\text { Rate of } \\
\text { decline in } \\
\text { Hb levels }\end{array}$ & $\begin{array}{l}0.60 \\
(S D=0.86)\end{array}$ & $1.06(\mathrm{SD}=1.18)$ & 0.05 \\
\hline
\end{tabular}

Abbreviation: -=not reported; $\mathrm{Hb}=$ hemoglobin

\section{Neonatal Outcomes for Coached Pushing Versus Uncoached Pushing}

While evidence is limited, there was no statistically significant difference between groups in the risk of fetal heart rate abnormalities, assisted respiration, acidemia, respiratory distress, sepsis evaluation, or stillbirth. ${ }^{72,224}$ One study showed a statistically significant difference in the level of cord blood $\mathrm{p}_{2}$ (28.29 [SD 11.76]) in the spontaneous pushing group vs 18.83 (SD 9.86) in the Valsalva group; $\mathrm{p}<0.001)$. Given the imprecise findings and the small numbers of events, the SOE was rated as insufficient.

\section{Strength of Evidence for Coached Pushing Versus Uncoached Pushing}

Table 80 summarizes the SOE for the findings described above. In general, SOE was judged insufficient for all outcomes, with the exception of the mode of delivery outcome. 
Table 80. Spontaneous pushing versus Valsalva pushing: Evidence profile in nulliparous women

\begin{tabular}{|c|c|c|c|c|}
\hline Category & Outcome & $\begin{array}{l}\text { Study Design } \\
\text { (Sample Size) }\end{array}$ & Conclusion & $\begin{array}{c}\text { SOE } \\
\text { (Rationale) }^{\mathrm{a}} \\
\end{array}$ \\
\hline \multirow[t]{2}{*}{$\begin{array}{l}\text { Intermediate } \\
\text { or Final } \\
\text { Outcomes }\end{array}$} & $\begin{array}{l}\text { Process Related } \\
\text { Outcomes - } \\
\text { Duration of } 2^{\text {nd }} \\
\text { Stage Labor }\end{array}$ & $\begin{array}{l}4 \mathrm{RCTS}^{72,224-226} \\
(605)\end{array}$ & $\begin{array}{l}\text { Inconclusive: SOE was } \\
\text { insufficient given inconsistent } \\
\text { and imprecise findings from } 4 \\
\text { studies. }\end{array}$ & $\begin{array}{l}\text { Insufficient (Medium } \\
\text { risk of bias, } \\
\text { inconsistent, imprecise) }\end{array}$ \\
\hline & $\begin{array}{l}\text { Process Related } \\
\text { Outcomes - Mode } \\
\text { of Delivery } \\
\text { (Cesarean } \\
\text { Delivery) } \\
\end{array}$ & $\begin{array}{l}3 \mathrm{RCT}^{72,225,226} \\
(508)\end{array}$ & $\begin{array}{l}\text { No difference: Three RCTs } \\
\text { reported no difference in the } \\
\text { rate of cesarean deliveries } \\
\text { between coached pushing and } \\
\text { uncoached pushing. }\end{array}$ & $\begin{array}{l}\text { Low (Medium risk of } \\
\text { bias, Imprecise) }\end{array}$ \\
\hline \multirow[t]{8}{*}{$\begin{array}{l}\text { Adverse } \\
\text { Events }\end{array}$} & $\begin{array}{l}\text { Maternal } \\
\text { Outcomes - } \\
\text { Trauma to the } \\
\text { Pelvic Floor; } \\
\text { postpartum } \\
\text { hemoglobin }\end{array}$ & $\begin{array}{l}3 \mathrm{RCTs}^{72,224,226} \\
(1,041)\end{array}$ & $\begin{array}{l}\text { Inconclusive: SOE was } \\
\text { insufficient given inconsistent } \\
\text { and imprecise findings from } 3 \\
\text { available studies about } \\
\text { heterogeneous outcomes. }\end{array}$ & $\begin{array}{l}\text { Insufficient (Medium } \\
\text { risk of bias, } \\
\text { inconsistent, imprecise) }\end{array}$ \\
\hline & $\begin{array}{l}\text { Neonatal } \\
\text { Outcomes - } \\
\text { Neonatal } \\
\text { Acidemia }\end{array}$ & $\begin{array}{l}1 \mathrm{RCT}^{72} \\
(320)\end{array}$ & $\begin{array}{l}\text { Inconclusive: SOE was } \\
\text { insufficient given imprecise } \\
\text { findings from } 1 \text { study. }\end{array}$ & $\begin{array}{l}\text { Insufficient (Imprecise, } \\
1 \text { study) }\end{array}$ \\
\hline & $\begin{array}{l}\text { Neonatal } \\
\text { Outcomes - } \\
\text { Respiratory } \\
\text { Distress }\end{array}$ & $\begin{array}{l}1 \mathrm{RCT}^{72} \\
(320)\end{array}$ & $\begin{array}{l}\text { Inconclusive: SOE was } \\
\text { insufficient given imprecise } \\
\text { findings from } 1 \text { study. }\end{array}$ & $\begin{array}{l}\text { Insufficient (Imprecise, } \\
1 \text { study) }\end{array}$ \\
\hline & $\begin{array}{l}\text { Neonatal } \\
\text { Outcomes - } \\
\text { Neonatal } \\
\text { Infection/Sepsis } \\
\end{array}$ & $\begin{array}{l}1 \mathrm{RCT}^{72} \\
(320)\end{array}$ & $\begin{array}{l}\text { Inconclusive: SOE was } \\
\text { insufficient given imprecise } \\
\text { findings from } 1 \text { study. }\end{array}$ & $\begin{array}{l}\text { Insufficient (Imprecise, } \\
1 \text { study) }\end{array}$ \\
\hline & $\begin{array}{l}\text { Neonatal } \\
\text { Outcomes - Long } \\
\text { Term Health }\end{array}$ & $\begin{array}{l}1 \mathrm{RCT}^{72} \\
(320)\end{array}$ & $\begin{array}{l}\text { Inconclusive: SOE was } \\
\text { insufficient given imprecise } \\
\text { findings from } 1 \text { study. }\end{array}$ & $\begin{array}{l}\text { Insufficient (Imprecise, } \\
1 \text { study) }\end{array}$ \\
\hline & $\begin{array}{l}\text { Process Related } \\
\text { Outcomes - Mode } \\
\text { of Delivery } \\
\text { (Instrumental } \\
\text { Delivery) } \\
\end{array}$ & $\begin{array}{l}1 \mathrm{RCT}^{72} \\
(320)\end{array}$ & $\begin{array}{l}\text { Inconclusive: SOE was } \\
\text { insufficient given imprecise } \\
\text { findings from } 1 \text { study. }\end{array}$ & $\begin{array}{l}\text { Insufficient (Imprecise, } \\
1 \text { study) }\end{array}$ \\
\hline & $\begin{array}{l}\text { Process Related } \\
\text { Outcomes - Mode } \\
\text { of Delivery } \\
\text { (Spontaneous) }\end{array}$ & $\begin{array}{l}1 \mathrm{RCT}^{72} \\
(320)\end{array}$ & $\begin{array}{l}\text { Inconclusive: SOE was } \\
\text { insufficient given imprecise } \\
\text { findings from } 1 \text { study. }\end{array}$ & $\begin{array}{l}\text { Insufficient (Imprecise, } \\
1 \text { study) }\end{array}$ \\
\hline & $\begin{array}{l}\text { Process Related } \\
\text { Outcomes - } \\
\text { Abnormal Fetal } \\
\text { Heart Tracing }\end{array}$ & $\begin{array}{l}1 \mathrm{RCT}^{224} \\
(100)\end{array}$ & $\begin{array}{l}\text { Inconclusive: SOE was } \\
\text { insufficient given imprecise } \\
\text { findings from } 1 \text { study. }\end{array}$ & $\begin{array}{l}\text { Insufficient (Medium } \\
\text { risk of bias, imprecise, } \\
1 \text { study) }\end{array}$ \\
\hline
\end{tabular}

${ }^{a}$ Criteria for downgrading SOE are described as Rationale; when these criteria are insufficient for understanding the final SOE, additional explanation is provided.

Abbreviations: RCT=randomized controlled trial; $\mathrm{SOE}=$ strength of evidence

\section{Immediate Versus Delayed Pushing Among Nulliparous Women}

Results for this intervention were reported for nulliparous women in one good-quality study. ${ }^{227}$ No relevant SR/MAs were identified.

\section{Results in Nulliparous Women}

One good-quality RCT compared pushing techniques (immediate versus delayed) among nulliparous women receiving neuraxial analgesia. 


\section{Duration of Labor and Cesarean Delivery Rates for Immediate Versus Delayed Pushing}

One large good-quality $\mathrm{RCT}^{227}$ demonstrated a statistically significant shorter mean duration of the second stage of labor in women randomized to immediate pushing compared to delayed pushing (102.4 vs 134.2 minutes, respectively; mean difference, -31.8 minutes [95\% CI, -36.7 to $-26.9], \mathrm{P}<.001)$. The cesarean delivery rate for women after randomization were not statistically ( $\mathrm{p}=0.55)$ different between immediate $(7.8 \%)$ and delayed $(7.6 \%)$ pushing groups. SOE was rated as low for both outcomes given findings from one study.

\section{Maternal Outcomes for Immediate Versus Delayed Pushing}

A statistically significant increase was found in the incidence of maternal adverse outcomes including postpartum hemorrhage, chorioamnionitis and third degree perineal laceration (low SOE) ${ }^{227}$ Postpartum hemorrhage was significantly greater in the delayed vs the immediate pushing group ( $4.0 \%$ versus $2.3 \%$, respectively; $\mathrm{p}=0.03$ ). Chorioamnionitis was significantly greater in the delayed vs the immediate pushing group (6.7\% versus $9.1 \%$, respectively; $\mathrm{p}=0.005$ ). In a prespecified exploratory analysis third degree perineal laceration was also significantly greater in the immediate versus delayed pushing group (6.7\% versus $9.1 \%$, respectively; $\mathrm{p}=0.005$ ). Vacuum assisted, forceps assisted delivery, endometritis, and perineal laceration of $\geq$ second degree were not significantly different between groups.

\section{Neonatal Outcomes for Immediate Versus Delayed Pushing}

While evidence is limited to one study, ${ }^{227}$ there was no statistically significant difference between groups in the risk of neonatal death, major birth injury, respiratory distress, transient tachypnea, hypoxic-ischemic encephalopathy, hypoglycemia, hypothermic treatment, shoulder dystocia, fetal sex, fetal weight or NICU admission. In prespecified exploratory analyses, a statistically significant difference in acidemia (umbilical cord arterial $\mathrm{pH}<7.1$ ) between immediate and delayed pushing groups $(0.8 \%$ versus $1.2 \%$, respectively; $\mathrm{p}=0.01)$. The proportion of suspected sepsis was significantly ( $\mathrm{p}=0.003$ ) higher in the delayed (4.4\%) versus immediate pushing group (3.2\%). SOE was rated as low for these neonatal outcomes.

\section{Strength of Evidence for Immediate Versus Delayed Pushing}

Table 81 summarizes the SOE for the findings described above for immediate versus delayed pushing. In general, SOE was judged low for all outcomes, given findings from just one study.

Table 81. Immediate versus delayed pushing: Evidence profile in nulliparous women

\begin{tabular}{|l|l|l|l|l|}
\hline \multicolumn{1}{|c|}{ Category } & \multicolumn{1}{|c|}{ Outcome } & $\begin{array}{l}\text { Study Design } \\
\text { (Sample Size) }\end{array}$ & \multicolumn{1}{c|}{ Conclusion } & \multicolumn{1}{c|}{$\begin{array}{c}\text { SOE } \\
\text { (Rationale) }^{\mathbf{a}}\end{array}$} \\
\hline $\begin{array}{l}\text { Intermediate } \\
\text { or Final } \\
\text { Outcomes }\end{array}$ & $\begin{array}{l}\text { Process Related } \\
\text { Outcomes - } \\
\text { Duration of Labor } \\
\text { (from intervention } \\
\text { to delivery) }\end{array}$ & $\begin{array}{l}1 \mathrm{RCT} 227 \\
(2,404)\end{array}$ & $\begin{array}{l}\text { Improvement with immediate } \\
\text { pushing: shorter mean duration } \\
\text { of the second stage of labor in } \\
\text { women randomized to } \\
\text { immediate pushing compared to } \\
\text { delayed pushing }\end{array}$ & Low (one study) \\
\cline { 2 - 5 } & $\begin{array}{l}\text { Process Related } \\
\text { Outcomes - Mode } \\
\text { of Delivery } \\
\text { (Cesarean } \\
\text { Delivery) }\end{array}$ & $\begin{array}{l}1 \mathrm{RCT}^{227} \\
(2,404)\end{array}$ & $\begin{array}{l}\text { No difference: No difference in } \\
\text { cesarean delivery rate between } \\
\text { women randomized to } \\
\text { immediate pushing compared to } \\
\text { delayed pushing. }\end{array}$ & Low (one study) \\
\hline
\end{tabular}




\begin{tabular}{|c|c|c|c|c|}
\hline Category & Outcome & $\begin{array}{l}\text { Study Design } \\
\text { (Sample Size) }\end{array}$ & Conclusion & $\begin{array}{c}\text { SOE } \\
\text { (Rationale) }^{a}\end{array}$ \\
\hline \multirow[t]{6}{*}{$\begin{array}{l}\text { Adverse } \\
\text { Events }\end{array}$} & $\begin{array}{l}\text { Maternal } \\
\text { Outcomes - } \\
\text { Postpartum } \\
\text { Hemorrhage }\end{array}$ & $\begin{array}{l}1 \mathrm{RCT}^{227} \\
(2,404)\end{array}$ & $\begin{array}{l}\text { Improvement with immediate } \\
\text { pushing: Postpartum } \\
\text { hemorrhage was significantly } \\
\text { greater in the delayed vs the } \\
\text { immediate pushing group }\end{array}$ & Low (one study) \\
\hline & $\begin{array}{l}\text { Maternal } \\
\text { Outcomes - } \\
\text { Chorioamnionitis }\end{array}$ & $\begin{array}{l}1 \mathrm{RCT}^{227} \\
(2,404)\end{array}$ & $\begin{array}{l}\text { Improvement with immediate } \\
\text { pushing: Chorioamnionitis was } \\
\text { significantly greater in the } \\
\text { delayed vs the immediate } \\
\text { pushing group }\end{array}$ & Low (one study) \\
\hline & $\begin{array}{l}\text { Process Related } \\
\text { Outcomes - Mode } \\
\text { of Delivery } \\
\text { (Instrumental } \\
\text { Delivery) } \\
\end{array}$ & $\begin{array}{l}1 \mathrm{RCT}^{227} \\
(2,404)\end{array}$ & $\begin{array}{l}\text { No difference: No different in } \\
\text { mode of delivery with delayed } \\
\text { vs immediate pushing }\end{array}$ & Low (one study) \\
\hline & $\begin{array}{l}\text { Neonatal } \\
\text { Outcomes - } \\
\text { Neonatal Death, } \\
\text { major birth injury, } \\
\text { respiratory } \\
\text { distress transient } \\
\text { tachypnea }\end{array}$ & $\begin{array}{l}1 \mathrm{RCT}^{227} \\
(2,404)\end{array}$ & $\begin{array}{l}\text { No difference: No different in } \\
\text { neonatal death with delayed vs } \\
\text { immediate pushing }\end{array}$ & Low (one study) \\
\hline & $\begin{array}{l}\text { Neonatal } \\
\text { Outcomes - } \\
\text { Neonatal } \\
\text { Acidemia }\end{array}$ & $\begin{array}{l}1 \mathrm{RCT}^{227} \\
(2,404)\end{array}$ & $\begin{array}{l}\text { Improvement with immediate } \\
\text { pushing: In prespecified } \\
\text { exploratory analyses, a lower } \\
\text { rate of acidemia with immediate } \\
\text { and delayed pushing groups }\end{array}$ & Low (one study) \\
\hline & $\begin{array}{l}\text { Neonatal } \\
\text { Outcomes - } \\
\text { Neonatal } \\
\text { Infection/Sepsis }\end{array}$ & $\begin{array}{l}1 \mathrm{RCT}^{227} \\
(2,404)\end{array}$ & $\begin{array}{l}\text { Improvement with immediate } \\
\text { pushing: The proportion of } \\
\text { suspected sepsis was higher in } \\
\text { the delayed versus immediate } \\
\text { pushing group }\end{array}$ & Low (one study) \\
\hline
\end{tabular}

${ }^{a}$ Criteria for downgrading SOE are described as Rationale; when these criteria are insufficient for understanding the final SOE, additional explanation is provided.

Abbreviations: RCT=randomized controlled trial; SOE=strength of evidence 


\section{Discussion}

In this comparative effectiveness review, we reviewed 158 studies described in 1167 publications relevant to criteria used to define protracted or arrested labor (Key Question [KQ 1]); the benefits and harms of amniotomy (KQ 2), supportive care measures (KQ 3), and epidural analgesia (KQ 4) in spontaneous labor, particularly in regards to increasing or decreasing the risk of a diagnosis of prolonged labor; the benefits and harms of cervical examination frequency (KQ 5) and intrauterine pressure catheters (KQ 6) in diagnosis and management of abnormal labor; the benefits and harms of high- and low-dose (including nipple stimulation) oxytocin augmentation in women diagnosed with abnormal labor progression (KQ 7); the benefits and harms of electronic fetal monitoring versus intermittent auscultation in women undergoing oxytocin augmentation for prolonged labor (KQ 8); and the benefit of delayed or Valsalva pushing during the second stage of labor (KQ 9).

\section{Key Findings and Strength of Evidence}

Our review included 167 articles (158 unique studies). This included 25 studies relevant to defining abnormal labor, 12 studies relevant to amniotomy, 75 studies relevant to supportive care measures, 25 studies relevant to epidural analgesia, 1 study relevant to cervical examination, 1 study relevant to intrauterine pressure catheters, 17 studies relevant to high-dose versus low-dose oxytocin protocols, 1 studies relevant to fetal monitoring strategies, and 7 studies relevant to timing of pushing in the second stage. Evidence suggests that the duration and pattern of "normal" labor progress based on modern management is quite different than historical data, and that labor progress is different in nulliparous compared to parous women. Use of partograms did not impact important maternal or neonatal outcomes, although the applicability of this evidence to modern U.S. settings is limited. Routine amniotomy decreases the total duration of labor in nulliparous women without affecting other outcomes (moderate strength of evidence [SOE]), while routine amniotomy with oxytocin augmentation as needed decreased duration of labor without increasing cesarean delivery (high SOE). Although supportive care therapies are often seen as benefiting parental satisfaction with the birthing process, these outcomes were rarely assessed in clinical trials meeting our inclusion criteria, although an existing systematic review of 11 studies did find that women receiving continuous emotional support were less likely to rate their birth experience negatively. Of the different types of supportive therapies, only emotional support interventions showed reductions in cesarean (low SOE for doula support, moderate SOE for continuous emotional support) and instrumental deliveries (moderate SOE). For women choosing analgesia, type (epidural vs. combined spinal epidural, or epidural vs. patientcontrolled intravenous analgesia) or timing during labor did not affect cesarean delivery rates (moderate SOE).

\section{Findings in Relationship to What Is Already Known}

In general, the findings of the review were consistent with current understanding of the overall strength of evidence for different strategies for management of labor. Estimates of the rate of progress of "normal" labor derived from contemporary data in the United States are quite different from the classic curves described by Friedman. ${ }^{19}$ These differences may be attributable to a number of factors, including secular trends in patient characteristics (e.g., increasing age at first birth and increasing rates of obesity) and increasing use of interventions such as induction of labor or the use of oxytocin to augment labor. More recent data suggest that the transition to 
active labor occurs later in the course of labor than originally described, which is reflected in more recent guidelines suggesting a higher threshold for observing labor duration before intervention with cesarean delivery.

The definition of "normal" labor is fundamental in evaluating the evidence related to managing "abnormal" labor progression, analogous to the threshold value used to define "normal" for a continuous laboratory value. Ideally, the definition would be derived based on data from a large group of women who were followed without intervention and had optimal maternal and neonatal outcomes, but there are obvious practical and ethical barriers to this. , The sensitivity and specificity of the test will vary depending on the choice of threshold, but so will the estimates of the effectiveness of interventions based on that threshold. Comparing results across studies requires a common definition for such "normal" labor and permeates our review.

There is evidence that partograms are useful in low-resource settings, but they have not been shown to improve labor outcomes in high-resource settings. This may be due in part to differences in the data sources for generating labor curves and thresholds. Feasibility and ethical challenges with obtaining a large, contemporary sample of women laboring with minimal to no intervention limits our fundamental scientific understanding of normal labor, normal labor progress, and when durations of labor lead to worse maternal/child outcomes.

In general, our findings that "normal" labor in modern settings is generally longer than earlier guidance are consistent with current guidelines ${ }^{3}$, which are largely informed by the Consortium on Safe Labor (CSL) data and encourage allowing longer durations for both first and second stages of labor before intervening with cesarean delivery. However, as noted, over half of women in the "normal" group received augmentation in the CSL data, and the data are not informative about optimal timing of augmentation. Routine amniotomy is not specifically recommended, although the recommendations note that amniotomy may be helpful in the transition from latent to active labor. Based on the same Cochrane review finding, improved satisfaction and lower cesarean and operative vaginal delivery rates, emotional support is recommended. The potential effect of epidural analgesia on duration of labor is noted as a potential consideration in allowing longer durations before intervention, but there are no recommendations about specific techniques. Cervical exam frequency, intrauterine pressure monitoring, oxytocin dosing protocols, methods for routine fetal monitoring, or timing of pushing in the second labor are not discussed, consistent with the relative paucity of evidence.

The impact of regional anesthesia on the length of the first stage of labor is uncertain, leading to conflicting recommendations from different professional societies. Our findings do not provide greater clarity.

\section{Applicability}

Table 82 summarizes the applicability scores across KQs. Applicability ratings provide information as to whether the population, interventions, comparators, outcomes, or settings evaluated in the included studies are applicable to clinical practice and specific KQs of interest. Note that applicability ratings were performed for the 124 primary included studies and not for the included systematic reviews. 
Table 82. Potential issues with applicability of included studies ${ }^{a}$

\begin{tabular}{|c|c|c|c|c|c|c|c|c|c|c|c|}
\hline & Issues & $\begin{array}{l}K Q 1 \\
N=19\end{array}$ & $\begin{array}{c}K Q 2 \\
N=9\end{array}$ & $\begin{array}{l}\mathrm{KQ} 3 \\
\mathrm{~N}=61\end{array}$ & $\begin{array}{l}K Q 4 \\
N=22\end{array}$ & $\begin{array}{c}K Q 5 \\
N=0\end{array}$ & $\begin{array}{c}\mathrm{KQ} 6 \\
\mathrm{~N}=0\end{array}$ & $\begin{array}{l}\mathrm{KQ} 7 \\
\mathrm{~N}=11\end{array}$ & $\begin{array}{c}\text { KQ } 8 \\
N=0\end{array}$ & $\begin{array}{c}\mathrm{KQ} 9 \\
\mathrm{~N}=5\end{array}$ & $\begin{array}{c}\text { Total } \\
\mathrm{N}=122\end{array}$ \\
\hline \multirow[t]{2}{*}{ Population } & $\begin{array}{l}\text { Study population } \\
\text { demographics } \\
\text { not } \\
\text { representative of } \\
\text { intended } \\
\text { population }\end{array}$ & 3 & 2 & 17 & 3 & 0 & 0 & 1 & 0 & 0 & 23 \\
\hline & $\begin{array}{l}\text { Narrow or } \\
\text { unrepresentative } \\
\text { severity/ stage/ } \\
\text { comorbidity }\end{array}$ & 1 & 0 & 0 & 0 & 0 & 0 & 3 & 0 & 0 & 4 \\
\hline \multirow[t]{2}{*}{ Intervention } & $\begin{array}{l}\text { Intervention } \\
\text { details not } \\
\text { representative of } \\
\text { current practice }\end{array}$ & 0 & 1 & 4 & 1 & 0 & 0 & 3 & 0 & 0 & 9 \\
\hline & $\begin{array}{l}\text { Change in } \\
\text { standard of care }\end{array}$ & 0 & 0 & 1 & 0 & 0 & 0 & 0 & 0 & 0 & 0 \\
\hline Comparator & $\begin{array}{l}\text { Comparator not } \\
\text { representative of } \\
\text { current practice }\end{array}$ & 0 & 0 & 12 & 3 & 0 & 0 & 0 & 0 & 0 & 13 \\
\hline Outcomes & $\begin{array}{l}\text { Timing of } \\
\text { outcome } \\
\text { assessment }\end{array}$ & 0 & 0 & 0 & 0 & 0 & 0 & 0 & 0 & 0 & 0 \\
\hline \multirow[t]{2}{*}{ Setting } & $\begin{array}{l}\text { Standards or } \\
\text { access to care } \\
\text { vary from US } \\
\text { setting }\end{array}$ & 3 & 1 & 46 & 5 & 0 & 0 & 6 & 0 & 1 & 59 \\
\hline & $\begin{array}{l}\text { Specialty } \\
\text { population or } \\
\text { level of care }\end{array}$ & 3 & 0 & 0 & 0 & 0 & 0 & 0 & 0 & 0 & 3 \\
\hline
\end{tabular}

${ }^{a}$ Numbers in cells represent the number of included studies that were identified as having potential issues related to the specific item. Columns represent numbers for each Key Question and then for all included studies.

Two broad issues relate to the overall applicability of the available evidence to clinical practice in the United States - one geographic and one temporal. Many of the randomized controlled trials (RCTs) meeting our criteria were performed outside of the United States. Aside from issues related to differences in study oversight or reporting, the populations of these studies may differ from U.S. women in labor in terms of health systems, patient preferences and expectations, provider perceptions of risk, availability of resources, and so on. This is particularly relevant to studies that directly compared management strategies based on explicit criteria for defining abnormal labor and studies that attempted to define a "normal" duration of labor (KQ 1). Particularly for studies where the primary outcome is cesarean delivery, factors that affect the threshold for performing cesarean—both the explicit "cutpoint" for duration of labor used and broader factors ranging from the relative safety of surgery versus vaginal delivery in low resource settings to cultural expectations to legal concerns - may affect the estimates of effectiveness of an intervention.

A number of studies included the use of a partogram—a graphical comparison of a woman's labor progress compared to a standard — with thresholds for intervention clearly identified. Strength of evidence was judged to be low, with one major factor being a lack of U.S.-based studies. In low-resource settings, the use of a partogram was associated with lower overall cesarean delivery rates compared with labor managed without a partogram, and earlier 
interventions were associated with lower cesarean delivery rates. In high-resource settings, the use of a partogram that included an assessment of latent phase duration, and which had a threshold for action at 3 hours compared to 4 hours, had higher cesarean delivery rates; but otherwise the use of a partogram compared with no partogram, or other time intervals for action lines, did not affect mode of delivery, duration of labor, indication for cesarean delivery, or complications including postpartum hemorrhage, maternal infection, or neonatal acidemia. Outside of U.S.-based settings, populations, health systems, and management of both prenatal and intrapartum care are quite different-and the impact of these differences on both the relative effectiveness and the absolute difference in outcomes is likely substantial.

Even more fundamentally, use of a tool such as a partogram, or specific interventions such as amniotomy, requires evidence on "normal” labor in order to define requires evidence on "normal" labor in order to define appropriate thresholds for action. The studies we reviewed that attempted to define "normal" labor differed based on parity, the time period in which the studies were conducted, and, among nulliparous women, maternal age. Evidence from the CSL, representing the most recent available large-scale population data ${ }^{21}$ suggest a longer duration of first stage of labor compared to earlier studies, including the National Collaborative Perinatal Project (NCPP). ${ }^{22}$ However, the most striking difference between these two studies was the proportion of women who received oxytocin augmentation (14.6\% in the NCPP cohort from 1959 to 1966 compared with 45.9\% in the CSL cohort from 2002 to 2008).

The CSL population that was used to generate new labor curves consists of women who had spontaneous onset of labor and a vaginal delivery, and thus the labor curves presented provide an estimate of "normal" labor that does not end in a cesarean delivery. Since such a large proportion of women received augmentation, these data do not provide insight into the range of rates of labor progression among women who do not receive augmentation, and cannot provide insight into the relative harms and benefits of augmentation, or the most appropriate thresholds for the timing or dosing of augmentation. The association between a longer duration of the first stage of labor and the greater use of oxytocin among women with a vaginal delivery is consistent with the possibility that greater use of oxytocin may avoid cesarean delivery, but not with observed secular trends in cesarean delivery rates. One would expect that any changes in the threshold for cesarean delivery caused by greater "patience” (allowing a longer duration) and/or "medical management” (greater use of oxytocin) would lead to decreases in cesarean delivery rates.

In summary, evidence suggests that the specific criteria used to define "normal” labor, or a specific threshold for intervention, may affect cesarean delivery rates but not other maternal or neonatal outcomes in some settings. Yet there is no available evidence for the United States. Among women in the United States with spontaneous onset of labor and vaginal delivery, labor progression is slower for women having their first baby compared to women with prior deliveries, but the high proportion of women receiving oxytocin augmentation prevents drawing any inferences about the "normal" labor curve in women with spontaneous onset of labor, no interventions to augment labor, and no adverse maternal or neonatal outcomes.

Many of these issues may also contribute to heterogeneity when trying to combine studies for the purposes of meta-analysis.

\section{Implications for Clinical and Policy Decision Making}

There is widespread consensus that the current cesarean delivery rate in the United States is too high, and national organizations suggest implementation of strategies to safely decrease the cesarean delivery rate. Cesarean delivery is performed for a range of indications, and any 
strategy to reduce the overall rate needs to be multifaceted and based on achieving an optimal rate (balancing both maternal and neonatal outcomes) for each indication-although the optimal cesarean delivery rate that balances maternal and neonatal outcomes is not known. Because abnormal labor is a common indication for cesarean delivery (particularly for first cesareans), strategies for reducing the rate of cesarean for prolonged labor have the potential to reduce the overall rate by decreasing both primary and repeat cesareans.

Data on the "normal" range of labor duration from the CSL are useful for developing guidance for when (or whether) to consider intervention with cesarean section. However, because (a) a very high proportion of women received oxytocin augmentation and (b) separate curves are not reported for those with and without augmentation, this evidence is not helpful in developing strategies for when to initially intervene with oxytocin or other labor stimulus.

Given the evidence that partograms have been useful in other settings, and the potential benefit of formal decision tools seen in other conditions, there may be potential for incorporating more direct decision aids to help guide when, or when not, to intervene in otherwise uncomplicated labor based on the temporal progress of labor. Such tools need to incorporate both clinical evidence and patient preferences for choices about the process of labor.

\section{Limitations of the Systematic Review Process}

Several aspects of the review process may have affected the results. First, there were constraints in our search strategy, developed in consultation with the Key Informants and Technical Expert Panel. We limited the search to papers published after January 2005. This meant that studies completed prior to the cutoff date, which otherwise might have met inclusion criteria, were excluded. While we believe that the majority of these studies were included in the systematic reviews we used to supplement each KQ, it is possible that potentially relevant articles were missed. Given broad changes in clinical practice over the past decade, the impact of missing earlier studies on conclusions about comparative effectiveness of currently used treatment alternatives is unclear.

We also did not include studies published in languages other than English, primarily due to resource limitations. Given the high volume of literature available in English-language publications, the focus of our review on applicability to populations in the United States, and the scope of our current KQs, non-English articles were excluded.

\section{Research Recommendations}

We identified several areas of needed future research:

- It would be extremely useful to have separate labor curves derived from contemporary U.S. data for women with spontaneous onset of labor, no augmentation with oxytocin or other pharmacologic agents, and vaginal delivery of healthy baby, stratified by parity, as well as for women with augmented labor. Such labor curves would provide a better understanding of the modern natural course of labor and may provide better information on when to initiate agents to augment labor and when to proceed with cesarean delivery. Such studies could also potentially include laboring women with cesareans for non-labor diagnoses, although the threshold for intervention might be influences by perceptions of the effect of labor duration on the condition leading to the intervention (e.g., women with pre-eclampsia). 
- Evaluation of specific labor management strategies (including the use of partograms) derived from contemporary data sources such as the CSL should be a priority. This evaluation should include comparison of different methods for integrating decision support into existing technologies, such as methods and timing of augmenting labor (oxytocin administration, artificial rupture of the membranes), fetal monitoring, tools to monitor uterine contraction strength and frequency, and the impact of supportive therapies (massage, fluids, nutrition, positioning) on mode of delivery. This evaluation would help generate best practice recommendations for safe reduction of the primary cesarean delivery rate while balancing maternal and neonatal outcomes. Given the potential difficulties in recruiting patients into randomized trials, consideration should be given to both high-quality observational studies as well as research designs that combine randomization with allowance for patient preferences. ${ }^{230,231}$

- Given the importance of the labor process to patient preferences and their birthing experience and the lack of evidence about the impact of available interventions on these preferences, the development of tools for estimating patient preferences for both the process and maternal and neonatal outcomes of labor should be a priority. Discrete choice experiments would be one method appropriate for estimating preferences for these complex tradeoffs.

- Comparison of patient preferences of nulliparous to parous women are of great interest as preferences may vary based on prior labor experiences and expectations.

- Studies of these tools/methods should also explore the complexity of decision making that needs to incorporate both maternal and paternal preferences, as well as preferences where parents are acting as surrogates for infants. For example, in a study which elicited preferences for an adverse neonatal outcome with long-term health implications for the purposes of economic analysis, each parent would have preferences that reflect the impact of the condition on their roles as parents, and could provide a preference acting as a surrogate for the child, but the child might have quite different preferences. ${ }^{232-234}$ Validated measures should be incorporated into clinical trials and prospective studies as specific outcomes.

- Encouragement of use of core outcome sets, such as those developed as part of the CROWN (Core Outcomes in Women's Health) initiative. ${ }^{235}$

\section{Conclusions}

Dystocia is a common indication for cesarean delivery. Recent data demonstrate that the normal progress of labor with current practice is quite different from curves originally described, although there is still uncertainty about the duration of "normal" labor in the absence of augmentation. Amniotomy and oxytocin decrease duration of labor without increasing cesarean delivery. Emotional support reduces operative delivery rates and patient satisfaction. Further work is needed to identify strategies for management of labor that optimize maternal and neonatal outcomes and patient preferences while minimizing cesarean delivery rates. 


\section{References}

1. Monte LM, Ellis RR. Fertility of women in the United States: June 2012. U.S. Census Bureau; July 2014. Available at: http://www.census.gov/content/dam/Census/ library/publications/2014/demo/p20575.pdf. Accessed August 7, 2018.

2. Neilson J, Lavender T, Quenby S, et al. Obstructed labour: reducing maternal death and disability during pregnancy. Br Med Bull. 2003 December 1, 2003;67(1):191204. doi: 10.1093/bmb/ldg018. PMID: 14711764.

3. American College of Obstetricians \& Gynecologists, Society for Maternal-Fetal Medicine. Obstetric care consensus no. 1: safe prevention of the primary cesarean delivery. Obstet Gynecol. 2014 Mar;123(3):693-711. doi: 10.1097/01.AOG.0000444441.04111.1d. PMID: 24553167.

4. Sheiner E, Levy A, Feinstein U, et al. Risk factors and outcome of failure to progress during the first stage of labor: a populationbased study. Acta Obstet Gynecol Scand. 2002 Mar;81(3):222-6. PMID: 11966478.

5. Rowe-Murray HJ, Fisher JR. Baby friendly hospital practices: cesarean section is a persistent barrier to early initiation of breastfeeding. Birth. 2002 Jun;29(2):124-31. PMID: 12000413.

6. Clark EA, Silver RM. Long-term maternal morbidity associated with repeat cesarean delivery. Am J Obstet Gynecol. 2011 Dec;205(6 Suppl):S2-10. doi: 10.1016/j.ajog.2011.09.028. PMID: 22114995.

7. Hartmann KE, Andrews JC, Jerome RN, et al. Strategies To Reduce Cesarean Birth in Low-Risk Women. Comparative Effectiveness Review No. 80. (Prepared by the Vanderbilt Evidence-based Practice Center under Contract No. 290-2007-10065I.) AHRQ Publication No. 12(13)-EHC128EF. Rockville, MD: Agency for Healthcare Research and Quality. October 2012. Available at: https://effectivehealthcare.ahrq.gov/topics/ce sarean-birth-2010/research. Accessed August 7, 2018. PMID: 23236638.
8. Clark SL, Garite TJ, Hamilton EF, et al. "Doing something" about the cesarean delivery rate. Am J Obstet Gynecol. 2018 Sep;219(3):267-71. doi: 10.1016/j.ajog.2018.04.044. PMID: 29733840.

9. Betran AP, Torloni MR, Zhang JJ, et al. WHO Statement on Caesarean Section Rates. BJOG. 2016 Apr;123(5):667-70. doi: 10.1111/1471-0528.13526. PMID: 26681211.

10. Birthtools.org. Tools for optimizing the outcomes of labor safely. Available at: http://birthtools.org/Reducing-PrimaryCesareans-NEW. Accessed June 28, 2019.

11. Barber EL, Lundsberg LS, Belanger K, et al. Indications contributing to the increasing cesarean delivery rate. Obstet Gynecol. 2011 Jul;118(1):29-38. doi: 10.1097/AOG.0b013e31821e5f65. PMID: 21646928.

12. Kozhimannil KB, Law MR, Virnig BA. Cesarean delivery rates vary tenfold among US hospitals; reducing variation may address quality and cost issues. Health Aff (Millwood). 2013 March 1, 2013;32(3):52735. doi: 10.1377/hlthaff.2012.1030. PMID: 23459732.

13. Hodnett Ellen D, Downe S, Walsh D. Alternative versus conventional institutional settings for birth. Cochrane Database Syst Rev. 2012;8:CD000012. doi: 10.1002/14651858.CD000012.pub4. PMID: 22895914.

14. Olsen O, Clausen JA. Planned hospital birth versus planned home birth. Cochrane Database Syst Rev. 2012;9:CD000352. doi: 10.1002/14651858.CD000352.pub2. PMID: 22972043.

15. Sharma PS, Eden KB, Guise JM, et al. Subjective risk vs. objective risk can lead to different post-cesarean birth decisions based on multiattribute modeling. J Clin Epidemiol. 2011 Jan;64(1):67-78. doi: 10.1016/j.jclinepi.2010.02.011. PMID: 20558035. 
16. Lyerly AD. A Good Birth: Finding the Positive and the Profound in Your Childbirth Experience. New York: Avery; 2014.

17. Spong CY, Berghella V, Wenstrom KD, et al. Preventing the first cesarean delivery: summary of a joint Eunice Kennedy Shriver National Institute of Child Health and Human Development, Society for MaternalFetal Medicine, and American College of Obstetricians and Gynecologists Workshop. Obstet Gynecol. 2012 Nov;120(5):1181-93. PMID: 23090537.

18. Friedman E. The graphic analysis of labor. Am J Obstet Gynecol. 1954 Dec;68(6):1568-75. PMID: 13207246.

19. Friedman EA. Primigravid labor; a graphicostatistical analysis. Obstet Gynecol. 1955 Dec;6(6):567-89. PMID: 13272981.

20. Harper LM, Caughey AB, Roehl KA, et al. Defining an abnormal first stage of labor based on maternal and neonatal outcomes. Am J Obstet Gynecol. 2014 Jun;210(6):536.e1-7. doi: 10.1016/j.ajog.2013.12.027. PMID: 24361789.

21. Zhang J, Landy HJ, Branch DW, et al. Contemporary patterns of spontaneous labor with normal neonatal outcomes. Obstet Gynecol. 2010 Dec;116(6):1281-7. doi: 10.1097/AOG.0b013e3181fdef6e. PMID: 21099592.

22. Zhang J, Troendle J, Mikolajczyk R, et al. The natural history of the normal first stage of labor. Obstet Gynecol. 2010 Apr;115(4):705-10. doi: 10.1097/AOG.0b013e3181d55925. PMID: 20308828.

23. Cohen WR, Friedman EA. Misguided guidelines for managing labor. Am J Obstet Gynecol. 2015 Apr 17doi: 10.1016/j.ajog.2015.04.012. PMID: 25891996.

24. Cohen WR, Friedman EA. Perils of the new labor management guidelines. Am J Obstet Gynecol. 2015 Apr;212(4):420-7. doi: 10.1016/j.ajog.2014.09.008. PMID: 25218127.
25. Zhang J, Troendle J, Grantz KL, et al. Statistical aspects of modeling the labor curve. Am J Obstet Gynecol. 2015 Apr 16doi: 10.1016/j.ajog.2015.04.014. PMID: 25891997.

26. Agency for Healthcare Research and Quality. Methods Guide for Effectiveness and Comparative Effectiveness Reviews. AHRQ Publication No. 10(14)-EHC063-EF. Rockville, MD: Agency for Healthcare Research and Quality. January 2014. Available at: https://effectivehealthcare.ahrq.gov/topics/ce r-methods-guide/overview. Accessed August 7, 2018.

27. Moher D, Liberati A, Tetzlaff J, et al. Preferred reporting items for systematic reviews and meta-analyses: the PRISMA statement. PLoS Med. 2009 Jul 21;6(7):e1000097. doi: http://dx.doi.org/10.1371/journal.pmed.1000 097. PMID: 19621072.

28. Agency for Healthcare Research and Quality (AHRQ). Evidence-based Practice Center Systematic Review Protocol. Project Title: Labor Dystocia. Available at: https://effectivehealthcare.ahrq.gov/searchfor-guides-reviews-andreports/?pageaction=displayproduct\&produc tid=2172. Accessed August 7, 2018.

29. Mollart LJ, Adam J, Foureur M. Impact of acupressure on onset of labour and labour duration: A systematic review. Women Birth. 2015 Sep;28(3):199-206. doi: 10.1016/j.wombi.2015.03.007. PMID: 25911499.

30. Sng BL, Leong WL, Zeng Y, et al. Early versus late initiation of epidural analgesia for labour. Cochrane Database Syst Rev. 2014;10:Cd007238. doi: 10.1002/14651858.CD007238.pub2. PMID: 25300169.

31. East CE, Begg L, Colditz PB, et al. Fetal pulse oximetry for fetal assessment in labour. Cochrane Database Syst Rev. 2014;10:Cd004075. doi: 10.1002/14651858.CD004075.pub4. PMID: 25287809. 
32. Gizzo S, Noventa M, Fagherazzi S, et al. Update on best available options in obstetrics anaesthesia: perinatal outcomes, side effects and maternal satisfaction. Fifteen years systematic literature review. Arch Gynecol Obstet. 2014 Jul;290(1):2134. doi: 10.1007/s00404-014-3212-X. PMID: 24659334.

33. Liu ZQ, Chen XB, Li HB, et al. A comparison of remifentanil parturientcontrolled intravenous analgesia with epidural analgesia: a meta-analysis of randomized controlled trials. Anesth Analg. 2014 Mar;118(3):598-603. doi: 10.1213/ane.0000000000000077. PMID: 24557106.

34. Lawrence A, Lewis L, Hofmeyr GJ, et al. Maternal positions and mobility during first stage labour. Cochrane Database Syst Rev. 2013;10:Cd003934. doi: 10.1002/14651858.CD003934.pub4. PMID: 24105444.

35. Brown HC, Paranjothy S, Dowswell T, et al. Package of care for active management in labour for reducing caesarean section rates in low-risk women. Cochrane Database Syst Rev. 2013;9:Cd004907. doi: 10.1002/14651858.CD004907.pub3. PMID: 24043476.

36. Singata M, Tranmer J, Gyte GM. Restricting oral fluid and food intake during labour. Cochrane Database Syst Rev. 2013;8:Cd003930. doi: 10.1002/14651858.CD003930.pub3. PMID: 23966209.

37. Bakker JJ, Janssen PF, van Halem K, et al. Internal versus external tocodynamometry during induced or augmented labour. Cochrane Database Syst Rev. 2013;8:Cd006947. doi: 10.1002/14651858.CD006947.pub3. PMID: 23913521.

38. Dawood F, Dowswell T, Quenby S. Intravenous fluids for reducing the duration of labour in low risk nulliparous women. Cochrane Database Syst Rev. 2013;6:Cd007715. doi: 10.1002/14651858.CD007715.pub2. PMID: 23780639 .
39. Simmons SW, Taghizadeh N, Dennis AT, et al. Combined spinal-epidural versus epidural analgesia in labour. Cochrane Database Syst Rev. 2012;10:Cd003401. doi: 10.1002/14651858.CD003401.pub3. PMID: 23076897.

40. Tuuli MG, Frey HA, Odibo AO, et al. Immediate compared with delayed pushing in the second stage of labor: a systematic review and meta-analysis. Obstet Gynecol. 2012 Sep;120(3):660-8. doi: 10.1097/AOG.0b013e3182639fae. PMID: 22872146.

41. Gupta JK, Hofmeyr GJ, Shehmar M. Position in the second stage of labour for women without epidural anaesthesia. Cochrane Database Syst Rev.

2012;5:Cd002006. doi: 10.1002/14651858.CD002006.pub3. PMID: 22592681.

42. Schnabel A, Hahn N, Broscheit J, et al. Remifentanil for labour analgesia: a metaanalysis of randomised controlled trials. Eur J Anaesthesiol. 2012 Apr;29(4):177-85. doi: 10.1097/EJA.0b013e32834fc260. PMID: 22273829.

43. Anim-Somuah M, Smyth RM, Jones L. Epidural versus non-epidural or no analgesia in labour. Cochrane Database Syst Rev. 2011(12):Cd000331. doi: 10.1002/14651858.CD000331.pub3. PMID: 22161362.

44. Leanza V, Leanza G, Monte S. A didactic protocol for labour and delivery: the partogram. Minerva Ginecol. 2011 Aug;63(4):325-32. PMID: 21747340.

45. Smith CA, Collins CT, Crowther CA, et al. Acupuncture or acupressure for pain management in labour. Cochrane Database Syst Rev. 2011(7):Cd009232. doi: 10.1002/14651858.cd009232. PMID: 21735441.

46. Prins M, Boxem J, Lucas C, et al. Effect of spontaneous pushing versus Valsalva pushing in the second stage of labour on mother and fetus: a systematic review of randomised trials. BJOG. 2011 May;118(6):662-70. doi: 10.1111/j.14710528.2011.02910.x. PMID: 21392242. 
47. Neal JL, Lowe NK, Ahijevych KL, et al. "Active labor" duration and dilation rates among low-risk, nulliparous women with spontaneous labor onset: a systematic review. J Midwifery Womens Health. 2010 Jul-Aug;55(4):308-18. doi: 10.1016/j.jmwh.2009.08.004. PMID: 20630357.

48. Cluett ER, Burns E. Immersion in water in labour and birth. Cochrane Database Syst Rev. 2009(2):Cd000111. doi: 10.1002/14651858.CD000111.pub3. PMID: 19370552.

49. Marucci M, Cinnella G, Perchiazzi G, et al. Patient-requested neuraxial analgesia for labor: impact on rates of cesarean and instrumental vaginal delivery. Anesthesiology. 2007 May;106(5):1035-45. doi: 10.1097/01.anes.0000265165.06760.c2. PMID: 17457137.

50. Souza JP, Miquelutti MA, Cecatti JG, et al. Maternal position during the first stage of labor: a systematic review. Reprod Health. 2006;3:10. doi: 10.1186/1742-4755-3-10. PMID: 17137501.

51. Blix E, Brurberg KG, Reierth E, et al. ST waveform analysis versus cardiotocography alone for intrapartum fetal monitoring: A systematic review and meta-analysis of randomized trials. Acta Obstet Gynecol Scand. 2016;95(1):16-27.

52. Fortier JH, Godwin M. Doula support compared with standard care: Meta-analysis of the effects on the rate of medical interventions during labour for low-risk women delivering at term. Can Fam Physician. 2015;61(6):e284-e92.

53. Neilson JP. Fetal electrocardiogram (ECG) for fetal monitoring during labour. Cochrane Database Syst Rev. 2013(5):N.PAG-N.PAG 1p. PMID: 105836264. Language: English. Entry Date: 20101029. Revision Date: 20150711. Publication Type: Journal Article.

54. Hodnett Ellen D, Gates S, Hofmeyr GJ, et al. Continuous support for women during childbirth. Cochrane Database Syst Rev: John Wiley \& Sons, Ltd; 2013.
55. Lutomski JE, Meaney S, Greene Richard A, et al. Expert systems for fetal assessment in labour. Cochrane Database Syst Rev: John Wiley \& Sons, Ltd; 2015.

56. Alfirevic Z, Devane D, Gyte Gillian ML. Continuous cardiotocography (CTG) as a form of electronic fetal monitoring (EFM) for fetal assessment during labour.

Cochrane Database Syst Rev: John Wiley \& Sons, Ltd; 2013.

57. Bosomworth A, Bettany-Saltikov J. Just take a deep breath...a review to compare the effects of spontaneous versus directed Valsalva pushing in the second stage of labour on maternal and fetal wellbeing. MIDIRS Midwifery Digest. 2006;16(2):15765 9p. PMID: 106208735. Language: English. Entry Date: 20070112. Revision Date: 20150820. Publication Type: Journal Article.

58. King M, Nazareth I, Lampe F, et al. Impact of participant and physician intervention preferences on randomized trials: a systematic review. JAMA. 2005 Mar 2;293(9):1089-99. doi: 10.1001/jama.293.9.1089. PMID: 15741531.

59. Shea BJ, Grimshaw JM, Wells GA, et al. Development of AMSTAR: a measurement tool to assess the methodological quality of systematic reviews. BMC Med Res Methodol. 2007 February 15;7(1):10. doi: 10.1186/1471-2288-7-10.

60. White CM, Ip S, McPheeters M, et al. AHRQ Methods for Effective Health Care. Using Existing Systematic Reviews To Replace De Novo Processes in Conducting Comparative Effectiveness Reviews. Methods Guide for Effectiveness and Comparative Effectiveness Reviews. Rockville (MD): Agency for Healthcare Research and Quality (US); 2008. 
61. Robinson KA, Chou R, Berkman ND, et al. Integrating Bodies of Evidence: Existing Systematic Reviews and Primary Studies. Methods Guide for Comparative Effectiveness Reviews (Prepared by the Scientific Resource Center under Contract No. 290-2012-00004-C). AHRQ Publication No. 15-EHC007-EF. Rockville, MD: Agency for Healthcare Research and Quality. February 2015. Available at: https://effectivehealthcare.ahrq.gov/topics/in tegrating-evidence/methods. Accessed August 7, 2018.

62. Owens DK, Lohr KN, Atkins D, et al. AHRQ series paper 5: grading the strength of a body of evidence when comparing medical interventions-Agency for Healthcare Research and Quality and the Effective Health Care Program. J Clin Epidemiol. 2010 May;63(5):513-23. PMID: 19595577.

63. Berkman ND, Lohr KN, Ansari M, et al. Grading the Strength of a Body of Evidence When Assessing Health Care Interventions for the Effective Health Care Program of the Agency for Healthcare Research and Quality: An Update. Methods Guide for Comparative Effectiveness Reviews (Prepared by the RTI-UNC Evidence-based Practice Center under Contract No. 2902007-10056-I). AHRQ Publication No. 13(14)-EHC130-EF. Rockville, MD: Agency for Healthcare Research and Quality. November 2013.

https://effectivehealthcare.ahrq.gov/topics/m ethods-guidance-grading-evidence/methods/ Accessed August 7, 2018.

64. Myers ER, Moorman P, Gierisch JM, et al. Benefits and harms of breast cancer screening: a systematic review. JAMA. 2015 Oct 20;314(15):1615-34. doi: 10.1001/jama.2015.13183. PMID: 26501537.

65. Atkins D, Chang SM, Gartlehner G, et al. Assessing applicability when comparing medical interventions: AHRQ and the Effective Health Care Program. J Clin Epidemiol. 2011 Nov;64(11):1198-207. PMID: 21463926.
66. Wilson MJ, MacArthur C, Cooper GM, et al. Ambulation in labour and delivery mode: a randomised controlled trial of high-dose vs mobile epidural analgesia. Anaesthesia. 2009 Mar;64(3):266-72. doi: 10.1111/j.1365-2044.2008.05756.x. PMID: 19302638.

67. Wilson MJ, Moore PA, Shennan A, et al. Long-term effects of epidural analgesia in labor: a randomized controlled trial comparing high dose with two mobile techniques. Birth. 2011 Jun;38(2):105-10. doi: 10.1111/j.1523-536X.2010.00466.x. PMID: 21599732.

68. Wassen MM, Smits LJ, Scheepers HC, et al. Routine labour epidural analgesia versus labour analgesia on request: a randomised non-inferiority trial. BJOG. 2015 Feb;122(3):344-50. doi: 10.1111/14710528.12854. PMID: 24849943.

69. van den Bosch AAS, Goossens M, Bonouvrie K, et al. Maternal quality of life in routine labor epidural analgesia versus labor analgesia on request: results of a randomized trial. Qual Life Res. 2018 Aug;27(8):2027-33. doi: 10.1007/s11136018-1838-z. PMID: 29603114.

70. Akbarzadeh M, Masoudi Z, Zare N, et al. Comparison of the Effects of Maternal Supportive Care and Acupressure (at BL32 Acupoint) on Labor Length and Infant's Apgar Score. Glob J Health Sci. 2015;8(3):48239. doi: 10.5539/gjhs.v8n3p236. PMID: 26493430.

71. Akbarzadeh M, Masoudi Z, Zare N, et al. Comparison of the effects of doula supportive care and acupressure at the BL32 point on the mother's anxiety level and delivery outcome. Iran J Nurs Midwifery Res. 2015 Mar-Apr;20(2):239-46. PMID: 25878703.

72. Bloom SL, Casey BM, Schaffer JI, et al. A randomized trial of coached versus uncoached maternal pushing during the second stage of labor. Am J Obstet Gynecol. 2006 Jan;194(1):10-3. doi: 10.1016/j.ajog.2005.06.022. PMID: 16389004. 
73. Schaffer JI, Bloom SL, Casey BM, et al. A randomized trial of the effects of coached vs uncoached maternal pushing during the second stage of labor on postpartum pelvic floor structure and function. Am J Obstet Gynecol. 2005 May;192(5):1692-6. doi: 10.1016/j.ajog.2004.11.043. PMID: 15902179.

74. Dencker A, Berg M, Bergqvist L, et al. Early versus delayed oxytocin augmentation in nulliparous women with prolonged labour--a randomised controlled trial. BJOG. 2009 Mar;116(4):530-6. doi: 10.1111/j.1471-0528.2008.01962.x. PMID: 19250364.

75. Bergqvist L, Dencker A, Taft C, et al. Women's experiences after early versus postponed oxytocin treatment of slow progress in first childbirth--a randomized controlled trial. Sex Reprod Healthc. 2012 Jun;3(2):61-5. doi: 10.1016/j.srhc.2012.03.003. PMID: 22578752.

76. de Orange FA, Passini R, Jr., Amorim MM, et al. Combined spinal and epidural anaesthesia and maternal intrapartum temperature during vaginal delivery: a randomized clinical trial. Br J Anaesth. 2011 Nov;107(5):762-8. doi: 10.1093/bja/aer218. PMID: 21743067.

77. Orange FA, Passini-Jr R, Melo AS, et al. Combined spinal-epidural anesthesia and non-pharmacological methods of pain relief during normal childbirth and maternal satisfaction: a randomized clinical trial. Rev Assoc Med Bras. 2012 Jan-Feb;58(1):112-7. PMID: 22392325.

78. Pascual-Ramirez J, Haya J, Perez-Lopez FR, et al. Effect of combined spinal-epidural analgesia versus epidural analgesia on labor and delivery duration. Int J Gynaecol Obstet. 2011 Sep;114(3):246-50. doi: 10.1016/j.ijgo.2011.04.004. PMID: 21719012.

79. Pascual-Ramirez J, Haya J, Perez-Lopez F, et al. Type of axial analgesia does not influence time to vaginal delivery in a Proportional Hazards Model. Arch Gynecol Obstet. 2012 Oct;286(4):873-80. doi: 10.1007/s00404-012-2360-0. PMID: 22639135.
80. Ragnar I, Altman D, Tyden T, et al. Comparison of the maternal experience and duration of labour in two upright delivery positions--a randomised controlled trial. BJOG. 2006 Feb;113(2):165-70. doi: 10.1111/j.1471-0528.2005.00824.x. PMID: 16411993.

81. Altman D, Ragnar I, Ekstrom A, et al. Anal sphincter lacerations and upright delivery postures--a risk analysis from a randomized controlled trial. Int Urogynecol J Pelvic Floor Dysfunct. 2007 Feb;18(2):141-6. doi: 10.1007/s00192-006-0123-9. PMID: 16636770.

82. Shafaie FS, Mohaddesi H, Mirghafourvand $\mathrm{M}$, et al. A Randomized, double-blinded, controlled trial comparing parenteral dextrose 5\%, Ringer's solution and oral intake on the delivery outcomes in Nulliparas. International Journal of Women's Health and Reproduction Sciences. 2017;5(4):283-9. doi: 10.15296/ijwhr.2017.48.

83. Ahadi Yulghunlu F, Sehhatie Shafaie F, Mirghafourvand M, et al. The effects of intravenous dextrose $5 \%$, Ringer's solution and oral intake on the duration of labor stages in nulliparous women: A doubleblind, randomized, controlled trial. J Matern Fetal Neonatal Med. 2018 Jun 18:1-151. doi: 10.1080/14767058.2018.1489792. PMID: 29909704.

84. Neal JL, Lamp JM, Buck JS, et al. Outcomes of nulliparous women with spontaneous labor onset admitted to hospitals in preactive versus active labor. J Midwifery Womens Health. 2014 JanFeb;59(1):28-34. doi: 10.1111/jmwh.12160. PMID: 24512265.

85. Frigo MG, Larciprete G, Rossi F, et al. Rebuilding the labor curve during neuraxial analgesia. J Obstet Gynaecol Res. 2011 Nov;37(11):1532-9. doi: 10.1111/j.14470756.2011.01568.x. PMID: 21676079.

86. Cheng YW, Shaffer BL, Bryant AS, et al. Length of the first stage of labor and associated perinatal outcomes in nulliparous women. Obstet Gynecol. 2010 Nov;116(5):1127-35. doi: 10.1097/AOG.0b013e3181f5eaf0. PMID: 20966698. 
87. Suzuki R, Horiuchi S, Ohtsu H. Evaluation of the labor curve in nulliparous Japanese women. Am J Obstet Gynecol. 2010

Sep;203(3):226.e1-6. doi: 10.1016/j.ajog.2010.04.014. PMID: 20494329.

88. Greenberg MB, Cheng YW, Sullivan M, et al. Does length of labor vary by maternal age? Am J Obstet Gynecol. 2007

Oct;197(4):428.e1-7. doi:

10.1016/j.ajog.2007.06.058. PMID: 17904990.

89. Lavender T, Alfirevic Z, Walkinshaw S. Effect of different partogram action lines on birth outcomes: a randomized controlled trial. Obstet Gynecol. 2006 Aug;108(2):295302. doi:

10.1097/01.AOG.0000226862.78768.5c. PMID: 16880298.

90. Fahdhy M, Chongsuvivatwong V. Evaluation of World Health Organization partograph implementation by midwives for maternity home birth in Medan, Indonesia. Midwifery. 2005 Dec;21(4):301-10. doi: 10.1016/j.midw.2004.12.010. PMID: 16076515.

91. Neal JL, Lowe NK, Caughey AB, et al. Applying a physiologic partograph to Consortium on Safe Labor data to identify opportunities for safely decreasing cesarean births among nulliparous women. Birth. 2018 May 30doi: 10.1111/birt.12358. PMID: 29851163.

92. Inde Y, Nakai A, Sekiguchi A, et al. Cervical Dilatation Curves of Spontaneous Deliveries in Pregnant Japanese Females. Int J Med Sci. 2018;15(6):549-56. doi: 10.7150/ijms.23505. PMID: 29725244.

93. Kauffman E, Souter VL, Katon JG, et al. Cervical Dilation on Admission in Term Spontaneous Labor and Maternal and Newborn Outcomes. Obstet Gynecol. 2016 Mar;127(3):481-8. doi: 10.1097/aog.0000000000001294. PMID: 26855106.

94. Lee NJ, Neal J, Lowe NK, et al. Comparing Different Partograph Designs for Use in Standard Labor Care: A Pilot Randomized Trial. Matern Child Health J. 2018 Mar;22(3):355-63. doi: 10.1007/s10995017-2366-0. PMID: 28936715.
95. Neal JL, Lowe NK, Phillippi JC, et al. Likelihood of cesarean delivery after applying leading active labor diagnostic guidelines. Birth. 2017 Jun;44(2):128-36. doi: 10.1111/birt.12274. PMID: 28198038.

96. Wood AM, Frey HA, Tuuli MG, et al. Optimal Admission Cervical Dilation in Spontaneously Laboring Women. Am J Perinatol. 2016 Jan;33(2):188-94. doi: 10.1055/s-0035-1563711. PMID: 26344012.

97. Mason BE, Matulich MC, Swanson K, et al. Labor Curves in Multiparous Women Related to Interbirth Intervals. Am J Perinatol. 2018doi: 10.1055/s-00381660469.

98. Tolba SM, Ali SS, Mohammed AM, et al. Management of Spontaneous Labor in Primigravidae: Labor Scale versus WHO Partograph (SLiP Trial) Randomized Controlled Trial. Am J Perinatol. 2018;35(1):48-54. doi: 10.1055/s-00371605575.

99. Zhang L, Troendle J, Branch DW, et al. The expected labor progression after labor augmentation with oxytocin: A retrospective cohort study. PLoS One.

2018;13(10):e0205735. doi: 10.1371/journal.pone.0205735. PMID: 30379856.

100. Hoppe KK, Schiff MA, Benedetti TJ, et al. Duration of Spontaneous Active Labor and Perinatal Outcomes Using Contemporary Labor Curves. Am J Perinatol. 2018;35(12):1186-91. doi: 10.1055/s-00381642045.

101. Oladapo OT, Diaz V, Bonet M, et al. Cervical dilatation patterns of 'low-risk' women with spontaneous labour and normal perinatal outcomes: a systematic review. BJOG. 2018 Jul;125(8):944-54. doi: 10.1111/1471-0528.14930. PMID: 28892266.

102. Lavender T, Cuthbert A, Smyth RM. Effect of partograph use on outcomes for women in spontaneous labour at term and their babies. Cochrane Database Syst Rev. 2018 Aug 6;8:Cd005461. doi: 10.1002/14651858.CD005461.pub5. PMID: 30080256. 
103. Abalos E, Oladapo OT, Chamillard M, et al. Duration of spontaneous labour in 'low-risk' women with 'normal' perinatal outcomes: A systematic review. European Journal of Obstetrics \& Gynecology \& Reproductive Biology. 2018;223:123-32. doi: 10.1016/j.ejogrb.2018.02.026. PMID: 128587525. Language: English. Entry Date: In Process. Revision Date: 20180416. Publication Type: journal article.

104. Béranger R, Chantry AA. Oxytocin administration during spontaneous labor: Guidelines for clinical practice. Chapter 1: Definition and characteristics of normal and abnormal labor. Journal of Gynecology Obstetrics and Human Reproduction. 2017;46(6):469-78. doi: 10.1016/j.jogoh.2017.04.011.

105. Philpott RH, Castle WM. Cervicographs in the management of labour in primigravidae. II. The action line and treatment of abnormal labour. J Obstet Gynaecol Br Commonw. 1972 Jul;79(7):599-602. PMID: 5043423.

106. World Health Organization. World Health Organization partograph in management of labour. World Health Organization Maternal Health and Safe Motherhood Programme. Lancet. 1994 Jun 4;343(8910):1399-404. PMID: 7910888.

107. Shazly SA, Embaby LH, Ali SS. The labour scale--assessment of the validity of a novel labour chart: a pilot study. Aust N Z J Obstet Gynaecol. 2014 Aug;54(4):322-6. doi: 10.1111/ajo.12209. PMID: 24835694.

108. Neal JL, Lowe NK. Physiologic partograph to improve birth safety and outcomes among low-risk, nulliparous women with spontaneous labor onset. Med Hypotheses. 2012 Feb;78(2):319-26. doi: 10.1016/j.mehy.2011.11.012. PMID: 22138426.

109. National Institute for Health and Care Excellence. Intrapartum care for healthy women and babies. Clinical guideline; 2014 (updated 2017). Available at: https://www.nice.org.uk/guidance/cg190. Accessed June 26, 2019.
110. Caughey AB, Cahill AG, Guise JM, et al. Safe prevention of the primary cesarean delivery. Am J Obstet Gynecol. 2014 Mar;210(3):179-93. doi: 10.1016/j.ajog.2014.01.026. PMID: 24565430.

111. O'Driscoll K, Jackson RJ, Gallagher JT. Active management of labour and cephalopelvic disproportion. J Obstet Gynaecol Br Commonw. 1970 May;77(5):385-9. PMID: 5427601.

112. Frigoletto FD, Jr., Lieberman E, Lang JM, et al. A clinical trial of active management of labor. N Engl J Med. 1995 Sep

21;333(12):745-50. doi: 10.1056/nejm199509213331201. PMID: 7643880 .

113. Ghafarzadeh M, Moeininasab S, Namdari M. Effect of early amniotomy on dystocia risk and cesarean delivery in nulliparous women: a randomized clinical trial. Arch Gynecol Obstet. 2015 Aug;292(2):321-5. doi: 10.1007/s00404-015-3645-x. PMID: 25666481.

114. Nachum Z, Garmi G, Kadan Y, et al. Comparison between amniotomy, oxytocin or both for augmentation of labor in prolonged latent phase: a randomized controlled trial. Reprod Biol Endocrinol. 2010;8:136. doi: 10.1186/1477-7827-8-136. PMID: 21054896.

115. Mikki N, Wick L, Abu-Asab N, et al. A trial of amniotomy in a Palestinian hospital. J Obstet Gynaecol. 2007 May;27(4):368-73. doi: 10.1080/01443610701327537. PMID: 17654188.

116. Ajadi MA, Kuti O, Orji EO, et al. The effect of amniotomy on the outcome of spontaneous labour in uncomplicated pregnancy. J Obstet Gynaecol. 2006 Oct;26(7):631-4. doi: 10.1080/01443610600903420. PMID: 17071428.

117. Somprasit C, Tanprasertkul C, Kamudhamas A. Reducing cesarean delivery rates: an active management labor program in a setting with limited resources. J Med Assoc Thai. 2005 Jan;88(1):20-5. PMID: 15960212. 
118. Abdullah A, Saboohi S, Hashami U. Effects of amniotomy versus spontaneous rupture of membrane on progress of labour and foetal outcome in primigravidae. Journal of the Liaquat University of Medical and Health Sciences. 2010;9(1):33-6.

119. Onah LN, Dim CC, Nwagha UI, et al. Effect of early amniotomy on the outcome of spontaneous labour: a randomized controlled trial of pregnant women in Enugu, Southeast Nigeria. Afr Health Sci. 2015 Dec;15(4):1097-103. doi: 10.4314/ahs.v15i4.7. PMID: 26958009.

120. Ruamsap K, Panichkul P. The Effect of Early Versus Late Amniotomy on The Course of Labor. J Med Assoc Thai. 2017 Feb;100(2):125-32. PMID: 29916231.

121. Vadivelu M, Rathore S, Benjamin SJ, et al. Randomized controlled trial of the effect of amniotomy on the duration of spontaneous labor. Int J Gynaecol Obstet. 2017 Aug;138(2):152-7. doi: 10.1002/ijgo.12203. PMID: 28485828.

122. Wei S, Wo BL, Qi HP, et al. Early amniotomy and early oxytocin for prevention of, or therapy for, delay in first stage spontaneous labour compared with routine care. Cochrane Database Syst Rev. 2013;8:Cd006794. doi: 10.1002/14651858.CD006794.pub4. PMID: 23926074.

123. Smyth RM, Markham C, Dowswell T. Amniotomy for shortening spontaneous labour. Cochrane Database Syst Rev. 2013;6:Cd006167. doi: 10.1002/14651858.CD006167.pub4. PMID: 23780653.

124. Liu Y, Xu M, Che X, et al. Effect of direct current pulse stimulating acupoints of JiaJi (T10-13) and Ciliao (BL 32) with Han's Acupoint Nerve Stimulator on labour pain in women: a randomized controlled clinical study. J Tradit Chin Med. 2015 Dec;35(6):620-5. PMID: 26742304.

125. Asadi N, Maharlouei N, Khalili A, et al. Effects of LI-4 and SP-6 Acupuncture on Labor Pain, Cortisol Level and Duration of Labor. J Acupunct Meridian Stud. 2015 Oct;8(5):249-54. doi: 10.1016/j.jams.2015.08.003. PMID: 26433802.
126. Allameh Z, Tehrani HG, Ghasemi M. Comparing the impact of acupuncture and pethidine on reducing labor pain. Adv Biomed Res. 2015;4:46. doi: 10.4103/22779175.151302. PMID: 25789272.

127. Kaviani M, Maghbool S, Azima S, et al. Comparison of the effect of aromatherapy with Jasminum officinale and Salvia officinale on pain severity and labor outcome in nulliparous women. Iran J Nurs Midwifery Res. 2014 Nov;19(6):666-72. PMID: 25558267.

128. Vixner L, Schytt E, Stener-Victorin E, et al. Acupuncture with manual and electrical stimulation for labour pain: a longitudinal randomised controlled trial. BMC Complement Altern Med. 2014;14:187. doi: 10.1186/1472-6882-14-187. PMID: 24913704.

129. Santhi, Anuratha, Kokilavani. Effectiveness of semi sitting position during 2nd stage of labour on maternal and neonatal outcomes among primigravida. Nurs J India. 2012 Nov-Dec;103(6):272-5. PMID: 23923599.

130. Edwards RK, Reed CA, Villano KS, et al. Effect of hydration on spontaneous labor outcomes in nulliparous pregnant women: a multicenter randomized controlled trial comparing three methods. Am J Perinatol. 2014 Jun;31(6):455-62. doi: 10.1055/s0033-1351661. PMID: 23884718.

131. Silva Gallo RB, Santana LS, Jorge Ferreira $\mathrm{CH}$, et al. Massage reduced severity of pain during labour: a randomised trial. J Physiother. 2013 Jun;59(2):109-16. doi: 10.1016/s1836-9553(13)70163-2. PMID: 23663796 .

132. Janssen P, Shroff F, Jaspar P. Massage therapy and labor outcomes: a randomized controlled trial. Int J Ther Massage Bodywork. 2012;5(4):15-20. PMID: 23429706.

133. Rahmani R, Khakbazan Z, Yavari P, et al. Effect of oral carbohydrate intake on labor progress: randomized controlled trial. Iran J Public Health. 2012;41(11):59-66. PMID: 23304677. 
134. Thies-Lagergren L, Kvist LJ, Sandin-Bojo AK, et al. Labour augmentation and fetal outcomes in relation to birth positions: a secondary analysis of an RCT evaluating birth seat births. Midwifery. 2013 Apr;29(4):344-50. doi: 10.1016/j.midw.2011.12.014. PMID: 23084490 .

135. Sharma C, Kalra J, Bagga R, et al. A randomized controlled trial comparing parenteral normal saline with and without $5 \%$ dextrose on the course of labor in nulliparous women. Arch Gynecol Obstet. 2012 Dec;286(6):1425-30. doi: 10.1007/s00404-012-2485-1. PMID: 22865033.

136. Direkvand-Moghadam A, Rezaeian M. Increased intravenous hydration of nulliparas in labor. Int J Gynaecol Obstet. 2012 Sep;118(3):213-5. doi: 10.1016/j.ijgo.2012.03.041. PMID: 22717414.

137. Hamidzadeh A, Shahpourian F, Orak RJ, et al. Effects of LI4 acupressure on labor pain in the first stage of labor. J Midwifery Womens Health. 2012 Mar-Apr;57(2):1338. doi: 10.1111/j.1542-2011.2011.00138.x. PMID: 22432484.

138. Mortazavi SH, Khaki S, Moradi R, et al. Effects of massage therapy and presence of attendant on pain, anxiety and satisfaction during labor. Arch Gynecol Obstet. 2012 Jul;286(1):19-23. doi: 10.1007/s00404-0122227-4. PMID: 22271239.

139. Kavitha A, Chacko KP, Thomas E, et al. A randomized controlled trial to study the effect of IV hydration on the duration of labor in nulliparous women. Arch Gynecol Obstet. 2012 Feb;285(2):343-6. doi: 10.1007/s00404-011-1978-7. PMID: 21748313.

140. Taavoni S, Abdolahian S, Haghani H, et al. Effect of birth ball usage on pain in the active phase of labor: a randomized controlled trial. J Midwifery Womens Health. 2011 Mar-Apr;56(2):137-40. doi: 10.1111/j.1542-2011.2010.00013.x. PMID: 21429078.
141. Ma W, Bai W, Lin C, et al. Effects of Sanyinjiao (SP6) with electroacupuncture on labour pain in women during labour. Complement Ther Med. 2011 Jan;19 Suppl 1:S13-8. doi: 10.1016/j.ctim.2010.09.001. PMID: 21195290.

142. Coco A, Derksen-Schrock A, Coco K, et al. A randomized trial of increased intravenous hydration in labor when oral fluid is unrestricted. Fam Med. 2010 Jan;42(1):52-6. PMID: 20063224.

143. Chaichian S, Akhlaghi A, Rousta F, et al. Experience of water birth delivery in Iran. Arch Iran Med. 2009 Sep;12(5):468-71. PMID: 19722768.

144. Shrivastava VK, Garite TJ, Jenkins SM, et al. A randomized, double-blinded, controlled trial comparing parenteral normal saline with and without dextrose on the course of labor in nulliparas. Am J Obstet Gynecol. 2009 Apr;200(4):379.e1-6. doi: 10.1016/j.ajog.2008.11.030. PMID: 19217592.

145. McGrath SK, Kennell JH. A randomized controlled trial of continuous labor support for middle-class couples: effect on cesarean delivery rates. Birth. 2008 Jun;35(2):92-7. doi: 10.1111/j.1523-536X.2008.00221.x. PMID: 18507579.

146. Miquelutti MA, Cecatti JG, Makuch MY. Upright position during the first stage of labor: a randomised controlled trial. Acta Obstet Gynecol Scand. 2007;86(5):553-8. doi: 10.1080/00016340601185251. PMID: 17464583.

147. Nasir A, Korejo R, Noorani KJ. Child birth in squatting position. J Pak Med Assoc. 2007 Jan;57(1):19-22. PMID: 17319414.

148. Eslamian L, Marsoosi V, Pakneeyat Y. Increased intravenous fluid intake and the course of labor in nulliparous women. Int $\mathrm{J}$ Gynaecol Obstet. 2006 May;93(2):102-5. doi: 10.1016/j.ijgo.2006.01.023. PMID: 16542657.

149. Albers LL, Sedler KD, Bedrick EJ, et al. Midwifery care measures in the second stage of labor and reduction of genital tract trauma at birth: a randomized trial. J Midwifery Womens Health. 2005 Sep-Oct;50(5):36572. doi: 10.1016/j.jmwh.2005.05.012. PMID: 16154062. 
150. Vaijayanthimala M, Judie A. Mobility is an adjuvant approach for intrapartum care - A clinical randomized interventional study. International Journal of Pharmaceutical and Clinical Research. 2014;6(4):356-62.

151. Kashanian M, Shahali S. Effects of acupressure at the Sanyinjiao point (SP6) on the process of active phase of labor in nulliparas women. Journal of Maternal-Fetal and Neonatal Medicine. 2010;23(7):638-41.

152. Bruggemann OM, Parpinelli MA, Osis MJD, et al. Support to woman by a companion of her choice during childbirth: A randomized controlled trial. Reproductive Health. 2007;4.

153. Prabhakar D, George LS, Karkada S. Effectiveness of Ambulation during First Stage of Labour, on the Outcome of Labour among Primigravid Women in Selected Hospitals of Palakkad District, Kerala. International Journal of Nursing Education. 2015;7(1):1-6 p. doi: 10.5958/09749357.2015.00001.X. PMID: 109736286. Language: English. Entry Date: 20150923. Revision Date: 20151008. Publication Type: Journal Article. Journal Subset: Continental Europe.

154. Tussey CM, Botsios E, Gerkin RD, et al. Reducing Length of Labor and Cesarean Surgery Rate Using a Peanut Ball for Women Laboring With an Epidural. Journal of Perinatal Education. 2015 Winter2015;24(1):16-24 9p. doi: 10.1891/1058-1243.24.1.16. PMID: 107772608. Language: English. Entry Date: 20150210. Revision Date: 20150819. Publication Type: Journal Article.

155. Hekmatzadeh SF, Bazarganipour F, Malekzadeh J, et al. A randomized clinical trial of the efficacy of applying a simple protocol of boiled Anethum Graveolens seeds on pain intensity and duration of labor stages. Complement Ther Med. 2014;22(6):970-6 7p. doi: 10.1016/j.ctim.2014.10.007. PMID: 103857382. Language: English. Entry Date: 20150605. Revision Date: 20150710. Publication Type: Journal Article.
156. Shirvani MA, Ganji Z. The influence of cold pack on labour pain relief and birth outcomes: a randomised controlled trial. J Clin Nurs. 2014;23(17/18):2473-80 8p. doi: 10.1111/jocn.12413. PMID: 103978082. Language: English. Entry Date: 20140724. Revision Date: 20150901. Publication Type: Journal Article.

157. Kaviani M, Azima S, Alavi N, et al. The effect of lavender aromatherapy on pain perception and intrapartum outcome in primiparous women. British Journal of Midwifery. 2014;22(2):125-8 4p. PMID: 104020847. Language: English. Entry Date: 20140207. Revision Date: 20150820. Publication Type: Journal Article.

158. Sasitorn P, Boonrueing M, Kitti R, et al. Effect of the Prince of Songkla University Birthing Bed on Duration, Pain, and Comfort Level during Second-Stage Labor in Primiparous Thais. Pacific Rim International Journal of Nursing Research. 2013;17(1):56-67 12p. PMID: 104241027. Language: English. Entry Date: 20130304. Revision Date: 20150819. Publication Type: Journal Article.

159. Ganapathy T. Childbirth in Supported Sitting Maternal Position. International Journal of Nursing Education. 2012;4(2):8791 5p. PMID: 104394668. Language: English. Entry Date: 20121228. Revision Date: 20150819. Publication Type: Journal Article.

160. Dahlen HG, Homer CS, Cooke M, et al. Perineal outcomes and maternal comfort related to the application of perineal warm packs in the second stage of labor: a randomized controlled trial. Birth: Issues in Perinatal Care. 2007;34(4):282-90 9p. PMID: 105948799. Language: English. Entry Date: 20140221. Revision Date: 20150820. Publication Type: Journal Article.

161. Phumdoung S, Youngvanichsate S, Jongpaiboonpatana W, et al. The effects of the PSU Cat position and music on length of time in the active phase of labor and labor pain. Thai Journal of Nursing Research. 2007;11(2):96-105 10p. PMID: 106181967. Language: English. Entry Date: 20071102. Revision Date: 20150818. Publication Type: Journal Article. 
162. El Hamid, Obaya HE, Gaafar HM. Effect of Acupressure on Labor Pain and Duration of Delivery among Laboring Women Attending Cairo University Hospital. Indian Journal of Physiotherapy \& Occupational Therapy. 2013;7(2):71-6.

163. Yuenyong S, O'Brien B, Jirapeet V. Effects of labor support from close female relative on labor and maternal satisfaction in a Thai setting. J Obstet Gynecol Neonatal Nurs. 2012 Jan;41(1):45-56. doi: 10.1111/j.15526909.2011.01311.x. PMID: 22834721.

164. Taavoni S, Sheikhan F, Abdolahian S, et al. Birth ball or heat therapy? A randomized controlled trial to compare the effectiveness of birth ball usage with sacrum-perineal heat therapy in labor pain management. Complement Ther Clin Pract. 2016 Aug;24:99-102. doi: 10.1016/j.ctcp.2016.04.001. PMID: 27502808.

165. Yazdkhasti M, Pirak A. The effect of aromatherapy with lavender essence on severity of labor pain and duration of labor in primiparous women. Complement Ther Clin Pract. 2016 Nov;25:81-6. doi: 10.1016/j.ctcp.2016.08.008. PMID: 27863615.

166. Bolbol-Haghighi N, Masoumi SZ, Kazemi F. Effect of Massage Therapy on Duration of Labour: A Randomized Controlled Trial. J Clin Diagn Res. 2016 Apr;10(4):Qc12-5. doi: 10.7860/jcdr/2016/17447.7688. PMID: 27190898.

167. Tanvisut R, Traisrisilp K, Tongsong T. Efficacy of aromatherapy for reducing pain during labor: a randomized controlled trial. Arch Gynecol Obstet. 2018 May;297(5):1145-50. doi: 10.1007/s00404018-4700-1. PMID: 29397442.

168. Moraloglu O, Kansu-Celik H, Tasci Y, et al. The influence of different maternal pushing positions on birth outcomes at the second stage of labor in nulliparous women. $\mathrm{J}$ Matern Fetal Neonatal Med. 2017 Jan;30(2):245-9. doi: 10.3109/14767058.2016.1169525. PMID: 27028537.
169. Simarro M, Espinosa JA, Salinas C, et al. A Prospective Randomized Trial of Postural Changes vs Passive Supine Lying during the Second Stage of Labor under Epidural Analgesia. Med Sci (Basel). 2017 Mar 8;5(1)doi: 10.3390/medsci5010005. PMID: 29099021.

170. Zhang H, Huang S, Guo X, et al. A randomised controlled trial in comparing maternal and neonatal outcomes between hands-and-knees delivery position and supine position in China. Midwifery. 2017 Jul;50:117-24. doi: 10.1016/j.midw.2017.03.022. PMID: 28414983.

171. Fong A, Serra AE, Caballero D, et al. A randomized, double-blinded, controlled trial of the effects of fluid rate and/or presence of dextrose in intravenous fluids on the labor course of nulliparas. Am J Obstet Gynecol. 2017 Aug;217(2):208.e1-.e7. doi: 10.1016/j.ajog.2017.03.010. PMID: 28322776.

172. Gallo RBS, Santana LS, Marcolin AC, et al. Sequential application of nonpharmacological interventions reduces the severity of labour pain, delays use of pharmacological analgesia, and improves some obstetric outcomes: a randomised trial. J Physiother. 2018 Jan;64(1):33-40. doi: 10.1016/j.jphys.2017.11.014. PMID: 29289579.

173. Epidural and Position Trial Collaborative Group. Upright versus lying down position in second stage of labour in nulliparous women with low dose epidural: BUMPES randomised controlled trial. BMJ. 2017 Oct 18;359:j4471. doi: 10.1136/bmj.j4471. PMID: 29046273.

174. Maddady SM, Mohammad-AlizadehCharandabi S, Shafaei FS, et al. Comparing the effects of hot shower and intravenous injection of hyoscine on the pain intensity and duration of active phase of labour in nulliparous women. Journal of Clinical and Diagnostic Research. 2018;12(8):QC07QC11. doi: 10.7860/JCDR/2018/35508.11950. 
175. Samadzadeh S, Rezavand N, Yari M, et al. Comparison of Entonox and Transcutaneous Electrical Nerve Stim-ulation (TENS) in labor pain. Journal of Medical and Biomedical Sciences. 2017;6(2):11-6. doi: 10.4314/jmbs.v6i2.2.

176. Wu L, Liu X, Yin Y, et al. Effectiveness of acupuncture versus spinal-epidural anesthesia on labor pain: a randomized controlled trial. J Tradit Chin Med. 2017;37(5):629-35.

177. Wiberg-Itzel E, Wray S, Åkerud H. A randomized controlled trial of a new treatment for labor dystocia. Journal of Maternal-Fetal and Neonatal Medicine. 2018;31(17):2237-44. doi: 10.1080/14767058.2017.1339268.

178. Shahoei R, Shahghebi S, Rezaei M, et al. The effect of transcutaneous electrical nerve stimulation on the severity of labor pain among nulliparous women: A clinical trial. Complement Ther Clin Pract. 2017;28:17680. doi: 10.1016/j.ctcp.2017.05.004. PMID: 124438951. Language: English. Entry Date: 20180330. Revision Date: 20180330. Publication Type: Article.

179. Darsareh F, Nourbakhsh S, Dabiri F. Effect of water immersion on labor outcomes: A randomized clinical trial. Nursing \& Midwifery Studies. 2018;7(3):111-5. doi: 10.4103/nms.nms_18_17. PMID: 130546966. Language: English. Entry Date: 20180710. Revision Date: 20180710. Publication Type: Article. Journal Subset: Continental Europe.

180. İsbir GG, Serçekuş P. The Effects of Intrapartum Supportive Care on Fear of Delivery and Labor Outcomes: A SingleBlind Randomized Controlled Trial. Journal of Nursing Research (Lippincott Williams \& Wilkins). 2017;25(2):112-9. doi: 10.1097/jnr.0000000000000129. PMID: 122434272. Language: English. Entry Date: 20170421. Revision Date: 20170421. Publication Type: Article.
181. Xiao J, Yi W, Wu L. Effects of electroacupuncture on reducing labor pain and complications in the labor analgesia process of combined spinal-epidural analgesia with patient-controlled epidural analgesia. Arch Gynecol Obstet. 2019;299(1):123-8. doi: 10.1007/s00404018-4955-6. PMID: 134079027. Language: English. Entry Date: In Process. Revision Date: 20190117. Publication Type: Journal Article. Journal Subset: Biomedical.

182. Malin GL, Bugg GJ, Thornton J, et al. Does oral carbohydrate supplementation improve labour outcome? A systematic review and individual patient data meta-analysis. BJOG. 2016 Mar;123(4):510-7. doi: 10.1111/14710528.13728. PMID: 26914893.

183. Ehsanipoor RM, Saccone G, Seligman NS, et al. Intravenous fluid rate for reduction of cesarean delivery rate in nulliparous women: a systematic review and meta-analysis. Acta Obstet Gynecol Scand. 2017 Jul;96(7):80411. doi: 10.1111/aogs.13121. PMID: 28236651.

184. Aquino CI, Guida M, Saccone G, et al. Perineal massage during labor: a systematic review and meta-analysis of randomized controlled trials. J Matern Fetal Neonatal Med. 2018 Aug 14:1-371. doi: 10.1080/14767058.2018.1512574. PMID: 30107756.

185. Ciardulli A, Saccone G, Anastasio H, et al. Less-restrictive food intake during labor in low-risk singleton pregnancies a systematic review and meta-analysis. Obstet Gynecol. 2017;129(3):473-80. doi: 10.1097/AOG.0000000000001898.

186. Kobayashi S, Hanada N, Matsuzaki M, et al. Assessment and support during early labour for improving birth outcomes. Cochrane Database Syst Rev. 2017 Apr 20;4:Cd011516. doi: 10.1002/14651858.CD011516.pub2. PMID: 28426160.

187. Bohren MA, Hofmeyr GJ, Sakala C, et al. Continuous support for women during childbirth. Cochrane Database Syst Rev. 2017 Jul 6;7:Cd003766. doi: 10.1002/14651858.CD003766.pub6. PMID: 28681500 . 
188. Cluett ER, Burns E, Cuthbert A. Immersion in water during labour and birth. Cochrane Database Syst Rev. 2018 May

16;5:Cd000111. doi: 10.1002/14651858.CD000111.pub4. PMID: 29768662.

189. Genc M, Sahin N, Maral J, et al. Does bupivacaine and fentanyl combination for epidural analgesia shorten the duration of labour? J Obstet Gynaecol. 2015;35(7):6725. doi: 10.3109/01443615.2014.991299. PMID: 25546524.

190. Patel NP, El-Wahab N, Fernando R, et al. Fetal effects of combined spinal-epidural vs epidural labour analgesia: a prospective, randomised double-blind study. Anaesthesia. 2014 May;69(5):458-67. doi: 10.1111/anae.12602. PMID: 24738803.

191. Ismail MT, Hassanin MZ. Neuraxial analgesia versus intravenous remifentanil for pain relief in early labor in nulliparous women. Arch Gynecol Obstet. 2012 Dec;286(6):1375-81. doi: 10.1007/s00404012-2459-3. PMID: 22810619.

192. Tveit TO, Seiler S, Halvorsen A, et al. Labour analgesia: a randomised, controlled trial comparing intravenous remifentanil and epidural analgesia with ropivacaine and fentanyl. Eur J Anaesthesiol. 2012 Mar;29(3):129-36. doi: 10.1097/EJA.0b013e32834dfa98. PMID: 22249153.

193. Sweed N, Sabry N, Azab T, et al. Regional versus IV analgesics in labor. Minerva Med. 2011 Oct;102(5):353-61. PMID: 22193345.

194. Douma MR, Middeldorp JM, Verwey RA, et al. A randomised comparison of intravenous remifentanil patient-controlled analgesia with epidural ropivacaine/sufentanil during labour. Int $\mathrm{J}$ Obstet Anesth. 2011 Apr;20(2):118-23. doi: 10.1016/j.ijoa.2010.11.009. PMID: 21376564.

195. Nakamura G, Ganem EM, Rugolo LM, et al. Effects on mother and fetus of epidural and combined spinal-epidural techniques for labor analgesia. Rev Assoc Med Bras. 2009 Jul-Aug;55(4):405-9. PMID: 19750306.
196. Abrao KC, Francisco RP, Miyadahira S, et al. Elevation of uterine basal tone and fetal heart rate abnormalities after labor analgesia: a randomized controlled trial. Obstet Gynecol. 2009 Jan;113(1):41-7. doi: 10.1097/AOG.0b013e31818f5eb6. PMID: 19104358.

197. Sezer OA, Gunaydin B. Efficacy of patientcontrolled epidural analgesia after initiation with epidural or combined spinal-epidural analgesia. Int J Obstet Anesth. 2007 Jul;16(3):226-30. doi: 10.1016/j.ijoa.2007.02.007. PMID: 17509869.

198. Nafisi S. Effects of epidural lidocaine analgesia on labor and delivery: a randomized, prospective, controlled trial. BMC Anesthesiol. 2006;6:15. doi: 10.1186/1471-2253-6-15. PMID: 17176461.

199. Ohel G, Gonen R, Vaida S, et al. Early versus late initiation of epidural analgesia in labor: does it increase the risk of cesarean section? A randomized trial. Am J Obstet Gynecol. 2006 Mar;194(3):600-5. doi: 10.1016/j.ajog.2005.10.821. PMID: 16522386.

200. Wong CA, Scavone BM, Peaceman AM, et al. The risk of cesarean delivery with neuraxial analgesia given early versus late in labor. N Engl J Med. 2005 Feb 17;352(7):655-65. doi: 10.1056/NEJMoa042573. PMID: 15716559.

201. Jaitley A, Singh S, Srivastava U, et al. A comparison between epidural and IV tramadol for painless labor and effect on perinatal outcome. Journal of Obstetrics and Gynecology of India. 2011;61(1):42-7.

202. Bhagwat A, Dua C, Saxena K, et al. Comparison of combined spinal epidural technique and low dose epidural technique in progress of labour. Indian J Anaesth. 2008;52(3):282-7.

203. Shen X, Li Y, Xu S, et al. Epidural Analgesia During the Second Stage of Labor: A Randomized Controlled Trial. Obstet Gynecol. 2017 Nov;130(5):1097103. doi: 10.1097/aog.0000000000002306. PMID: 29016499. 
204. Weibel S, Jelting Y, Afshari A, et al. Patient-controlled analgesia with remifentanil versus alternative parenteral methods for pain management in labour. Cochrane Database Syst Rev. 2017 Apr 13;4:Cd011989. doi: 10.1002/14651858.CD011989.pub2. PMID: 28407220 .

205. Lee M, Zhu F, Moodie J, et al. Remifentanil as an alternative to epidural analgesia for vaginal delivery: A meta-analysis of randomized trials. J Clin Anesth. 2017 Jun;39:57-63. doi: 10.1016/j.jclinane.2017.03.026. PMID: 28494909.

206. Downe S, Gyte GM, Dahlen HG, et al. Routine vaginal examinations for assessing progress of labour to improve outcomes for women and babies at term. Cochrane Database Syst Rev. 2013;7:Cd010088. doi: 10.1002/14651858.CD010088.pub2. PMID: 23857468.

207. Abukhalil IH, Kilby MD, Aiken J, et al. Can the frequency of vaginal examinations influence the duration of labour? A prospective randomised study. J Obstet Gynaecol. 1996;16:22-5.

208. Kenyon S, Armstrong N, Johnston T, et al. Standard- or high-dose oxytocin for nulliparous women with confirmed delay in labour: quantitative and qualitative results from a pilot randomised controlled trial. BJOG. 2013 Oct;120(11):1403-12. doi: 10.1111/1471-0528.12331. PMID: 23786339.

209. Tribe RM, Crawshaw SE, Seed P, et al. Pulsatile versus continuous administration of oxytocin for induction and augmentation of labor: two randomized controlled trials. Am J Obstet Gynecol. 2012 Mar;206(3):230.e18. doi: 10.1016/j.ajog.2011.11.001. PMID: 22206748.

210. Hinshaw K, Simpson S, Cummings S, et al. A randomised controlled trial of early versus delayed oxytocin augmentation to treat primary dysfunctional labour in nulliparous women. BJOG. 2008 Sep;115(10):1289-95; discussion 95-6. doi: 10.1111/j.14710528.2008.01819.x. PMID: 18715415.
211. Palomaki O, Uotila J, Tammela O, et al. A double blind, randomized trial on augmentation of labour with a combination of intravenous propranolol and oxytocin versus oxytocin only. Eur J Obstet Gynecol Reprod Biol. 2006 Mar 1;125(1):44-9. doi: 10.1016/j.ejogrb.2005.06.016. PMID: 16051416.

212. Dy J, Rainey J, Walker MC, et al. Accelerated Titration of Oxytocin in Nulliparous Women with Labour Dystocia: Results of the ACTION Pilot Randomized Controlled Trial. J Obstet Gynaecol Can. 2018 Jun;40(6):690-7. doi: 10.1016/j.jogc.2017.08.046. PMID: 29276166.

213. Liu J, Yi Y, Weiwei X. Effects of Increased Frequency, High Dose, and Pulsatile Oxytocin Regimens on Abnormal Labor Delivery. Med Sci Monit. 2018 Apr 7;24:2063-71. PMID: 29626416.

214. Geeta D, Go R, Sudesh G, et al. Low-dose versus high-dose oxytocin in augmentation of labor: A prospective study. J Indian Med Assoc. 2015;113(10):102.

215. Selin L, Wennerholm UB, Jonsson M, et al. High-dose versus low-dose of oxytocin for labour augmentation: a randomised controlled trial. Women Birth. 2018 Oct 16doi: 10.1016/j.wombi.2018.09.002. PMID: 30341003.

216. Wei SQ, Luo ZC, Qi HP, et al. High-dose vs low-dose oxytocin for labor augmentation: a systematic review. Am J Obstet Gynecol. 2010 Oct;203(4):296-304. doi: 10.1016/j.ajog.2010.03.007. PMID: 20451894.

217. Kenyon S, Tokumasu H, Dowswell T, et al. High-dose versus low-dose oxytocin for augmentation of delayed labour. Cochrane Database Syst Rev. 2013;7:Cd007201. doi: 10.1002/14651858.CD007201.pub3. PMID: 23853046.

218. Gaucher L, Le Ray C. Oxytocin administration during spontaneous labor: Guidelines for clinical practice. Chapter 2: Indications of oxytocin according the first and second stages of spontaneous labor. Journal of Gynecology Obstetrics and Human Reproduction. 2017;46(6):479-87. doi: 10.1016/j.jogoh.2017.04.007. 
219. Wei SQ, Luo ZC, Xu H, et al. The effect of early oxytocin augmentation in labor: a meta-analysis. Obstet Gynecol. 2009

Sep;114(3):641-9. doi: 10.1097/AOG.0b013e3181b11cb8. PMID: 19701046.

220. Bugg GJ, Siddiqui F, Thornton JG. Oxytocin versus no treatment or delayed treatment for slow progress in the first stage of spontaneous labour. Cochrane Database Syst Rev. 2013;6:Cd007123. doi: 10.1002/14651858.CD007123.pub3. PMID: 23794255.

221. Costley PL, East CE. Oxytocin augmentation of labour in women with epidural analgesia for reducing operative deliveries. Cochrane Database Syst Rev. 2012;5:Cd009241. doi: 10.1002/14651858.CD009241.pub2. PMID: 22592738.

222. . ACOG Practice Bulletin No. 107: Induction of labor. Obstet Gynecol. 2009 Aug;114(2 Pt 1):386-97. doi: 10.1097/AOG.0b013e3181b48ef5. PMID: 19623003.

223. Martis R, Emilia O, Nurdiati DS, et al. Intermittent auscultation (IA) of fetal heart rate in labour for fetal well-being. Cochrane Database Syst Rev. 2017(2)doi: 10.1002/14651858.CD008680.pub2. PMID: CD008680.

224. Yildirim G, Beji NK. Effects of pushing techniques in birth on mother and fetus: a randomized study. Birth. 2008 Mar;35(1):25-30. doi: 10.1111/j.1523536X.2007.00208.x. PMID: 18307484.

225. Vaziri F, Arzhe A, Asadi N, et al. Spontaneous Pushing in Lateral Position versus Valsalva Maneuver During Second Stage of Labor on Maternal and Fetal Outcomes: A Randomized Clinical Trial. Iran Red Crescent Med J. 2016 Oct;18(10):e29279. doi: 10.5812/ircmj.29279. PMID: 28180019.

226. Koyucu RG, Demirci N. Effects of pushing techniques during the second stage of labor: A randomized controlled trial. Taiwan $\mathrm{J}$ Obstet Gynecol. 2017 Oct;56(5):606-12. doi: 10.1016/j.tjog.2017.02.005. PMID: 29037544.
227. Cahill AG, Srinivas SK, Tita ATN, et al. Effect of Immediate vs Delayed Pushing on Rates of Spontaneous Vaginal Delivery Among Nulliparous Women Receiving Neuraxial Analgesia: A Randomized Clinical Trial. JAMA. 2018 Oct 9;320(14):1444-54. doi: 10.1001/jama.2018.13986. PMID: 30304425.

228. Lemos A, Amorim MM, Dornelas de Andrade A, et al. Pushing/bearing down methods for the second stage of labour. Cochrane Database Syst Rev. 2017 Mar 26;3:Cd009124. doi: 10.1002/14651858.CD009124.pub3. PMID: 28349526.

229. Barasinski C, Lemery D, Vendittelli F. Do maternal pushing techniques during labour affect obstetric or neonatal outcomes? Gynecol Obstet Fertil. 2016 Oct;44(10):57883. doi: 10.1016/j.gyobfe.2016.07.004. PMID: 27568414.

230. Knox D, Yamamoto T, Baum MA, et al. Design, identification, and sensitivity analysis for patient preference trials. Journal of the American Statistical Association. 2019 Feb 27(just-accepted):1-25.

231. Walter SD, Turner RM, Macaskill P. Optimising the two-stage randomised trial design when some participants are indifferent in their treatment preferences. Stat Med. 2019 Jun 15;38(13):2317-31. doi: 10.1002/sim.8119. PMID: 30793786.

232. Goldhaber-Fiebert JD, Brandeau ML. Evaluating Cost-effectiveness of Interventions That Affect Fertility and Childbearing: How Health Effects Are Measured Matters. Med Decis Making. 2015 Oct;35(7):818-46. doi: 10.1177/0272989X15583845. PMID: 25926281.

233. Matza LS, Boye KS, Feeny DH, et al. Impact of caregiver and parenting status on time trade-off and standard gamble utility scores for health state descriptions. Health Qual Life Outcomes. 2014 Apr 9;12:48. doi: 10.1186/1477-7525-12-48. PMID: 24716709. 
234. Saigal S, Tyson J. Measurement of quality of life of survivors of neonatal intensive care: critique and implications. Semin Perinatol. 2008 Feb;32(1):59-66. doi: 10.1053/j.semperi.2007.12.007. PMID: 18249241.
235. Duffy J, Rolph R, Gale C, et al. Core outcome sets in women's and newborn health: a systematic review. BJOG. 2017 Sep;124(10):1481-9. doi: 10.1111/14710528.14694. PMID: 28421657. 


\section{Acronyms and Abbreviations}

AE

AHRQ

AMSTAR

aOR

AROM

BMI

CDSR

CI

CPAP

CSE

CSL

EA

EHC

FHR

$\mathrm{HOB}$

IQR

KQ

MA

MD

NA

NCPP

NICU

NR

NS

NRFHT

OR

PCIA

PICOTS

PSU

RCT

$\mathrm{RR}$

SD

SOE

SR

WMD
Adverse events

Agency for Healthcare Research and Quality

A Measurement Tool to Assess Systematic Reviews

Adjusted odds ratio

Artificial rupture of membranes

Body mass index

Cochrane Database of Systematic Reviews

Confidence interval

Continuous positive airway pressure;

Combined spinal epidural

Consortium on Safe Labor

Epidural analgesia

Effective Health Care

Fetal heart rate

Head of bed

Interquartile range

Key Question

Meta-analysis

Mean difference

Not applicable

National Collaborative Perinatal Project

Neonatal intensive care unit

Not reported

Not significant

Nonreassuring Fetal Heart Rate Tracing

Odds ratio

Patient-controlled intravenous analgesia

Population, Intervention, Comparator, Outcomes, Timing, Setting

Prince of Songkla University

Randomized controlled trial

Relative risk

Standard deviation

Strength of evidence

Systematic review

Weighted mean difference 


\section{Appendix A. Exact Search Strings}

\section{PubMed $^{\circledR}$ Search Strategy (February 15, 2019)}

\begin{tabular}{|c|c|}
\hline $\begin{array}{l}\text { Search } \\
\text { Number }\end{array}$ & Search String \\
\hline$\# 1$ & $\begin{array}{l}\text { "Dystocia"[Mesh] OR "Dystocia"[tiab] OR "Dystocias"[tiab] OR "hypotonic contractions"[tiab] OR "slow } \\
\text { progress"[tiab] OR "lack of progress"[tiab] OR "unsatisfactory progress"[tiab] OR "failure to } \\
\text { progress"[tiab] OR "abnormal labor"[tiab] OR "labor arrest"[tiab] OR "labour arrest"[tiab] OR "arrested } \\
\text { labor"[tiab] OR "arrest of labor"[tiab] OR "prolonged labor"[tiab] OR "dysfunctional labor"[tiab] OR } \\
\text { "obstructed labor"[tiab] OR "labor obstruction"[tiab] OR "abnormal labour"[tiab] OR "labour arrest"[tiab] } \\
\text { OR "arrested labour"[tiab] OR "arrest of labour"[tiab] OR "prolonged labour"[tiab] OR "dysfunctional } \\
\text { labour"[tiab] OR "obstructed labour"[tiab] OR "labour obstruction"[tiab] OR "inefficient uterine } \\
\text { contractions"[tiab] OR "protracted"[tiab] OR "arrested descent"[tiab] OR "arrest of descent"[tiab] OR } \\
\text { "inertia uteri"[tiab] OR "uterine inertia"[tiab] OR "uterus inertia"[tiab] OR "Uterine Atony"[tiab] OR } \\
\text { "inefficient uterine action"[tiab] OR "prolonged deceleration phase"[tiab] OR "abnormal progress"[tiab] } \\
\text { OR "transverse arrest"[tiab] OR "prolonged second stage"[tiab] OR "delayed second stage"[tiab] OR } \\
\text { "non-progressive labor"[tiab] OR "non-progressive labour"[tiab] OR "protraction disorder"[tiab] OR } \\
\text { "protraction disorders"[tiab] OR "arrest disorder"[tiab] OR "arrest disorders"[tiab] OR "hypocontractile } \\
\text { labour"[tiab] OR "hypocontractile labor"[tiab] }\end{array}$ \\
\hline$\# 2$ & $\begin{array}{l}\text { "Labor, Obstetric"[Mesh] OR "Delivery, Obstetric"[Mesh] OR "Labor Onset"[Mesh] OR "Obstetric } \\
\text { Delivery"[tiab] OR "Obstetric Deliveries"[tiab] OR "obstetric labor"[tiab] OR "obstetric labour"[tiab] OR } \\
\text { "normal labor"[tiab] OR "normal labour" OR "term labor" OR "term labour" OR "labor onset"[tiab] OR } \\
\text { "labour onset"[tiab] OR "Second Labor Stages"[tiab] OR "Second Labour Stages"[tiab] OR "Second } \\
\text { Stage of Labor"[tiab] OR "Second Stage of Labour"[tiab] OR "Second Stage Labor"[tiab] OR "Second } \\
\text { Stage Labour"[tiab] OR "First Stage of Labor"[tiab] OR "First Stage of Labour"[tiab] OR "First Stage } \\
\text { Labor"[tiab] OR "First Stage Labor""tiab] OR ((labour[tiab] OR labor[tiab]) AND } \\
\text { ("Pregnancy"[Mesh:NoExp] OR "Pregnant Women"[Mesh] OR "pregnancy"[tiab] OR "pregnant"[tiab] } \\
\text { OR "pregnancies"[tiab] OR "gestation"[tiab] OR "Prenatal Care"[Mesh] OR "childbirth"[tiab] OR } \\
\text { "Parity"[Mesh] OR "nulliparous"[tiab] OR "multiparous"[tiab] OR "Cervical Dilatation"[tiab] OR "Cervical } \\
\text { Dilatations"[tiab])) }\end{array}$ \\
\hline$\# 3$ & \#1 AND \#2 \\
\hline \#4 & $\begin{array}{l}\text { ("Labor Onset"[Mesh] OR "labor onset"[tiab] OR "labour onset"[tiab] OR "Second Labor Stages"[tiab] } \\
\text { OR “Second Labour Stages"[tiab] OR "Second Stage of Labor"[tiab] OR "Second Stage of } \\
\text { Labour"[tiab] OR "Second Stage Labor"[tiab] OR "Second Stage Labour"[tiab] OR "First Stage of } \\
\text { Labor"[tiab] OR "First Stage of Labour"[tiab] OR “First Stage Labor"[tiab] OR "First Stage Labor"[tiab]) } \\
\text { AND ("Time Factors"[Mesh] OR "Pregnancy Outcome"[Mesh]) }\end{array}$ \\
\hline$\# 5$ & \#3 OR \#4 \\
\hline \#6 & $\begin{array}{l}\text { \#5 NOT (Editorial[ptyp] OR Letter[ptyp] OR Case Reports[ptyp] OR Comment[ptyp]) NOT (animals[mh] } \\
\text { NOT humans[mh]) }\end{array}$ \\
\hline$\# 7$ & Limits: English; Date-2005 - Present \\
\hline \#8 & "Amnion/surgery"[Mesh] OR "Amniotomy"[tiab] \\
\hline
\end{tabular}




\begin{tabular}{|c|c|}
\hline $\begin{array}{l}\text { Search } \\
\text { Number }\end{array}$ & Search String \\
\hline$\# 9$ & $\begin{array}{l}\text { "Exercise"[Mesh] OR "walking"[tiab] OR "ambulation"[tiab] OR "Nutrition Processes"[Mesh] OR } \\
\text { "Eating"[tiab] OR "drinking"[tiab] OR "Diet"[Mesh:NoExp] OR "Fasting"[Mesh] OR "fasting"[tiab] OR } \\
\text { "nutrition"[tiab] OR "intravenous dextrose"[tiab] OR "normal saline"[tiab] OR "Infusions, } \\
\text { Intravenous"[Mesh] OR "Intravenous Drip"[tiab] OR "Infusion Drip"[tiab] OR "IV hydration"[tiab] OR } \\
\text { "intravenous hydration"[tiab] OR "Ringer solution"[tiab] OR "Ringer-locke solution"[tiab] OR "hydration } \\
\text { fluids"[tiab] OR "oral fluids"[tiab] OR "Bradley Method"[tiab] OR "Pain/prevention and control"[Mesh] } \\
\text { OR "Doulas"[Mesh] OR "Doulas"[tiab] OR "Doula"[tiab] OR "labor coach"[tiab] OR "labor coaches"[tiab] } \\
\text { OR "Natural Childbirth"[Mesh] OR "emotional support"[tiab] OR "Coaching"[tiab] OR "Peanut ball"[tiab] } \\
\text { OR "birthing ball"[tiab] OR "childbirth education"[tiab] OR "Lamaze"[tiab] OR "hypnobirthing"[tiab] OR } \\
\text { "hypnosis"[tiab] OR "HypnoBabies"[tiab] OR "Complementary Therapies"[Mesh] OR "Healthy } \\
\text { Birth"[tiab] OR "Patient Care Planning"[Mesh:NoExp] OR "supplemental oxygen"[tiab] OR "oxygen } \\
\text { supplementation"[tiab] OR "Fetal Distress/therapy"[Mesh] OR "Oxygen Inhalation } \\
\text { Therapy"[Mesh:NoExp] OR "Hydrotherapy"[Mesh] OR "hydrotherapy"[tiab] OR "hydrotherapies"[tiab] } \\
\text { OR "Whirlpool Baths"[tiab] OR "Whirlpool Bath"[tiab] OR "birthing tub"[tiab] OR "Warm Baths"[tiab] OR } \\
\text { "warm bath"[tiab] OR "Patient Positioning"[Mesh] OR "supine"[tiab] OR "Posture"[Mesh] OR } \\
\text { "Psychoprophylaxis""[tiab] OR "Acupuncture"[tiab] OR "Acupressure"[tiab] OR "Aromatherapy"[tiab] OR } \\
\text { "music therapy"[tiab] OR "massage"[tiab]) }\end{array}$ \\
\hline \#10 & "analgesia, epidural"[MeSH] OR "Anesthesia, Epidural"[Mesh] OR "epidural"[tiab] \\
\hline$\# 11$ & $\begin{array}{l}\text { "Gynecological Examination"[Mesh] OR "Gynecological Examination"[tiab] OR "Gynecological } \\
\text { Examinations"[tiab] OR "Gynecological Exam"[tiab] OR "Gynecological Exams"[tiab] OR } \\
\text { "Gynaecological Examination"[tiab] OR "Gynaecological Examinations"[tiab] OR "Gynaecological } \\
\text { Exam"[tiab] OR "Gynaecological Exams"[tiab] OR "Vaginal Examination"[tiab] OR "Vaginal } \\
\text { Examinations"[tiab] OR "Vaginal Exam"[tiab] OR "Vaginal Exams"[tiab] OR "Cervical Examination"[tiab] } \\
\text { OR "Cervical Examinations"[tiab] OR "Cervical Exam"[tiab] OR "Cervical Exams"[tiab] OR ("Cervix } \\
\text { Uteri"[Mesh] AND ("Examination"[tiab] OR "Examinations"[tiab] OR "Exam"[tiab] OR "Exams"[tiab])) } \\
\text { OR "Pelvic Examination"[tiab] OR "Pelvic Examinations"[tiab] OR "Pelvic Exam"[tiab] OR "Pelvic } \\
\text { Exams"[tiab] }\end{array}$ \\
\hline$\# 12$ & $\begin{array}{l}\text { "Uterine Monitoring"[Mesh] OR "Uterine Monitoring"[tiab] OR "intrauterine pressure catheter"[tiab] OR } \\
\text { "intrauterine pressure catheters"[tiab] OR "IUPC"[tiab] OR Tocodynamometry[tiab] OR } \\
\text { Tocography[tiab] OR Tocograms[tiab] OR Tocogram[tiab] }\end{array}$ \\
\hline$\# 13$ & $\begin{array}{l}\text { "Oxytocin"[Mesh] OR "Oxytocics"[Mesh] OR “Ocytocin"[tiab] OR "Syntocinon"[tiab] OR “Pitocin"[tiab] } \\
\text { OR "nipple stimulation"[tiab] }\end{array}$ \\
\hline$\# 14$ & $\begin{array}{l}\text { "Valsalva Maneuver"[Mesh] OR "Valsalva Maneuvers"[tiab] OR "Valsalva Maneuver"[tiab] OR } \\
\text { "Valsalva pushing"[tiab] OR "passive descent"[tiab] OR "delayed pushing"[tiab] OR "open glottis } \\
\text { pushing"[tiab] }\end{array}$ \\
\hline$\# 15$ & $\begin{array}{l}\text { (randomized controlled trial[pt] OR controlled clinical trial[pt] OR randomized[tiab] OR randomised[tiab] } \\
\text { OR randomization[tiab] OR randomisation[tiab] OR placebo[tiab] OR drug therapy[sh] OR } \\
\text { randomly[tiab] OR trial[tiab] OR groups[tiab] OR systematic[sb] OR "meta-analysis"[Publication Type] } \\
\text { OR "meta-analysis as topic"[MeSH Terms] OR "meta-analysis"[tiab] OR "meta-analyses"[tiab]) NOT } \\
\text { (Editorial[ptyp] OR Letter[ptyp] OR Case Reports[ptyp] OR Comment[ptyp]) NOT (animals[mh] NOT } \\
\text { humans[mh]) }\end{array}$ \\
\hline$\# 16$ & (\#8 OR \#9 OR \#10 OR \#11 OR \#12 OR \#13 OR \#14) \\
\hline$\# 17$ & \#2 AND \#15 AND \#16 \\
\hline$\# 18$ & Limits: English; Date-2005 - Present \\
\hline \#19 & \#7 OR \#18 \\
\hline
\end{tabular}




\section{Embase $^{\circledR}$ Search Strategy (February 15, 2019)}

Platform: Embase.com

\begin{tabular}{|c|c|}
\hline $\begin{array}{l}\text { Search } \\
\text { Number }\end{array}$ & Search String \\
\hline \#1 & $\begin{array}{l}\text { 'dystocia'/exp OR 'dystocia':ab,ti OR 'dystocias':ab,ti OR 'hypotonic contractions':ab,ti OR 'slow } \\
\text { progress':ab,ti OR 'lack of progress':ab,ti OR 'unsatisfactory progress':ab,ti OR 'failure to progress':ab,ti } \\
\text { OR 'abnormal labor':ab,ti OR 'labor arrest':ab,ti OR 'arrested labor':ab,ti OR 'arrest of labor':ab,ti OR } \\
\text { 'prolonged labor':ab,ti OR 'dysfunctional labor':ab,ti OR 'obstructed labor':ab,ti OR 'labor } \\
\text { obstruction':ab,ti OR 'abnormal labour':ab,ti OR 'labour arrest':ab,ti OR 'arrested labour':ab,ti OR 'arrest } \\
\text { of labour':ab,ti OR 'prolonged labour':ab,ti OR 'dysfunctional labour':ab,ti OR 'obstructed labour':ab,ti } \\
\text { OR 'labour obstruction':ab,ti OR 'inefficient uterine contractions':ab,ti OR 'protracted':ab,ti OR 'arrested } \\
\text { descent':ab,ti OR 'arrest of descent':ab,ti OR 'inertia uteri':ab,ti OR 'uterine inertia':ab,ti OR 'uterus } \\
\text { inertia':ab,ti OR 'uterine atony':ab,ti OR 'inefficient uterine action':ab,ti OR 'prolonged deceleration } \\
\text { phase':ab,ti OR 'abnormal progress':ab,ti OR 'transverse arrest':ab,ti OR 'prolonged second stage':ab,ti } \\
\text { OR 'delayed second stage':ab,ti OR 'non-progressive labor':ab,ti OR 'non-progressive labour':ab,ti OR } \\
\text { 'protraction disorder':ab,ti OR 'protraction disorders':ab,ti OR 'arrest disorder':ab,ti OR 'arrest } \\
\text { disorders':ab,ti OR 'hypocontractile labour':ab,ti OR 'hypocontractile labor':ab,ti }\end{array}$ \\
\hline \#2 & $\begin{array}{l}\text { 'delivery'/exp OR 'childbirth'/exp OR 'obstetric delivery':ab,ti OR 'obstetric deliveries':ab,ti OR 'obstetric } \\
\text { labor':ab,ti OR 'obstetric labour':ab,ti OR 'normal labor':ab,ti OR 'normal labour' OR 'term labor' OR } \\
\text { 'term labour' OR 'labor onset':ab,ti OR 'labour onset':ab,ti OR 'second labor stages':ab,ti OR 'second } \\
\text { labour stages':ab,ti OR 'second stage of labor':ab,ti OR 'second stage of labour':ab,ti OR 'second stage } \\
\text { labor':ab,ti OR 'second stage labour':ab,ti OR 'first stage of labor':ab,ti OR 'first stage of labour':ab,ti } \\
\text { OR 'first stage labor':ab,ti OR (labour:ab,ti OR labor:ab,ti AND 'pregnancy'/de) OR 'pregnant } \\
\text { woman'/exp OR 'pregnancy':ab,ti OR 'pregnant':ab,ti OR 'pregnancies':ab,ti OR 'gestation':ab,ti OR } \\
\text { 'prenatal care'/exp OR 'childbirth':ab,ti OR 'parity'/exp OR 'nulliparous':ab,ti OR 'multiparous':ab,ti OR } \\
\text { 'cervical dilatation':ab,ti OR 'cervical dilatations':ab,ti }\end{array}$ \\
\hline \#3 & \#1 AND \#2 \\
\hline \#4 & $\begin{array}{l}\text { 'labor stage'/exp OR 'labor onset':ab,ti OR 'labour onset':ab,ti OR 'second labor stages':ab,ti OR } \\
\text { 'second labour stages':ab,ti OR 'second stage of labor':ab,ti OR 'second stage of labour':ab,ti OR } \\
\text { 'second stage labor':ab,ti OR 'second stage labour':ab,ti OR 'first stage of labor':ab,ti OR 'first stage of } \\
\text { labour':ab,ti OR 'first stage labor':ab,ti AND 'parameters concerning the fetus, newborn and } \\
\text { pregnancy'/exp }\end{array}$ \\
\hline \#5 & \#3 OR \#4 \\
\hline \#6 & $\begin{array}{l}\text { \#5 NOT ('case report'/exp OR 'case study'/exp OR 'editorial'/exp OR 'letter'/exp OR 'note'/exp OR } \\
\text { 'conference paper'/exp OR [conference abstract]/lim OR [conference paper]/lim OR [editorial]/lim OR } \\
\text { [letter]/lim OR [note]/lim) }\end{array}$ \\
\hline \#7 & \#6 AND [humans]/lim AND [english]/lim AND [2005-2016]/py \\
\hline \#8 & 'amniotomy'/exp OR 'amniotomy':ab,ti \\
\hline$\# 9$ & $\begin{array}{l}\text { 'exercise'/exp OR 'walking':ab,ti OR 'ambulation':ab,ti OR 'nutrition'/exp OR 'eating':ab,ti OR } \\
\text { 'drinking':ab,ti OR 'diet'/de OR 'diet restriction'/exp OR 'fasting':ab,ti OR 'nutrition':ab,ti OR 'intravenous } \\
\text { dextrose':ab,ti OR 'normal saline':ab,ti OR 'intravenous drug administration'/exp OR 'intravenous } \\
\text { drip':ab,ti OR 'infusion drip':ab,ti OR 'iv hydration':ab,ti OR 'intravenous hydration':ab,ti OR 'ringer } \\
\text { solution':ab,ti OR 'ringer locke solution':ab,ti OR 'hydration fluids':ab,ti OR 'oral fluids':ab,ti OR 'bradley } \\
\text { method':ab,ti OR ('prevention and control'/exp AND 'pain'/exp) OR 'doula'/exp OR 'doulas':ab,ti OR } \\
\text { 'doula':ab,ti OR 'labor coach':ab,ti OR 'labor coaches':ab,ti OR 'natural childbirth'/exp OR 'emotional } \\
\text { support':ab,ti OR 'coaching':ab,ti OR 'peanut ball':ab,ti OR 'birthing ball':ab,ti OR 'childbirth } \\
\text { education':ab,ti OR 'lamaze':ab,ti OR 'hypnobirthing':ab,ti OR 'hypnosis':ab,ti OR 'hypnobabies':ab,ti } \\
\text { OR 'alternative medicine'/exp OR 'healthy birth':ab,ti OR 'patient care planning'/exp OR 'supplemental } \\
\text { oxygen':ab,ti OR 'oxygen supplementation':ab,ti OR ('fetus distress'/exp AND 'therapy'/de) OR 'oxygen } \\
\text { therapy'/exp OR 'hydrotherapy'/exp OR 'hydrotherapy':ab,ti OR 'hydrotherapies':ab,ti OR 'whirlpool } \\
\text { baths':ab,ti OR 'whirlpool bath':ab,ti OR 'birthing tub':ab,ti OR 'warm baths':ab,ti OR 'warm bath':ab,ti } \\
\text { OR 'patient positioning'/exp OR 'birthing position'/exp OR 'supine':ab,ti OR 'psychoprophylaxis':ab,ti OR } \\
\text { 'acupuncture':ab,ti OR 'acupressure':ab,ti OR 'aromatherapy':ab,ti OR 'music therapy':ab,ti OR } \\
\text { 'massage':ab,ti }\end{array}$ \\
\hline \#10 & 'analgesia'/exp OR 'epidural anesthesia'/exp OR 'epidural':ab,ti \\
\hline \#11 & $\begin{array}{l}\text { 'gynecological examination'/exp OR 'gynecological examination':ab,ti OR 'gynecological } \\
\text { examinations':ab,ti OR 'gynecological exam':ab,ti OR 'gynecological exams':ab,ti OR 'gynaecological }\end{array}$ \\
\hline
\end{tabular}




\begin{tabular}{|c|c|}
\hline $\begin{array}{l}\text { Search } \\
\text { Number }\end{array}$ & Search String \\
\hline & $\begin{array}{l}\text { examination':ab,ti OR 'gynaecological examinations':ab,ti OR 'gynaecological exam':ab,ti OR } \\
\text { 'gynaecological exams':ab,ti OR 'vaginal examination':ab,ti OR 'vaginal examinations':ab,ti OR 'vaginal } \\
\text { exam':ab,ti OR 'vaginal exams':ab,ti OR 'cervical examination':ab,ti OR 'cervical examinations':ab,ti OR } \\
\text { 'cervical exam':ab,ti OR 'cervical exams':ab,ti OR ('uterine cervix'/exp AND ('examination':ab,ti OR } \\
\text { 'examinations':ab,ti OR 'exam':ab,ti OR 'exams':ab,ti)) OR 'pelvic examination':ab,ti OR 'pelvic } \\
\text { examinations':ab,ti OR 'pelvic exam':ab,ti OR 'pelvic exams':ab,ti }\end{array}$ \\
\hline$\# 12$ & $\begin{array}{l}\text { 'fetus monitoring'/exp OR 'uterine monitoring':ab,ti OR 'intrauterine pressure catheter'/exp OR } \\
\text { 'intrauterine pressure catheter':ab,ti OR 'intrauterine pressure catheters':ab,ti OR 'iupc':ab,ti OR } \\
\text { tocodynamometry:ab,ti OR tocography:ab,ti OR tocograms:ab,ti OR tocogram:ab,ti }\end{array}$ \\
\hline$\# 13$ & $\begin{array}{l}\text { 'oxytocin'/exp OR 'oxytocic agent'/exp OR 'ocytocin':ab,ti OR 'syntocinon':ab,ti OR 'pitocin':ab,ti OR } \\
\text { 'nipple stimulation':ab,ti }\end{array}$ \\
\hline$\# 14$ & $\begin{array}{l}\text { 'valsalva maneuver'/exp OR 'valsalva maneuvers':ab,ti OR 'valsalva maneuver':ab,ti OR 'valsalva } \\
\text { pushing':ab,ti OR 'passive descent':ab,ti OR 'delayed pushing':ab,ti OR 'open glottis pushing':ab,ti }\end{array}$ \\
\hline \#15 & \#8 OR \#9 OR \#10 OR \#11 OR \#12 OR \#13 OR \#14 \\
\hline \#16 & 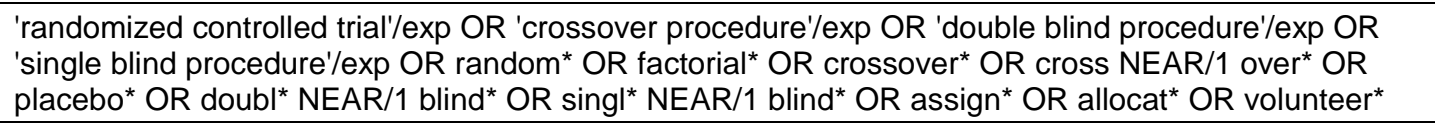 \\
\hline \#17 & \#2 AND \#15 AND \#16 \\
\hline \#18 & $\begin{array}{l}\text { \#17 NOT ('case report'/exp OR 'case study'/exp OR 'editorial'/exp OR 'letter'/exp OR 'note'/exp OR } \\
\text { 'conference paper'/exp OR [conference abstract]/lim) }\end{array}$ \\
\hline \#19 & \#18 AND [humans]/lim AND [english]/lim AND [2005-2016]/py \\
\hline$\# 20$ & \#7 OR \#19 \\
\hline \#21 & \#20 AND [embase]/lim NOT [medline]/lim \\
\hline
\end{tabular}




\section{CINAHL (Cumulative Index to Nursing \& Allied Health Literature) Search Strategy (February 15, 2019)}

\begin{tabular}{|c|c|}
\hline $\begin{array}{l}\text { Search } \\
\text { Number }\end{array}$ & Search String \\
\hline S1 & $\begin{array}{l}\text { TI ("dystocia" OR "dystocias" OR "hypotonic contractions" OR "slow progress" OR "lack of progress" } \\
\text { OR "unsatisfactory progress" OR "failure to progress" OR "abnormal labor" OR "labor arrest" OR } \\
\text { "arrested labor" OR "arrest of labor" OR "prolonged labor" OR "dysfunctional labor" OR "obstructed } \\
\text { labor" OR "labor obstruction" OR "abnormal labour" OR "labour arrest" OR "arrested labour" OR "arrest } \\
\text { of labour" OR "prolonged labour" OR "dysfunctional labour" OR "obstructed labour" OR "labour } \\
\text { obstruction" OR "inefficient uterine contractions" OR "protracted" OR "arrested descent" OR "arrest of } \\
\text { descent" OR "inertia uteri" OR "uterine inertia" OR "uterus inertia" OR "uterine atony" OR "inefficient } \\
\text { uterine action" OR "prolonged deceleration phase" OR "abnormal progress" OR "transverse arrest" OR } \\
\text { "prolonged second stage" OR "delayed second stage" OR "non-progressive labor" OR "non- } \\
\text { progressive labour" OR "protraction disorder" OR "protraction disorders" OR "arrest disorder" OR } \\
\text { "arrest disorders" OR "hypocontractile labour" OR "hypocontractile labor") OR AB ("dystocia" OR } \\
\text { "dystocias" OR "hypotonic contractions" OR "slow progress" OR "lack of progress" OR "unsatisfactory } \\
\text { progress" OR "failure to progress" OR "abnormal labor" OR "labor arrest" OR "arrested labor" OR } \\
\text { "arrest of labor" OR "prolonged labor" OR "dysfunctional labor" OR "obstructed labor" OR "labor } \\
\text { obstruction" OR "abnormal labour" OR "labour arrest" OR "arrested labour" OR "arrest of labour" OR } \\
\text { "prolonged labour" OR "dysfunctional labour" OR "obstructed labour" OR "labour obstruction" OR } \\
\text { "inefficient uterine contractions" OR "protracted" OR "arrested descent" OR "arrest of descent" OR } \\
\text { "inertia uteri" OR "uterine inertia" OR "uterus inertia" OR "uterine atony" OR "inefficient uterine action" } \\
\text { OR "prolonged deceleration phase" OR "abnormal progress" OR "transverse arrest" OR "prolonged } \\
\text { second stage" OR "delayed second stage" OR "non-progressive labor" OR "non-progressive labour" } \\
\text { OR "protraction disorder" OR "protraction disorders" OR "arrest disorder" OR "arrest disorders" OR } \\
\text { "hypocontractile labour" OR "hypocontractile labor") OR (MH "Dystocia+") }\end{array}$ \\
\hline S2 & $\begin{array}{l}\text { TI ("childbirth" OR "obstetric delivery" OR "obstetric deliveries" OR "obstetric labor" OR "obstetric } \\
\text { labour" OR "normal labor" OR "normal labour" OR "term labor" OR "term labour" OR "labor onset" OR } \\
\text { "labour onset" OR "second labor stages" OR "second labour stages" OR "second stage of labor" OR } \\
\text { "second stage of labour" OR "second stage labor" OR "second stage labour" OR "first stage of labor" } \\
\text { OR "first stage of labour" OR "first stage labor" OR (labour OR labor AND pregnancy) OR "pregnant } \\
\text { woman" OR "pregnancy" OR "pregnant" OR "pregnancies" OR "gestation" OR "prenatal care" OR } \\
\text { "childbirth" OR "parity" OR "nulliparous" OR "multiparous" OR "cervical dilatation" OR "cervical } \\
\text { dilatations") OR AB ("childbirth" OR "obstetric delivery" OR "obstetric deliveries" OR "obstetric labor" } \\
\text { OR "obstetric labour" OR "normal labor" OR "normal labour" OR "term labor" OR "term labour" OR } \\
\text { "labor onset" OR "labour onset" OR "second labor stages" OR "second labour stages" OR "second } \\
\text { stage of labor" OR "second stage of labour" OR "second stage labor" OR "second stage labour" OR } \\
\text { "first stage of labor" OR "first stage of labour" OR "first stage labor" OR (labour OR labor AND } \\
\text { pregnancy) OR "pregnant woman" OR "pregnancy" OR "pregnant" OR "pregnancies" OR "gestation" } \\
\text { OR "prenatal care" OR "childbirth" OR "parity" OR "nulliparous" OR "multiparous" OR "cervical } \\
\text { dilatation" OR "cervical dilatations") OR ((MH "Labor Stages+") AND (MH "Time Factors" OR MH } \\
\text { "Pregnancy Outcomes")) }\end{array}$ \\
\hline S3 & S1 AND S2 \\
\hline S4 & $\begin{array}{l}\text { TI ("labor stage" OR "labor onset" OR "labour onset" OR "second labor stages" OR "second labour } \\
\text { stages" OR "second stage of labor" OR "second stage of labour" OR "second stage labor" OR "second } \\
\text { stage labour" OR "first stage of labor" OR "first stage of labour" OR "first stage labor" AND ("Time } \\
\text { Factors" OR "Pregnancy Outcome")) OR AB ("labor stage" OR "labor onset" OR "labour onset" OR } \\
\text { "second labor stages" OR "second labour stages" OR "second stage of labor" OR "second stage of } \\
\text { labour" OR "second stage labor" OR "second stage labour" OR "first stage of labor" OR "first stage of } \\
\text { labour" OR "first stage labor" AND ("Time Factors" OR "Pregnancy Outcome")) OR (MH "Labor } \\
\text { Stages+") AND (MH "Time Factors" OR MH "Pregnancy Outcomes") }\end{array}$ \\
\hline S5 & S3 OR S4 \\
\hline S6 & $\begin{array}{l}\text { S5 NOT PT (Abstract OR Book OR Book Chapter OR Book Review OR Case Study OR Commentary } \\
\text { OR Doctoral Dissertation OR Editorial OR Letter OR Masters Thesis OR Pamphlet OR Pamphlet } \\
\text { Chapter OR Poetry ) }\end{array}$ \\
\hline S7 & $\begin{array}{l}\text { S6 } \\
\text { Limiters - English Language; Published Date: 20050101-20161231 }\end{array}$ \\
\hline
\end{tabular}




\begin{tabular}{|c|c|}
\hline $\begin{array}{l}\text { Search } \\
\text { Number }\end{array}$ & Search String \\
\hline S8 & $\begin{array}{l}\text { TI ("Amnion surgery" or Amniotomy ) OR AB ( "Amnion surgery" or Amniotomy ) OR (MH "Fetal } \\
\text { Membranes, Artificial Rupture") }\end{array}$ \\
\hline S9 & $\begin{array}{l}\text { TI ("walking" OR "ambulation" OR "fasting" OR "intravenous dextrose" OR "normal saline" OR } \\
\text { "intravenous drug administration" OR "intravenous drip" OR "infusion drip" OR "iv hydration" OR } \\
\text { "intravenous hydration" OR "ringer solution" OR "ringer locke solution" OR "hydration fluids" OR "oral } \\
\text { fluids" OR "bradley method" OR "doulas" OR "doula" OR "labor coach" OR "labor coaches" OR } \\
\text { "natural childbirth" OR "emotional support" OR "coaching" OR "peanut ball" OR "birthing ball" OR } \\
\text { "childbirth education" OR "lamaze" OR "hypnobirthing" OR "hypnosis" OR "hypnobabies" OR } \\
\text { "alternative medicine" OR "healthy birth" OR "patient care planning" OR "supplemental oxygen" OR } \\
\text { "oxygen supplementation" OR "oxygen therapy" OR "hydrotherapy" OR "hydrotherapies" OR "whirlpool } \\
\text { baths" OR "whirlpool bath" OR "birthing tub" OR "warm baths" OR "warm bath" OR "patient } \\
\text { positioning" OR "birthing position" OR "supine" OR "psychoprophylaxis" OR "acupuncture" OR } \\
\text { "acupressure" OR "aromatherapy" OR "music therapy" OR "massage") OR AB ("walking" OR } \\
\text { "ambulation" OR "fasting" OR "intravenous dextrose" OR "normal saline" OR "intravenous drug } \\
\text { administration" OR "intravenous drip" OR "infusion drip" OR "iv hydration" OR "intravenous hydration" } \\
\text { OR "ringer solution" OR "ringer locke solution" OR "hydration fluids" OR "oral fluids" OR "bradley } \\
\text { method" OR "doulas" OR "doula" OR "labor coach" OR "labor coaches" OR "natural childbirth" OR } \\
\text { "emotional support" OR "coaching" OR "peanut ball" OR "birthing ball" OR "childbirth education" OR } \\
\text { "lamaze" OR "hypnobirthing" OR "hypnosis" OR "hypnobabies" OR "alternative medicine" OR "healthy } \\
\text { birth" OR "patient care planning" OR "supplemental oxygen" OR "oxygen supplementation" OR } \\
\text { "oxygen therapy" OR "hydrotherapy" OR "hydrotherapies" OR "whirlpool baths" OR "whirlpool bath" } \\
\text { OR "birthing tub" OR "warm baths" OR "warm bath" OR "patient positioning" OR "birthing position" OR } \\
\text { "supine" OR "psychoprophylaxis" OR "acupuncture" OR "acupressure" OR "aromatherapy" OR "music } \\
\text { therapy" OR "massage") OR (MH "Exercise+" OR MH "Hydrotherapy+" OR MH "Alternative Birth } \\
\text { Methods+" OR MH "Alternative Therapies+" OR MH "Prepared Childbirth") }\end{array}$ \\
\hline S10 & $\begin{array}{l}\text { TI ("analgesia" OR "epidural") OR AB ("analgesia" OR "epidural") OR (MH "Analgesia, Epidural" OR } \\
\text { MH "Anesthesia, Epidural") }\end{array}$ \\
\hline S11 & $\begin{array}{l}\text { TI ("gynecological examination" OR "gynecological examinations" OR "gynecological exam" OR } \\
\text { "gynecological exams" OR "gynaecological examination" OR "gynaecological examinations" OR } \\
\text { "gynaecological exam" OR "gynaecological exams" OR "vaginal examination" OR "vaginal } \\
\text { examinations" OR "vaginal exam" OR "vaginal exams" OR "cervical examination" OR "cervical } \\
\text { examinations" OR "cervical exam" OR "cervical exams" OR ("cervix" AND ("examination" OR } \\
\text { "examinations" OR "exam" OR "exams")) OR "pelvic examination" OR "pelvic examinations" OR } \\
\text { "pelvic exam" OR "pelvic exams") OR AB ("gynecological examination" OR "gynecological } \\
\text { examinations" OR "gynecological exam" OR "gynecological exams" OR "gynaecological examination" } \\
\text { OR "gynaecological examinations" OR "gynaecological exam" OR "gynaecological exams" OR "vaginal } \\
\text { examination" OR "vaginal examinations" OR "vaginal exam" OR "vaginal exams" OR "cervical } \\
\text { examination" OR "cervical examinations" OR "cervical exam" OR "cervical exams" OR ("cervix" AND } \\
\text { ("examination" OR "examinations" OR "exam" OR "exams")) OR "pelvic examination" OR "pelvic } \\
\text { examinations" OR "pelvic exam" OR "pelvic exams") OR (MH "Gynecologic Examination") }\end{array}$ \\
\hline S12 & $\begin{array}{l}\text { TI ("fetus monitoring" OR "uterine monitoring" OR "intrauterine pressure catheter" OR "intrauterine } \\
\text { pressure catheter" OR "intrauterine pressure catheters" OR "iupc" OR tocodynamometry OR } \\
\text { tocography OR tocograms OR tocogram) OR AB ("fetus monitoring" OR "uterine monitoring" OR } \\
\text { "intrauterine pressure catheter" OR "intrauterine pressure catheter" OR "intrauterine pressure } \\
\text { catheters" OR "iupc" OR tocodynamometry OR tocography OR tocograms OR tocogram) OR (MH } \\
\text { "Uterine Monitoring" OR MH "Fetal Monitoring+" OR MH "Fetal Monitoring, Electronic+") }\end{array}$ \\
\hline S13 & $\begin{array}{l}\text { TI ("oxytocin" OR "oxytocic agent" OR "ocytocin" OR "syntocinon" OR "pitocin" OR "nipple stimulation") } \\
\text { OR AB ("oxytocin" OR "oxytocic agent" OR "ocytocin" OR "syntocinon" OR "pitocin" OR "nipple } \\
\text { stimulation") OR (MH "Oxytocin" OR MH "Oxytocics+") }\end{array}$ \\
\hline S14 & $\begin{array}{l}\text { TI ("valsalva maneuvers" OR "valsalva maneuver" OR "valsalva pushing" OR "passive descent" OR } \\
\text { "delayed pushing" OR "open glottis pushing") OR AB ("valsalva maneuvers" OR "valsalva maneuver" } \\
\text { OR "valsalva pushing" OR "passive descent" OR "delayed pushing" OR "open glottis pushing") OR } \\
\text { (MH "Valsalva's Maneuver") }\end{array}$ \\
\hline S15 & S8 OR S9 OR S10 OR S11 OR S12 OR S13 OR S14 \\
\hline S16 & $\begin{array}{l}\text { TI ("randomized controlled trial" OR "controlled clinical trial" OR "randomized" OR "randomized" OR } \\
\text { "randomization" OR "randomization" OR "placebo" OR "randomly" OR "trial" OR "groups" OR } \\
\text { "systematic review" OR "meta-analysis" OR "meta-analyses" OR AB ("randomized controlled trial" OR } \\
\text { "controlled clinical trial" OR "randomized" OR "randomized" OR "randomization" OR "randomization" }\end{array}$ \\
\hline
\end{tabular}




\begin{tabular}{|l|l|}
\hline $\begin{array}{l}\text { Search } \\
\text { Number }\end{array}$ & $\begin{array}{l}\text { Search String } \\
\text { OR "placebo" OR "randomly" OR "trial" OR "groups" OR "systematic review" OR "meta-analysis" OR } \\
\text { "meta-analyses") OR (MH "Randomized Controlled Trials" OR MH "Systematic Review" OR MH "Meta } \\
\text { Analysis") }\end{array}$ \\
\hline S17 & S2 AND S15 AND S16 \\
\hline S18 & $\begin{array}{l}\text { S17 NOT PT ( Abstract OR Book OR Book Chapter OR Book Review OR Case Study OR } \\
\text { Commentary OR Doctoral Dissertation OR Editorial OR Letter OR Masters Thesis OR Pamphlet OR } \\
\text { Pamphlet Chapter OR Poetry ) }\end{array}$ \\
\hline S19 & S18 Limiters - English Language; Published Date: 20050101-20161231 \\
\hline S20 & S7 OR S19 \\
\hline
\end{tabular}

\section{Cochane Search Strategy (February 15, 2019)}

Platform: Wiley

Database searched: Cochrane Database of Systematic Reviews

\begin{tabular}{|c|c|}
\hline $\begin{array}{l}\text { Search } \\
\text { Number }\end{array}$ & Search String \\
\hline \#1 & $\begin{array}{l}\text { Dystocia or Dystocias or hypotonic contractions or slow progress or lack of progress or unsatisfactory } \\
\text { progress or failure to progress or abnormal labor or labor arrest or labour arrest or arrested labor or } \\
\text { arrest of labor or prolonged labor or dysfunctional labor or obstructed labor or labor obstruction or } \\
\text { abnormal labour or labour arrest or arrested labour or arrest of labour or prolonged labour or } \\
\text { dysfunctional labour or obstructed labour or labour obstruction or inefficient uterine contractions or } \\
\text { protracted or arrested descent or arrest of descent or inertia uteri or uterine inertia or uterus inertia or } \\
\text { Uterine Atony or inefficient uterine action or prolonged deceleration phase or abnormal progress or } \\
\text { transverse arrest or prolonged second stage or delayed second stage or non-progressive labor or non- } \\
\text { progressive labour or protraction disorder or protraction disorders or arrest disorder or arrest disorders } \\
\text { or hypocontractile labour or hypocontractile labor }\end{array}$ \\
\hline \#2 & $\begin{array}{l}\text { Obstetric Delivery or Obstetric Deliveries or obstetric labor or obstetric labour or normal labor or normal } \\
\text { labour or term labor or term labour or labor onset or labour onset or Second Labor Stages or Second } \\
\text { Labour Stages or Second Stage of Labor or Second Stage of Labour or Second Stage Labor or } \\
\text { Second Stage Labour or First Stage of Labor or First Stage of Labour or First Stage Labor or First } \\
\text { Stage Labor or ((labour or labor) and (Pregnant Women or pregnancy or pregnant or pregnancies or } \\
\text { gestation or Prenatal Care or childbirth or Parity or nulliparous or multiparous or Cervical Dilatation or } \\
\text { Cervical Dilatations)) }\end{array}$ \\
\hline \#3 & $\# 1$ and \#2 \\
\hline \#4 & $\begin{array}{l}\text { (labor onset or labour onset or Second Labor Stages or Second Labour Stages or Second Stage of } \\
\text { Labor or Second Stage of Labour or Second Stage Labor or Second Stage Labour or First Stage of } \\
\text { Labor or First Stage of Labour or First Stage Labor or First Stage Labor) and (Time Factors or } \\
\text { Pregnancy Outcome) }\end{array}$ \\
\hline \#5 & \#3 or \#4 \\
\hline \#6 & \#5 Publication Year from 2005 to 2016, in Cochrane Reviews (Reviews and Protocols) \\
\hline \#7 & Amnion surgery or Amniotomy \\
\hline \#8 & $\begin{array}{l}\text { Exercise or walking or ambulation or Nutrition Processes or Eating or drinking or Diet or fasting or } \\
\text { nutrition or intravenous dextrose or normal saline or Intravenous Drip or Infusion Drip or IV hydration or } \\
\text { intravenous hydration or Ringer solution or Ringer-locke solution or hydration fluids or oral fluids or } \\
\text { Bradley Method or Doulas or Doula or labor coach or labor coaches or Natural Childbirth or emotional } \\
\text { support or Coaching or Peanut ball or birthing ball or childbirth education or Lamaze or hypnobirthing } \\
\text { or hypnosis or HypnoBabies or Complementary Therapies or Healthy Birth or Patient Care Planning or } \\
\text { supplemental oxygen or oxygen supplementation or Fetal Distress or Oxygen Inhalation Therapy or } \\
\text { Hydrotherapy or hydrotherapy or hydrotherapies or Whirlpool Baths or Whirlpool Bath or birthing tub or } \\
\text { Warm Baths or warm bath or Patient Positioning or supine or Posture or Psychoprophylaxis or } \\
\text { Acupuncture or Acupressure or Aromatherapy or music therapy or massage }\end{array}$ \\
\hline$\# 9$ & epidural \\
\hline$\# 10$ & $\begin{array}{l}\text { Gynecological Examination or Gynecological Examinations or Gynecological Exam or Gynecological } \\
\text { Exams or Gynaecological Examination or Gynaecological Examinations or Gynaecological Exam or }\end{array}$ \\
\hline
\end{tabular}




\begin{tabular}{|c|c|}
\hline Search & Search String \\
\hline & $\begin{array}{l}\text { Gynaecological Exams or Vaginal Examination or Vaginal Examinations or Vaginal Exam or Vaginal } \\
\text { Exams or Cervical Examination or Cervical Examinations or Cervical Exam or Cervical Exams or } \\
\text { (Cervix and (Examination or Examinations or Exam or Exams)) or Pelvic Examination or Pelvic } \\
\text { Examinations or Pelvic Exam or Pelvic Exams }\end{array}$ \\
\hline \#11 & $\begin{array}{l}\text { Uterine Monitoring or intrauterine pressure catheter or intrauterine pressure catheters or IUPC or } \\
\text { Tocodynamometry or Tocography or Tocograms or Tocogram }\end{array}$ \\
\hline \#12 & Oxytocics or Ocytocin or Syntocinon or Pitocin or nipple stimulation \\
\hline$\# 13$ & $\begin{array}{l}\text { Valsalva Maneuvers or Valsalva Maneuver or Valsalva pushing or passive descent or delayed pushing } \\
\text { or open glottis pushing }\end{array}$ \\
\hline \#14 & $\{$ or $\# 7-\# 13\}$ \\
\hline \#15 & $\# 2$ and \#14 \\
\hline \#16 & \#15 Publication Year from 2005 to 2016, in Cochrane Reviews (Reviews and Protocols) \\
\hline \#17 & \#6 or \#16 \\
\hline
\end{tabular}

\section{Grey Literature Searches}

\section{ClinicalTrials.gov (September 26, 2018)}

\begin{tabular}{|l|l|l|l|}
\hline Search Terms & Recruitment & Study Results & Study Type \\
\hline $\begin{array}{l}\text { labor dystocia OR partogram OR (labor progress AND } \\
\text { Obstetric) }\end{array}$ & Completed studies & All studies & All studies \\
\hline
\end{tabular}

Total number of results: 33

\section{WHO: International Clinical Trials Registry Platform Search Portal (September 26, 2018)}

\begin{tabular}{|l|l|}
\hline Search Terms & labor dystocia OR partogram OR labor progress \\
\hline
\end{tabular}

Total number of results: 44

\section{National Guidelines Clearinghouse (March 23, 2016)}

Platform: www.guideline.gov

\begin{tabular}{|l|ll|}
\hline Keyword & & Clinical Specialty \\
\hline Labor & Obstetrics and Gynecology & \\
\hline
\end{tabular}

Total number of results: 49 


\section{Appendix B. Data Abstraction Elements}

\section{Study Characteristics}

- $\quad$ Study Identifiers

o Study Name or Acronym

o NCT number

o Last name of first author

- Additional Articles Used in This Abstraction

- Study Sites

o Single Center, Multicenter, Unclear/Not reported

o Number of sites

- Geographic Location (Select all that apply)

o US, Canada, UK/Europe, Latin America, Middle East (includes Israel), Asia, Africa, Australia/NZ, Unclear/Not reported

- Study Design

o RCT

o Observational

- Funding Source

o Government, Industry, Non-government/non-industry, Unclear/Not reported

- Setting

o Hospital, Birthing Center, Home Birth, Other (specify), Unclear/Not reported

- Provider

o Obstetrician, Family Physician, Nurse Midwife, Lay Midwife, Doula, Other (specify), Unclear/Not reported

- Study Definition of Dystocia as reported

- Study Enrollment/Study Completion

o $\mathrm{N}$ enrolled/included

o N completed

- $\quad$ Key Question Applicability

o KQ1, KQ2, KQ3, KQ4, KQ5, KQ6, KQ7, KQ8, KQ9

- Comments

Baseline Characteristics - Record the following elements for Total Population, Arm 1, Arm 2, Arm 3, Arm 4, Arm 5, and Arm 6 (as applicable)

- Number of Patients ( $\mathrm{N}$ and \%)

- Age in years

o Mean

o Median

o Standard Deviation

o Minimum

o Maximum

o $25 \%$ inter-quartile range

o $75 \%$ inter-quartile range

o Categorical

o Other (specify)

- $\quad$ Gender ( $\mathrm{N}$ and \%) 
o Women

o Men (Unclear/Not Reported)

- $\quad$ Race/Ethnicity (N and \%) (indicate if Reported or Unclear/Not Reported)

o Hispanic or Latino

o Black/African American

o American Indian or Alaska Native

o Asian

o Native Hawaiian or Pacific Islander

o White

o Multiracial

o Other (specify)

- Body Weight (indicate if Reported or Unclear/Not Reported)

- Parity (indicate if Unclear/Not Reported)

- Socioeconomic Factors

o Insurance Status

o Income Level

o Social Class

o Level of Education

o Other (specify)

o Unclear/Not Reported

- $\quad$ Stage of Labor at Entry into Study

0 1st stage latent ( $<4 \mathrm{~cm}$ dilation)

0 1st stage active (4 - $10 \mathrm{~cm}$ dilation)

0 2nd stage (full dilation - delivery)

o Not reported/Unclear

o Other, specify

o Additional comments

- Study Definition of Labor

- Were there potentially relevant $(\mathrm{p}<0.1)$ differences noted between groups in any baseline characteristics? (Yes/No)

0 If yes, please explain the differences

- Is this study entirely composed of a population that would be considered a subgroup of interest? (Yes/No)

o If yes, which subgroup?

- Maternal age (particularly adolescents and women 35-44 years old)

- Parity

- Maternal race/ethnicity

- Maternal socioeconomic status, including insurance status

- Maternal obesity

- Comments

\section{Intervention Characteristics}

- If applicable, describe the usual care intervention applied across all arms.

- Intervention Descriptors

o Describe the intervention received by patients in each arm (Arms 1, 2, 3, 4, 5, and 6 as applicable). 
- Intervention Components (for each Arm)

o Amniotomy

- Routine amniotomy

- Amniotomy for specific indications (e.g., placement of fetal scalp monitor or intrauterine pressure catheter)

o Supportive care measures

- Ambulation

- Routine maternal oxygen supplementation

- Specific nutritional recommendations or limitations

- Specific oral or parenteral hydration recommendations or limitations

- Continuous emotional support

- Peanut ball or birthing ball

- Lamaze

- Hypnobirthing

- Positioning

- Acupuncture

- Hydrotherapy

- Acupressure

- Aromatherapy

- Massage/warm compresses

- Cold packs

- TENS

- Anethum Graveolens (dill) supplement

- Other (specify)

o Analgesia/Pain management

- Epidural

- Other methods of analgesia (parenteral narcotics, morphine, nitrous oxide)

- Nonpharmacological methods of pain management

o Cervical examination

- Routine (indicate frequency)

- As indicated (describe indication)

- Unclear/Not reported

o Contraction monitoring

- Internal pressure catheter

- External tocodynamometry

o Oxytocin

- Low dose oxytocin

- High dose oxytocin

- Nipple stimulation

- Maternal oxygen supplementation as an adjunct to oxytocin

- Different formulations of oxytocin (specify)

o Fetal monitoring

- Internal electronic fetal monitoring

- External electronic fetal monitoring

- Intermittent auscultation of fetal heart rate

o Pushing strategy. 
- Immediate pushing

- Delayed/Valsalva pushing

- Other

o No intervention/expectant management

o Other "usual care" as defined in study

o Placebo

- Comments

\section{Outcomes}

- Select the outcome category reported on this form:

o Maternal outcomes

- Infection (chorioamnionitis, endometritis, wound infection)

- Hemorrhage

- Uterine rupture

- Hysterectomy

- Transfusion

- Trauma to the pelvic floor (vaginal/perineal/cervical/bladder/rectal injury at the time of delivery)

- Pelvic floor dysfunction (long-term urinary or fecal incontinence, fistulae, pelvic organ prolapse)

o Neonatal outcomes

- Neonatal acidemia $(\mathrm{pH}<7.1)$

- Hypoxic encephalopathy

- Respiratory distress (need for oxygen supplementation, CPAP, intubation/ventilatory support)

- Meconium aspiration syndrome

- Neonatal infection/sepsis

- Shoulder dystocia

- Birth trauma (including brachial plexus injury)

- Long-term neonatal health and developmental abnormalities (including cerebral palsy)

- Admission to NICU $>24$ hours

- Neonatal length of stay

o Process-related outcomes

- Abnormal fetal heart rate tracing

- Duration of labor

- Mode of delivery (vaginal delivery, assisted vaginal delivery, cesarean delivery)

- Parental preferences/satisfaction

- Any additional description / clarification of the outcome reported on this form

- Is this outcome form for a subgroup of interest? (Yes/No)

o What subpopulation is this outcome reported for on this form?

- Maternal age

- Maternal race/ethnicity

- Maternal obesity/BMI

- Parity 
- Socioeconomic status, including insurance status

o Any additional description / clarification of subgroup reported on this form

- Total N Analyzed for this outcome

- What timepoint is reported on this form

o Short-term: from beginning of spontaneous labor until discharge home (or equivalent for home delivery) for mother and infant

o Long-term: from discharge onwards

o Unclear

- Specify the timepoint for this outcome (with units: minutes, hours, days, weeks, months, years, NA)

- For each arm:

o N Analyzed (UNK if unknown)

o Unadjusted Result

- Mean

- Median

- Mean within group change

- Mean between group change

- Number of patients with outcome

- \% of patients with outcome

- Events/denominator

- Odds ratio

- Hazard ratio

- Relative risk

- Other (specify)

o Unadjusted Result Variability

- Standard Error (SE)

- Standard Deviation (SD)

- IQR

- $95 \% \mathrm{CI}$

- Other \% CI (specify)

- Other (specify)

o Unadjusted Result, p-value between groups

o Unadjusted Result, Reference group (for comparison between groups)

o Adjusted Result

- Mean

- Median

- Mean within group change

- Mean between group change

- Number of patients with outcome

- $\%$ of patients with outcome

- Events/denominator

- Odds ratio

- Hazard ratio

- Relative risk

- Other (specify)

o Adjusted Result Variability 
- Standard Error (SE)

- Standard Deviation (SD)

- IQR

- $95 \% \mathrm{CI}$

- Other \% CI (specify)

- Other (specify)

o Adjusted Result, p-value between groups

o Adjusted Result, Reference group (for comparison between groups)

- If adjusted data is recorded, indicate the adjustments applied

- Comments

\section{Quality}

- Study Type (select one): RCT, Observational (Case-Control or Cohort)

- If RCT, select Yes/No/Unclear for each of the following questions:

o Random sequence generation

- Was the allocation sequence generated adequately (e.g., random number table, computer-generated randomization)?

o Allocation concealment

- Was the allocation of treatment adequately concealed (e.g., pharmacycontrolled randomization or use of sequentially numbered sealed envelopes)?

o Blinding of participants, personnel and outcome assessors

- Was knowledge of the allocated intervention adequately prevented during the study?

- Were participants analyzed within the groups they were originally assigned to?

- Does the design or analysis control account for important confounding and modifying variables through matching, stratification, multivariable analysis, or other approaches?

o Incomplete outcome data

- Were incomplete outcome data adequately addressed?

o Selective outcome reporting

- Are reports of the study free of suggestion of selective outcome reporting?

0 Other sources of bias

- Was the study apparently free of other problems that could put it at a high risk of bias?

- If Case-Control, answer each of the following questions:

o Selection

- Is the case definition adequate?

- Yes, with independent validation

- Yes, e.g., record linkage or base on self reports

- No description

- Representativeness of the cases

- Consecutive or obviously representative series of cases

- Potential for selection biases or not stated

- Selection of controls 
- Community controls

- Hospital controls

- No description

- Definition of controls

- No history of disease (endpoint)

- No description of source

o Comparability

- Comparability of cases and controls on the basis of the design or analysis

- Study controls

- Study controls for any additional factor

o Exposure

- Ascertainment of exposure

- Secure record (e.g., surgical records)

- Structured interview where blind to case/control status

- Interview not blinded to case/control status

- Written self report or medical record only

- No description

- Same method of ascertainment for cases and controls

- Yes

- No

- Non-response rate

- Same rate for both groups

- Non-respondent described

- Rate different and no designation

- If Cohort, answer each of the following questions:

o Selection

- Representativeness of the exposed cohort

- Truly representative of the average _ in the community

- Somewhat representative of the average _ in the community

- Selected group of users (e.g., nurses, volunteers)

- No description of the derivation of the cohort

- Selection of the non-exposed cohort

- Drawn from the same community as the exposed cohort

- Drawn from a different source

- No description of the derivation of the non-exposed cohort

- Ascertainment of exposure

- Secure record (e.g., surgical records)

- Structured interview

- Written self report

- No description

- Demonstration that outcome of interest was not present at start of study

- Yes

- No

o Comparability

- Comparability of cohorts on the basis of the design or analysis 
- Study controls

- Study controls for any additional factor

o Outcome

- Assessment of outcome

- Independent blind assessment

- Record linkage

- Self report

- No description

- Was follow-up long enough for outcome to occur

- Yes

- No

- Adequacy of follow up of cohorts

- Complete follow up-all subjects accounted for

- Subjects lost to follow up unlikely to introduce bias - small number lost - >95\% follow up, or description provided of those lost

- Follow up rate $<95 \%$ and no description of those lost

- No statement

- Overall Study Rating (Good/Fair/Poor)

o Good (low risk of bias). These studies have the least bias, and the results are considered valid. These studies adhere to the commonly held concepts of high quality, including the following: a clear description of the population, setting, approaches, and comparison groups; appropriate measurement of outcomes; appropriate statistical and analytical methods and reporting; no reporting errors; a low dropout rate; and clear reporting of dropouts.

o Fair. These studies are susceptible to some bias, but not enough to invalidate the results. They do not meet all the criteria required for a rating of good quality because they have some deficiencies, but no flaw is likely to cause major bias. The study may be missing information, making it difficult to assess limitations and potential problems.

o Poor (high risk of bias). These studies have significant flaws that may have invalidated the results. They have serious errors in design, analysis, or reporting; large amounts of missing information; or discrepancies in reporting.

o If the study is rated as "Fair" or "Poor," provide rationale.

- Outcome-specific quality rating

0 Do you think that any of the outcomes abstracted for this study should be assigned a quality rating DIFFERENT from the overall study rating? (No/Yes)

- If you think any of the abstracted outcomes should have a quality rating different from the overall study, please provide the outcome(s), rating(s) and rationale(s). 
Applicability - Use the PICOS format to identify specific issues, if any, that may limit the applicability of the study.

- Population (P)

o Study population demographics not representative of intended population

o Narrow or unrepresentative severity/stage/comorbidity

- Intervention (I)

o Treatment protocol not representative of current practice

o Change in standard of care

- Comparator (C)

o Comparator not representative of current practice

- Outcomes $(\mathrm{O})$

o Timing of outcome assessment

- $\quad$ Setting (S)

o Standards or access to care vary from US setting

o Specialty population or level of care

- $\quad$ Do you have any other concerns regarding applicability of this study? (Yes/No)

- Comments 


\section{Appendix C. List of Included Studies}

Abdullah A, Saboohi S and Hashami U. Effects of amniotomy versus spontaneous rupture of membrane on progress of labour and foetal outcome in primigravidae. Journal of the Liaquat University of Medical and Health Sciences 2010;9(1):33-36.

Abrao KC, Francisco RP, Miyadahira S, et al. Elevation of uterine basal tone and fetal heart rate abnormalities after labor analgesia: a randomized controlled trial. Obstet Gynecol 2009;113(1):41-7. DOI: 10.1097/AOG.0b013e31818f5eb6. PMID: 19104358.

Ajadi MA, Kuti O, Orji EO, et al. The effect of amniotomy on the outcome of spontaneous labour in uncomplicated pregnancy. J Obstet Gynaecol 2006;26(7):631-4. DOI:

10.1080/01443610600903420. PMID: 17071428.

Akbarzadeh M, Masoudi Z, Zare N, et al. Comparison of the effects of doula supportive care and acupressure at the BL32 point on the mother's anxiety level and delivery outcome. Iran J Nurs Midwifery Res 2015;20(2):239-46. PMID: 25878703.

Akbarzadeh M, Masoudi Z, Zare N, et al. Comparison of the Effects of Maternal Supportive Care and Acupressure (at BL32 Acupoint) on Labor Length and Infant's Apgar Score. Glob J Health Sci 2015;8(3):48239. DOI: 10.5539/gjhs.v8n3p236. PMID: 26493430.

Albers LL, Sedler KD, Bedrick EJ, et al. Midwifery care measures in the second stage of labor and reduction of genital tract trauma at birth: a randomized trial. J Midwifery Womens Health 2005;50(5):365-72. DOI:

10.1016/j.jmwh.2005.05.012. PMID: 16154062.

Allameh Z, Tehrani HG and Ghasemi M. Comparing the impact of acupuncture and pethidine on reducing labor pain. Adv Biomed Res 2015;4:46. DOI: 10.4103/2277-9175.151302. PMID: 25789272.

Altman D, Ragnar I, Ekstrom A, et al. Anal sphincter lacerations and upright delivery postures--a risk analysis from a randomized controlled trial. Int Urogynecol J Pelvic Floor Dysfunct 2007;18(2):1416. DOI: 10.1007/s00192-006-0123-9. PMID: 16636770.
Anim-Somuah M, Smyth RM and Jones L. Epidural versus non-epidural or no analgesia in labour. Cochrane Database Syst Rev 2011;(12):Cd000331. DOI: 10.1002/14651858.CD000331.pub3. PMID: 22161362.

Asadi N, Maharlouei N, Khalili A, et al. Effects of LI-4 and SP-6 Acupuncture on Labor Pain, Cortisol Level and Duration of Labor. J Acupunct Meridian Stud 2015;8(5):249-54. DOI:

10.1016/j.jams.2015.08.003. PMID: 26433802.

Bakker JJ, Janssen PF, van Halem K, et al. Internal versus external tocodynamometry during induced or augmented labour. Cochrane Database Syst Rev 2013;8:Cd006947. DOI: 10.1002/14651858.CD006947.pub3. PMID: 23913521.

Bergqvist L, Dencker A, Taft C, et al. Women's experiences after early versus postponed oxytocin treatment of slow progress in first childbirth--a randomized controlled trial. Sex Reprod Healthc 2012;3(2):61-5. DOI: 10.1016/j.srhc.2012.03.003. PMID: 22578752.

Bhagwat A, Dua C, Saxena K, et al. Comparison of combined spinal epidural technique and low dose epidural technique in progress of labour. Indian J Anaesth 2008;52(3):282-7.

Bloom SL, Casey BM, Schaffer JI, et al. A randomized trial of coached versus uncoached maternal pushing during the second stage of labor. Am J Obstet Gynecol 2006;194(1):10-3. DOI: 10.1016/j.ajog.2005.06.022. PMID: 16389004.

Brown HC, Paranjothy S, Dowswell T, et al. Package of care for active management in labour for reducing caesarean section rates in low-risk women. Cochrane Database Syst Rev 2013;9:Cd004907. DOI: 10.1002/14651858.CD004907.pub3. PMID: 24043476.

Bruggemann OM, Parpinelli MA, Osis MJD, et al. Support to woman by a companion of her choice during childbirth: A randomized controlled trial. Reproductive Health 2007;4. 
Bugg GJ, Siddiqui F and Thornton JG. Oxytocin versus no treatment or delayed treatment for slow progress in the first stage of spontaneous labour. Cochrane Database Syst Rev 2013;6:Cd007123. DOI: 10.1002/14651858.CD007123.pub3. PMID: 23794255.

Cahill AG, Srinivas SK, Tita ATN, et al. Effect of Immediate vs Delayed Pushing on Rates of Spontaneous Vaginal Delivery Among Nulliparous Women Receiving Neuraxial Analgesia: A Randomized Clinical Trial. Jama 2018;320(14):14441454. DOI: 10.1001/jama.2018.13986. PMID: 30304425.

Chaichian S, Akhlaghi A, Rousta F, et al. Experience of water birth delivery in Iran. Arch Iran Med 2009;12(5):468-71. PMID: 19722768.

Cheng YW, Shaffer BL, Bryant AS, et al. Length of the first stage of labor and associated perinatal outcomes in nulliparous women. Obstet Gynecol 2010;116(5):1127-35. DOI: 10.1097/AOG.0b013e3181f5eaf0. PMID: 20966698.

Cluett ER and Burns E. Immersion in water in labour and birth. Cochrane Database Syst Rev 2009;(2):Cd000111. DOI: 10.1002/14651858.CD000111.pub3. PMID: 19370552.

Coco A, Derksen-Schrock A, Coco K, et al. A randomized trial of increased intravenous hydration in labor when oral fluid is unrestricted. Fam Med 2010;42(1):52-6. PMID: 20063224.

Costley PL and East CE. Oxytocin augmentation of labour in women with epidural analgesia for reducing operative deliveries. Cochrane Database Syst Rev 2012;5:Cd009241. DOI: 10.1002/14651858.CD009241.pub2. PMID: 22592738.

Dahlen HG, Homer CS, Cooke M, et al. Perineal outcomes and maternal comfort related to the application of perineal warm packs in the second stage of labor: a randomized controlled trial. Birth: Issues in Perinatal Care 2007;34(4):282-290 9p.

Dawood F, Dowswell T and Quenby S. Intravenous fluids for reducing the duration of labour in low risk nulliparous women. Cochrane Database Syst Rev 2013;6:Cd007715. DOI: 10.1002/14651858.CD007715.pub2. PMID: 23780639. de Orange FA, Passini R, Jr., Amorim MM, et al. Combined spinal and epidural anaesthesia and maternal intrapartum temperature during vaginal delivery: a randomized clinical trial. Br J Anaesth 2011;107(5):762-8. DOI: 10.1093/bja/aer218. PMID: 21743067.

Dencker A, Berg M, Bergqvist L, et al. Early versus delayed oxytocin augmentation in nulliparous women with prolonged labour--a randomised controlled trial. Bjog 2009;116(4):530-6. DOI: 10.1111/j.14710528.2008.01962.x. PMID: 19250364.

Direkvand-Moghadam A and Rezaeian M. Increased intravenous hydration of nulliparas in labor. Int $\mathrm{J}$ Gynaecol Obstet 2012;118(3):213-5. DOI: 10.1016/j.ijgo.2012.03.041. PMID: 22717414.

Douma MR, Middeldorp JM, Verwey RA, et al. A randomised comparison of intravenous remifentanil patient-controlled analgesia with epidural ropivacaine/sufentanil during labour. Int J Obstet Anesth 2011;20(2):118-23. DOI: 10.1016/j.ijoa.2010.11.009. PMID: 21376564.

Downe S, Gyte GM, Dahlen HG, et al. Routine vaginal examinations for assessing progress of labour to improve outcomes for women and babies at term. Cochrane Database Syst Rev 2013;7:Cd010088. DOI: 10.1002/14651858.CD010088.pub2. PMID: 23857468.

Edwards RK, Reed CA, Villano KS, et al. Effect of hydration on spontaneous labor outcomes in nulliparous pregnant women: a multicenter randomized controlled trial comparing three methods. Am J Perinatol 2014;31(6):455-62. DOI: 10.1055/s0033-1351661. PMID: 23884718.

El Hamid, Obaya HE and Gaafar HM. Effect of Acupressure on Labor Pain and Duration of Delivery among Laboring Women Attending Cairo University Hospital. Indian Journal of Physiotherapy \& Occupational Therapy 2013;7(2):71-76.

Eslamian L, Marsoosi V and Pakneeyat Y. Increased intravenous fluid intake and the course of labor in nulliparous women. Int J Gynaecol Obstet 2006;93(2):102-5. DOI: 10.1016/j.ijgo.2006.01.023. PMID: 16542657. 
Fahdhy M and Chongsuvivatwong V. Evaluation of World Health Organization partograph implementation by midwives for maternity home birth in Medan, Indonesia. Midwifery 2005;21(4):301-10. DOI: 10.1016/j.midw.2004.12.010. PMID: 16076515.

Fortier JH and Godwin M. Doula support compared with standard care: Meta-analysis of the effects on the rate of medical interventions during labour for low-risk women delivering at term. Canadian Family Physician 2015;61(6):e284-e292.

Frigo MG, Larciprete G, Rossi F, et al. Rebuilding the labor curve during neuraxial analgesia. J Obstet Gynaecol Res 2011;37(11):1532-9. DOI:

10.1111/j.1447-0756.2011.01568.x. PMID: 21676079.

Ganapathy T. Childbirth in Supported Sitting Maternal Position. International Journal of Nursing Education 2012;4(2):87-91 5p.

Genc M, Sahin N, Maral J, et al. Does bupivacaine and fentanyl combination for epidural analgesia shorten the duration of labour?. J Obstet Gynaecol 2015;35(7):672-5. DOI:

10.3109/01443615.2014.991299. PMID: 25546524.

Ghafarzadeh M, Moeininasab S and Namdari M. Effect of early amniotomy on dystocia risk and cesarean delivery in nulliparous women: a randomized clinical trial. Arch Gynecol Obstet 2015;292(2):321-5. DOI: 10.1007/s00404-015-3645x. PMID: 25666481.

Greenberg MB, Cheng YW, Sullivan M, et al. Does length of labor vary by maternal age? Am J Obstet Gynecol 2007;197(4):428.e1-7. DOI: 10.1016/j.ajog.2007.06.058. PMID: 17904990.

Hamidzadeh A, Shahpourian F, Orak RJ, et al. Effects of LI4 acupressure on labor pain in the first stage of labor. J Midwifery Womens Health 2012;57(2):133-8. DOI: 10.1111/j.15422011.2011.00138.x. PMID: 22432484.

Hekmatzadeh SF, Bazarganipour F, Malekzadeh J, et al. A randomized clinical trial of the efficacy of applying a simple protocol of boiled Anethum Graveolens seeds on pain intensity and duration of labor stages. Complementary Therapies in Medicine 2014;22(6):970-976 7p. DOI:

10.1016/j.ctim.2014.10.007.
Hinshaw K, Simpson S, Cummings S, et al. A randomised controlled trial of early versus delayed oxytocin augmentation to treat primary dysfunctional labour in nulliparous women. Bjog 2008;115(10):1289-95; discussion 1295-6. DOI: 10.1111/j.1471-0528.2008.01819.x. PMID: 18715415.

Hodnett Ellen D, Gates S, Hofmeyr GJ, et al. Continuous support for women during childbirth. 2013;(7). DOI: 10.1002/14651858.CD003766.pub5. PMID: CD003766.

Hoppe KK, Schiff MA, Benedetti TJ, et al. Duration of Spontaneous Active Labor and Perinatal Outcomes Using Contemporary Labor Curves. American Journal of Perinatology 2018;35(12):1186-1191. DOI: $10.1055 / \mathrm{s}-0038-1642045$.

Ismail MT and Hassanin MZ. Neuraxial analgesia versus intravenous remifentanil for pain relief in early labor in nulliparous women. Arch Gynecol Obstet 2012;286(6):1375-81. DOI: 10.1007/s00404012-2459-3. PMID: 22810619.

Jaitley A, Singh S, Srivastava U, et al. A comparison between epidural and IV tramadol for painless labor and effect on perinatal outcome. Journal of Obstetrics and Gynecology of India 2011;61(1):42-47.

Jalil NA and Omar M. Does ropivacaine $0.2 \%$ with fentanyl change the labour epidural profile? International Medical Journal 2009;16(2):149-155.

Janssen P, Shroff F and Jaspar P. Massage therapy and labor outcomes: a randomized controlled trial. Int J Ther Massage Bodywork 2012;5(4):15-20. PMID: 23429706.

Kashanian M and Shahali S. Effects of acupressure at the Sanyinjiao point (SP6) on the process of active phase of labor in nulliparas women. Journal of Maternal-Fetal and Neonatal Medicine 2010;23(7):638-641.

Kaviani M, Azima S, Alavi N, et al. The effect of lavender aromatherapy on pain perception and intrapartum outcome in primiparous women. British Journal of Midwifery 2014;22(2):125-128 4p.

Kaviani M, Maghbool S, Azima S, et al. Comparison of the effect of aromatherapy with Jasminum officinale and Salvia officinale on pain severity and labor outcome in nulliparous women. Iran J Nurs Midwifery Res 2014;19(6):666-72. PMID: 25558267. 
Kavitha A, Chacko KP, Thomas E, et al. A randomized controlled trial to study the effect of IV hydration on the duration of labor in nulliparous women. Arch Gynecol Obstet 2012;285(2):343-6. DOI: 10.1007/s00404-011-1978-7. PMID: 21748313.

Kenyon S, Armstrong N, Johnston T, et al. Standardor high-dose oxytocin for nulliparous women with confirmed delay in labour: quantitative and qualitative results from a pilot randomised controlled trial. Bjog 2013;120(11):1403-12. DOI: 10.1111/1471-0528.12331. PMID: 23786339.

Kenyon S, Tokumasu H, Dowswell T, et al. Highdose versus low-dose oxytocin for augmentation of delayed labour. Cochrane Database Syst Rev 2013;7:Cd007201. DOI:

10.1002/14651858.CD007201.pub3. PMID: 23853046.

Kotaska AJ, Klein MC and Liston RM. Epidural analgesia associated with low-dose oxytocin augmentation increases cesarean births: a critical look at the external validity of randomized trials. Am J Obstet Gynecol 2006;194(3):809-14. DOI: 10.1016/j.ajog.2005.09.014. PMID: 16522417.

Lavender T, Alfirevic Z and Walkinshaw S. Effect of different partogram action lines on birth outcomes: a randomized controlled trial. Obstet Gynecol 2006;108(2):295-302. DOI:

10.1097/01.AOG.0000226862.78768.5c. PMID: 16880298.

Lavender T, Hart A and Smyth RM. Effect of partogram use on outcomes for women in spontaneous labour at term. Cochrane Database Syst Rev 2013;7:Cd005461. DOI:

10.1002/14651858.CD005461.pub4. PMID: 23843091.

Lawrence A, Lewis L, Hofmeyr GJ, et al. Maternal positions and mobility during first stage labour. Cochrane Database Syst Rev 2013;10:Cd003934. DOI: 10.1002/14651858.CD003934.pub4. PMID: 24105444.

Leanza V, Leanza G and Monte S. A didactic protocol for labour and delivery: the partogram. Minerva Ginecol 2011;63(4):325-32. PMID: 21747340.
Liu Y, Xu M, Che X, et al. Effect of direct current pulse stimulating acupoints of JiaJi (T10-13) and Ciliao (BL 32) with Han's Acupoint Nerve Stimulator on labour pain in women: a randomized controlled clinical study. J Tradit Chin Med 2015;35(6):620-5. PMID: 26742304.

Liu ZQ, Chen XB, Li HB, et al. A comparison of remifentanil parturient-controlled intravenous analgesia with epidural analgesia: a meta-analysis of randomized controlled trials. Anesth Analg 2014;118(3):598-603. DOI: 10.1213/ane.0000000000000077. PMID: 24557106.

Ma W, Bai W, Lin C, et al. Effects of Sanyinjiao (SP6) with electroacupuncture on labour pain in women during labour. Complement Ther Med 2011;19(Suppl 1):S13-8. DOI: 10.1016/j.ctim.2010.09.001. PMID: 21195290.

Marucci M, Cinnella G, Perchiazzi G, et al. Patientrequested neuraxial analgesia for labor: impact on rates of cesarean and instrumental vaginal delivery. Anesthesiology 2007;106(5):1035-45. DOI: 10.1097/01.anes.0000265165.06760.c2. PMID: 17457137.

McGrath SK and Kennell JH. A randomized controlled trial of continuous labor support for middle-class couples: effect on cesarean delivery rates. Birth 2008;35(2):92-7. DOI: 10.1111/j.1523536X.2008.00221.x. PMID: 18507579.

Mikki N, Wick L, Abu-Asab N, et al. A trial of amniotomy in a Palestinian hospital. J Obstet Gynaecol 2007;27(4):368-73. DOI: 10.1080/01443610701327537. PMID: 17654188.

Miquelutti MA, Cecatti JG and Makuch MY. Upright position during the first stage of labor: a randomised controlled trial. Acta Obstet Gynecol Scand 2007;86(5):553-8. DOI: 10.1080/00016340601185251. PMID: 17464583.

Mortazavi SH, Khaki S, Moradi R, et al. Effects of massage therapy and presence of attendant on pain, anxiety and satisfaction during labor. Arch Gynecol Obstet 2012;286(1):19-23. DOI: 10.1007/s00404012-2227-4. PMID: 22271239.

Nachum Z, Garmi G, Kadan Y, et al. Comparison between amniotomy, oxytocin or both for augmentation of labor in prolonged latent phase: a randomized controlled trial. Reprod Biol Endocrinol 2010;8:136. DOI: 10.1186/1477-7827-8-136. PMID: 21054896. 
Nafisi S. Effects of epidural lidocaine analgesia on labor and delivery: a randomized, prospective, controlled trial. BMC Anesthesiol 2006;6:15. DOI: 10.1186/1471-2253-6-15. PMID: 17176461.

Nakamura G, Ganem EM, Rugolo LM, et al. Effects on mother and fetus of epidural and combined spinalepidural techniques for labor analgesia. Rev Assoc Med Bras 2009;55(4):405-9. PMID: 19750306.

Nasir A, Korejo R and Noorani KJ. Child birth in squatting position. J Pak Med Assoc 2007;57(1):1922. PMID: 17319414.

Neal JL, Lamp JM, Buck JS, et al. Outcomes of nulliparous women with spontaneous labor onset admitted to hospitals in preactive versus active labor. J Midwifery Womens Health 2014;59(1):28-34. DOI: 10.1111/jmwh.12160. PMID: 24512265.

Neal JL, Lowe NK, Ahijevych KL, et al. "Active labor" duration and dilation rates among low-risk, nulliparous women with spontaneous labor onset: a systematic review. J Midwifery Womens Health 2010;55(4):308-18. DOI: 10.1016/j.jmwh.2009.08.004. PMID: 20630357.

Ohel G, Gonen R, Vaida S, et al. Early versus late initiation of epidural analgesia in labor: does it increase the risk of cesarean section? A randomized trial. Am J Obstet Gynecol 2006;194(3):600-5. DOI: 10.1016/j.ajog.2005.10.821. PMID: 16522386.

Orange FA, Passini-Jr R, Melo AS, et al. Combined spinal-epidural anesthesia and non-pharmacological methods of pain relief during normal childbirth and maternal satisfaction: a randomized clinical trial. Rev Assoc Med Bras 2012;58(1):112-7. PMID: 22392325.

Palomaki O, Uotila J, Tammela O, et al. A double blind, randomized trial on augmentation of labour with a combination of intravenous propranolol and oxytocin versus oxytocin only. Eur J Obstet Gynecol Reprod Biol 2006;125(1):44-9. DOI: 10.1016/j.ejogrb.2005.06.016. PMID: 16051416.

Pascual-Ramirez J, Haya J, Perez-Lopez F, et al. Type of axial analgesia does not influence time to vaginal delivery in a Proportional Hazards Model. Arch Gynecol Obstet 2012;286(4):873-80. DOI: 10.1007/s00404-012-2360-0. PMID: 22639135.
Pascual-Ramirez J, Haya J, Perez-Lopez FR, et al. Effect of combined spinal-epidural analgesia versus epidural analgesia on labor and delivery duration. Int J Gynaecol Obstet 2011;114(3):246-50. DOI: 10.1016/j.ijgo.2011.04.004. PMID: 21719012.

Patel NP, El-Wahab N, Fernando R, et al. Fetal effects of combined spinal-epidural vs epidural labour analgesia: a prospective, randomised doubleblind study. Anaesthesia 2014;69(5):458-67. DOI: 10.1111/anae.12602. PMID: 24738803.

Phumdoung S, Youngvanichsate S, Jongpaiboonpatana $\mathrm{W}$, et al. The effects of the PSU Cat position and music on length of time in the active phase of labor and labor pain. Thai Journal of Nursing Research 2007;11(2):96-105 10p.

Prabhakar D, George LS and Karkada S. Effectiveness of Ambulation during First Stage of Labour, on the Outcome of Labour among Primigravid Women in Selected Hospitals of Palakkad District, Kerala. International Journal of Nursing Education 2015;7(1):1-6 6p. DOI: 10.5958/0974-9357.2015.00001.X.

Ragnar I, Altman D, Tyden T, et al. Comparison of the maternal experience and duration of labour in two upright delivery positions--a randomised controlled trial. Bjog 2006;113(2):165-70. DOI: 10.1111/j.14710528.2005.00824.x. PMID: 16411993.

Rahmani R, Khakbazan Z, Yavari P, et al. Effect of oral carbohydrate intake on labor progress: randomized controlled trial. Iran J Public Health 2012;41(11):59-66. PMID: 23304677.

Santhi, Anuratha and Kokilavani. Effectiveness of semi sitting position during 2nd stage of labour on maternal and neonatal outcomes among primigravida. Nurs J India 2012;103(6):272-5. PMID: 23923599.

Sasitorn P, Boonrueing M, Kitti R, et al. Effect of the Prince of Songkla University Birthing Bed on Duration, Pain, and Comfort Level during SecondStage Labor in Primiparous Thais. Pacific Rim International Journal of Nursing Research 2013;17(1):56-67 12p.

Schaffer JI, Bloom SL, Casey BM, et al. A randomized trial of the effects of coached vs uncoached maternal pushing during the second stage of labor on postpartum pelvic floor structure and function. Am J Obstet Gynecol 2005;192(5):1692-6. DOI: 10.1016/j.ajog.2004.11.043. PMID: 15902179. 
Selin L, Wennerholm UB, Jonsson M, et al. Highdose versus low-dose of oxytocin for labour augmentation: a randomised controlled trial. Women Birth 2018. DOI: 10.1016/j.wombi.2018.09.002. PMID: 30341003.

Sezer OA and Gunaydin B. Efficacy of patientcontrolled epidural analgesia after initiation with epidural or combined spinal-epidural analgesia. Int $\mathrm{J}$ Obstet Anesth 2007;16(3):226-30. DOI: 10.1016/j.ijoa.2007.02.007. PMID: 17509869.

Sharma C, Kalra J, Bagga R, et al. A randomized controlled trial comparing parenteral normal saline with and without $5 \%$ dextrose on the course of labor in nulliparous women. Arch Gynecol Obstet 2012;286(6):1425-30. DOI: 10.1007/s00404-0122485-1. PMID: 22865033.

Shirvani MA and Ganji Z. The influence of cold pack on labour pain relief and birth outcomes: a randomised controlled trial. Journal of Clinical Nursing 2014;23(17/18):2473-2480 8p. DOI: 10.1111/jocn.12413.

Shrivastava VK, Garite TJ, Jenkins SM, et al. A randomized, double-blinded, controlled trial comparing parenteral normal saline with and without dextrose on the course of labor in nulliparas. Am J Obstet Gynecol 2009;200(4):379.e1-6. DOI: 10.1016/j.ajog.2008.11.030. PMID: 19217592.

Silva Gallo RB, Santana LS, Jorge Ferreira CH, et al. Massage reduced severity of pain during labour: a randomised trial. J Physiother 2013;59(2):109-16. DOI: 10.1016/s1836-9553(13)70163-2. PMID: 23663796.

Singata M, Tranmer J and Gyte GM. Restricting oral fluid and food intake during labour. Cochrane Database Syst Rev 2013;8:Cd003930. DOI: 10.1002/14651858.CD003930.pub3. PMID: 23966209.

Smith CA, Collins CT, Crowther CA, et al. Acupuncture or acupressure for pain management in labour. Cochrane Database Syst Rev

2011;(7):Cd009232. DOI:

10.1002/14651858.cd009232. PMID: 21735441.

Smyth RM, Markham C and Dowswell T. Amniotomy for shortening spontaneous labour. Cochrane Database Syst Rev 2013;6:Cd006167. DOI: 10.1002/14651858.CD006167.pub4. PMID: 23780653.
Somprasit C, Tanprasertkul C and Kamudhamas A. Reducing cesarean delivery rates: an active management labor program in a setting with limited resources. J Med Assoc Thai 2005;88(1):20-5.

PMID: 15960212.

Souza JP, Miquelutti MA, Cecatti JG, et al. Maternal position during the first stage of labor: a systematic review. Reprod Health 2006;3:10. DOI:

10.1186/1742-4755-3-10. PMID: 17137501.

Suzuki R, Horiuchi S and Ohtsu H. Evaluation of the labor curve in nulliparous Japanese women. Am J Obstet Gynecol 2010;203(3):226.e1-6. DOI: 10.1016/j.ajog.2010.04.014. PMID: 20494329.

Sweed N, Sabry N, Azab T, et al. Regional versus IV analgesics in labor. Minerva Med 2011;102(5):35361. PMID: 22193345.

Taavoni S, Abdolahian S, Haghani H, et al. Effect of birth ball usage on pain in the active phase of labor: a randomized controlled trial. J Midwifery Womens Health 2011;56(2):137-40. DOI: 10.1111/j.15422011.2010.00013.x. PMID: 21429078.

Thies-Lagergren L, Kvist LJ, Sandin-Bojo AK, et al. Labour augmentation and fetal outcomes in relation to birth positions: a secondary analysis of an RCT evaluating birth seat births. Midwifery 2013;29(4):344-50. DOI: 10.1016/j.midw.2011.12.014. PMID: 23084490.

Tribe RM, Crawshaw SE, Seed P, et al. Pulsatile versus continuous administration of oxytocin for induction and augmentation of labor: two randomized controlled trials. Am J Obstet Gynecol

2012;206(3):230.e1-8. DOI:

10.1016/j.ajog.2011.11.001. PMID: 22206748.

Tussey CM, Botsios E, Gerkin RD, et al. Reducing Length of Labor and Cesarean Surgery Rate Using a Peanut Ball for Women Laboring With an Epidural. Journal of Perinatal Education 2015;24(1):16-24 9p. DOI: 10.1891/1058-1243.24.1.16.

Tveit TO, Seiler S, Halvorsen A, et al. Labour analgesia: a randomised, controlled trial comparing intravenous remifentanil and epidural analgesia with ropivacaine and fentanyl. Eur J Anaesthesiol 2012;29(3):129-36. DOI: 10.1097/EJA.0b013e32834dfa98. PMID: 22249153. 
Vaijayanthimala M and Judie A. Mobility is an adjuvant approach for intrapartum care - A clinical randomized interventional study. International Journal of Pharmaceutical and Clinical Research 2014;6(4):356-362.

Vixner L, Schytt E, Stener-Victorin E, et al. Acupuncture with manual and electrical stimulation for labour pain: a longitudinal randomised controlled trial. BMC Complement Altern Med 2014;14:187.

DOI: 10.1186/1472-6882-14-187. PMID: 24913704.

Wassen MM, Smits LJ, Scheepers HC, et al. Routine labour epidural analgesia versus labour analgesia on request: a randomised non-inferiority trial. Bjog 2015;122(3):344-50. DOI: 10.1111/14710528.12854. PMID: 24849943.

Wei SQ, Luo ZC, Qi HP, et al. High-dose vs lowdose oxytocin for labor augmentation: a systematic review. Am J Obstet Gynecol 2010;203(4):296-304. DOI: 10.1016/j.ajog.2010.03.007. PMID: 20451894.

Wei SQ, Luo ZC, Xu H, et al. The effect of early oxytocin augmentation in labor: a meta-analysis. Obstet Gynecol 2009;114(3):641-9. DOI: 10.1097/AOG.0b013e3181b11cb8. PMID: 19701046.

Wilson MJ, MacArthur C, Cooper GM, et al. Ambulation in labour and delivery mode: a randomised controlled trial of high-dose vs mobile epidural analgesia. Anaesthesia 2009;64(3):266-72. DOI: 10.1111/j.1365-2044.2008.05756.x. PMID: 19302638.

Wilson MJ, Moore PA, Shennan A, et al. Long-term effects of epidural analgesia in labor: a randomized controlled trial comparing high dose with two mobile techniques. Birth 2011;38(2):105-10. DOI:

10.1111/j.1523-536X.2010.00466.x. PMID: 21599732.
Wong CA, Scavone BM, Peaceman AM, et al. The risk of cesarean delivery with neuraxial analgesia given early versus late in labor. N Engl J Med 2005;352(7):655-65. DOI: 10.1056/NEJMoa042573. PMID: 15716559.

Xiao J, Yi W and Wu L. Effects of electroacupuncture on reducing labor pain and complications in the labor analgesia process of combined spinal-epidural analgesia with patientcontrolled epidural analgesia. Archives of Gynecology \& Obstetrics 2019;299(1):123-128. DOI: 10.1007/s00404-018-4955-6. PMID: 134079027

Yildirim G and Beji NK. Effects of pushing techniques in birth on mother and fetus: a randomized study. Birth 2008;35(1):25-30. DOI: 10.1111/j.1523-536X.2007.00208.x. PMID: 18307484.

Yuenyong S, O'Brien B and Jirapeet V. Effects of labor support from close female relative on labor and maternal satisfaction in a Thai setting. J Obstet Gynecol Neonatal Nurs 2012;41(1):45-56. DOI: 10.1111/j.1552-6909.2011.01311.x. PMID: 22834721.

Zhang J, Landy HJ, Branch DW, et al. Contemporary patterns of spontaneous labor with normal neonatal outcomes. Obstet Gynecol 2010;116(6):1281-7. DOI: 10.1097/AOG.0b013e3181fdef6e. PMID: 21099592.

Zhang J, Troendle J, Mikolajczyk R, et al. The natural history of the normal first stage of labor. Obstet Gynecol 2010;115(4):705-10. DOI: 10.1097/AOG.0b013e3181d55925. PMID: 20308828.

Zhang L, Troendle J, Branch DW, et al. The expected labor progression after labor augmentation with oxytocin: A retrospective cohort study. PLoS One 2018;13(10):e0205735. DOI: 10.1371/journal.pone.0205735. PMID: 30379856. 


\section{Appendix D. List of Excluded Studies}

All studies listed below were reviewed in their full-text version and excluded for the reasons cited. Reasons for exclusion signify only the usefulness of the articles for this study and are not intended as criticisms of the articles.

\section{Not a full publication (abstract or poster only) OR article retracted/withdrawn OR publication not available:}

Aghamohammadi A. Using transcutaneous electrical nerve stimulation on acupuncture points for labor augmentation. HealthMED 2012;6(9):2965-2968.

Ajoodani Z, Heidari P and Nasrollahi S. A randomized controlled trial of labor management based on Partogram. International Journal of Academic Research 2015;7(1):514-517.

Akbarzadeh M, Moradi Z, Zare N, et al. Comparison of the Effects of One-Step Acupressure of Spleen Point 6 (SP-6) and Gall Bladder 21 (GB-21) on the Duration and Type of Delivery in Nulliparous Women Referred to Hospitals in Shiraz University of Medical Sciences, Iran: A Randomized. Qom University of Medical Sciences Journal 2013;7(3):23-25 3p.

Anonymous. Birthing in an upright position protects the perineum. Journal of Midwifery \& Women’s Health 2016;61(4):519-520. DOI: 10.1111/jmwh.12496_7. PMID: 117042674.

Becker J, Westerhuis M, Sterrenburg K, et al. Fetal blood sampling in the Dutch STAN-trial: Reason to adjust the clinical guidelines?. American Journal of Obstetrics and Gynecology 2009;201(6):S190.

Belfort MA, Saade GR, Thom E, et al. A Randomized Trial of Intrapartum Fetal ECG STSegment Analysis. New England Journal of Medicine 2015;373(7):632-641 10p. DOI: 10.1056/NEJMoa1500600.

Bellussi F, Youssef A, Ghi T, et al. OP26.06: Traditionally coached versus sonographically coached second stage of labour: a randomised control trial. Ultrasound in Obstetrics \& Gynecology 2016;48:136-137. DOI: 10.1002/uog.16410. PMID: 117953857.

Cohen SM, Lipschuetz M, Kabiri D, et al. EP19.08: Prolonging the second stage of labour increases risks of complications. Ultrasound in Obstetrics \& Gynecology 2017;50:349-350. DOI: 10.1002/uog.18635. PMID: 125201160.

Duhig K, MacArthur C and Shennan A. The hypotensive and fetal heart rate response to low dose epidurals: analysis of an RCT data set [abstract]. Journal of Obstetrics and Gynaecology 2007;27(Suppl 1):S63-64.

Duhig K, MacArthur C, May A, et al. The hypotensive and fetal heart rate response to low-dose epidurals: analysis of a randomised trial dataset [abstract]. Int J Obstet Anesth 2007;16(Suppl 1):S7. 
Fotinos C. Use of a 2 hour partogram action line instead of a 4 hour action line did not reduce caesarean delivery rate: Commentary. Evidence-Based Medicine 2007;12(2):46.

Gilliam ML. Oxytocin versus no treatment or delayed treatment for slow progress in the first stage of spontaneous labour. Obstetrics and Gynecology 2011;118(5):1174-1175.

Hanson U. Cardiotocography and ST analysis for intrapartum fetal monitoring. The Lancet 2011;378(9797):1137-1138.

Hodnett ED. WITHDRAWN: Caregiver support for women during childbirth. Cochrane Database Syst Rev 2002;(1):Cd000199. DOI: 10.1002/14651858.cd000199. PMID: 17636618.

Kripke C. Upright vs. recumbent maternal position during first stage of labor. American Family Physician 2010;81(3):285-285 1p.

Kwee A. Cardiotocography plus ST-analysis of the fetal electrocardiogram versus cardiotocography only for intrapartum monitoring: a Dutch randomized trial. Journal of Perinatal Medicine 2009;37(Suppl 1):66.

Lawrence A, Lewis L, Hofmeyr GJ, et al. Maternal positions and mobility during first stage labour. Sao Paulo Medical Journal 2011;129(5):362.

Levett KM, Smith CA, Bensoussan A, et al. Complementary therapies for labour and birth study: a randomised controlled trial of antenatal integrative medicine for pain management in labour. BMJ Open 2016;6(7):e010691. Digital Object Identifier: 10.1136/bmjopen-2015-010691. PMID: 27406639.

Lian Q and Ye X. The effects of neuraxial analgesia of combination of ropivacaine and fentanyl on uterine contraction. Anesthesiology 2008;109:A1332.

Maderia L, Hoffman M, Wilson S, et al. Effect of intravenous hydration on labor length and delivery mode [abstract]. Obstetrics \& Gynecology 2007;109(4 Suppl):90S.

Moffatt M. The safety of acupuncture during pregnancy: a systematic review. Journal of the Acupuncture Association of Chartered Physiotherapists 2014;30:109-110.

Ozgoli G, Aryamanesh Z, Mojab F, et al. A Study of Inhalation of Peppermint Aroma on the Pain and Anxiety of the First Stage of Labor in Nulliparous Women: A Randomized Clinical Trial. Qom University of Medical Sciences Journal 2013;7(3):11-13.

Parameswara G, Kshama K, Murthy HK, et al. Early epidural labour analgesia: Does it increase the chances of operative delivery?. British Journal of Anaesthesia 2012;108:ii213-ii214.

Ray A and Ray S. Antibiotics prior to amniotomy for reducing infectious morbidity in mother and infant. Cochrane Database Syst Rev 2014;10:Cd010626. DOI:

10.1002/14651858.CD010626.pub2. PMID: 25272330. 
Roberts CL, Algert CS, Olive E, et al. Ambulation during the first stage of labour with epidural analgesia has no effect on mode of delivery - Meta-analysis. Evidence-based Obstetrics and Gynecology 2005;7(3):122-124.

Rouse DJ and Shriver E. Second stage of labour duration: relationship to maternal and perinatal outcomes. American Journal of Obstetrics \& Gynecology 2008;199(6 Suppl 1):537. DOI: 10.1016/j.ajog.2008.09.112.

Stocki D, Matot I and Weiniger CF. A prospective randomized controlled trial to compare the efficacy and safety of remifentanil IV PCA to epidural PECA in labor analgesia. European Journal of Anaesthesiology 2011;28:164-165.

Taavoni S, Abdolahian S and Haghani H. Effect of birth ball on active phase of physiologic labor: Randomized control trial study. Internal Medicine Journal 2010;40:171.

Taavoni S, Abdolahian S, Haghani H, et al. Effect of pelvic tilt by using birth ball on active phase of physiologic labor: A randomized control trial study. International Journal of Gynecology and Obstetrics 2012;119:S496.

Titrated oral misoprostol for augmenting labour to improve maternal and neonatal outcomes. Essentially MIDIRS 2013;4(11):14-14 1p.

Vayssiere C, David E, Haberstich R, et al. A French randomized controlled trial on ST analysis in a population with abnormal FHR in labor. American Journal of Obstetrics and Gynaecology 2006;195(6 Suppl 1):S222.

Wilson B. A Randomized Controlled Trial of the Influence of Intermittent Versus Continuous Bladder Catheterization on Labor Outcomes. JOGNN: Journal of Obstetric, Gynecologic \& Neonatal Nursing 2015;44:S59-S59. DOI: 10.1111/1552-6909.12630.

Wilson M, MacArthur C and Shennan A. The effect of epidural analgesia on breast feeding: analysis of a randomised controlled trial. Int J Obstet Anesth 2009;18(Suppl 1):S7.

Wong C, Scavone B, Sullivan J, et al. The risk of cesarean delivery with early neuraxial analgesia in nulliparous induction of labor. Anesthesiology 2007;107:Abstract no: 1204.

Yayci F, Yayci E, Devrim S, et al. A prospective trial of epidural versus intravenous meperidine analgesia during labor: Effects on perinatal and maternal outcome. HealthMED 2012;6(10):3268-3274.

Young G. Review: Delayed pushing reduces rotational or mid pelvic instrumental deliveries but increases duration of the second stage of labour in women having epidural analgesia:

Commentary. Evidence-Based Medicine 2005;10(4):122.

\section{Not available in English:}


Ben Regaya L, Fatnassi R, Khlifi A, et al. [Role of deambulation during labour: A prospective randomized study]. J Gynecol Obstet Biol Reprod (Paris) 2010;39(8):656-62. DOI:

10.1016/j.jgyn.2010.06.007. PMID: 20692774.

Golmakani N, Pourshirazi M, Zagami SE, et al. The relationship between cormic index and labor progress. Iranian Journal of Obstetrics, Gynecology and Infertility 2015;18(175):7-15.

Kordi M, Salek Nasiri N, Safarian M.A., et al. The effect of oral honey-date syrup intake during labor on labor progress of nulliparous women. Iran J Obstet Gyneocol Infertil 2010;13(2):23-30.

Rahimiyan MN, Rahnavard T and Lari MZ. Effect of the one to one midwifery care during labor on modes of delivery and duration of labor and increase satisfaction with childbirth. Biosciences Biotechnology Research Asia 2015;12:839-845.

Salehian T, Dehcheshmaei FS, Pirak A, et al. Comparison of the effect of Hoku point (LI4) acupressure with that of San-Yin-Jiao (SP6) acupressure on labor pain and the length of delivery time in primiparous women. Scientific Journal of Kurdistan University of Medical Sciences 2011;16(1):64-72.

Wilson RD, Gagnon A, Audibert F, et al. Interventions et techniques de diagnostic prénatal visant l'obtention d'un prélèvement fœtal à des fins diagnostiques : Risques et avantages pour la mère et le fœtus. Journal of Obstetrics and Gynaecology Canada 2016;38(12):S688-S703. DOI: 10.1016/j.jogc.2016.09.071.

\section{Not original peer-reviewed data OR publication date prior to Jan 1, 2005:}

Active management of the third stage of labour: a global discussion. Midwifery News 2008;(51):36-39 4p.

Upright Versus Lying Down Position in Second Stage of Labour in Nulliparous Women With Low Dose Epidural: BUMPES Randomised Controlled Trial. Obstetrical \& Gynecological Survey 2018;73(3):133-134. PMID: 29046273

Arendt KW and Segal BS. The association between epidural labor analgesia and maternal fever. Clin Perinatol 2013;40(3):385-98. DOI: 10.1016/j.clp.2013.06.002. PMID: 23972746.

Avery MD. Current resources for evidence-based practice, September/October 2013. Journal of Midwifery and Women's Health 2013;58(5):569-573.

Ayerle GM, Schafers R, Mattern E, et al. Effects of the birthing room environment on vaginal births and client-centred outcomes for women at term planning a vaginal birth: BE-UP, a multicentre randomised controlled trial. Trials 2018;19(1):641. PMID: 30454075.

Bakker JJH, Janssen PF, Mol BWJ, et al. Use of intra-uterine pressure catheter (IUPC) versus external tocodynamometry (TOCO) during labour for reducing adverse outcomes. Cochrane Database of Systematic Reviews 2008;(1). 
Barclay C. Position during second stage of labour may influence spontaneous vaginal delivery rates. Practitioner 2017;261(1810):8-8. PMID: 127162177.

Bedwell C, Dowswell T, Neilson JP, et al. The use of transcutaneous electrical nerve stimulation (TENS) for pain relief in labour: a review of the evidence. Midwifery 2011;27(5):e141-8. DOI: 10.1016/j.midw.2009.12.004. PMID: 20170995.

Bernitz S, Dalbye R, Oian P, et al. Study protocol: the Labor Progression Study, LAPS - does the use of a dynamic progression guideline in labor reduce the rate of intrapartum cesarean sections in nulliparous women? A multicenter, cluster randomized trial in Norway. BMC Pregnancy Childbirth 2017;17(1):370. DOI: 10.1186/s12884-017-1553-8. PMID: 29132336.

Bianchi AL and Adams ED. Labor support during second stage labor for women with epidurals. Nursing for Women's Health 2009;13(1):38-47 10p. DOI: 10.1111/j.1751-486X.2009.01372.x.

Bloom SL, Belfort M and Saade G. What we have learned about intrapartum fetal monitoring trials in the MFMU Network. Seminars in Perinatology 2016;40(5):307-317. DOI:

10.1053/j.semperi.2016.03.008. PMID: 117317303.

Brown DC and Hammond DC. Evidence-based clinical hypnosis for obstetrics, labor and delivery, and preterm labor. Int J Clin Exp Hypn 2007;55(3):355-71. DOI:

10.1080/00207140701338654. PMID: 17558723.

Bugg GJ, Siddiqui F and Thornton JG. Oxytocin versus placebo or no treatment for slow progress in the first stage of spontaneous labour. Cochrane Database of Systematic Reviews 2008;(2)

Byrom A and Downe S. Second stage of labour: challenging the use of directed pushing. RCM Midwives 2005;8(4):168-9. PMID: 15839141.

Cahill AG and Spain J. Intrapartum Fetal Monitoring. Clinical Obstetrics \& Gynecology 2015;58(2):263-268 6p. DOI: 10.1097/GRF.0000000000000109.

Cambic CR and Wong CA. Labour analgesia and obstetric outcomes. Br J Anaesth 2010;105(Suppl 1):i50-60. DOI: 10.1093/bja/aeq311. PMID: 21148655.

Cargill YM and MacKinnon CJ. No. 148-Guidelines for Operative Vaginal Birth. Journal of Obstetrics and Gynaecology Canada 2018;40(2):e74-e80. DOI: 10.1016/j.jogc.2017.11.003.

Carlson NS. Current Resources for Evidence-Based Practice, January/February 2016. JOGNN: Journal of Obstetric, Gynecologic \& Neonatal Nursing 2016;45(1):90-97. PMID: 115318353.

Carlson NS. Current Resources for Evidence-Based Practice, January/February 2016. Journal of Midwifery \& Women's Health 2016;61(1):116-121. DOI: 10.1111/jmwh.12430. PMID: 112642363 
Caughey AB, Cahill AG, Guise JM, et al. Safe prevention of the primary cesarean delivery. Am J Obstet Gynecol 2014;210(3):179-93. DOI: 10.1016/j.ajog.2014.01.026. PMID: 24565430.

Cheng YW and Caughey AB. Second stage of labor. Clin Obstet Gynecol 2015;58(2):227-40. DOI: 10.1097/grf.0000000000000113. PMID: 25851851.

Cohen WR and Friedman EA. Perils of the new labor management guidelines. Am J Obstet Gynecol 2015;212(4):420-7. DOI: 10.1016/j.ajog.2014.09.008. PMID: 25218127.

Cox KJ and King TL. Preventing Primary Cesarean Births: Midwifery Care. Clinical Obstetrics \& Gynecology 2015;58(2):282-293 12p. DOI: 10.1097/GRF.0000000000000108.

Crago MS, Gauer R and Frazier J. Clinical inquiry: Does cervical membrane stripping in women with group B Streptococcus put the fetus at risk?. J Fam Pract 2012;61(1):60a-b. PMID: 22220298.

Dawood F and Quenby S. Intravenous fluids for preventing dehydration and prolonged labour in nulliparous women. Cochrane Database of Systematic Reviews 2009;(2).

Dresang LT and Yonke N. Management of Spontaneous Vaginal Delivery. Am Fam Physician 2015;92(3):202-8. PMID: 26280140.

Dupont C, Dupont C, Dupont C, et al. Oxytocin administration during spontaneous labor: Guidelines for clinical practice. Introduction and methodology. Journal of Gynecology Obstetrics and Human Reproduction 2017;46(6):465-467. DOI: 10.1016/j.jogoh.2017.04.006.

East CE, Leader LR, Colditz PB, et al. Intrapartum fetal scalp lactate sampling for fetal assessment in the presence of a non-reassuring fetal heart rate trace. Cochrane Database of Systematic Reviews 2006;(4).

Elmi A, Ratcliffe SJ and Guo W. The estimation of branching curves in the presence of subjectspecific random effects. Stat Med 2014;33(29):5166-76. DOI: 10.1002/sim.6289. PMID: 25196299.

El-Sayed YY. Diagnosis and management of arrest disorders: duration to wait. Semin Perinatol 2012;36(5):374-8. DOI: 10.1053/j.semperi.2012.04.022. PMID: 23009971.

Fischer C. Oxytocin administration during spontaneous labor: Guidelines for clinical practice. Chapter 7: Epidural analgesia and use of oxytocin during spontaneous labor. Journal of Gynecology Obstetrics and Human Reproduction 2017;46(6):531-538. DOI: 10.1016/j.jogoh.2017.04.013.

Goetzl L. Should we be concerned about epidural-induced maternal fever?. Contemporary OB/GYN 2008;53(12):36-44 6p. 
Grant EN, Tao W, Craig M, et al. Neuraxial analgesia effects on labour progression: facts, fallacies, uncertainties and the future. Bjog 2015;122(3):288-93. DOI: 10.1111/1471-

0528.12966. PMID: 25088476.

Guittier MJ, Othenin-Girard V, Irion O, et al. Maternal positioning to correct occipito-posterior fetal position in labour: a randomised controlled trial. BMC Pregnancy Childbirth 2014;14:83. DOI: 10.1186/1471-2393-14-83. PMID: 24564746.

Hanson L. Second-stage labor care: challenges in spontaneous bearing down. J Perinat Neonatal Nurs 2009;23(1):31-9. DOI: 10.1097/JPN.0b013e318196526b. PMID: 19209057.

Hastings-Tolsma M, Bernard R, Brody MG, et al. Chorioamnionitis: prevention and management. MCN Am J Matern Child Nurs 2013;38(4):206-12. DOI: 10.1097/NMC.0b013e3182836bb7. PMID: 23579417.

Hawkins JL. Epidural analgesia for labor and delivery. N Engl J Med 2010;362(16):1503-10. DOI: 10.1056/NEJMct0909254. PMID: 20410515.

Higgins $\mathrm{M}$ and Farine D. Assessment of labor progress. Expert Review of Obstetrics and Gynecology 2013;8(1):83-95.

Jackson S and Gregory KD. Management of the first stage of labor: potential strategies to lower the cesarean delivery rate. Clin Obstet Gynecol 2015;58(2):217-26. DOI:

10.1097/grf.0000000000000102. PMID: 25860323.

Jokinen J, Weibel S, Afshari A, et al. Patient-controlled analgesia with remifentanil versus alternative parenteral methods for pain management in labour. Cochrane Database of Systematic Reviews 2015;2015(12). DOI: 10.1002/14651858.CD011989.

Jung $\mathrm{H}$ and Kwak KH. Neuraxial analgesia: a review of its effects on the outcome and duration of labor. Korean J Anesthesiol 2013;65(5):379-84. DOI: 10.4097/kjae.2013.65.5.379. PMID: 24363839.

Karacam Z, Walsh D and Bugg GJ. Evolving understanding and treatment of labour dystocia. Eur J Obstet Gynecol Reprod Biol 2014;182:123-7. DOI: 10.1016/j.ejogrb.2014.09.011. PMID: 25268780.

Kibuka M, Thornton JG and Kingswood CJ. Position in the second stage of labour for women with epidural anaesthesia. Cochrane Database of Systematic Reviews 2009;(4).

Kopas ML. A review of evidence-based practices for management of the second stage of labor. J Midwifery Womens Health 2014;59(3):264-76. DOI: 10.1111/jmwh.12199. PMID: 24850283.

Lee N, Martensson LB, Homer C, et al. Impact on caesarean section rates following injections of sterile water (ICARIS): a multicentre randomised controlled trial. BMC Pregnancy Childbirth 2013;13:105. DOI: 10.1186/1471-2393-13-105. PMID: 23642147. 
Leveno KJ, Nelson DB and McIntire DD. Second-stage labor: how long is too long?. Am J Obstet Gynecol 2016;214(4):484-489. DOI: 10.1016/j.ajog.2015.10.926. PMID: 26546847.

Liao JB, Buhimschi CS and Norwitz ER. Normal labor: mechanism and duration. Obstet Gynecol Clin North Am 2005;32(2):145-64, vii. DOI: 10.1016/j.ogc.2005.01.001. PMID: 15899352.

Lowe NK. A review of factors associated with dystocia and cesarean section in nulliparous women. J Midwifery Womens Health 2007;52(3):216-28. DOI: 10.1016/j.jmwh.2007.03.003. PMID: 17467588.

Malvasi A, Giacci F, Gustapane S, et al. Intrapartum sonographic signs: new diagnostic tools in malposition and malrotation. J Matern Fetal Neonatal Med 2015:1-6. DOI:

10.3109/14767058.2015.1092137. PMID: 26444321.

Mancuso MS and Rouse DJ. Cesarean delivery for abnormal labor. Clin Perinatol 2008;35(3):479-90, ix. DOI: 10.1016/j.clp.2008.06.004. PMID: 18952016.

Manning JB, Tolcher MC, Chandraharan E, et al. Delivery of an Impacted Fetal Head During Cesarean: A Literature Review and Proposed Management Algorithm. Obstet Gynecol Surv 2015;70(11):719-24. DOI: 10.1097/ogx.0000000000000248. PMID: 26584721.

Millen KR, Kuo K, Zhao L, et al. Evidence-based guidelines in labor management. Obstet Gynecol Surv 2014;69(4):209-17. DOI: 10.1097/ogx.0000000000000057. PMID: 25101596.

Minty RG, Kelly L, Minty A, et al. Single-dose intrathecal analgesia to control labour pain: is it a useful alternative to epidural analgesia?. Can Fam Physician 2007;53(3):437-42. PMID: 17872679.

Mori R, Ullman R, Pledge D, et al. High dose versus low dose oxytocin for augmentation of labour. Cochrane Database of Systematic Reviews 2008;(3).

Nakimuli A, Chazara O, Byamugisha J, et al. Pregnancy, parturition and preeclampsia in women of African ancestry. Am J Obstet Gynecol 2014;210(6):510-520.e1. DOI:

10.1016/j.ajog.2013.10.879. PMID: 24184340.

Neal JL and Lowe NK. Physiologic partograph to improve birth safety and outcomes among low-risk, nulliparous women with spontaneous labor onset. Med Hypotheses 2012;78(2):319-26. DOI: 10.1016/j.mehy.2011.11.012. PMID: 22138426.

Neal JL, Lowe NK, Patrick TE, et al. What is the slowest-yet-normal cervical dilation rate among nulliparous women with spontaneous labor onset?. J Obstet Gynecol Neonatal Nurs 2010;39(4):361-9. DOI: 10.1111/j.1552-6909.2010.01154.x. PMID: 20629924. 
Ness A, Goldberg J and Berghella V. Abnormalities of the first and second stages of labor. Obstet Gynecol Clin North Am 2005;32(2):201-20, viii. DOI: 10.1016/j.ogc.2005.01.007. PMID: 15899355.

Niesen AD and Jacob AK. Combined spinal-epidural versus epidural analgesia for labor and delivery. Clin Perinatol 2013;40(3):373-84. DOI: 10.1016/j.clp.2013.05.010. PMID: 23972745.

O'Brien-Abel N. TOWARD EVIDENCE-BASED PRACTICE. Electrocardiogram ST Analysis During Labor: A Systematic Review and Meta-Analysis of Randomized Controlled Trials. MCN: The American Journal of Maternal Child Nursing 2016;41(3):193-193. DOI: 10.1097/NMC.0000000000000241. PMID: 115240157.

Obstetric care consensus no. 1: safe prevention of the primary cesarean delivery. Obstet Gynecol 2014;123(3):693-711. DOI: 10.1097/01.AOG.0000444441.04111.1d. PMID: 24553167.

Olofsson P, Ayres-de-Campos D, Kessler J, et al. A critical appraisal of the evidence for using cardiotocography plus ECG ST interval analysis for fetal surveillance in labor. Part II: the metaanalyses. Acta Obstet Gynecol Scand 2014;93(6):571-86; discussion 587-8. DOI: 10.1111/aogs.12412. PMID: 24797318.

Osborne K and Hanson L. Labor down or bear down: a strategy to translate second-stage labor evidence to perinatal practice. J Perinat Neonatal Nurs 2014;28(2):117-26. DOI: 10.1097/jpn.0000000000000023. PMID: 24781770.

Ozgoli G, Mobarakabadi SS, Heshmat R, et al. Effect of L14 and BL32 acupressure on labor pain and delivery outcome in the first stage of labor in primiparous women: a randomized controlled trial. MIDIRS Midwifery Digest 2017;27(2):201-202. PMID: 124319479.

Payne JL. The management of bipolar disorder during and after pregnancy. 2016:331-361. DOI: 10.1007/978-3-319-31689-5_15.

Priddis H, Dahlen H and Schmied V. What are the facilitators, inhibitors, and implications of birth positioning? A review of the literature. Women Birth 2012;25(3):100-6. DOI: 10.1016/j.wombi.2011.05.001. PMID: 21664208.

Rice Simpson K. Perinatal Patient Safety. New Evidence for Reconsideration of Normal Labor Progress. MCN: The American Journal of Maternal Child Nursing 2012;37(6):408-408 1p. DOI: 10.1097/NMC.0b013e318269a277.

Roberts $\mathrm{J}$ and Hanson L. Best practices in second stage labor care: maternal bearing down and positioning. J Midwifery Womens Health 2007;52(3):238-45. DOI: 10.1016/j.jmwh.2006.12.011. PMID: 17467590.

Romano AM and Lothian JA. Promoting, protecting, and supporting normal birth: a look at the evidence. J Obstet Gynecol Neonatal Nurs 2008;37(1):94-104; quiz 104-5. DOI: 10.1111/j.15526909.2007.00210.x. PMID: 18226163. 
Said S and Geary M. Prevention of obstetric haemorrhage. Fetal and Maternal Medicine Review 2007;18(3):257-288.

Schmuke AD. Water Immersion During Labor: Implications for Childbirth Educators. International Journal of Childbirth Education 2017;32(4):16-20. PMID: 127211900.

Searson S, Blackwell JC and Neher JO. Clinical inquiries. Does routine amniotomy have a role in normal labor?. J Fam Pract 2009;58(3):E2. PMID: 19284935.

Shields SG, Ratcliffe SD, Fontaine P, et al. Dystocia in nulliparous women. Am Fam Physician 2007;75(11):1671-8. PMID: 17575657.

Silva M and Halpern SH. Epidural analgesia for labor: Current techniques. 2010;3:143-153.

Smith V. Early versus late initiation of epidural analgesia for labour. Practising Midwife 2014;17(11):30-32 3p.

Sperling JD, Dahlke JD and Sibai BM. Restriction of oral intake during labor: whither are we bound?. American Journal of Obstetrics \& Gynecology 2016;214(5):592-596. DOI: 10.1016/j.ajog.2016.01.166. PMID: 114878192.

Steen M. Encourage a woman to remain active in labour. Midwives 2012;15(2):34-5. PMID: 24868639.

Steer PJ and Hvidman LE. Scientific and clinical evidence for the use of fetal ECG ST segment analysis (STAN). Acta Obstetricia et Gynecologica Scandinavica 2014;93(6):533-538.

Talibear S. Friedman's curve vs. the pure heart approach to labor. Midwifery Today Int Midwife 2011;(97):31, 66-7. PMID: 21523987.

Tita AT. When is primary cesarean appropriate: maternal and obstetrical indications. Semin Perinatol 2012;36(5):324-7. DOI: 10.1053/j.semperi.2012.04.014. PMID: 23009963.

Tournaire $\mathrm{M}$ and Theau-Yonneau A. Complementary and alternative approaches to pain relief during labor. Evidence-based Complementary and Alternative Medicine 2007;4(4):409-417.

Tully G. Opening the pelvic brim with Walcher's position. Midwifery Today Int Midwife 2011;(97):20-1. PMID: 21523982.

Vahratian A, Troendle JF, Siega-Riz AM, et al. Methodological challenges in studying labour progression in contemporary practice. Paediatr Perinat Epidemiol 2006;20(1):72-8. DOI: 10.1111/j.1365-3016.2006.00696.x. PMID: 16420344.

Wise J. Inducing labour in women with suspected large babies shows benefits. BMJ (Online) 2016;353. DOI: 10.1136/bmj.i2967. 
Ziaei S and Hajipour L. Effect of acupuncture on labor. Int J Gynaecol Obstet 2006;92(1):71-2. DOI: 10.1016/j.ijgo.2005.09.008. PMID: 16253255.

\section{Not an applicable study design (For KQ1: SRs, MAs, RCTs, or observational studies of 100} or more subjects. For KQs 2-9: SRs, MAs, or RCTs.):

Acosta Díez J, Schuitemaker Requena JB, Cortadellas Rosel T, et al. Impact of physicians decision making on cesarean section in nulliparous women in spontaneous labor. Internet Journal of Gynecology and Obstetrics 2016;21(1). DOI: 10.5580/IJGO.45898.

Afshar Y, Mei JY, Gregory KD, et al. Birth plans-Impact on mode of delivery, obstetrical interventions, and birth experience satisfaction: A prospective cohort study. Birth 2018;45(1):4349. DOI: 10.1111/birt.12320. PMID: 29094374.

Agarwal K, Agarwal L, Agrawal VK, et al. Evaluation of paperless partogram as a bedside tool in the management of labor. J Family Med Prim Care 2013;2(1):47-9. DOI: 10.4103/22494863.109944. PMID: 24479043.

Agrawal D, Makhija B, Arora M, et al. The effect of epidural analgesia on labour, mode of delivery and neonatal outcome in nullipara of India, 2011-2014. J Clin Diagn Res 2014;8(10):Oc03-6. DOI: 10.7860/jcdr/2014/9974.4930. PMID: 25478409.

Alijahan R, Kordi M, Poorjavad M, et al. Diagnostic accuracy of maternal anthropometric measurements as predictors for dystocia in nulliparous women. Iran J Nurs Midwifery Res 2014;19(1):11-8. PMID: 24554954.

Allen VM, Baskett TF, O'Connell CM, et al. Maternal and perinatal outcomes with increasing duration of the second stage of labor. Obstet Gynecol 2009;113(6):1248-58. DOI: 10.1097/AOG.0b013e3181a722d6. PMID: 19461419.

Altman MR and Lydon-Rochelle MT. Prolonged second stage of labor and risk of adverse maternal and perinatal outcomes: a systematic review. Birth 2006;33(4):315-22. DOI: 10.1111/j.1523-536X.2006.00129.x. PMID: 17150071.

Anand LK, Sama R and Mitra S. A comparison of $0.1 \%$ ropivacaine and $0.1 \%$ bupivacaine with patient-controlled epidural analgesia for labor: A double blind study. Anaesthesia, Pain and Intensive Care 2016;20(3):278-284.

Anant M, Bindra V and Mukherji J. The impact of cervical dilatation at admission on labour outcomes. International Research Journal of Pharmacy 2016;7(11):43-46. DOI: 10.7897/22308407.0711126.

Aneiros F, Vazquez M, Valino C, et al. Does epidural versus combined spinal-epidural analgesia prolong labor and increase the risk of instrumental and cesarean delivery in nulliparous women?. J Clin Anesth 2009;21(2):94-7. DOI: 10.1016/j.jclinane.2008.06.020. PMID: 19329011. 
Anwar S, Anwar MW and Ahmad S. EFFECT OF EPIDURAL ANALGESIA ON LABOR AND ITS OUTCOMES. J Ayub Med Coll Abbottabad 2015;27(1):146-50. PMID: 26182762.

Badiou W, Bousquet PJ, Prat-Pradal D, et al. Short vs long second stage of labour: is there a difference in terms of postpartum anal incontinence?. Eur J Obstet Gynecol Reprod Biol 2010;152(2):168-71. DOI: 10.1016/j.ejogrb.2010.06.004. PMID: 20650561.

Bakker PC, Van Rijsiwijk S and van Geijn HP. Uterine activity monitoring during labor. Journal of Perinatal Medicine 2007;35(6):468-477.

Bannister-Tyrrell M, Miladinovic B, Roberts CL, et al. Adjustment for compliance behavior in trials of epidural analgesia in labor using instrumental variable meta-analysis. J Clin Epidemiol 2015;68(5):525-33. DOI: 10.1016/j.jclinepi.2014.11.005. PMID: 25592169

Barger M, Faucher MA and Murphy PA. Part I: Theorists and Historical Influences. Journal of Midwifery \& Women's Health 2015;60(1):89-98 10p. DOI: 10.1111/jmwh.12288.

Basu JK, Buchmann EJ and Basu D. Role of a second stage partogram in predicting the outcome of normal labour. Aust N Z J Obstet Gynaecol 2009;49(2):158-61. DOI: 10.1111/j.1479828X.2009.00987.x. PMID: 19432603.

Beckmann M, Kildea S and Gibbons K. Midwifery group practice and mode of birth. Women Birth 2012;25(4):187-93. DOI: 10.1016/j.wombi.2011.11.001. PMID: 22169396.

Bedwell C, Levin K, Pett C, et al. A realist review of the partograph: when and how does it work for labour monitoring?. BMC Pregnancy Childbirth 2017;17(1):31. DOI: 10.1186/s12884-0161213-4. PMID: 28086823.

Berghella V, Baxter JK and Chauhan SP. Evidence-based labor and delivery management. Am J Obstet Gynecol 2008;199(5):445-54. DOI: 10.1016/j.ajog.2008.06.093. PMID: 18984077.

Bergstrom M, Kieler $\mathrm{H}$ and Waldenstrom U. Psychoprophylaxis during labor: associations with labor-related outcomes and experience of childbirth. Acta Obstet Gynecol Scand 2010;89(6):794-800. DOI: 10.3109/00016341003694978. PMID: 20225989.

Bernitz S, Oian P, Rolland R, et al. Oxytocin and dystocia as risk factors for adverse birth outcomes: a cohort of low-risk nulliparous women. Midwifery 2014;30(3):364-70. DOI: 10.1016/j.midw.2013.03.010. PMID: 23684697.

Bhatt H, Pandya S, Kolar G, et al. The impact of labour epidural analgesia on the childbirth expectation and experience at a tertiary care center in southern India. J Clin Diagn Res 2014;8(3):73-6. DOI: 10.7860/jcdr/2014/8039.4111. PMID: 24783086.

Bischoff K, Nothacker M, Lehane C, et al. Lack of controlled studies investigating the risk of postpartum haemorrhage in cesarean delivery after prior use of oxytocin: a scoping review. BMC Pregnancy Childbirth 2017;17(1):399. DOI: 10.1186/s12884-017-1584-1. PMID: 29187156. 
Bonnet MP, Prunet C, Baillard C, et al. Anesthetic and Obstetrical Factors Associated With the Effectiveness of Epidural Analgesia for Labor Pain Relief: An Observational Population-Based Study. Reg Anesth Pain Med 2017;42(1):109-116. DOI: 10.1097/aap.0000000000000517. PMID: 27831958.

Borders N, Wendland C, Haozous E, et al. Midwives' Verbal Support of Nulliparous Women in Second-Stage Labor. JOGNN: Journal of Obstetric, Gynecologic \& Neonatal Nursing 2013;42(3):311-320 10p. DOI: 10.1111/1552-6909.12028. PMID: 104292068. Language:

English. Entry Date: 20130523. Revision Date: 20150818. Publication Type: Journal Article.

Boyle A, Reddy UM, Landy HJ, et al. Primary cesarean delivery in the United States. Obstet Gynecol 2013;122(1):33-40. DOI: 10.1097/AOG.0b013e3182952242. PMID: 23743454.

Brennan DJ, McGee SF, Rexhepaj E, et al. Identification of a myometrial molecular profile for dystocic labor. BMC Pregnancy Childbirth 2011;11:74. DOI: 10.1186/1471-2393-11-74. PMID: 21999197.

Brocklehurst P. A study of an intelligent system to support decision making in the management of labour using the cardiotocograph - the INFANT study protocol. BMC Pregnancy \& Childbirth 2016;16:1-15. DOI: 10.1186/s12884-015-0780-0. PMID: 112384597.

Brown SJ, Gartland D, Donath S, et al. Effects of prolonged second stage, method of birth, timing of caesarean section and other obstetric risk factors on postnatal urinary incontinence: an Australian nulliparous cohort study. Bjog 2011;118(8):991-1000. DOI: 10.1111/j.14710528.2011.02928.x. PMID: 21489125.

Bugg GJ, Stanley E, Baker PN, et al. Outcomes of labours augmented with oxytocin. Eur J Obstet Gynecol Reprod Biol 2006;124(1):37-41. DOI: 10.1016/j.ejogrb.2005.04.015. PMID: 15955617.

Bullingham A, Liang S, Edmonds E, et al. Continuous epidural infusion vs programmed intermittent epidural bolus for labour analgesia: a prospective, controlled, before-and-after cohort study of labour outcomes. Br J Anaesth 2018;121(2):432-437. DOI: 10.1016/j.bja.2018.03.038. PMID: 30032882.

Butwick A, Carvalho B, Danial C, et al. Retrospective analysis of anesthetic interventions for obese patients undergoing elective cesarean delivery. J Clin Anesth 2010;22(7):519-26. DOI: 10.1016/j.jclinane.2010.01.005. PMID: 21056808.

Carlhall S, Kallen K and Blomberg M. Maternal body mass index and duration of labor. Eur J Obstet Gynecol Reprod Biol 2013;171(1):49-53. DOI: 10.1016/j.ejogrb.2013.08.021. PMID: 24041847. 
Carseldine WJ, Phipps H, Zawada SF, et al. Does occiput posterior position in the second stage of labour increase the operative delivery rate?. Australian \& New Zealand Journal of Obstetrics \& Gynaecology 2013;53(3):265-270 6p. DOI: 10.1111/ajo.12041. PMID: 104175486. Language: English. Entry Date: 20130614. Revision Date: 20150711. Publication Type: Journal Article.

Carta G, D'Alfonso A, Franchi V, et al. Analgesia: effects on the first and second stages of labor. Clin Exp Obstet Gynecol 2016;43(5):718-722. PMID: 30074325.

Chalmers B, Kaczorowski J, O'Brien B, et al. Rates of interventions in labor and birth across Canada: findings of the Canadian Maternity Experiences Survey. Birth 2012;39(3):203-10. DOI: 10.1111/j.1523-536X.2012.00549.x. PMID: 23281902.

Chang SC, Chou MM, Lin KC, et al. Effects of a pushing intervention on pain, fatigue and birthing experiences among Taiwanese women during the second stage of labour. Midwifery 2011;27(6):825-31. DOI: 10.1016/j.midw.2010.08.009. PMID: 20952110.

Chen YL, Chang Y and Yeh YL. Timing of epidural analgesia intervention for labor pain in nulliparous women in Taiwan: a retrospective study. Acta Anaesthesiol Taiwan 2013;51(3):1125. DOI: 10.1016/j.aat.2013.09.001. PMID: 24148739.

Cheng YW, Shaffer BL, Nicholson JM, et al. Second stage of labor and epidural use: a larger effect than previously suggested. Obstet Gynecol 2014;123(3):527-35. DOI: 10.1097/aog.0000000000000134. PMID: 24499753.

Cherian A and Peter L. Effectiveness of Abdominal Effleurage versus Pharmacological Intervention on Labour Pain among Primi Parturients Admitted in Labour Room. International Journal of Nursing Education 2016;8(3):93-98. DOI: 10.5958/0974-9357.2016.00091.X. PMID: 116837121.

Cheyney M, Bovbjerg M, Everson C, et al. Outcomes of care for 16,924 planned home births in the United States: the Midwives Alliance of North America Statistics Project, 2004 to 2009. J Midwifery Womens Health 2014;59(1):17-27. DOI: 10.1111/jmwh.12172. PMID: 24479690.

Clements RV. Obstetric brachial plexus injury. Clinical Risk 2006;12(1):3-11.

Committee opinion no. 594: immersion in water during labor and delivery. Obstetrics \& Gynecology 2014;123(4):912-915 4p. DOI: 10.1097/01.AOG.0000445585.52522.14.

Conversano F, Peccarisi M, Pisani P, et al. Automatic ultrasound technique to measure angle of progression during labor. Ultrasound in Obstetrics \& Gynecology 2017;50(6):766-775. DOI: 10.1002/uog.17441. PMID: 126564682.

Cooper K. Exploring the effects of second stage management from the maternal and midwifery perspectives: are there any benefits to directing women?. MIDIRS Midwifery Digest 2016;26(2):209-216. PMID: 127644534. 
Coppens M, Anssens S, Parashchanka A, et al. Determination of the median effective dose (ED50) of spinal chloroprocaine in labour analgesia. Anaesthesia 2017;72(5):598-602. DOI: 10.1111/anae.13808.

Costa-Martins JM, Dias CC, Pereira M, et al. Effects of local anesthetic on the time between analgesic boluses and the duration of labor in patient-controlled epidural analgesia: prospective study of two ultra-low dose regimens of ropivacaine and sufentanil. Acta Med Port 2015;28(1):70-6. PMID: 25817501.

Coulm B and Tessier V. Oxytocin administration during spontaneous labor: Guidelines for clinical practice. Chapter 4: Oxytocin efficiency according to implementation in insufficient spontaneous labor. Journal of Gynecology Obstetrics and Human Reproduction 2017;46(6):499507. DOI: 10.1016/j.jogoh.2017.05.005.

D'Angelo R, Smiley RM, Riley ET, et al. Serious complications related to obstetric anesthesia: the serious complication repository project of the society for obstetric anesthesia and perinatology. Anesthesiology 2014;120(6):1505-1512 8p. DOI: 10.1097/ALN.0000000000000253.

de Carvalho Leite JR and Awoko Higginbottom GM. Doulas in Canada: A Scoping Review. Canadian Journal of Midwifery Research \& Practice 2017;16(1):23-38. PMID: 125251054.

de Jonge A, Rijnders M, van Diem MT, et al. Birthing positions during second stage of labor and long-term psychological outcomes in low-risk women. International Journal of Childbirth 2011;1(4):242-253 12p.

De Jonge A, Van Diem MT, Scheepers PL, et al. Risk of perineal damage is not a reason to discourage a sitting birthing position: a secondary analysis. Int J Clin Pract 2010;64(5):611-8. DOI: 10.1111/j.1742-1241.2009.02316.x. PMID: 20456214.

Dencker A, Berg M, Bergqvist L, et al. Identification of latent phase factors associated with active labor duration in low-risk nulliparous women with spontaneous contractions. Acta Obstet Gynecol Scand 2010;89(8):1034-9. DOI: 10.3109/00016349.2010.499446. PMID: 20636242.

DeMaria AL, Sundstrom B, Moxley GE, et al. Castor oil as a natural alternative to labor induction: A retrospective descriptive study. Women Birth 2018;31(2):e99-e104. DOI: 10.1016/j.wombi.2017.08.001. PMID: 28838804.

Devereaux Y and Sullivan H. Doula Support While Laboring: Does it Help Achieve a More Natural Birth? International Journal of Childbirth Education 2013;28(2):54-61 8p.

DiFranco JT and Curl M. Healthy Birth Practice \#5: Avoid Giving Birth on Your Back and Follow Your Body’s Urge to Push. Journal of Perinatal Education 2014;23(4):207-210 4p. DOI: 10.1891/1058-1243.23.4.207.

Djuric J, Arsenijevic S, Bankovic D, et al. Dystocia as a cause of untimely cesarean section. Vojnosanit Pregl 2012;69(7):589-93. PMID: 22838170. 
Duckelmann AM, Michaelis SA, Bamberg C, et al. Impact of intrapartal ultrasound to assess fetal head position and station on the type of obstetrical interventions at full cervical dilatation. $\mathrm{J}$ Matern Fetal Neonatal Med 2012;25(5):484-8. DOI: 10.3109/14767058.2011.587057. PMID: 21726168.

Dupont C, Carayol M, Le Ray C, et al. Oxytocin administration during spontaneous labor: Guidelines for clinical practice. Guidelines short text. Journal of Gynecology Obstetrics and Human Reproduction 2017;46(6):539-543. DOI: 10.1016/j.jogoh.2017.04.010.

Eggebo TM, Wilhelm-Benartzi C, Hassan WA, et al. A model to predict vaginal delivery in nulliparous women based on maternal characteristics and intrapartum ultrasound. Am J Obstet Gynecol 2015;213(3):362.e1-6. DOI: 10.1016/j.ajog.2015.05.044. PMID: 26008180.

Ekelin M, Svensson J, Evehammar S, et al. Sense and sensibility: Swedish midwives' ambiguity to the use of synthetic oxytocin for labour augmentation. Midwifery 2015;31(3):e36-42. DOI: 10.1016/j.midw.2014.12.006. PMID: 25595350.

El-Hamamy E and Arulkumaran S. Poor progress of labour. Current Obstetrics and Gynaecology 2005;15(1):1-8.

Elliott C, Warrick PA, Graham E, et al. Graded classification of fetal heart rate tracings: association with neonatal metabolic acidosis and neurologic morbidity. American Journal of Obstetrics \& Gynecology 2010;202(3):258.e1-8 1p. DOI: 10.1016/j.ajog.2009.06.026.

Elvander C, Ahlberg M, Thies-Lagergren L, et al. Birth position and obstetric anal sphincter injury: a population-based study of 113000 spontaneous births. BMC Pregnancy Childbirth 2015;15:252. DOI: 10.4103/1735-9066.164513. PMID: 26453177.

Elvander C, Hogberg U and Ekeus C. The influence of fetal head circumference on labor outcome: a population-based register study. Acta Obstet Gynecol Scand 2012;91(4):470-5. DOI: 10.1111/j.1600-0412.2012.01358.x. PMID: 22229662.

Essa RM and Ismail NIAA. Effect of second stage perineal warm compresses on perineal pain and outcome among primiparae. Journal of Nursing Education \& Practice 2016;6(4):48-58. DOI: 10.5430/jnep.v6n4p48. PMID: 115331300.

Farrar D. How evidence-based practice can provide the way forward for third stage care. Midwives 2009;12(6):20-20.

Favilli A, Laganà AS, Indraccolo U, et al. What women want? Results from a prospective multicenter study on women's preference about pain management during labour. European Journal of Obstetrics \& Gynecology \& Reproductive Biology 2018;228:197-202. DOI: 10.1016/j.ejogrb.2018.06.038. PMID: 131402549. 
Feng BB, Wang L and Zhai JJ. Investigation on delivery analgesia effect of combined spinal epidural anesthesia plus Doula and safety of mother and baby. Clin Exp Obstet Gynecol 2013;40(4):574-8. PMID: 24597260.

Finnbogadottir H, Dejin-Karlsson E and Dykes AK. A multi-centre cohort study shows no association between experienced violence and labour dystocia in nulliparous women at term. BMC Pregnancy Childbirth 2011;11:14. DOI: 10.1186/1471-2393-11-14. PMID: 21338523.

Frey HA, Tuuli MG, Roehl KA, et al. Can contraction patterns predict neonatal outcomes? J Matern Fetal Neonatal Med 2014;27(14):1422-7. DOI: 10.3109/14767058.2013.866645. PMID: 24228752.

Gaudernack LC, Frøslie KF, Michelsen TM, et al. De-medicalization of birth by reducing the use of oxytocin for augmentation among first-time mothers - A prospective intervention study. BMC Pregnancy and Childbirth 2018;18(1). DOI: 10.1186/s12884-018-1706-4.

Gerli S, Favilli A, Acanfora MM, et al. Effect of epidural analgesia on labor and delivery: a retrospective study. J Matern Fetal Neonatal Med 2011;24(3):458-60. DOI: 10.3109/14767058.2010.498904. PMID: 20608807.

Ghodsi Z and Asltoghiri M. Effects of aerobic exercise training on maternal and neonatal outcome: a randomized controlled trial on pregnant women in Iran. J Pak Med Assoc 2014;64(9):1053-6. PMID: 25823187.

Gibson E. Women's expectations and experiences with labour pain in medical and midwifery models of birth in the United States. Women \& Birth 2014;27(3):185-189 5p. DOI: 10.1016/j.wombi.2014.05.002.

Gimovsky AC, Guarente J and Berghella V. Prolonged second stage in nulliparous with epidurals: a systematic review. J Matern Fetal Neonatal Med 2017;30(4):461-465. DOI: 10.1080/14767058.2016.1174999. PMID: 27050812.

Gizzo S, Noventa M, Fagherazzi S, et al. Update on best available options in obstetrics anaesthesia: perinatal outcomes, side effects and maternal satisfaction. Fifteen years systematic literature review. Arch Gynecol Obstet 2014;290(1):21-34. DOI: 10.1007/s00404-014-3212-x. PMID: 24659334.

Gizzo S, Di Gangi S, Noventa M, et al. Women's choice of positions during labour: return to the past or a modern way to give birth? A cohort study in Italy. Biomed Res Int 2014;2014:638093. DOI: 10.1155/2014/638093. PMID: 24955365.

Gizzo S, Di Gangi S, Saccardi C, et al. Epidural analgesia during labor: impact on delivery outcome, neonatal well-being, and early breastfeeding. Breastfeed Med 2012;7:262-8. DOI: 10.1089/bfm.2011.0099. PMID: 22166068. 
Graseck AS, Odibo AO, Tuuli M, et al. Normal first stage of labor in women undergoing trial of labor after cesarean delivery. Obstet Gynecol 2012;119(4):732-6. DOI:

10.1097/AOG.0b013e31824c096c. PMID: 22433336.

Grobman WA, Bailit J, Lai Y, et al. Association of the Duration of Active Pushing With Obstetric Outcomes. Obstet Gynecol 2016;127(4):667-73. DOI:

10.1097/aog.0000000000001354. PMID: 26959213.

Gross MM, Drobnic S and Keirse MJ. Influence of fixed and time-dependent factors on duration of normal first stage labor. Birth 2005;32(1):27-33. DOI: 10.1111/j.0730-7659.2005.00341.x. PMID: 15725202.

Grotegut CA, Dulitzki M, Gaughan JP, et al. Transvaginal ultrasound of cervical length and its correlation to digital cervical examination, time to spontaneous labor and mode of delivery. Arch Gynecol Obstet 2011;284(4):855-9. DOI: 10.1007/s00404-010-1745-1. PMID: 21079982.

Grotegut CA, Paglia MJ, Johnson LN, et al. Oxytocin exposure during labor among women with postpartum hemorrhage secondary to uterine atony. Am J Obstet Gynecol 2011;204(1):56.e1-6. DOI: 10.1016/j.ajog.2010.08.023. PMID: 21047614.

Halpern SH and Abdallah FW. Effect of labor analgesia on labor outcome. Current Opinion in Anesthesiology 2010;23(3):317-322 6p. DOI: 10.1097/ACO.0b013e3283385492.

Hamilton EF, Simoneau G, Ciampi A, et al. Descent of the fetal head (station) during the first stage of labor. Am J Obstet Gynecol 2015. DOI: 10.1016/j.ajog.2015.10.005. PMID: 26475422.

Harper LM, Odibo AO, Macones GA, et al. Predicting Cesarean in the Second Stage of Labor. American Journal of Perinatology 2013;30(11):827-832 6p. DOI: 10.1055/s-0032-1333411.

Hartley C. Trusting birth even more. Midwifery Today 2007;(81):16-17.

Hautakangas T, Palomaki O, Eidsto K, et al. Impact of obesity and other risk factors on labor dystocia in term primiparous women: a case control study. BMC Pregnancy Childbirth 2018;18(1):304. DOI: 10.1186/s12884-018-1938-3. PMID: 30021565.

Heavey E. Obesity in pregnancy: Deliver sensitive care...Issues in Obesity, Part 1. Nursing 2011;41(10):42-51 10p. DOI: 10.1097/01. NURSE.0000405101.68864.1.

Heelan L. Fetal monitoring: creating a culture of safety with informed choice. J Perinat Educ 2013;22(3):156-65. DOI: 10.1891/1058-1243.22.3.156. PMID: 24868127.

Hehir MP, McHugh AF, Maguire PJ, et al. Extreme macrosomia--obstetric outcomes and complications in birthweights at 5000 g. Aust N Z J Obstet Gynaecol 2015;55(1):42-6. DOI: 10.1111/ajo.12285. PMID: 25688818. 
Hendler I, Kirshenbaum M, Barg M, et al. Choosing between bad, worse and worst: what is the preferred mode of delivery for failure of the second stage of labor?(). J Matern Fetal Neonatal Med 2017;30(15):1861-1864. DOI: 10.1080/14767058.2016.1228058. PMID: 27550831.

Henry DE, Cheng YW, Shaffer BL, et al. Perinatal outcomes in the setting of active phase arrest of labor. Obstet Gynecol 2008;112(5):1109-15. DOI: 10.1097/AOG.0b013e31818b46a2. PMID: 18978113.

Herstad L, Klungsoyr K, Skjaerven R, et al. Maternal age and emergency operative deliveries at term: a population-based registry study among low-risk primiparous women. Bjog 2015;122(12):1642-51. DOI: 10.1111/1471-0528.12962. PMID: 25100277.

Hoffman MK, Bailit JL, Branch DW, et al. A comparison of obstetric maneuvers for the acute management of shoulder dystocia. Obstet Gynecol 2011;117(6):1272-8. DOI: 10.1097/AOG.0b013e31821a12c9. PMID: 21555962.

Holvey N. Supporting women in the second stage of labour. British Journal of Midwifery 2014;22(3):182-186.

Hosseini SE, Bagheri M and Honarparvaran N. Investigating the effect of music on labor pain and progress in the active stage of first labor. Eur Rev Med Pharmacol Sci 2013;17(11):1479-87. PMID: 23894767.

Hung TH, Chen SF, Lo LM, et al. Contemporary second stage labor patterns in Taiwanese women with normal neonatal outcomes. Taiwanese Journal of Obstetrics and Gynecology 2015;54(4):416-420.

Hunt L. Literature review: Eating and drinking in labour. British Journal of Midwifery 2013;21(7):499-502.

Ijaiya MA, Adesina KT, Raji HO, et al. Duration of labor with spontaneous onset at the University of Ilorin Teaching Hospital, Ilorin, Nigeria. Ann Afr Med 2011;10(2):115-9. DOI: 10.4103/1596-3519.82074. PMID: 21691017.

Iliadou M. Supporting women in labour. Health Science Journal 2012;6(3):385-391.

Indra V. A study to assess the effectiveness of Aromatherapy during First Stage of Labour among women in Selected Hospitals, Puducherry. Asian Journal of Nursing Education \& Research 2017;7(4):495-498. DOI: 10.5958/2349-2996.2017.00096.9. PMID: 126778651.

Islam MM and Bakheit CS. Advanced Maternal Age and Risks for Adverse Pregnancy Outcomes: A Population-Based Study in Oman. Health Care Women Int 2015;36(10):1081-103. DOI: 10.1080/07399332.2014.990560. PMID: 25531021. 
Jaiswal S, Ranjan P, Tewari N, et al. Comparative study of epidural midazolam and butorphanol as adjuvant with bupivacaine for labor analgesia: a double blind study. Internet Journal of Anesthesiology 2007;14(1):16p-16p.

Janula R and John E. Effectiveness of Expectant Father's Presence during First Stage of Labour. International Journal of Nursing Education 2013;5(1):77-81 5p. DOI: 10.5958/j.09749357.5.1.018.

Ji ES, Lundeen SP and Lee J. Effect of prenatal Qi exercise on mother-infant interaction and behavioral state. Journal of Child Health Care 2015;19(4):504-512. DOI: 10.1177/1367493514522575. PMID: 112017861.

Jimin P, Youngjoo S, White AR, et al. The safety of acupuncture during pregnancy: a systematic review. Acupuncture in Medicine 2014;32(3):257-266 10p. DOI: 10.1136/acupmed-2013010480.

John N and Angeline A. Effectiveness of Music Therapy on Anxiety and Pain among Mothers During First Stage of Labour in Selected Hospitals at Kollam. International Journal of Nursing Education 2017;9(2):24-29. DOI: 10.5958/0974-9357.2017.00030.7. PMID: 122807536.

Karlstrom A. Women's self-reported experience of unplanned caesarean section: Results of a Swedish study. Midwifery 2017;50:253-258. DOI: 10.1016/j.midw.2017.04.016. PMID: 28505479.

Kashanian M, Dadkhah F, Baradaran HR, et al. Evaluation of the relationship between high maternal weight and the duration of different stages of labor, delivery route, neonatal weight and Apgar score. Obesity Research and Clinical Practice 2008;2(4):225-230.

Kenyon S, Sanders J, Middleton L, et al. What is the best treatment to reduce the need for caesarean section in nulliparous women at term with delayed first stage of labour?. Bmj 2017;357:j2469. DOI: 10.1136/bmj.j2469. PMID: 28588033.

Khalili M, Menati L, Daeichin S, et al. A comparative study of maternal and neonatal outcomes of physiological and non-physiological delivery in nulliparous women and their infants, admitted to Motazedi hospital of Kermanshah, Iran in 2011-2012. Research Journal of Medical Sciences 2016;10(4):217-222.

Kim TH, Kim JM, Lee HH, et al. Effect of nalbuphine hydrochloride on the active phase during first stage of labour: a pilot study. J Obstet Gynaecol 2011;31(8):724-7. DOI: 10.3109/01443615.2011.602139. PMID: 22085063.

Kither H and Samangaya R. Abnormal labour. Obstetrics, Gynaecology \& Reproductive Medicine 2013;23(4):121-125 5p. DOI: 10.1016/j.ogrm.2013.02.008. 
Kjaergaard H, Olsen J, Ottesen B, et al. Obstetric risk indicators for labour dystocia in nulliparous women: a multi-centre cohort study. BMC Pregnancy Childbirth 2008;8:45. DOI: 10.1186/1471-2393-8-45. PMID: 18837972.

Kondo Y, Sawa R, Ebina A, et al. Influence of Habitual Physical Activity During Late Pregnancy on the Duration of Labor. J Phys Act Health 2017;14(3):203-207. DOI: 10.1123/jpah.2016-0163. PMID: 27918683.

Korhonen U, Taipale P and Heinonen S. Fetal pelvic index to predict cephalopelvic disproportion - a retrospective clinical cohort study. Acta Obstet Gynecol Scand 2015;94(6):61521. DOI: 10.1111/aogs.12608. PMID: 25682690.

Kotaska AJ, Klein MC and Liston RM. Epidural analgesia associated with low-dose oxytocin augmentation increases cesarean births: a critical look at the external validity of randomized trials. Am J Obstet Gynecol 2006;194(3):809-14. DOI: 10.1016/j.ajog.2005.09.014. PMID: 16522417.

Krapp M, Kühn A, Baumann K, et al. Reproducibility of fetal ductus venosus blood flow velocity waveforms during first stage of labor. Archives of Gynecology \& Obstetrics 2012;285(1):87-92.

Lai ML, Lin KC, Li HY, et al. Effects of delayed pushing during the second stage of labor on postpartum fatigue and birth outcomes in nulliparous women. J Nurs Res 2009;17(1):62-72. DOI: 10.1097/JNR.0b013e3181999e78. PMID: 19352230.

Lalooei A, Hashemi SR and Khosravi MH. Comparing the effect of painless labor methods on the duration of active phase of labor. Razavi International Journal of Medicine 2015;3(4):18-21.

Lamxay V, de Boer HJ and Björk L. Traditions and plant use during pregnancy, childbirth and postpartum recovery by the Kry ethnic group in Lao PDR. Journal of Ethnobiology \& Ethnomedicine 2011;7(1):14-29 16p. DOI: 10.1186/1746-4269-7-14.

Laughon SK, Branch DW, Beaver J, et al. Changes in labor patterns over 50 years. Am J Obstet Gynecol 2012;206(5):419.e1-9. DOI: 10.1016/j.ajog.2012.03.003. PMID: 22542117.

Le Ray C, Audibert F, Goffinet F, et al. When to stop pushing: effects of duration of secondstage expulsion efforts on maternal and neonatal outcomes in nulliparous women with epidural analgesia. Am J Obstet Gynecol 2009;201(4):361.e1-7. DOI: 10.1016/j.ajog.2009.08.002. PMID: 19788968.

Le Ray C, Fraser W, Rozenberg P, et al. Duration of passive and active phases of the second stage of labour and risk of severe postpartum haemorrhage in low-risk nulliparous women. Eur J Obstet Gynecol Reprod Biol 2011;158(2):167-72. DOI: 10.1016/j.ejogrb.2011.04.035. PMID: 21640464. 
Leanza V, Scavone F, Mastellone O, et al. Active delivery: Is it advantageous?. Giornale Italiano di Ostetricia e Ginecologia 2007;29(12):389-392.

Leanza V, Leanza G and Monte S. A didactic protocol for labour and delivery: the partogram. Minerva Ginecol 2011;63(4):325-32. PMID: 21747340.

Lee HL, Lo LM, Chou CC, et al. Comparison between 0.08\% ropivacaine and 0.06\% levobupivacaine for epidural analgesia during nulliparous labor: a retrospective study in a single center. Chang Gung Med J 2011;34(3):286-92. PMID: 21733358.

Lee L, Dy J and Azzam H. Management of Spontaneous Labour at Term in Healthy Women. J Obstet Gynaecol Can 2016;38(9):843-865. DOI: 10.1016/j.jogc.2016.04.093. PMID: 27670710.

Lee SM, Lee KA, Lee J, et al. "Early rupture of membranes” after the spontaneous onset of labor as a risk factor for cesarean delivery. Eur J Obstet Gynecol Reprod Biol 2010;148(2):152-7. DOI: 10.1016/j.ejogrb.2009.10.031. PMID: 20005623.

Lee YM and D'Alton ME. Cesarean delivery on maternal request: the impact on mother and newborn. Clinics in Perinatology 2008;35(3):505-518.

Lemos A, Dean E and de Andrade AD. The Valsalva maneuver duration during labor expulsive stage: repercussions on the maternal and neonatal birth condition. Rev Bras Fisioter 2011;15(1):66-72. PMID: 21519717.

Levine LD and Srinivas SK. Length of second stage of labor and preterm birth in a subsequent pregnancy. Am J Obstet Gynecol 2015. DOI: 10.1016/j.ajog.2015.10.919. PMID: 26529372.

Lewis C. Perinatal brachial plexus injury - A legal perspective. Clinical Risk 2006;12(1):18-20.

Lewkowitz AK, Tuuli MG, Stout MJ, et al. Epidurals and the Modern Labor Curve: How Epidural Timing Impacts Fetal Station during Active Labor. Am J Perinatol 2018;35(5):421-426. DOI: 10.1055/s-0037-1617457. PMID: 29287297.

Li WH, Zhang HY, Ling Y, et al. Effect of prolonged second stage of labor on maternal and neonatal outcomes. Asian Pac J Trop Med 2011;4(5):409-11. DOI: 10.1016/s19957645(11)60114-4. PMID: 21771687.

Lippert T, Nesje E, Koss KS, et al. Change in risk status during labor in a large Norwegian obstetric department: a prospective study. Acta Obstet Gynecol Scand 2013;92(6):671-8. DOI: 10.1111/aogs.12092. PMID: 23362836.

Liu Y, Liu Y, Huang X, et al. A comparison of maternal and neonatal outcomes between water immersion during labor and conventional labor and delivery. BMC Pregnancy Childbirth 2014;14:160. DOI: 10.1186/1471-2393-14-160. PMID: 24886438. 
Lodge F and Haith-Cooper M. The effect of maternal position at birth on perineal trauma: A systematic review. British Journal of Midwifery 2016;24(3):172-180. PMID: 113491565.

Looft E, Simic M, Ahlberg M, et al. Duration of Second Stage of Labour at Term and Pushing Time: Risk Factors for Postpartum Haemorrhage. Paediatr Perinat Epidemiol 2017;31(2):126133. DOI: 10.1111/ppe.12344. PMID: 28195653.

Maeda K, Utsu M, Noguchi Y, et al. Central Computerized Automatic Fetal Heart Rate Diagnosis with a Rapid and Direct Alarm System. Open Medical Devices Journal 2012;4(SPL. ISS.).

Maged AM, Mosaad M, AbdelHak AM, et al. The effect of hyoscine butylbromide on the duration and progress of labor in primigravidae: a randomized controlled trial. Journal of Maternal-Fetal \& Neonatal Medicine 2018;31(22):2959-2964. DOI:

10.1080/14767058.2017.1359828. PMID: 131034896.

Marijic V, Bukovic D, Mihaljevic S, et al. Intermittent epidural TOP-UPS vs. patient control epidural analgesia during labor. Coll Antropol 2013;37(4):1339-41. PMID: 24611353.

Maroni E, Youssef A, Rainaldi MP, et al. The descent of the fetal head is not modified by mobile epidural analgesia: a controlled sonographic study. Acta Obstet Gynecol Scand 2014;93(5):5126. DOI: 10.1111/aogs.12370. PMID: 24754606.

Marsoosi V, Jamal A, Eslamian L, et al. Prolonged second stage of labor and levator ani muscle injuries. Glob J Health Sci 2015;7(1):267-73. DOI: 10.5539/gjhs.v7n1p267. PMID: 25560352.

Martin CJH. Effects of valsalva manoeuvre on maternal and fetal wellbeing. British Journal of Midwifery 2009;17(5):279-285.

Masturzo B, De Ruvo D, Gaglioti P, et al. Ultrasound imaging in prolonged second stage of labor: does it reduce the operative delivery rate?. J Matern Fetal Neonatal Med 2014;27(15):1560-3. DOI: 10.3109/14767058.2013.868430. PMID: 24261875.

Mathew A, Nayak S and Vandana K. A Comparative study on effect of ambulation and birthing ball on maternal and newborn outcome among primigravida mothers in selected hospitals in Mangalore. Nitte University Journal of Health Science 2012;2(2):2-5.

McDermott AM. Factors associated with non-normal birth outcomes for low-risk women in an inner-city hospital. J Midwifery Womens Health 2010;55(2):101-6. DOI:

10.1016/j.jmwh.2009.07.003. PMID: 20189128.

McPherson JA, Tuuli M, Odibo AO, et al. Labor progression in teenage women. Am J Perinatol 2014;31(9):753-8. DOI: 10.1055/s-0033-1359722. PMID: 24338116. 
Mikolajczyk RT, Zhang J, Grewal J, et al. Early versus Late Admission to Labor Affects Labor Progression and Risk of Cesarean Section in Nulliparous Women. Front Med (Lausanne) 2016;3:26. DOI: 10.3389/fmed.2016.00026. PMID: 27446924.

Mohamed Emam AM and Al-Zahrani AE. Upright versus recumbent position during first stage of labor among primipara women on labor outcomes. Journal of Nursing Education \& Practice 2018;8(7):113-124. DOI: 10.5430/jnep.v8n7p113. PMID: 130620697.

Moiety FM and Azzam AZ. Fundal pressure during the second stage of labor in a tertiary obstetric center: a prospective analysis. J Obstet Gynaecol Res 2014;40(4):946-53. DOI: 10.1111/jog.12284. PMID: 24428496.

Mol BW, Logtenberg SL, Verhoeven CJ, et al. Does measurement of intrauterine pressure have predictive value during oxytocin-augmented labor?. J Matern Fetal Neonatal Med 2015:1-4. DOI: 10.3109/14767058.2015.1123243. PMID: 26699193.

Moore E and Moorhead C. Promoting normality in the management of the perineum during the second stage of labour. British Journal of Midwifery 2013;21(9):616-620.

Moran AC, Wahed T and Afsana K. Oxytocin to augment labour during home births: an exploratory study in the urban slums of Dhaka, Bangladesh. Bjog 2010;117(13):1608-15. DOI: 10.1111/j.1471-0528.2010.02714.x. PMID: 21078056.

Morhason-Bello IO, Adedokun BO, Ojengbede OA, et al. Assessment of the effect of psychosocial support during childbirth in Ibadan, south-west Nigeria: a randomised controlled trial. Aust N Z J Obstet Gynaecol 2009;49(2):145-50. DOI: 10.1111/j.1479-828X.2009.00983.x. PMID: 19432601.

Moschini V, Marra G and Dabrowska D. Complications of epidural and combined spinalepidural analgesia in labour. Minerva Anestesiol 2006;72(1-2):47-58. PMID: 16407806.

Mousa WF, Al-Metwalli R and Mostafa M. Epidural analgesia during labor vs no analgesia: A comparative study. Saudi J Anaesth 2012;6(1):36-40. DOI: 10.4103/1658-354x.93055. PMID: 22412775.

Mucuk S and Baser M. Effects of noninvasive electroacupuncture on labour pain and duration. J Clin Nurs 2014;23(11-12):1603-10. DOI: 10.1111/jocn.12256. PMID: 23786544.

Mulatya CM, McLain AC, Cai B, et al. Estimating time to event characteristics via longitudinal threshold regression models - an application to cervical dilation progression. Stat Med 2016;35(24):4368-4379. DOI: 10.1002/sim.7031. PMID: 27405611.

Munro A, George RB and Allen VM. The impact of analgesic intervention during the second stage of labour: a retrospective cohort study. Canadian Journal of Anesthesia 2018:1-8. DOI: 10.1007/s12630-018-1184-1. 
Neal JL, Ryan SL, Lowe NK, et al. Labor Dystocia: Uses of Related Nomenclature. J Midwifery Womens Health 2015;60(5):485-98. DOI: 10.1111/jmwh.12355. PMID: 26461188.

Newman M. Does extending time limits in the second stage of labour compromise maternal and neonatal outcomes?. British Journal of Midwifery 2017;25(8):506-510. PMID: 124437347.

Nieuwenhuijze M, de Jonge A, Korstjens I, et al. Factors influencing the fulfillment of women's preferences for birthing positions during second stage of labor. Journal of Psychosomatic Obstetrics \& Gynecology 2012;33(1):25-31.

Nieuwenhuijze MJ, de Jonge A, Korstjens I, et al. Influence on birthing positions affects women's sense of control in second stage of labour. Midwifery 2013;29(11):e107-14 1p. DOI: 10.1016/j.midw.2012.12.007.

Nieuwenhuijze MJ, Low LK, Korstjens I, et al. The Role of Maternity Care Providers in Promoting Shared Decision Making Regarding Birthing Positions During the Second Stage of Labor. Journal of Midwifery \& Women's Health 2014;59(3):277-285 9p. DOI: 10.1111/jmwh.12187.

Norman SM, Tuuli MG, Odibo AO, et al. The effects of obesity on the first stage of labor. Obstetrics \& Gynecology 2012;120(1):130-135 6p. DOI: 10.1097/AOG.0b013e318259589c.

Nunes RD, Locatelli P and Traebert J. Use of the purple line to diagnose cervical dilatation and fetal head station during labor. International Journal of Gynecology and Obstetrics 2018;141(2):250-251. DOI: 10.1002/ijgo.12459.

Nyflot LT, Stray-Pedersen B, Forsen L, et al. Duration of labor and the risk of severe postpartum hemorrhage: A case-control study. PLoS One 2017;12(4):e0175306. DOI:

10.1371/journal.pone.0175306. PMID: 28384337.

Obido L. Does epidural analgesia affect the second stage of labour?. British Journal of Midwifery 2007;15(7):429-435.

Oboro VO, Tabowei TO and Bosah JO. Fetal station at the time of labour arrest and risk of caesarean delivery. J Obstet Gynaecol 2005;25(1):20-2. DOI: 10.1080/01443610400022512. PMID: 16147687.

Okazaki A, Fukushima R, Nagashima S, et al. Outcomes of labor epidural analgesia among women aged over 40: A single-institution retrospective study. J Obstet Gynaecol Res 2016;42(12):1712-1718. DOI: 10.1111/jog.13109. PMID: 27640890.

Okewole IA, Faiola S, Fakounde A, et al. The relationship of ethnicity, maternal height and shoe size, and method of delivery. J Obstet Gynaecol 2011;31(7):608-11. DOI: 10.3109/01443615.2011.590907. PMID: 21973133. 
Olfati F, Golshahi T, Laluha F, et al. Relationship between amniotomy and rate of cesarean section: A cohort study. Biomedical Research (India) 2017;28(4):1761-1764.

Ophir E, Bornstein J, Odeh M, et al. Labor progress indices and dynamics of the individual uterine contraction during the active stage of labor. J Obstet Gynaecol Res 2014;40(3):686-93. DOI: 10.1111/jog.12218. PMID: 24246065.

Orbach-Zinger S, Aviram A, Ioscovich A, et al. Anesthetic considerations in pregnant women at advanced maternal age. Journal of Maternal-Fetal \& Neonatal Medicine 2015;28(1):59-62. DOI: 10.3109/14767058.2014.900751.

Osborne K and Hanson L. Labor Down or Bear Down. Journal of Perinatal \& Neonatal Nursing 2013;28(2):117-126. DOI: 10.1097/JPN.0000000000000023.

Overgaard C, Moller AM, Fenger-Gron M, et al. Freestanding midwifery unit versus obstetric unit: a matched cohort study of outcomes in low-risk women. BMJ Open 2011;1(2):e000262. DOI: 10.1136/bmjopen-2011-000262. PMID: 22021892.

Ozdurak I, Goymen A, Simsek Y, et al. Impacts of childbirth on the subsequent risk of stress urinary incontinence. Konuralp Tip Dergisi 2018;10(2):149-152. DOI: 10.18521/ktd.399972.

Page $\mathrm{M}$ and Mander R. Intrapartum uncertainty: a feature of normal birth, as experienced by midwives in Scotland. Midwifery 2014;30(1):28-35. DOI: 10.1016/j.midw.2013.01.012. PMID: 23453698.

Papadias K, Christopoulos P, Deligeoroglou E, et al. Maternal age and the duration of the second stage of labor. Ann N Y Acad Sci 2006;1092:414-7. DOI: 10.1196/annals.1365.039. PMID: 17308167.

Papile L-A, Baley JE, Benitz W, et al. Immersion in Water During Labor and Delivery. Pediatrics 2014;133(4):758-761. DOI: 10.1542/peds.2013-3794.

Park JM, Odibo AO, Shanks AL, et al. Application of second-stage passive descent in morbidly obese women. Obstet Gynecol 2012;120(6):1338-44. DOI:

http://10.1097/AOG.0b013e318270ea73. PMID: 23168758.

Paterno MT, McElroy K and Regan M. Electronic Fetal Monitoring and Cesarean Birth: A Scoping Review. Birth: Issues in Perinatal Care 2016;43(4):277-284. DOI: 10.1111/birt.12247. PMID: 119477798.

Petersen A, Poetter U, Michelsen C, et al. The sequence of intrapartum interventions: a descriptive approach to the cascade of interventions. Arch Gynecol Obstet 2013;288(2):245-54. DOI: 10.1007/s00404-013-2737-8. PMID: 23417149. 
Petrocnik P and Marshall JE. Hands-poised technique: The future technique for perineal management of second stage of labour? A modified systematic literature review. Midwifery 2015;31(2):274-279 6p. DOI: 10.1016/j.midw.2014.10.004.

Phipps H, Vries B, Jagadish U, et al. Management of Occiput Posterior Position in the Second Stage of Labor: A Survey of Midwifery Practice in Australia. Birth: Issues in Perinatal Care 2014;41(1):64-69. DOI: 10.1111/birt.12094.

Phipps H, Vries B, Lee PN, et al. Management of occiput posterior position in the second stage of labour: A survey of obstetric practice in Australia and New Zealand. Australian \& New Zealand Journal of Obstetrics \& Gynaecology 2012;52(5):450-454 5p. DOI: 10.1111/j.1479828X.2012.01458.x.

Poma S, Scudeller L, Verga C, et al. Effects of combined spinal-epidural analgesia on first stage of labor: a cohort study. Journal of Maternal-Fetal and Neonatal Medicine 2018:1-7. DOI: 10.1080/14767058.2018.1467892.

Pratinidhi AK, Javadekar SS, Shrotri AN, et al. Feasibility of use of color-coded rings by nurse midwives: an appropriate technology based on partographic principles. Indian J Community Med 2013;38(3):157-61. DOI: 10.4103/0970-0218.116352. PMID: 24019601.

Presteena CJ. Effect of Lamaze Method on Child Birth Experiences among Primi Gravid Women During First Stage of Labour in a Selected Hospital of Udupi. Asian Journal of Nursing Education \& Research 2016;6(4):443-453. DOI: 10.5958/2349-2996.2016.00084.7. PMID: 120819892.

Prosser SJ, Barnett AG and Miller YD. Factors promoting or inhibiting normal birth. BMC Pregnancy and Childbirth 2018;18(1). DOI: 10.1186/s12884-018-1871-5.

Quincy MME, Weng C, Shafer SL, et al. Impact of Cervical Effacement and Fetal Station on Progress during the First Stage of Labor: A Biexponential Model. American Journal of Perinatology 2014;31(9):745-751. DOI: 10.1055/s-0033-1359721.

Ramphul M, Kennelly M and Murphy DJ. Establishing the accuracy and acceptability of abdominal ultrasound to define the foetal head position in the second stage of labour: a validation study. European Journal of Obstetrics \& Gynecology \& Reproductive Biology 2012;164(1):35-39. DOI: 10.1016/j.ejogrb.2012.06.001.

Reed R. The Assessment of Progress. AIMS Journal 2011;23(2):11-13 3p.

Rimaitis K, Klimenko O, Rimaitis M, et al. Labor epidural analgesia and the incidence of instrumental assisted delivery. Medicina (Kaunas) 2015;51(2):76-80. DOI: 10.1016/j.medici.2015.02.002. PMID: 25975875. 
Rossen J, Klungsoyr K, Albrechtsen S, et al. Can oxytocin augmentation modify the risk of epidural analgesia by maternal age in cesarean sections?. Acta Obstet Gynecol Scand 2018;97(7):872-879. DOI: 10.1111/aogs.13341. PMID: 29512836.

Rousseau A and Burguet A. Oxytocin administration during spontaneous labor: Guidelines for clinical practice. Chapter 5: Maternal risk and adverse effects of using oxytocin augmentation during spontaneous labor. Journal of Gynecology Obstetrics and Human Reproduction 2017;46(6):509-521. DOI: 10.1016/j.jogoh.2017.04.009.

Saadia Z. Rates and indicators for amniotomy during labor--a descriptive cross sectional study between primigravidas and gravida 2 and above. Med Arch 2014;68(2):110-2. PMID: 24937934.

Saadia Z. Rates and indicators of Continuous Electronic fetal monitoring - A study from Saudi Arabia. Int J Health Sci (Qassim) 2015;9(1):3-8. PMID: 25901127.

Sahin HG, Kolusari A, Kamaci M, et al. The effect of oxytocin infusion and misoprostol on neonatal bilirubin levels. Arch Gynecol Obstet 2010;281(1):11-4. DOI: 10.1007/s00404-0091021-4. PMID: 19326137.

Sanchez-Migallon V, Sanchez E, Raynard M, et al. Analysis and evaluation of the effectiveness of epidural analgesia and its relationship with eutocic or dystocic delivery. Rev Esp Anestesiol Reanim 2017;64(7):369-374. DOI: 10.1016/j.redar.2016.10.004. PMID: 28089318.

Sandstrom A, Altman M, Cnattingius S, et al. Durations of second stage of labor and pushing, and adverse neonatal outcomes: a population-based cohort study. J Perinatol 2017;37(3):236242. DOI: 10.1038/jp.2016.214. PMID: 27929527.

Sandstrom A, Cnattingius S, Wikstrom AK, et al. Labour dystocia--risk of recurrence and instrumental delivery in following labour--a population-based cohort study. Bjog 2012;119(13):1648-56. DOI: 10.1111/j.1471-0528.2012.03502.x. PMID: 23078516.

Sarbhjit K, S KB, Parmjit K, et al. To compare the effect of camylofin dihydrochloride (anafortin) with combination of valethamate bromide (epidosin) and hyoscine butyl-N-bormide (buscopan) on cervical dilation. J Clin Diagn Res 2013;7(9):1897-9. DOI: 10.7860/jcdr/2013/6231.3345. PMID: 24179892.

Schiessl B, Janni W, Jundt K, et al. Obstetrical parameters influencing the duration of the second stage of labor. Eur J Obstet Gynecol Reprod Biol 2005;118(1):17-20. DOI: 10.1016/j.ejogrb.2004.01.045. PMID: 15596266.

Schwarz GL, Volmanen P, Albrechtsen S, et al. Remifentanil target-controlled infusion during second stage labour in high-risk parturients: a case series. Acta Anaesthesiologica Scandinavica 2013;57(6):802-808. DOI: 10.1111/aas.12096. 
Senecal J, Xiong X and Fraser WD. Effect of fetal position on second-stage duration and labor outcome. Obstet Gynecol 2005;105(4):763-72. DOI: 10.1097/01.aog.0000154889.47063.84. PMID: 15802403.

Sfandiary M, Parvizi S, Almasi A, et al. Effect of pre-pregnancy maternal body mass index on pregnancy outcomes in nulliparous women in the Islamic Republic of Iran. Eastern Mediterranean Health Journal 2017;23(10):657-661. DOI: 10.26719/2017.23.10.657.

Shaban MM, Bassiouny YA, Elzahaby IM, et al. Body mass index and labour outcome in Egyptian women. J Obstet Gynaecol 2014;34(3):248-50. DOI: 10.3109/01443615.2013.844113. PMID: 24294988.

Shaw-Battista J. Systematic Review of Hydrotherapy Research: Does a Warm Bath in Labor Promote Normal Physiologic Childbirth?. J Perinat Neonatal Nurs 2017;31(4):303-316. DOI: 10.1097/jpn.0000000000000260. PMID: 28520654.

Shazly SA, Embaby LH and Ali SS. The labour scale--assessment of the validity of a novel labour chart: a pilot study. Aust N Z J Obstet Gynaecol 2014;54(4):322-6. DOI: 10.1111/ajo.12209. PMID: 24835694.

Shiro M, Nakahata K, Minami S, et al. Perinatal outcome of vaginal delivery with epidural analgesia initiated at the early or late phase of labor period: A retrospective cohort study in the Japanese population. J Obstet Gynaecol Res 2018;44(8):1415-1423. DOI: 10.1111/jog.13671. PMID: 29888832.

Shmueli A, Salman L, Ashwal E, et al. Perinatal outcomes of vacuum assisted versus cesarean deliveries for prolonged second stage of delivery at term(). J Matern Fetal Neonatal Med 2017;30(8):886-889. DOI: 10.1080/14767058.2016.1191066. PMID: 27188481.

Shmueli A, Salman L, Orbach-Zinger S, et al. The impact of epidural analgesia on the duration of the second stage of labor. Birth 2018. DOI: 10.1111/birt.12355. PMID: 29790194.

Singh SK, Yahya N, Misiran K, et al. Combined spinal-epidural analgesia in labour: its effects on delivery outcome. Braz J Anesthesiol 2016;66(3):259-64. DOI: 10.1016/j.bjane.2014.09.006. PMID: 27108822.

Smith CA and Cochrane S. Does acupuncture have a place as an adjunct treatment during pregnancy? A review of randomized controlled trials and systematic reviews. Birth 2009;36(3):246-53. DOI: 10.1111/j.1523-536X.2009.00329.x. PMID: 19747272.

Sng BL, Zhang Q, Leong WL, et al. Incidence and characteristics of breakthrough pain in parturients using computer-integrated patient-controlled epidural analgesia. J Clin Anesth 2015;27(4):277-84. DOI: 10.1016/j.jclinane.2015.01.003. PMID: 25690278. 
Sosa CG, Althabe F, Belizan JM, et al. Use of oxytocin during early stages of labor and its effect on active management of third stage of labor. Am J Obstet Gynecol 2011;204(3):238.e1-5. DOI: 10.1016/j.ajog.2010.10.005. PMID: 21145034.

Stevenson J. The Bristol third-stage trial. Midwifery Today 2005;(73):41-43.

Stourac P, Suchomelova H, Stodulkova M, et al. Comparison of parturient - controlled remifentanil with epidural bupivacain and sufentanil for labour analgesia: randomised controlled trial. Biomed Pap Med Fac Univ Palacky Olomouc Czech Repub 2014;158(2):227-32. DOI: 10.5507/bp.2012.073. PMID: 23128818.

Strouch ZY, Dakik CG, White WD, et al. Anesthetic technique for cesarean delivery and neonatal acid-base status: a retrospective database analysis. Can J Anaesth 2015;24(1):22-9. DOI: 10.1007/s12630-014-0291-x. PMID: 25499813.

Svardby K, Nordstrom L and Sellstrom E. Primiparas with or without oxytocin augmentation: a prospective descriptive study. J Clin Nurs 2007;16(1):179-84. DOI: 10.1111/j.13652702.2005.01481.x. PMID: 17181680.

Tan PS, Tan JKH, Tan EL, et al. Comparison of Caesarean sections and instrumental deliveries at full cervical dilatation: a retrospective review. Singapore Med J 2018. DOI:

10.11622/smedj.2018040. PMID: 29670996.

Thies-Lagergren L, Kvist LJ, Christensson K, et al. Striving for scientific stringency: a reanalysis of a randomised controlled trial considering first-time mothers' obstetric outcomes in relation to birth position. BMC Pregnancy Childbirth 2012;12:135. DOI: 10.1186/1471-2393-12135. PMID: 23173988.

Thirawat S and Kovavisarach E. Maternal and neonatal outcomes of parturients with or without amniotomy for augmentation of labor. Journal of the Medical Association of Thailand 2017;100(11):1156-1161.

Tien M, Allen TK, Mauritz A, et al. A retrospective comparison of programmed intermittent epidural bolus with continuous epidural infusion for maintenance of labor analgesia. Curr Med Res Opin 2016;32(8):1435-40. DOI: 10.1080/03007995.2016.1181619. PMID: 27100210.

Torkamani SA, Kangani F and Janani F. The effects of delivery in water on duration of delivery and pain compared with normal delivery. Pakistan Journal of Medical Sciences 2010;26(3):551555.

Torkildsen EA, Salvesen K and Eggebø TM. Prediction of delivery mode with transperineal ultrasound in women with prolonged first stage of labor. Ultrasound in Obstetrics \& Gynecology 2011;37(6):702-708. DOI: 10.1002/uog.8951. 
Tranquilli AL, Biagini A, Greco P, et al. The correlation between fetal bradycardia area in the second stage of labor and acidemia at birth. Journal of Maternal-Fetal \& Neonatal Medicine 2013;26(14):1425-1429 5p. DOI: 10.3109/14767058.2013.784263.

Tranquilli AL. Fetal heart rate in the second stage of labor: recording, reading, interpreting and acting. Journal of Maternal-Fetal \& Neonatal Medicine 2012;25(12):2551-2554 4p. DOI: 10.3109/14767058.2012.718395.

Triebwasser JE, Colvin R, Macones GA, et al. Nonreassuring Fetal Status in the Second Stage of Labor: Fetal Monitoring Features and Association with Neonatal Outcomes. Am J Perinatol 2016;33(7):665-70. DOI: 10.1055/s-0036-1571316. PMID: 26862724.

Tugrul S, Oral O, Bakacak M, et al. Effects of epidural analgesia using ropivacaine on the mother and the newborn during labor. Saudi Med J 2006;27(12):1853-8. PMID: 17143364.

Tutschek B, Braun T, Chantraine F, et al. A study of progress of labour using intrapartum translabial ultrasound, assessing head station, direction, and angle of descent. Bjog 2011;118(1):62-9. DOI: 10.1111/j.1471-0528.2010.02775.x. PMID: 21083864.

Varner CA. Comparison of the Bradley Method and HypnoBirthing Childbirth Education Classes. Journal of Perinatal Education 2015;24(2):128-136. DOI: 10.1891/1058-1243.24.2.128.

Villano KS, Lo JY, Alexander JM, et al. A dose-finding study of oral misoprostol for labor augmentation. Am J Obstet Gynecol 2011;204(6):560.e1-5. DOI: 10.1016/j.ajog.2011.02.064. PMID: 21514556.

Vincent M. Amniotomy: to do or not to do?. RCM Midwives 2005;8(5):228-229.

Vixner L, Schytt E and Martensson LB. Associations between maternal characteristics and women's responses to acupuncture during labour: a secondary analysis from a randomised controlled trial. Acupunct Med 2017;35(3):180-188. DOI: 10.1136/acupmed-2016-011164. PMID: 27986648.

Waldenstrom U and Ekeus C. Risk of labor dystocia increases with maternal age irrespective of parity: a population-based register study. Acta Obstet Gynecol Scand 2017;96(9):1063-1069. DOI: 10.1111/aogs.13167. PMID: 28498626.

Walsh J, Foley M and O'Herlihy C. Dystocia correlates with body mass index in both spontaneous and induced nulliparous labors. J Matern Fetal Neonatal Med 2011;24(6):817-21. DOI: 10.3109/14767058.2010.531313. PMID: 21158492.

Warmink-Perdijk WDB, Koelewijn JM, de Jonge A, et al. Better perineal outcomes in sitting birthing position cannot be explained by changing from upright to supine position for performing an episiotomy. Midwifery 2016;34:1-6. DOI: 10.1016/j.midw.2016.01.010. PMID: 26971440. 
Wiberg-Itzel E, Pembe AB, Wray S, et al. Level of lactate in amniotic fluid and its relation to the use of oxytocin and adverse neonatal outcome. Acta Obstet Gynecol Scand 2014;93(1):80-5. DOI: 10.1111/aogs.12261. PMID: 24102442.

Wong CA and Peaceman AM. Effect of early epidural analgesia on labor: cutting through the confusion. Contemporary OB/GYN 2006;51(7):64-68.

Woo JH, Kim JH, Lee GY, et al. The degree of labor pain at the time of epidural analgesia in nulliparous women influences the obstetric outcome. 2015;68(3):249-53. DOI:

10.4097/kjae.2015.68.3.249. PMID: 26045927.

Wu M, Jin W, Chen S, et al. Maternal and perinatal outcomes among low risk women giving birth in water: A retrospective study in a maternity \& infant health hospital over 7 years. International Journal of Clinical and Experimental Medicine 2018;11(2):1318-1323.

Yee LM, Sandoval G, Bailit J, et al. Maternal and Neonatal Outcomes With Early Compared With Delayed Pushing Among Nulliparous Women. Obstet Gynecol 2016;128(5):1039-1047. DOI: 10.1097/aog.0000000000001683. PMID: 27741203.

Yoshida M, Matsuda H, Kawakami Y, et al. Effectiveness of epidural anesthesia for external cephalic version (ECV). J Perinatol 2010;30(9):580-3. DOI: 10.1038/jp.2010.61. PMID: 20485361.

Zhang J, Branch DW, Ramirez MM, et al. Oxytocin regimen for labor augmentation, labor progression, and perinatal outcomes. Obstet Gynecol 2011;118(2 Pt 1):249-56. DOI: 10.1097/AOG.0b013e3182220192. PMID: 21775839.

Zhu BP, Grigorescu V, Le T, et al. Labor dystocia and its association with interpregnancy interval. Am J Obstet Gynecol 2006;195(1):121-8. DOI: 10.1016/j.ajog.2005.12.016. PMID: 16635468.

\section{Not study population of interest or does not provide a definition of dystocia:}

Agur W, Steggles P, Waterfield M, et al. Does antenatal pelvic floor muscle training affect the outcome of labour? A randomised controlled trial. Int Urogynecol J Pelvic Floor Dysfunct 2008;19(1):85-8. DOI: 10.1007/s00192-007-0391-z. PMID: 17530154.

Akkamahadevi P, Srinivas HT, Siddesh A, et al. Comparision of efficacy of sufentanil and fentanyl with low-concentration bupivacaine for combined spinal epidural labour analgesia. Indian Journal of Anaesthesia 2012;56(4):365-369.

Alexander S, Boulvain M, Ceysens G, et al. Repeat digital cervical assessment in pregnancy for identifying women at risk of preterm labour. Cochrane Database Syst Rev 2010;(6):Cd005940. DOI: 10.1002/14651858.CD005940.pub2. PMID: 20556763. 
Anim-Somuah M, Smyth RM, Cyna AM, et al. Epidural versus non-epidural or no analgesia for pain management in labour. Cochrane Database Syst Rev 2018;5:Cd000331. DOI:

10.1002/14651858.CD000331.pub4. PMID: 29781504.

Atukunda EC, Siedner MJ, Obua C, et al. Sublingual misoprostol versus intramuscular oxytocin for prevention of postpartum hemorrhage in Uganda: a double-blind randomized non-inferiority trial. PLoS Med 2014;11(11):e1001752. DOI: 10.1371/journal.pmed.1001752. PMID: 25369200.

Bailit JL, Dierker L, Blanchard MH, et al. Outcomes of women presenting in active versus latent phase of spontaneous labor. Obstet Gynecol 2005;105(1):77-9. DOI:

10.1097/01.aog.0000147843.12196.00. PMID: 15625145.

Bain E, Crane M, Tieu J, et al. Diet and exercise interventions for preventing gestational diabetes mellitus. Cochrane Database Syst Rev 2015;4:Cd010443. DOI:

10.1002/14651858.CD010443.pub2. PMID: 25864059.

Bakker JJ, Verhoeven CJ, Janssen PF, et al. Outcomes after internal versus external tocodynamometry for monitoring labor. N Engl J Med 2010;362(4):306-13. DOI: 10.1056/NEJMoa0902748. PMID: 20107216.

Bala A, Bagga R, Kalra J, et al. Early versus delayed amniotomy during labor induction with oxytocin in women with Bishop's score of $\geq 6$ : a randomized trial. Journal of Maternal-Fetal and Neonatal Medicine 2017:1-8. DOI: 10.1080/14767058.2017.1362381.

Barakat R, Franco E, Perales M, et al. Exercise during pregnancy is associated with a shorter duration of labor. A randomized clinical trial. Eur J Obstet Gynecol Reprod Biol 2018;224:3340. DOI: 10.1016/j.ejogrb.2018.03.009. PMID: 29529475.

Bawdane KD, Magar JS and Tendolkar BA. Double blind comparison of combination of $0.1 \%$ ropivacaine and fentanyl to combination of $0.1 \%$ bupivacaine and fentanyl for extradural analgesia in labour. Journal of Anaesthesiology Clinical Pharmacology 2016;32(1):38-43. DOI: 10.4103/0970-9185.173350.

Beckmann M. Predicting a failed induction. Aust N Z J Obstet Gynaecol 2007;47(5):394-8. DOI: 10.1111/j.1479-828X.2007.00763.x. PMID: 17877597.

Beckmann MM and Garrett AJ. Antenatal perineal massage for reducing perineal trauma. Cochrane Database Syst Rev 2006;(1):Cd005123. DOI: 10.1002/14651858.CD005123.pub2. PMID: 16437520.

Beddoe AE and Lee KA. Mind-body interventions during pregnancy. J Obstet Gynecol Neonatal Nurs 2008;37(2):165-75. DOI: 10.1111/j.1552-6909.2008.00218.x. PMID: 18336440.

Bloom SL, Spong CY, Thom E, et al. Fetal pulse oximetry and cesarean delivery. N Engl J Med 2006;355(21):2195-202. DOI: 10.1056/NEJMoa061170. PMID: 17124017. 
Boie S, Glavind J, Velu AV, et al. Discontinuation of intravenous oxytocin in the active phase of induced labour. Cochrane Database Syst Rev 2018;8:Cd012274. DOI:

10.1002/14651858.CD012274.pub2. PMID: 30125998.

Bor P, Ledertoug S, Boie S, et al. Continuation versus discontinuation of oxytocin infusion during the active phase of labour: A randomised controlled trial. BJOG: An International Journal of Obstetrics and Gynaecology 2016;123(1):129-135.

Borup L, Wurlitzer W, Hedegaard M, et al. Acupuncture as pain relief during delivery: a randomized controlled trial. Birth 2009;36(1):5-12. DOI: 10.1111/j.1523-536X.2008.00290.x. PMID: 19278378.

Bosomworth A and Bettany-Saltikov J. Just take a deep breath...a review to compare the effects of spontaneous versus directed Valsalva pushing in the second stage of labour on maternal and fetal wellbeing. MIDIRS Midwifery Digest 2006;16(2):157-165.

Brancato RM, Church S and Stone PW. A meta-analysis of passive descent versus immediate pushing in nulliparous women with epidural analgesia in the second stage of labor. J Obstet Gynecol Neonatal Nurs 2008;37(1):4-12. DOI: 10.1111/j.1552-6909.2007.00205.x. PMID: 18226152.

Brane E, Olsson A and Andolf E. A randomized controlled trial on early induction compared to expectant management of nulliparous women with prolonged latent phases. Acta Obstet Gynecol Scand 2014;93(10):1042-9. DOI: 10.1111/aogs.12447. PMID: 24974855.

Brixval CS, Axelsen SF, Lauemøller SG, et al. The effect of antenatal education in small classes on obstetric and psycho-social outcomes - a systematic review. Systematic Reviews 2015;4(1).

Brown J, Ceysens G and Boulvain M. Exercise for pregnant women with gestational diabetes for improving maternal and fetal outcomes. Cochrane Database Syst Rev 2017;6:Cd012202. DOI: 10.1002/14651858.CD012202.pub2. PMID: 28639706.

Buchberger B and Krabbe L. Evaluation of outpatient acupuncture for relief of pregnancy-related conditions. Int J Gynaecol Obstet 2018;141(2):151-158. DOI: 10.1002/ijgo.12446. PMID: 29355951.

Burns E, Zobbi V, Panzeri D, et al. Aromatherapy in childbirth: a pilot randomised controlled trial. Bjog 2007;114(7):838-44. DOI: 10.1111/j.1471-0528.2007.01381.x. PMID: 17506789.

Campbell DA, Lake MF, Falk M, et al. A randomized control trial of continuous support in labor by a lay doula. J Obstet Gynecol Neonatal Nurs 2006;35(4):456-64. DOI: 10.1111/j.15526909.2006.00067.x. PMID: 16881989.

Carlson NS and Lowe NK. Intrapartum management associated with obesity in nulliparous women. J Midwifery Womens Health 2014;59(1):43-53. DOI: 10.1111/jmwh.12073. PMID: 24400789. 
Chaillet N, Belaid L, Crochetiere C, et al. Nonpharmacologic approaches for pain management during labor compared with usual care: a meta-analysis. Birth 2014;41(2):122-37. DOI:

10.1111/birt.12103. PMID: 24761801.

Chen SF, Wang CH, Chan PT, et al. Labor pain control by aromatherapy: A meta-analysis of randomized controlled trials. Women Birth 2018. PMID: 30344029.

Chen Y-W and Wang H-H. The Effectiveness of Acupressure on Relieving Pain: A Systematic Review. Pain Management Nursing 2014;15(2):539-550. DOI: 10.1016/j.pmn.2012.12.005.

Cheyne H, Hundley V, Dowding D, et al. Effects of algorithm for diagnosis of active labour: cluster randomised trial. Bmj 2008;337:a2396. DOI: 10.1136/bmj.a2396. PMID: 19064606.

Chhabra S and Tickoo C. Low-dose sublingual misoprostol versus methylergometrine for active management of the third stage of labor. J Obstet Gynaecol Res 2008;34(5):820-3. DOI:

10.1111/j.1447-0756.2008.00843.x. PMID: 18834340.

Chuang LL, Lin LC, Cheng PJ, et al. Effects of a relaxation training programme on immediate and prolonged stress responses in women with preterm labour. J Adv Nurs 2012;68(1):170-80. DOI: 10.1111/j.1365-2648.2011.05765.x. PMID: 21771042.

Chuang LL, Lin LC, Cheng PJ, et al. The effectiveness of a relaxation training program for women with preterm labour on pregnancy outcomes: a controlled clinical trial. Int J Nurs Stud 2012;49(3):257-64. DOI: 10.1016/j.ijnurstu.2011.09.007. PMID: 21968280.

Chuntharapat S, Petpichetchian W and Hatthakit U. Yoga during pregnancy: effects on maternal comfort, labor pain and birth outcomes. Complement Ther Clin Pract 2008;14(2):105-15. DOI: 10.1016/j.ctcp.2007.12.007. PMID: 18396254.

Cluett ER, Burns E and Cuthbert A. Immersion in water during labour and birth. Cochrane Database Syst Rev 2018;5:Cd000111. DOI: 10.1002/14651858.CD000111.pub4. PMID: 29768662.

Connolly KA, Kohari KS, Factor SH, et al. A Randomized Trial of Foley Balloon Induction of Labor Trial in Multiparas (FIAT-M). American Journal of Perinatology 2017;34(11):1108-1114. DOI: $10.1055 / \mathrm{s}-0037-1603994$.

Costley PL and East CE. Oxytocin augmentation of labour in women with epidural analgesia for reducing operative deliveries. Cochrane Database Syst Rev 2013;7:Cd009241. DOI:

10.1002/14651858.CD009241.pub3. PMID: 23846738.

Da Costa AG, Barros JG, Clode N, et al. Levels of agreement between clinical examination and transabdominal ultrasound evaluation of fetal head position in the second stage of labor. Journal of Maternal-Fetal and Neonatal Medicine 2016;29(3):473-476. 
Dahan MH and Dahan S. Fetal weight, maternal age and height are poor predictors of the need for caesarean section for arrest of labor. Arch Gynecol Obstet 2005;273(1):20-5. DOI:

10.1007/s00404-005-0001-6. PMID: 16001202.

Darmstadt GL, Yakoob MY, Haws RA, et al. Reducing stillbirths: interventions during labour. BMC Pregnancy Childbirth 2009;9(Suppl 1):S6. DOI: 10.1186/1471-2393-9-s1-s6. PMID: 19426469.

Dashtinejad E, Abedi P and Afshari P. Comparison of the effect of breast pump stimulation and oxytocin administration on the length of the third stage of labor, postpartum hemorrhage, and anemia: A randomized controlled trial. BMC Pregnancy and Childbirth 2018;18(1). DOI: 10.1186/s12884-018-1832-z.

Deighan M, Briain DO, Shakeban H, et al. A randomised controlled trial using the Epidrum for labour epidurals. Ir Med J 2015;108(3):73-5. PMID: 25876297.

Demiraran Y, Albayrak M, Seker IS, et al. Effect of anesthesiological strategies on neonatal bilirubin levels during cesarean section: a prospective and randomized trial. Arch Gynecol Obstet 2011;284(5):1059-65. DOI: 10.1007/s00404-010-1783-8. PMID: 21136268.

Demirel G and Guler H. The Effect of Uterine and Nipple Stimulation on Induction With Oxytocin and the Labor Process. Worldviews Evid Based Nurs 2015;12(5):273-80. DOI: 10.1111/wvn.12116. PMID: 26444882.

Desbriere R, Blanc J, Le Du R, et al. Is maternal posturing during labor efficient in preventing persistent occiput posterior position? A randomized controlled trial. Am J Obstet Gynecol 2013;208(1):60.e1-8. DOI: 10.1016/j.ajog.2012.10.882. PMID: 23107610.

Devane D, Lalor Joan G, Daly S, et al. Cardiotocography versus intermittent auscultation of fetal heart on admission to labour ward for assessment of fetal wellbeing. 2012;(2). DOI: 10.1002/14651858.CD005122.pub4. PMID: CD005122.

Dillner J, Kjaer SK, Wheeler CM, et al. Four year efficacy of prophylactic human papillomavirus quadrivalent vaccine against low grade cervical, vulvar, and vaginal intraepithelial neoplasia and anogenital warts: Randomised controlled trial. BMJ (Online) 2010;341(7766):239.

Direkvand-Moghadam A, Jaafarpour M, Khani A, et al. The effect of oral propranolol plus oxytocin versus oxytocin only on the process and outcome of labor: A double-blind randomized trial. Iran J Nurs Midwifery Res 2014;19(5):491-5. PMID: 25400677.

Dong C, Hu L, Liang F, et al. Effects of electro-acupuncture on labor pain management. Arch Gynecol Obstet 2015;291(3):531-6. DOI: 10.1007/s00404-014-3427-X. PMID: 25138127.

Downe S, Finlayson K, Melvin C, et al. Self-hypnosis for intrapartum pain management in pregnant nulliparous women: a randomised controlled trial of clinical effectiveness. Bjog 2015;122(9):1226-34. DOI: 10.1111/1471-0528.13433. PMID: 25958769. 
Du Y, Xu L, Ding L, et al. The effect of antenatal pelvic floor muscle training on labor and delivery outcomes: a systematic review with meta-analysis. International Urogynecology Journal and Pelvic Floor Dysfunction 2015;26(10):1415-1427.

East CE, Brennecke SP, King JF, et al. The effect of intrapartum fetal pulse oximetry, in the presence of a nonreassuring fetal heart rate pattern, on operative delivery rates: a multicenter, randomized, controlled trial (the FOREMOST trial). American Journal of Obstetrics \& Gynecology 2006;194(3):606-616.

Eggebo TM, Hassan WA, Salvesen KA, et al. Sonographic prediction of vaginal delivery in prolonged labor: a two-center study. Ultrasound Obstet Gynecol 2014;43(2):195-201. DOI: 10.1002/uog.13210. PMID: 24105705.

Esmaelzadeh-Saeieh S, Rahimzadeh M, Khosravi-Dehaghi N, et al. The Effects of Inhalation Aromatherapy with Boswellia carterii Essential Oil on the Intensity of Labor Pain among Nulliparous Women. Nursing \& Midwifery Studies 2018;7(2):45-49. DOI: 10.4103/nms.nms_70_17. PMID: 128694744 .

Farmer DL, Thom EA, Iiibrock JW, et al. The Management of Myelomeningocele Study: full cohort 30-month pediatric outcomes. American Journal of Obstetrics \& Gynecology 2018;218(2):256.e1-256.e13. DOI: 10.1016/j.ajog.2017.12.001. PMID: 127589535.

Fatima S, Rizvi S, Saeed G, et al. Expectant vs active management of prelabour rupture of membranes at term. Pakistan Journal of Medical and Health Sciences 2015;9(4):1353-1357.

Fawole B and Hofmeyr GJ. Maternal oxygen administration for fetal distress. Cochrane Database Syst Rev 2012;12:Cd000136. DOI: 10.1002/14651858.CD000136.pub2. PMID: 23235574.

Fleet J, cert G, Jones M, et al. Subcutaneous administration of fentanyl in childbirth: An observational study on the clinical effectiveness of fentanyl for mother and neonate. Midwifery 2014;30(1):36-42 7p. DOI: 10.1016/j.midw.2013.01.014.

Freeman LM, Bloemenkamp KW, Franssen MT, et al. Patient controlled analgesia with remifentanil versus epidural analgesia in labour: randomised multicentre equivalence trial. Bmj 2015;350:h846. DOI: 10.1136/bmj.h846. PMID: 25713015.

Frolova AI, Stout MJ, Tuuli MG, et al. Duration of the Third Stage of Labor and Risk of Postpartum Hemorrhage. Obstet Gynecol 2016;127(5):951-6. DOI: 10.1097/aog.0000000000001399. PMID: 27054942.

Gagnon-Gervais K, Bujold E, Iglesias MH, et al. Early versus late amniotomy for labour induction: a randomized controlled trial. J Matern Fetal Neonatal Med 2012;25(11):2326-9. DOI: 10.3109/14767058.2012.695819. PMID: 22616980. 
Galazios G, Tica V, Vrachnis N, et al. Assessment of labor using a new type partogram compared to the classical Fisher partogram. Journal of Maternal-Fetal and Neonatal Medicine 2015;28(1):82-87.

Gau ML, Chang CY, Tian SH, et al. Effects of birth ball exercise on pain and self-efficacy during childbirth: a randomised controlled trial in Taiwan. Midwifery 2011;27(6):e293-300. DOI: 10.1016/j.midw.2011.02.004. PMID: 21459499.

Gilad R, Hochner H, Savitsky B, et al. Castor oil for induction of labor in post-date pregnancies: A randomized controlled trial. Women Birth 2018;31(1):e26-e31. DOI: 10.1016/j.wombi.2017.06.010. PMID: 28750937.

Gillesby E, Burns S, Dempsey A, et al. Comparison of delayed versus immediate pushing during second stage of labor for nulliparous women with epidural anesthesia. J Obstet Gynecol Neonatal Nurs 2010;39(6):635-44. DOI: 10.1111/j.1552-6909.2010.01195.x. PMID: 21044148.

Gimovsky AC and Berghella V. Randomized controlled trial of prolonged second stage: extending the time limit vs usual guidelines. Am J Obstet Gynecol 2016;214(3):361.e1-6. DOI: 10.1016/j.ajog.2015.12.042. PMID: 26928148.

Ginosar Y, Birnbach DJ, Shirov TT, et al. Duration of analgesia and pruritus following intrathecal fentanyl for labour analgesia: no significant effect of A118G [mu]-opioid receptor polymorphism, but a marked effect of ethnically distinct hospital populations. BJA: The British Journal of Anaesthesia 2013;111(3):433-444 12p. DOI: bja/aet075.

Girard B, Vardon D, Creveuil C, et al. Discontinuation of oxytocin in the active phase of labor. Acta Obstet Gynecol Scand 2009;88(2):172-7. DOI: 10.1080/00016340802649816. PMID: 19169930.

Grantz KL, Sundaram R, Ma L, et al. Reassessing the duration of the second stage of labor in relation to maternal and neonatal morbidity. Obstetrics and Gynecology 2018;131(2):345-353. DOI: 10.1097/AOG.0000000000002431.

Greenberg MB, Cheng YW, Hopkins LM, et al. Are there ethnic differences in the length of labor?. Am J Obstet Gynecol 2006;195(3):743-8. DOI: 10.1016/j.ajog.2006.06.016. PMID: 16949407.

Grivell RM, Alfirevic Z, Gyte GM, et al. Antenatal cardiotocography for fetal assessment. Cochrane Database of Systematic Reviews 2012;(12):N.PAG-N.PAG. DOI: 10.1002/14651858.CD007863.pub2.

Gündüz Ş, Yalçın SE, Karakoç G, et al. Comparison of bupivacaine and ropivacaine in combination with fentanyl used for walking epidural anesthesia in labor. Turk Jinekoloji ve Obstetrik Dernegi Dergisi 2017;14(3):170-175. DOI: 10.4274/tjod.87404. 
Gupta JK, Hofmeyr GJ and Shehmar M. Position in the second stage of labour for women without epidural anaesthesia. Cochrane Database Syst Rev 2012;5:Cd002006. DOI:

10.1002/14651858.CD002006.pub3. PMID: 22592681.

Gupta JK, Sood A, Hofmeyr GJ, et al. Position in the second stage of labour for women without epidural anaesthesia. Cochrane Database Syst Rev 2017;5:Cd002006. DOI:

10.1002/14651858.CD002006.pub4. PMID: 28539008.

Halem KV, Bakker JJ, Verhoeven CJ, et al. Does use of an intrauterine catheter during labor increase risk of infection? J Matern Fetal Neonatal Med 2012;25(4):415-8. DOI: 10.3109/14767058.2011.582905. PMID: 21649507.

Halem KV, Bakker JJ, Verhoeven CJ, et al. Does use of an intrauterine catheter during labor increase risk of infection? J Matern Fetal Neonatal Med 2012;25(4):415-8. DOI: 10.3109/14767058.2011.582905. PMID: 21649507.

Hamilton EF, Warrick PA, Collins K, et al. Assessing first-stage labor progression and its relationship to complications. American Journal of Obstetrics and Gynecology 2015.

Harper LM, Caughey AB, Roehl KA, et al. Defining an abnormal first stage of labor based on maternal and neonatal outcomes. Am J Obstet Gynecol 2014;210(6):536.e1-7. DOI:

10.1016/j.ajog.2013.12.027. PMID: 24361789.

Hernández-Martínez A, Arias-Arias A, Morandeira-Rivas A, et al. Oxytocin discontinuation after the active phase of induced labor: A systematic review. Women and Birth 2018. DOI: 10.1016/j.wombi.2018.07.003.

Hilliard AM, Chauhan SP, Zhao Y, et al. Effect of obesity on length of labor in nulliparous women. Am J Perinatol 2012;29(2):127-32. DOI: 10.1055/s-0031-1295653. PMID: 22105434.

Hjelmstedt A, Shenoy ST, Stener-Victorin E, et al. Acupressure to reduce labor pain: a randomized controlled trial. Acta Obstet Gynecol Scand 2010;89(11):1453-9. DOI: 10.3109/00016349.2010.514323. PMID: 20822474.

Hodnett ED, Stremler R, Halpern SH, et al. Repeated hands-and-knees positioning during labour: A randomized pilot study. PeerJ 2013;2013(1).

Hoffman MK, Vahratian A, Sciscione AC, et al. Comparison of labor progression between induced and noninduced multiparous women. Obstet Gynecol 2006;107(5):1029-34. DOI: 10.1097/01.AOG.0000210528.32940.c6. PMID: 16648407.

Hofmeyr GJ and Kulier R. Hands and knees posture in late pregnancy or labour for fetal malposition (lateral or posterior). Cochrane Database Syst Rev 2005;(2):Cd001063. DOI: 10.1002/14651858.CD001063.pub2. PMID: 15846611. 
Hofmeyr GJ and Lawrie TA. Amnioinfusion for potential or suspected umbilical cord compression in labour. Cochrane Database Syst Rev 2012;1:Cd000013. DOI:

10.1002/14651858.CD000013.pub2. PMID: 22258939.

Igarashi T. Physical and Psychologic Effects of Aromatherapy Inhalation on Pregnant Women: A Randomized Controlled Trial. Journal of Alternative \& Complementary Medicine 2013;19(10):805-810 6p. DOI: 10.1089/acm.2012.0103.

Incerti M, Locatelli A, Ghidini A, et al. Variability in rate of cervical dilation in nulliparous women at term. Birth 2011;38(1):30-5. DOI: 10.1111/j.1523-536X.2010.00443.x. PMID: 21332772.

Jahdi F, Shahnazari M, Kashanian M, et al. A randomized controlled trial comparing the physiological and directed pushing on the duration of the second stage of labor, the mode of delivery and apgar score. International Journal of Collaborative Research on Internal Medicine and Public Health 2011;3(2):159-165.

Jahdi F, Sheikhan F, Haghani H, et al. Yoga during pregnancy: The effects on labor pain and delivery outcomes (A randomized controlled trial). Complement Ther Clin Pract 2017;27:1-4. DOI: 10.1016/j.ctcp.2016.12.002. PMID: 28438273.

Jallo N, Jeanne Ruiz R, Elswick Jr RK, et al. Guided Imagery for Stress and Symptom Management in Pregnant African American Women. Evidence-based Complementary \& Alternative Medicine (eCAM) 2014;2014:1-13 13p.

Jamilian M, Karamali M, Sadeghi B, et al. The effect of intramuscular administration of atropine and hyoscine combination on labor progress and maternal and neonatal outcomes in primigravid women. Iranian Journal of Neonatology 2016;7(1):13-18.

Janula R and Mahipal S. Effectiveness of Aromatherapy and Biofeedback in Promotion of Labour Outcome during Childbirth among Primigravidas. Health Science Journal 2015;9(1):1-5.

Javed I, Bhutta S and Shoaib T. Role of partogram in preventing prolonged labour. J Pak Med Assoc 2007;57(8):408-11. PMID: 17902525.

Jiang XM, Chen QY, Guo SB, et al. Effect of midwife-led care on birth outcomes of primiparas. Int J Nurs Pract 2018;24(6):e12686. PMID: 30109750.

Jun W, Zhengzhuang A and Li O. Analgesic efficacy of dexmedetomidine used for epidural anesthesia on labor analgesia. Biomedical Research (India) 2018;29(3):426-430.

Kavanagh J, Kelly AJ and Thomas J. Breast stimulation for cervical ripening and induction of labour. Cochrane Database of Systematic Reviews 2005:N.PAG-N.PAG. 
Kelly M, Johnson E, Lee V, et al. Delayed versus immediate pushing in second stage of labor. MCN Am J Matern Child Nurs 2010;35(2):81-8. DOI: 10.1097/NMC.0b013e3181cae7ad. PMID: 20215948.

Kemp E, Kingswood CJ, Kibuka M, et al. Position in the second stage of labour for women with epidural anaesthesia. Cochrane Database Syst Rev 2013;1:Cd008070. DOI: 10.1002/14651858.CD008070.pub2. PMID: 23440824.

Khunpradit S, Tavender E, Lumbiganon P, et al. Non-clinical interventions for reducing unnecessary caesarean section. 2011;(6). DOI: 10.1002/14651858.CD005528.pub2. PMID: CD005528.

Kibuka M and Thornton JG. Position in the second stage of labour for women with epidural anaesthesia. Cochrane Database Syst Rev 2017;2:Cd008070. DOI:

10.1002/14651858.CD008070.pub3. PMID: 28231607.

Kimber L, McNabb M, Mc Court C, et al. Massage or music for pain relief in labour: a pilot randomised placebo controlled trial. Eur J Pain 2008;12(8):961-9. DOI:

10.1016/j.ejpain.2008.01.004. PMID: 18304848.

Klauser CK, Christensen EE, Chauhan SP, et al. Use of fetal pulse oximetry among high-risk women in labor: a randomized clinical trial. Am J Obstet Gynecol 2005;192(6):1810-7; discussion 1817-9. DOI: 10.1016/j.ajog.2004.12.047. PMID: 15970816.

Langen ES, Weiner SJ, Bloom SL, et al. Association of Cervical Effacement With the Rate of Cervical Change in Labor Among Nulliparous Women. Obstet Gynecol 2016;127(3):489-95. DOI: 10.1097/aog.0000000000001299. PMID: 26855099.

Larsen S, Dobbin J, McCallion O, et al. Intrauterine fetal death and risk of shoulder dystocia at delivery. Acta Obstet Gynecol Scand 2016;95(12):1345-1351. DOI: 10.1111/aogs.13033. PMID: 27687568.

Laughon SK, Berghella V, Reddy UM, et al. Neonatal and maternal outcomes with prolonged second stage of labor. Obstet Gynecol 2014;124(1):57-67. DOI: 10.1097/aog.0000000000000278. PMID: 24901265.

Laursen M, Johansen C and Hedegaard M. Fear of childbirth and risk for birth complications in nulliparous women in the Danish National Birth Cohort. Bjog 2009;116(10):1350-5. DOI: 10.1111/j.1471-0528.2009.02250.x. PMID: 19538412.

Lee S-L, Liu C-Y, Lu Y-Y, et al. Efficacy of Warm Showers on Labor Pain and Birth Experiences During the First Labor Stage. JOGNN: Journal of Obstetric, Gynecologic \& Neonatal Nursing 2013;42(1):19-28 10p. DOI: 10.1111/j.1552-6909.2012.01424.x.

Leftwich HK, Gao W and Wilkins I. Does increase in birth weight change the normal labor curve?. Am J Perinatol 2015;32(1):87-92. DOI: 10.1055/s-0034-1376180. PMID: 24839146. 
Lemos A, Amorim MM, Dornelas de Andrade A, et al. Pushing/bearing down methods for the second stage of labour. Cochrane Database Syst Rev 2015;10:Cd009124. DOI: 10.1186/s12884015-0683-0. PMID: 26451755.

Lim J, Kwon JY, Song J, et al. Quantitative comparison of entropy analysis of fetal heart rate variability related to the different stages of labor. Early Hum Dev 2014;90(2):81-5. DOI: 10.1016/j.earlhumdev.2013.12.007. PMID: 24411495.

Liu J, Song G, Meng T, et al. Foley catheter with simultaneous oxytocin on labor induction: a meta-analysis of randomized controlled trials. Journal of Maternal-Fetal and Neonatal Medicine 2018:1-8. DOI: 10.1080/14767058.2018.1459551.

Low LK, Miller JM, Guo Y, et al. Spontaneous pushing to prevent postpartum urinary incontinence: a randomized, controlled trial. Int Urogynecol J 2013;24(3):453-60. DOI: 10.1007/s00192-012-1884-y. PMID: 22829349.

Mackenzie IZ, Xu J, Cusick C, et al. Acupuncture for pain relief during induced labour in nulliparae: a randomised controlled study. Bjog 2011;118(4):440-7. DOI: 10.1111/j.14710528.2010.02825.x. PMID: 21244615.

Madden K, Middleton P, Cyna AM, et al. Hypnosis for pain management during labour and childbirth. Cochrane Database Syst Rev 2012;11:Cd009356. DOI: 10.1002/14651858.CD009356.pub2. PMID: 23152275.

Mafetoni RR and Shimo AK. Effects of acupressure on progress of labor and cesarean section rate: randomized clinical trial. Rev Saude Publica 2015;49:9. PMID: 25741644.

Mahomed K, Bhutta Z and Middleton P. Zinc supplementation for improving pregnancy and infant outcome. Cochrane Database Syst Rev 2007;(2):Cd000230. DOI: 10.1002/14651858.CD000230.pub3. PMID: 17443499.

Maimburg RD, Vaeth M and Dahlen H. Women's experience of childbirth - A five year followup of the randomised controlled trial "Ready for Child Trial". Women Birth 2016;29(5):450-454. DOI: 10.1016/j.wombi.2016.02.003. PMID: 27038559.

Maimburg RD, Vaeth M, Durr J, et al. Randomised trial of structured antenatal training sessions to improve the birth process. Bjog 2010;117(8):921-8. DOI: 10.1111/j.1471-0528.2010.02584.x. PMID: 20536430.

Makvandi S, Mirzaiinajmabadi K, Mirteimoori M, et al. Effect of normal physiologic childbirth program in mother-friendly hospitals on duration of labor. Electronic Journal of General Medicine 2018;15(3):1-6. DOI: 10.29333/ejgm/85941. PMID: 130313315.

Makvandi S, Mirzaiinajmabadi K, Sadeghi R, et al. Meta-analysis of the effect of acupressure on duration of labor and mode of delivery. Int J Gynaecol Obstet 2016;135(1):5-10. DOI: 10.1016/j.ijgo.2016.04.017. PMID: 27569023. 
Martins RF and Pinto e Silva JL. Treatment of Pregnancy-Related Lumbar and Pelvic Girdle Pain by the Yoga Method: A Randomized Controlled Study. Journal of Alternative \& Complementary Medicine 2014;20(1):24-31 8p. DOI: 10.1089/acm.2012.0715.

Mazouni C, Bretelle F, Collette E, et al. Maternal and neonatal morbidity after first vaginal delivery using Thierry's spatulas. Australian \& New Zealand Journal of Obstetrics \& Gynaecology 2005;45(5):405-409.

Mei-dan E, Walfisch A, Raz I, et al. Perineal massage during pregnancy: a prospective controlled trial. Isr Med Assoc J 2008;10(7):499-502. PMID: 18751626.

Molina FS, Terra R, Carrillo MP, et al. What is the most reliable ultrasound parameter for assessment of fetal head descent?. Ultrasound in Obstetrics \& Gynecology 2010;36(4):493-499. DOI: 10.1002/uog.7709.

Moura D, Canavarro M and Figueiredo-Braga M. Oxytocin and depression in the perinatal period-a systematic review. Archives of Women's Mental Health 2016;19(4):561-570. DOI: 10.1007/s00737-016-0643-3. PMID: 117042409.

Najafi F, Jaafarpour M, Sayehmiri K, et al. An Evaluation of Acupressure on the Sanyinjiao (SP6) and Hugo (LI4) Points on the Pain Severity and Length of Labor: A Systematic Review and Meta-analysis Study. Iran J Nurs Midwifery Res 2018;23(1):1-7. DOI:

10.4103/ijnmr.IJNMR_184_15. PMID: 29344038.

Neilson James P. Fetal electrocardiogram (ECG) for fetal monitoring during labour. 2015;(12). DOI: 10.1002/14651858.CD000116.pub5. PMID: CD000116.

Neilson JP. Fetal electrocardiogram (ECG) for fetal monitoring during labour. Cochrane Database of Systematic Reviews 2013;(5):N.PAG-N.PAG.

Nelson DB, McIntire DD and Leveno KJ. Relationship of the length of the first stage of labor to the length of the second stage. Obstet Gynecol 2013;122(1):27-32. DOI:

10.1097/AOG.0b013e3182972907. PMID: 23743461.

Odent M. Breech birth from a primal health research perspective. Midwifery Today 2007;(83):22-65.

Oladapo OT, Souza JP, Fawole B, et al. Progression of the first stage of spontaneous labour: A prospective cohort study in two sub-Saharan African countries. PLoS Medicine 2018;15(1). DOI: 10.1371/journal.pmed.1002492.

O'Sullivan G, Liu B, Hart D, et al. Effect of food intake during labour on obstetric outcome: randomised controlled trial. Bmj 2009;338:b784. DOI: 10.1136/bmj.b784. PMID: 19318702. 
Ostborg TB, Romundstad PR and Eggebo TM. Duration of the active phase of labor in spontaneous and induced labors. Acta Obstet Gynecol Scand 2017;96(1):120-127. DOI: 10.1111/aogs.13039. PMID: 27731890.

Oteng-Ntim E, Varma R, Croker H, et al. Lifestyle interventions for overweight and obese pregnant women to improve pregnancy outcome: systematic review and meta-analysis. BMC Medicine 2012;10(1):47-47.

Ozturk FH, Yilmaz SS, Yalvac S, et al. Effect of oxytocin discontinuation during the active phase of labor. J Matern Fetal Neonatal Med 2015;28(2):196-8. DOI: 10.3109/14767058.2014.906573. PMID: 24646336.

Pallivalappila AR, Stewart D, Shetty A, et al. Complementary and Alternative Medicines Use during Pregnancy: A Systematic Review of Pregnant Women and Healthcare Professional Views and Experiences. Evidence-based Complementary \& Alternative Medicine (eCAM) 2013;2013:1-10.

Pare J, Pasquier JC, Lewin A, et al. Reduction of total labor length through the addition of parenteral dextrose solution in induction of labor in nulliparous: results of DEXTRONS prospective randomized controlled trial. Am J Obstet Gynecol 2017;216(5):508.e1-508.e7. DOI: 10.1016/j.ajog.2017.01.010. PMID: 28153654.

Pergialiotis V, Frountzas M, Prodromidou A, et al. Propranolol and oxytocin versus oxytocin alone for induction and augmentation of labor: a meta-analysis of randomized trials. Arch Gynecol Obstet 2016;293(4):721-9. DOI: 10.1007/s00404-015-3991-8. PMID: 26695642.

Philip J, Sharma SK, Sparks TJ, et al. Randomized controlled trial of the clinical efficacy of multiport versus uniport wire-Reinforced flexible catheters for labor epidural analgesia. Anesthesia and Analgesia 2018;126(2):537-544. DOI: 10.1213/ANE.0000000000002359.

Phipps H, Charlton S and Dietz HP. Can antenatal education influence how women push in labour?. Aust N Z J Obstet Gynaecol 2009;49(3):274-8. DOI: 10.1111/j.1479828X.2009.00984.x. PMID: 19566559.

Pimentel VM, Arabkhazaeli M, Moon JY, et al. Induction of labor using one dose vs multiple doses of misoprostol: a randomized controlled trial. American Journal of Obstetrics and Gynecology 2018;218(6):614.e1-614.e8. DOI: 10.1016/j.ajog.2018.03.034.

Poyatos-Leon R, Garcia-Hermoso A, Sanabria-Martinez G, et al. Effects of exercise during pregnancy on mode of delivery: a meta-analysis. Acta Obstet Gynecol Scand 2015;94(10):103947. DOI: 10.1111/aogs.12675. PMID: 25965378.

Prins M, Boxem J, Lucas C, et al. Effect of spontaneous pushing versus Valsalva pushing in the second stage of labour on mother and fetus: a systematic review of randomised trials. Bjog 2011;118(6):662-70. DOI: 10.1111/j.1471-0528.2011.02910.x. PMID: 21392242. 
Quibel T, Ghout I, Goffinet F, et al. Active Management of the Third Stage of Labor With a Combination of Oxytocin and Misoprostol to Prevent Postpartum Hemorrhage: A Randomized Controlled Trial. Obstet Gynecol 2016;128(4):805-11. DOI: 10.1097/aog.0000000000001626. PMID: 27607864.

Rahimi-Kian F, Shahbazi S, Mohammadi S, et al. The effects of ice pack application on pain intensity in the active phase of labor and on birth satisfaction among primiparous women. Nursing Practice Today 2018;5(3):355-362. PMID: 130936751.

Rani J, Sharma D and Sehgal A. Role of partogram in high risk pregnancies: an experience at a tertiary centre. Arch Gynecol Obstet 2015;291(1):73-8. DOI: 10.1007/s00404-014-3387-1. PMID: 25096954.

Raymond EG, Shochet T and Bracken H. Low-sensitivity urine pregnancy testing to assess medical abortion outcome: A systematic review. Contraception 2018;98(1):30-35. DOI: 10.1016/j.contraception.2018.03.013.

Rezaie M, Farhadifar F, Sadegh SM, et al. Comparison of Vaginal and Oral Doses of Misoprostol for Labour Induction in Post-Term Pregnancies. J Clin Diagn Res 2016;10(3):Qc0811. DOI: 10.7860/jcdr/2016/17389.7402. PMID: 27134946.

Richards E, van Kessel G, Virgara R, et al. Does antenatal physical therapy for pregnant women with low back pain or pelvic pain improve functional outcomes? A systematic review. Acta Obstetricia et Gynecologica Scandinavica 2012;91(9):1038-1045 8p. DOI: 10.1111/j.16000412.2012.01462.x.

Riegel M, Quist-Nelson J, Saccone G, et al. Dextrose intravenous fluid therapy in labor reduces the length of the first stage of labor. European Journal of Obstetrics Gynecology and Reproductive Biology 2018;228:284-294. DOI: 10.1016/j.ejogrb.2018.07.019.

Rivard C, Awad M, Liebermann M, et al. Bladder drainage during labor: a randomized controlled trial. J Obstet Gynaecol Res 2012;38(8):1046-51. DOI: 10.1111/j.14470756.2011.01837.x. PMID: 22540248.

Roberts CL, Algert CS, Cameron CA, et al. A meta-analysis of upright positions in the second stage to reduce instrumental deliveries in women with epidural analgesia. Acta Obstet Gynecol Scand 2005;84(8):794-8. DOI: 10.1111/j.0001-6349.2005.00786.x. PMID: 16026407.

Robinson BK, Mapp DC, Bloom SL, et al. Increasing maternal body mass index and characteristics of the second stage of labor. Obstetrics \& Gynecology 2011;118(6):1309-1313.

Rosenbloom JI, Stout MJ, Tuuli MG, et al. New labor management guidelines and changes in cesarean delivery patterns. Am J Obstet Gynecol 2017;217(6):689.e1-689.e8. DOI: 10.1016/j.ajog.2017.10.007. PMID: 29037483. 
Roth C, Dent SA, Parfitt SE, et al. Randomized Controlled Trial of Use of the Peanut Ball During Labor. MCN Am J Matern Child Nurs 2016;41(3):140-6. DOI:

10.1097/nmc.0000000000000232. PMID: 26859467.

Roth C, Dent SA, Parfitt SE, et al. RANDOMIZED CONTROLLED TRIAL OF Use of the Peanut Ball During Labor. MCN: The American Journal of Maternal Child Nursing 2016;41(3):140-146. DOI: 10.1097/NMC.0000000000000232. PMID: 115240142.

Rouse DJ, Weiner SJ, Bloom SL, et al. Failed labor induction: toward an objective diagnosis. Obstet Gynecol 2011;117(2 Pt 1):267-72. DOI: 10.1097/AOG.0b013e318207887a. PMID: 21252738.

Saccone G, Caissutti C, Ciardulli A, et al. Uterine massage as part of active management of the third stage of labour for preventing postpartum haemorrhage during vaginal delivery: a systematic review and meta-analysis of randomised trials. BJOG: An International Journal of Obstetrics \& Gynaecology 2018;125(7):778-781. DOI: 10.1111/1471-0528.14923. PMID: 129934648.

Saccone G, Ciardulli A, Baxter JK, et al. Discontinuing Oxytocin Infusion in the Active Phase of Labor: A Systematic Review and Meta-analysis. Obstet Gynecol 2017;130(5):1090-1096. DOI: 10.1097/aog.0000000000002325. PMID: 29016497.

Sadan O, Shushan S, Eldar I, et al. The effects of an external nasal dilator on labor. Am J Rhinol 2005;19(2):221-4. PMID: 15921225.

Salam Rehana A, Zuberi Nadeem F and Bhutta Zulfiqar A. Pyridoxine (vitamin B6) supplementation during pregnancy or labour for maternal and neonatal outcomes. 2015;(6). DOI: 10.1002/14651858.CD000179.pub3. PMID: CD000179.

Sananes N, Roth GE, Aissi GA, et al. Acupuncture version of breech presentation: a randomized sham-controlled single-blinded trial. Eur J Obstet Gynecol Reprod Biol 2016;204:24-30. DOI: 10.1016/j.ejogrb.2016.07.492. PMID: 27521594.

Selby C, Valencia S, Garcia L, et al. Activity level during a one-hour labor check evaluation: walking versus bed rest. MCN Am J Matern Child Nurs 2012;37(2):101-7; quiz 108-9. DOI: 10.1097/NMC.0b013e318244625d. PMID: 22270179.

Simpson KR and James DC. Effects of immediate versus delayed pushing during second-stage labor on fetal well-being: a randomized clinical trial. Nurs Res 2005;54(3):149-57. PMID: 15897790.

Singh N, Tripathi R, Mala YM, et al. Breast stimulation in low-risk primigravidas at term: does it aid in spontaneous onset of labour and vaginal delivery? A pilot study. 2014;2014:695037. DOI: 10.1155/2014/695037. PMID: 25525601. 
Smith CA, Armour M and Dahlen HG. Acupuncture or acupressure for induction of labour. Cochrane Database Syst Rev 2017;10:Cd002962. DOI: 10.1002/14651858.CD002962.pub4. PMID: 29036756.

Smith CA, Collins CT and Crowther CA. Aromatherapy for pain management in labour. Cochrane Database Syst Rev 2011;(7):Cd009215. DOI: 10.1002/14651858.cd009215. PMID: 21735438.

Smith CA, Levett KM, Collins CT, et al. Massage, reflexology and other manual methods for pain management in labour. Cochrane Database Syst Rev 2018;3:Cd009290. DOI: 10.1002/14651858.CD009290.pub3. PMID: 29589380.

Smith CA, Levett KM, Collins CT, et al. Relaxation techniques for pain management in labour. Cochrane Database Syst Rev 2011;(12):Cd009514. DOI: 10.1002/14651858.cd009514. PMID: 22161453.

Smith CA, Levett KM, Collins CT, et al. Relaxation techniques for pain management in labour. Cochrane Database Syst Rev 2018;3:Cd009514. DOI: 10.1002/14651858.CD009514.pub2. PMID: 29589650.

Smith V, Begley CM, Clarke M, et al. Professionals' views of fetal monitoring during labour: a systematic review and thematic analysis. BMC Pregnancy \& Childbirth 2012;12(1):166-166 1p. DOI: 10.1186/1471-2393-12-166.

Sniezek DP and Siddiqui IJ. Acupuncture for treating anxiety and depression in women: A clinical systematic review. Medical Acupuncture 2013;25(3):164-172.

Solbiati M, Costantino G, Casazza G, et al. Implantable loop recorder versus conventional diagnostic workup for unexplained recurrent syncope. Cochrane Database of Systematic Reviews 2016(4). DOI: 10.1002/14651858.CD011637.pub2. PMID: CD011637.

Steel A, Adams J and Sibbritt D. Complementary and Alternative Medicine in Pregnancy: a Systematic Review. Journal of the Australian Traditional-Medicine Society 2011;17(4):205-209.

Stremler R, Hodnett E, Petryshen P, et al. Randomized controlled trial of hands-and-knees positioning for occipitoposterior position in labor. Birth 2005;32(4):243-51. DOI: 10.1111/j.0730-7659.2005.00382.x. PMID: 16336365.

Teimoori B, Sakhavar N, Mirteimoori M, et al. Nitrous oxide versus pethidine with promethasine for reducing labor pain. African Journal of Pharmacy and Pharmacology 2011;5(17):2013-2017.

Thangaratinam S, Rogozinska E, Jolly K, et al. Effects of interventions in pregnancy on maternal weight and obstetric outcomes: meta-analysis of randomised evidence. BMJ: British Medical Journal (Clinical Research Edition) 2012;344:e2088-e2088 1p. DOI: 10.1136/bmj.e2088. 
Thies-Lagergren L and Kvist LJ. Assessing the feasibility of a randomised controlled trial of birth on a birthing seat. Evidence Based Midwifery 2009;7(4):122-127.

Thies-Lagergren L, Kvist LJ, Christensson K, et al. No reduction in instrumental vaginal births and no increased risk for adverse perineal outcome in nulliparous women giving birth on a birth seat: results of a Swedish randomized controlled trial. BMC Pregnancy Childbirth 2011;11:22. DOI: 10.1186/1471-2393-11-22. PMID: 21435238.

Thuillier C, Roy S, Peyronnet V, et al. Impact of recommended changes in labor management for prevention of the primary cesarean delivery. Am J Obstet Gynecol 2018;218(3):341.e1-341.e9. DOI: 10.1016/j.ajog.2017.12.228. PMID: 29291413.

Tita AT, Szychowski JM, Rouse DJ, et al. Higher-dose oxytocin and hemorrhage after vaginal delivery: a randomized controlled trial. Obstet Gynecol 2012;119(2 Pt 1):293-300. DOI: 10.1097/AOG.0b013e318242da74. PMID: 22227638.

Toohill J, Soong B and Flenady V. Interventions for ketosis during labour. Cochrane Database Syst Rev 2008;(3):Cd004230. DOI: 10.1002/14651858.CD004230.pub2. PMID: 18646103.

Torkzahrani S, Mahmoudikohani F, Saatchi K, et al. The effect of acupressure on the initiation of labor: A randomized controlled trial. Women Birth 2017;30(1):46-50. DOI:

10.1016/j.wombi.2016.07.002. PMID: 27444642.

Tranmer JE, Hodnett ED, Hannah ME, et al. The effect of unrestricted oral carbohydrate intake on labor progress. J Obstet Gynecol Neonatal Nurs 2005;34(3):319-28. DOI:

10.1177/0884217505276155. PMID: 15890830.

Tuuli MG, Frey HA, Odibo AO, et al. Immediate compared with delayed pushing in the second stage of labor: a systematic review and meta-analysis. Obstet Gynecol 2012;120(3):660-8. DOI: 10.1097/AOG.0b013e3182639fae. PMID: 22872146.

Tuuli MG, Odibo AO, Caughey AB, et al. Are there differences in the first stage of labor between Black and White women?. Am J Perinatol 2015;32(3):233-8. DOI: 10.1055/s-00341382254. PMID: 24960077.

Ustunyurt E, Ugur M, Ustunyurt BO, et al. Prospective randomized study of oxytocin discontinuation after the active stage of labor is established. J Obstet Gynaecol Res 2007;33(6):799-803. DOI: 10.1111/j.1447-0756.2007.00659.x. PMID: 18001445.

Vacca A. Vacuum-assisted delivery: an analysis of traction force and maternal and neonatal outcomes. Australian \& New Zealand Journal of Obstetrics \& Gynaecology 2006;46(2):124-127.

Vahratian A, Hoffman MK, Troendle JF, et al. The impact of parity on course of labor in a contemporary population. Birth 2006;33(1):12-7. DOI: 10.1111/j.0730-7659.2006.00069.x. PMID: 16499527. 
Vakilian K, Keramat A and Gharacheh M. Controlled breathing with or without lavender aromatherapy for labor pain at the first stage: A randomized clinical trial. Crescent Journal of Medical and Biological Sciences 2018;5(3):172-175.

Valverde M, Puertas AM, Lopez-Gallego MF, et al. Effectiveness of pulse oximetry versus fetal electrocardiography for the intrapartum evaluation of nonreassuring fetal heart rate. Eur J Obstet Gynecol Reprod Biol 2011;159(2):333-7. DOI: 10.1016/j.ejogrb.2011.09.021. PMID: 21978943.

Van Benten E, Pool J, Mens J, et al. Recommendations for Physical Therapists on the Treatment of Lumbopelvic Pain During Pregnancy: A Systematic Review. Journal of Orthopaedic \& Sports Physical Therapy 2014;44(7):464-473. DOI: 10.2519/jospt.2014.5098.

Vedagiri Sai R, Singh SI, Qasem F, et al. Onset of labour epidural analgesia with low-dose bupivacaine and different doses of fentanyl. Anaesthesia 2017;72(11):1371-1378. DOI: 10.1111/anae.14000.

Walker C, Rodriguez T, Herranz A, et al. Alternative model of birth to reduce the risk of assisted vaginal delivery and perineal trauma. Int Urogynecol J 2012;23(9):1249-56. DOI:

10.1007/s00192-012-1675-5. PMID: 22297706.

Walsh JM, Hehir MP, Robson MS, et al. Mode of delivery and outcomes by birth weight among spontaneous and induced singleton cephalic nulliparous labors. Int J Gynaecol Obstet 2015;129(1):22-5. DOI: 10.1016/j.ijgo.2014.10.029. PMID: 25575424.

Wang X, Li GY and Deng ML. Pelvic floor muscle training as a persistent nursing intervention: Effect on delivery outcome and pelvic floor myodynamia. International Journal of Nursing Sciences 2014;1(1):48-52.

Wangping Z and Ming R. Optimal Dose of Epidural Dexmedetomidine Added to Ropivacaine for Epidural Labor Analgesia: A Pilot Study. Evidence-based Complementary and Alternative Medicine 2017;2017. DOI: 10.1155/2017/7924148.

Weomoger CF, Ginosar Y, Elchalal U, et al. External cephalix version for breech presentation with or without spinal analgesia in nulliparous women at term: a randomized controlled trial. Obstetrics \& Gynecology 2007;110(6):1343-1350.

Werner A, Uldbjerg N, Zachariae R, et al. Effect of self-hypnosis on duration of labor and maternal and neonatal outcomes: a randomized controlled trial. Acta Obstet Gynecol Scand 2013;92(7):816-23. DOI: 10.1111/aogs.12141. PMID: 23550694.

Westerhuis ME, Visser GH, Moons KG, et al. Cardiotocography plus ST analysis of fetal electrocardiogram compared with cardiotocography only for intrapartum monitoring: a randomized controlled trial. Obstet Gynecol 2010;115(6):1173-80. DOI: 10.1097/AOG.0b013e3181dfffd6. PMID: 20502287. 
Windrim R, Seaward PG, Hodnett E, et al. A randomized controlled trial of a bedside partogram in the active management of primiparous labour. J Obstet Gynaecol Can 2007;29(1):27-34.

PMID: 17346475.

Xu Z, Shen F, Zhang Y, et al. Combined spinal-epidural anesthesia with hypobaric ropivacaine in sitting position significantly increases the incidence of hypotension in parturients undergoing cesarean section. J Obstet Gynaecol Res 2017;43(4):669-675. DOI: 10.1111/jog.13253. PMID: 28026887.

Yakoob MY, Menezes EV, Soomro T, et al. Reducing stillbirths: behavioural and nutritional interventions before and during pregnancy. BMC Pregnancy Childbirth 2009;9(Suppl 1):S3. DOI: 10.1186/1471-2393-9-s1-s3. PMID: 19426466.

Yee LM, Costantine MM, Rice MM, et al. Racial and Ethnic Differences in Utilization of Labor Management Strategies Intended to Reduce Cesarean Delivery Rates. Obstet Gynecol 2017;130(6):1285-1294. DOI: 10.1097/aog.0000000000002343. PMID: 29112649.

Yildirim D, Ozyurek SE, Ekiz A, et al. Comparison of active vs. expectant management of the third stage of labor in women with low risk of postpartum hemorrhage: a randomized controlled trial. Ginekol Pol 2016;87(5):399-404. DOI: 10.5603/gp.2016.0015. PMID: 27304659.

Yilmaz B, Kart C, Kelekci S, et al. Meperidine versus valethamate bromide in shortening the duration of active labor. Int J Gynaecol Obstet 2009;107(2):126-9. DOI:

10.1016/j.ijgo.2009.06.021. PMID: 19664769.

Yuel VI, Kaur V and Kaur D. Programmed labor for optimizing labor and delivery. JK Science 2008;10(2):62-64.

Zaki MN, Hibbard JU and Kominiarek MA. Contemporary labor patterns and maternal age. Obstet Gynecol 2013;122(5):1018-24. DOI: 10.1097/AOG.0b013e3182a9c92c. PMID: 24104787.

Zaretsky MV, Alexander JM, McIntire DD, et al. Magnetic resonance imaging pelvimetry and the prediction of labor dystocia. Obstet Gynecol 2005;106(5 Pt 1):919-26. DOI:

10.1097/01.AOG.0000182575.81843.e7. PMID: 16260507.

Zarezadeh T and Nemati N. The effect of exercise on childbirth in primiparous women: A clinical trial study. Nursing Practice Today 2016;3(2):36-48. PMID: 119323061.

Zhang JW, Branch W, Hoffman M, et al. In which groups of pregnant women can the caesarean delivery rate likely be reduced safely in the USA? A multicentre cross-sectional study. BMJ Open 2018;8(8).

\section{No intervention of interest:}


Aasheim V, Nilsen AB, Lukasse M, et al. Perineal techniques during the second stage of labour for reducing perineal trauma. Cochrane Database Syst Rev 2011;(12):Cd006672. DOI:

10.1002/14651858.CD006672.pub2. PMID: 22161407.

Abdollahi MH, Mojibian M, Pishgahi A, et al. Intravenous paracetamol versus intramuscular pethidine in relief of labour pain in primigravid women. Niger Med J 2014;55(1):54-7. DOI: 10.4103/0300-1652.128167. PMID: 24970971.

Abraham W and Berhan Y. Predictors of labor abnormalities in university hospital: unmatched case control study. BMC Pregnancy Childbirth 2014;14:256. DOI: 10.1186/1471-2393-14-256. PMID: 25086729.

Agah J, Baghani R, Nazarzadeh M, et al. Comparison of effacement curve with dilatation curve for prediction of labor progression. J Obstet Gynaecol Res 2018;44(1):102-108. DOI:

10.1111/jog.13478. PMID: 29094486.

Aggarwal P, Zutshi V and Batra S. Role of hyoscine N-butyl bromide (HBB, buscopan) as labor analgesic. Indian J Med Sci 2008;62(5):179-84. PMID: 18579976.

Alfirevic Z, Devane D, Gyte GM, et al. Continuous cardiotocography (CTG) as a form of electronic fetal monitoring (EFM) for fetal assessment during labour. Cochrane Database Syst Rev 2017;2:Cd006066. Digital Object Identifier: 10.1002/14651858.CD006066.pub3. PMID: 28157275

Ali HM and Wahdan A. Using dexamethasone as an adjuvant to levobupivacaine in epidural anesthesia to change the pain intensity and duration in painless labor. Saudi J Anaesth 2018;12(2):209-214. DOI: 10.4103/sja.SJA_435_17. PMID: 29628829.

Alijahan R and Kordi M. Risk factors of dystocia in nulliparous women. Iran J Med Sci 2014;39(3):254-60. PMID: 24850982.

Anderson FW and Johnson CT. Complementary and alternative medicine in obstetrics. Int J Gynaecol Obstet 2005;91(2):116-24. DOI: 10.1016/j.ijgo.2005.07.009. PMID: 16168989.

Ängeby K, Wilde-Larsson B, Hildingsson I, et al. Prevalence of Prolonged Latent Phase and Labor Outcomes: Review of Birth Records in a Swedish Population. Journal of Midwifery and Women's Health 2018;63(1):33-44. DOI: 10.1111/jmwh.12704.

Api O, Balcin ME, Ugurel V, et al. The effect of uterine fundal pressure on the duration of the second stage of labor: a randomized controlled trial. Acta Obstet Gynecol Scand 2009;88(3):3204. DOI: 10.1080/00016340902730326. PMID: 19172441.

Aquino CI, Saccone G, Troisi J, et al. Use of lubricant gel to shorten the second stage of labor during vaginal delivery. J Matern Fetal Neonatal Med 2018:1-8. DOI:

10.1080/14767058.2018.1482271. PMID: 29804505. 
Aviram A, Ashwal E, Hiersch L, et al. The effect of intrapartum dental support use among nulliparous during the second stage of labor - a randomized controlled study. J Matern Fetal Neonatal Med 2016;29(6):868-71. DOI: 10.3109/14767058.2015.1024648. PMID: 25777794.

Barragan Loayza IM, Sola I and Juando Prats C. Biofeedback for pain management during labour. Cochrane Database Syst Rev 2011;(6):Cd006168. DOI: 10.1002/14651858.CD006168.pub2. PMID: 21678353.

Bellizzi S, Sobel HL, Mathai M, et al. Does place and attendance at birth improve early neonatal mortality? Secondary analysis of nine Demographic and Health Surveys. BJOG: An International Journal of Obstetrics \& Gynaecology 2017;124(10):1558-1565. DOI: 10.1111/1471-0528.14422. PMID: 124751789.

Bellussi F, Alcamisi L, Guizzardi G, et al. Traditionally vs sonographically coached pushing in second stage of labor: a pilot randomized controlled trial. Ultrasound Obstet Gynecol 2018;52(1):87-90. DOI: 10.1002/uog.19044. PMID: 29532533.

Bergstrom M, Kieler $\mathrm{H}$ and Waldenstrom U. Effects of natural childbirth preparation versus standard antenatal education on epidural rates, experience of childbirth and parental stress in mothers and fathers: a randomised controlled multicentre trial. Bjog 2009;116(9):1167-76. DOI: 10.1111/j.1471-0528.2009.02144.x. PMID: 19538406.

Bernitz S, Aas E and Oian P. Economic evaluation of birth care in low-risk women. A comparison between a midwife-led birth unit and a standard obstetric unit within the same hospital in Norway. A randomised controlled trial. Midwifery 2012;28(5):591-9. DOI: 10.1016/j.midw.2012.06.001. PMID: 22901492.

Bix E, Reiner LM, Klovning A, et al. Prognostic value of the labour admission test and its effectiveness compared with auscultation only: a systematic review. Bjog 2005;112(12):1595604. DOI: 10.1111/j.1471-0528.2005.00766.x. PMID: 16305561.

Blix E, Kumle M, Kjaergaard H, et al. Transfer to hospital in planned home births: a systematic review. BMC Pregnancy Childbirth 2014;14:179. DOI: 10.1186/1471-2393-14-179. PMID: 24886482.

Brancadoro M, Tognarelli S, Fambrini F, et al. Devices for Measuring Cervical Dilation During Labor: Systematic Review and Meta-analysis. Obstetrical \& Gynecological Survey 2018;73(4):231-241. DOI: 10.1097/OGX.0000000000000548. PMID: 129318036.

Byaruhanga R, Bassani DG, Jagau A, et al. Use of wind-up fetal Doppler versus Pinard for fetal heart rate intermittent monitoring in labour: A randomised clinical trial. BMJ Open 2015;5(1). Calvert I. Ginger: an essential oil for shortening labour?. Pract Midwife 2005;8(1):30-4. PMID: 15690883. 
Chao AS, Chao A, Wang TH, et al. Pain relief by applying transcutaneous electrical nerve stimulation (TENS) on acupuncture points during the first stage of labor: a randomized doubleblind placebo-controlled trial. Pain 2007;127(3):214-20. DOI: 10.1016/j.pain.2006.08.016. PMID: 17030438.

Chaudhary S, Farrukh R, Dar A, et al. Outcome of labour in nullipara at term with unengaged vertex. J Ayub Med Coll Abbottabad 2009;21(3):131-4. PMID: 20929031.

Chen I, Opiyo N, Tavender E, et al. Non-clinical interventions for reducing unnecessary caesarean section. Cochrane Database Syst Rev 2018;9:Cd005528. PMID: 30264405.

Chen SY, Lin PL, Yang YH, et al. The effects of different epidural analgesia formulas on labor and mode of delivery in nulliparous women. Taiwan J Obstet Gynecol 2014;53(1):8-11. DOI: 10.1016/j.tjog.2012.01.039. PMID: 24767638.

Cheng YW, Hopkins LM, Laros RK, Jr., et al. Duration of the second stage of labor in multiparous women: maternal and neonatal outcomes. Am J Obstet Gynecol 2007;196(6):585.e1-6. DOI: 10.1016/j.ajog.2007.03.021. PMID: 17547906.

Chuma C, Kihunrwa A, Matovelo D, et al. Labour management and Obstetric outcomes among pregnant women admitted in latent phase compared to active phase of labour at Bugando Medical Centre in Tanzania. BMC Pregnancy Childbirth 2014;14:68. DOI: 10.1186/1471-239314-68. PMID: 24521301.

Cicek S and Basar F. The effects of breathing techniques training on the duration of labor and anxiety levels of pregnant women. Complement Ther Clin Pract 2017;29:213-219. DOI: 10.1016/j.ctcp.2017.10.006. PMID: 29122264.

Cilliers JBF, Schoon MG, Bam RH, et al. A randomised clinical trial to determine the effect of beta-adrenergic blocking with propranolol on labour. South African Journal of Obstetrics and Gynaecology 2013;19(2):53-55.

Connelly NR, Cho AR, Parker RK, et al. Epidural infusion volume and its effect on analgesia in early labor. Internet Journal of Anesthesiology 2008;17(1):3-3.

Cortes CA, Sanchez CA, Oliveira AS, et al. Labor analgesia: a comparative study between combined spinal-epidural anesthesia versus continuous epidural anesthesia. Rev Bras Anestesiol 2007;57(1):39-51. PMID: 19468617.

Craig MG, Grant EN, Tao W, et al. A randomized control trial of bupivacaine and fentanyl versus fentanyl-only for epidural analgesia during the second stage of labor. Anesthesiology 2015;122(1):172-7. DOI: 10.1097/aln.0000000000000454. PMID: 25254902.

Cromi A, Ghezzi F, Agosti M, et al. Use of an antispasmodic (rociverine) to shorten the length of labor: a randomized, placebo-controlled trial. Acta Obstet Gynecol Scand 2011;90(12):1371-8. DOI: 10.1111/j.1600-0412.2011.01265.x. PMID: 21880029. 
Cuervo LG, del Pilar Bernal M and Mendoza N. Effects of high volume saline enemas vs no enema during labour - The N-Ma Randomised Controlled Trial [ISRCTN43153145]. BMC Pregnancy and Childbirth 2006;6.

Dall'Asta A, Ghi T, Pedrazzi G, et al. Does vacuum delivery carry a higher risk of shoulder dystocia? Review and meta-analysis of the literature. Eur J Obstet Gynecol Reprod Biol 2016;204:62-8. DOI: 10.1016/j.ejogrb.2016.07.506. PMID: 27522245.

Dante G, Pedrielli G, Annessi E, et al. Herb remedies during pregnancy: a systematic review of controlled clinical trials. J Matern Fetal Neonatal Med 2013;26(3):306-12. DOI:

10.3109/14767058.2012.722732. PMID: 22928540.

Davey MA, McLachlan HL, Forster D, et al. Influence of timing of admission in labour and management of labour on method of birth: results from a randomised controlled trial of caseload midwifery (COSMOS trial). Midwifery 2013;29(12):1297-302. DOI:

10.1016/j.midw.2013.05.014. PMID: 23890679.

de Souza Caroci da Costa A and Gonzalez Riesco ML. A comparison of "hands off” versus "hands on" techniques for decreasing perineal lacerations during birth. J Midwifery Womens Health 2006;51(2):106-11. DOI: 10.1016/j.jmwh.2005.10.017. PMID: 16504907.

Demirel G and Golbasi Z. Effect of perineal massage on the rate of episiotomy and perineal tearing. Int J Gynaecol Obstet 2015;131(2):183-6. DOI: 10.1016/j.ijgo.2015.04.048. PMID: 26410801.

Derry S, Straube S, Moore RA, et al. Intracutaneous or subcutaneous sterile water injection compared with blinded controls for pain management in labour. Cochrane Database Syst Rev 2012;1:Cd009107. DOI: 10.1002/14651858.CD009107.pub2. PMID: 22258999.

Devane D, Lalor JG, Daly S, et al. Cardiotocography versus intermittent auscultation of fetal heart on admission to labour ward for assessment of fetal wellbeing. Cochrane Database of Systematic Reviews 2017(1). DOI: 10.1002/14651858.CD005122.pub5. PMID: CD005122.

Dias LA, Driusso P, Aita DL, et al. Effect of pelvic floor muscle training on labour and newborn outcomes: a randomized controlled trial. Rev Bras Fisioter 2011;15(6):487-93. PMID: 21860990.

Direkvand-Moghadam A, Delpisheh A and Direkvand-Moghadam A. The effects of Pethedine on maternal outcome of labor in nulli-parous women; A randomized controlled trial. Der Pharmacia Lettre 2015;7(9):30-34.

Dolatian M, Hasanpour A, Montazeri S, et al. The effect of reflexology on pain intensity and duration of labor on primiparas. Iran Red Crescent Med J 2011;13(7):475-9. PMID: 22737514. 
Dostbil A, Celik M, Alici HA, et al. Maternal and neonatal effects of adding morphine to lowdose bupivacaine for epidural labor analgesia. Niger J Clin Pract 2014;17(2):205-11. DOI: 10.4103/1119-3077.127559. PMID: 24553033.

Downe S, Finlayson K, Oladapo O, et al. What matters to women during childbirth: A systematic qualitative review. PLoS One 2018;13(4):e0194906. DOI: 10.1371/journal.pone.0194906. PMID: 29664907.

Dowswell T, Bedwell C, Lavender T, et al. Transcutaneous electrical nerve stimulation (TENS) for pain management in labour. 2009;(2). DOI: 10.1002/14651858.CD007214.pub2. PMID: CD007214.

Duale C, Nicolas-Courbon A, Gerbaud L, et al. Maternal satisfaction as an outcome criterion in research on labor analgesia: data analysis from the recent literature. Clin J Pain 2015;31(3):23546. DOI: 10.1097/ajp.0000000000000106. PMID: 24709627.

Dube P, Mitra S, Singh J, et al. Intravenous dexamethasone as an adjunct to improve labor analgesia: A randomized, double-blinded, placebo controlled clinical trial. J Clin Anesth 2017;43:6-10. DOI: 10.1016/j.jclinane.2017.09.003. PMID: 28915426.

East CE, Begg L, Colditz PB, et al. Fetal pulse oximetry for fetal assessment in labour. Cochrane Database Syst Rev 2014;10:Cd004075. DOI: 10.1002/14651858.CD004075.pub4. PMID: 25287809.

East CE, Leader LR, Sheehan P, et al. Intrapartum fetal scalp lactate sampling for fetal assessment in the presence of a non-reassuring fetal heart rate trace. Cochrane Database Syst Rev 2015;5:Cd006174. DOI: 10.1002/14651858.CD006174.pub3. PMID: 25929461.

East CE, Smyth RM, Leader LR, et al. Vibroacoustic stimulation for fetal assessment in labour in the presence of a nonreassuring fetal heart rate trace. Cochrane Database Syst Rev 2013;1:Cd004664. DOI: 10.1002/14651858.CD004664.pub3. PMID: 23440793.

Ebrahimzadeh Zagami S, Golmakani N, Saadatjoo SA, et al. The shape of uterine contractions and labor progress in the spontaneous active labor. Iran J Med Sci 2015;40(2):98-103. PMID: 25821288.

El-Refaie TA, El-Said MM, Shoukry AA, et al. Meperidine for uterine dystocia and its effect on duration of labor and neonatal acid-base status: a randomized clinical trial. J Obstet Gynaecol Res 2012;38(2):383-9. DOI: 10.1111/j.1447-0756.2011.01719.x. PMID: 22229712.

Evron S, Dimitrochenko V, Khazin V, et al. The effect of intermittent versus continuous bladder catheterization on labor duration and postpartum urinary retention and infection: a randomized trial. J Clin Anesth 2008;20(8):567-72. DOI: 10.1016/j.jclinane.2008.06.009. PMID: 19100928. 
Fardiazar Z, Niknami F, Mashayekhi S, et al. Hyoscine-N-butylbromide versus atropine as labour accelerant and analgesic: a randomized clinical trial. Pak J Biol Sci 2013;16(9):443-5. PMID: 24498810.

Foroughipour A, Firuzeh F, Ghahiri A, et al. The effect of perineal control with hands-on and hand-poised methods on perineal trauma and delivery outcome. Journal of Research in Medical Sciences 2011;16(8):1040-1046.

Galinimoghaddam T, Moslemizadeh N, Seifollahpour Z, et al. Uterine contractions' pattern in active phase of labor as a predictor of failure to progress. Glob J Health Sci 2014;6(3):200-5. DOI: 10.5539/gjhs.v6n3p200. PMID: 24762363.

Gaudernack LC, Forbord S and Hole E. Acupuncture administered after spontaneous rupture of membranes at term significantly reduces the length of birth and use of oxytocin. A randomized controlled trial. Acta Obstet Gynecol Scand 2006;85(11):1348-53. DOI: 10.1080/00016340600935839. PMID: 17091416.

George RB, Allen TK and Habib AS. Intermittent epidural bolus compared with continuous epidural infusions for labor analgesia: a systematic review and meta-analysis. Anesth Analg 2013;116(1):133-44. DOI: 10.1213/ANE.0b013e3182713b26. PMID: 23223119.

Geranmayeh M, Rezaei Habibabadi Z, Fallahkish B, et al. Reducing perineal trauma through perineal massage with vaseline in second stage of labor. Arch Gynecol Obstet 2012;285(1):7781. DOI: 10.1007/s00404-011-1919-5. PMID: 21614497.

Gross MM, Burian RA, Fromke C, et al. Onset of labour: women's experiences and midwives' assessments in relation to first stage duration. Arch Gynecol Obstet 2009;280(6):899-905. DOI: 10.1007/s00404-009-0990-7. PMID: 19283397.

Guo S, Li B, Gao C, et al. Epidural Analgesia With Bupivacaine and Fentanyl Versus Ropivacaine and Fentanyl for Pain Relief in Labor: A Meta-Analysis. Medicine (Baltimore) 2015;94(23):e880. DOI: 10.1097/md.0000000000000880. PMID: 26061307.

Halpern SH and Carvalho B. Patient-controlled epidural analgesia for labor. Anesth Analg 2009;108(3):921-8. DOI: 10.1213/ane.0b013e3181951a7f. PMID: 19224805.

Hantoushzadeh S, Alhusseini $\mathrm{N}$ and Lebaschi AH. The effects of acupuncture during labour on nulliparous women: a randomised controlled trial. Aust N Z J Obstet Gynaecol 2007;47(1):2630. DOI: 10.1111/j.1479-828X.2006.00674.x. PMID: 17261096.

Heesen M, Bohmer J, Klohr S, et al. The effect of adding a background infusion to patientcontrolled epidural labor analgesia on labor, maternal, and neonatal outcomes: a systematic review and meta-analysis. Anesth Analg 2015;121(1):149-58. DOI:

10.1213/ane.0000000000000743. PMID: 25902319. 
Hehir MP, Ananth CV, Siddiq Z, et al. Cesarean delivery in the United States 2005 through 2014: a population-based analysis using the Robson 10-Group Classification System. American Journal of Obstetrics and Gynecology 2018;219(1):105.e1-105.e11. DOI:

10.1016/j.ajog.2018.04.012.

Hodnett ED, Downe S and Walsh D. Alternative versus conventional institutional settings for birth. Cochrane Database Syst Rev 2012;8:Cd000012. DOI: 10.1002/14651858.CD000012.pub4. PMID: 22895914.

Hodnett ED, Downe S, Walsh D, et al. Alternative versus conventional institutional settings for birth. Cochrane Database Syst Rev 2010;(9):Cd000012. DOI:

10.1002/14651858.CD000012.pub3. PMID: 20824824.

Hodnett ED, Stremler R, Weston JA, et al. Re-conceptualizing the hospital labor room: the PLACE (pregnant and laboring in an ambient clinical environment) Pilot Trial. Birth: Issues in Perinatal Care 2009;36(2):159-166. DOI: 10.1111/j.1523-536X.2009.00311.x.

Hutton EK, Kasperink M, Rutten M, et al. Sterile water injection for labour pain: a systematic review and meta-analysis of randomised controlled trials. Bjog 2009;116(9):1158-66. DOI: 10.1111/j.1471-0528.2009.02221.x. PMID: 19459860.

Ibrahim MI, Alzeeniny HA, Ellaithy MI, et al. Drotaverine to improve progression of labor among nulliparous women. Int J Gynaecol Obstet 2014;124(2):112-7. DOI:

10.1016/j.ijgo.2013.08.013. PMID: 24299975.

Incerti M, Locatelli A, Ghidini A, et al. Prediction of duration of active labor in nulliparous women at term. Am J Perinatol 2008;25(2):85-9. DOI: 10.1055/s-2007-1004827. PMID: 18075962.

Iravani M, Janghorbani M, Zarean E, et al. An overview of systematic reviews of normal labor and delivery management. Iran J Nurs Midwifery Res 2015;20(3):293-303. PMID: 26120327.

Jahani Shoorab N, Ebrahimzadeh Zagami S, Mirzakhani K, et al. The effect of intravenous fentanyl on pain and duration of the active phase of first stage labor. Oman Medical Journal 2013;28(5):306-310.

Jamal A, Choobak N and Tabassomi F. Intrapartum maternal glucose infusion and fetal acidbase status. Int J Gynaecol Obstet 2007;97(3):187-9. DOI: 10.1016/j.ijgo.2007.01.016. PMID: 17368645.

Janssen PA and Weissinger S. Women's perception of pre-hospital labour duration and obstetrical outcomes; a prospective cohort study. BMC Pregnancy Childbirth 2014;14:182. DOI: 10.1186/1471-2393-14-182. PMID: 24884415. 
Jingchun G, Ruifang S, Changting Y, et al. Combined epidural/spinal anaesthesia with new needle-beside-needle technique for caesarean section: A randomized controlled trial.

International Journal of Clinical and Experimental Medicine 2018;11(7):6840-6847.

Jorgensen JS and Weber T. Fetal scalp blood sampling in labor--a review. Acta Obstet Gynecol Scand 2014;93(6):548-55. DOI: 10.1111/aogs.12421. PMID: 24806978.

Junttila EK, Karjalainen PK, Ohtonen PP, et al. A comparison of paracervical block with singleshot spinal for labour analgesia in multiparous women: a randomised controlled trial. Int J Obstet Anesth 2009;18(1):15-21. DOI: 10.1016/j.ijoa.2008.01.020. PMID: 18823774.

Kalache KD, Duckelmann AM, Michaelis SA, et al. Transperineal ultrasound imaging in prolonged second stage of labor with occipitoanterior presenting fetuses: how well does the 'angle of progression' predict the mode of delivery?. Ultrasound Obstet Gynecol 2009;33(3):32630. DOI: 10.1002/uog.6294. PMID: 19224527.

Kang JH, Lee GH, Park YB, et al. The efficacy and safety of inflatable obstetric belts for management of the second stage of labor. J Korean Med Sci 2009;24(5):951-5. DOI: 10.3346/jkms.2009.24.5.951. PMID: 19794998.

Karkal E, Kharde S and Dhumale H. Effectiveness of Music Therapy in Reducing Pain and Anxiety among Primigravid Women during Active Phase of First Stage of Labor. International Journal of Nursing Education 2017;9(2):57-60. DOI: 10.5958/0974-9357.2017.00036.8. PMID: 122807542.

Kaur Makkar J, Jain K, Bhatia N, et al. Comparison of analgesic efficacy of paracetamol and tramadol for pain relief in active labor. J Clin Anesth 2015;27(2):159-63. DOI: 10.1111/birt.12137; 10.1016/j.jclinane.2014.08.008. PMID: 25434500.

Khooshideh $\mathrm{M}$ and Shahriari A. A comparison of tramadol and pethidine analgesia on the duration of labour: a randomised clinical trial. Aust N Z J Obstet Gynaecol 2009;49(1):59-63. DOI: 10.1111/j.1479-828X.2009.00949.x. PMID: 19281581.

Khunpradit S, Lumbiganon P and Laopaiboon M. Admission tests other than cardiotocography for fetal assessment during labour.2011;(6). DOI: 10.1002/14651858.CD008410.pub2. PMID: CD008410.

Kim JW, Kim YH, Cho HY, et al. The effect of inflatable obstetric belts in nulliparous pregnant women receiving patient-controlled epidural analgesia during the second stage of labor. J Matern Fetal Neonatal Med 2013;26(16):1623-7. DOI: 10.3109/14767058.2013.789851. PMID: 23528153.

Kirim S, Asicioglu O, Yenigul N, et al. Effect of intravenous hyoscine-N-butyl bromide on active phase of labor progress: A randomized double blind placebo controlled trial. Journal of Maternal-Fetal and Neonatal Medicine 2015;28(9):1038-1042. 
Klomp T, van Poppel M, Jones L, et al. Inhaled analgesia for pain management in labour. 2012;(9). DOI: 10.1002/14651858.CD009351.pub2. PMID: CD009351.

Kordi M, Irani M, Tara F, et al. The diagnostic accuracy of purple line in prediction of labor progress in omolbanin hospital, iran. Iran Red Crescent Med J 2014;16(11):e16183. DOI: 10.5812/ircmj.16183. PMID: 25763210.

Korhonen U, Taipale P and Heinonen S. The diagnostic accuracy of pelvic measurements: threshold values and fetal size. Arch Gynecol Obstet 2014;290(4):643-8. DOI: 10.1007/s00404014-3271-z. PMID: 24816688.

Kwast BE, Poovan P, Vera E, et al. The modified WHO partograph: do we need a latent phase?. British Journal of Midwifery 2008;16(8):527-532.

Lee N, Webster J, Beckmann M, et al. Comparison of a single vs. a four intradermal sterile water injection for relief of lower back pain for women in labour: A randomised controlled trial. Midwifery 2013;29(6):585-591. DOI: 10.1016/j.midw.2012.05.001.

Likis FE, Andrews JC, Collins MR, et al. Nitrous oxide for the management of labor pain: a systematic review. Anesth Analg 2014;118(1):153-67. DOI: 10.1213/ANE.0b013e3182a7f73c. PMID: 24356165.

Ma J, Shao H, Lu X, et al. Safety and efficacy of airbag midwifery in promoting normal vaginal delivery and reducing caesarean section. Iranian Journal of Reproductive Medicine 2012;10(6):595-600.

Madden K, Middleton P, Cyna AM, et al. Hypnosis for pain management during labour and childbirth. Cochrane Database Syst Rev 2016(5):Cd009356. DOI: 10.1002/14651858.CD009356.pub3. PMID: 27192949.

Madhu C, Mahavarkar S and Bhave S. A randomised controlled study comparing Drotaverine hydrochloride and Valethamate bromide in the augmentation of labour. Arch Gynecol Obstet 2010;282(1):11-5. DOI: 10.1007/s00404-009-1188-8. PMID: 19644697.

Mafetoni RR and Shimo AK. Effects of auriculotherapy on labour pain: a randomized clinical trial. Rev Esc Enferm USP 2016;50(5):726-732. DOI: 10.1590/s0080-623420160000600003. PMID: 27982389.

Maged AM, Soliman EM, Abdellatif AA, et al. Measurement of the fetal occiput-spine angle during the first stage of labor as predictor of the progress and outcome of labor. Journal of Maternal-Fetal and Neonatal Medicine 2018:1-6. DOI: 10.1080/14767058.2018.1432589.

Mahendru R. Shortening the second stage of labor?. Journal of the Turkish-German Gynecological Association 2010;11(2):95-98. DOI: 10.5152/jtgga.2010.07. 
Majoko F and Gardener G. Trial of instrumental delivery in theatre versus immediate caesarean section for anticipated difficult assisted births. Cochrane Database Syst Rev 2012;10:Cd005545. DOI: 10.1002/14651858.CD005545.pub3. PMID: 23076915.

Martensson L, Stener-Victorin E and Wallin G. Acupuncture versus subcutaneous injections of sterile water as treatment for labour pain. Acta Obstet Gynecol Scand 2008;87(2):171-7. DOI: 10.1080/00016340701797799. PMID: 18231884.

Martin CJH, Kenney L, Pratt T, et al. The Development and Validation of An Activity Monitoring System for Use in Measurement of Posture of Childbearing Women During First Stage of Labor. Journal of Midwifery \& Women's Health 2015;60(2):182-186. DOI: 10.1111/jmwh.12230.

Matsuo K, Mudd JV, Kopelman JN, et al. Duration of the second stage of labor while wearing a dental support device: a pilot study. J Obstet Gynaecol Res 2009;35(4):672-8. DOI: 10.1111/j.1447-0756.2008.01010.x. PMID: 19751326.

Matsuo K, Shiki Y, Yamasaki M, et al. Use of uterine fundal pressure maneuver at vaginal delivery and risk of severe perineal laceration. Arch Gynecol Obstet 2009;280(5):781-6. DOI: 10.1007/s00404-009-1015-2. PMID: 19263062.

McLachlan HL, Forster DA, Davey MA, et al. Effects of continuity of care by a primary midwife (caseload midwifery) on caesarean section rates in women of low obstetric risk: the COSMOS randomised controlled trial. Bjog 2012;119(12):1483-92. DOI: 10.1111/j.14710528.2012.03446.x. PMID: 22830446.

Metz TD, Allshouse AA, Gilbert SAB, et al. Variation in primary cesarean delivery rates by individual physician within a single-hospital laborist model. Am J Obstet Gynecol 2016;214(4):531.e1-531.e6. DOI: 10.1016/j.ajog.2016.01.002. PMID: 26922481.

Miquelutti MA, Cecatti JG and Makuch MY. Developing strategies to be added to the protocol for antenatal care: an exercise and birth preparation program. Clinics (Sao Paulo) 2015;70(4):231-6. DOI: 10.6061/clinics/2015(04)02. PMID: 26017787.

Mir S and Aziz R. Programmed labour and its outcome. JK Practitioner 2011;16(1-2):36-39. Mitchell K. The effect of the labour electronic fetal monitoring admission test on operative delivery in low-risk women: a randomised controlled trial. Evidence Based Midwifery 2008;6(1):18-26.

Mobaraki N, Yousefian M, Seifi S, et al. A randomized controlled trial comparing use of enthonox with pethidine for pain relief in primigravid women during the active phase of labor. Anesthesiology and Pain Medicine 2016;6(4). DOI: 10.5812/aapm.37420.

Narayanan R, Wahal R, Bhushan S, et al. Comparison of two different doses of bupivacaine with sufentanil on ambulatory labour analgesia. Journal of Anaesthesiology Clinical Pharmacology 2009;25(1):49-53. 
Neal JL, Lamp JM, Lowe NK, et al. Differences in inflammatory markers between nulliparous women admitted to hospitals in preactive vs active labor. Am J Obstet Gynecol 2015;212(1):68.e1-8. DOI: 10.1016/j.ajog.2014.07.050. PMID: 25086275.

Neal JL, Lowe NK, Phillippi JC, et al. Likelihood of cesarean birth among parous women after applying leading active labor diagnostic guidelines. Midwifery 2018;67:64-69. PMID: 132488228.

Ng TK, Cheng BC, Chan WS, et al. A double-blind randomised comparison of intravenous patient-controlled remifentanil with intramuscular pethidine for labour analgesia*. Anaesthesia 2011;66(9):796-801. DOI: 10.1111/j.1365-2044.2011.06790.x.

Novikova $\mathrm{N}$ and Cluver C. Local anaesthetic nerve block for pain management in labour. 2012;(4). DOI: 10.1002/14651858.CD009200.pub2. PMID: CD009200.

O'Brien OA, McCarthy M, Gibney ER, et al. Technology-supported dietary and lifestyle interventions in healthy pregnant women: a systematic review. European Journal of Clinical Nutrition 2014;68(7):760-766. DOI: 10.1038/ejcn.2014.59.

Ojala K, Vääräsmäki M, Mäkikallio K, et al. A comparison of intrapartum automated fetal electrocardiography and conventional cardiotocography--a randomised controlled study. BJOG: An International Journal of Obstetrics \& Gynaecology 2006;113(4):419-423.

Oladejo M and Bewley S. Adherence In Pregnancy: A Systematic Review Of The Literature. Fetal \& Maternal Medicine Review 2012;23(3/4):201-229. DOI: 10.1017/S0965539512000113.

Olsen O and Clausen JA. Planned hospital birth versus planned home birth. Cochrane Database Syst Rev 2012;9:Cd000352. DOI: 10.1002/14651858.CD000352.pub2. PMID: 22972043.

Oppenheimer LW, Labrecque M, Wells G, et al. Prostaglandin E vaginal gel to treat dystocia in spontaneous labour: a multicentre randomised placebo-controlled trial. Bjog 2005;112(5):612-8. DOI: 10.1111/j.1471-0528.2005.00484.x. PMID: 15842286.

Ouzounian JG. Risk factors for neonatal brachial plexus palsy. Semin Perinatol 2014;38(4):21921. DOI: 10.1053/j.semperi.2014.04.008. PMID: 24863028.

Parsa P, Saeedzadeh N, Roshanaei G, et al. The effect of entonox on labour pain relief among nulliparous women: A randomized controlled trial. Journal of Clinical and Diagnostic Research 2017;11(3):QC08-QC11. DOI: 10.7860/JCDR/2017/21611.9362.

Parveen T, Hussain H and Nasir Khattak N. Effects of phloroglucinol on augmentation of labour in primigravida. Journal of Medical Sciences (Peshawar) 2013;21(3):131-133. 
Pinar S and Karaçam Z. Applying fundal pressure in the second stage of labour and its impact on mother and infant health. Health Care for Women International 2018;39(1):110-125. DOI: 10.1080/07399332.2017.1376332. PMID: 127116063.

Popowski T, Porcher R, Fort J, et al. Influence of ultrasound determination of fetal head position on mode of delivery: a pragmatic randomized trial. Ultrasound Obstet Gynecol 2015;46(5):5205. DOI: 10.1002/uog.14785. PMID: 25583399.

Rahnama P, Ziaei S and Faghihzadeh S. Impact of early admission in labor on method of delivery. Int J Gynaecol Obstet 2006;92(3):217-20. DOI: 10.1016/j.ijgo.2005.12.016. PMID: 16434043.

Ramphul M, Ooi P, Burke G, et al. Instrumental delivery and ultrasound : a multicentre randomised controlled trial of ultrasound assessment of the fetal head position versus standard care as an approach to prevent morbidity at instrumental delivery. BJOG: An International Journal of Obstetrics \& Gynaecology 2007;114(11):1029-1038. DOI: 10.1111/1471-0528.12810.

Reveiz L, Gaitán Hernando G and Cuervo Luis G. Enemas during labour. 2013;(7). DOI: 10.1002/14651858.CD000330.pub4. PMID: CD000330.

Rohwer AC, Khondowe O and Young T. Antispasmodics for labour. Cochrane Database Syst Rev 2012;8:Cd009243. DOI: 10.1002/14651858.CD009243.pub2. PMID: 22895986.

Rohwer AC, Khondowe O and Young T. Antispasmodics for labour. Cochrane Database Syst Rev 2013;6:Cd009243. DOI: 10.1002/14651858.CD009243.pub3. PMID: 23737030.

Ross VH, Pan PH, Owen MD, et al. Neostigmine decreases bupivacaine use by patientcontrolled epidural analgesia during labor: a randomized controlled study. Anesth Analg 2009;109(2):524-31. DOI: 10.1213/ane.0b013e31819518e4. PMID: 19377050.

Rossignol M, Chaillet N, Boughrassa F, et al. Interrelations between four antepartum obstetric interventions and cesarean delivery in women at low risk: a systematic review and modeling of the cascade of interventions. Birth 2014;41(1):70-8. DOI: 10.1111/birt.12088. PMID: 24654639.

Roy A, Patra KK, Mukhopadhyay S, et al. Study of drotaverine on first stage of labour and pregnancy outcome. J Indian Med Assoc 2007;105(8):450, 452. PMID: 18236908.

Samuels LA, Christie L, Roberts-Gittens B, et al. The effect of hyoscine butylbromide on the first stage of labour in term pregnancies. Bjog 2007;114(12):1542-6. DOI: 10.1111/j.14710528.2007.01497.x. PMID: 17903230.

Sanda B, Vistad I, Sagedal LR, et al. What is the effect of physical activity on duration and mode of delivery? Secondary analysis from the Norwegian Fit for Delivery trial. Acta Obstet Gynecol Scand 2018;97(7):861-871. DOI: 10.1111/aogs.13351. PMID: 29744866. 
Sandall J, Soltani H, Gates S, et al. Midwife-led continuity models versus other models of care for childbearing women. Cochrane Database of Systematic Reviews 2013;(8):N.PAG-N.PAG.

Schaub AF, Litschgi M, Hoesli I, et al. Obstetric gel shortens second stage of labor and prevents perineal trauma in nulliparous women: a randomized controlled trial on labor facilitation. $\mathrm{J}$ Perinat Med 2008;36(2):129-35. DOI: 10.1515/jpm.2008.024. PMID: 18211256.

Schnabel A, Hahn N, Broscheit J, et al. Remifentanil for labour analgesia: a meta-analysis of randomised controlled trials. Eur J Anaesthesiol 2012;29(4):177-85. DOI: 10.1097/EJA.0b013e32834fc260. PMID: 22273829.

Sekhavat L, Karbasi SA, Fallah R, et al. Effect of hyoscine butylbromide first stage of labour in multiparus women. Afr Health Sci 2012;12(4):408-11. PMID: 23515202.

Seval MM, Yüce T, Yakıştıran B, et al. Effects of obstetric gel on the process and duration of labour in pregnant women: Randomised controlled trial. Journal of Obstetrics \& Gynaecology 2017;37(6):714-718. DOI: 10.1080/01443615.2017.1288711. PMID: 123763308.

Shepherd E, Salam RA, Middleton P, et al. Antenatal and intrapartum interventions for preventing cerebral palsy: an overview of Cochrane systematic reviews. Cochrane Database Syst Rev 2017;8:Cd012077. DOI: 10.1002/14651858.CD012077.pub2. PMID: 28786098.

Shetty J, Vishalakshi A and Pandey D. Labour Analgesia When Epidural Is Not a Choice: Tramadol versus Pentazocine. ISRN Obstetrics \& Gynecology 2014:930349-930349. DOI: 2014/930349.

Sia AT, Leo S and Ocampo CE. A randomised comparison of variable-frequency automated mandatory boluses with a basal infusion for patient-controlled epidural analgesia during labour and delivery. Anaesthesia 2013;68(3):267-75. DOI: 10.1111/anae.12093. PMID: 23278328.

Simic M, Cnattingius S, Petersson G, et al. Duration of second stage of labor and instrumental delivery as risk factors for severe perineal lacerations: population-based study. BMC Pregnancy \& Childbirth 2017;17(\#issue\#):1-8. DOI: 10.1186/s12884-017-1251-6. PMID: 121404072.

Simmons SW, Taghizadeh N, Dennis AT, et al. Combined spinal-epidural versus epidural analgesia in labour. Cochrane Database Syst Rev 2012;10:Cd003401. DOI: 10.1002/14651858.CD003401.pub3. PMID: 23076897.

Singh S, Singh A and Srivastava U. Low Dose Epidural Analgesia During Labor: Comparison Between Patient Controlled Epidural Analgesia with Basal Continuous Infusion and Intermittent Bolus Technique. J Obstet Gynaecol India 2011;61(4):404-7. DOI: 10.1007/s13224-011-0059-y. PMID: 22851821.

Skupski DW, Abramovitz S, Samuels J, et al. Adverse effects of combined spinal-epidural versus traditional epidural analgesia during labor. Int J Gynaecol Obstet 2009;106(3):242-5. DOI: 10.1016/j.ijgo.2009.04.019. PMID: 19481203. 
Smith LA, Burns E and Cuthbert A. Parenteral opioids for maternal pain management in labour. Cochrane Database Syst Rev 2018;6:Cd007396. DOI: 10.1002/14651858.CD007396.pub3. PMID: 29870574.

Sng BL, Zeng Y, de Souza NNA, et al. Automated mandatory bolus versus basal infusion for maintenance of epidural analgesia in labour. Cochrane Database Syst Rev 2018;5:Cd011344. DOI: 10.1002/14651858.CD011344.pub2. PMID: 29770432.

Sultan P, Murphy C, Halpern S, et al. The effect of low concentrations versus high concentrations of local anesthetics for labour analgesia on obstetric and anesthetic outcomes: a meta-analysis. Can J Anaesth 2013;60(9):840-54. DOI: 10.1007/s12630-013-9981-z. PMID: 23925722.

Sun YC, Hung YC, Chang Y, et al. Effects of a prenatal yoga programme on the discomforts of pregnancy and maternal childbirth self-efficacy in Taiwan. Midwifery 2010;26(6):e31-6. DOI: 10.1016/j.midw.2009.01.005. PMID: 19246136.

Tabassum S, Afridi B and Aman Z. Phloroglucinol for acceleration of labour: double blind, randomized controlled trial. J Pak Med Assoc 2005;55(7):270-3. PMID: 16108507.

Tahir S, Liaqat M, Jabeen S, et al. Effectiveness of phloroglucinol to accelerate labor in Primigravidas at term: Double blind, randomized controlled trial. Pakistan Journal of Medical and Health Sciences 2015;9(1):169-172.

Torkzahrani S, Ghobadi K, Heshmat R, et al. Effect of Acupressure on Cervical Ripening. Iran Red Crescent Med J 2015;17(8):e28691. DOI: 10.5812/ircmj.28691. PMID: 26430530.

Transcutaneous electrical nerve stimulation (TENS) reduces pain and postpones the need for pharmacological analgesia during labour: a randomised trial. 2016;62:29-34 6p. DOI: 10.1016/j.jphys.2015.11.002.

Ullman R, Smith LA, Burns E, et al. Parenteral opioids for maternal pain relief in labour. Cochrane Database of Systematic Reviews 2010;:N.PAG-N.PAG.

Ullman R, Smith Lesley A, Burns E, et al. Parenteral opioids for maternal pain management in labour. 2010;(9). DOI: 10.1002/14651858.CD007396.pub2. PMID: CD007396.

Valsky DV, Lipschuetz M, Bord A, et al. Fetal head circumference and length of second stage of labor are risk factors for levator ani muscle injury, diagnosed by 3-dimensional transperineal ultrasound in primiparous women. Am J Obstet Gynecol 2009;201(1):91.e1-7. DOI: 10.1016/j.ajog.2009.03.028. PMID: 19481726.

Verheijen EC, Raven JH and Hofmeyr GJ. Fundal pressure during the second stage of labour. Cochrane Database Syst Rev 2009;(4):Cd006067. DOI: 10.1002/14651858.CD006067.pub2. PMID: 19821352. 
Vlachos D-EG, Pergialiotis V, Papantoniou N, et al. Oxytocin discontinuation after the active phase of labor is established. Journal of Maternal-Fetal \& Neonatal Medicine 2015;28(12):14211427. DOI: 10.3109/14767058.2014.955000.

Vlachos G, Tsikouras P, Manav B, et al. The effect of the use of a new type of partogram on the cesarean section rates. J Turk Ger Gynecol Assoc 2015;16(3):145-8. DOI: 10.5152/jtgga.2015.15074. PMID: 26401106.

Walker KF, Kibuka M, Thornton JG, et al. Maternal position in the second stage of labour for women with epidural anaesthesia. Cochrane Database Syst Rev 2018;11:Cd008070. PMID: 30411804.

Wan Q and Wen FY. Effects of acupressure and music therapy on reducing labor pain. International Journal of Clinical and Experimental Medicine 2018;11(2):898-903.

Wang F, Shen X, Guo X, et al. Epidural analgesia in the latent phase of labor and the risk of cesarean delivery: a five-year randomized controlled trial. Anesthesiology 2009;111(4):871-80. DOI: 10.1097/ALN.0b013e3181b55e65. PMID: 19741492.

Wang K, Cao L, Deng Q, et al. The effects of epidural/spinal opioids in labour analgesia on neonatal outcomes: a meta-analysis of randomized controlled trials. Can J Anaesth 2014;61(8):695-709. DOI: 10.1007/s12630-014-0185-y. PMID: 25011701.

Wee M, Tuckey J, Thomas P, et al. A comparison of intramuscular diamorphine and intramuscular pethidine for labour analgesia: a two-centre randomised blinded controlled trial. BJOG: An International Journal of Obstetrics \& Gynaecology 2014;121(4):447-456. DOI: 10.1111/1471-0528.12532.

Wee MY, Tuckey JP, Thomas P, et al. The IDvIP Trial: A two-centre randomised double-blind controlled trial comparing intramuscular diamorphine and intramuscular pethidine for labour analgesia. BMC Pregnancy \& Childbirth 2011;11(1):51-51.

Wei S, Wo BL, Qi HP, et al. Early amniotomy and early oxytocin for prevention of, or therapy for, delay in first stage spontaneous labour compared with routine care. Cochrane Database Syst Rev 2013;8:Cd006794. DOI: 10.1002/14651858.CD006794.pub4. PMID: 23926074.

Werner A, Uldbjerg N, Zachariae R, et al. Antenatal hypnosis training and childbirth experience: a randomized controlled trial. Birth 2013;40(4):272-80. DOI: 10.1111/birt.12071. PMID: 24344708.

Wilson MJA, MacArthur C, Hewitt CA, et al. Intravenous remifentanil patient-controlled analgesia versus intramuscular pethidine for pain relief in labour (RESPITE): an open-label, multicentre, randomised controlled trial. Lancet 2018;392(10148):662-672. DOI: 10.1016/s01406736(18)31613-1. PMID: 30115484. 
Yuksel H, Cayir Y, Kosan Z, et al. Effectiveness of breathing exercises during the second stage of labor on labor pain and duration: a randomized controlled trial. J Integr Med 2017;15(6):456461. DOI: 10.1016/s2095-4964(17)60368-6. PMID: 29103415.

Zhao S, Wen J, Niu J, et al. The clinical research into the application of multifunctional airbag abdominal pressure belt in midwifery and in the prevention of postpartum hemorrhage. Journal of Maternal-Fetal \& Neonatal Medicine 2018;31(1):128-134. DOI:

10.1080/14767058.2016.1277699. PMID: 126002790.

Zutshi V, Usha Rani K, Marwah S, et al. Efficacy of intravenous infusion of acetaminophen for intrapartum analgesia. Journal of Clinical and Diagnostic Research 2016;10(8):QC18-QC21. DOI: 10.7860/JCDR/2016/19786.8375.

\section{No comparator of interest:}

Agah J. Effects of continuous use of Entonox in comparison with intermittent method on obstetric outcomes: a randomized clinical trial. Biomed Res Int 2014;2014:245907. DOI: 10.1155/2014/695037; 10.1155/2014/245907. PMID: 25525519.

Ahirwar A, Prakash R, Kushwaha BB, et al. Patient controlled epidural labour analgesia (PCEA): A comparison between ropivacaine, ropivacaine-fentanyl and ropivacaine-clonidine. Journal of Clinical and Diagnostic Research 2014;8(8):GC09-GC13.

Alavi MH, Talaie Rad Z and Dadgar SR. Assessment of the effects of increased intravenous hydration on the course of labor in nulliparous term pregnancies. Medical Journal of the Islamic Republic of Iran 2005;18(4):289-292.

Alfirevic Z, Devane D and Gyte Gillian ML. Continuous cardiotocography (CTG) as a form of electronic fetal monitoring (EFM) for fetal assessment during labour. 2013;(5). DOI: 10.1002/14651858.CD006066.pub2. PMID: CD006066.

Anonymous. Computerised interpretation of fetal heart rate during labour (INFANT): a randomised controlled trial. Lancet 2017;389 North American Edition(10080):1719-1729. DOI: 10.1016/S0140-6736(17)30568-8. PMID: 122970942.

Attri JP, Makhni R and Sethi S. Levobupivacaine for labor analgesia. Anesth Essays Res 2016;10(3):493-496. DOI: 10.4103/0259-1162.179309. PMID: 27746539.

Bang EC, Lee HS, Kang YI, et al. Onset of labor epidural analgesia with ropivacaine and a varying dose of fentanyl: a randomized controlled trial. Int J Obstet Anesth 2012;21(1):45-50. DOI: 10.1016/j.ijoa.2011.10.002. PMID: 22153132.

Baliuliene V, Macas A and Rimaitis K. The optimal concentration of bupivacaine and levobupivacaine for labor pain management using patient-controlled epidural analgesia: a double-blind, randomized controlled trial. Int J Obstet Anesth 2018;35:17-25. DOI: 10.1016/j.ijoa.2018.05.002. PMID: 29914785. 
Bazin M, Bonnin M, Storme B, et al. Addition of clonidine to a continuous patient-controlled epidural infusion of low-concentration levobupivacaine plus sufentanil in primiparous women during labour. Anaesthesia 2011;66(9):769-79. DOI: 10.1111/j.1365-2044.2011.06785.x. PMID: 21707560.

Beilin Y, Guinn NR, Bernstein HH, et al. Local anesthetics and mode of delivery: bupivacaine versus ropivacaine versus levobupivacaine. Anesth Analg 2007;105(3):756-63. DOI: 10.1213/01.ane.0000278131.73472.f4. PMID: 17717236.

Bleich AT, Villano KS, Lo JY, et al. Oral misoprostol for labor augmentation: a randomized controlled trial. Obstet Gynecol 2011;118(6):1255-60. DOI: 10.1097/AOG.0b013e318236df5b. PMID: 22105254.

Blix E, Brurberg KG, Reierth E, et al. ST waveform analysis versus cardiotocography alone for intrapartum fetal monitoring: A systematic review and meta-analysis of randomized trials. Acta Obstetricia et Gynecologica Scandinavica 2016;95(1):16-27.

Bolukbasi D, Sener EB, Sarihasan B, et al. Comparison of maternal and neonatal outcomes with epidural bupivacaine plus fentanyl and ropivacaine plus fentanyl for labor analgesia. Int J Obstet Anesth 2005;14(4):288-93. DOI: 10.1016/j.ijoa.2005.04.007. PMID: 16140519.

Brogly N, Schiraldi R, Vazquez B, et al. A randomized control trial of patient-controlled epidural analgesia (PCEA) with and without a background infusion using levobupivacaine and fentanyl. Minerva Anestesiol 2011;77(12):1149-54. PMID: 21623342.

Burns DA. Effectiveness of a novel device in the reduction of cesarean deliveries. ISRN Obstetrics \& Gynecology 2013:173278-173278.

Çakirca M, Bektaş M, Özcan A, et al. Comparison of two different bupivacaine doses with sufentanil for epidural obstetric analgesia. Turkiye Klinikleri Journal of Medical Sciences 2013;33(2):516-521.

Carvalho B, Cohen SE, Giarrusso K, et al. "Ultra-light” patient-controlled epidural analgesia during labor: effects of varying regimens on analgesia and physician workload. Int J Obstet Anesth 2005;14(3):223-9. DOI: 10.1016/j.ijoa.2005.02.003. PMID: 15935646.

Chaurasia M, Saxena AK and Chilkoti GT. Comparison of Epidural Butorphanol with Neostigmine and Epidural Sufentanyl with Neostigmine for First Stage of Labor Analgesia: A Randomized Controlled Trial. Anesth Essays Res 2017;11(2):365-371. DOI: 10.4103/02591162.206271. PMID: 28663623.

Chellammal KR and Anand Kumar GS. Effect of early vs. delayed epidural labour analgesia on maternal and its outcome. Research Journal of Pharmaceutical, Biological and Chemical Sciences 2015;6(1):1365-1373. 
Cohen WR and Hayes-Gill B. Influence of maternal body mass index on accuracy and reliability of external fetal monitoring techniques. Acta Obstet Gynecol Scand 2014;93(6):590-5. DOI: 10.1111/aogs.12387. PMID: 24684703.

Connelly NR, Freiman JP, Lucas T, et al. Addition of epinephrine to epidural bupivacaine infusions following initiation of labor analgesia with epidural fentanyl. J Clin Anesth 2011;23(4):265-9. DOI: 10.1016/j.jclinane.2010.09.005. PMID: 21489769.

Dapuzzo-Argiriou LM, Smulian JC, Rochon ML, et al. A multi-center randomized trial of two different intravenous fluids during labor. Journal of Maternal-Fetal and Neonatal Medicine 2016;29(2):191-196.

Das D, Thakur DP and Tendolkar BA. Labour epidural analgesia: A randomised double blind comparative study of $0.1 \%$ levobupivacaine with fentanyl vs. $0.1 \%$ ropivacaine with fentanyl. Journal of Clinical and Diagnostic Research 2018;12(7):UC06-UC10. DOI: 10.7860/JCDR/2018/31764.11769.

Dewandre PY, Decurninge V, Bonhomme V, et al. Side effects of the addition of clonidine 75 microg or sufentanil 5 microg to $0.2 \%$ ropivacaine for labour epidural analgesia. Int J Obstet Anesth 2010;19(2):149-54. DOI: 10.1016/j.ijoa.2009.08.003. PMID: 20202819.

Douma MR, Verwey RA, Kam-Endtz CE, et al. Obstetric analgesia: a comparison of patientcontrolled meperidine, remifentanil, and fentanyl in labour. Br J Anaesth 2010;104(2):209-15. DOI: 10.1093/bja/aep359. PMID: 20008859.

El-Shaarawy AM, Asfour MS, Rashwan DA, et al. Comparison of Three Different Concentrations of Levobupivacaine for Epidural Labor Analgesia: Clinical Effect and Pharmacokinetic Profile. Anesth Essays Res 2018;12(1):60-66. DOI: 10.4103/aer.AER_145_17. PMID: 29628556.

Epsztein Kanczuk M, Barrett NM, Arzola C, et al. Programmed Intermittent Epidural Bolus for Labor Analgesia During First Stage of Labor: A Biased-Coin Up-and-Down Sequential Allocation Trial to Determine the Optimum Interval Time Between Boluses of a Fixed Volume of $10 \mathrm{~mL}$ of Bupivacaine 0.0625\% With Fentanyl $2 \mathrm{mug} / \mathrm{mL}$. Anesth Analg 2017;124(2):537541. DOI: 10.1213/ane.0000000000001655. PMID: 27755057.

Evron S, Glezerman M, Sadan O, et al. Remifentanil: a novel systemic analgesic for labor pain. Anesth Analg 2005;100(1):233-8. DOI: 10.1213/01.ane.0000143351.64538.bc. PMID: 15616083.

Fan Y, Ji M, Zang L, et al. Comparison of epidural tramadol-ropivacaine and fentanylropivacaine for labor analgesia: a prospective randomized study. Ups J Med Sci 2011;116(4):252-7. DOI: 10.3109/03009734.2011.601532. PMID: 22066973. 
Ferrer LE, Romero DJ, Vasquez OI, et al. Effect of programmed intermittent epidural boluses and continuous epidural infusion on labor analgesia and obstetric outcomes: a randomized controlled trial. Arch Gynecol Obstet 2017;296(5):915-922. DOI: 10.1007/s00404-017-4510-X. PMID: 28884414.

Ginosar Y, Davidson EM, Firman N, et al. A randomized controlled trial using patient-controlled epidural analgesia with $0.25 \%$ versus $0.0625 \%$ bupivacaine in nulliparous labor: effect on analgesia requirement and maternal satisfaction. Int J Obstet Anesth 2010;19(2):171-8. DOI: 10.1016/j.ijoa.2009.11.002. PMID: 20223648.

Gupta K, Mitra S, Kazal S, et al. I.V. paracetamol as an adjunct to patient-controlled epidural analgesia with levobupivacaine and fentanyl in labour: a randomized controlled study. $\mathrm{Br} \mathrm{J}$ Anaesth 2016;117(5):617-622. DOI: 10.1093/bja/aew311. PMID: 27799176.

Hassan WA, Eggebø T, Ferguson M, et al. The sonopartogram: a novel method for recording progress of labor by ultrasound. Ultrasound in Obstetrics \& Gynecology 2014;43(2):189-194. DOI: $10.1002 /$ uog.13212.

Hattler J, Klimek M, Rossaint R, et al. The Effect of Combined Spinal-Epidural Versus Epidural Analgesia in Laboring Women on Nonreassuring Fetal Heart Rate Tracings: Systematic Review and Meta-analysis. Anesth Analg 2016;123(4):955-64. DOI: 10.1213/ane.0000000000001412. PMID: 27509225.

Haydon ML, Larson D, Reed E, et al. Obstetric outcomes and maternal satisfaction in nulliparous women using patient-controlled epidural analgesia. Am J Obstet Gynecol 2011;205(3):271.e1-6. DOI: 10.1016/j.ajog.2011.06.041. PMID: 22071061.

He ZY, Jiao QL, Miao Y, et al. Clinical observation of ropivacaine compuled with sufentanil for painless childbirth. Pak J Pharm Sci 2016;29(2 Suppl):707-9. PMID: 27113310.

Hemanth Kumar VR, Mishra SK, Rupavani K, et al. Ultra low concentrations of epidural bupivacaine with fentanyl along with intrathecal fentanyl for labor analgesia. Journal of Anaesthesiology Clinical Pharmacology 2009;25(3):293-296.

Ho M, Cheng SY and Li TC. Titrated oral misoprostol solution compared with intravenous oxytocin for labor augmentation: a randomized controlled trial. Obstet Gynecol 2010;116(3):612-8. DOI: 10.1097/AOG.0b013e3181ed36cc. PMID: 20733443.

How Long Is a Normal Labor? Contemporary Patterns of Labor and Birth in a Low-Risk Sample of 1,612 Women from Four Nordic Countries. Birth: Issues in Perinatal Care 2015;42(4):346353.

Ignatov PN and Lutomski JE. Quantitative cardiotocography to improve fetal assessment during labor: a preliminary randomized controlled trial. European Journal of Obstetrics \& Gynecology \& Reproductive Biology 2016;205:91-97. DOI: 10.1016/j.ejogrb.2016.08.023. PMID:

118341070. 
Jalil NA and Omar M. Does ropivacaine $0.2 \%$ with fentanyl change the labour epidural profile?. International Medical Journal 2009;16(2):149-155.

Kjaergaard H, Olsen J, Ottesen B, et al. Incidence and outcomes of dystocia in the active phase of labor in term nulliparous women with spontaneous labor onset. Acta Obstet Gynecol Scand 2009;88(4):402-7. DOI: 10.1080/00016340902811001. PMID: 19330572.

Kumar TS, Rani P, Hemanth Kumar VR, et al. Quality of Labor Epidural Analgesia and Maternal Outcome With Levobupivacaine and Ropivacaine: A Double-Blinded Randomized Trial. Anesth Essays Res 2017;11(1):28-33. DOI: 10.4103/0259-1162.194573. PMID: 28298752.

Kumari I, Sharma K, Bedi V, et al. Comparison of ropivacaine (0.2\%) with or without clonidine $1 \mathrm{mug} / \mathrm{kg}$ for epidural labor analgesia: A randomized controlled study. J Anaesthesiol Clin Pharmacol 2018;34(1):18-22. DOI: 10.4103/joacp.JOACP_233_16. PMID: 29643617.

Lavender T, Hart A, Walkinshaw S, et al. Progress of first stage of labour for multiparous women: an observational study. Bjog 2005;112(12):1663-5. DOI: 10.1111/j.14710528.2005.00758.x. PMID: 16305573.

Leo S, Ocampo CE, Lim Y, et al. A randomized comparison of automated intermittent mandatory boluses with a basal infusion in combination with patient-controlled epidural analgesia for labor and delivery. Int J Obstet Anesth 2010;19(4):357-64. DOI:

10.1016/j.ijoa.2010.07.006. PMID: 20832282.

Li Y, Hu C, Fan Y, et al. Epidural analgesia with amide local anesthetics, bupivacaine, and ropivacaine in combination with fentanyl for labor pain relief: a meta-analysis. Med Sci Monit 2015;21:921-8. DOI: 10.12659/msm.892276. PMID: 25816849.

Lilker S, Rofaeel A, Balki M, et al. Comparison of fentanyl and sufentanil as adjuncts to bupivacaine for labor epidural analgesia. J Clin Anesth 2009;21(2):108-12. DOI: 10.1016/j.jclinane.2008.06.027. PMID: 19329014.

Lim Y, Chakravarty S, Ocampo CE, et al. Comparison of automated intermittent low volume bolus with continuous infusion for labour epidural analgesia. Anaesth Intensive Care 2010;38(5):894-9. PMID: 20865875.

Lim Y, Ocampo CE, Supandji M, et al. A randomized controlled trial of three patient-controlled epidural analgesia regimens for labor. Anesth Analg 2008;107(6):1968-72. DOI: 10.1213/ane.0b013e3181887ffb. PMID: 19020146.

Lin Y, Li Q, Liu J, et al. Comparison of continuous epidural infusion and programmed intermittent epidural bolus in labor analgesia. Ther Clin Risk Manag 2016;12:1107-12. DOI: 10.2147/tcrm.s106021. PMID: 27471390. 
Lutomski Jennifer E, Meaney S, Greene Richard A, et al. Expert systems for fetal assessment in labour. 2015;(4). DOI: 10.1002/14651858.CD010708.pub2. PMID: CD010708.

Mebazaa MS, Tanoubi I, Mestiri T, et al. Efficacy of patient controlled epidural analgesia during labor analgesia--a prospective randomized study using $0.1 \%$ bupivacaine with fentanyl $2 \mathrm{mg} / \mathrm{ml}$. Tunis Med 2008;86(6):540-5. PMID: 19216444.

Mercer SW, Sevar K and Sadutshan TD. Using clinical audit to improve the quality of obstetric care at the Tibetan Delek Hospital in North India: A longitudinal study. Reproductive Health 2006;3

Mousa WF, Al-Metwalli RR and Mostafa M. Epidural analgesia during labor--0.5\% lidocaine with fentanyl vs. 0.08\% ropivacaine with fentanyl. Middle East J Anaesthesiol 2010;20(4):521-7. PMID: 20394248.

Nakamura G, Ganem EM, Modolo NS, et al. Labor analgesia with ropivacaine added to clonidine: a randomized clinical trial. Sao Paulo Med J 2008;126(2):102-6. PMID: 18553032.

Nelson KE and Eisenach JC. Intravenous butorphanol, meperidine, and their combination relieve pain and distress in women in labor. Anesthesiology 2005;102(5):1008-1013.

Nunes I, Ayres-de-Campos D, Ugwumadu A, et al. Central Fetal Monitoring With and Without Computer Analysis: A Randomized Controlled Trial. Obstet Gynecol 2017;129(1):83-90. DOI: 10.1097/aog.0000000000001799. PMID: 27926647.

Nunes J, Nunes S, Veiga M, et al. A prospective, randomized, blinded-endpoint, controlled study - continuous epidural infusion versus programmed intermittent epidural bolus in labor analgesia. Braz J Anesthesiol 2016;66(5):439-44. DOI: 10.1016/j.bjane.2014.12.006. PMID: 27591455.

Nurani R, Chandraharan E, Lowe V, et al. Misidentification of maternal heart rate as fetal on cardiotocography during the second stage of labor: the role of the fetal electrocardiograph. Acta Obstetricia et Gynecologica Scandinavica 2012;91(12):1428-1432. DOI: 10.1111/j.16000412.2012.01511.x.

Orji E. Evaluating progress of labor in nulliparas and multiparas using the modified WHO partograph. Int J Gynaecol Obstet 2008;102(3):249-52. DOI: 10.1016/j.ijgo.2008.04.024. PMID: 18603248.

Pan PH, Lee S and Harris L. Chronobiology of subarachnoid fentanyl for labor analgesia. Anesthesiology 2005;103(3):595-9. PMID: 16129985.

Riddell CA, Kaufman JS, Strumpf EC, et al. Cervical dilation at time of caesarean delivery in nulliparous women: a population-based cohort study. Bjog 2017;124(11):1753-1761. DOI: 10.1111/1471-0528.14275. PMID: 27561206. 
Ristev G, Sipes AC, Mahoney B, et al. Initiation of labor analgesia with injection of local anesthetic through the epidural needle compared to the catheter. Journal of Pain Research 2017;10:2789-2796. DOI: 10.2147/JPR.S145138.

Rodriguez-Campoo MB, Curto A, Gonzalez M, et al. Patient intermittent epidural boluses (PIEB) plus very low continuous epidural infusion (CEI) versus patient-controlled epidural analgesia (PCEA) plus continuous epidural infusion (CEI) in primiparous labour: a randomized trial. J Clin Monit Comput 2018. PMID: 30506299.

Rogers R, Leeman L, Borders N, et al. Contribution of the second stage of labour to pelvic floor dysfunction: a prospective cohort comparison of nulliparous women. BJOG: An International Journal of Obstetrics \& Gynaecology 2014;121(9):1145-1154. DOI: 10.1111/1471-0528.12571.

Sah N, Vallejo M, Phelps A, et al. Efficacy of ropivacaine, bupivacaine, and levobupivacaine for labor epidural analgesia. J Clin Anesth 2007;19(3):214-7. DOI: 10.1016/j.jclinane.2006.11.003. PMID: 17531731.

Saito M, Okutomi T, Kanai Y, et al. Patient-controlled epidural analgesia during labor using ropivacaine and fentanyl provides better maternal satisfaction with less local anesthetic requirement. J Anesth 2005;19(3):208-12. DOI: 10.1007/s00540-005-0316-2. PMID: 16032448.

Salim R, Nachum Z, Moscovici R, et al. Continuous compared with intermittent epidural infusion on progress of labor and patient satisfaction. Obstet Gynecol 2005;106(2):301-6. DOI: 10.1097/01.AOG.0000171109.53832.8d. PMID: 16055579.

Sarkar M, Mahapatra S and Dewoolkar. Comparative study of sufentanyl with bupivacaine versus plain bupivacaine for labour analgesia in A S A grade 1 and 2 patients. Internet Journal of Anesthesiology 2007;12(2):10p-10p.

Schuit E, Amer-Wahlin I, Ojala K, et al. Effectiveness of electronic fetal monitoring with additional ST analysis in vertex singleton pregnancies at $>36$ weeks of gestation: an individual participant data metaanalysis. American Journal of Obstetrics \& Gynecology 2013;208(3):187.e1-187.e13. DOI: 10.1016/j.ajog.2013.01.028.

Selin L, Almstrom E, Wallin G, et al. Use and abuse of oxytocin for augmentation of labor. Acta Obstet Gynecol Scand 2009;88(12):1352-7. DOI: 10.3109/00016340903358812. PMID: 19878049.

Seval MM, Yuce T, Kalafat E, et al. Comparison of effects of digital vaginal examination with transperineal ultrasound during labor on pain and anxiety levels: a randomized controlled trial. Ultrasound Obstet Gynecol 2016;48(6):695-700. DOI: 10.1002/uog.15994. PMID: 27300158.

Shokry M, Manaa EM, Shoukry RA, et al. Effects of intrapartum epidural analgesia at high altitudes: maternal, fetal, and neonatal outcomes. A randomized controlled trial of two formulations of analgesics. Acta Obstet Gynecol Scand 2010;89(7):909-15. DOI: 10.3109/00016349.2010.484042. PMID: 20583937. 
Skrablin S, Grgic O, Mihaljevic S, et al. Comparison of intermittent and continuous epidural analgesia on delivery and progression of labour. J Obstet Gynaecol 2011;31(2):134-8. DOI: 10.3109/01443615.2010.542840. PMID: 21281028.

Sng BL, Leong WL, Zeng Y, et al. Early versus late initiation of epidural analgesia for labour. Cochrane Database Syst Rev 2014;10:Cd007238. DOI: 10.1002/14651858.CD007238.pub2. PMID: 25300169.

Sng BL, Sia AT, Lim Y, et al. Comparison of computer-integrated patient-controlled epidural analgesia and patient-controlled epidural analgesia with a basal infusion for labour and delivery. Anaesth Intensive Care 2009;37(1):46-53. PMID: 19157345.

Sng BL, Woo D, Leong WL, et al. Comparison of computer-integrated patient-controlled epidural analgesia with no initial basal infusion versus moderate basal infusion for labor and delivery : A randomized controlled trial. Journal of Anaesthesiology Clinical Pharmacology 2014;30(4):496-501.

Steer PJ. The INFANT trial of computer-assisted fetal heart rate pattern interpretation. Obstetrics, Gynaecology and Reproductive Medicine 2017;27(10):322-323. DOI: 10.1016/j.ogrm.2017.07.004.

Syal K, Dogra R, Ohri A, et al. Epidural labour analgesia using Bupivacaine and Clonidine. J Anaesthesiol Clin Pharmacol 2011;27(1):87-90. PMID: 21804714.

Tilden EL, Lee VR, Allen AJ, et al. Cost-Effectiveness Analysis of Latent versus Active Labor Hospital Admission for Medically Low-Risk, Term Women. Birth: Issues in Perinatal Care 2015;42(3):219-226. DOI: 10.1111/birt.12179.

Topcu I, Erincler T, Tekin S, et al. The comparison of efficiency of ropivacaine and addition of fentanyl or clonidine in patient controlled epidural analgesia for labour. Internet Journal of Anesthesiology 2007;11(2):15p-15p.

Vogel JP, West HM and Dowswell T. Titrated oral misoprostol for augmenting labour to improve maternal and neonatal outcomes. Cochrane Database Syst Rev 2013;9:Cd010648. DOI: 10.1002/14651858.CD010648.pub2. PMID: 24058051.

Wallet F, Clement HJ, Bouret C, et al. Effects of a continuous low-dose clonidine epidural regimen on pain, satisfaction and adverse events during labour: a randomized, double-blind, placebo-controlled trial. Eur J Anaesthesiol 2010;27(5):441-7. DOI:

10.1097/EJA.0b013e3283365944. PMID: 20299988.

Wang LZ, Chang XY, Liu X, et al. Comparison of bupivacaine, ropivacaine and levobupivacaine with sufentanil for patient-controlled epidural analgesia during labor: a randomized clinical trial. Chin Med J (Engl) 2010;123(2):178-83. PMID: 20137366. 
Wassen MM, Zuijlen J, Roumen FJ, et al. Early versus late epidural analgesia and risk of instrumental delivery in nulliparous women: a systematic review. Bjog 2011;118(6):655-61. DOI: 10.1111/j.1471-0528.2011.02906.x. PMID: 21392241.

Wilson BL, Passante T, Rauschenbach D, et al. Bladder Management With Epidural Anesthesia During Labor: A Randomized Controlled Trial. MCN Am J Matern Child Nurs 2015;40(4):23442; quiz E17-8. DOI: 10.1097/nmc.0000000000000156. PMID: 25798748.

Wilson SH, Wolf BJ, Bingham K, et al. Labor analgesia onset with dural puncture epidural versus traditional epidural using a 26-gauge whitacre needle and 0.125\% bupivacaine bolus: A randomized clinical trial. Anesthesia and Analgesia 2018;126(2):545-551. DOI:

10.1213/ANE.0000000000002129.

Wong CA, McCarthy RJ and Hewlett B. The effect of manipulation of the programmed intermittent bolus time interval and injection volume on total drug use for labor epidural analgesia: a randomized controlled trial. Anesth Analg 2011;112(4):904-11. DOI:

10.1213/ANE.0b013e31820e7c2f. PMID: 21430035.

Zhang Y, Qin QR and Hui LT. Motor blocks and operative deliveries with ropivacaine and fentanyl for labor epidural analgesia: A meta-analysis. J Obstet Gynaecol Res 2018. DOI: 10.1111/jog.13772. PMID: 30084116.

\section{No outcomes of interest:}

Aasheim V, Nilsen ABV, Reinar LM, et al. Perineal techniques during the second stage of labour for reducing perineal trauma. Cochrane Database Syst Rev 2017;6:Cd006672. DOI: 10.1002/14651858.CD006672.pub3. PMID: 28608597.

Abdelbarr T, Elshalakany NA and Shafik YM. Single dose spinal analgesia: Is it a good alternative to epidural analgesia in controlling labour pain?. Egyptian Journal of Anaesthesia 2014;30(3):241-246.

Abdolahian S, Ghavi F, Abdollahifard S, et al. Effect of dance labor on the management of active phase labor pain \& clients' satisfaction: a randomized controlled trial study. Glob J Health Sci 2014;6(3):219-26. DOI: 10.5539/gjhs.v6n3p219. PMID: 24762366.

Bala I, Babu M and Rastogi S. Effectiveness of Back Massage versus Ambulation During First Stage of Labour among Primigravida Mothers in Terms of Pain and Anxiety. International Journal of Nursing Education 2017;9(3):28-32. DOI: 10.5958/0974-93572017.00066.6. PMID: 125086364.

Barbieri M, Henrique AJ, Chors FM, et al. Warm shower aspersion, perineal exercises with Swiss ball and pain in labor. Acta Paulista de Enfermagem 2013;26(5):478-484. 
Begley CM, Gross MM, Dencker A, et al. Outcome measures in studies on the use of oxytocin for the treatment of delay in labour: a systematic review. Midwifery 2014;30(9):975-82. DOI: 10.1016/j.midw.2014.06.005. PMID: 25017174.

Bharathi BJ. Effective nursing interventions on pain during labour among primi mothers. Nurs J India 2010;101(6):133-5. PMID: 23520818.

Bolbol-Haghighi N, Keshavarz M, Delvarianzadeh M, et al. Evaluation of the alert line of partogram in recognizing the need for neonatal resuscitation. Acta Obstet Gynecol Scand 2015;20(5):560-4. DOI: 10.1111/aogs.12800; 10.4103/1735-9066.164513. PMID: 26457092.

Brown H, Hofmeyr GJ, Nikodem VC, et al. Promoting childbirth companions in South Africa: a randomised pilot study. BMC Med 2007;5:7. DOI: 10.1186/1741-7015-5-7. PMID: 17470267.

Bulchandani S, Watts E, Sucharitha A, et al. Manual perineal support at the time of childbirth: a systematic review and meta-analysis. Bjog 2015;122(9):1157-65. DOI: 10.1111/14710528.13431. PMID: 25976557.

Campbell D, Scott KD, Klaus MH, et al. Female relatives or friends trained as labor doulas: outcomes at 6 to 8 weeks postpartum. Birth 2007;34(3):220-7. DOI: 10.1111/j.1523536X.2007.00174.x. PMID: 17718872.

Cho SH, Lee H and Ernst E. Acupuncture for pain relief in labour: a systematic review and metaanalysis. Bjog 2010;117(8):907-20. DOI: 10.1111/j.1471-0528.2010.02570.x. PMID: 20438555.

Clarkson CE, O'Mahony D and Jones DE. Adverse event reporting in studies of penetrating acupuncture during pregnancy: a systematic review. Acta Obstetricia et Gynecologica Scandinavica 2015;94(5):453-464. DOI: 10.1111/aogs.12587.

Dabiri F and Shahi A. The Effect of LI4 Acupressure on Labor Pain Intensity and Duration of Labor: A Randomized Controlled Trial. Oman Med J 2014;29(6):425-9. DOI: 10.5001/omj.2014.113. PMID: 25584160.

Dahlen HG, Homer CSE, Cooke M, et al. 'Soothing the ring of fire': Australian women's and midwives' experiences of using perineal warm packs in the second stage of labour. Midwifery 2009;25(2):e39-48. DOI: 10.1016/j.midw.2007.08.002.

Ferrer LE, Romero DJ, Vasquez OI, et al. Effect of programmed intermittent epidural boluses and continuous epidural infusion on labor analgesia and obstetric outcomes: a randomized controlled trial. Arch Gynecol Obstet 2017;296(5):915-922. DOI: 10.1007/s00404-017-4510-X. PMID: 28884414.

Finlayson K, Downe S, Hinder S, et al. Unexpected consequences: women's experiences of a self-hypnosis intervention to help with pain relief during labour. BMC Pregnancy Childbirth 2015;15:229. DOI: 10.1186/s12884-015-0659-0. PMID: 26407981. 
Flood P, Dexter F, Ledolter J, et al. Large Heterogeneity in Mean Durations of Labor Analgesia Among Hospitals Reporting to the American Society of Anesthesiologists' Anesthesia Quality Institute. Anesth Analg 2015;121(5):1283-9. DOI: 10.1213/ane.0000000000000897. PMID: 26284432.

Gunnarsson B, Skogvoll E, Jonsdottir IH, et al. On predicting time to completion for the first stage of spontaneous labor at term in multiparous women. BMC Pregnancy Childbirth 2017;17(1):183. DOI: 10.1186/s12884-017-1345-1. PMID: 28606063.

Hamlaci Y and Yazici S. The Effect of Acupressure Applied to Point LI4 on Perceived Labor Pains. Holist Nurs Pract 2017;31(3):167-176. DOI: 10.1097/hnp.0000000000000205. PMID: 28406870.

Hanley GE, Munro S, Greyson D, et al. Diagnosing onset of labor: a systematic review of definitions in the research literature. BMC Pregnancy \& Childbirth 2016;16:1-11. DOI: 10.1186/s12884-016-0857-4. PMID: 114247160.

Heesen M, Klöhr S, Rossaint R, et al. Labour epidural analgesia and anti-infectious management of the neonate: A meta-analysis. Journal of Perinatal Medicine 2012;40(6):625-630.

Heidari-fard S, Mohammadi M and Fallah S. The effect of chamomile odor on contractions of the first stage of delivery in primpara women: A clinical trial. Complementary Therapies in Clinical Practice 2018;32:61-64. DOI: 10.1016/j.ctcp.2018.04.009. PMID: 130948957.

Henrique AJ, Gabrielloni MC, Rodney P, et al. Non-pharmacological interventions during childbirth for pain relief, anxiety, and neuroendocrine stress parameters: A randomized controlled trial. Int J Nurs Pract 2018;24(3):e12642. DOI: 10.1111/ijn.12642. PMID: 29512230.

Henrique AJ, Gabrielloni MC, Varandas Cavalcanti AC, et al. Hydrotherapy and the Swiss ball in labor: randomized clinical trial. Acta Paulista de Enfermagem 2016;29(6):686-692. DOI: 10.1590/1982-0194201600096. PMID: 122041566.

Hoh JK, Cha KJ, Park MI, et al. Estimating time to full uterine cervical dilation using genetic algorithm. Kaohsiung J Med Sci 2012;28(8):423-8. DOI: 10.1016/j.kjms.2012.02.012. PMID: 22892163.

Ka Po C. Effects of perinatal meditation on pregnant Chinese women in Hong Kong: A randomized controlled trial. Journal of Nursing Education \& Practice 2015;5(1):1-18. DOI: 10.5430/jnep.v5n1p1.

Kamalifard M, Shahnazi M, Sayyah Melli M, et al. The efficacy of massage therapy and breathing techniques on pain intensity and physiological responses to labor pain. J Caring Sci 2012;1(2):73-8. DOI: 10.5681/jcs.2012.011. PMID: 25276679. 
Kheirkhah M, Vali Pour NS, Nisani L, et al. Comparing the effects of aromatherapy with rose oils and warm foot bath on anxiety in the first stage of labor in nulliparous women. Iran Red Crescent Med J 2014;16(9):e14455. DOI: 10.5812/ircmj.14455. PMID: 25593713.

Kjaergaard H, Dykes AK, Ottesen B, et al. Risk indicators for dystocia in low-risk nulliparous women: a study on lifestyle and anthropometrical factors. J Obstet Gynaecol 2010;30(1):25-9. DOI: 10.3109/01443610903276417. PMID: 20121499.

Levett KM, Smith CA, Dahlen HG, et al. Acupuncture and acupressure for pain management in labour and birth: a critical narrative review of current systematic review evidence. Complement Ther Med 2014;22(3):523-40. DOI: 10.1016/j.ctim.2014.03.011. PMID: 24906592.

Liu YH, Chang MY and Chen CH. Effects of music therapy on labour pain and anxiety in Taiwanese first-time mothers. J Clin Nurs 2010;19(7-8):1065-72. DOI: 10.1111/j.13652702.2009.03028.x. PMID: 20492051.

Mantha VR, Vallejo MC, Ramesh V, et al. Maternal and cord serum cytokine changes with continuous and intermittent labor epidural analgesia: a randomized study. ScientificWorldJournal 2012;2012:607938. DOI: 10.1100/2012/607938. PMID: 22629160.

Mollart LJ, Adam J and Foureur M. Impact of acupressure on onset of labour and labour duration: A systematic review. Women Birth 2015;28(3):199-206. DOI:

10.1016/j.wombi.2015.03.007. PMID: 25911499.

Mozurkewich EL and Wolf FM. Near-infrared spectroscopy for fetal assessment during labour. Cochrane Database of Systematic Reviews 2009;(4).

Mucuk S, Baser M and Ozkan T. Effects of noninvasive electroacupuncture on labor pain, adrenocorticotropic hormone, and cortisol. Altern Ther Health Med 2013;19(3):26-30. PMID: 23709457.

Namazi M, Amir Ali Akbari S, Mojab F, et al. Aromatherapy with citrus aurantium oil and anxiety during the first stage of labor. Iran Red Crescent Med J 2014;16(6):e18371. DOI: 10.5812/ircmj.18371. PMID: 25068058.

Namazi M, Amir Ali Akbari S, Mojab F, et al. Effects of citrus aurantium (bitter orange) on the severity of first-stage labor pain. Iran J Pharm Res 2014;13(3):1011-8. PMID: 25276203.

Nystedt A and Hildingsson I. Diverse definitions of prolonged labour and its consequences with sometimes subsequent inappropriate treatment. BMC Pregnancy Childbirth 2014;14:233. DOI: 10.1186/1471-2393-14-233. PMID: 25031035.

Ozyurt S, Aksoy H, Gedikbasi A, et al. Screening occult anal sphincter injuries in primigravid women after vaginal delivery with transperineal use of vaginal probe: a prospective, randomized controlled trial. Arch Gynecol Obstet 2015;292(4):853-9. DOI: 10.1007/s00404-015-3708-z.

PMID: 25859828. 
Ravangard R, Basiri A, Sajjadnia Z, et al. Comparison of the Effects of Using Physiological Methods and Accompanying a Doula in Deliveries on Nulliparous Women's Anxiety and Pain: A Case Study in Iran. Health Care Manager 2017;36(4):372-379. DOI:

10.1097/HCM.0000000000000188. PMID: 126065303.

Sado M, Ota E, Stickley A, et al. Hypnosis during pregnancy, childbirth, and the postnatal period for preventing postnatal depression. Cochrane Database Syst Rev 2012;6:Cd009062. DOI: 10.1002/14651858.CD009062.pub2. PMID: 22696381.

Samadi P, Alipour Z and Lamyian M. The Effect of Acupressure at Spleen 6 Acupuncture Point on the Anxiety Level and Sedative and Analgesics Consumption of Women during Labor: A Randomized, Single-blind Clinical Trial. Iran J Nurs Midwifery Res 2018;23(2):87-92. DOI: 10.4103/ijnmr.IJNMR_199_16. PMID: 29628954.

Sehhatie-Shafaie F, Kazemzadeh R, Amani F, et al. The effect of acupressure on sanyinjiao and hugo points on labor pain in nulliparous women: a randomized clinical trial. J Caring Sci 2013;2(2):123-9. DOI: 10.5681/jcs.2013.015. PMID: 25276718.

Sekhavat L and Behdad S. The Effects of Meperidine Analgesia during Labor on Fetal Heart Rate. Int J Biomed Sci 2009;5(1):59-62. PMID: 23675116.

Selva Olid A, Martinez Zapata MJ, Sola I, et al. Efficacy and Safety of Needle Acupuncture for Treating Gynecologic and Obstetric Disorders: An Overview. Med Acupunct 2013;25(6):386397. DOI: 10.1089/acu.2013.0976. PMID: 24761184.

Simavli S, Gumus I, Kaygusuz I, et al. Effect of music on labor pain relief, anxiety level and postpartum analgesic requirement: a randomized controlled clinical trial. Gynecol Obstet Invest 2014;78(4):244-50. DOI: 10.1159/000365085. PMID: 25227477.

Smith CA, Levett KM, Collins CT, et al. Massage, reflexology and other manual methods for pain management in labour. Cochrane Database Syst Rev 2012;2:Cd009290. DOI: 10.1002/14651858.CD009290.pub2. PMID: 22336862.

Stocki D, Matot I, Einav S, et al. A randomized controlled trial of the efficacy and respiratory effects of patient-controlled intravenous remifentanil analgesia and patient-controlled epidural analgesia in laboring women. Anesth Analg 2014;118(3):589-97. DOI:

10.1213/ANE.0b013e3182a7cd1b. PMID: 24149580.

Taghinejad H, Delpisheh A and Suhrabi Z. Comparison between massage and music therapies to relieve the severity of labor pain. Womens Health (Lond Engl) 2010;6(3):377-81. DOI: 10.2217/whe.10.15. PMID: 20426604.

Xing JJ, Liu XF, Xiong XM, et al. Effects of combined spinal-epidural analgesia during labor on postpartum electrophysiological function of maternal pelvic floor muscle: A randomized controlled trial. PLoS ONE 2015;10(9). 
Zahalka N, Sadan O, Malinger G, et al. Comparison of transvaginal sonography with digital examination and transabdominal sonography for the determination of fetal head position in the second stage of labor. American Journal of Obstetrics \& Gynecology 2005;193(2):381-386.

\section{Timing or Setting Not Applicable:}

Karaçam Z, Ekmen H and Çalişir H. The Use of Perineal Massage in the Second Stage of Labor and Follow-Up of Postpartum Perineal Outcomes. Health Care for Women International 2012;33(8):697-718. DOI: 10.1080/07399332.2012.655385 


\section{Appendix E. Characteristics of Included Studies}

Table E-1 shows the study characteristics for the included studies. For full study citations, please refer to the report's main reference list.

Table E-1. Characteristics of included RCTs and observational studies, KQs 1-9

\begin{tabular}{|c|c|c|c|c|c|c|}
\hline $\begin{array}{l}\text { Study } \\
\text { Acronym } \\
\text { Key Question } \\
\text { Companion } \\
\text { Article }\end{array}$ & $\begin{array}{l}\text { Study Design } \\
\text { Geographic } \\
\text { Location } \\
\mathrm{N} \text { enrolled } \\
\mathrm{N} \text { completed }\end{array}$ & $\begin{array}{l}\text { Age Data (Years } \\
\text { Unless Specified) }\end{array}$ & $\begin{array}{l}\text { Stage of Labor at Entry } \\
\text { Study Definition of Labor } \\
\text { Parity in Population }\end{array}$ & Comparisons & $\begin{array}{c}\text { Outcomes } \\
\text { (Subgroup Analyzed) }\end{array}$ & Quality \\
\hline $\begin{array}{l}\text { Abdullah, } \\
2010^{118} \\
\text { KQ } 2\end{array}$ & $\begin{array}{l}\text { RCT } \\
\text { Middle East } \\
\text { N enrolled: } \\
200 \text { patients } \\
\text { N completed: } \\
200 \text { patients }\end{array}$ & $\begin{array}{l}\text { Total } \\
\text { Mean: } 24.69 \\
\text { SD: } 3.03\end{array}$ & $\begin{array}{l}\text { Stage of Labor at Entry: First } \\
\text { stage active, Second stage } \\
\text { Study's Definition of Labor: } \\
\text { First stage active }(4-10 \mathrm{~cm}) \text {, } \\
\text { Second stage }(10 \mathrm{~cm}- \\
\text { delivery) } \\
\text { Parity: Nulliparous }\end{array}$ & $\begin{array}{l}\text { Artificial rupture of membranes } \\
\text { and prophylactic antibiotic } \\
\text { vs. } \\
\text { Spontaneous rupture of } \\
\text { membranes }\end{array}$ & $\begin{array}{l}\text { Duration of Labor; } \\
\text { Mode of delivery; } \\
\text { Maternal Trauma to the } \\
\text { Pelvic Floor } \\
\text { (Parity) }\end{array}$ & Fair \\
\hline $\begin{array}{l}\text { Abrao, 2009196 } \\
\text { KQ } 4\end{array}$ & $\begin{array}{l}\text { RCT } \\
\text { Latin America } \\
\text { N enrolled: } \\
91 \text { patients } \\
\text { N completed: } \\
77 \text { patients }\end{array}$ & $\begin{array}{l}\text { Arm } 1 \\
\text { Mean: } 23.95 \\
\text { SD: } 5.99 \\
\text { Arm } 2 \\
\text { Mean: } 23.61 \\
\text { SD: } 6.84\end{array}$ & $\begin{array}{l}\text { Stage of Labor at Entry: First } \\
\text { stage latent, first stage } \\
\text { active } \\
\text { Study's Definition of Labor: } \\
\text { First stage latent (<4 cm } \\
\text { dilation), first stage active (4- } \\
10 \mathrm{~cm} \text { dilation) } \\
\text { Parity: Nulliparous, Mixed } \\
\text { Parity }\end{array}$ & $\begin{array}{l}\text { Epidural } \\
\text { vs. } \\
\text { Combined Spinal Epidural } \\
\text { (CSE) }\end{array}$ & $\begin{array}{l}\text { Mode of delivery; } \\
\text { Abnormal fetal heart } \\
\text { rate tracing }\end{array}$ & Fair \\
\hline
\end{tabular}




\begin{tabular}{|c|c|c|c|c|c|c|}
\hline $\begin{array}{c}\text { Study } \\
\text { Acronym } \\
\text { Key Question } \\
\text { Companion } \\
\text { Article }\end{array}$ & $\begin{array}{l}\text { Study Design } \\
\text { Geographic } \\
\text { Location } \\
\text { N enrolled } \\
\mathbf{N} \text { completed }\end{array}$ & $\begin{array}{l}\text { Age Data (Years } \\
\text { Unless Specified) }\end{array}$ & $\begin{array}{l}\text { Stage of Labor at Entry } \\
\text { Study Definition of Labor } \\
\text { Parity in Population }\end{array}$ & Comparisons & $\begin{array}{c}\text { Outcomes } \\
\text { (Subgroup Analyzed) }\end{array}$ & Quality \\
\hline $\begin{array}{l}\text { Ajadi, } 2006^{116} \\
\text { KQ } 2\end{array}$ & $\begin{array}{l}\text { RCT } \\
\text { Africa } \\
\text { N enrolled: } \\
128 \text { patients } \\
\text { N completed: } \\
128 \text { patients }\end{array}$ & $\begin{array}{l}\text { Arm } 1 \\
\text { Mean: } 29.4 \\
\text { SD: } 5.7 \\
\text { Arm } 2 \\
\text { Mean: } 28.6 \\
\text { SD: } 6.9\end{array}$ & $\begin{array}{l}\text { Stage of Labor at Entry: First } \\
\text { stage active } \\
\text { Study's Definition of Labor: } \\
\text { First stage active }(4-10 \mathrm{~cm} \\
\text { dilation) } \\
\text { Parity: Parous }\end{array}$ & $\begin{array}{l}\text { Amniotomy - Follow labor with } \\
\text { partogram, and augment with } \\
\text { oxytocin if needed } \\
\text { vs. } \\
\text { Control - follow with a } \\
\text { partogram and augment if } \\
\text { needed with oxytocin. If this did } \\
\text { not result in progress, then } \\
\text { amniotomy was performed after } \\
1 \mathrm{~h} \text { more }\end{array}$ & $\begin{array}{l}\text { Mode of delivery; } \\
\text { Duration of Labor }\end{array}$ & Good \\
\hline $\begin{array}{l}\text { Akbarzadeh, } \\
2015^{70} \\
\text { KQ } 3 \\
\text { Companion: } \\
\text { Akbarzadeh, } \\
2015^{71}\end{array}$ & $\begin{array}{l}\text { RCT } \\
\text { Middle East } \\
\text { N enrolled: } \\
150 \text { patients } \\
\text { N completed: } \\
150 \text { patients }\end{array}$ & $\begin{array}{l}\text { Total } \\
\text { Min. age: } 18 \\
\text { Max. age: } 35\end{array}$ & $\begin{array}{l}\text { Stage of Labor at Entry: First } \\
\text { stage active } \\
\text { Study's Definition of Labor: } 4 \\
\text { cm dilation and at least } 2-3 \\
\text { contractions in } 10 \text { min } \\
\text { Parity: First or Second } \\
\text { Pregnancy }\end{array}$ & $\begin{array}{l}\text { Supportive care - Doula } \\
\text { provided emotional support, } \\
\text { information, massage and help } \\
\text { in changing position } \\
\text { vs. } \\
\text { Acupressure - Pressure applied } \\
\text { at BL32 acupoint during } \\
\text { contractions. } \\
\text { vs. } \\
\text { Usual care - routine care, not } \\
\text { further described }\end{array}$ & Duration of Labor & Poor \\
\hline $\begin{array}{l}\text { Albers, } 2005^{149} \\
\text { KQ } 3\end{array}$ & $\begin{array}{l}\text { RCT } \\
\text { U.S. } \\
\text { N enrolled: } \\
\text { 1,211 patients } \\
\text { N completed: } \\
1,211 \text { patients }\end{array}$ & $\begin{array}{l}\text { Arm } 1 \\
\text { Mean: } 24.9 \\
\text { SD: } 5.3 \\
\text { Arm } 2 \\
\text { Mean: } 24.5 \\
\text { SD: } 5.2 \\
\text { Arm } 3 \\
\text { Mean: } 24.5 \\
\text { SD: } 5.1\end{array}$ & $\begin{array}{l}\text { Stage of Labor at Entry: } \\
\text { Second stage } \\
\text { Study's Definition of Labor: } \\
\text { Active fetal descent or fetal } \\
\text { head visible with a uterine } \\
\text { contraction. } \\
\text { Parity: Nulliparous, Parous }\end{array}$ & $\begin{array}{l}\text { Warm compresses applied to } \\
\text { perineum continuously } \\
\text { vs. } \\
\text { Perineal massage with lubricant } \\
\text { was gentle, slow massage, with } \\
2 \text { fingers of the midwife's gloved } \\
\text { hand moving from side to side } \\
\text { just inside the patient's vagina. } \\
\text { vs. } \\
\text { No touch meant no touching of } \\
\text { the woman's perineum during } \\
\text { the second stage until crowning } \\
\text { of the infant's } \\
\text { head }\end{array}$ & $\begin{array}{l}\text { Duration of Labor; } \\
\text { Mode of delivery; } \\
\text { Maternal Trauma to the } \\
\text { Pelvic Floor; } \\
\text { Abnormal fetal heart } \\
\text { rate tracing }\end{array}$ & Good \\
\hline
\end{tabular}




\begin{tabular}{|c|c|c|c|c|c|c|}
\hline $\begin{array}{c}\text { Study } \\
\text { Acronym } \\
\text { Key Question } \\
\text { Companion } \\
\text { Article } \\
\end{array}$ & $\begin{array}{l}\text { Study Design } \\
\text { Geographic } \\
\text { Location } \\
\text { N enrolled } \\
\text { N completed }\end{array}$ & $\begin{array}{l}\text { Age Data (Years } \\
\text { Unless Specified) }\end{array}$ & $\begin{array}{l}\text { Stage of Labor at Entry } \\
\text { Study Definition of Labor } \\
\text { Parity in Population }\end{array}$ & Comparisons & $\begin{array}{c}\text { Outcomes } \\
\text { (Subgroup Analyzed) }\end{array}$ & Quality \\
\hline $\begin{array}{l}\text { Allameh, } \\
2015^{126} \\
\text { KQ } 3\end{array}$ & $\begin{array}{l}\text { RCT } \\
\text { Middle East } \\
\text { N enrolled: } \\
85 \text { patients } \\
\text { N completed: } \\
\text { Unclear }\end{array}$ & $\begin{array}{l}\text { Total } \\
\text { Min. age: } 18 \\
\text { Max. age: } 35\end{array}$ & $\begin{array}{l}\text { Stage of Labor at Entry: First } \\
\text { stage active } \\
\text { Study's Definition of Labor: } \\
4-5 \mathrm{~cm} \text { dilatation } \\
\text { Parity: First or Second } \\
\text { Pregnancy }\end{array}$ & $\begin{array}{l}\text { Acupuncture -- } 2 \text { needles in } \mathrm{LI} 4 \\
\text { point in two hands and in ST-36 } \\
\text { points in two legs, left in for 20- } \\
30 \text { min } \\
\text { vs. } \\
\text { Usual care - oral } \\
\text { communication and no } \\
\text { painkiller. }\end{array}$ & $\begin{array}{l}\text { Duration of Labor; } \\
\text { Maternal Hemorrhage; } \\
\text { Mode of delivery }\end{array}$ & Poor \\
\hline $\begin{array}{l}\text { Asadi, } 2015^{125} \\
\text { KQ } 3\end{array}$ & $\begin{array}{l}\text { RCT } \\
\text { Middle East } \\
\text { N enrolled: } \\
71 \text { patients } \\
\mathrm{N} \text { completed: } \\
63 \text { patients }\end{array}$ & $\begin{array}{l}\text { Total } \\
\text { Mean: } 26.1 \\
\text { SD: } 4\end{array}$ & $\begin{array}{l}\text { Stage of Labor at Entry: First } \\
\text { stage active } \\
\text { Study's Definition of Labor: } \\
\geq 4 \mathrm{~cm} \text { dilation and } 3+ \\
\text { contractions lasting }>40 \mathrm{~s} \\
\text { within } 10 \text { min } \\
\text { Parity: Nulliparous }\end{array}$ & $\begin{array}{l}\text { Acupuncture - Needles at LI-4 } \\
\text { and SP-6 for } 20 \text { min } \\
\text { Manipulated until DeQi } \\
\text { sensation, manipulated every } 5 \\
\text { min } \\
\text { vs. } \\
\text { Sham acupuncture - Superficial } \\
\text { contact of needles at sites other } \\
\text { than correct points for } \\
\text { acupuncture. Shaken every } 5 \\
\text { min }\end{array}$ & Duration of Labor & Fair \\
\hline $\begin{array}{l}\text { Bhagwat, } \\
2008^{202} \\
\text { KQ } 4\end{array}$ & $\begin{array}{l}\text { RCT } \\
\text { Asia } \\
\text { N enrolled: } \\
60 \text { patients } \\
\mathrm{N} \text { completed: } \\
59 \text { patients }\end{array}$ & $\begin{array}{l}\text { Arm } 1 \\
\text { Mean: } 24.15 \\
\text { SD: } 1.872 \\
\text { Arm } 2 \\
\text { Mean: } 23.30 \\
\text { SD: } 2.130\end{array}$ & $\begin{array}{l}\text { Stage of Labor at Entry: First } \\
\text { stage active } \\
\text { Study's Definition of Labor: } \\
4-5 \mathrm{~cm} \text { dilatation } \\
\text { Parity: Nulliparous }\end{array}$ & $\begin{array}{l}\text { Epidural } \\
\text { vs. } \\
\text { Combined Spinal Epidural } \\
\text { (CSE) }\end{array}$ & $\begin{array}{l}\text { Duration of Labor; } \\
\text { Mode of delivery; } \\
\text { Neonatal Birth Trauma } \\
\text { (Parity) }\end{array}$ & Good \\
\hline
\end{tabular}




\begin{tabular}{|c|c|c|c|c|c|c|}
\hline $\begin{array}{l}\text { Study } \\
\text { Acronym } \\
\text { Key Question } \\
\text { Companion } \\
\text { Article } \\
\end{array}$ & $\begin{array}{l}\text { Study Design } \\
\text { Geographic } \\
\text { Location } \\
\text { N enrolled } \\
\text { N completed } \\
\end{array}$ & $\begin{array}{l}\text { Age Data (Years } \\
\text { Unless Specified) }\end{array}$ & $\begin{array}{l}\text { Stage of Labor at Entry } \\
\text { Study Definition of Labor } \\
\text { Parity in Population }\end{array}$ & Comparisons & $\begin{array}{c}\text { Outcomes } \\
\text { (Subgroup Analyzed) }\end{array}$ & Quality \\
\hline $\begin{array}{l}\text { Bloom, 200672 } \\
\text { KQ } 9 \\
\text { Companion: } \\
\text { Schaffer, } \\
2005^{73}\end{array}$ & $\begin{array}{l}\text { RCT } \\
\text { U.S. } \\
\text { N enrolled: } \\
325 \text { patients } \\
\text { N completed: } \\
320 \text { patients }\end{array}$ & $\begin{array}{l}\text { Arm } 1 \\
\text { Mean: } 21.1 \\
\text { SD: } 3.7 \\
\text { Arm } 2 \\
\text { Mean: } 21.1 \\
\text { SD: } 3.7\end{array}$ & $\begin{array}{l}\text { Stage of Labor at Entry: } \\
\text { Second stage } \\
\text { Study's Definition of Labor: } \\
\text { Second stage (full dilation - } \\
\text { delivery) } \\
\text { Parity: Nulliparous }\end{array}$ & $\begin{array}{l}\text { Coach patient to pull back on } \\
\text { both knees and tuck her chin } \\
\text { while the provider or partner } \\
\text { supports the legs } \\
\text { vs. } \\
\text { "Do what comes natural" }\end{array}$ & $\begin{array}{l}\text { Duration of Labor; } \\
\text { Mode of delivery; } \\
\text { Maternal Trauma to the } \\
\text { Pelvic Floor; } \\
\text { Neonatal acidemia; } \\
\text { Neonatal Respiratory } \\
\text { distress; } \\
\text { Neonatal } \\
\text { infection/sepsis; } \\
\text { Long-term neonatal } \\
\text { health } \\
\text { (Parity) }\end{array}$ & Good \\
\hline $\begin{array}{l}\text { Bolbol- } \\
\text { Haghighi, } \\
2016^{166} \\
\text { KQ } 3\end{array}$ & $\begin{array}{l}\text { RCT } \\
\text { Middle East } \\
\text { N enrolled: } \\
100 \text { patients } \\
\text { N completed: } \\
100 \text { patients } \\
\end{array}$ & $\begin{array}{l}\text { Total } \\
\text { Mean: } 24.63 \\
\text { SD: } 5.02\end{array}$ & $\begin{array}{l}\text { Stage of Labor at Entry: } \\
\text { Unclear/NR } \\
\text { Study's Definition of Labor: } \\
\text { Unclear/NR } \\
\text { Parity: Mixed Parity }\end{array}$ & $\begin{array}{l}\text { Massage Therapy } \\
\text { vs. } \\
\text { Control group }\end{array}$ & $\begin{array}{l}\text { Duration of Labor; } \\
\text { Mode of delivery }\end{array}$ & Good \\
\hline $\begin{array}{l}\text { Bruggemann, } \\
2007^{152} \\
\text { KQ } 3\end{array}$ & $\begin{array}{l}\text { RCT } \\
\text { Latin America } \\
\text { N enrolled: } \\
212 \text { patients } \\
\mathrm{N} \text { completed: } \\
212 \text { patients } \\
\end{array}$ & $\begin{array}{l}\text { Arm } 1 \\
\text { Mean: } 20.6 \\
\text { Arm } 2 \\
\text { Mean: } 20.1\end{array}$ & $\begin{array}{l}\text { Stage of Labor at Entry: First } \\
\text { stage active } \\
\text { Study's Definition of Labor: } \\
3-6 \mathrm{~cm} \text { cervical dilation } \\
\text { Parity: Nulliparous }\end{array}$ & $\begin{array}{l}\text { Presence of a chosen } \\
\text { companion during labor and } \\
\text { delivery } \\
\text { vs. } \\
\text { No companion support }\end{array}$ & $\begin{array}{l}\text { Duration of Labor; } \\
\text { Mode of delivery; } \\
\text { Abnormal fetal heart } \\
\text { rate tracing } \\
\text { (Parity) }\end{array}$ & Good \\
\hline $\begin{array}{l}\text { Cahill, } 2018^{227} \\
\text { KQ } 9\end{array}$ & $\begin{array}{l}\text { RCT } \\
\text { U.S. } \\
\text { N enrolled: } \\
\text { 2,414 patients } \\
\text { N completed: } \\
\text { 2,404 patients }\end{array}$ & $\begin{array}{l}\text { Arm } 1 \\
\text { Mean: } 26.5 \\
\text { SD: } 5.9 \\
\text { Arm } 2 \\
\text { Mean: } 26.6 \\
\text { SD: } 6.2\end{array}$ & $\begin{array}{l}\text { Stage of Labor at Entry: Full } \\
\text { cervical dilation }(10 \mathrm{~cm}) \\
\text { Study's Definition of Labor: } \\
\text { Full cervical dilation }(10 \mathrm{~cm}) \\
\text { Parity: Nulliparous }\end{array}$ & $\begin{array}{l}\text { Immediate pushing } \\
\text { vs. } \\
\text { Delayed pushing }\end{array}$ & $\begin{array}{l}\text { Duration of Labor; } \\
\text { Mode of delivery }\end{array}$ & Good \\
\hline
\end{tabular}




\begin{tabular}{|c|c|c|c|c|c|c|}
\hline $\begin{array}{l}\text { Study } \\
\text { Acronym } \\
\text { Key Question } \\
\text { Companion } \\
\text { Article } \\
\end{array}$ & $\begin{array}{l}\text { Study Design } \\
\text { Geographic } \\
\text { Location } \\
\text { N enrolled } \\
\text { N completed } \\
\end{array}$ & $\begin{array}{l}\text { Age Data (Years } \\
\text { Unless Specified) }\end{array}$ & $\begin{array}{l}\text { Stage of Labor at Entry } \\
\text { Study Definition of Labor } \\
\text { Parity in Population }\end{array}$ & Comparisons & $\begin{array}{c}\text { Outcomes } \\
\text { (Subgroup Analyzed) }\end{array}$ & Quality \\
\hline $\begin{array}{l}\text { Chaichian, } \\
2009^{143} \\
\text { KQ } 3\end{array}$ & $\begin{array}{l}\text { RCT } \\
\text { Middle East } \\
\text { N enrolled: } \\
106 \text { patients } \\
\text { N completed: } \\
106 \text { patients }\end{array}$ & $\begin{array}{l}\text { Arm } 1 \\
\text { Mean: } 26.4 \\
\text { SD: } 5.9 \\
\text { Arm } 2 \\
\text { Mean: } 27.1 \\
\text { SD: } 5.9\end{array}$ & $\begin{array}{l}\text { Stage of Labor at Entry: } \\
\text { Unclear/NR } \\
\text { Study's Definition of Labor: } \\
\text { Unclear/NR } \\
\text { Parity: Nulliparous, Parous }\end{array}$ & $\begin{array}{l}\text { Water birth - Labor and delivery } \\
\text { in standardized warm water } \\
\text { pools } \\
\text { vs. } \\
\text { Control - Conventional delivery } \\
\text { method at the hospital }\end{array}$ & $\begin{array}{l}\text { Mode of delivery; } \\
\text { Duration of Labor }\end{array}$ & Fair \\
\hline $\begin{array}{l}\text { Cheng, } 2010^{86} \\
\text { KQ } 1\end{array}$ & $\begin{array}{l}\text { Observational } \\
\text { U.S. } \\
\text { N enrolled: } \\
\text { 10,661 patients } \\
\text { N completed: } \\
\text { 10,661 patients }\end{array}$ & $\begin{array}{l}\text { Total } \\
<35 \text { yrs }(9,006) \\
\geq 35 \text { yrs } \\
(1,640)\end{array}$ & $\begin{array}{l}\text { Stage of Labor at Entry: First } \\
\text { stage latent, first stage } \\
\text { active } \\
\text { Study's Definition of Labor: } \\
\text { Onset of labor defined as } \\
\text { regular, painful contractions } \\
\text { occurring at least every } 5 \\
\text { min or three contractions in } \\
10 \text { min and cervical change. } \\
\text { Parity: Nulliparous, Mixed } \\
\text { Parity }\end{array}$ & $\begin{array}{l}\text { Duration of First stage of labor } \\
<5 \% \\
\text { vs. } \\
\text { Duration of the First stage of } \\
\text { labor } 5-95 \% \\
\text { vs. } \\
\text { Duration of the First stage of } \\
\text { labor }>95 \%\end{array}$ & $\begin{array}{l}\text { Maternal Trauma to the } \\
\text { Pelvic Floor; } \\
\text { Maternal Infection; } \\
\text { Maternal Hemorrhage; } \\
\text { Mode of delivery; } \\
\text { Neonatal acidemia; } \\
\text { Meconium aspiration } \\
\text { syndrome; } \\
\text { Neonatal } \\
\text { infection/sepsis; } \\
\text { Neonatal Shoulder } \\
\text { dystocia; } \\
\text { Neonatal Birth trauma } \\
\text { (Parity) }\end{array}$ & Good \\
\hline $\begin{array}{l}\text { Coco, } 2010^{142} \\
\text { KQ } 3\end{array}$ & $\begin{array}{l}\text { RCT } \\
\text { U.S. } \\
\text { N enrolled: } \\
80 \text { patients } \\
\text { N completed: } \\
80 \text { patients }\end{array}$ & $\begin{array}{l}\text { Arm } 1 \\
\text { Mean: } 22.7 \\
\text { SD: } 4.3 \\
\text { Arm } 2 \\
\text { Mean: } 20.5 \\
\text { SD: } 4.3\end{array}$ & $\begin{array}{l}\text { Stage of Labor at Entry: } \\
\text { active } \\
\text { Study's Definition of Labor: } \\
\text { Spontaneous active labor (2- } \\
5 \mathrm{~cm} \text { ) } \\
\text { Parity: Nulliparous }\end{array}$ & $\begin{array}{l}\text { IV fluid of lactated Ringer's } \\
\text { solution at } 250 \mathrm{~mL} / \mathrm{hr} \text { plus } \\
\text { unrestricted access to oral fluids } \\
\text { vs. } \\
\text { Usual care - lactated Ringer's } \\
\text { solution for medical indications } \\
\text { at the discretion of the provider } \\
\text { plus unrestricted access to oral } \\
\text { fluids }\end{array}$ & $\begin{array}{l}\text { Mode of delivery; } \\
\text { Duration of Labor }\end{array}$ & Good \\
\hline
\end{tabular}




\begin{tabular}{|c|c|c|c|c|c|c|}
\hline $\begin{array}{c}\text { Study } \\
\text { Acronym } \\
\text { Key Question } \\
\text { Companion } \\
\text { Article } \\
\end{array}$ & $\begin{array}{l}\text { Study Design } \\
\text { Geographic } \\
\text { Location } \\
\text { N enrolled } \\
\text { N completed } \\
\end{array}$ & $\begin{array}{l}\text { Age Data (Years } \\
\text { Unless Specified) }\end{array}$ & $\begin{array}{l}\text { Stage of Labor at Entry } \\
\text { Study Definition of Labor } \\
\text { Parity in Population }\end{array}$ & Comparisons & $\begin{array}{c}\text { Outcomes } \\
\text { (Subgroup Analyzed) }\end{array}$ & Quality \\
\hline $\begin{array}{l}\text { Dahlen, } \\
2007^{160} \\
\text { KQ } 3\end{array}$ & $\begin{array}{l}\text { RCT } \\
\text { Australia/NZ } \\
\text { N enrolled: } \\
717 \text { patients } \\
\text { N completed: } \\
599 \text { patients }\end{array}$ & $\begin{array}{l}\text { Arm } 1 \\
\text { Mean: } 27 \\
\text { SD: } 5.5 \\
\text { Arm } 2 \\
\text { Mean: } 27.2 \\
\text { SD: } 4.9\end{array}$ & $\begin{array}{l}\text { Stage of Labor at Entry: Late } \\
\text { second stage } \\
\text { Study's Definition of Labor: } \\
\text { Baby's head began to } \\
\text { distend the perineum. } \\
\text { Parity: Nulliparous }\end{array}$ & $\begin{array}{l}\text { Warm pack applied to perineum } \\
\text { at second stage of labor } \\
\text { vs. } \\
\text { Standard Care }\end{array}$ & $\begin{array}{l}\text { Duration of Labor; } \\
\text { Mode of delivery; } \\
\text { Maternal Trauma to the } \\
\text { Pelvic Floor; } \\
\text { Maternal Pelvic floor } \\
\text { dysfunction } \\
\text { (Parity) }\end{array}$ & Good \\
\hline $\begin{array}{l}\text { Darsareh, } \\
2018^{179} \\
\text { KQ } 3\end{array}$ & $\begin{array}{l}\text { RCT } \\
\text { Middle East } \\
\text { N enrolled: } \\
180 \text { patients } \\
\text { N completed: } \\
180 \text { patients }\end{array}$ & $\begin{array}{l}\text { Arm } 1 \\
\text { Mean: } 23 \\
\text { SD: } 2.08 \\
\text { Arm } 2 \\
\text { Mean: } 22 \\
\text { SD: } 2.87\end{array}$ & $\begin{array}{l}\text { Stage of Labor at Entry: First } \\
\text { stage active } \\
\text { Study's Definition of Labor: } \\
\text { First stage active ( } 4 \mathrm{~cm} \\
\text { dilation) } \\
\text { Parity: Nulliparous }\end{array}$ & $\begin{array}{l}\text { Water immersion during First } \\
\text { stage of active labor } \\
\text { vs. } \\
\text { Routine care }\end{array}$ & $\begin{array}{l}\text { Duration of Labor; } \\
\text { Mode of delivery; } \\
\text { Cesarean delivery; } \\
\text { Operative vaginal } \\
\text { delivery; } \\
\text { Maternal Trauma to the } \\
\text { Pelvic Floor; } \\
\text { Neonatal Respiratory } \\
\text { distress; Neonatal NICU } \\
\text { admissions; } \\
\text { Maternal satisfaction }\end{array}$ & Fair \\
\hline $\begin{array}{l}\text { de Orange, } \\
2011^{76} \\
\text { KQ } 4 \\
\text { Companion: } \\
\text { Orange, } 2012^{77}\end{array}$ & $\begin{array}{l}\text { RCT } \\
\text { Latin America } \\
\text { N enrolled: } \\
70 \text { patients } \\
\text { N completed: } \\
70 \text { patients }\end{array}$ & $\begin{array}{l}\text { Arm } 1 \\
\text { Mean: } 22.57 \\
\text { Arm } 2 \\
\text { Mean: } 21.65\end{array}$ & $\begin{array}{l}\text { Stage of Labor at Entry: } \\
\text { Entered in study at dilation } \\
3-6 \mathrm{~cm} \\
\text { Study's Definition of Labor: } \\
\text { First stage latent (<4 cm } \\
\text { dilation), first stage active (4- } \\
10 \mathrm{~cm} \text { dilation) } \\
\text { Parity: Nulliparous, Mixed } \\
\text { Parity }\end{array}$ & $\begin{array}{l}\text { Epidural plus Combined Spinal } \\
\text { Epidural (CSE) } \\
\text { vs. } \\
\text { Usual care }\end{array}$ & $\begin{array}{l}\text { Abnormal fetal heart } \\
\text { rate tracing; } \\
\text { Mode of delivery; } \\
\text { Duration of Labor; } \\
\text { Parental preferences }\end{array}$ & Good \\
\hline
\end{tabular}




\begin{tabular}{|c|c|c|c|c|c|c|}
\hline $\begin{array}{c}\text { Study } \\
\text { Acronym } \\
\text { Key Question } \\
\text { Companion } \\
\text { Article } \\
\end{array}$ & $\begin{array}{l}\text { Study Design } \\
\text { Geographic } \\
\text { Location } \\
\text { N enrolled } \\
\text { N completed }\end{array}$ & $\begin{array}{l}\text { Age Data (Years } \\
\text { Unless Specified) }\end{array}$ & $\begin{array}{l}\text { Stage of Labor at Entry } \\
\text { Study Definition of Labor } \\
\text { Parity in Population }\end{array}$ & Comparisons & $\begin{array}{c}\text { Outcomes } \\
\text { (Subgroup Analyzed) }\end{array}$ & Quality \\
\hline $\begin{array}{l}\text { Dencker, } \\
2009^{74} \\
\text { KQ } 7 \\
\text { Companion: } \\
\text { Bergqvist, } \\
2012^{75}\end{array}$ & $\begin{array}{l}\text { RCT } \\
\text { UK/Europe } \\
\text { N enrolled: } \\
630 \text { patients } \\
\text { N completed: } \\
630 \text { patients }\end{array}$ & $\begin{array}{l}\text { Arm } 1 \\
\text { Mean: } 28.4 \\
\text { SD: } 4.4 \\
\text { Arm } 2 \\
\text { Mean: } 28 \\
\text { SD: } 4.5\end{array}$ & $\begin{array}{l}\text { Stage of Labor at Entry: } \\
\text { stage active } \\
\text { Study's Definition of Labor: } \\
\text { First stage active }(4-10 \mathrm{~cm} \\
\text { dilation) } \\
\text { Parity: Nulliparous }\end{array}$ & $\begin{array}{l}\text { Labor augmentation by oxytocin } \\
\text { within } 20 \text { min of diagnosis of } \\
\text { arrest of cervical dilation } \\
\text { vs. } \\
\text { Labor augmentation by oxytocin } \\
\text { was delayed until } 3 \mathrm{~h} \text { after } \\
\text { diagnosis of arrest of cervical } \\
\text { dilation }\end{array}$ & $\begin{array}{l}\text { Maternal Trauma to the } \\
\text { Pelvic Floor; } \\
\text { Maternal Hemorrhage; } \\
\text { Mode of delivery; } \\
\text { Duration of Labor; } \\
\text { Neonatal acidemia }\end{array}$ & Fair \\
\hline $\begin{array}{l}\text { Direkvand- } \\
\text { Moghadam, } \\
2012^{136} \\
\text { KQ } 3\end{array}$ & $\begin{array}{l}\text { RCT } \\
\text { Middle East } \\
\text { N enrolled: } \\
120 \text { patients } \\
\text { N completed: } \\
120 \text { patients }\end{array}$ & $\begin{array}{l}\text { Arm } 1 \\
\text { Mean: } 25.9 \\
\text { SD: } 4.6 \\
\text { Arm } 2 \\
\text { Mean: } 25.5 \\
\text { SD: } 4.6 \\
\text { Arm } 3 \\
\text { Mean: } 25.5 \\
\text { SD: } 4.7 \\
\text { Arm } 4 \\
\text { Mean: } 25.7 \\
\text { SD: } 4.8\end{array}$ & $\begin{array}{l}\text { Stage of Labor at Entry: } \\
\text { Spontaneous active } \\
\text { Study's Definition of Labor: } \\
\text { active } 4 \text { - } 5 \mathrm{~cm} \\
\text { Parity: Nulliparous, Mixed } \\
\text { Parity }\end{array}$ & $\begin{array}{l}60 \mathrm{~mL} / \mathrm{h} \text { IV Ringer lactate } \\
\text { solution and oral fluids at will } \\
\text { vs. } \\
120 \mathrm{~mL} / \mathrm{h} \text { IV Ringer lactate } \\
\text { solution and oral fluids at will } \\
\text { vs. } \\
240 \mathrm{~mL} / \mathrm{h} \text { IV Ringer lactate } \\
\text { solution and oral fluids at will } \\
\text { vs. } \\
\text { Usual care - oral fluids at will }\end{array}$ & $\begin{array}{l}\text { Duration of Labor; Mode } \\
\text { of delivery }\end{array}$ & Fair \\
\hline $\begin{array}{l}\text { Douma, } \\
2011^{194} \\
\text { KQ } 4\end{array}$ & $\begin{array}{l}\text { RCT } \\
\text { UK/Europe } \\
\text { N enrolled: } \\
26 \text { patients } \\
\text { N completed: } \\
20 \text { patients }\end{array}$ & $\begin{array}{l}\text { Arm } 1 \\
\text { Mean: } 32.7 \\
\text { SD: } 5.9 \\
\text { Arm } 2 \\
\text { Mean: } 31.0 \\
\text { SD: } 5.2\end{array}$ & $\begin{array}{l}\text { Stage of Labor at Entry: } \\
\text { Excluded if }>5 \mathrm{~cm} \text { dilation } \\
\text { Study's Definition of Labor: } \\
\text { First stage latent ( }<4 \mathrm{~cm} \\
\text { dilation), first stage active (4- } \\
5 \mathrm{~cm} \text { dilation) } \\
\text { Parity: Nulliparous }\end{array}$ & $\begin{array}{l}\text { Epidural } \\
\text { vs. } \\
\text { Patient Controlled IV Analgesia }\end{array}$ & $\begin{array}{l}\text { Mode of delivery; } \\
\text { Duration of Labor; } \\
\text { Neonatal acidemia }\end{array}$ & Poor \\
\hline
\end{tabular}




\begin{tabular}{|c|c|c|c|c|c|c|}
\hline $\begin{array}{l}\text { Study } \\
\text { Acronym } \\
\text { Key Question } \\
\text { Companion } \\
\text { Article }\end{array}$ & $\begin{array}{l}\text { Study Design } \\
\text { Geographic } \\
\text { Location } \\
\text { N enrolled } \\
\mathrm{N} \text { completed }\end{array}$ & $\begin{array}{l}\text { Age Data (Years } \\
\text { Unless Specified) }\end{array}$ & $\begin{array}{l}\text { Stage of Labor at Entry } \\
\text { Study Definition of Labor } \\
\text { Parity in Population }\end{array}$ & Comparisons & $\begin{array}{c}\text { Outcomes } \\
\text { (Subgroup Analyzed) }\end{array}$ & Quality \\
\hline $\begin{array}{l}\text { Dy, } 2018^{212} \\
\text { KQ } 7\end{array}$ & $\begin{array}{l}\text { RCT } \\
\text { Canada } \\
\text { N enrolled: } \\
137 \text { patients } \\
\text { N completed: } \\
79 \text { patients }\end{array}$ & $\begin{array}{l}\text { Arm } 1 \\
\text { Mean: } 29.6 \\
\text { SD: } 5.2 \\
\text { Arm } 2 \\
\text { Mean: } 29.7 \\
\text { SD: } 5.1\end{array}$ & $\begin{array}{l}\text { Stage of Labor at Entry: } \\
\text { Active Stage } \\
\text { Study's Definition of Labor: } \\
\text { Active } \\
\text { labour, cervical dilatation } \\
<10 \mathrm{~cm} \\
\text { Parity: Nulliparous }\end{array}$ & $\begin{array}{l}\text { Gradual Oxytocin Titration } \\
\text { (GOT) } \\
\text { vs. } \\
\text { Accelerated Oxytocin Titration } \\
\text { (AOT) }\end{array}$ & $\begin{array}{l}\text { Duration of Labor; } \\
\text { Mode of delivery; } \\
\text { Hemorrhage; Neonatal } \\
\text { respiratory distress; } \\
\text { Neonatal NICU } \\
\text { admissions; } \\
\text { Maternal satisfaction }\end{array}$ & Fair \\
\hline $\begin{array}{l}\text { Edwards, } \\
2014^{130} \\
\text { KQ } 3\end{array}$ & $\begin{array}{l}\text { RCT } \\
\text { U.S. } \\
\text { N enrolled: } \\
324 \text { patients } \\
\text { N completed: } \\
311 \text { patients }\end{array}$ & $\begin{array}{l}\text { Arm } 1 \\
\text { Mean: } 21.9 \\
\text { SD: } 5.1 \\
\text { Arm } 2 \\
\text { Mean: } 21.3 \\
\text { SD: } 4.6 \\
\text { Arm } 3 \\
\text { Mean: } 21.7 \\
\text { SD: } 5.6\end{array}$ & $\begin{array}{l}\text { Stage of Labor at Entry: } \\
\text { Active } \\
\text { Study's Definition of Labor: } \\
\text { Active (at least } 2 \mathrm{~cm} \text { ) } \\
\text { Parity: Nulliparous }\end{array}$ & $\begin{array}{l}125 \mathrm{~mL} / \mathrm{hr} \text { IV of lactated ringers } \\
\text { with } 5 \% \text { dextrose-ice chips, } \\
\text { popsicles, hard candy } \\
\text { vs. } \\
250 \mathrm{~mL} / \mathrm{h} \text { IV of lactated ringers } \\
\text { with } 5 \% \text { dextrose-ice chips, } \\
\text { popsicles, hard candy } \\
\text { vs. } \\
25 \mathrm{~mL} / \mathrm{hr} \text { IV of lactated ringers } \\
\text { with } 5 \% \text { dextrose-oral hydration } \\
\text { ad libitum with water, Gatorade, } \\
\text { ice chips, popsicles, hard candy }\end{array}$ & $\begin{array}{l}\text { Duration of Labor; } \\
\text { Mode of delivery }\end{array}$ & Fair \\
\hline $\begin{array}{l}\text { El Hamid, } \\
2013^{162} \\
\text { KQ } 3\end{array}$ & $\begin{array}{l}\text { RCT } \\
\text { Middle East } \\
\text { N enrolled: } \\
100 \text { patients } \\
\text { N completed: } \\
100 \text { patients }\end{array}$ & $\begin{array}{l}\text { Total } \\
\text { Min. age: } 20 \\
\text { Max. age: } 30\end{array}$ & $\begin{array}{l}\text { Stage of Labor at Entry: } \\
\text { Early First stage active } \\
\text { Study's Definition of Labor: } \\
\text { 3-4cm dilation } \\
\text { Parity: Nulliparous }\end{array}$ & $\begin{array}{l}\text { Acupressure applied at sp6 } \\
\text { acupoint of both sides during } \\
\text { each uterine contraction } \\
\text { vs. } \\
\text { Routine hospital procedures - } \\
\text { Insertion of IV fluids, enema, } \\
\text { providing hygienic care, and } \\
\text { routine medical methods for } \\
\text { pain relief. }\end{array}$ & $\begin{array}{l}\text { Duration of Labor } \\
\text { (Parity) }\end{array}$ & Fair \\
\hline
\end{tabular}




\begin{tabular}{|c|c|c|c|c|c|c|}
\hline $\begin{array}{c}\text { Study } \\
\text { Acronym } \\
\text { Key Question } \\
\text { Companion } \\
\text { Article }\end{array}$ & $\begin{array}{l}\text { Study Design } \\
\text { Geographic } \\
\text { Location } \\
\text { N enrolled } \\
\text { N completed }\end{array}$ & $\begin{array}{l}\text { Age Data (Years } \\
\text { Unless Specified) }\end{array}$ & $\begin{array}{l}\text { Stage of Labor at Entry } \\
\text { Study Definition of Labor } \\
\text { Parity in Population }\end{array}$ & Comparisons & $\begin{array}{c}\text { Outcomes } \\
\text { (Subgroup Analyzed) }\end{array}$ & Quality \\
\hline $\begin{array}{l}\text { Eslamian, } \\
2006^{148} \\
\text { KQ } 3\end{array}$ & $\begin{array}{l}\text { RCT } \\
\text { Middle East } \\
\\
N \text { enrolled: } \\
300 \text { patients } \\
N \text { completed: } \\
300 \text { patients }\end{array}$ & $\begin{array}{l}\text { Arm } 1 \\
\text { Mean: } 21.6 \\
\text { SD: } 4.1 \\
\text { Arm } 2 \\
\text { Mean: } 21.79 \\
\text { SD: } 4.2\end{array}$ & $\begin{array}{l}\text { Stage of Labor at Entry: First } \\
\text { stage latent, first stage } \\
\text { active } \\
\text { Study's Definition of Labor: } \\
3-5 \mathrm{~cm} \text {, First stage latent }(<4 \\
\mathrm{cm}) \text {, First stage active (4-10 } \\
\mathrm{cm}) \\
\text { Parity: Nulliparous }\end{array}$ & $\begin{array}{l}125 \mathrm{~mL} / \mathrm{h} \text { Ringer solution IV } \\
\text { vs. } \\
250 \mathrm{~mL} / \mathrm{h} \text { Ringer solution IV }\end{array}$ & $\begin{array}{l}\text { Mode of delivery; } \\
\text { Duration of Labor } \\
\text { (Parity) }\end{array}$ & Good \\
\hline $\begin{array}{l}\text { The Epidural } \\
\text { and Position } \\
\text { Trial } \\
\text { Collaborative } \\
\text { Group, 2017 } \\
\text { KQ } 3\end{array}$ & $\begin{array}{l}\text { RCT } \\
\text { UK/Europe } \\
\text { N enrolled: } \\
\text { 3,236 patients } \\
\text { N completed: } \\
\text { 3,093 patients }\end{array}$ & $\begin{array}{l}\text { Arm } 1 \\
\text { Mean: } 28.4 \\
\text { SD: } 5.7 \\
\text { Arm } 2 \\
\text { Mean: } 28.4 \\
\text { SD: } 5.6\end{array}$ & $\begin{array}{l}\text { Stage of Labor at Entry: } \\
\text { Second stage } \\
\text { Study's Definition of Labor: } \\
\text { Cervical fully dilated of the } \\
\text { presenting part was visible } \\
\text { Parity: Nulliparous }\end{array}$ & $\begin{array}{l}\text { Upright position during second } \\
\text { stage of labor } \\
\text { vs. } \\
\text { Lying down position }\end{array}$ & $\begin{array}{l}\text { Duration of Labor; } \\
\text { Mode of delivery; } \\
\text { Cesarean delivery; } \\
\text { Operative vaginal } \\
\text { delivery; } \\
\text { Maternal Trauma to the } \\
\text { Pelvic Floor; Pelvic floor } \\
\text { dysfunction; } \\
\text { Hemorrhage; } \\
\text { Transfusion; Neonatal } \\
\text { acidemia; Neonatal } \\
\text { Respiratory distress; } \\
\text { Neonatal } \\
\text { infection/sepsis; } \\
\text { Long-term neonatal } \\
\text { health; Maternal } \\
\text { satisfaction }\end{array}$ & Good \\
\hline
\end{tabular}




\begin{tabular}{|c|c|c|c|c|c|c|}
\hline $\begin{array}{c}\text { Study } \\
\text { Acronym } \\
\text { Key Question } \\
\text { Companion } \\
\text { Article }\end{array}$ & $\begin{array}{l}\text { Study Design } \\
\text { Geographic } \\
\text { Location } \\
\text { N enrolled } \\
\text { N completed }\end{array}$ & $\begin{array}{l}\text { Age Data (Years } \\
\text { Unless Specified) }\end{array}$ & $\begin{array}{l}\text { Stage of Labor at Entry } \\
\text { Study Definition of Labor } \\
\text { Parity in Population }\end{array}$ & Comparisons & $\begin{array}{c}\text { Outcomes } \\
\text { (Subgroup Analyzed) }\end{array}$ & Quality \\
\hline $\begin{array}{l}\text { Fahdhy, } 2005^{90} \\
\text { KQ } 1\end{array}$ & $\begin{array}{l}\text { RCT } \\
\text { Asia } \\
\text { N enrolled: } \\
721 \text { patients } \\
\text { N completed: } \\
626 \text { patients }\end{array}$ & $\begin{array}{l}\text { Arm } 1 \\
\text { Mean: } 26.8 \\
\text { SD: } 5.4 \\
\text { Arm } 2 \\
\text { Mean: } 26.4 \\
\text { SD: } 4.9\end{array}$ & $\begin{array}{l}\text { Stage of Labor at Entry: First } \\
\text { stage active } \\
\text { Study's Definition of Labor: } \\
\text { Women presenting with } \\
\text { cervical dilatation of more } \\
\text { than } 8 \mathrm{~cm} \text { were excluded } \\
\text { from the study but cared for } \\
\text { according to standard } \\
\text { procedure of the Ministry of } \\
\text { Health } \\
\text { Parity: Unclear/NR }\end{array}$ & $\begin{array}{l}\text { A 2-day training program was } \\
\text { held on the use of the WHO } \\
\text { partograph for the } 10 \text { midwives } \\
\text { in the intervention group } \\
\text { vs. } \\
\text { Provide usual care to patients. } \\
\text { No partograph training was } \\
\text { provided }\end{array}$ & $\begin{array}{l}\text { Mode of delivery; } \\
\text { Maternal Hemorrhage; } \\
\text { Neonatal Respiratory } \\
\text { distress }\end{array}$ & Good \\
\hline $\begin{array}{l}\text { Fong, } 2017^{171} \\
\text { KQ } 3\end{array}$ & $\begin{array}{l}\text { RCT } \\
\text { U.S. } \\
\text { N enrolled: } \\
285 \text { patients } \\
\text { N completed: } \\
274 \text { patients }\end{array}$ & $\begin{array}{l}\text { Arm } 1 \\
\text { Mean: } 25.0 \\
\text { SD: } 5.6 \\
\text { Arm } 2 \\
\text { Mean: } 25.1 \\
\text { SD: } 5.5 \\
\text { Arm } 3 \\
\text { Mean: } 25.3 \\
\text { SD: } 5.4\end{array}$ & $\begin{array}{l}\text { Stage of Labor at Entry: First } \\
\text { stage active } \\
\text { Study's Definition of Labor: } \\
\text { First stage active }(3-5 \mathrm{~cm} \\
\text { dilation) } \\
\text { Parity: Nulliparous }\end{array}$ & $\begin{array}{l}\text { Control - Normal saline at } 250 \\
\mathrm{~mL} / \mathrm{h} \\
\text { vs. } \\
\text { High dose intravenous fluids at: } \\
5 \% \text { dextrose in normal saline at } \\
125 \mathrm{~mL} / \mathrm{h} \\
\text { vs. } \\
2.5 \% \text { dextrose in normal saline } \\
\text { at } 250 \mathrm{~mL} / \mathrm{h}\end{array}$ & $\begin{array}{l}\text { Duration of Labor; Mode } \\
\text { of delivery; Cesarean } \\
\text { delivery; Operative } \\
\text { vaginal delivery; } \\
\text { Maternal Infection } \\
\text { (chorioamnionitis); } \\
\text { Neonatal NICU } \\
\text { admissions; } \\
\text { Neonatal Respiratory } \\
\text { distress }\end{array}$ & Good \\
\hline $\begin{array}{l}\text { Frigo, } 2011^{85} \\
\text { KQ } 1\end{array}$ & $\begin{array}{l}\text { Observational } \\
\text { UK/Europe } \\
\text { N enrolled: } \\
600 \text { patients } \\
\text { N completed: } \\
545 \text { patients }\end{array}$ & $\begin{array}{l}\text { Arm } 1 \\
\text { Mean: } 31.26 \\
\text { SD: } 4.92 \\
\text { Arm } 2 \\
\text { Mean: } 30.85 \\
\text { SD: } 4.23\end{array}$ & $\begin{array}{l}\text { Stage of Labor at Entry: First } \\
\text { stage latent } \\
\text { Study's Definition of Labor: } \\
\text { All were in labor at less than } \\
4 \mathrm{~cm} \\
\text { Parity: Nulliparous }\end{array}$ & $\begin{array}{l}\text { Combined Spinal Epidural } \\
\text { (CSE) } \\
\text { vs. } \\
\text { Usual care - Epidural }\end{array}$ & Duration of Labor & Fair \\
\hline
\end{tabular}




\begin{tabular}{|c|c|c|c|c|c|c|}
\hline $\begin{array}{c}\text { Study } \\
\text { Acronym } \\
\text { Key Question } \\
\text { Companion } \\
\text { Article } \\
\end{array}$ & $\begin{array}{c}\text { Study Design } \\
\text { Geographic } \\
\text { Location } \\
\text { N enrolled } \\
\text { N completed }\end{array}$ & $\begin{array}{l}\text { Age Data (Years } \\
\text { Unless Specified) }\end{array}$ & $\begin{array}{l}\text { Stage of Labor at Entry } \\
\text { Study Definition of Labor } \\
\text { Parity in Population }\end{array}$ & Comparisons & $\begin{array}{c}\text { Outcomes } \\
\text { (Subgroup Analyzed) }\end{array}$ & Quality \\
\hline $\begin{array}{l}\text { Gallo, 2018 } \\
\text { KQ } 3\end{array}$ & $\begin{array}{l}\text { RCT } \\
\text { Latin America } \\
\text { N enrolled: } \\
286 \text { patients } \\
\mathrm{N} \text { completed: } \\
80 \text { patients }\end{array}$ & $\begin{array}{l}\text { Total } \\
\text { Min. age: } 18 \\
\text { Max. age: } 35\end{array}$ & $\begin{array}{l}\text { Stage of Labor at Entry: First } \\
\text { stage active } \\
\text { Study's Definition of Labor: } \\
4-5 \mathrm{~cm} \text { dilation } \\
\text { Parity: Primagravida }\end{array}$ & $\begin{array}{l}\text { Pelvic motion exercises using } \\
\text { Swiss ball at beginning of active } \\
\text { labor; } 40 \text { min massage along } \\
\text { path that corresponds with the } \\
\text { hypogastric plexus and } \\
\text { pudendal nerve path by } \\
\text { physiotherapist; warm shower } \\
\text { for } 40 \text { min } \\
\text { vs. } \\
\text { Usual care - routine care, not } \\
\text { further described }\end{array}$ & $\begin{array}{l}\text { Duration of Labor; Mode } \\
\text { of delivery; Cesarean } \\
\text { delivery; Operative } \\
\text { vaginal delivery; } \\
\text { Hemorrhage; } \\
\text { Trauma to the pelvic } \\
\text { floor; } \\
\text { Maternal experience; } \\
\text { Maternal satisfaction; } \\
\text { Neonatal respiratory } \\
\text { distress; } \\
\text { Shoulder dystocia }\end{array}$ & Good \\
\hline $\begin{array}{l}\text { Ganapathy, } \\
2012^{159} \\
\text { KQ } 3\end{array}$ & $\begin{array}{l}\text { RCT } \\
\text { Asia } \\
\text { N enrolled: } \\
200 \text { patients } \\
\text { N completed: } \\
200 \text { patients }\end{array}$ & $\begin{array}{l}\text { Arm } 1 \\
\text { Mean: } 21.4 \\
\text { SD: } 2.02 \\
\text { Arm } 2 \\
\text { Mean: } 21.3 \\
\text { SD: } 1.94\end{array}$ & $\begin{array}{l}\text { Stage of Labor at Entry: } \\
\text { Active labor } \\
\text { Study's Definition of Labor: } \\
\text { First stage active }(-4-10 \mathrm{~cm}) \\
\text { Parity: Nulliparous }\end{array}$ & $\begin{array}{l}\text { Patient's upper back was } \\
\text { elevated to } 60^{\circ} \text { angle to } \\
\text { assume upright supported } \\
\text { sitting birthing position by the } \\
\text { simple backrest attached } \\
\text { adjustable standard delivery cot } \\
\text { as felt most comfortable and } \\
\text { desirable by the participants } \\
\text { vs. } \\
\text { Supine position - lying flat on } \\
\text { back }\end{array}$ & $\begin{array}{l}\text { Duration of Labor; } \\
\text { Mode of delivery; } \\
\text { Abnormal fetal heart } \\
\text { rate tracing; } \\
\text { Parental preferences } \\
\text { (Parity) }\end{array}$ & Poor \\
\hline $\begin{array}{l}\text { Geeta, } 2015^{214} \\
\text { KQ } 7\end{array}$ & $\begin{array}{l}\text { RCT } \\
\text { Asia } \\
\text { N enrolled: } \\
211 \text { patients } \\
\text { N completed: } \\
211 \text { patients }\end{array}$ & $\begin{array}{l}\text { Arm } 1 \\
\text { Mean: } 26.4 \\
\text { SD: } 3.64 \\
\text { Arm } 2 \\
\text { Mean: } 25.38 \\
\text { SD: } 3.95\end{array}$ & $\begin{array}{l}\text { Stage of Labor at Entry: First } \\
\text { stage } \\
\text { Study's Definition of Labor: } \\
>4 \mathrm{~cm} \text { dilation and } 50 \% \\
\text { effacement } \\
\text { Parity: Nulliparous, Parous }\end{array}$ & $\begin{array}{l}\text { Low dose oxytocin }-1 \mathrm{IU} \text { to } 500 \\
\mathrm{~mL} \text { of ringer lactate, infused at } \\
\text { the rate of } 1 \mathrm{mlU} / \mathrm{min} \text {; increased } \\
\text { by } 1 \mathrm{mIU} / \mathrm{min} \text { until } 3 \\
\text { contractions per } 10 \mathrm{~min} \\
\text { vs. } \\
\text { High dose oxytocin }-5 \mathrm{IU} \text { to } \\
500 \mathrm{~mL} \text { of ringer lactate, infused } \\
\text { at the rate of } 5 \mathrm{mIU} / \mathrm{min} \text { every } \\
20 \text { min until three contractions } \\
\text { per } 10 \mathrm{~min}\end{array}$ & $\begin{array}{l}\text { Duration of Labor; } \\
\text { Mode of delivery; } \\
\text { Cesarean delivery; } \\
\text { Operative vaginal } \\
\text { delivery }\end{array}$ & Fair \\
\hline
\end{tabular}




\begin{tabular}{|c|c|c|c|c|c|c|}
\hline $\begin{array}{c}\text { Study } \\
\text { Acronym } \\
\text { Key Question } \\
\text { Companion } \\
\text { Article }\end{array}$ & $\begin{array}{l}\text { Study Design } \\
\text { Geographic } \\
\text { Location } \\
\mathrm{N} \text { enrolled } \\
\mathrm{N} \text { completed }\end{array}$ & $\begin{array}{l}\text { Age Data (Years } \\
\text { Unless Specified) }\end{array}$ & $\begin{array}{l}\text { Stage of Labor at Entry } \\
\text { Study Definition of Labor } \\
\text { Parity in Population }\end{array}$ & Comparisons & $\begin{array}{c}\text { Outcomes } \\
\text { (Subgroup Analyzed) }\end{array}$ & Quality \\
\hline $\begin{array}{l}\text { Genc, 2015 } \\
\text { KQ } 4\end{array}$ & $\begin{array}{l}\text { RCT } \\
\text { UK/Europe } \\
\text { N enrolled: } \\
100 \text { patients } \\
\text { N completed: } \\
95 \text { patients }\end{array}$ & $\begin{array}{l}\text { Arm } 1 \\
\text { Mean: } 22.1 \\
\text { SD: } 2.1 \\
\text { Arm } 2 \\
\text { Mean: } 21.8 \\
\text { SD: } 4.2\end{array}$ & $\begin{array}{l}\text { Stage of Labor at Entry: First } \\
\text { stage active } \\
\text { Study's Definition of Labor: } \\
\text { Cervical dilation of } 3-5 \mathrm{~cm} \\
\text { and } 3-5 \text { uterine contractions } \\
\text { per } 10 \text { min with a mean } \\
\text { intensity of } 60 \text { (range, } 40-80 \text { ) } \\
\text { mmHg and a mean duration } \\
\text { of } 60 \text { (range, 30-90) s in } \\
\text { NST } \\
\text { Parity: Nulliparous }\end{array}$ & $\begin{array}{l}\text { Epidural anesthesia } \\
\text { vs. } \\
\text { No epidural anesthesia }\end{array}$ & Duration of Labor & Fair \\
\hline $\begin{array}{l}\text { Ghafarzadeh, } \\
2015^{113} \\
\text { KQ } 2\end{array}$ & $\begin{array}{l}\text { RCT } \\
\text { Middle East } \\
\text { N enrolled: } \\
300 \text { patients } \\
\text { N completed: } \\
300 \text { patients }\end{array}$ & $\begin{array}{l}\text { Arm } 1 \\
\text { Mean: } 25.7 \\
\text { SD: } 3.3 \\
\text { Arm } 2 \\
\text { Mean: } 25.6 \\
\text { SD: } 2.6\end{array}$ & $\begin{array}{l}\text { Stage of Labor at Entry: } \\
\text { Spontaneous labor } \\
\text { Study's Definition of Labor: } \\
\text { Spontaneous labor }(<4 \mathrm{~cm} \\
\text { dilation) } \\
\text { Parity: Unclear }\end{array}$ & $\begin{array}{l}\text { Amniotomy at less than or equal } \\
\text { to } 4 \mathrm{~cm} \text { dilation } \\
\text { vs. } \\
\text { Usual care (which included fetal } \\
\text { heart rate monitoring, } \\
\text { contraction monitoring, } \\
\text { analgesia or supportive } \\
\text { measures) }\end{array}$ & $\begin{array}{l}\text { Duration of Labor; } \\
\text { Mode of delivery; } \\
\text { Neonatal Umbilical cord } \\
\text { prolapse }\end{array}$ & Fair \\
\hline $\begin{array}{l}\text { Greenberg, } \\
2007^{88} \\
\text { KQ } 1\end{array}$ & $\begin{array}{l}\text { Observational } \\
\text { U.S. } \\
\text { N enrolled: } \\
\text { 31,976 patients } \\
\text { N completed: } \\
\text { 31,976 patients }\end{array}$ & $\begin{array}{l}\text { Arm } 1 \\
<20 \\
\text { Arm } 2 \\
20-24 \\
\text { Arm } 3 \\
25-29 \\
\text { Arm } 4 \\
30-34 \\
\text { Arm } 5 \\
35-39 \\
\text { Arm } 6 \\
\geq 40\end{array}$ & $\begin{array}{l}\text { Stage of Labor at Entry: First } \\
\text { stage active } \\
\text { Study's Definition of Labor: } \\
\text { First stage active }(4-10 \mathrm{~cm} \\
\text { dilation) } \\
\text { Parity: Nulliparous, Parous }\end{array}$ & $\begin{array}{l}\text { Age category }<20 \\
\text { vs. } \\
\text { Age category } 20-24 \\
\text { vs. } \\
\text { Age category } 25-29 \\
\text { vs. } \\
\text { Age category } 30-34 \\
\text { vs. } \\
\text { Age category } 35-39 \\
\text { vs. } \\
\text { Age category } \geq 40\end{array}$ & $\begin{array}{l}\text { Duration of Labor } \\
\text { (Parity) }\end{array}$ & Good \\
\hline
\end{tabular}




\begin{tabular}{|c|c|c|c|c|c|c|}
\hline $\begin{array}{c}\text { Study } \\
\text { Acronym } \\
\text { Key Question } \\
\text { Companion } \\
\text { Article } \\
\end{array}$ & $\begin{array}{l}\text { Study Design } \\
\text { Geographic } \\
\text { Location } \\
\text { N enrolled } \\
\text { N completed }\end{array}$ & $\begin{array}{l}\text { Age Data (Years } \\
\text { Unless Specified) }\end{array}$ & $\begin{array}{l}\text { Stage of Labor at Entry } \\
\text { Study Definition of Labor } \\
\text { Parity in Population }\end{array}$ & Comparisons & $\begin{array}{c}\text { Outcomes } \\
\text { (Subgroup Analyzed) }\end{array}$ & Quality \\
\hline $\begin{array}{l}\text { Hamidzadeh, } \\
2012^{137} \\
\text { KQ } 3\end{array}$ & $\begin{array}{l}\text { RCT } \\
\text { Middle East } \\
\text { N enrolled: } \\
100 \text { patients } \\
\text { N completed: } \\
100 \text { patients }\end{array}$ & $\begin{array}{l}\text { Total } \\
\text { Min. age: } 20 \\
\text { Max. age: } 40\end{array}$ & $\begin{array}{l}\text { Stage of Labor at Entry: First } \\
\text { active stage } \\
\text { Study's Definition of Labor: } \\
\text { 3-5 cm dilation } \\
\text { Parity: Nulliparous, Parous, }\end{array}$ & $\begin{array}{l}\text { Acupressure at L14 point } \\
\text { (between thumb and index } \\
\text { finger) on both hands. Ten s of } \\
\text { pressure and } 2 \mathrm{~s} \text { of rest } \\
\text { repeated } 5 \text { times with each } \\
\text { contraction, starting at the onset } \\
\text { of active labor ( } 3-4 \mathrm{~cm} \text { dilation) } \\
\text { and done for } 20 \text { min } \\
\text { vs. } \\
\text { Control - touched at the L14 } \\
\text { point but pressure was not } \\
\text { applied }\end{array}$ & $\begin{array}{l}\text { Duration of Labor; } \\
\text { Parental preferences }\end{array}$ & Fair \\
\hline $\begin{array}{l}\text { Hekmatzadeh, } \\
2014^{155} \\
\text { KQ } 3\end{array}$ & $\begin{array}{l}\text { RCT } \\
\text { Middle East } \\
\text { N enrolled: } \\
105 \text { patients } \\
\text { N completed: } \\
103 \text { patients }\end{array}$ & $\begin{array}{l}\text { Arm } 1 \\
\text { Mean: } 22.82 \\
\text { SD: } 2.36 \\
\text { Arm } 2 \\
\text { Mean: } 24.49 \\
\text { SD: } 2.83\end{array}$ & $\begin{array}{l}\text { Stage of Labor at Entry: First } \\
\text { stage active } \\
\text { Study's Definition of Labor: } \\
\text { 3-4 cm dilation with regular } \\
\text { uterine contractions. } \\
\text { Parity: Unclear }\end{array}$ & $\begin{array}{l}\text { Consumption of } 100 \mathrm{cc} \text { of water } \\
\text { in which } 10 \mathrm{~g} \text { (two tablespoon) } \\
\text { of Anethum Graveolens seeds } \\
\text { were boiled for } 10 \text { min. Once } \\
\text { after beginning active phase of } \\
\text { labor } \\
\text { vs. } \\
\text { Routine care }\end{array}$ & $\begin{array}{l}\text { Duration of Labor } \\
\text { (Parity) }\end{array}$ & Fair \\
\hline $\begin{array}{l}\text { Hinshaw, } \\
2008^{210} \\
\text { KQ } 7\end{array}$ & $\begin{array}{l}\text { RCT } \\
\text { UK/Europe } \\
\text { N enrolled: } \\
412 \text { patients } \\
\text { N completed: } \\
412 \text { patients }\end{array}$ & $\begin{array}{l}\text { Arm } 1 \\
\text { Median: } 22 \\
(20,28) \\
\text { Arm } 2 \\
\text { Median: } 23 \\
(19,29)\end{array}$ & $\begin{array}{l}\text { Stage of Labor at Entry: } \\
\text { Early active phase of labor. } \\
\text { Study's Definition of Labor: } \\
\text { Dilation of at least } 3 \mathrm{~cm} \text { with } \\
\text { at least } 2 \text { contractions in } 10 \\
\text { min. } \\
\text { Parity: Nulliparous }\end{array}$ & $\begin{array}{l}\text { Active management - Oxytocin } \\
2 \text { mu/min started within } 20 \text { min } \\
\text { of randomization. Dose was } \\
\text { doubled every } 30 \text { min until } \\
\text { contraction rate of } 4-5 \\
\text { contractions in } 10 \text { min was } \\
\text { achieved or max dose of } 32 \\
\text { mu/min } \\
\text { vs. } \\
\text { Conservative management - } \\
\text { Oxytocin was withheld for } 8 \mathrm{~h} \\
\text { unless intervention became } \\
\text { clinically indicated. If women did } \\
\text { not progress to delivery within } 8 \\
\mathrm{~h}, \text { oxytocin was started if } \\
\text { clinically indicated }\end{array}$ & $\begin{array}{l}\text { Mode of delivery; } \\
\text { Maternal Hemorrhage; } \\
\text { Maternal Transfusion; } \\
\text { Duration of Labor; } \\
\text { Neonatal } \\
\text { infection/sepsis; } \\
\text { Neonatal Respiratory } \\
\text { distress }\end{array}$ & Good \\
\hline
\end{tabular}




\begin{tabular}{|c|c|c|c|c|c|c|}
\hline $\begin{array}{c}\text { Study } \\
\text { Acronym } \\
\text { Key Question } \\
\text { Companion } \\
\text { Article }\end{array}$ & $\begin{array}{l}\text { Study Design } \\
\text { Geographic } \\
\text { Location } \\
\text { N enrolled } \\
\text { N completed }\end{array}$ & $\begin{array}{l}\text { Age Data (Years } \\
\text { Unless Specified) }\end{array}$ & $\begin{array}{l}\text { Stage of Labor at Entry } \\
\text { Study Definition of Labor } \\
\text { Parity in Population }\end{array}$ & Comparisons & $\begin{array}{c}\text { Outcomes } \\
\text { (Subgroup Analyzed) }\end{array}$ & Quality \\
\hline $\begin{array}{l}\text { Hoppe, } 2018^{100} \\
\text { KQ } 1\end{array}$ & $\begin{array}{l}\text { Observational } \\
\text { U.S. } \\
\text { N enrolled: } \\
642 \text { patients } \\
\text { N completed: } \\
642 \text { patients }\end{array}$ & $\begin{array}{l}\text { Arm 1: } \\
\text { 18-24: } 49(22.6 \%) \\
\text { 25-34: } 130(59.9 \%) \\
\text { 35+: } 38(17.5 \%) \\
\text { Arm 2: } \\
\text { 18-24: } 56(18.8 \%) \\
\text { 25-34: } 196(65.8 \%) \\
\text { 35+: } 46(15.4 \%) \\
\text { Arm 3: } \\
\text { 18-24: } 26(20.5 \%) \\
\text { 25-34: } 79(62.2 \%) \\
35+: 22(17.3 \%)\end{array}$ & $\begin{array}{l}\text { Stage of Labor at Entry: } \\
\text { Active Stage } \\
\text { Study's Definition of Labor: } 6 \\
\text { cm dilatation } \\
\text { Parity: Nulliparous }\end{array}$ & $\begin{array}{l}\text { Women progressing at or below } \\
\text { the median labor duration } \\
\text { vs. } \\
\text { Women progressing between } \\
\text { the median and the } 95^{\text {th }} \\
\text { percentile } \\
\text { Vs. } \\
\text { Women exceeding the } 95 \text { th } \\
\text { percentile }\end{array}$ & $\begin{array}{l}\text { Duration of Labor; } \\
\text { Mode of delivery; } \\
\text { Maternal hemorrhage; } \\
\text { NICU admissions }\end{array}$ & Fair \\
\hline $\begin{array}{l}\text { Inde, } 2018^{92} \\
\text { KQ } 1\end{array}$ & $\begin{array}{l}\text { Observational } \\
\text { Asia } \\
\text { N enrolled: } \\
\text { 3,172 patients } \\
\text { N completed: } \\
\text { 3,172 patients }\end{array}$ & $\begin{array}{l}\text { Arm } 1 \\
\text { Median: } 30(23,37) \\
\text { Arm } 2 \\
\text { Median: } 32(25,38) \\
\text { Arm } 3 \\
\text { Median: } 34(27,39)\end{array}$ & $\begin{array}{l}\text { Stage of Labor at Entry: } \\
\text { Admission to hospital } \\
\text { Study's Definition of Labor: } \\
\text { Onset of labor was defined } \\
\text { as onset of labor pains, } \\
\text { which continued to delivery, } \\
\text { with } \leq 10 \text { min interval } \\
\text { between contractions, or } \geq 6 \\
\text { times the number of } \\
\text { contractions per hr } \\
\text { Parity: Primiparous, Parous }\end{array}$ & $\begin{array}{l}\text { Cervical dilation curve in } \\
\text { women with different parities. } \\
\text { Primiparous } \\
\text { vs. } \\
\text { Parous (parity=1) } \\
\text { vs. } \\
\text { Parous (parity } \geq 2 \text { ) }\end{array}$ & $\begin{array}{l}\text { Duration of Labor; } \\
\text { Mode of delivery }\end{array}$ & Good \\
\hline $\begin{array}{l}\text { İsbir, } 2017^{180} \\
\text { KQ } 3\end{array}$ & $\begin{array}{l}\text { RCT } \\
\text { UK/Europe } \\
\text { N enrolled: } \\
72 \text { patients } \\
\text { N completed: } \\
63 \text { patients }\end{array}$ & $\begin{array}{l}\text { Arm } 1 \\
\text { Mean: } 24.9 \\
\text { SD: } 5.9 \\
\text { Arm } 2 \\
\text { Mean: } 25.0 \\
\text { SD: } 4.7\end{array}$ & $\begin{array}{l}\text { Stage of Labor at Entry: First } \\
\text { stage } \\
\text { Study's Definition of Labor: } \\
\leq 3 \mathrm{~cm} \text { dilatation } \\
\text { Parity: Nulliparous, Parous }\end{array}$ & $\begin{array}{l}\text { Continuous intrapartum } \\
\text { supportive care during labor } \\
\text { and delivery (physical, } \\
\text { emotional, instructional, } \\
\text { informational, and advocacy } \\
\text { support) } \\
\text { vs. } \\
\text { Routine care }\end{array}$ & $\begin{array}{l}\text { Duration of Labor; } \\
\text { Maternal experience } \\
\text { and satisfaction }\end{array}$ & Fair \\
\hline
\end{tabular}




\begin{tabular}{|c|c|c|c|c|c|c|}
\hline $\begin{array}{c}\text { Study } \\
\text { Acronym } \\
\text { Key Question } \\
\text { Companion } \\
\text { Article } \\
\end{array}$ & $\begin{array}{l}\text { Study Design } \\
\text { Geographic } \\
\text { Location } \\
\text { N enrolled } \\
\text { N completed }\end{array}$ & $\begin{array}{l}\text { Age Data (Years } \\
\text { Unless Specified) }\end{array}$ & $\begin{array}{l}\text { Stage of Labor at Entry } \\
\text { Study Definition of Labor } \\
\text { Parity in Population }\end{array}$ & Comparisons & $\begin{array}{c}\text { Outcomes } \\
\text { (Subgroup Analyzed) }\end{array}$ & Quality \\
\hline $\begin{array}{l}\text { Ismail, } 2012^{191} \\
\text { KQ } 4\end{array}$ & $\begin{array}{l}\text { RCT } \\
\text { Middle East } \\
\text { N enrolled: } \\
\text { 1,140 patients } \\
\text { N completed: } \\
\text { 1,140 patients }\end{array}$ & $\begin{array}{l}\text { Arm } 1 \\
\text { Mean: } 28.6 \\
\text { SD: } 5.49 \\
\text { Arm } 2 \\
\text { Mean: } 28.35 \\
\text { SD: } 5.54 \\
\text { Arm } 3 \\
\text { Mean: } 28.8 \\
\text { SD: } 5.50\end{array}$ & $\begin{array}{l}\text { Stage of Labor at Entry: } \\
\text { Excluded if dilation }>4 \mathrm{~cm} \text { at } \\
\text { time of first analgesic event } \\
\text { Study's Definition of Labor: } \\
\text { First stage latent }(<4 \mathrm{~cm} \\
\text { dilation) } \\
\text { Parity: Nulliparous }\end{array}$ & $\begin{array}{l}\text { Epidural } \\
\text { vs. } \\
\text { Combined Spinal Epidural } \\
\text { (CSE) } \\
\text { vs. } \\
\text { Patient Controlled IV Analgesia }\end{array}$ & $\begin{array}{l}\text { Duration of Labor; Mode } \\
\text { of delivery; } \\
\text { Parental preferences } \\
\text { (Parity) }\end{array}$ & Good \\
\hline $\begin{array}{l}\text { Jaitley, } 2011^{201} \\
\text { KQ } 4\end{array}$ & $\begin{array}{l}\text { RCT } \\
\text { Asia } \\
\text { N enrolled: } \\
90 \text { patients } \\
\mathrm{N} \text { completed: } \\
90 \text { patients }\end{array}$ & $\begin{array}{l}\text { Arm } 1 \\
\text { Mean: } 24.67 \\
\text { Arm } 2 \\
\text { Mean: } 25 \\
\text { Arm } 3 \\
\text { Mean: } 24.76\end{array}$ & $\begin{array}{l}\text { Stage of Labor at Entry: } \\
\text { Established active stage of } \\
\text { labor (uterine contraction } 2 \\
\text { per } 10 \mathrm{~s} \text {, lasting for } 30 \text { to } 40 \\
\text { s and cervical dilation more } \\
\text { than } 3 \mathrm{~cm} \text {.) } \\
\text { Study's Definition of Labor: } \\
\text { First stage active (4-10 cm } \\
\text { dilation) } \\
\text { Parity: Nulliparous, Parous }\end{array}$ & $\begin{array}{l}\text { IV tramadol } \\
\text { vs. } \\
\text { Epidural tramadol and } \\
\text { bupivacaine } \\
\text { vs. } \\
\text { Control }\end{array}$ & $\begin{array}{l}\text { Parental preferences; } \\
\text { Mode of delivery }\end{array}$ & Poor \\
\hline $\begin{array}{l}\text { Janssen, } \\
2012^{132} \\
\text { KQ } 3\end{array}$ & $\begin{array}{l}\text { RCT } \\
\text { Canada } \\
\text { N enrolled: } \\
77 \text { patients } \\
\text { N completed: } \\
77 \text { patients }\end{array}$ & $\begin{array}{l}\text { Arm } 1 \\
18-24 \text { yrs } 16.7 \% \\
25-29 \text { yrs } 30.6 \% \\
30-34 \text { yrs } 38.9 \% \\
35+\text { yrs } 13.9 \% \\
\text { Arm } 2 \\
18-24 \text { yrs } 8.8 \% \\
25-29 \text { yrs } 20.6 \% \\
30-34 \text { yrs } 55.9 \% \\
35+\text { yrs } 14.7 \%\end{array}$ & $\begin{array}{l}\text { Stage of Labor at Entry: First } \\
\text { stage } \\
\text { Study's Definition of Labor: } \\
\text { Spontaneous labor defined } \\
\text { as painful contractions with } \\
\text { cervix } \geq 1 \mathrm{~cm} \text { dilated and } \\
\geq 25 \% \text { effacement } \\
\text { Parity: Nulliparous }\end{array}$ & $\begin{array}{l}\text { Massage - up to } 5 \mathrm{~h} \text { of Swedish } \\
\text { massage during labor as } \\
\text { woman wished, ending if she } \\
\text { decided to have epidural } \\
\text { analgesia } \\
\text { vs. } \\
\text { Control - massage during the } \\
\text { first } 24 \mathrm{~h} \text { postpartum }\end{array}$ & $\begin{array}{l}\text { Duration of Labor; Mode } \\
\text { of delivery }\end{array}$ & Good \\
\hline
\end{tabular}




\begin{tabular}{|c|c|c|c|c|c|c|}
\hline $\begin{array}{c}\text { Study } \\
\text { Acronym } \\
\text { Key Question } \\
\text { Companion } \\
\text { Article }\end{array}$ & $\begin{array}{l}\text { Study Design } \\
\text { Geographic } \\
\text { Location } \\
\text { N enrolled } \\
\text { N completed }\end{array}$ & $\begin{array}{l}\text { Age Data (Years } \\
\text { Unless Specified) }\end{array}$ & $\begin{array}{l}\text { Stage of Labor at Entry } \\
\text { Study Definition of Labor } \\
\text { Parity in Population }\end{array}$ & Comparisons & $\begin{array}{c}\text { Outcomes } \\
\text { (Subgroup Analyzed) }\end{array}$ & Quality \\
\hline $\begin{array}{l}\text { Kashanian, } \\
2010^{151} \\
\text { KQ } 3\end{array}$ & $\begin{array}{l}\text { RCT } \\
\text { Middle East } \\
\text { N enrolled: } \\
120 \text { patients } \\
\text { N completed: } \\
120 \text { patients }\end{array}$ & $\begin{array}{l}\text { Arm } 1 \\
\text { Mean: } 23.17 \\
\text { SD: } 4.54 \\
\text { Arm } 2 \\
\text { Mean: } 23.16 \\
\text { SD: } 4.6\end{array}$ & $\begin{array}{l}\text { Stage of Labor at Entry: First } \\
\text { stage active } \\
\text { Study's Definition of Labor: } \\
3-4 \mathrm{~cm} \text { dilation with at least } \\
3 \text { contractions of } 45-60 \\
\text { second duration in } 10 \text { min } \\
\text { Parity: Nulliparous }\end{array}$ & $\begin{array}{l}\text { Acupressure at the Sanyinjiao } \\
\text { point was performed by the } \\
\text { investigator during the } \\
\text { contractions for a total duration } \\
\text { of acupressure of } 30 \text { min } \\
\text { vs. } \\
\text { Just the touch of this point by } \\
\text { the same investigator was } \\
\text { performed }\end{array}$ & $\begin{array}{l}\text { Duration of Labor; } \\
\text { Mode of delivery } \\
\text { (Parity) }\end{array}$ & Good \\
\hline $\begin{array}{l}\text { Kauffman, } \\
2016^{93} \\
\text { KQ } 1\end{array}$ & $\begin{array}{l}\text { Observational } \\
\text { U.S. } \\
\text { N enrolled: } \\
\text { 11,368 patients } \\
\text { N completed: } \\
\text { 11,368 patients }\end{array}$ & $\begin{array}{l}\text { Total: } \\
<20: 5.8 \% \\
21-34: 78.1 \% \\
>35: 16.2 \%\end{array}$ & $\begin{array}{l}\text { Stage of Labor at Entry: } \\
\text { Unclear/NR } \\
\text { Study's Definition of Labor: } \\
\text { Cervical dilation } \\
\text { Parity: Mixed Parity }\end{array}$ & $\begin{array}{l}\text { Cervical dilation on admission: } \\
<4 \mathrm{~cm} \\
\text { vs. } \\
\geq 4 \mathrm{~cm}\end{array}$ & $\begin{array}{l}\text { Duration of Labor; Mode } \\
\text { of delivery; Cesarean } \\
\text { delivery; Operative } \\
\text { vaginal delivery; } \\
\text { Hemorrhage; } \\
\text { Trauma to the pelvic } \\
\text { floor; } \\
\text { Admission to NICU }\end{array}$ & Good \\
\hline $\begin{array}{l}\text { Kaviani, } \\
2014^{127} \\
\text { KQ } 3\end{array}$ & $\begin{array}{l}\text { RCT } \\
\text { Middle East } \\
\text { N enrolled: } \\
156 \text { patients } \\
\text { N completed: } \\
139 \text { patients }\end{array}$ & $\begin{array}{l}\text { Total } \\
\text { Min. age: } 18 \\
\text { Max. age: } 30\end{array}$ & $\begin{array}{l}\text { Stage of Labor at Entry: First } \\
\text { stage active } \\
\text { Study's Definition of Labor: } \\
3-4 \mathrm{~cm} \text { dilation } \\
\text { Parity: Nulliparous }\end{array}$ & $\begin{array}{l}\text { Aromatherapy jasmine - Used in } \\
\text { incense device with water tank } \\
\text { and mask, used for } 15 \text { min } \\
\text { vs. } \\
\text { Aromatherapy salvia - Used in } \\
\text { incense device with water tank } \\
\text { and mask, used for } 15 \text { min } \\
\text { vs. } \\
\text { Control }\end{array}$ & $\begin{array}{l}\text { Duration of Labor; } \\
\text { Mode of delivery }\end{array}$ & Poor \\
\hline $\begin{array}{l}\text { Kaviani, } \\
2014^{157} \\
\text { KQ } 3\end{array}$ & $\begin{array}{l}\text { RCT } \\
\text { Middle East } \\
\text { N enrolled: } \\
160 \text { patients } \\
\text { N completed: } \\
160 \text { patients }\end{array}$ & $\begin{array}{l}\text { Arm } 1 \\
\text { Mean: } 23 \\
\text { SD: } 3.9 \\
\text { Arm } 2 \\
\text { Mean: } 22 \\
\text { SD: } 3.86\end{array}$ & $\begin{array}{l}\text { Stage of Labor at Entry: First } \\
\text { stage } \\
\text { Study's Definition of Labor: } \\
3-4 \mathrm{~cm} \text { dilation } \\
\text { Parity: Nulliparous }\end{array}$ & $\begin{array}{l}\text { In the aroma group, } 15 \times 15 \mathrm{~cm} \\
\text { tissues containing } 0.1 \mathrm{~mL} \text { of } \\
\text { lavender essence mixed with } 1 \\
\mathrm{~mL} \text { of distilled water were used } \\
\text { vs. } \\
\text { The control group inhaled } 2 \mathrm{~mL} \\
\text { of distilled water }\end{array}$ & $\begin{array}{l}\text { Duration of Labor; } \\
\text { Parental preferences } \\
\text { (Parity) }\end{array}$ & Fair \\
\hline
\end{tabular}




\begin{tabular}{|c|c|c|c|c|c|c|}
\hline $\begin{array}{c}\text { Study } \\
\text { Acronym } \\
\text { Key Question } \\
\text { Companion } \\
\text { Article } \\
\end{array}$ & $\begin{array}{l}\text { Study Design } \\
\text { Geographic } \\
\text { Location } \\
\text { N enrolled } \\
\text { N completed }\end{array}$ & $\begin{array}{l}\text { Age Data (Years } \\
\text { Unless Specified) }\end{array}$ & $\begin{array}{l}\text { Stage of Labor at Entry } \\
\text { Study Definition of Labor } \\
\text { Parity in Population }\end{array}$ & Comparisons & $\begin{array}{c}\text { Outcomes } \\
\text { (Subgroup Analyzed) }\end{array}$ & Quality \\
\hline $\begin{array}{l}\text { Kavitha, } \\
2012^{139} \\
\text { KQ } 3\end{array}$ & $\begin{array}{l}\text { RCT } \\
\text { Asia } \\
\text { N enrolled: } \\
293 \text { patients } \\
\text { N completed: } \\
293 \text { patients }\end{array}$ & $\begin{array}{l}\text { Arm } 1 \\
\text { Mean: } 23.8 \\
\text { Arm } 2 \\
\text { Mean: } 23.9 \\
\text { Arm } 3 \\
\text { Mean: } 24.1\end{array}$ & $\begin{array}{l}\text { Stage of Labor at Entry: } \\
\text { Spontaneous active } \\
\text { Study's Definition of Labor: } \\
3-6 \mathrm{~cm} \text { dilation } \\
\text { Parity: Nulliparous }\end{array}$ & $\begin{array}{l}\text { Oral hydration } \\
\text { vs. } \\
125 \mathrm{~mL} / \mathrm{hr} \text { Lactated Ringer's } \\
\text { solution with oral fluids on } \\
\text { request } \\
\text { vs. } \\
250 \mathrm{~mL} / \mathrm{hr} \text { Lactated Ringer's } \\
\text { solution with oral fluids on } \\
\text { request }\end{array}$ & $\begin{array}{l}\text { Mode of delivery; } \\
\text { Duration of Labor }\end{array}$ & Good \\
\hline $\begin{array}{l}\text { Kenyon, } \\
2013^{208} \\
\text { KQ } 7\end{array}$ & $\begin{array}{l}\text { RCT } \\
\text { UK/Europe } \\
\text { N enrolled: } \\
94 \text { patients } \\
\mathrm{N} \text { completed: } \\
92 \text { patients }\end{array}$ & $\begin{array}{l}\text { Arm } 1 \\
\text { Mean: } 28 \\
\text { SD: } 5.2 \\
\text { Arm } 2 \\
\text { Mean: } 26 \\
\text { SD: } 5.0\end{array}$ & $\begin{array}{l}\text { Stage of Labor at Entry: First } \\
\text { stage active } \\
\text { Study's Definition of Labor: } \\
\geq 4 \mathrm{~cm} \text { dilation and regular } \\
\text { painful contractions. } \\
\text { Parity: Nulliparous }\end{array}$ & $\begin{array}{l}\text { High Dose Oxytocin: Start at } 4 \\
\mathrm{mU} / \mathrm{min} \text { and increase every } 30 \\
\mathrm{~min} \text { by } 4 \mathrm{mU} / \mathrm{min} \text { to a maximal } \\
\text { rate of } 64 \mathrm{mU} / \mathrm{min} \\
\text { vs. } \\
\text { Standard Dose Oxytocin: Start } \\
\text { at } 2 \mathrm{mU} / \mathrm{min} \text { and increase every } \\
30 \mathrm{~min} \text { by } 2 \mathrm{mU} / \mathrm{min} \text { to a } \\
\text { maximal rate of } 32 \mathrm{mU} / \mathrm{min}\end{array}$ & $\begin{array}{l}\text { Duration of Labor; Mode } \\
\text { of delivery; } \\
\text { Neonatal length of stay; } \\
\text { Maternal Trauma to the } \\
\text { Pelvic Floor; } \\
\text { Maternal Infection; } \\
\text { Maternal Hemorrhage; } \\
\text { Neonatal Respiratory } \\
\text { distress }\end{array}$ & Good \\
\hline $\begin{array}{l}\text { Koyucu, } \\
2017^{226} \\
\text { KQ } 9\end{array}$ & $\begin{array}{l}\text { RCT } \\
\text { UK/Europe } \\
\text { N enrolled: } \\
116 \text { patients } \\
\text { N completed: } \\
116 \text { patients }\end{array}$ & $\begin{array}{l}\text { Arm } 1 \\
\text { Mean: } 22.4 \\
\text { SD: } 3.5 \\
\text { Arm } 2 \\
\text { Mean: } 22.6 \\
\text { SD: } 3.6\end{array}$ & $\begin{array}{l}\text { Stage of Labor at Entry: First } \\
\text { Stage } \\
\text { Study's Definition of Labor: } \\
\text { Unclear/NR } \\
\text { Parity: Nulliparous }\end{array}$ & $\begin{array}{l}\text { Spontaneous pushing } \\
\text { vs. } \\
\text { Valsalva pushing }\end{array}$ & $\begin{array}{l}\text { Duration of Labor; Mode } \\
\text { of delivery; Cesarean } \\
\text { delivery; Operative } \\
\text { vaginal delivery; } \\
\text { Hemorrhage; } \\
\text { Trauma to the pelvic } \\
\text { floor; } \\
\text { Meconium aspiration } \\
\end{array}$ & Fair \\
\hline $\begin{array}{l}\text { Lavender, } \\
2006^{89} \\
\text { KQ } 1\end{array}$ & $\begin{array}{l}\text { RCT } \\
\text { UK/Europe } \\
\text { N enrolled: } \\
\text { 3,000. } \\
\text { N completed: } \\
\text { 2,975 patients }\end{array}$ & $\begin{array}{l}\text { Arm } 1 \\
\text { Mean: } 25.4 \\
\text { SD: } 5.5 \\
\text { Arm } 2 \\
\text { Mean: } 25.3 \\
\text { SD: } 5.5\end{array}$ & $\begin{array}{l}\text { Stage of Labor at Entry: First } \\
\text { stage latent, first stage } \\
\text { active } \\
\text { Study's Definition of Labor: } \\
\geq 3 \mathrm{~cm} \text { dilation, cervix was } \\
\text { effaced, and regular } \\
\text { contractions at least every } 5 \\
\text { min and lasting } \geq 20 \text { sec } \\
\text { Parity: Nulliparous }\end{array}$ & $\begin{array}{l}\text { Women were assigned to have } \\
\text { their labors recorded on a } \\
\text { partogram with an action line } 2 \\
\mathrm{~h} \text { to the right of the alert line } \\
\text { vs. } \\
\text { Women were assigned to have } \\
\text { their labors recorded on a } \\
\text { partogram with an action line } 4 \\
\mathrm{~h} \text { to the right of the alert line }\end{array}$ & $\begin{array}{l}\text { Mode of delivery; } \\
\text { Duration of Labor; } \\
\text { Maternal Hemorrhage; } \\
\text { Parental preferences } \\
\text { (Parity) }\end{array}$ & Good \\
\hline
\end{tabular}




\begin{tabular}{|c|c|c|c|c|c|c|}
\hline $\begin{array}{c}\text { Study } \\
\text { Acronym } \\
\text { Key Question } \\
\text { Companion } \\
\text { Article } \\
\end{array}$ & $\begin{array}{l}\text { Study Design } \\
\text { Geographic } \\
\text { Location } \\
\text { N enrolled } \\
\text { N completed }\end{array}$ & $\begin{array}{l}\text { Age Data (Years } \\
\text { Unless Specified) }\end{array}$ & $\begin{array}{l}\text { Stage of Labor at Entry } \\
\text { Study Definition of Labor } \\
\text { Parity in Population }\end{array}$ & Comparisons & $\begin{array}{c}\text { Outcomes } \\
\text { (Subgroup Analyzed) }\end{array}$ & Quality \\
\hline $\begin{array}{l}\text { Lee, } 2018^{94} \\
\text { KQ } 1\end{array}$ & $\begin{array}{l}\text { RCT } \\
\text { Australia/NZ } \\
\text { N enrolled: } \\
116 \text { patients } \\
\text { N completed: } \\
99 \text { patients }\end{array}$ & $\begin{array}{l}\text { Arm } 1 \\
\text { Mean: } 28 \\
\text { SD: } 5 \\
\text { Arm } 2 \\
\text { Mean: } 29.6 \\
\text { SD: } 4.7\end{array}$ & $\begin{array}{l}\text { Stage of Labor at Entry: } \\
\text { Unclear/NR } \\
\text { Study's Definition of Labor: } \\
\text { Unclear/NR } \\
\text { Parity: Nulliparous }\end{array}$ & $\begin{array}{l}\text { Dystocia line partograph } \\
\text { vs. } \\
\text { Action line partograph }\end{array}$ & $\begin{array}{l}\text { Duration of Labor; Mode } \\
\text { of delivery; Cesarean } \\
\text { delivery; Operative } \\
\text { vaginal delivery; } \\
\text { Maternal experience } \\
\text { and satisfaction; } \\
\text { Admission to NICU }\end{array}$ & Good \\
\hline $\begin{array}{l}\text { Liu, 2015'124 } \\
\text { KQ 3, KQ } 4\end{array}$ & $\begin{array}{l}\text { RCT } \\
\text { Asia } \\
\text { N enrolled: } \\
120 \text { patients } \\
\text { N completed: } \\
120 \text { patients }\end{array}$ & $\begin{array}{l}\text { Total } \\
\text { Min. age: } 20 \\
\text { Max. age: } 29\end{array}$ & $\begin{array}{l}\text { Stage of Labor at Entry: First } \\
\text { stage active } \\
\text { Study's Definition of Labor: } 3 \\
\text { cm dilation } \\
\text { Parity: Unclear }\end{array}$ & $\begin{array}{l}\text { Han's Acupoint Nerve } \\
\text { Stimulator } \\
\text { vs. } \\
\text { Epidural } \\
\text { vs. } \\
\text { Patient-controlled IV analgesia } \\
\text { vs. } \\
\text { Control }\end{array}$ & $\begin{array}{l}\text { Duration of Labor; } \\
\text { Mode of delivery; } \\
\text { Maternal Hemorrhage; } \\
\text { Neonatal Respiratory } \\
\text { distress }\end{array}$ & Fair \\
\hline $\begin{array}{l}\text { Liu, } 2018^{213} \\
\text { KQ } 7\end{array}$ & $\begin{array}{l}\text { RCT } \\
\text { Asia } \\
\text { N enrolled: } \\
810 \text { patients } \\
\text { N completed: } \\
810 \text { patients }\end{array}$ & $\begin{array}{l}\text { Arm } 1 \\
\text { Mean: } 25.75 \\
\text { SD: } 1.84 \\
\text { Arm } 2 \\
\text { Mean: } 25.46 \\
\text { SD: } 1.95 \\
\text { Arm } 3 \\
\text { Mean: } 25.53 \\
\text { SD: } 2.46 \\
\text { Arm } 4 \\
\text { Mean: } 26.84 \\
\text { SD: } 1.62 \\
\text { Arm } 5 \\
\text { Mean: } 28.44 \\
\text { SD: } 3.07\end{array}$ & $\begin{array}{l}\text { Stage of Labor at Entry: } \\
\text { Arrested progress of labor } \\
\text { as defined by the partogram } \\
\text { Study's Definition of Labor: } \\
\text { Unclear/NR } \\
\text { Parity: Primiparous }\end{array}$ & $\begin{array}{l}\text { Oxytocin Administration: } \\
16 \mathrm{mU} / \mathrm{min} \text { continuous } \\
\text { administration } \\
\text { vs. } \\
2 \mathrm{mU} / \mathrm{min} \text { following } 1 \mathrm{mU} / \mathrm{min} \\
\text { normal } \\
\text { frequency } \\
\text { vs. } \\
8 \mathrm{mU} / \mathrm{min} \text { following } 4 \mathrm{mU} / \mathrm{min} \\
\text { normal frequency } \\
\text { vs. } \\
5 \mathrm{mU} / \mathrm{min} \text { quarter-hourly } \\
\text { vs. } \\
\text { Pulsatile preparations }\end{array}$ & $\begin{array}{l}\text { Duration of Labor; Mode } \\
\text { of delivery; Cesarean } \\
\text { delivery; Operative } \\
\text { vaginal delivery; } \\
\text { Hemorrhage; } \\
\text { Trauma to the pelvic } \\
\text { floor; } \\
\text { Admission to NICU; } \\
\text { Mortality }\end{array}$ & Poor \\
\hline
\end{tabular}




\begin{tabular}{|c|c|c|c|c|c|c|}
\hline $\begin{array}{c}\text { Study } \\
\text { Acronym } \\
\text { Key Question } \\
\text { Companion } \\
\text { Article } \\
\end{array}$ & $\begin{array}{l}\text { Study Design } \\
\text { Geographic } \\
\text { Location } \\
\text { N enrolled } \\
\text { N completed } \\
\end{array}$ & $\begin{array}{l}\text { Age Data (Years } \\
\text { Unless Specified) }\end{array}$ & $\begin{array}{l}\text { Stage of Labor at Entry } \\
\text { Study Definition of Labor } \\
\text { Parity in Population }\end{array}$ & Comparisons & $\begin{array}{c}\text { Outcomes } \\
\text { (Subgroup Analyzed) }\end{array}$ & Quality \\
\hline $\begin{array}{l}\text { Ma, } 2011^{141} \\
\text { KQ } 3\end{array}$ & $\begin{array}{l}\text { RCT } \\
\text { Asia } \\
\text { N enrolled: } \\
350 \text { patients } \\
\text { N completed: } \\
350 \text { patients }\end{array}$ & $\begin{array}{l}\text { Arm } 1 \\
\text { Mean: } 26.15 \\
\text { SD: } 2.83 \\
\text { Arm } 2 \\
\text { Mean: } 26.39 \\
\text { SD: } 2.96 \\
\text { Arm } 3 \\
\text { Mean: } 25.55 \\
\text { SD: } 3.00\end{array}$ & $\begin{array}{l}\text { Stage of Labor at Entry: First } \\
\text { stage latent } \\
\text { Study's Definition of Labor: } \\
\text { 2-3 dilation and regular } \\
\text { uterine contractions. } \\
\text { Parity: Nulliparous, Parous }\end{array}$ & $\begin{array}{l}\text { Acupuncture - } \\
\text { Electroacupuncture at SP6 } \\
\text { vs. } \\
\text { Sham acupuncture - Needle did } \\
\text { not penetrate skin and no } \\
\text { electricity applied } \\
\text { vs. } \\
\text { Control - usual care }\end{array}$ & Duration of Labor & Good \\
\hline $\begin{array}{l}\text { Maddady, } \\
2018^{174} \\
\text { KQ } 3\end{array}$ & $\begin{array}{l}\text { RCT } \\
\text { Middle East } \\
\text { N enrolled: } \\
162 \text { patients } \\
\text { N completed: } \\
147 \text { patients }\end{array}$ & $\begin{array}{l}\text { Arm } 1 \\
\text { Mean: } 23.6 \\
\text { SD: } 3.8 \\
\text { Arm } 2 \\
\text { Mean: } 22.6 \\
\text { SD: } 3.8 \\
\text { Arm } 3 \\
\text { Mean: } 24.5 \\
\text { SD: } 4.14\end{array}$ & $\begin{array}{l}\text { Stage of Labor at Entry: First } \\
\text { stage active } \\
\text { Study's Definition of Labor: } 4 \\
\text { cm dilatation } \\
\text { Parity: Nulliparous }\end{array}$ & $\begin{array}{l}\text { Hot shower } \\
\text { vs. } \\
\text { IV injection of hyoscine } \\
\text { vs. } \\
\text { Routine care }\end{array}$ & $\begin{array}{l}\text { Duration of Labor; } \\
\text { Maternal experience; } \\
\text { Admission to NICU }\end{array}$ & Fair \\
\hline $\begin{array}{l}\text { Mason, } 2018^{97} \\
\text { KQ } 1\end{array}$ & $\begin{array}{l}\text { Observational } \\
\text { U.S. } \\
\text { N enrolled: } \\
250 \text { patients } \\
\text { N completed: } \\
245 \text { patients }\end{array}$ & $\begin{array}{l}\text { Arm } 1 \\
\text { Mean: } 33.1 \\
\text { SD: } 13.3 \\
\text { Arm } 2 \\
\text { Mean: } 31.3 \\
\text { SD: } 5.2 \\
\text { Arm } 3 \\
\text { Mean: } 33.7 \\
\text { SD: } 4.1\end{array}$ & $\begin{array}{l}\text { Stage of Labor at Entry: } \\
\text { Spontaneous labor } \\
\text { Study's Definition of Labor: } \\
\text { Unclear/NR } \\
\text { Parity: Parous }\end{array}$ & $\begin{array}{l}\text { Interbirth interval between } \\
\text { studied pregnancy and most } \\
\text { recent birth: } \\
0-59 \text { months } \\
\text { vs. } \\
60-119 \text { months } \\
\text { vs. } \\
\geq 120 \text { months }\end{array}$ & $\begin{array}{l}\text { Duration of Labor; } \\
\text { Birthweight }\end{array}$ & Good \\
\hline
\end{tabular}




\begin{tabular}{|c|c|c|c|c|c|c|}
\hline $\begin{array}{l}\text { Study } \\
\text { Acronym } \\
\text { Key Question } \\
\text { Companion } \\
\text { Article }\end{array}$ & $\begin{array}{l}\text { Study Design } \\
\text { Geographic } \\
\text { Location } \\
\text { N enrolled } \\
\text { N completed }\end{array}$ & $\begin{array}{l}\text { Age Data (Years } \\
\text { Unless Specified) }\end{array}$ & $\begin{array}{l}\text { Stage of Labor at Entry } \\
\text { Study Definition of Labor } \\
\text { Parity in Population }\end{array}$ & Comparisons & $\begin{array}{c}\text { Outcomes } \\
\text { (Subgroup Analyzed) }\end{array}$ & Quality \\
\hline $\begin{array}{l}\text { McGrath, } \\
2008^{145} \\
\text { KQ } 3\end{array}$ & $\begin{array}{l}\text { RCT } \\
\text { U.S. } \\
\text { N enrolled: } \\
387 \text { patients } \\
\text { N completed: } \\
387 \text { patients }\end{array}$ & $\begin{array}{l}\text { Arm } 1 \\
\text { Mean: } 28.97 \\
\text { SD: } 4.83 \\
\text { Arm } 2 \\
\text { Mean: } 28.60 \\
\text { SD: } 4.49\end{array}$ & $\begin{array}{l}\text { Stage of Labor at Entry: First } \\
\text { stage active (early) } \\
\text { Study's Definition of Labor: } \\
\text { Not specified } \\
\text { Parity: Nulliparous }\end{array}$ & $\begin{array}{l}\text { Doula care - Close physical } \\
\text { proximity, touch, eye contact } \\
\text { and verbal encouragement } \\
\text { vs. } \\
\text { Control }\end{array}$ & $\begin{array}{l}\text { Mode of delivery } \\
\text { (Parity) }\end{array}$ & Good \\
\hline $\begin{array}{l}\text { Mikki, } 2007^{115} \\
\text { KQ } 2\end{array}$ & $\begin{array}{l}\text { RCT } \\
\text { Middle East } \\
\text { N enrolled: } \\
690 \text { patients } \\
\text { N completed: } \\
690 \text { patients }\end{array}$ & $\begin{array}{l}\text { Arm } 1 \\
\text { Mean: } 27.3 \\
\text { SD: } 5.3 \\
\text { Arm } 2 \\
\text { Mean: } 26.9 \\
\text { SD: } 5.1 \\
\text { Arm } 3 \\
\text { Mean: } 21.7 \\
\text { SD: } 3.7 \\
\text { Arm } 4 \\
\text { Mean: } 21.4 \\
\text { SD: } 4.2\end{array}$ & $\begin{array}{l}\text { Stage of Labor at Entry: First } \\
\text { stage latent, first stage } \\
\text { active } \\
\text { Study's Definition of Labor: } \\
\text { Active labor } \\
\text { Parity: Nulliparous, Parous }\end{array}$ & $\begin{array}{l}\text { Parous Intervention- } \\
\text { membranes ruptured shortly } \\
\text { after randomization } \\
\text { vs. } \\
\text { Parous Control - amniotomy if } \\
\text { indicated ( } 2 \mathrm{~h} \text { arrest of cervical } \\
\text { dilation, dystocia, fetal monitor } \\
\text { insertion) } \\
\text { vs. } \\
\text { Nulliparous Intervention- } \\
\text { membranes ruptured shortly } \\
\text { after randomization } \\
\text { vs. } \\
\text { Nulliparous Control - amniotomy } \\
\text { if indicated ( } 2 \text { h arrest of } \\
\text { cervical dilation, dystocia, fetal } \\
\text { monitor insertion) }\end{array}$ & $\begin{array}{l}\text { Duration of Labor; } \\
\text { Maternal Hemorrhage; } \\
\text { Maternal Infection; } \\
\text { Maternal Trauma to the } \\
\text { Pelvic Floor; } \\
\text { Neonatal Respiratory } \\
\text { distress; } \\
\text { Neonatal } \\
\text { infection/sepsis; } \\
\text { Mode of delivery } \\
\text { (Parity) }\end{array}$ & Good \\
\hline $\begin{array}{l}\text { Miquelutti, } \\
2007^{146} \\
\text { KQ } 3\end{array}$ & $\begin{array}{l}\text { RCT } \\
\text { Latin America } \\
\text { N enrolled: } \\
107 \text { patients } \\
\mathrm{N} \text { completed: } \\
107 \text { patients }\end{array}$ & $\begin{array}{l}\text { Total } \\
\text { Median: } 21\end{array}$ & $\begin{array}{l}\text { Stage of Labor at Entry: First } \\
\text { stage active } \\
\text { Study's Definition of Labor: } \\
\geq 3 \mathrm{~cm} \text { and } \leq 5 \mathrm{~cm} \text { dilation. } \\
\text { Parity: Nulliparous }\end{array}$ & $\begin{array}{l}\text { Information that provided } \\
\text { possible benefits of upright } \\
\text { position and encouraged to } \\
\text { assume this position during } \\
\text { labor. Encouraged to return to } \\
\text { upright position whenever they } \\
\text { had been in the supine position } \\
\text { for }>30 \text { min } \\
\text { vs. } \\
\text { Usual care. No orientation } \\
\text { concerning upright position. } \\
\text { Free to move around during } \\
\text { labor. }\end{array}$ & $\begin{array}{l}\text { Mode of delivery; } \\
\text { Duration of Labor }\end{array}$ & Good \\
\hline
\end{tabular}




\begin{tabular}{|c|c|c|c|c|c|c|}
\hline $\begin{array}{c}\text { Study } \\
\text { Acronym } \\
\text { Key Question } \\
\text { Companion } \\
\text { Article }\end{array}$ & $\begin{array}{l}\text { Study Design } \\
\text { Geographic } \\
\text { Location } \\
\mathrm{N} \text { enrolled } \\
\mathrm{N} \text { completed }\end{array}$ & $\begin{array}{l}\text { Age Data (Years } \\
\text { Unless Specified) }\end{array}$ & $\begin{array}{l}\text { Stage of Labor at Entry } \\
\text { Study Definition of Labor } \\
\text { Parity in Population }\end{array}$ & Comparisons & $\begin{array}{c}\text { Outcomes } \\
\text { (Subgroup Analyzed) }\end{array}$ & Quality \\
\hline $\begin{array}{l}\text { Moraloglu, } \\
2017^{168} \\
\text { KQ } 3\end{array}$ & $\begin{array}{l}\text { RCT } \\
\text { UK/Europe } \\
\text { N enrolled: } \\
102 \text { patients } \\
N \text { completed: } \\
100 \text { patients }\end{array}$ & $\begin{array}{l}\text { Arm } 1 \\
\text { Mean: } 23.96 \\
\text { SD: } 3.75 \\
\text { Arm } 2 \\
\text { Mean: } 22.04 \\
\text { SD: } 3.46\end{array}$ & $\begin{array}{l}\text { Stage of Labor at Entry: } \\
\text { Second stage } \\
\text { Study's Definition of Labor: } \\
\text { Second the interval between } \\
\text { the complete opening of the } \\
\text { cervix until delivery } \\
\text { Parity: Nulliparous }\end{array}$ & $\begin{array}{l}\text { Influence of position on birth } \\
\text { outcomes: } \\
\text { Squatting using a bar } \\
\text { vs. } \\
\text { Supine position modified to } 45 \\
\text { degree of semi-fowler }\end{array}$ & $\begin{array}{l}\text { Mode of delivery; } \\
\text { Cesarean delivery; } \\
\text { Operative vaginal } \\
\text { delivery; } \\
\text { Duration of Labor; } \\
\text { Hemorrhage; Maternal } \\
\text { experience and } \\
\text { satisfaction; Neonatal } \\
\text { respiratory distress } \\
\end{array}$ & Fair \\
\hline $\begin{array}{l}\text { Mortazavi, } \\
2012^{138} \\
\text { KQ } 3\end{array}$ & $\begin{array}{l}\text { RCT } \\
\text { Middle East } \\
\\
N \text { enrolled: } \\
120 \text { patients } \\
N \text { completed: } \\
120 \text { patients }\end{array}$ & $\begin{array}{l}\text { Arm } 1 \\
\text { Mean: } 23.12 \\
\text { SD: } 3.17 \\
\text { Arm 2 } \\
\text { Mean: } 22.45 \\
\text { SD: } 3.45 \\
\\
\text { Arm } 3 \\
\text { Mean: } 23.50 \\
\text { SD: } 4.24\end{array}$ & $\begin{array}{l}\text { Stage of Labor at Entry: First } \\
\text { stage latent } \\
\text { Study's Definition of Labor: } \\
\leq 4 \mathrm{~cm} \\
\text { Parity: Nulliparous }\end{array}$ & $\begin{array}{l}\text { Massage - Massage of shoulder } \\
\text { or back, abdominal effleurage } \\
\text { and sacral pressure for } 30 \mathrm{~min} \\
\text { in all labor phases } \\
\text { vs. } \\
\text { Attendant - Attendant } \\
\text { accompanied women during } \\
\text { entire labor } \\
\text { vs. } \\
\text { Control - Usual care }\end{array}$ & Duration of Labor & Poor \\
\hline $\begin{array}{l}\text { Nachum, } \\
2010^{114} \\
\text { KQ 2,KQ } 7\end{array}$ & $\begin{array}{l}\text { RCT } \\
\text { Middle East } \\
\text { N enrolled: } \\
283 \text { patients } \\
N \text { completed: } \\
283 \text { patients }\end{array}$ & $\begin{array}{l}\text { Arm } 1 \\
\text { Mean: } 28.1 \\
\text { SD: } 4.9 \\
\text { Arm } 2 \\
\text { Mean: } 28.5 \\
\text { SD: } 5.3 \\
\text { Arm } 3 \\
\text { Mean: } 28.2 \\
\text { SD: } 5.0 \\
\text { Arm } 4 \\
\text { Mean: } 28.7 \\
\text { SD: } 4.7\end{array}$ & $\begin{array}{l}\text { Stage of Labor at Entry: First } \\
\text { stage latent } \\
\text { Study's Definition of Labor: } \\
2-4 \mathrm{~cm} \text { dilation, prolonged } \\
\text { latent phase } \\
\text { Parity: Nulliparous, Parous }\end{array}$ & $\begin{array}{l}\text { Amniotomy } \\
\text { vs. } \\
\text { Oxytocin } \\
\text { vs. } \\
\text { Both Amniotomy and Oxytocin } \\
\text { performed and started } \\
\text { simultaneously after admission } \\
\text { to the delivery ward. } \\
\text { vs. } \\
\text { Control }\end{array}$ & $\begin{array}{l}\text { Maternal Trauma to the } \\
\text { Pelvic Floor; } \\
\text { Maternal Infection; } \\
\text { Maternal Hemorrhage; } \\
\text { Mode of delivery; } \\
\text { Duration of Labor; } \\
\text { Parental preferences } \\
\text { (Parity) }\end{array}$ & Good \\
\hline
\end{tabular}




\begin{tabular}{|c|c|c|c|c|c|c|}
\hline $\begin{array}{l}\text { Study } \\
\text { Acronym } \\
\text { Key Question } \\
\text { Companion } \\
\text { Article }\end{array}$ & $\begin{array}{l}\text { Study Design } \\
\text { Geographic } \\
\text { Location } \\
\text { N enrolled } \\
\text { N completed }\end{array}$ & $\begin{array}{l}\text { Age Data (Years } \\
\text { Unless Specified) }\end{array}$ & $\begin{array}{l}\text { Stage of Labor at Entry } \\
\text { Study Definition of Labor } \\
\text { Parity in Population }\end{array}$ & Comparisons & $\begin{array}{c}\text { Outcomes } \\
\text { (Subgroup Analyzed) }\end{array}$ & Quality \\
\hline $\begin{array}{l}\text { Nafisi, } 2006^{198} \\
\text { KQ } 4\end{array}$ & $\begin{array}{l}\text { RCT } \\
\text { Middle East } \\
\text { N enrolled: } \\
395 \text { patients } \\
\text { N completed: } \\
395 \text { patients }\end{array}$ & $\begin{array}{l}\text { Arm } 1 \\
\text { Mean: } 23.2 \\
\text { SD: } 2 \\
\text { Arm } 2 \\
\text { Mean: } 22.03 \\
\text { SD: } 3\end{array}$ & $\begin{array}{l}\text { Stage of Labor at Entry: First } \\
\text { stage active } \\
\text { Study's Definition of Labor: } \\
\text { Active labor, }<+4 \mathrm{~cm} \\
\text { dilation) } \\
\text { Parity: Nulliparous }\end{array}$ & $\begin{array}{l}\text { Epidural } \\
\text { vs. } \\
\text { Intravenous meperidine plus } \\
\text { single dose meperidine. }\end{array}$ & $\begin{array}{l}\text { Mode of delivery; } \\
\text { Duration of Labor; } \\
\text { Neonatal admission to } \\
\text { NICU }\end{array}$ & Fair \\
\hline $\begin{array}{l}\text { Nakamura, } \\
2009^{195} \\
\text { KQ } 4\end{array}$ & $\begin{array}{l}\text { RCT } \\
\text { Latin America } \\
\text { N enrolled: } \\
40 \text { patients } \\
\mathrm{N} \text { completed: } \\
40 \text { patients }\end{array}$ & $\begin{array}{l}\text { Arm } 1 \\
\text { Mean: } 21.4 \\
\text { SD: } 4.4 \\
\text { Arm } 2 \\
\text { Mean: } 19.9 \\
\text { SD: } 3.6\end{array}$ & $\begin{array}{l}\text { Stage of Labor at Entry: } \\
\text { Unclear/NR } \\
\text { Study's Definition of Labor: } \\
\text { Unclear/NR } \\
\text { Parity: Nulliparous, Parous }\end{array}$ & $\begin{array}{l}\text { Epidural } \\
\text { vs. } \\
\text { Combined Spinal Epidural } \\
\text { (CSE) }\end{array}$ & Mode of delivery & Fair \\
\hline $\begin{array}{l}\text { Nasir, } 2007^{147} \\
\text { KQ } 3\end{array}$ & $\begin{array}{l}\text { RCT } \\
\text { Middle East } \\
\text { N enrolled: } \\
200 \text { patients } \\
\text { N completed: } \\
200 \text { patients }\end{array}$ & Unclear/NR & $\begin{array}{l}\text { Stage of Labor at Entry: } \\
\text { Active } \\
\text { Study's Definition of Labor: } \\
\text { Active labor with cephalic } \\
\text { presentation and longitudinal } \\
\text { lie } \\
\text { Parity: Unclear }\end{array}$ & $\begin{array}{l}\text { Squatting position during } \\
\text { Second stage of labor } \\
\text { vs. } \\
\text { Supine in lithotomy position } \\
\text { during Second stage of labor }\end{array}$ & $\begin{array}{l}\text { Maternal Trauma to the } \\
\text { Pelvic Floor } \\
\text { Neonatal Shoulder } \\
\text { dystocia } \\
\text { Maternal Hemorrhage; } \\
\text { Mode of delivery }\end{array}$ & Fair \\
\hline $\begin{array}{l}\text { Neal, } 2014^{84} \\
\text { KQ } 1\end{array}$ & $\begin{array}{l}\text { Observational } \\
\text { U.S. } \\
\text { N enrolled: } \\
223 \text { patients } \\
\text { N completed: } \\
216 \text { patients }\end{array}$ & $\begin{array}{l}\text { Arm } 1 \\
\text { Median: } 26 \\
\text { Arm } 2 \\
\text { Median: } 26.5\end{array}$ & $\begin{array}{l}\text { Stage of Labor at Entry: First } \\
\text { stage latent, first stage } \\
\text { active } \\
\text { Study's Definition of Labor: } \\
\text { Spontaneous labor onset, } \\
\text { dilated at least } 1 \mathrm{~cm} \text { but no } \\
\text { more than } 6 \mathrm{~cm} \\
\text { Parity: Nulliparous }\end{array}$ & $\begin{array}{l}\text { Admission of women in active } \\
\text { labor } \\
\text { vs. } \\
\text { Admission of women in pre- } \\
\text { active/early labor }\end{array}$ & $\begin{array}{l}\text { Duration of Labor; } \\
\text { Mode of delivery; } \\
\text { Maternal Infection }\end{array}$ & Poor \\
\hline
\end{tabular}




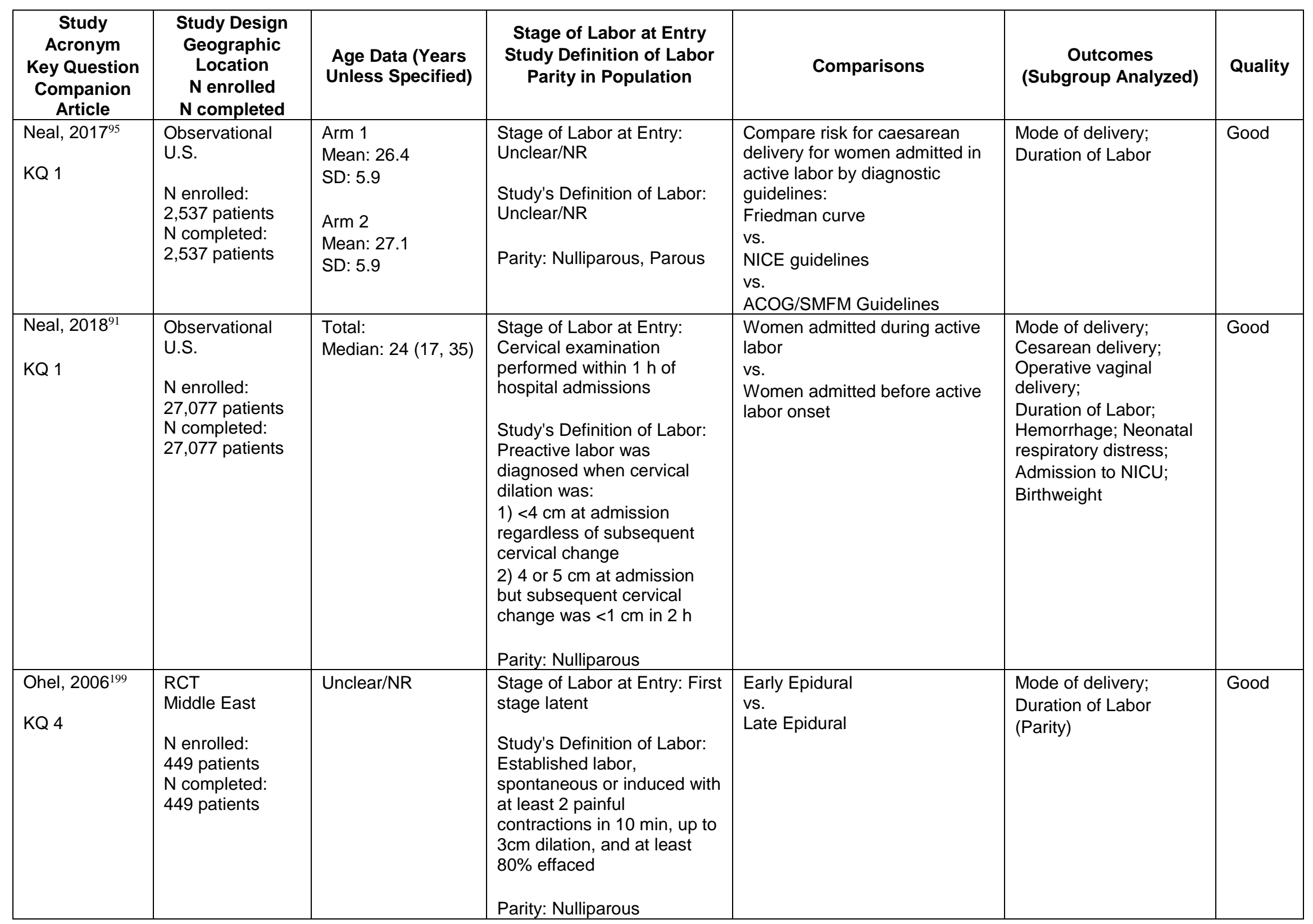




\begin{tabular}{|c|c|c|c|c|c|c|}
\hline $\begin{array}{c}\text { Study } \\
\text { Acronym } \\
\text { Key Question } \\
\text { Companion } \\
\text { Article } \\
\end{array}$ & $\begin{array}{c}\text { Study Design } \\
\text { Geographic } \\
\text { Location } \\
\mathrm{N} \text { enrolled } \\
\mathrm{N} \text { completed } \\
\end{array}$ & $\begin{array}{l}\text { Age Data (Years } \\
\text { Unless Specified) }\end{array}$ & $\begin{array}{l}\text { Stage of Labor at Entry } \\
\text { Study Definition of Labor } \\
\text { Parity in Population }\end{array}$ & Comparisons & $\begin{array}{c}\text { Outcomes } \\
\text { (Subgroup Analyzed) }\end{array}$ & Quality \\
\hline $\begin{array}{l}\text { Onah, 2015 } \\
\text { KQ } 2\end{array}$ & $\begin{array}{l}\text { RCT } \\
\text { Africa } \\
N \text { enrolled: } \\
214 \text { patients } \\
N \text { completed: } \\
214 \text { patients }\end{array}$ & $\begin{array}{l}\text { Arm } 1 \\
20-24: 8.4 \% \\
25-29: 16.8 \% \\
30-34: 8.4 \% \\
35-39: 45.8 \% \\
40-44: 20.6 \% \\
\\
\text { Arm 2 } \\
20-24: 11.2 \% \\
25-29: 20.6 \% \\
30-34: 10.3 \% \\
35-39: 42.1 \% \\
40-44: 15.9 \% \\
\end{array}$ & $\begin{array}{l}\text { Stage of Labor at Entry: } \\
\text { Active labor } \\
\text { Study's Definition of Labor: } \\
\text { Active labor (dilation }<5 \mathrm{~cm} \text {. } \\
\text { Parity: Mixed parity }\end{array}$ & $\begin{array}{l}\text { Amniotomy } \\
\text { vs. } \\
\text { Control }\end{array}$ & $\begin{array}{l}\text { Mode of delivery; } \\
\text { Cesarean delivery; } \\
\text { Operative vaginal } \\
\text { delivery; } \\
\text { Duration of Labor }\end{array}$ & Good \\
\hline $\begin{array}{l}\text { Palomaki, } \\
2006^{211} \\
\text { KQ } 7\end{array}$ & $\begin{array}{l}\text { RCT } \\
\text { UK/Europe } \\
\\
\text { N enrolled: } \\
107 \text { patients } \\
\text { N completed: } \\
107 \text { patients }\end{array}$ & $\begin{array}{l}\text { Arm } 1 \\
\text { Median: } 27 \\
(20,43) \\
\text { Arm 2 } \\
\text { Median: } 27 \\
(18,39)\end{array}$ & $\begin{array}{l}\text { Stage of Labor at Entry: First } \\
\text { stage active } \\
\text { Study's Definition of Labor: } \\
\text { Enrolled with failure to } \\
\text { progress in the active phase } \\
\text { of the first stage of labor. } \\
\text { Parity: Nulliparous, Parous }\end{array}$ & $\begin{array}{l}\text { Propranolol and Oxytocin - } 2 \mathrm{mg} \\
\text { Propranol with Oxytocin } 2.5 \\
\mathrm{mIU} / \mathrm{min} \text { IV over } 10 \mathrm{~min} \text {, raised } \\
\text { by } 2.5 \mathrm{mIU} / \mathrm{min} \text { every } 30 \mathrm{~min} \\
\text { until contractions reached } 150 \\
\text { Montevideo units } \\
\text { vs. } \\
\text { Placebo and Oxytocin - } \\
\text { Oxytocin } 2.5 \mathrm{mIU} / \mathrm{min} \text { IV over } \\
10 \mathrm{~min}, \text { raised by } 2.5 \mathrm{mIU} / \mathrm{min} \\
\text { every } 30 \text { min until contractions } \\
\text { reached } 150 \text { Montevideo units }\end{array}$ & $\begin{array}{l}\text { Mode of delivery; } \\
\text { Duration of Labor }\end{array}$ & Good \\
\hline
\end{tabular}




\begin{tabular}{|c|c|c|c|c|c|c|}
\hline $\begin{array}{c}\text { Study } \\
\text { Acronym } \\
\text { Key Question } \\
\text { Companion } \\
\text { Article }\end{array}$ & $\begin{array}{l}\text { Study Design } \\
\text { Geographic } \\
\text { Location } \\
\text { N enrolled } \\
\mathbf{N} \text { completed }\end{array}$ & $\begin{array}{l}\text { Age Data (Years } \\
\text { Unless Specified) }\end{array}$ & $\begin{array}{l}\text { Stage of Labor at Entry } \\
\text { Study Definition of Labor } \\
\text { Parity in Population }\end{array}$ & Comparisons & $\begin{array}{c}\text { Outcomes } \\
\text { (Subgroup Analyzed) }\end{array}$ & Quality \\
\hline $\begin{array}{l}\text { Pascual- } \\
\text { Ramirez, } \\
2011^{78} \\
\text { KQ } 4 \\
\text { Companion: } \\
\text { Pascual- } \\
\text { Ramirez, } \\
2012^{79}\end{array}$ & $\begin{array}{l}\text { RCT } \\
\text { UK/Europe } \\
\text { N enrolled: } \\
144 \text { patients } \\
\text { N completed: } \\
144 \text { patients }\end{array}$ & $\begin{array}{l}\text { Arm } 1 \\
\text { Mean: } 31 \\
\text { SD: } 5 \\
\text { Arm } 2 \\
\text { Mean: } 29 \\
\text { SD: } 6\end{array}$ & $\begin{array}{l}\text { Stage of Labor at Entry: First } \\
\text { stage latent (<4 cm dilation), } \\
\text { first stage active ( } 4-10 \mathrm{~cm} \\
\text { dilation) } \\
\text { Study's Definition of Labor: } \\
\text { Eligible individuals had to } \\
\text { meet at least } 2 \text { out of } 3 \\
\text { criteria (in addition to } \\
\text { analgesia request): regular } \\
\text { contractions every } 2- \\
3 \text { min, cervical effacement, } \\
\text { and cervix dilation of } 2 \mathrm{~cm} \text {. } \\
\text { Parity: Nulliparous, Parous }\end{array}$ & $\begin{array}{l}\text { Low-dose epidural } \\
\text { vs. } \\
\text { Combined Spinal Epidural } \\
\text { (CSE) }\end{array}$ & $\begin{array}{l}\text { Mode of delivery; } \\
\text { Duration of Labor; } \\
\text { Parental preferences } \\
\text { (Parity) }\end{array}$ & Good \\
\hline $\begin{array}{l}\text { Patel, } 2014^{190} \\
\text { KQ } 4\end{array}$ & $\begin{array}{l}\text { RCT } \\
\text { UK/Europe } \\
\text { N enrolled: } \\
115 \text { patients } \\
\text { N completed: } \\
115 \text { patients }\end{array}$ & $\begin{array}{l}\text { Arm } 1 \\
\text { Mean: } 30.3 \\
\text { SD: } 5.2 \\
\text { Arm } 2 \\
\text { Mean: } 31.0 \\
\text { SD: } 5.3\end{array}$ & $\begin{array}{l}\text { Stage of Labor at Entry: First } \\
\text { stage active, 2-6 cm dilation } \\
\text { Study's Definition of Labor: } \\
\text { Active labor between } 2 \text { and } \\
6 \mathrm{~cm} \text { dilation. } \\
\text { Parity: Nulliparous, Mixed } \\
\text { Parity }\end{array}$ & $\begin{array}{l}\text { Epidural } \\
\text { vs. } \\
\text { Combined Spinal Epidural } \\
\text { (CSE) }\end{array}$ & $\begin{array}{l}\text { Duration of Labor; } \\
\text { Mode of delivery; } \\
\text { Neonatal admission to } \\
\text { NICU; } \\
\text { Abnormal fetal heart } \\
\text { rate tracing }\end{array}$ & Fair \\
\hline $\begin{array}{l}\text { Phumdoung, } \\
2007^{161} \\
\text { KQ } 3\end{array}$ & $\begin{array}{l}\text { RCT } \\
\text { Asia } \\
\text { N enrolled: } \\
210 \text { patients } \\
\text { N completed: } \\
164 \text { patients }\end{array}$ & $\begin{array}{l}\text { Total } \\
\text { Mean: } 21.51 \\
\text { SD: } 3.62\end{array}$ & $\begin{array}{l}\text { Stage of Labor at Entry: } \\
\text { Unclear/NR } \\
\text { Study's Definition of Labor } \\
\text { Unclear/NR } \\
\text { Parity: Nulliparous }\end{array}$ & $\begin{array}{l}\text { Prince of Songkla University } \\
\text { (PSU) bed and cat position } \\
\text { (alternate with high head) } \\
\text { VS. } \\
\text { PSU bed and cat position } \\
\text { (alternate with supine) } \\
\text { vs. } \\
\text { High head position group - } \\
\text { Women in the high head group } \\
\text { were assigned to lie in the bed } \\
\text { with a 45deg lift } \\
\text { vs. } \\
\text { Supine position }\end{array}$ & $\begin{array}{l}\text { Duration of Labor } \\
\text { (Parity) }\end{array}$ & Poor \\
\hline
\end{tabular}




\begin{tabular}{|c|c|c|c|c|c|c|}
\hline $\begin{array}{c}\text { Study } \\
\text { Acronym } \\
\text { Key Question } \\
\text { Companion } \\
\text { Article } \\
\end{array}$ & $\begin{array}{l}\text { Study Design } \\
\text { Geographic } \\
\text { Location } \\
\text { N enrolled } \\
\mathbf{N} \text { completed } \\
\end{array}$ & $\begin{array}{l}\text { Age Data (Years } \\
\text { Unless Specified) }\end{array}$ & $\begin{array}{l}\text { Stage of Labor at Entry } \\
\text { Study Definition of Labor } \\
\text { Parity in Population }\end{array}$ & Comparisons & $\begin{array}{c}\text { Outcomes } \\
\text { (Subgroup Analyzed) }\end{array}$ & Quality \\
\hline $\begin{array}{l}\text { Phumdoung, } \\
2013^{158} \\
\text { KQ } 3\end{array}$ & $\begin{array}{l}\text { RCT } \\
\text { Asia } \\
\text { N enrolled: } \\
332 \text { patients } \\
\text { N completed: } \\
264 \text { patients }\end{array}$ & $\begin{array}{l}\text { Total } \\
\text { Mean: } 23.38 \\
\text { SD: } 4.31\end{array}$ & $\begin{array}{l}\text { Stage of Labor at Entry: } \\
\text { Unclear/NR } \\
\text { Study's Definition of Labor: } \\
\text { Unclear/NR } \\
\text { Parity: Nulliparous }\end{array}$ & $\begin{array}{l}\text { Prince of Songkla University } \\
\text { (PSU) birthing bed without the } \\
\text { holding bar } \\
\text { vs. } \\
\text { PSU birthing bed with the } \\
\text { holding bar } \\
\text { vs. } \\
\text { Usual birthing bed with the head } \\
\text { of the bed elevated } 45 \text { to } 60 \\
\text { degrees } \\
\text { vs. } \\
\text { Usual birthing bed with the head } \\
\text { of the bed elevated } 15 \text { degrees }\end{array}$ & $\begin{array}{l}\text { Duration of Labor } \\
\text { (Parity) }\end{array}$ & Fair \\
\hline $\begin{array}{l}\text { Prabhakar, } \\
2015^{153} \\
\text { KQ } 3\end{array}$ & $\begin{array}{l}\text { RCT } \\
\text { Asia } \\
\text { N enrolled: } \\
60 \text { patients } \\
\mathrm{N} \text { completed: } \\
60 \text { patients }\end{array}$ & $\begin{array}{l}\text { Arm 1 } \\
\text { 16-20:53.3\% } \\
21-25: 40 \% \\
26-30: 6.7 \% \\
\text { Arm 2 } \\
16-20: 30 \% \\
21-25: 53.3 \% \\
26-30: 16.7 \%\end{array}$ & $\begin{array}{l}\text { Stage of Labor at Entry: First } \\
\text { stage labor } \\
\text { Study's Definition of Labor: } \\
\text { Unclear/NR } \\
\text { Parity: Unclear/NR }\end{array}$ & $\begin{array}{l}\text { Each woman in the } \\
\text { experimental group was } \\
\text { ambulated for an average of 1- } \\
1.5 \mathrm{~h} \text { according to their } \\
\text { tolerance and giving rest } \\
\text { periods in between. } \\
\text { vs. } \\
\text { The control group women were } \\
\text { confined to bed most of the time }\end{array}$ & $\begin{array}{l}\text { Duration of Labor; } \\
\text { Mode of delivery; } \\
\text { Neonatal Birth trauma } \\
\text { (Parity) }\end{array}$ & Good \\
\hline $\begin{array}{l}\text { Ragnar, } 2006^{80} \\
\text { KQ } 3 \\
\text { Companion: } \\
\text { Altman, } 2007^{81}\end{array}$ & $\begin{array}{l}\text { RCT } \\
\text { UK/Europe } \\
\text { N enrolled: } \\
271 \text { patients } \\
\text { N completed: } \\
218 \text { patients }\end{array}$ & $\begin{array}{l}\text { Arm } 1 \\
\text { Mean: } 26.4 \\
\text { SD: } 4.0 \\
\text { Arm } 2 \\
\text { Mean: } 26.5 \\
\text { SD: } 4.3\end{array}$ & $\begin{array}{l}\text { Stage of Labor at Entry: } \\
\text { Second stage } \\
\text { Study's Definition of Labor: } \\
\text { Second stage (fully dilated } \\
\text { and retracted cervix) } \\
\text { Parity: Nulliparous }\end{array}$ & $\begin{array}{l}\text { Kneeling position, leaning } \\
\text { towards the head of the delivery } \\
\text { bed or a cushion, } \\
\text { vs. } \\
\text { Sitting position on the delivery } \\
\text { bed, with the head of the bed } \\
\text { raised at least } 60 \text { degrees from } \\
\text { the horizontal plane }\end{array}$ & $\begin{array}{l}\text { Mode of delivery; } \\
\text { Duration of Labor; } \\
\text { Maternal Trauma to the } \\
\text { Pelvic Floor } \\
\text { (Parity) }\end{array}$ & Good \\
\hline $\begin{array}{l}\text { Rahmani, } \\
2012^{133} \\
\text { KQ } 3\end{array}$ & $\begin{array}{l}\text { RCT } \\
\text { Middle East } \\
\text { N enrolled: } \\
180 \text { patients } \\
\text { N completed: } \\
180 \text { patients }\end{array}$ & $\begin{array}{l}\text { Arm } 1 \\
\text { Mean: } 25.4 \\
\text { SD: } 4.1 \\
\text { Arm } 2 \\
\text { Mean: } 26.8 \\
\text { SD: } 3.6\end{array}$ & $\begin{array}{l}\text { Stage of Labor at Entry: } \\
\text { Unclear, 3-4cm dilation } \\
\text { Study's Definition of Labor: } \\
3-4 \mathrm{~cm} \text { dilation } \\
\text { Parity: Mixed parity }\end{array}$ & $\begin{array}{l}\text { Carbohydrates - } 3 \text { medium } \\
\text { dates with } 110 \mathrm{~mL} \text { water OR } 3 \\
\text { dates with light tea without } \\
\text { sugar OR } 110 \mathrm{~mL} \text { orange juice } \\
\text { drink } \\
\text { vs. } \\
\text { Control - water only }\end{array}$ & $\begin{array}{l}\text { Duration of Labor; Mode } \\
\text { of delivery }\end{array}$ & Fair \\
\hline
\end{tabular}




\begin{tabular}{|c|c|c|c|c|c|c|}
\hline $\begin{array}{c}\text { Study } \\
\text { Acronym } \\
\text { Key Question } \\
\text { Companion } \\
\text { Article } \\
\end{array}$ & $\begin{array}{l}\text { Study Design } \\
\text { Geographic } \\
\text { Location } \\
\text { N enrolled } \\
\text { N completed }\end{array}$ & $\begin{array}{l}\text { Age Data (Years } \\
\text { Unless Specified) }\end{array}$ & $\begin{array}{l}\text { Stage of Labor at Entry } \\
\text { Study Definition of Labor } \\
\text { Parity in Population }\end{array}$ & Comparisons & $\begin{array}{c}\text { Outcomes } \\
\text { (Subgroup Analyzed) }\end{array}$ & Quality \\
\hline $\begin{array}{l}\text { Ruamsap, } \\
2017^{120} \\
\text { KQ } 2\end{array}$ & $\begin{array}{l}\text { RCT } \\
\text { Asia } \\
\text { N enrolled: } \\
120 \text { patients } \\
\text { N completed: } \\
120 \text { patients }\end{array}$ & $\begin{array}{l}\text { Arm } 1 \\
\text { Median: } 25(15,35) \\
\text { Arm } 2 \\
\text { Median: } 23(15,34)\end{array}$ & $\begin{array}{l}\text { Stage of Labor at Entry: } \\
\text { Active labor } \\
\text { Study's Definition of Labor: } \\
\text { Active labor (dilation < } 5 \mathrm{~cm} \text {. } \\
\text { Parity: Mixed parity }\end{array}$ & $\begin{array}{l}\text { Early amniotomy } \\
\text { vs. } \\
\text { Late amniotomy }\end{array}$ & $\begin{array}{l}\text { Mode of delivery; } \\
\text { Cesarean delivery; } \\
\text { Operative vaginal } \\
\text { delivery; } \\
\text { Duration of Labor; } \\
\text { Hemorrhage; } \\
\text { Fetal heart rate }\end{array}$ & Fair \\
\hline $\begin{array}{l}\text { Samadzadeh, } \\
2017^{175} \\
\text { KQ } 3\end{array}$ & $\begin{array}{l}\text { RCT } \\
\text { Middle East } \\
\text { N enrolled: } \\
120 \text { patients } \\
\text { N completed: } \\
120 \text { patients }\end{array}$ & $\begin{array}{l}\text { Arm } 1 \\
\text { Mean: } 25.9 \\
\text { SD: } 5.84 \\
\text { Arm } 2 \\
\text { Mean: } 26.68 \\
\text { SD: } 6.49 \\
\text { Arm } 3 \\
\text { Mean: } 29.31 \\
\text { SD: } 6.41\end{array}$ & $\begin{array}{l}\text { Stage of Labor at Entry: First } \\
\text { stage } \\
\text { Study's Definition of Labor: } \\
\text { First stage with dilation }<4 \\
\text { cm } \\
\text { Parity: Unclear }\end{array}$ & $\begin{array}{l}\text { TENS unit plus oxygen } \\
\text { vs. } \\
\text { Entonox plus TENS unit applied } \\
\text { to participant but not turned on } \\
\text { vs. } \\
\text { TENS unit plus Entonox }\end{array}$ & $\begin{array}{l}\text { Duration of Labor; } \\
\text { Maternal experience } \\
\text { and satisfaction } \\
\text { (Parity) }\end{array}$ & Fair \\
\hline $\begin{array}{l}\text { Santhi, } 2012^{129} \\
\text { KQ } 3\end{array}$ & $\begin{array}{l}\text { RCT } \\
\text { Asia } \\
\text { N enrolled: } \\
50 \text { patients } \\
\mathrm{N} \text { completed: } \\
50 \text { patients }\end{array}$ & Unclear/NR & $\begin{array}{l}\text { Stage of Labor at Entry: } \\
\text { Second stage } \\
\text { Study's Definition of Labor: } \\
\text { Second stage complete } \\
\text { cervical dilation: } 10 \mathrm{~cm} \\
\text { Parity: Nulliparous }\end{array}$ & $\begin{array}{l}\text { Semi-sitting position - Head of } \\
\text { labor table propped up to } 45 \\
\text { degrees during stage } 2 \text { labor } \\
\text { vs. } \\
\text { Supine position }\end{array}$ & Duration of Labor & Fair \\
\hline $\begin{array}{l}\text { Selin, } 2018^{215} \\
\text { KQ } 7\end{array}$ & $\begin{array}{l}\text { RCT } \\
\text { UK/Europe } \\
\text { N enrolled: } \\
\text { 1,351 patients } \\
\mathrm{N} \text { completed: } \\
1,295 \text { patients }\end{array}$ & $\begin{array}{l}\text { Arm } 1 \\
\text { Mean: } 29 \\
\text { SD: } 4.5 \\
\text { Arm } 2 \\
\text { Mean: } 29 \\
\text { SD: } 4.6\end{array}$ & $\begin{array}{l}\text { Stage of Labor at Entry: First } \\
\text { stage active } \\
\text { Study's Definition of Labor: } \\
\text { Active labor with }<6 \mathrm{~cm} \\
\text { dilation } \\
\text { Parity: Nulliparous }\end{array}$ & $\begin{array}{l}\text { High-dose Oxytocin } \\
\text { vs. } \\
\text { Low-dose Oxytocin }\end{array}$ & $\begin{array}{l}\text { Mode of delivery; } \\
\text { Cesarean delivery; } \\
\text { Operative vaginal } \\
\text { delivery; } \\
\text { Duration of Labor; } \\
\text { Hemorrhage; } \\
\text { Fetal heart rate; } \\
\text { NICU admissions; } \\
\text { Maternal experience } \\
\text { and satisfaction }\end{array}$ & $x x x$ \\
\hline
\end{tabular}




\begin{tabular}{|c|c|c|c|c|c|c|}
\hline $\begin{array}{c}\text { Study } \\
\text { Acronym } \\
\text { Key Question } \\
\text { Companion } \\
\text { Article } \\
\end{array}$ & $\begin{array}{l}\text { Study Design } \\
\text { Geographic } \\
\text { Location } \\
\text { N enrolled } \\
\text { N completed } \\
\end{array}$ & $\begin{array}{l}\text { Age Data (Years } \\
\text { Unless Specified) }\end{array}$ & $\begin{array}{l}\text { Stage of Labor at Entry } \\
\text { Study Definition of Labor } \\
\text { Parity in Population }\end{array}$ & Comparisons & $\begin{array}{c}\text { Outcomes } \\
\text { (Subgroup Analyzed) }\end{array}$ & Quality \\
\hline $\begin{array}{l}\text { Sezer, } 2007^{197} \\
\text { KQ } 4\end{array}$ & $\begin{array}{l}\text { RCT } \\
\text { UK/Europe } \\
\text { N enrolled: } \\
40 \text { patients } \\
\text { N completed: } \\
40 \text { patients }\end{array}$ & $\begin{array}{l}\text { Arm } 1 \\
\text { Mean: } 24.2 \\
\text { SD: } 3.3 \\
\text { Arm } 2 \\
\text { Mean: } 24.2 \\
\text { SD: } 3.4\end{array}$ & $\begin{array}{l}\text { Stage of Labor at Entry: First } \\
\text { stage active } \\
\text { Study's Definition of Labor: } \\
\text { Active labor with }<6 \mathrm{~cm} \\
\text { dilation } \\
\text { Parity: Nulliparous }\end{array}$ & $\begin{array}{l}\text { Epidural } \\
\text { vs. } \\
\text { Combined Spinal Epidural } \\
\text { (CSE) }\end{array}$ & $\begin{array}{l}\text { Mode of delivery; } \\
\text { Duration of Labor }\end{array}$ & Fair \\
\hline $\begin{array}{l}\text { Shafaie, } \\
2017^{82} \\
\text { KQ } 3 \\
\text { Companion: } \\
\text { Yulghunlu, } \\
2018^{83}\end{array}$ & $\begin{array}{l}\text { RCT } \\
\text { Middle East } \\
\text { N enrolled: } \\
201 \text { patients } \\
\text { N completed: } \\
201 \text { patients }\end{array}$ & $\begin{array}{l}\text { Arm } 1 \\
\text { Mean: } 23.0 \\
\text { SD: } 3.4 \\
\text { Arm } 2 \\
\text { Mean: } 22.8 \\
\text { SD: } 3.2 \\
\text { Arm } 3 \\
\text { Mean: } 24.0 \\
\text { SD: } 4.4\end{array}$ & $\begin{array}{l}\text { Stage of Labor at Entry: First } \\
\text { stage active } \\
\text { Study's Definition of Labor: } \\
\text { Spontaneous active labor (4 } \\
\text { cm) } \\
\text { Parity: Nulliparous }\end{array}$ & $\begin{array}{l}\text { IV fluid - Ringer's solution at } \\
125 \mathrm{~mL} / \mathrm{h} \text { plus access to oral } \\
\text { fluids per dietitians guidance } \\
\text { vs. } \\
\text { IV fluid - dextrose } 5 \% \text { at } 125 \\
\mathrm{~mL} / \mathrm{h} \text { plus access to oral fluids } \\
\text { per dietitians guidance } \\
\text { vs. } \\
\text { Usual care - access to oral } \\
\text { fluids per dietitians guidance }\end{array}$ & $\begin{array}{l}\text { Mode of delivery; } \\
\text { Cesarean delivery; } \\
\text { Operative vaginal } \\
\text { delivery; } \\
\text { Duration of Labor }\end{array}$ & Fair \\
\hline
\end{tabular}




\begin{tabular}{|c|c|c|c|c|c|c|}
\hline $\begin{array}{l}\text { Study } \\
\text { Acronym } \\
\text { Key Question } \\
\text { Companion } \\
\text { Article }\end{array}$ & $\begin{array}{l}\text { Study Design } \\
\text { Geographic } \\
\text { Location } \\
\text { N enrolled } \\
\text { N completed }\end{array}$ & $\begin{array}{l}\text { Age Data (Years } \\
\text { Unless Specified) }\end{array}$ & $\begin{array}{l}\text { Stage of Labor at Entry } \\
\text { Study Definition of Labor } \\
\text { Parity in Population }\end{array}$ & Comparisons & $\begin{array}{c}\text { Outcomes } \\
\text { (Subgroup Analyzed) }\end{array}$ & Quality \\
\hline $\begin{array}{l}\text { Shahoei, } \\
2017^{178} \\
\text { KQ } 3\end{array}$ & $\begin{array}{l}\text { RCT } \\
\text { Middle East } \\
\text { N enrolled: } \\
90 \text { patients } \\
\text { N completed: } \\
90 \text { patients }\end{array}$ & $\begin{array}{l}\text { Arm 1: } \\
\text { 16-20:13.4\% } \\
\text { 21-25: } 40 \% \\
\text { 26-30: } 40 \% \\
\text { 31-35: 3.3\% } \\
>36: 3.3 \% \\
\text { Arm 2: } \\
\text { 16-20:26.7\% } \\
\text { 21-25:56.7\% } \\
\text { 26-30: } 10 \% \\
\text { 31-35: 3.3\% } \\
>36: 3.3 \% \\
\text { Arm 3: } \\
\text { 16-20: } 20 \% \\
21-25: 40 \% \\
26-30: 30 \% \\
\text { 31-35: } 6.7 \% \\
>36: 3.3 \%\end{array}$ & $\begin{array}{l}\text { Stage of Labor at Entry: } \\
\text { Active phase of labor } \\
\text { Study's Definition of Labor: } \\
\text { Unclear/NR } \\
\text { Parity: Nulliparous }\end{array}$ & $\begin{array}{l}\text { Switched-on TENS device } \\
\text { vs. } \\
\text { Switched-off TENS device } \\
\text { vs. } \\
\text { No TENS device }\end{array}$ & $\begin{array}{l}\text { Mode of delivery; } \\
\text { Operative vaginal } \\
\text { delivery; } \\
\text { Maternal Trauma to the } \\
\text { Pelvic Floor; } \\
\text { Hemorrhage }\end{array}$ & Fair \\
\hline $\begin{array}{l}\text { Sharma, } \\
2012^{135} \\
\text { KQ } 3\end{array}$ & $\begin{array}{l}\text { RCT } \\
\text { Asia } \\
\text { N enrolled: } \\
250 \text { patients } \\
\text { N completed: } \\
243 \text { patients }\end{array}$ & $\begin{array}{l}\text { Arm } 1 \\
\text { Mean: } 25.1 \\
\text { Arm } 2 \\
\text { Mean: } 25.1\end{array}$ & $\begin{array}{l}\text { Stage of Labor at Entry: First } \\
\text { stage active } \\
\text { Study's Definition of Labor: } \\
3-5 \mathrm{~cm} \text { dilation, active } \\
\text { spontaneous labor with or } \\
\text { without ruptured membranes } \\
\text { Parity: Nulliparous }\end{array}$ & $\begin{array}{l}\text { Normal saline with dextrose } \\
(500 \mathrm{~mL}) \text { alternating with } \\
\text { normal saline }(500 \mathrm{~mL}) \text { at rate of } \\
175 \mathrm{~mL} / \mathrm{hr} \\
\text { vs. } \\
\text { Normal saline at rate of } 175 \\
\mathrm{~mL} / \mathrm{hr}\end{array}$ & $\begin{array}{l}\text { Duration of Labor; Mode } \\
\text { of delivery; } \\
\text { Maternal Infection }\end{array}$ & Good \\
\hline $\begin{array}{l}\text { Shen, } 2017^{203} \\
\text { KQ } 4\end{array}$ & $\begin{array}{l}\text { RCT } \\
\text { Asia } \\
\text { N enrolled: } \\
400 \text { patients } \\
\text { N completed: } \\
400 \text { patients }\end{array}$ & $\begin{array}{l}\text { Arm } 1 \\
\text { Mean: } 28.0 \\
\text { SD: } 3.1 \\
\text { Arm } 2 \\
\text { Mean: } 28.1 \\
\text { SD: } 3\end{array}$ & $\begin{array}{l}\text { Stage of Labor at Entry: } \\
\text { Second stage } \\
\text { Study's Definition of Labor: } \\
<6 \mathrm{~cm} \text { dilation } \\
\text { Parity: Nulliparous }\end{array}$ & $\begin{array}{l}\text { Motor sparing epidural } \\
\text { analgesia infusion } \\
\text { vs. } \\
\text { Placebo }\end{array}$ & $\begin{array}{l}\text { Mode of delivery; } \\
\text { Cesarean delivery; } \\
\text { Operative vaginal } \\
\text { delivery; } \\
\text { Duration of Labor; } \\
\text { Maternal preferences } \\
\text { and satisfaction }\end{array}$ & Good \\
\hline
\end{tabular}




\begin{tabular}{|c|c|c|c|c|c|c|}
\hline $\begin{array}{c}\text { Study } \\
\text { Acronym } \\
\text { Key Question } \\
\text { Companion } \\
\text { Article } \\
\end{array}$ & $\begin{array}{c}\text { Study Design } \\
\text { Geographic } \\
\text { Location } \\
\text { N enrolled } \\
\text { N completed }\end{array}$ & $\begin{array}{l}\text { Age Data (Years } \\
\text { Unless Specified) }\end{array}$ & $\begin{array}{l}\text { Stage of Labor at Entry } \\
\text { Study Definition of Labor } \\
\text { Parity in Population }\end{array}$ & Comparisons & $\begin{array}{c}\text { Outcomes } \\
\text { (Subgroup Analyzed) }\end{array}$ & Quality \\
\hline $\begin{array}{l}\text { Shirvani, } \\
2014^{156} \\
\text { KQ } 3\end{array}$ & $\begin{array}{l}\text { RCT } \\
\text { Middle East } \\
\text { N enrolled: } \\
64 \text { patients } \\
\mathrm{N} \text { completed: } \\
64 \text { patients }\end{array}$ & $\begin{array}{l}\text { Total } \\
\text { Min. age: } 18 \\
\text { Max. age: } 35\end{array}$ & $\begin{array}{l}\text { Stage of Labor at Entry: } \\
\text { Beginning of First stage } \\
\text { active } \\
\text { Study's Definition of Labor: } \\
\text { 3-4 cm dilation } \\
\text { Parity: Nulliparous }\end{array}$ & $\begin{array}{l}\text { Ice pack, applied by } \\
\text { doula/midwife to back, } \\
\text { abdomen and lower parts of the } \\
\text { abdomen for } 10 \text { min since } \\
\text { initiation of active phase, } \\
\text { applied to perineum during } \\
\text { Second phase } \\
\text { vs. } \\
\text { No additional interventions } \\
\text { beyond routine care }\end{array}$ & $\begin{array}{l}\text { Duration of Labor; } \\
\text { Mode of delivery; } \\
\text { Maternal Trauma to the } \\
\text { Pelvic Floor } \\
\text { (Parity) }\end{array}$ & Fair \\
\hline $\begin{array}{l}\text { Shrivastava, } \\
2009^{144} \\
\text { KQ } 3\end{array}$ & $\begin{array}{l}\text { RCT } \\
\text { U.S. } \\
\text { N enrolled: } \\
300 \text { patients } \\
\text { N completed: } \\
289 \text { patients }\end{array}$ & $\begin{array}{l}\text { Arm } 1 \\
\text { Mean: } 23.9 \\
\text { SD: } 5.8 \\
\text { Arm } 2 \\
\text { Mean: } 24.2 \\
\text { SD: } 5.7 \\
\text { Arm } 3 \\
\text { Mean: } 23.7 \\
\text { SD: } 5.7\end{array}$ & $\begin{array}{l}\text { Stage of Labor at Entry: First } \\
\text { stage active } \\
\text { Study's Definition of Labor: } \\
3-5 \mathrm{~cm} \text { dilation, spontaneous } \\
\text { active labor with or without } \\
\text { ruptured membranes. } \\
\text { Parity: Nulliparous }\end{array}$ & $\begin{array}{l}5 \% \text { dextrose solution in normal } \\
\text { saline } \\
\text { vs. } \\
10 \% \text { dextrose solution in normal } \\
\text { saline } \\
\text { vs. } \\
\text { normal saline }\end{array}$ & $\begin{array}{l}\text { Maternal Infection; } \\
\text { Maternal Hemorrhage; } \\
\text { Mode of delivery; } \\
\text { Duration of Labor } \\
\text { Abnormal fetal heart } \\
\text { rate tracing }\end{array}$ & Good \\
\hline $\begin{array}{l}\text { Silva Gallo, } \\
2013^{131} \\
\text { KQ } 3\end{array}$ & $\begin{array}{l}\text { RCT } \\
\text { Latin America } \\
\text { N enrolled: } \\
46 \text { patients } \\
\mathrm{N} \text { completed: } \\
46 \text { patients }\end{array}$ & $\begin{array}{l}\text { Arm } 1 \\
\text { Mean: } 19 \\
\text { SD: } 3 \\
\text { Arm } 2 \\
\text { Mean: } 19 \\
\text { SD: } 4\end{array}$ & $\begin{array}{l}\text { Stage of Labor at Entry: First } \\
\text { stage active } \\
\text { Study's Definition of Labor: } \\
4-5 \mathrm{~cm} \text { dilation } \\
\text { Parity: Nulliparous }\end{array}$ & $\begin{array}{l}\text { Massage - } 30 \text { min of massage } \\
\text { delivered during contractions by } \\
\text { physiotherapist beginning when } \\
4-5 \mathrm{~cm} \text { dilated. } \\
\text { vs. } \\
\text { Control - Physiotherapist } \\
\text { accompanied patient for } 30 \text { min } \\
\text { at } 4-5 \mathrm{~cm} \text { dilation. Observed and } \\
\text { answered questions only. }\end{array}$ & $\begin{array}{l}\text { Duration of Labor; Mode } \\
\text { of delivery }\end{array}$ & Good \\
\hline
\end{tabular}




\begin{tabular}{|c|c|c|c|c|c|c|}
\hline $\begin{array}{c}\text { Study } \\
\text { Acronym } \\
\text { Key Question } \\
\text { Companion } \\
\text { Article } \\
\end{array}$ & $\begin{array}{l}\text { Study Design } \\
\text { Geographic } \\
\text { Location } \\
\text { N enrolled } \\
\text { N completed } \\
\end{array}$ & $\begin{array}{l}\text { Age Data (Years } \\
\text { Unless Specified) }\end{array}$ & $\begin{array}{l}\text { Stage of Labor at Entry } \\
\text { Study Definition of Labor } \\
\text { Parity in Population }\end{array}$ & Comparisons & $\begin{array}{c}\text { Outcomes } \\
\text { (Subgroup Analyzed) }\end{array}$ & Quality \\
\hline $\begin{array}{l}\text { Simarro, } \\
2017^{169} \\
\text { KQ } 3\end{array}$ & $\begin{array}{l}\text { RCT } \\
\text { UK/Europe } \\
\text { N enrolled: } \\
150 \text { patients } \\
\text { N completed: } \\
150 \text { patients }\end{array}$ & $\begin{array}{l}\text { Arm } 1 \\
\text { Mean: } 33.4 \\
\text { SD: } 3 \\
\text { Arm } 2 \\
\text { Mean: } 33.9 \\
\text { SD: } 3\end{array}$ & $\begin{array}{l}\text { Stage of Labor at Entry: } \\
\text { Second stage } \\
\text { Study's Definition of Labor: } \\
\text { Second stage after full } \\
\text { cervical dilation } \\
\text { Parity: Mixed Parity }\end{array}$ & $\begin{array}{l}\text { Postural changes during } \\
\text { Second stage of parturients with } \\
\text { epidural analgesia } \\
\text { vs. } \\
\text { Supine position only }\end{array}$ & $\begin{array}{l}\text { Mode of delivery; } \\
\text { Duration of Labor; } \\
\text { Cesarean delivery; } \\
\text { Operative vaginal } \\
\text { delivery }\end{array}$ & Fair \\
\hline $\begin{array}{l}\text { Somprasit, } \\
2005^{117} \\
\text { KQ 2,KQ } 7\end{array}$ & $\begin{array}{l}\text { RCT } \\
\text { Asia } \\
\text { N enrolled: } \\
975 \text { patients } \\
\text { N completed: } \\
960 \text { patients }\end{array}$ & $\begin{array}{l}\text { Arm } 1 \\
\text { Mean: } 24.4 \\
\text { SD: } 4.5 \\
\text { Arm } 2 \\
\text { Mean: } 24.2 \\
\text { SD: } 4.5\end{array}$ & $\begin{array}{l}\text { Stage of Labor at Entry: First } \\
\text { stage active, Second stage } \\
\text { Study's Definition of Labor: } \\
\text { Regular painful contractions } \\
\text { occurring at least once every } \\
5 \text { min; contraction duration } \\
\text { of at least } 40 \text { sec/min; either } \\
\text { spontaneous rupture of } \\
\text { membranes or bloody show } \\
\text { with cervical dilatation and } \\
\text { full effacement } \\
\text { Parity: Nulliparous }\end{array}$ & $\begin{array}{l}\text { Active management: AROM } \\
\text { within } 1 \mathrm{~h} \text { of admission, } 2 \text {-hourly } \\
\text { vaginal assessments; high dose } \\
\text { oxytocin augmentation if } \\
\text { cervical dilatation was less than } \\
1 \mathrm{~cm} / \mathrm{h} \text { in the first stage of labor. } \\
\text { vs. } \\
\text { Conventional management }\end{array}$ & $\begin{array}{l}\text { Mode of delivery; } \\
\text { Duration of Labor; } \\
\text { Maternal Infection } \\
\text { (Parity) }\end{array}$ & Good \\
\hline $\begin{array}{l}\text { Suzuki, } 2010^{87} \\
\text { KQ } 1\end{array}$ & $\begin{array}{l}\text { Observational } \\
\text { Asia } \\
\text { N enrolled: } \\
\text { 2,369 patients } \\
\mathrm{N} \text { completed: } \\
\text { 2,369 patients }\end{array}$ & $\begin{array}{l}\text { Arm } 1 \\
\text { Unclear/NR } \\
\text { Arm } 2 \\
\text { Mean: } 23 \\
\text { Arm } 3 \\
\text { Mean: } 28.4\end{array}$ & $\begin{array}{l}\text { Stage of Labor at Entry: First } \\
\text { stage latent, first stage } \\
\text { active } \\
\text { Study's Definition of Labor: } \\
<7 \mathrm{~cm} \text { dilation at admission, } \\
\text { spontaneous onset of labor } \\
\text { Parity: Nulliparous }\end{array}$ & $\begin{array}{l}\text { Friedman Curve } \\
\text { vs. } \\
\text { Zhang curve } \\
\text { vs. } \\
\text { Suzuki curve (current cohort) }\end{array}$ & Duration of Labor & Poor \\
\hline
\end{tabular}




\begin{tabular}{|c|c|c|c|c|c|c|}
\hline $\begin{array}{l}\text { Study } \\
\text { Acronym } \\
\text { Key Question } \\
\text { Companion } \\
\text { Article }\end{array}$ & $\begin{array}{l}\text { Study Design } \\
\text { Geographic } \\
\text { Location } \\
\text { N enrolled } \\
\text { N completed }\end{array}$ & $\begin{array}{l}\text { Age Data (Years } \\
\text { Unless Specified) }\end{array}$ & $\begin{array}{l}\text { Stage of Labor at Entry } \\
\text { Study Definition of Labor } \\
\text { Parity in Population }\end{array}$ & Comparisons & $\begin{array}{c}\text { Outcomes } \\
\text { (Subgroup Analyzed) }\end{array}$ & Quality \\
\hline $\begin{array}{l}\text { Sweed, } \\
2011^{193} \\
\text { KQ } 4\end{array}$ & $\begin{array}{l}\text { RCT } \\
\text { Africa } \\
\text { N enrolled: } \\
60 \text { patients } \\
\text { N completed: } \\
59 \text { patients }\end{array}$ & $\begin{array}{l}\text { Arm } 1 \\
\text { Mean: } 22 \\
\text { Arm } 2 \\
\text { Mean: } 22 \\
\text { Arm } 3 \\
\text { Mean: } 23.05\end{array}$ & $\begin{array}{l}\text { Stage of Labor at Entry: First } \\
\text { stage active ( } 4-10 \mathrm{~cm} \\
\text { dilation) } \\
\text { Study's Definition of Labor: } \\
\text { Nulliparous women in active } \\
\text { labor with cervical dilatation } \\
\text { of } 5 \mathrm{~cm} \text { and cephalic } \\
\text { presenting fetus } \\
\text { Parity: Nulliparous }\end{array}$ & $\begin{array}{l}\text { Epidural } \\
\text { vs. } \\
\text { Combined Spinal Epidural } \\
\text { (CSE) } \\
\text { VS. } \\
\text { IV Analgesia }\end{array}$ & $\begin{array}{l}\text { Mode of delivery; } \\
\text { Duration of Labor }\end{array}$ & Poor \\
\hline $\begin{array}{l}\text { Taavoni, } \\
2011^{140} \\
\text { KQ } 3\end{array}$ & $\begin{array}{l}\text { RCT } \\
\text { Middle East } \\
\text { N enrolled: } \\
62 \text { patients } \\
\text { N completed: } \\
60 \text { patients }\end{array}$ & $\begin{array}{l}\text { Arm } 1 \\
\text { Mean: } 31.26 \\
\text { SD: } 4.92 \\
\text { Arm } 2 \\
\text { Mean: } 30.85 \\
\text { SD: } 4.23\end{array}$ & $\begin{array}{l}\text { Stage of Labor at Entry: First } \\
\text { stage } \\
\text { Study's Definition of Labor: } \\
\text { First stage active }(4-8 \mathrm{~cm} \\
\text { dilation) } \\
\text { Parity: Nulliparous }\end{array}$ & $\begin{array}{l}\text { Birth ball - } 30 \text { min of sitting on } \\
\text { ball, rocking hips in back and } \\
\text { forth or circular motion } \\
\text { vs. } \\
\text { Usual care - Reclining on bed } \\
\text { without ambulation }\end{array}$ & Duration of Labor & Fair \\
\hline $\begin{array}{l}\text { Taavoni, } \\
2016^{164} \\
\text { KQ } 3\end{array}$ & $\begin{array}{l}\text { RCT } \\
\text { Middle East } \\
\text { N enrolled: } \\
90 \text { patients } \\
\text { N completed: } \\
87 \text { patients }\end{array}$ & $\begin{array}{l}\text { Arm } 1 \\
\text { Mean: } 24.80 \\
\text { SD: } 3.30 \\
\text { Arm } 2 \\
\text { Mean: } 24.43 \\
\text { SD: } 3.67 \\
\text { Arm } 3 \\
\text { Mean: } 23.73 \\
\text { SD: } 4.07\end{array}$ & $\begin{array}{l}\text { Stage of Labor at Entry: First } \\
\text { stage } \\
\text { Study's Definition of Labor: } \\
\text { Cervical dilation between 4- } \\
8 \mathrm{~cm} \\
\text { Parity: Primiparous }\end{array}$ & $\begin{array}{l}\text { Control } \\
\text { vs. } \\
\text { Heat Therapy } \\
\text { vs. } \\
\text { Birthing Ball }\end{array}$ & $\begin{array}{l}\text { Mode of delivery; } \\
\text { Cesarean delivery; } \\
\text { Operative vaginal } \\
\text { delivery; } \\
\text { Duration of Labor; } \\
\text { Maternal preferences } \\
\text { and satisfaction; } \\
\text { Neonatal Respiratory } \\
\text { distress }\end{array}$ & Fair \\
\hline
\end{tabular}




\begin{tabular}{|c|c|c|c|c|c|c|}
\hline $\begin{array}{l}\text { Study } \\
\text { Acronym } \\
\text { Key Question } \\
\text { Companion } \\
\text { Article }\end{array}$ & $\begin{array}{l}\text { Study Design } \\
\text { Geographic } \\
\text { Location } \\
\text { N enrolled } \\
\text { N completed }\end{array}$ & $\begin{array}{l}\text { Age Data (Years } \\
\text { Unless Specified) }\end{array}$ & $\begin{array}{l}\text { Stage of Labor at Entry } \\
\text { Study Definition of Labor } \\
\text { Parity in Population }\end{array}$ & Comparisons & $\begin{array}{c}\text { Outcomes } \\
\text { (Subgroup Analyzed) }\end{array}$ & Quality \\
\hline $\begin{array}{l}\text { Tanvisut, } \\
2018^{167} \\
\text { KQ } 3\end{array}$ & $\begin{array}{l}\text { RCT } \\
\text { Asia } \\
\text { N enrolled: } \\
106 \text { patients } \\
\text { N completed: } \\
104 \text { patients }\end{array}$ & $\begin{array}{l}\text { Arm } 1 \\
\text { Mean: } 26.54 \\
\text { SD: } 4.692 \\
\text { Arm } 2 \\
\text { Mean: } 24.92 \\
\text { SD: } 4.315\end{array}$ & $\begin{array}{l}\text { Stage of Labor at Entry: First } \\
\text { stage } \\
\text { Study's Definition of Labor: } \\
\text { Regular contractions more } \\
\text { than } 3 \text { times in } 10 \text { min with } \\
\text { cervical progression } \\
\text { Parity: Primagravidae }\end{array}$ & $\begin{array}{l}\text { Aromatherapy } \\
\text { vs. } \\
\text { Routine care }\end{array}$ & $\begin{array}{l}\text { Mode of delivery; } \\
\text { Cesarean delivery; } \\
\text { Operative vaginal } \\
\text { delivery; } \\
\text { Duration of Labor; } \\
\text { Fetal heart rate }\end{array}$ & Good \\
\hline $\begin{array}{l}\text { Thies- } \\
\text { Lagergren, } \\
2013^{134} \\
\text { KQ } 3\end{array}$ & $\begin{array}{l}\text { RCT } \\
\text { UK/Europe } \\
\text { N enrolled: } \\
\text { 1,020 patients } \\
\mathrm{N} \text { completed: } \\
\text { 1,002 patients }\end{array}$ & $\begin{array}{l}\text { Total } \\
<25: 17.5 \% \\
25-34: 71.8 \% \\
>35: 10.6 \%\end{array}$ & $\begin{array}{l}\text { Stage of Labor at Entry: } \\
\text { Active } \\
\text { Study's Definition of Labor: } \\
\text { Spontaneous onset of labor } \\
\text { and women induced after } \\
\text { spontaneous rupture of } \\
\text { membranes without } \\
\text { spontaneous contractions } \\
\text { for }>24 \text { hrs } \\
\text { Parity: Mixed parity }\end{array}$ & $\begin{array}{l}\text { Birth seat } \\
\text { vs. } \\
\text { Usual care - position of } \\
\text { mother's choice, most were } \\
\text { supine or supine with stirrups }\end{array}$ & $\begin{array}{l}\text { Duration of Labor; Mode } \\
\text { of delivery }\end{array}$ & Fair \\
\hline $\begin{array}{l}\text { Tolba, } 2018^{98} \\
\text { KQ } 1\end{array}$ & $\begin{array}{l}\text { RCT } \\
\text { Middle East } \\
\text { N enrolled: } \\
122 \text { patients } \\
\text { N completed: } \\
110 \text { patients }\end{array}$ & $\begin{array}{l}\text { Arm } 1 \\
\text { Mean: } 20 \\
(19-21) \\
\text { Arm } 2 \\
\text { Mean: } 21 \\
(19-22.5)\end{array}$ & $\begin{array}{l}\text { Stage of Labor at Entry: First } \\
\text { stage } \\
\text { Study's Definition of Labor: } \\
\text { Unclear/NR } \\
\text { Parity: Nulliparous }\end{array}$ & $\begin{array}{l}\text { Novel labor scale } \\
\text { vs. } \\
\text { WHO partograph }\end{array}$ & $\begin{array}{l}\text { Cesarean delivery; } \\
\text { Duration of Labor; } \\
\text { Hemorrhage }\end{array}$ & Fair \\
\hline
\end{tabular}




\begin{tabular}{|c|c|c|c|c|c|c|}
\hline $\begin{array}{c}\text { Study } \\
\text { Acronym } \\
\text { Key Question } \\
\text { Companion } \\
\text { Article }\end{array}$ & $\begin{array}{l}\text { Study Design } \\
\text { Geographic } \\
\text { Location } \\
\text { N enrolled } \\
\text { N completed }\end{array}$ & $\begin{array}{l}\text { Age Data (Years } \\
\text { Unless Specified) }\end{array}$ & $\begin{array}{l}\text { Stage of Labor at Entry } \\
\text { Study Definition of Labor } \\
\text { Parity in Population }\end{array}$ & Comparisons & $\begin{array}{c}\text { Outcomes } \\
\text { (Subgroup Analyzed) }\end{array}$ & Quality \\
\hline $\begin{array}{l}\text { Tribe, } 2012^{209} \\
\text { PULSE } \\
\text { KQ } 7\end{array}$ & $\begin{array}{l}\text { RCT } \\
\text { UK/Europe } \\
\text { N enrolled: } \\
502 \text { patients } \\
\text { N completed: } \\
500 \text { patients }\end{array}$ & $\begin{array}{l}\text { Arm } 1 \\
\text { Mean: } 30.1 \\
\text { SD: } 5.9 \\
\text { Arm } 2 \\
\text { Mean: } 29.7 \\
\text { SD: } 5.3\end{array}$ & $\begin{array}{l}\text { Stage of Labor at Entry: } \\
\text { Unclear } \\
\text { Study's Definition of Labor: } \\
\text { Requiring oxytocin } \\
\text { augmentation because of } \\
\text { failure to maintain adequate } \\
\text { contractility. } \\
\text { Parity: Nulliparous, Parous }\end{array}$ & $\begin{array}{l}\text { Continuous oxytocin infusion: } \\
\text { Start at } 2 \mathrm{mU} / \mathrm{min} \text { then follow } \\
\text { protocol } \\
\text { vs. } \\
\text { Pulsatile oxytocin infusion: Start } \\
\text { at } 2 \mathrm{mU} / \text { pulse and then follow } \\
\text { protocol }\end{array}$ & $\begin{array}{l}\text { Mode of delivery; } \\
\text { Duration of Labor }\end{array}$ & Good \\
\hline $\begin{array}{l}\text { Tussey, } \\
2015^{154} \\
\text { KQ } 3\end{array}$ & $\begin{array}{l}\text { RCT } \\
\text { U.S. } \\
\text { N enrolled: } \\
142 \text { patients } \\
\text { N completed: } \\
142 \text { patients }\end{array}$ & $\begin{array}{l}\text { Arm } 1 \\
\text { Mean: } 27.5 \\
\text { SD: } 6.7 \\
\text { Arm } 2 \\
\text { Mean: } 27.3 \\
\text { SD: } 6.2\end{array}$ & $\begin{array}{l}\text { Stage of Labor at Entry: First } \\
\text { stage active } \\
\text { Study's Definition of Labor: } \\
\text { Unclear/NR } \\
\text { Parity: Nulliparous, Parous }\end{array}$ & $\begin{array}{l}\text { The peanut ball } \\
\text { vs. } \\
\text { Control }\end{array}$ & $\begin{array}{l}\text { Mode of delivery; } \\
\text { Duration of Labor } \\
\text { (Parity) }\end{array}$ & Fair \\
\hline $\begin{array}{l}\text { Tveit, } 2012^{192} \\
\text { KQ } 4\end{array}$ & $\begin{array}{l}\text { RCT } \\
\text { UK/Europe } \\
\text { N enrolled: } \\
39 \text { patients } \\
\text { N completed: } \\
37 \text { patients }\end{array}$ & $\begin{array}{l}\text { Arm } 1 \\
\text { Mean: } 26 \\
\text { Arm } 2 \\
\text { Mean: } 27\end{array}$ & $\begin{array}{l}\text { Stage of Labor at Entry: First } \\
\text { stage latent, First stage } \\
\text { active } \\
\text { Study's Definition of Labor: } \\
>2 \mathrm{~cm} \text { dilation, regular } \\
\text { uterine contractions } \\
\text { Parity: Mixed parity }\end{array}$ & $\begin{array}{l}\text { Epidural } \\
\text { vs. } \\
\text { Patient Controlled IV Analgesia }\end{array}$ & $\begin{array}{l}\text { Abnormal fetal heart } \\
\text { rate tracing; } \\
\text { Mode of delivery; } \\
\text { Duration of Labor; } \\
\text { Neonatal academia; } \\
\text { Long-term neonatal } \\
\text { health; } \\
\text { Parental preferences }\end{array}$ & Fair \\
\hline $\begin{array}{l}\text { Vadivelu, } \\
2017^{121} \\
\text { KQ } 2\end{array}$ & $\begin{array}{l}\text { RCT } \\
\text { Asia } \\
\text { N enrolled: } \\
288 \text { patients } \\
\text { N completed: } \\
287 \text { patients }\end{array}$ & $\begin{array}{l}\text { Arm } 1 \\
\text { Mean: } 24.9 \\
\text { SD: } 3.9 \\
\text { Arm } 2 \\
\text { Mean: } 25.4 \\
\text { SD: } 4.1\end{array}$ & $\begin{array}{l}\text { Stage of Labor at Entry: First } \\
\text { stage active } \\
\text { Study's Definition of Labor: } \\
\text { Regular and strong } \\
\text { contraction and } 3-5 \mathrm{~cm} \\
\text { dilation } \\
\text { Parity: Mixed Parity }\end{array}$ & $\begin{array}{l}\text { Amniotomy } \\
\text { vs. } \\
\text { Conservative management }\end{array}$ & $\begin{array}{l}\text { Duration of Labor; } \\
\text { Mode of delivery; } \\
\text { Umbilical cord prolapse; } \\
\text { Maternal hemorrhage; } \\
\text { Maternal infection; } \\
\text { Neonatal Respiratory } \\
\text { distress; } \\
\text { Admission to NICU; } \\
\text { Maternal and parental } \\
\text { satisfaction }\end{array}$ & Good \\
\hline
\end{tabular}




\begin{tabular}{|c|c|c|c|c|c|c|}
\hline $\begin{array}{l}\text { Study } \\
\text { Acronym } \\
\text { Key Question } \\
\text { Companion } \\
\text { Article } \\
\end{array}$ & $\begin{array}{l}\text { Study Design } \\
\text { Geographic } \\
\text { Location } \\
\text { N enrolled } \\
\text { N completed }\end{array}$ & $\begin{array}{l}\text { Age Data (Years } \\
\text { Unless Specified) }\end{array}$ & $\begin{array}{l}\text { Stage of Labor at Entry } \\
\text { Study Definition of Labor } \\
\text { Parity in Population }\end{array}$ & Comparisons & $\begin{array}{c}\text { Outcomes } \\
\text { (Subgroup Analyzed) }\end{array}$ & Quality \\
\hline $\begin{array}{l}\text { Vaijayanthimal } \\
\text { a, 2014 }{ }^{150} \\
\text { KQ } 3\end{array}$ & $\begin{array}{l}\text { RCT } \\
\text { Asia } \\
\text { N enrolled: } \\
240 \text { patients } \\
\text { N completed: } \\
211 \text { patients }\end{array}$ & Unclear/NR & $\begin{array}{l}\text { Stage of Labor at Entry: } \\
\text { Active } \\
\text { Study's Definition of Labor: } \\
\text { Active stage of labor (3-6 cm } \\
\text { dilation) } \\
\text { Parity: Nulliparous, }\end{array}$ & $\begin{array}{l}\text { Movement throughout labor } \\
\text { vs. } \\
\text { Control }\end{array}$ & $\begin{array}{l}\text { Duration of Labor; } \\
\text { Mode of delivery; } \\
\text { Abnormal fetal heart } \\
\text { rate tracing; } \\
\text { Parental preferences } \\
\text { (Parity) }\end{array}$ & Poor \\
\hline $\begin{array}{l}\text { Vaziri, } 2016^{225} \\
\text { KQ } 9\end{array}$ & $\begin{array}{l}\text { RCT } \\
\text { Middle East } \\
\text { N enrolled: } \\
102 \text { patients } \\
\text { N completed: } \\
72 \text { patients }\end{array}$ & $\begin{array}{l}\text { Arm } 1 \\
\text { Mean: } 22.23 \\
\text { SD: } 4.32 \\
\text { Arm } 2 \\
\text { Mean: } 22.18 \\
\text { SD: } 4.60\end{array}$ & $\begin{array}{l}\text { Stage of Labor at Entry: } \\
\text { Entering Second stage } \\
\text { Study's Definition of Labor: } \\
\text { Second stage } \\
\text { Parity: Nulliparous }\end{array}$ & $\begin{array}{l}\text { Valsalva method while in supine } \\
\text { position } \\
\text { vs. } \\
\text { Spontaneous pushing while in } \\
\text { lateral position }\end{array}$ & $\begin{array}{l}\text { Mode of delivery; } \\
\text { Duration of Labor; } \\
\text { Maternal experience; } \\
\text { Abnormal fetal heart } \\
\text { rate tracing }\end{array}$ & Fair \\
\hline $\begin{array}{l}\text { Vixner, } 2014^{128} \\
\text { KQ } 3\end{array}$ & $\begin{array}{l}\text { RCT } \\
\text { UK/Europe } \\
\text { N enrolled: } \\
303 \text { patients } \\
\text { N completed: } \\
253 \text { patients }\end{array}$ & $\begin{array}{l}\text { Arm } 1 \\
\text { Mean: } 28.1 \\
\text { SD: } 5.1 \\
\text { Arm } 2 \\
\text { Mean: } 26.5 \\
\text { SD: } 4.7 \\
\text { Arm } 3 \\
\text { Mean: } 27.7 \\
\text { SD: } 4.6\end{array}$ & $\begin{array}{l}\text { Stage of Labor at Entry: First } \\
\text { stage latent, first stage } \\
\text { active } \\
\text { Study's Definition of Labor: } \\
\text { Not specified } \\
\text { Parity: Nulliparous }\end{array}$ & $\begin{array}{l}\text { Manual acupuncture } \\
\text { vs. } \\
\text { Electro-acupuncture - } \\
\text { Acupuncture location chosen } \\
\text { with regard to pain location } \\
\text { vs. } \\
\text { Usual care--had access to } \\
\text { analgesia }\end{array}$ & $\begin{array}{l}\text { Duration of Labor; } \\
\text { Mode of delivery; } \\
\text { Maternal Trauma to the } \\
\text { Pelvic Floor }\end{array}$ & Fair \\
\hline
\end{tabular}




\begin{tabular}{|c|c|c|c|c|c|c|}
\hline $\begin{array}{c}\text { Study } \\
\text { Acronym } \\
\text { Key Question } \\
\text { Companion } \\
\text { Article } \\
\end{array}$ & $\begin{array}{c}\text { Study Design } \\
\text { Geographic } \\
\text { Location } \\
\mathbf{N} \text { enrolled } \\
\mathbf{N} \text { completed } \\
\end{array}$ & $\begin{array}{l}\text { Age Data (Years } \\
\text { Unless Specified) }\end{array}$ & $\begin{array}{l}\text { Stage of Labor at Entry } \\
\text { Study Definition of Labor } \\
\text { Parity in Population }\end{array}$ & Comparisons & $\begin{array}{c}\text { Outcomes } \\
\text { (Subgroup Analyzed) }\end{array}$ & Quality \\
\hline $\begin{array}{l}\text { Wiberg-Itzel, } \\
2018^{177} \\
\text { KQ } 3\end{array}$ & $\begin{array}{l}\text { RCT } \\
\text { UK/Europe } \\
\text { N enrolled: } \\
200 \text { patients } \\
\text { N completed: } \\
200 \text { patients }\end{array}$ & $\begin{array}{l}\text { Arm } 1 \\
\text { Mean: } 32.2 \\
\text { SD: } 5.2 \\
\text { Arm } 2 \\
\text { Mean: } 31.9 \\
\text { SD: } 4.8\end{array}$ & $\begin{array}{l}\text { Stage of Labor at Entry: } \\
\text { Unclear/NR } \\
\text { Study's Definition of Labor: } \\
\text { Unclear/NR } \\
\text { Parity: Primiparous }\end{array}$ & $\begin{array}{l}\text { Bicarbonate } \\
\text { vs. } \\
\text { No bicarbonate }\end{array}$ & $\begin{array}{l}\text { Mode of delivery; } \\
\text { Cesarean delivery; } \\
\text { Operative vaginal } \\
\text { delivery; Maternal } \\
\text { Hemorrhage; Maternal } \\
\text { infection; } \\
\text { Neonatal Respiratory } \\
\text { distress; Admission to } \\
\text { NICU }\end{array}$ & Fair \\
\hline $\begin{array}{l}\text { Wilson, } 2009^{66} \\
\text { COMET } \\
\text { KQ } 4 \\
\text { Companion: } \\
\text { Wilson, 201167 }\end{array}$ & $\begin{array}{l}\text { RCT } \\
\text { UK/Europe } \\
\text { N enrolled: } \\
\text { 1,054 patients } \\
\text { N completed: } \\
\text { 1,054 patients }\end{array}$ & $\begin{array}{l}\text { Arm 1 } \\
<19: 14.7 \% \\
25-29: 30.9 \% \\
30-34: 23.2 \% \\
35+: 9.1 \% \\
\text { Arm 2 } \\
<19: 14 \% \\
25-29: 30.5 \% \\
30-34: 23.6 \% \\
35+: 9.1 \% \\
\text { Arm 3 } \\
<19: 14.9 \% \\
25-29: 30.9 \% \\
30-34: 22.6 \% \\
35+: 9.4 \%\end{array}$ & $\begin{array}{l}\text { Stage of Labor at Entry: } \\
\text { Unclear/NR } \\
\text { Study's Definition of Labor: } \\
\text { Unclear/NR } \\
\text { Parity: Nulliparous }\end{array}$ & $\begin{array}{l}\text { High-dose Epidural (control) } \\
\text { vs. } \\
\text { Combined Spinal Epidural } \\
\text { (CSE) } \\
\text { vs. } \\
\text { Low-dose Infusion Epidural }\end{array}$ & Mode of delivery & Fair \\
\hline
\end{tabular}




\begin{tabular}{|c|c|c|c|c|c|c|}
\hline $\begin{array}{c}\text { Study } \\
\text { Acronym } \\
\text { Key Question } \\
\text { Companion } \\
\text { Article } \\
\end{array}$ & $\begin{array}{l}\text { Study Design } \\
\text { Geographic } \\
\text { Location } \\
\text { N enrolled } \\
\text { N completed } \\
\end{array}$ & $\begin{array}{l}\text { Age Data (Years } \\
\text { Unless Specified) }\end{array}$ & $\begin{array}{l}\text { Stage of Labor at Entry } \\
\text { Study Definition of Labor } \\
\text { Parity in Population }\end{array}$ & Comparisons & $\begin{array}{c}\text { Outcomes } \\
\text { (Subgroup Analyzed) }\end{array}$ & Quality \\
\hline $\begin{array}{l}\text { Wong, } 2005^{200} \\
\text { KQ } 4\end{array}$ & $\begin{array}{l}\text { RCT } \\
\text { U.S. } \\
\text { N enrolled: } \\
750 \text { patients } \\
\text { N completed: } \\
720 \text { patients }\end{array}$ & $\begin{array}{l}\text { Arm } 1 \\
\text { Mean: } 31.3 \\
\text { SD: } 5.2 \\
\text { Arm } 2 \\
\text { Mean: } 31.3 \\
\text { SD: } 5.4\end{array}$ & $\begin{array}{l}\text { Stage of Labor at Entry: First } \\
\text { stage latent } \\
\text { Study's Definition of Labor: } \\
\text { Spontaneous labor or } \\
\text { spontaneous rupture of the } \\
\text { membranes and }<4 \mathrm{~cm} \\
\text { dilation } \\
\text { Parity: Nulliparous }\end{array}$ & $\begin{array}{l}\text { Combined Spinal Epidural } \\
\text { (CSE) } \\
\text { vs. } \\
\text { IV and IM Analgesia }\end{array}$ & $\begin{array}{l}\text { Duration of Labor; } \\
\text { Mode of delivery; } \\
\text { Abnormal fetal heart } \\
\text { rate tracing }\end{array}$ & Good \\
\hline $\begin{array}{l}\text { Wood, } 2016^{96} \\
\text { KQ } 1\end{array}$ & $\begin{array}{l}\text { Observational } \\
\text { U.S. } \\
\text { N enrolled: } \\
2033 \text { patients } \\
\text { N completed: } \\
2033 \text { patients }\end{array}$ & $\begin{array}{l}\text { Arm } 1 \\
\text { Mean: } 31.26 \\
\text { SD: } 4.92 \\
\text { Arm } 2 \\
\text { Mean: } 30.85 \\
\text { SD: } 4.23\end{array}$ & $\begin{array}{l}\text { Stage of Labor at Entry: First } \\
\text { stage latent } \\
\text { Study's Definition of Labor: } \\
\text { All were in labor at less than } \\
4 \mathrm{~cm} \\
\text { Parity: Nulliparous }\end{array}$ & $\begin{array}{l}\text { Combined Spinal Epidural } \\
\text { (CSE) } \\
\text { vs. } \\
\text { Usual care - Epidural }\end{array}$ & Duration of Labor & Good \\
\hline $\begin{array}{l}\text { Wu, } 2017^{176} \\
\text { KQ 3, } 4\end{array}$ & $\begin{array}{l}\text { RCT } \\
\text { Asia } \\
\text { N enrolled: } \\
150 \text { patients } \\
\mathrm{N} \text { completed: } \\
131 \text { patients }\end{array}$ & $\begin{array}{l}\text { Arm } 1 \\
\text { Mean: } 25.0 \\
\text { SD: } 3.2 \\
\text { Arm } 2 \\
\text { Mean: } 25.8 \\
\text { SD: } 3.3 \\
\text { Arm } 3 \\
\text { Mean: } 25.8 \\
\text { SD: } 3.1\end{array}$ & $\begin{array}{l}\text { Stage of Labor at Entry: } \\
\text { Active labor } \\
\text { Study's Definition of Labor: } \\
\text { First stage active }(-4-10 \mathrm{~cm}) \\
\text { Parity: Nulliparous }\end{array}$ & $\begin{array}{l}\text { Respiratory guidance plus: } \\
\text { Acupuncture analgesia } \\
\text { vs. } \\
\text { Spinal-epidural anesthesia } \\
\text { vs. } \\
\text { No additional treatment }\end{array}$ & $\begin{array}{l}\text { Duration of Labor; } \\
\text { Maternal Hemorrhage; } \\
\text { Pelvic floor dysfunction; } \\
\text { Maternal experience; } \\
\text { Neonatal Respiratory } \\
\text { distress }\end{array}$ & Fair \\
\hline $\begin{array}{l}\text { Xiao, } 2019^{181} \\
\text { KQ 3, } 4\end{array}$ & $\begin{array}{l}\text { RCT } \\
\text { Asia } \\
\text { N enrolled: } \\
127 \text { patients } \\
\mathrm{N} \text { completed: } \\
120 \text { patients }\end{array}$ & $\begin{array}{l}\text { Arm } 1 \\
\text { Mean: } 27.62 \\
\text { SD: } 2.86 \\
\text { Arm } 2 \\
\text { Mean: } 27.72 \\
\text { SD: } 2.6\end{array}$ & $\begin{array}{l}\text { Stage of Labor at Entry: First } \\
\text { stage } \\
\text { Study's Definition of Labor: } \\
\text { First stage }-2-3 \mathrm{~cm} \\
\text { Parity: Primiparous }\end{array}$ & $\begin{array}{l}\text { CSEA with PCEA + Epidural } \\
\text { Analgesia } \\
\text { vs. } \\
\text { CSEA with PCEA }\end{array}$ & $\begin{array}{l}\text { Duration of Labor; } \\
\text { Mode of delivery; } \\
\text { Maternal Hemorrhage; } \\
\text { Umbilical cord pH }\end{array}$ & Fair \\
\hline
\end{tabular}




\begin{tabular}{|c|c|c|c|c|c|c|}
\hline $\begin{array}{c}\text { Study } \\
\text { Acronym } \\
\text { Key Question } \\
\text { Companion } \\
\text { Article } \\
\end{array}$ & $\begin{array}{c}\text { Study Design } \\
\text { Geographic } \\
\text { Location } \\
\text { N enrolled } \\
\text { N completed }\end{array}$ & $\begin{array}{l}\text { Age Data (Years } \\
\text { Unless Specified) }\end{array}$ & $\begin{array}{l}\text { Stage of Labor at Entry } \\
\text { Study Definition of Labor } \\
\text { Parity in Population }\end{array}$ & Comparisons & $\begin{array}{c}\text { Outcomes } \\
\text { (Subgroup Analyzed) }\end{array}$ & Quality \\
\hline $\begin{array}{l}\text { Yazdkhasti, } \\
2016^{165} \\
\text { KQ } 3\end{array}$ & $\begin{array}{l}\text { RCT } \\
\text { Middle East } \\
\text { N enrolled: } \\
121 \text { patients } \\
\text { N completed: } \\
120 \text { patients } \\
\end{array}$ & $\begin{array}{l}\text { Arm } 1 \\
\text { Mean: } 18.26 \\
\text { SD: } 2.83 \\
\text { Arm } 2 \\
\text { Mean: } 19.13 \\
\text { SD: } 2.56 \\
\end{array}$ & $\begin{array}{l}\text { Stage of Labor at Entry: First } \\
\text { stage active } \\
\text { Study's Definition of Labor: } \\
\text { First stage active }>3-4 \mathrm{~cm} \\
\text { Parity: Nulliparous }\end{array}$ & $\begin{array}{l}\text { Control } \\
\text { vs. } \\
\text { Aromatherapy (lavender } \\
\text { essence }\end{array}$ & $\begin{array}{l}\text { Duration of Labor; Mode } \\
\text { of delivery }\end{array}$ & Good \\
\hline $\begin{array}{l}\text { Yildirim, } \\
2008^{224} \\
\text { KQ } 9\end{array}$ & $\begin{array}{l}\text { RCT } \\
\text { UK/Europe } \\
\text { N enrolled: } \\
100 \text { patients } \\
\text { N completed: } \\
100 \text { patients }\end{array}$ & $\begin{array}{l}\text { Total } \\
\text { Mean: } 22.9 \\
\text { SD: } 3\end{array}$ & $\begin{array}{l}\text { Stage of Labor at Entry: } \\
\text { Second stage } \\
\text { Study's Definition of Labor: } \\
\text { Second stage, full dilation } \\
\text { (10 cm to delivery) } \\
\text { Parity: Nulliparous }\end{array}$ & $\begin{array}{l}\text { Spontaneous pushing - } \\
\text { encouraged and supported to } \\
\text { push spontaneously in the } \\
\text { second stage of labor, bearing } \\
\text { down in response to } \\
\text { contractions. } \\
\text { vs. } \\
\text { Valsalva pushing - Valsalva } \\
\text { type pushing in the second } \\
\text { stage of labor }\end{array}$ & $\begin{array}{l}\text { Abnormal fetal heart } \\
\text { rate tracing; } \\
\text { Duration of Labor; } \\
\text { Maternal Trauma to the } \\
\text { pelvic floor } \\
\text { (Parity) }\end{array}$ & Fair \\
\hline $\begin{array}{l}\text { Yuenyong, } \\
2012^{163} \\
\text { KQ } 3\end{array}$ & $\begin{array}{l}\text { RCT } \\
\text { Asia } \\
\text { N enrolled: } \\
120 \text { patients } \\
\text { N completed: } \\
114 \text { patients }\end{array}$ & $\begin{array}{l}\text { Total } \\
\text { Mean: } 22.8 \\
\text { SD: } 3.6\end{array}$ & $\begin{array}{l}\text { Stage of Labor at Entry: } \\
\text { Unclear/NR } \\
\text { Study's Definition of Labor: } \\
\text { Whenever women arrived at } \\
\text { hospital believing they were } \\
\text { in labor. } \\
\text { Parity: Nulliparous }\end{array}$ & $\begin{array}{l}\text { Support of close female relative } \\
\text { vs. } \\
\text { Control }\end{array}$ & $\begin{array}{l}\text { Duration of Labor } \\
\text { (Parity) }\end{array}$ & Good \\
\hline
\end{tabular}




\begin{tabular}{|c|c|c|c|c|c|c|}
\hline $\begin{array}{c}\text { Study } \\
\text { Acronym } \\
\text { Key Question } \\
\text { Companion } \\
\text { Article }\end{array}$ & $\begin{array}{c}\text { Study Design } \\
\text { Geographic } \\
\text { Location } \\
\text { N enrolled } \\
\mathbf{N} \text { completed }\end{array}$ & $\begin{array}{l}\text { Age Data (Years } \\
\text { Unless Specified) }\end{array}$ & $\begin{array}{l}\text { Stage of Labor at Entry } \\
\text { Study Definition of Labor } \\
\text { Parity in Population }\end{array}$ & Comparisons & $\begin{array}{c}\text { Outcomes } \\
\text { (Subgroup Analyzed) }\end{array}$ & Quality \\
\hline $\begin{array}{l}\text { Zhang, 201021 } \\
\text { CSL } \\
\text { KQ } 1\end{array}$ & $\begin{array}{l}\text { Observational } \\
\text { U.S. } \\
\text { N enrolled: } \\
62,415 \text { patients } \\
\text { N completed: } \\
62,415 \text { patients }\end{array}$ & $\begin{array}{l}\text { Arm } 1 \\
\text { Mean: } 24.6 \\
\text { SD: } 5.8 \\
\text { Arm } 2 \\
\text { Mean: } 27.7 \\
\text { SD: } 5.7 \\
\text { Arm } 3 \\
\text { Mean: } 30.0 \\
\text { SD: } 5.4\end{array}$ & $\begin{array}{l}\text { Stage of Labor at Entry: } \\
\text { Median (10th, 90th } \\
\text { percentiles at admission) } \\
\text { Parity 0: } 4(1,7) \\
\text { Parity 1: } 4.5(2,8) \\
\text { Parity 2+: } 5(2,8) \\
\text { Study's Definition of Labor: } \\
\text { Unclear/NR } \\
\text { Parity: Nulliparous, Parous }\end{array}$ & $\begin{array}{l}\text { Nulliparous } \\
\text { vs. } \\
\text { Parity } 1 \\
\text { vs. } \\
\text { Parity } 2 \text { or more }\end{array}$ & Duration of Labor & Fair \\
\hline $\begin{array}{l}\text { Zhang, 201022 } \\
\text { KQ } 1\end{array}$ & $\begin{array}{l}\text { Observational } \\
\text { U.S. } \\
\text { N enrolled: } \\
\text { 40,973 patients } \\
\text { N completed: } \\
\text { 26,838 patients }\end{array}$ & $\begin{array}{l}\text { Arm } 1 \\
\text { Mean: } 20.3 \\
\text { SD: } 3.9 \\
\text { Arm } 2 \\
\text { Mean: } 22.7 \\
\text { SD: } 4.4 \\
\text { Arm } 3 \\
\text { Mean: } 27.4 \\
\text { SD: } 5.5\end{array}$ & $\begin{array}{l}\text { Stage of Labor at Entry: } \\
\text { Cervical dilation at } \\
\text { admission }(\mathrm{cm}) \text { - } \\
\text { Parity 0: median (10th } \\
\text { percentile, } 90 \text { th percentile) }= \\
3(1,6) \\
\text { Parity 1: median (10th } \\
\text { percentile, 90th percentile) = } \\
3.5(2,7) \\
\text { Parity 2+: median (10th } \\
\text { percentile, 90th percentile) = } \\
3.5(1.5,6.5) \\
\text { Study's Definition of Labor: } \\
\text { Unclear/NR } \\
\text { Parity: Nulliparous, Parous }\end{array}$ & $\begin{array}{l}\text { Nulliparous } \\
\text { vs. } \\
\text { Parity } 1 \\
\text { vs. } \\
\text { Parity } 2 \text { or more }\end{array}$ & $\begin{array}{l}\text { Mode of delivery; } \\
\text { Duration of Labor } \\
\text { (Parity) }\end{array}$ & Good \\
\hline
\end{tabular}




\begin{tabular}{|c|c|c|c|c|c|c|}
\hline $\begin{array}{c}\text { Study } \\
\text { Acronym } \\
\text { Key Question } \\
\text { Companion } \\
\text { Article }\end{array}$ & $\begin{array}{l}\text { Study Design } \\
\text { Geographic } \\
\text { Location } \\
\text { N enrolled } \\
\text { N completed }\end{array}$ & $\begin{array}{l}\text { Age Data (Years } \\
\text { Unless Specified) }\end{array}$ & $\begin{array}{l}\text { Stage of Labor at Entry } \\
\text { Study Definition of Labor } \\
\text { Parity in Population }\end{array}$ & Comparisons & $\begin{array}{c}\text { Outcomes } \\
\text { (Subgroup Analyzed) }\end{array}$ & Quality \\
\hline $\begin{array}{l}\text { Zhang, } 2017^{170} \\
\text { KQ } 3\end{array}$ & $\begin{array}{l}\text { RCT } \\
\text { Asia } \\
\text { N enrolled: } \\
1400 \text { patients } \\
\text { N completed: } \\
886 \text { patients }\end{array}$ & $\begin{array}{l}\text { Arm } 1 \\
\text { Mean: } 25.9 \\
\text { SD: } 3.9 \\
\text { Arm } 2 \\
\text { Mean: } 26.5 \\
\text { SD: } 4.2\end{array}$ & $\begin{array}{l}\text { Stage of Labor at Entry: First } \\
\text { stage active } \\
\text { Study's Definition of Labor: } \\
\text { First stage active (not } \\
\text { defined) } \\
\text { Parity: Nulliparous }\end{array}$ & $\begin{array}{l}\text { Hands-and-knees position } \\
\text { vs. } \\
\text { Supine position }\end{array}$ & $\begin{array}{l}\text { Duration of Labor; } \\
\text { Mode of delivery; } \\
\text { Cesarean delivery; } \\
\text { Operative vaginal } \\
\text { delivery; Maternal } \\
\text { Hemorrhage; } \\
\text { Neonatal Respiratory } \\
\text { distress; } \\
\text { Shoulder dystocia; } \\
\text { Abnormal fetal heart } \\
\text { rate tracing }\end{array}$ & Fair \\
\hline $\begin{array}{l}\text { Zhang, 201899 } \\
\text { KQ } 1\end{array}$ & $\begin{array}{l}\text { Observational } \\
\text { U.S. } \\
\text { N enrolled: } \\
\text { 8,988 patients } \\
\text { N completed: } \\
\text { 8,988 patients }\end{array}$ & $\begin{array}{l}\text { Arm } 1 \text { (Nulliparous } \\
\text { women) } \\
\text { Mean: } 24.1 \\
\text { SD: } 4.4 \\
\text { Arm } 2 \text { (Parous } \\
\text { women) } \\
\text { Mean: } 28.6 \\
\text { SD: } 4.8\end{array}$ & $\begin{array}{l}\text { Stage of Labor at Entry: } \\
\text { When high-dose Oxytocin } \\
\text { was administered } \\
\text { Study's Definition of Labor: } \\
\text { High-dose Oxytocin was } \\
\text { administered on average at } \\
\text { 2-3 cm dilation. } \\
\text { Parity: Nulliparous, Parous }\end{array}$ & $\begin{array}{l}\text { Progress of labor among } \\
\text { women requiring oxytocin } \\
\text { augmentation during labor } \\
\text { stratified by parity } \\
4-5 \mathrm{~cm} \\
\text { vs. } \\
5-6 \mathrm{~cm} \\
\text { vs. } \\
6-7 \mathrm{~cm} \\
\text { vs. } \\
7-8 \mathrm{~cm} \\
\text { vs. } \\
8-9 \mathrm{~cm} \\
\text { vs. } \\
9-10 \mathrm{~cm} \\
\text { vs. } \\
6-10 \mathrm{~cm}\end{array}$ & $\begin{array}{l}\text { Duration of Labor; } \\
\text { Mode of delivery; } \\
\text { (Parity) }\end{array}$ & Good \\
\hline
\end{tabular}

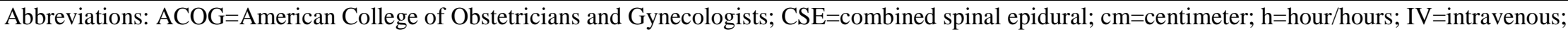
$\mathrm{mL}=$ =milliliter; $\mathrm{mmHG}=$ millimeter of mercury; LI4=acupuncture location; min=minute/minutes; $\mathrm{N}=$ number; NICU=neonatal intensive care unit; $\mathrm{NR}=$ not reported; RCT=randomized controlled trial; s=second/seconds; SD=standard deviation; SMFM=Society for Material-Fetal Medicine; WHO=World Health Organization 


\section{Appendix F. AMSTAR Quality Assessment for Systematic Reviews}

Table F-1 shows the AMSTAR (A Measurement Tool to Assess Systematic Reviews) quality assessment for the included systematic reviews. For full study citations, please refer to the report's main reference list.

Table F-1. AMSTAR assessment for included systematic reviews

\begin{tabular}{|c|c|c|c|c|c|c|c|c|}
\hline Study & $\begin{array}{c}\text { Duplicate } \\
\text { study } \\
\text { selection } \\
\text { and data } \\
\text { abstraction? }\end{array}$ & $\begin{array}{l}\text { Comprehensive } \\
\text { literature search } \\
\text { performed? }\end{array}$ & $\begin{array}{c}\text { Status of } \\
\text { publication } \\
\text { (i.e. grey } \\
\text { literature) } \\
\text { used as an } \\
\text { inclusion } \\
\text { criterion? }\end{array}$ & $\begin{array}{c}\text { List of studies } \\
\text { (included and } \\
\text { excluded) } \\
\text { provided? }\end{array}$ & $\begin{array}{c}\text { Characteristics } \\
\text { of included } \\
\text { studies } \\
\text { provided? }\end{array}$ & $\begin{array}{c}\text { Scientific } \\
\text { quality of the } \\
\text { included } \\
\text { studies used } \\
\text { appropriately } \\
\text { in formulating } \\
\text { conclusions? }\end{array}$ & $\begin{array}{l}\text { Methods used } \\
\text { to combine the } \\
\text { findings of } \\
\text { studies } \\
\text { appropriate? }\end{array}$ & $\begin{array}{c}\text { Conflict } \\
\text { of } \\
\text { interest } \\
\text { included? }\end{array}$ \\
\hline $\begin{array}{l}\text { Abalos, } \\
2018^{103}\end{array}$ & $\mathrm{Y}$ & $\mathrm{Y}$ & - & $\mathrm{Y}$ & $\mathrm{Y}$ & (1) & $\mathrm{Y}$ & $\mathrm{Y}$ \\
\hline $\begin{array}{l}\text { Anim-Somuah, } \\
2011^{43}\end{array}$ & $\mathrm{Y}$ & $\mathrm{Y}$ & $\mathrm{Y}$ & $\mathrm{Y}$ & $\mathrm{Y}$ & $\mathrm{Y}$ & $\mathrm{Y}$ & $\mathrm{Y}$ \\
\hline $\begin{array}{l}\text { Aquino, } \\
2018^{184}\end{array}$ & $Y$ & $\mathrm{Y}$ & C & $\mathrm{N}$ & $\mathrm{Y}$ & $\mathrm{Y}$ & C & C \\
\hline Bakker, $2013^{37}$ & $\mathrm{Y}$ & $\mathrm{Y}$ & $\mathrm{Y}$ & $\mathrm{Y}$ & $\mathrm{Y}$ & $\mathrm{Y}$ & $\mathrm{Y}$ & $\mathrm{Y}$ \\
\hline $\begin{array}{l}\text { Barasinski, } \\
2016^{229}\end{array}$ & $\mathrm{~N}$ & $\mathrm{Y}$ & $\mathrm{Y}$ & $\mathrm{N}$ & $\mathrm{Y}$ & $\mathrm{Y}$ & $\mathrm{Y}$ & $\mathrm{Y}$ \\
\hline $\begin{array}{l}\text { Béranger, } \\
2017^{104}\end{array}$ & $Y$ & $\mathrm{~N}$ & $\mathrm{~N}$ & $\mathrm{~N}$ & $\mathrm{~N}$ & $\mathrm{~N}$ & $Y$ & $Y$ \\
\hline $\begin{array}{l}\text { Bohren, } \\
2017^{187}\end{array}$ & $\mathrm{Y}$ & $\mathrm{Y}$ & $\mathrm{Y}$ & $\mathrm{Y}$ & $\mathrm{Y}$ & $\mathrm{Y}$ & $\mathrm{Y}$ & $\mathrm{Y}$ \\
\hline Brown, $2013^{35}$ & $\mathrm{Y}$ & $\mathrm{Y}$ & $\mathrm{Y}$ & $\mathrm{Y}$ & $\mathrm{Y}$ & $Y$ & $\mathrm{Y}$ & $\mathrm{Y}$ \\
\hline Bugg, $2013^{220}$ & $\mathrm{Y}$ & $Y$ & $Y$ & $Y$ & $Y$ & $Y$ & $Y$ & $Y$ \\
\hline $\begin{array}{l}\text { Ciardulli, } \\
2017^{185}\end{array}$ & $\mathrm{Y}$ & $\mathrm{Y}$ & $\mathrm{N}$ & $\mathrm{N}$ & Y & $\mathrm{Y}$ & C & C \\
\hline Cluett, $2009^{48}$ & $\mathrm{Y}$ & $\mathrm{Y}$ & $\mathrm{Y}$ & $\mathrm{Y}$ & $\mathrm{Y}$ & $\mathrm{Y}$ & $\mathrm{Y}$ & $\mathrm{Y}$ \\
\hline $\begin{array}{l}\text { Costlet, } \\
2012^{221} \\
\end{array}$ & $\mathrm{Y}$ & $\mathrm{Y}$ & $\mathrm{Y}$ & $\mathrm{Y}$ & $\mathrm{Y}$ & $\mathrm{Y}$ & $\mathrm{Y}$ & $\mathrm{Y}$ \\
\hline $\begin{array}{l}\text { Dawood, } \\
2013^{38}\end{array}$ & $\mathrm{Y}$ & $\mathrm{Y}$ & $\mathrm{Y}$ & $\mathrm{Y}$ & $\mathrm{Y}$ & $\mathrm{Y}$ & $\mathrm{Y}$ & $\mathrm{Y}$ \\
\hline $\begin{array}{l}\text { Downe, } \\
2013^{206}\end{array}$ & $\mathrm{Y}$ & $\mathrm{Y}$ & $\mathrm{Y}$ & $\mathrm{Y}$ & $\mathrm{Y}$ & $\mathrm{Y}$ & $\mathrm{Y}$ & $\mathrm{Y}$ \\
\hline $\begin{array}{l}\text { Ehsanipoor, } \\
2017^{183}\end{array}$ & Y & $Y$ & C & $N$ & $\mathrm{Y}$ & Y & Y & $N$ \\
\hline Fortier, $2015^{52}$ & $\mathrm{Y}$ & $\mathrm{Y}$ & $\mathrm{N}$ & $\mathrm{N}$ & $\mathrm{Y}$ & $Y$ & $\mathrm{Y}$ & $\mathrm{Y}$ \\
\hline $\begin{array}{l}\text { Gaucher, } \\
2017^{218}\end{array}$ & $\mathrm{Y}$ & $Y$ & C & $\mathrm{Y}$ & $\mathrm{Y}$ & $\mathrm{Y}$ & $\mathrm{Y}$ & $\mathrm{N}$ \\
\hline
\end{tabular}




\begin{tabular}{|c|c|c|c|c|c|c|c|c|}
\hline Study & $\begin{array}{l}\text { Duplicate } \\
\text { study } \\
\text { selection } \\
\text { and data } \\
\text { abstraction? }\end{array}$ & $\begin{array}{l}\text { Comprehensive } \\
\text { literature search } \\
\text { performed? }\end{array}$ & $\begin{array}{c}\text { Status of } \\
\text { publication } \\
\text { (i.e. grey } \\
\text { literature) } \\
\text { used as an } \\
\text { inclusion } \\
\text { criterion? }\end{array}$ & $\begin{array}{l}\text { List of studies } \\
\text { (included and } \\
\text { excluded) } \\
\text { provided? }\end{array}$ & $\begin{array}{l}\text { Characteristics } \\
\text { of included } \\
\text { studies } \\
\text { provided? }\end{array}$ & $\begin{array}{c}\text { Scientific } \\
\text { quality of the } \\
\text { included } \\
\text { studies used } \\
\text { appropriately } \\
\text { in formulating } \\
\text { conclusions? }\end{array}$ & $\begin{array}{l}\text { Methods used } \\
\text { to combine the } \\
\text { findings of } \\
\text { studies } \\
\text { appropriate? }\end{array}$ & $\begin{array}{l}\text { Conflict } \\
\text { of } \\
\text { interest } \\
\text { included? }\end{array}$ \\
\hline $\begin{array}{l}\text { Hodnett, } \\
2013^{54}\end{array}$ & $\mathrm{Y}$ & $\mathrm{Y}$ & $\mathrm{Y}$ & $\mathrm{Y}$ & $\mathrm{Y}$ & $\mathrm{Y}$ & $\mathrm{Y}$ & $\mathrm{Y}$ \\
\hline $\begin{array}{l}\text { Kenyon, } \\
2013^{217}\end{array}$ & $\mathrm{Y}$ & $\mathrm{Y}$ & $\mathrm{Y}$ & $\mathrm{Y}$ & $\mathrm{Y}$ & $\mathrm{Y}$ & $\mathrm{Y}$ & $\mathrm{Y}$ \\
\hline $\begin{array}{l}\text { Kobayashi, } \\
2017^{186}\end{array}$ & $\mathrm{Y}$ & $Y$ & $\mathrm{Y}$ & Y & $Y$ & $\mathrm{Y}$ & Y & $Y$ \\
\hline $\begin{array}{l}\text { Lavender, } \\
2018^{102}\end{array}$ & $Y$ & $Y$ & $Y$ & $Y$ & $Y$ & $Y$ & $Y$ & $Y$ \\
\hline $\begin{array}{l}\text { Lawrence, } \\
2013^{34}\end{array}$ & $\mathrm{Y}$ & $Y$ & $Y$ & $\mathrm{Y}$ & Y & $\mathrm{Y}$ & $Y$ & $\mathrm{Y}$ \\
\hline Liu, $2014^{33}$ & $\mathrm{Y}$ & $\mathrm{Y}$ & $\mathrm{Y}$ & $\mathrm{N}$ & $\mathrm{Y}$ & $\mathrm{Y}$ & $\mathrm{Y}$ & $\mathrm{Y}$ \\
\hline Malin, $2016^{182}$ & $\mathrm{~N}$ & $\mathrm{Y}$ & $\mathrm{Y}$ & $\mathrm{N}$ & $\mathrm{Y}$ & $\mathrm{Y}$ & $\mathrm{Y}$ & $\mathrm{N}$ \\
\hline Martis, $2017^{223}$ & $\mathrm{Y}$ & $\mathrm{Y}$ & $\mathrm{Y}$ & $\mathrm{Y}$ & $\mathrm{Y}$ & $\mathrm{Y}$ & $\mathrm{Y}$ & $\mathrm{Y}$ \\
\hline $\begin{array}{l}\text { Marucci, } \\
2007^{49}\end{array}$ & $\mathrm{Y}$ & $\mathrm{Y}$ & $\mathrm{Y}$ & $\mathrm{Y}$ & $\mathrm{Y}$ & $\mathrm{Y}$ & $\mathrm{Y}$ & $\mathrm{Y}$ \\
\hline Neal, $2010^{47}$ & $\mathrm{~N}$ & $\mathrm{~N}$ & $\mathrm{~N}$ & $\mathrm{~N}$ & $\mathrm{Y}$ & $\mathrm{Y}$ & $\mathrm{C}$ & $\mathrm{Y}$ \\
\hline $\begin{array}{l}\text { Oladapo, } \\
2018^{101}\end{array}$ & $Y$ & $Y$ & $Y$ & $\mathrm{~N}$ & $Y$ & $Y$ & $Y$ & $Y$ \\
\hline $\begin{array}{l}\text { Singata, } \\
2013^{36}\end{array}$ & $\mathrm{Y}$ & $\mathrm{Y}$ & $\mathrm{Y}$ & $\mathrm{Y}$ & $\mathrm{Y}$ & $\mathrm{Y}$ & $\mathrm{Y}$ & $\mathrm{Y}$ \\
\hline Smith, $2011^{45}$ & $\mathrm{Y}$ & $\mathrm{Y}$ & $\mathrm{Y}$ & $\mathrm{Y}$ & $\mathrm{Y}$ & $\mathrm{Y}$ & $\mathrm{Y}$ & $\mathrm{Y}$ \\
\hline Smyth, $2013^{123}$ & $\mathrm{Y}$ & $\mathrm{Y}$ & $\mathrm{Y}$ & $\mathrm{Y}$ & $\mathrm{Y}$ & $\mathrm{Y}$ & $\mathrm{Y}$ & $\mathrm{Y}$ \\
\hline Souza, $2006^{50}$ & $\mathrm{Y}$ & $\mathrm{Y}$ & $\mathrm{Y}$ & $\mathrm{Y}$ & $\mathrm{Y}$ & $\mathrm{Y}$ & $Y$ & $Y$ \\
\hline Wei, $2013^{122}$ & $\mathrm{Y}$ & $\mathrm{Y}$ & $\mathrm{Y}$ & $\mathrm{Y}$ & $\mathrm{Y}$ & $\mathrm{Y}$ & $\mathrm{Y}$ & $\mathrm{Y}$ \\
\hline Wei, $2010^{216}$ & $\mathrm{Y}$ & $\mathrm{Y}$ & $\mathrm{C}$ & $\mathrm{Y}$ & $\mathrm{Y}$ & $\mathrm{Y}$ & $\mathrm{Y}$ & $\mathrm{Y}$ \\
\hline Wei, $2009^{219}$ & $\mathrm{Y}$ & $\mathrm{Y}$ & $\mathrm{Y}$ & $\mathrm{Y}$ & $Y$ & $Y$ & $\mathrm{Y}$ & $\mathrm{Y}$ \\
\hline
\end{tabular}

Abbreviations: $\mathrm{C}=$ Can't answer; $\mathrm{N}=\mathrm{No}$; $\mathrm{Y}=\mathrm{Yes}$ 
Figure F-1. Summary of AMSTAR quality assessment for included systematic reviews

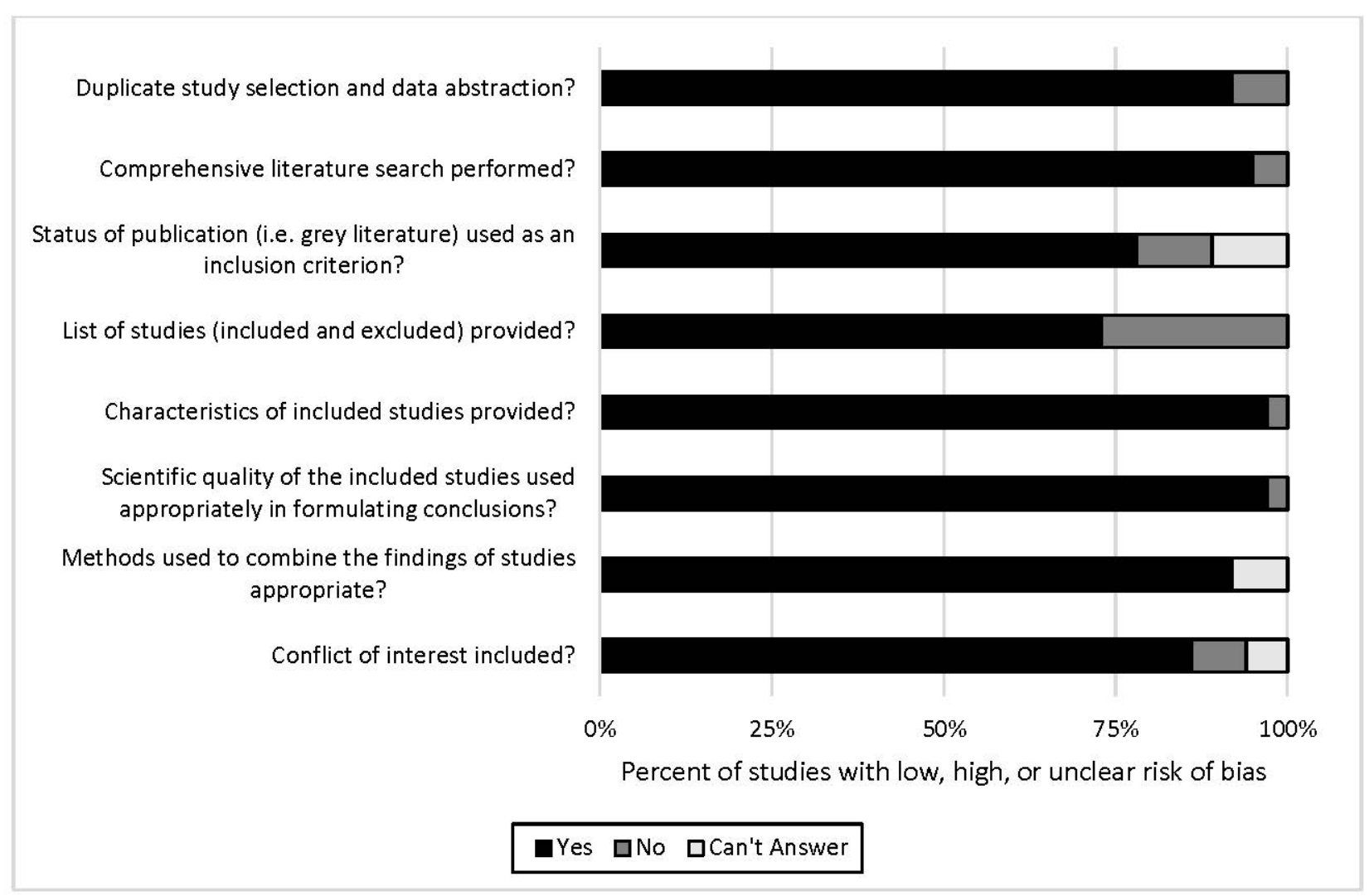




\section{Appendix G. Risk of Bias Assessment for Included Studies}

Table G-1 shows the risk of bias quality assessment for the included cohort studies. For full study citations, please refer to the report's main reference list.

Table G-1. Risk of bias assessment for included cohort studies

\begin{tabular}{|c|c|c|c|}
\hline Study & Potential Issues with Selection & Potential Issues with Comparability & Potential Issues with Outcomes \\
\hline Cheng, $2010^{86}$ & $\mathrm{~N}$ & $\mathrm{~N}$ & $\mathrm{~N}$ \\
\hline Frigo, $2011^{85}$ & $\mathrm{~N}$ & $\mathrm{~N}$ & $\mathrm{~N}$ \\
\hline Greenberg, $2007^{88}$ & $\mathrm{~N}$ & $\mathrm{~N}$ & $\mathrm{Y}$ \\
\hline Hoppe, $2018^{100}$ & $\mathrm{Y}$ & $\mathrm{N}$ & $\mathrm{N}$ \\
\hline Inde, $2018^{92}$ & $\mathrm{Y}$ & $\mathrm{N}$ & $\mathrm{N}$ \\
\hline Kauffman, $2016^{93}$ & $\mathrm{~N}$ & $\mathrm{~N}$ & $\mathrm{~N}$ \\
\hline Mason, $2018^{97}$ & $\mathrm{Y}$ & $\mathrm{Y}$ & $\mathrm{N}$ \\
\hline Neal, $2018^{91}$ & $\bar{Y}$ & $\mathrm{~N}$ & $\mathrm{~N}$ \\
\hline Neal, $2017^{95}$ & $\mathrm{Y}$ & $\mathrm{N}$ & $\mathrm{N}$ \\
\hline Neal, $2014^{84}$ & $\mathrm{~N}$ & $\mathrm{Y}$ & $\mathrm{N}$ \\
\hline Suzuki, $2010^{87}$ & $\mathrm{~N}$ & $\mathrm{~N}$ & $\mathrm{~N}$ \\
\hline Wood, $2016^{96}$ & $\mathrm{Y}$ & $\mathrm{N}$ & $\mathrm{N}$ \\
\hline Zhang, $2010^{21}$ & $\mathrm{~N}$ & $\mathrm{Y}$ & $\mathrm{N}$ \\
\hline Zhang, $2010^{22}$ & $\mathrm{~N}$ & $\mathrm{~N}$ & $\mathrm{Y}$ \\
\hline Zhang, $2018^{99}$ & $\mathrm{~N}$ & $\mathrm{~N}$ & $\mathrm{~N}$ \\
\hline
\end{tabular}

Abbreviations: $\mathrm{N}=\mathrm{No}$; $\mathrm{Y}=\mathrm{Yes}$ 
Figure G-1. Summary of risk of bias assessment for included cohort studies

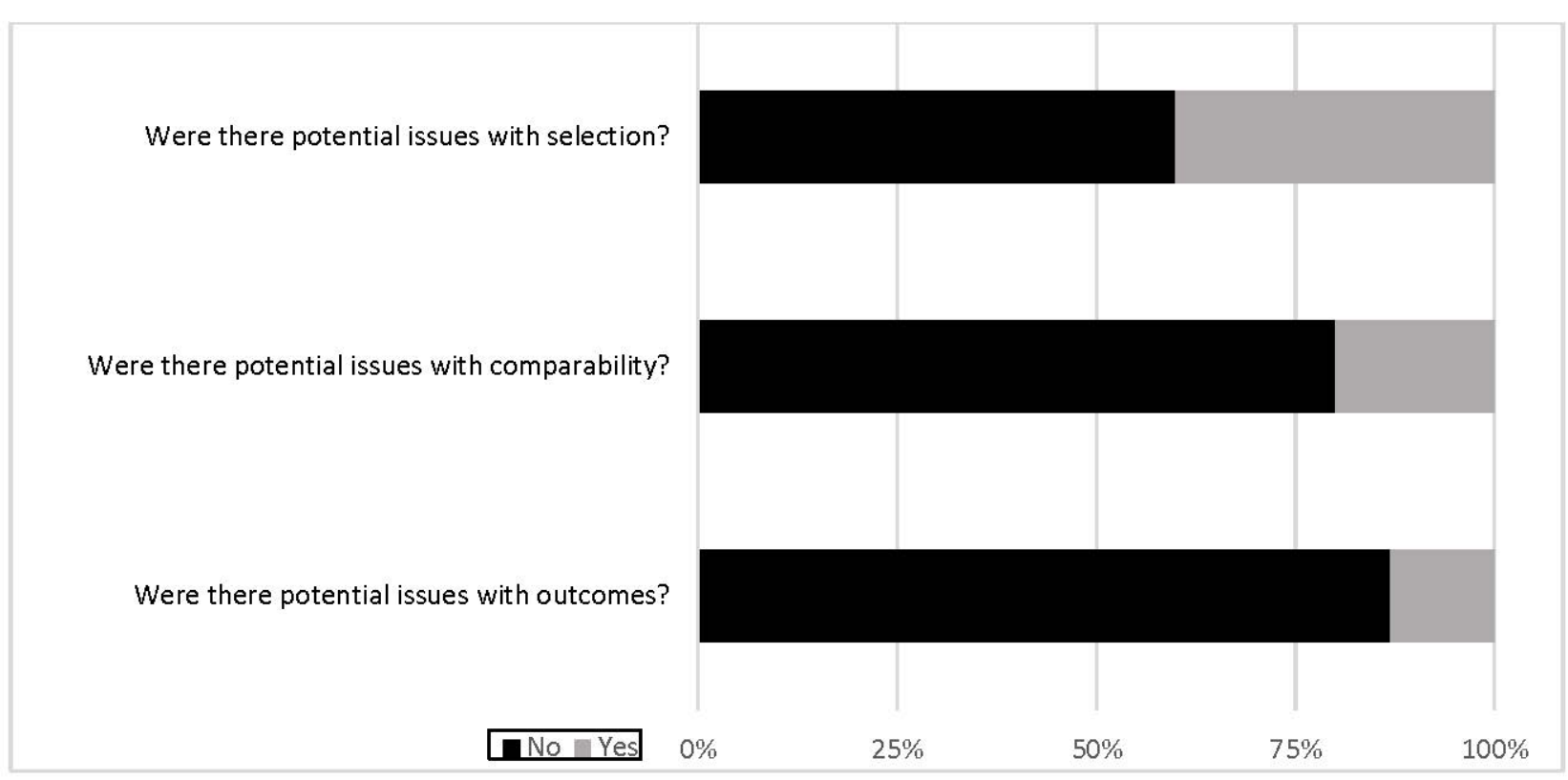


Table G-2 shows the risk of bias quality assessment for the included RCTs. For full study citations, please refer to the report's main reference list.

Table G-2. Risk of bias assessment for included RCTs

\begin{tabular}{|c|c|c|c|c|c|c|}
\hline Study & $\begin{array}{l}\text { Allocation } \\
\text { sequence } \\
\text { generated } \\
\text { adequately? }\end{array}$ & $\begin{array}{l}\text { Allocation of } \\
\text { Treatment } \\
\text { adequately } \\
\text { concealed? }\end{array}$ & $\begin{array}{l}\text { Was knowledge of } \\
\text { the allocated } \\
\text { intervention } \\
\text { adequately prevented } \\
\text { during the study? }\end{array}$ & $\begin{array}{l}\text { Were incomplete } \\
\text { outcome data } \\
\text { adequately } \\
\text { addressed? }\end{array}$ & $\begin{array}{l}\text { Are reports of the } \\
\text { study free of } \\
\text { suggestion of } \\
\text { selective outcome } \\
\text { reporting? }\end{array}$ & $\begin{array}{c}\text { Was the study } \\
\text { apparently free of } \\
\text { other problems that } \\
\text { could put it at a high } \\
\text { risk of bias? }\end{array}$ \\
\hline Abdullah, $2010^{118}$ & $\mathrm{~N}$ & $\mathrm{U}$ & $\mathrm{U}$ & $\mathrm{N}$ & $\mathrm{U}$ & $\mathrm{Y}$ \\
\hline Abrao, $2009^{196}$ & $\mathrm{Y}$ & $\mathrm{Y}$ & $\mathrm{Y}$ & $\mathrm{N}$ & $\mathrm{Y}$ & $\mathrm{N}$ \\
\hline Ajadi, $2006^{116}$ & $Y$ & $\mathrm{Y}$ & $Y$ & $\mathrm{Y}$ & $\mathrm{Y}$ & $\mathrm{Y}$ \\
\hline Akbarzadeh, $2015^{70}$ & $\mathrm{U}$ & $\mathrm{N}$ & $\mathrm{N}$ & $\mathrm{Y}$ & $\mathrm{Y}$ & $\mathrm{N}$ \\
\hline Albers, $2005^{149}$ & $\mathrm{Y}$ & $\mathrm{Y}$ & $\mathrm{N}$ & $\mathrm{Y}$ & $\mathrm{Y}$ & $\mathrm{Y}$ \\
\hline Allameh, $2015^{126}$ & $\mathrm{~N}$ & $\mathrm{U}$ & $\mathrm{N}$ & $\mathrm{U}$ & $\mathrm{Y}$ & $\mathrm{N}$ \\
\hline Asadi, $2015^{125}$ & $\mathrm{~N}$ & $\mathrm{~N}$ & $\mathrm{U}$ & $\mathrm{N}$ & $\mathrm{Y}$ & $\mathrm{N}$ \\
\hline Bhagwat, $2008^{202}$ & $\mathrm{Y}$ & $\mathrm{Y}$ & $\mathrm{Y}$ & $\mathrm{Y}$ & $\mathrm{Y}$ & $\mathrm{Y}$ \\
\hline Bloom, $2006^{72}$ & $\mathrm{Y}$ & $\mathrm{Y}$ & $\mathrm{Y}$ & $\mathrm{Y}$ & $\mathrm{Y}$ & $\mathrm{Y}$ \\
\hline $\begin{array}{l}\text { Bolbol-Haghighi, } \\
2016^{166}\end{array}$ & $\mathrm{Y}$ & $\mathrm{Y}$ & $\mathrm{N}$ & $\mathrm{Y}$ & $\mathrm{Y}$ & $\mathrm{Y}$ \\
\hline Bruggemann, $2007^{152}$ & $\mathrm{Y}$ & $\mathrm{Y}$ & $\mathrm{N}$ & $\mathrm{Y}$ & $\mathrm{Y}$ & $\mathrm{Y}$ \\
\hline Cahill, $2018^{227}$ & $\mathrm{Y}$ & $\mathrm{Y}$ & $\mathrm{N}$ & $\mathrm{Y}$ & $\mathrm{Y}$ & $\mathrm{Y}$ \\
\hline Chaichian, $2009^{143}$ & $\mathrm{U}$ & $\mathrm{U}$ & $\mathrm{N}$ & $\mathrm{Y}$ & $\mathrm{U}$ & $\mathrm{Y}$ \\
\hline Coco, $2010^{142}$ & $\mathrm{Y}$ & $\mathrm{Y}$ & $\mathrm{U}$ & $\mathrm{Y}$ & $\mathrm{Y}$ & $\mathrm{Y}$ \\
\hline Dahlen, $2007^{160}$ & $\mathrm{Y}$ & $\mathrm{N}$ & $\mathrm{N}$ & $\mathrm{Y}$ & $\mathrm{Y}$ & $\mathrm{U}$ \\
\hline Darsareh, $2018^{179}$ & $\mathrm{U}$ & $\mathrm{Y}$ & $\mathrm{N}$ & $\mathrm{Y}$ & $\mathrm{Y}$ & $\mathrm{Y}$ \\
\hline de Orange, $2011^{76}$ & $\mathrm{Y}$ & $\mathrm{Y}$ & $\mathrm{N}$ & $\mathrm{Y}$ & $\mathrm{Y}$ & $\mathrm{Y}$ \\
\hline Dencker, $2009^{74}$ & $\mathrm{Y}$ & $\mathrm{Y}$ & $\mathrm{U}$ & $\mathrm{Y}$ & $\mathrm{Y}$ & $\mathrm{U}$ \\
\hline $\begin{array}{l}\text { Direkvand- } \\
\text { Moghadam, 2012 } 136\end{array}$ & $\mathrm{Y}$ & $\mathrm{Y}$ & $\mathrm{U}$ & $\mathrm{N}$ & $\mathrm{Y}$ & $\mathrm{Y}$ \\
\hline Douma, 2011 194 & $\mathrm{U}$ & $\mathrm{U}$ & $\mathrm{N}$ & $\mathrm{N}$ & $\mathrm{Y}$ & $\mathrm{N}$ \\
\hline Dy, $2018^{212}$ & $\mathrm{Y}$ & $Y$ & $Y$ & $Y$ & $\mathrm{U}$ & $\mathrm{U}$ \\
\hline Edwards, $2014^{130}$ & $\mathrm{Y}$ & $\mathrm{Y}$ & $\mathrm{N}$ & $\mathrm{N}$ & $\mathrm{Y}$ & $\mathrm{N}$ \\
\hline $\begin{array}{l}\text { Epidural and Position } \\
\text { Trial Collaborative } \\
\text { Group, } 2017^{173}\end{array}$ & $\mathrm{Y}$ & $\mathrm{Y}$ & $\mathrm{N}$ & $\mathrm{Y}$ & $\mathrm{Y}$ & $\mathrm{Y}$ \\
\hline El Hamid, $2013^{162}$ & $\mathrm{U}$ & $\mathrm{U}$ & $\mathrm{U}$ & $\mathrm{U}$ & $\mathrm{U}$ & $\mathrm{U}$ \\
\hline Eslamian, $2006^{148}$ & $\mathrm{Y}$ & $\mathrm{Y}$ & $\mathrm{Y}$ & $\mathrm{Y}$ & $\mathrm{Y}$ & $\mathrm{Y}$ \\
\hline Fahdhy, $2005^{90}$ & $\mathrm{~N}$ & $\mathrm{U}$ & $\mathrm{U}$ & $\mathrm{Y}$ & $\mathrm{Y}$ & $\mathrm{Y}$ \\
\hline Fong, $2017^{171}$ & $\mathrm{Y}$ & $\mathrm{Y}$ & $\mathrm{Y}$ & $\mathrm{U}$ & $\mathrm{Y}$ & $\mathrm{Y}$ \\
\hline Gallo, $2018^{172}$ & $\mathrm{Y}$ & $\mathrm{Y}$ & $\mathrm{N}$ & $\mathrm{Y}$ & $\mathrm{Y}$ & $\mathrm{Y}$ \\
\hline Ganapthy, $2012^{159}$ & $\mathrm{Y}$ & $\mathrm{U}$ & $\mathrm{N}$ & $\mathrm{Y}$ & $\mathrm{Y}$ & $\mathrm{Y}$ \\
\hline
\end{tabular}




\begin{tabular}{|c|c|c|c|c|c|c|}
\hline Study & $\begin{array}{c}\text { Allocation } \\
\text { sequence } \\
\text { generated } \\
\text { adequately? }\end{array}$ & $\begin{array}{l}\text { Allocation of } \\
\text { Treatment } \\
\text { adequately } \\
\text { concealed? }\end{array}$ & $\begin{array}{c}\text { Was knowledge of } \\
\text { the allocated } \\
\text { intervention } \\
\text { adequately prevented } \\
\text { during the study? }\end{array}$ & $\begin{array}{l}\text { Were incomplete } \\
\text { outcome data } \\
\text { adequately } \\
\text { addressed? }\end{array}$ & $\begin{array}{l}\text { Are reports of the } \\
\text { study free of } \\
\text { suggestion of } \\
\text { selective outcome } \\
\text { reporting? }\end{array}$ & $\begin{array}{c}\text { Was the study } \\
\text { apparently free of } \\
\text { other problems that } \\
\text { could put it at a high } \\
\text { risk of bias? }\end{array}$ \\
\hline Geeta, $2015^{214}$ & $\mathrm{U}$ & $\mathrm{U}$ & $\mathrm{U}$ & $\mathrm{N}$ & $\mathrm{U}$ & $\mathrm{U}$ \\
\hline Genc, $2015^{189}$ & $U$ & $\mathrm{U}$ & $U$ & $\mathrm{Y}$ & $\mathrm{Y}$ & $\mathrm{Y}$ \\
\hline Ghafarzadeh, $2015^{113}$ & $\mathrm{Y}$ & U & $\mathrm{U}$ & $\mathrm{Y}$ & $\mathrm{U}$ & $\mathrm{U}$ \\
\hline Hamidzadeh, $2012^{137}$ & $\mathrm{U}$ & $\mathrm{U}$ & $\mathrm{N}$ & $\mathrm{Y}$ & $\mathrm{Y}$ & $\mathrm{Y}$ \\
\hline $\begin{array}{l}\text { Hekmatzadeh, } \\
2014^{155}\end{array}$ & $\mathrm{Y}$ & $U$ & $U$ & $\mathrm{Y}$ & $\mathrm{Y}$ & $\mathrm{Y}$ \\
\hline Hinshaw, $2008^{210}$ & $\mathrm{Y}$ & $\mathrm{Y}$ & $\mathrm{N}$ & $\mathrm{Y}$ & $\mathrm{Y}$ & $\mathrm{Y}$ \\
\hline Isbir, $2017^{180}$ & $\mathrm{Y}$ & $\mathrm{U}$ & $\mathrm{N}$ & $\mathrm{N}$ & $\mathrm{Y}$ & $\mathrm{Y}$ \\
\hline Ismail, $2012^{191}$ & $\mathrm{Y}$ & $\mathrm{Y}$ & $\mathrm{N}$ & $\mathrm{Y}$ & $\mathrm{Y}$ & $\mathrm{Y}$ \\
\hline Jaitley, 2011201 & $\mathrm{U}$ & $U$ & $\mathrm{~N}$ & $\mathrm{~N}$ & $\mathrm{~N}$ & $\mathrm{~N}$ \\
\hline Janssen, $2012^{132}$ & $\mathrm{Y}$ & $\mathrm{Y}$ & $\mathrm{N}$ & $\mathrm{Y}$ & $\mathrm{Y}$ & $\mathrm{Y}$ \\
\hline Kashanian, $2010^{151}$ & $\mathrm{Y}$ & $\mathrm{Y}$ & $\mathrm{N}$ & $\mathrm{Y}$ & $\mathrm{Y}$ & $\mathrm{Y}$ \\
\hline Kaviani, $2014^{157}$ & $\mathrm{~N}$ & $\mathrm{~N}$ & $\mathrm{~N}$ & $\mathrm{Y}$ & $\mathrm{Y}$ & $\mathrm{Y}$ \\
\hline Kaviani, $2014^{127}$ & $\mathrm{~N}$ & $U$ & $\mathrm{~N}$ & $\mathrm{Y}$ & $\mathrm{Y}$ & $\mathrm{Y}$ \\
\hline Kavitha, $2012^{139}$ & $\mathrm{Y}$ & $\mathrm{Y}$ & $\mathrm{U}$ & $\mathrm{Y}$ & $Y$ & $\mathrm{Y}$ \\
\hline Kenyon, $2013^{208}$ & $\mathrm{Y}$ & $\mathrm{Y}$ & $\mathrm{Y}$ & $\mathrm{Y}$ & $\mathrm{U}$ & $\mathrm{U}$ \\
\hline Koyucu, $2017^{226}$ & $\mathrm{~N}$ & $\mathrm{U}$ & $\mathrm{N}$ & $\mathrm{Y}$ & $\mathrm{Y}$ & $\mathrm{Y}$ \\
\hline Lavender, $2006^{89}$ & $\mathrm{Y}$ & $\mathrm{Y}$ & $\mathrm{N}$ & $\mathrm{Y}$ & $\mathrm{Y}$ & $\mathrm{Y}$ \\
\hline Lee, $2018^{94}$ & $\mathrm{Y}$ & $\mathrm{Y}$ & $\mathrm{N}$ & $\mathrm{Y}$ & $\mathrm{Y}$ & $Y$ \\
\hline Liu, $2018^{213}$ & $\mathrm{U}$ & $\mathrm{U}$ & $\mathrm{U}$ & $\mathrm{Y}$ & $\mathrm{U}$ & $\mathrm{U}$ \\
\hline Liu, $2015^{124}$ & $\mathrm{Y}$ & $\mathrm{N}$ & $\mathrm{N}$ & $\mathrm{Y}$ & $U$ & $Y$ \\
\hline $\mathrm{Ma}, 2011^{141}$ & $Y$ & $U$ & $\mathrm{Y}$ & $\mathrm{Y}$ & $\mathrm{Y}$ & $\mathrm{Y}$ \\
\hline Maddady, $2018^{174}$ & $\mathrm{U}$ & $\mathrm{Y}$ & $\mathrm{N}$ & $\mathrm{Y}$ & $\mathrm{Y}$ & $\mathrm{Y}$ \\
\hline McGrath, $2008^{145}$ & $Y$ & $Y$ & $\mathrm{~N}$ & $\mathrm{Y}$ & $Y$ & $Y$ \\
\hline Mikki, $2007^{115}$ & $\mathrm{Y}$ & $\mathrm{Y}$ & $\mathrm{Y}$ & $\mathrm{Y}$ & $\mathrm{Y}$ & $\mathrm{Y}$ \\
\hline Miquelutti, $2007^{146}$ & $\mathrm{Y}$ & $\mathrm{Y}$ & $\mathrm{N}$ & $\mathrm{Y}$ & $\mathrm{Y}$ & $\mathrm{Y}$ \\
\hline Moraloglu, $2017^{168}$ & $\mathrm{~N}$ & $\mathrm{U}$ & $\mathrm{N}$ & $\mathrm{Y}$ & $\mathrm{Y}$ & $\mathrm{Y}$ \\
\hline Mortazavi, $2012^{138}$ & $\mathrm{~N}$ & $\mathrm{~N}$ & U & $\mathrm{Y}$ & $\mathrm{N}$ & $\mathrm{U}$ \\
\hline Nachum, $2010^{114}$ & $\mathrm{Y}$ & $\mathrm{Y}$ & $\mathrm{Y}$ & $\mathrm{Y}$ & $\mathrm{Y}$ & $\mathrm{Y}$ \\
\hline Nafisi, $2006^{198}$ & $\mathrm{~N}$ & $\mathrm{~N}$ & $\mathrm{~N}$ & $\mathrm{Y}$ & $\mathrm{Y}$ & $\mathrm{Y}$ \\
\hline Nakamura, $2009^{195}$ & $\mathrm{U}$ & $\mathrm{U}$ & $\mathrm{U}$ & $\mathrm{U}$ & $\mathrm{N}$ & $\mathrm{Y}$ \\
\hline Nasir, $2007^{147}$ & $\mathrm{~N}$ & $\mathrm{~N}$ & $\mathrm{U}$ & $\mathrm{U}$ & $U$ & $\mathrm{U}$ \\
\hline Ohel, $2006^{199}$ & $\mathrm{U}$ & $\mathrm{Y}$ & $\mathrm{N}$ & $\mathrm{Y}$ & $\mathrm{Y}$ & $\mathrm{Y}$ \\
\hline Onah, $2015^{119}$ & $\mathrm{Y}$ & $\mathrm{Y}$ & $\mathrm{U}$ & $\mathrm{Y}$ & $\mathrm{Y}$ & $\mathrm{Y}$ \\
\hline Palomaki, $2006^{211}$ & $\mathrm{Y}$ & $\mathrm{U}$ & $\mathrm{Y}$ & $\mathrm{Y}$ & $\mathrm{Y}$ & $\mathrm{Y}$ \\
\hline $\begin{array}{l}\text { Pascual-Ramirez, } \\
2011^{78}\end{array}$ & $\mathrm{Y}$ & $\mathrm{Y}$ & $Y$ & $\mathrm{Y}$ & $\mathrm{Y}$ & $\mathrm{Y}$ \\
\hline Patel, $2014^{190}$ & $U$ & $\mathrm{Y}$ & $\mathrm{Y}$ & $\mathrm{Y}$ & $\mathrm{Y}$ & $U$ \\
\hline
\end{tabular}




\begin{tabular}{|c|c|c|c|c|c|c|}
\hline Study & $\begin{array}{l}\text { Allocation } \\
\text { sequence } \\
\text { generated } \\
\text { adequately? }\end{array}$ & $\begin{array}{l}\text { Allocation of } \\
\text { Treatment } \\
\text { adequately } \\
\text { concealed? }\end{array}$ & $\begin{array}{l}\text { Was knowledge of } \\
\text { the allocated } \\
\text { intervention } \\
\text { adequately prevented } \\
\text { during the study? }\end{array}$ & $\begin{array}{l}\text { Were incomplete } \\
\text { outcome data } \\
\text { adequately } \\
\text { addressed? }\end{array}$ & $\begin{array}{l}\text { Are reports of the } \\
\text { study free of } \\
\text { suggestion of } \\
\text { selective outcome } \\
\text { reporting? }\end{array}$ & $\begin{array}{c}\text { Was the study } \\
\text { apparently free of } \\
\text { other problems that } \\
\text { could put it at a high } \\
\text { risk of bias? }\end{array}$ \\
\hline Phumdoung, $2007^{161}$ & $\mathrm{U}$ & $\mathrm{U}$ & $U$ & $\mathrm{~N}$ & $\mathrm{~N}$ & $\mathrm{U}$ \\
\hline Prabhakar, $2015^{153}$ & $\mathrm{Y}$ & $\mathrm{U}$ & $\mathrm{N}$ & $\mathrm{U}$ & $\mathrm{Y}$ & $\mathrm{Y}$ \\
\hline Ragnar, $2006^{80}$ & $\mathrm{Y}$ & $\mathrm{Y}$ & $\mathrm{N}$ & $\mathrm{Y}$ & $Y$ & $\mathrm{Y}$ \\
\hline Rahmani, $2012^{133}$ & $\mathrm{Y}$ & $\mathrm{N}$ & $\mathrm{N}$ & $\mathrm{N}$ & $\mathrm{Y}$ & $\mathrm{Y}$ \\
\hline Ruamsap, $2017^{120}$ & $\mathrm{Y}$ & $U$ & $U$ & $\mathrm{Y}$ & $\mathrm{Y}$ & $\mathrm{Y}$ \\
\hline $\begin{array}{l}\text { Samadzadeh, } \\
2017^{175}\end{array}$ & $\mathrm{~N}$ & $\mathrm{~N}$ & Y & Y & Y & $\mathrm{Y}$ \\
\hline Santhi, $2012^{129}$ & $\mathrm{U}$ & $U$ & $\mathrm{~N}$ & $\mathrm{Y}$ & $\mathrm{Y}$ & $\mathrm{Y}$ \\
\hline Sasitorn, $2013^{158}$ & $\mathrm{U}$ & $\mathrm{U}$ & $\mathrm{U}$ & $\mathrm{Y}$ & $\mathrm{Y}$ & $Y$ \\
\hline Schaffer, $2005^{73}$ & $\mathrm{Y}$ & $\mathrm{Y}$ & $\mathrm{Y}$ & $\mathrm{Y}$ & $\mathrm{Y}$ & $\mathrm{Y}$ \\
\hline Selin, $2018^{215}$ & $Y$ & $\mathrm{Y}$ & $Y$ & $Y$ & $\mathrm{Y}$ & $Y$ \\
\hline Sezer, $2007^{197}$ & $\mathrm{U}$ & $\mathrm{Y}$ & $\mathrm{U}$ & $\mathrm{Y}$ & $\mathrm{Y}$ & $\mathrm{Y}$ \\
\hline Shafaie, $2017^{82}$ & $\mathrm{U}$ & $\mathrm{U}$ & $\mathrm{U}$ & $\mathrm{Y}$ & $Y$ & $\mathrm{Y}$ \\
\hline Shahoei, $2017^{178}$ & $\mathrm{~N}$ & $\mathrm{~N}$ & $\mathrm{U}$ & $\mathrm{Y}$ & $\mathrm{Y}$ & $\mathrm{Y}$ \\
\hline Sharma, $2012^{135}$ & $\mathrm{Y}$ & $\mathrm{U}$ & $\mathrm{N}$ & $\mathrm{Y}$ & $\mathrm{Y}$ & $\mathrm{Y}$ \\
\hline Shen, $2017^{203}$ & $\mathrm{Y}$ & $\mathrm{Y}$ & $\mathrm{Y}$ & $\mathrm{Y}$ & $\mathrm{Y}$ & $\mathrm{Y}$ \\
\hline Shirvani, $2014^{156}$ & $\mathrm{Y}$ & $\mathrm{U}$ & $\mathrm{N}$ & $\mathrm{Y}$ & $\mathrm{Y}$ & $\mathrm{Y}$ \\
\hline Shrivastava, $2009^{144}$ & $Y$ & $\mathrm{Y}$ & $\mathrm{Y}$ & $Y$ & $\mathrm{Y}$ & $Y$ \\
\hline Silva Gallo, $2013^{131}$ & $\mathrm{Y}$ & $\mathrm{U}$ & $\mathrm{Y}$ & $\mathrm{Y}$ & $\mathrm{Y}$ & $\mathrm{Y}$ \\
\hline Simarro, $2017^{169}$ & $\mathrm{~N}$ & $\mathrm{~N}$ & $\mathrm{~N}$ & $\mathrm{~N}$ & $Y$ & $Y$ \\
\hline Somprasit, $2005^{117}$ & $\mathrm{Y}$ & $\mathrm{Y}$ & $\mathrm{Y}$ & $\mathrm{Y}$ & $\mathrm{Y}$ & $\mathrm{Y}$ \\
\hline Sweed, $2011^{193}$ & $\mathrm{U}$ & $\mathrm{U}$ & $\mathrm{N}$ & $\mathrm{Y}$ & $\mathrm{N}$ & $\mathrm{N}$ \\
\hline Taavoni, $2016^{164}$ & $\mathrm{U}$ & $\mathrm{U}$ & $\mathrm{N}$ & $Y$ & $\mathrm{Y}$ & $\mathrm{N}$ \\
\hline Taavoni, $2011^{140}$ & $\mathrm{Y}$ & $\mathrm{N}$ & $\mathrm{N}$ & $\mathrm{U}$ & $Y$ & $Y$ \\
\hline Tanvisut, $2018^{167}$ & $Y$ & $\mathrm{Y}$ & $\mathrm{N}$ & $\mathrm{N}$ & $\mathrm{Y}$ & $Y$ \\
\hline $\begin{array}{l}\text { Thies-Lagergren, } \\
2013^{134}\end{array}$ & $\mathrm{~N}$ & $Y$ & $\mathrm{~N}$ & $\mathrm{Y}$ & $\mathrm{Y}$ & $\mathrm{Y}$ \\
\hline Tolba, $2018^{98}$ & $\mathrm{Y}$ & $\mathrm{Y}$ & $\mathrm{Y}$ & $\mathrm{Y}$ & $\mathrm{Y}$ & $\mathrm{Y}$ \\
\hline Tribe, $2012^{209}$ & $\mathrm{Y}$ & $\mathrm{Y}$ & $\mathrm{N}$ & $\mathrm{Y}$ & $\mathrm{Y}$ & $\mathrm{Y}$ \\
\hline Tussey, $2015^{154}$ & $\mathrm{Y}$ & $\mathrm{Y}$ & $\mathrm{N}$ & $\mathrm{U}$ & $\mathrm{Y}$ & $\mathrm{N}$ \\
\hline Tveit, $1501^{192}$ & $\mathrm{Y}$ & $\mathrm{Y}$ & $\mathrm{N}$ & $\mathrm{Y}$ & $\mathrm{Y}$ & $\mathrm{Y}$ \\
\hline Vadivelu, $2017^{121}$ & $\mathrm{Y}$ & $\mathrm{Y}$ & $\mathrm{Y}$ & $\mathrm{Y}$ & $\mathrm{Y}$ & $\mathrm{Y}$ \\
\hline $\begin{array}{l}\text { Vaijayanthimala, } \\
\text { 2014 }\end{array}$ & $U$ & $U$ & $U$ & Y & $U$ & $\mathrm{~N}$ \\
\hline $\begin{array}{l}\text { van den Bosch, } \\
2018^{69}\end{array}$ & Y & $\mathrm{N}$ & $\mathrm{N}$ & $\mathrm{Y}$ & $\mathrm{Y}$ & $\mathrm{Y}$ \\
\hline Vaziri, $2016^{225}$ & $\mathrm{Y}$ & $\mathrm{U}$ & $\mathrm{U}$ & $\mathrm{Y}$ & $\mathrm{Y}$ & $\mathrm{Y}$ \\
\hline Vixner, $2014^{128}$ & $Y$ & $\mathrm{Y}$ & $\mathrm{N}$ & $\mathrm{U}$ & $\mathrm{Y}$ & $Y$ \\
\hline
\end{tabular}




\begin{tabular}{|c|c|c|c|c|c|c|}
\hline Study & $\begin{array}{l}\text { Allocation } \\
\text { sequence } \\
\text { generated } \\
\text { adequately? }\end{array}$ & $\begin{array}{l}\text { Allocation of } \\
\text { Treatment } \\
\text { adequately } \\
\text { concealed? }\end{array}$ & $\begin{array}{l}\text { Was knowledge of } \\
\text { the allocated } \\
\text { intervention } \\
\text { adequately prevented } \\
\text { during the study? }\end{array}$ & $\begin{array}{l}\text { Were incomplete } \\
\text { outcome data } \\
\text { adequately } \\
\text { addressed? }\end{array}$ & $\begin{array}{l}\text { Are reports of the } \\
\text { study free of } \\
\text { suggestion of } \\
\text { selective outcome } \\
\text { reporting? }\end{array}$ & $\begin{array}{c}\text { Was the study } \\
\text { apparently free of } \\
\text { other problems that } \\
\text { could put it at a high } \\
\text { risk of bias? }\end{array}$ \\
\hline Wassen, $2015^{68}$ & $\mathrm{Y}$ & $\mathrm{Y}$ & $\mathrm{N}$ & $\mathrm{Y}$ & $\mathrm{Y}$ & $\mathrm{Y}$ \\
\hline Wiberg-Itzel, $2018^{177}$ & $\mathrm{U}$ & $\mathrm{U}$ & $\mathrm{N}$ & $\mathrm{N}$ & $Y$ & $\mathrm{Y}$ \\
\hline Wilson, $2009^{66}$ & $U$ & $\mathrm{U}$ & $U$ & $\mathrm{Y}$ & $Y$ & $Y$ \\
\hline Wong, $2005^{200}$ & $Y$ & $\mathrm{Y}$ & $\mathrm{U}$ & $Y$ & $\mathrm{Y}$ & $Y$ \\
\hline Wu, $2017^{176}$ & $\mathrm{U}$ & $\mathrm{N}$ & $\mathrm{N}$ & $U$ & $\mathrm{Y}$ & $\mathrm{U}$ \\
\hline Xiao, $2019^{181}$ & $U$ & $\mathrm{Y}$ & $\mathrm{N}$ & $\mathrm{N}$ & $\mathrm{Y}$ & $\mathrm{Y}$ \\
\hline Yazdkhasti, $2016^{165}$ & $\mathrm{Y}$ & $\mathrm{Y}$ & $\mathrm{N}$ & $\mathrm{Y}$ & $\mathrm{Y}$ & $\mathrm{Y}$ \\
\hline Yildirim, $2008^{224}$ & $\mathrm{U}$ & $\mathrm{U}$ & $\mathrm{U}$ & $\mathrm{Y}$ & $\bar{Y}$ & $\mathrm{Y}$ \\
\hline Yuenyong, $2012^{163}$ & $\mathrm{Y}$ & $\mathrm{Y}$ & $\mathrm{N}$ & $\mathrm{Y}$ & $\mathrm{Y}$ & $\mathrm{Y}$ \\
\hline Zhang, $2017^{170}$ & $\mathrm{Y}$ & $\mathrm{Y}$ & $\mathrm{N}$ & $\mathrm{N}$ & $\mathrm{Y}$ & $\mathrm{Y}$ \\
\hline
\end{tabular}

Abbreviations: N=No; U=Unclear; $\mathrm{Y}=\mathrm{Yes}$ 


\section{Figure G-2. Summary of risk of bias assessment for included RCTs}

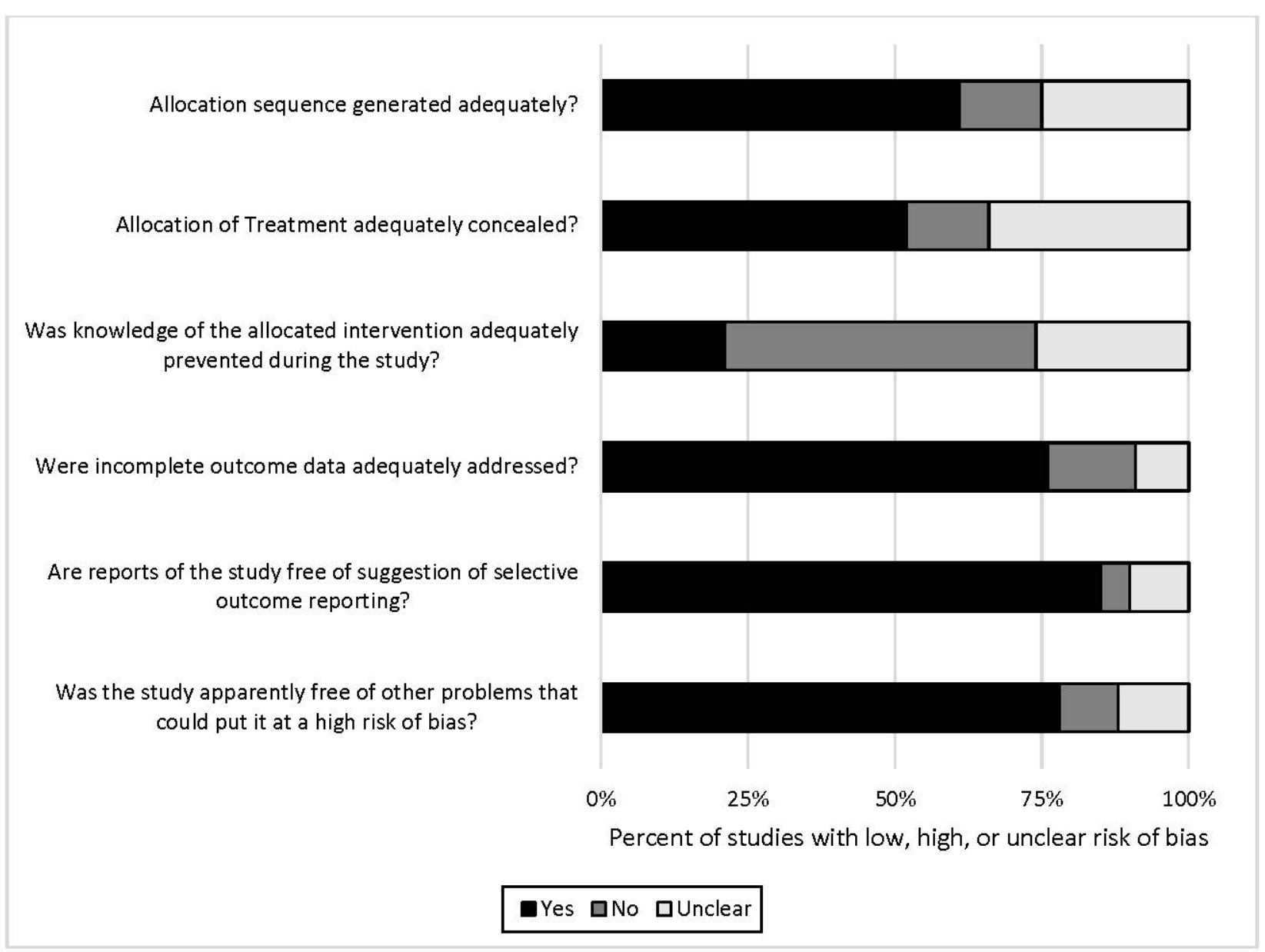

